\title{
Far-Field Ground Strain Failure Mode Assessment for Mineral Extraction Near Dams
}

Harold Russell

Follow this and additional works at: https://researchrepository.wvu.edu/etd

\section{Recommended Citation}

Russell, Harold, "Far-Field Ground Strain Failure Mode Assessment for Mineral Extraction Near Dams" (2017). Graduate Theses, Dissertations, and Problem Reports. 6543.

https://researchrepository.wvu.edu/etd/6543

This Dissertation is protected by copyright and/or related rights. It has been brought to you by the The Research Repository @ WVU with permission from the rights-holder(s). You are free to use this Dissertation in any way that is permitted by the copyright and related rights legislation that applies to your use. For other uses you must obtain permission from the rights-holder(s) directly, unless additional rights are indicated by a Creative Commons license in the record and/ or on the work itself. This Dissertation has been accepted for inclusion in WVU Graduate Theses, Dissertations, and Problem Reports collection by an authorized administrator of The Research Repository @ WVU.

For more information, please contact researchrepository@mail.wvu.edu. 


\title{
Far-Field Ground Strain Failure Mode Assessment for Mineral Extraction Near Dams
}

\author{
Harold Russell, MSCE, EIT \\ Dissertation submitted to the \\ Benjamin M. Statler College of Engineering and Mineral Resources \\ at West Virginia University \\ in partial fulfillment of the requirements for the degree of \\ Doctor of Philosophy in \\ Civil and Environmental Engineering \\ John D. Quaranta, Ph.D., P.E., Chair \\ Hema Siriwardane, Ph.D., P.E. \\ Keith A. Heasley, Ph.D., P.E. \\ Joe Donovan, Ph.D. \\ Avinash Unnikrishnan, Ph.D. \\ Department of Civil and Environmental Engineering
}

Morgantown, West Virginia

2017

KEYWORDS: Ground strain, subsidence, dam, coal mining, finite element modeling, failure mode analysis

Copyright 2017 Harold Russell 


\section{ABSTRACT \\ Far-Field Ground Strain Failure Mode Assessment for Mineral Extraction Near Dams Harold B. Russell}

Steeply sloped, high relief landforms with fractured sedimentary geology in proximity to underground mine voids have the potential to produce far-field ground strains which initiate strain failure modes for cross valley dams. The Ryerson Station Dam breach in 2005 brought attention to the possibility of increased hazard to dams due to far-field ground strain phenomena from underground mining.

The mapping study found that three United States Army Corps of Engineers (U.S.ACE) owned and operated dams were within the 1-mile buffer radius, and four within the 2.7-mile buffer radius of mine permits in West Virginia. Some U.S.ACE dams can be very large in their length, changing the offset distances used herein significantly. There were zero U.S.ACE dams found to have any underground mine permit directly underneath their location. The total frequency of occurrence for U.S.ACE dams considered nearby to underground mine permits in WV was $17.4 \%$.

There are many more dams considered in the National Inventory of Dams (NID) than U.S.ACE dams alone. The same buffer radii were chosen to assess the offset distances of NID dams to underground mine permits as were used for the U.S.ACE dam assessment. There were found to be 115 NID dams within the 2.7-mile buffer radius with 79 of those within 1 mile, and 45 directly undermined. The total frequency of occurrence for NID dams existing nearby to permitted underground mines was found to be $18.9 \%$.

This research incorporates a case study performed on the Ryerson Station Dam and is based on three-dimensional Finite Element Method (FEM) stress/deformation modeling to study and predict the effects of ground movement which caused cracking of the dam's concrete abutments and terminated with the breach. The failure modes for far-field ground strain initiated by underground mining were mapped into a Root Cause Analysis (RCA), based on a Potential Failure Mode Analysis (PFMA) and numerical modeling.

The FEM model was built to study far-field ground movement on a surface grid measuring 1,219 $\mathrm{m}(4,000 \mathrm{ft}$.) x 1,676 m (5,500 ft.), and elevation of $305 \mathrm{~m}$ (1,000 ft.). The model was calibrated from three field survey stations for "best case" and "worst case" ground movements based on field site-specific material testing values to identify causal factors initiating far-field stresses. Sensitivity analysis using the field laboratory tested input parameters was performed on three levels of detail for the eleven stages of mine progression. Sixty-six model analysis were performed. The outcome of the calibration analysis identified the level of detail needed to delineate the variation of geologic strata depth above the mine panels due to mountainous topography. The analysis compared results from increasing the subsurface strata precision from 3 layers (Bulk Analysis) to 8 layers (Detail 1), then culminating at 14 layers (Detail 2). The modeling showed that the number of rock layers had little influence on the precision of the model to predict actual field site ground displacements. This showed that a high degree of subsurface delineation is not required to obtain predictive models with accurate correlation to the field data. 
The sensitivity study also investigated resultant stress magnitudes in the subsurface strata based on the ground displacement of geo-referenced control station survey data. The outcome revealed that the offset distance from the mined panel to the survey station(s) did not control resultant stresses developed in the strata formation. The FEM model was calibrated to field survey station displacement, and the model computed geologic strata stresses. The stress analysis identified that the largest stresses in the subsurface strata are developed after the mine void reached the landform valley. It is concluded that the underground mine encroachment on the ridge hillside landform adjoining the Ryerson Dam reservoir had a greater influence on resultant stresses than the offset distance to the mine.

Station 931 and Station 934 showed the most significant movement after the landform was affected on 6/7/2006, however no abrupt changes occurred at this point. This provides evidence that the landform encroachment may influence stress and deformation more significantly than the offset distance alone. The offset distance was equal to or greater than the distances upon which the greatest movements occurred.

Model results revealed that when mining came to a 19-degree offset angle, the stress began to increase significantly at Station 922.1. Remaining stress percentages were $(66 \%, 81 \%, 81 \%)$ with respect to the total encountered stress at Station 922.1 upon reaching extraction region R7. This result is significant; however, the stress was at its greatest when mining was under the ridge of the western landform at an offset angle of 75 degrees. This observation indicates that the landform is of greater significance than the offset. Since a landform has more degrees of freedom than flat ground, effects on one part of the landform have the potential to affect the entire body.

Strain calculations were computed from Hooke's Law based on laboratory rock testing and model determined stress data. Failure modes at the survey stations were based on the following threshold exceedance limits: tensile concrete strains at the dam (6E-5), foundation bearing strain capacity exceedance (1E-4), foundation rock strain effecting seepage (1E-3), compressive concrete cracking strain (1E-3), and concrete joint stress threshold incorporated at $896 \mathrm{kPa}$ $(18,720 \mathrm{psf})$. Model results were investigated for fourteen survey stations, totaling 140 calculated strains at eleven time dates from April 26, 2006 through July 27, 2006 to determine the failure mode occurrence potential. Approximately $86 \%$ of the identified failure modes exist after the ridge hillside landform are influenced by mining. Foundation bearing capacity strain thresholds at the fourteen survey stations were exceeded up to $1005 \mathrm{~m}(3,298 \mathrm{ft}$.) away, while dam joint stress thresholds were surpassed at offsets up to $566 \mathrm{~m}(1,857 \mathrm{ft}$.). Approximately $10 \%$ of the 140 failure scenarios modeled resulted in strain magnitudes which may result in seepage and structural failure modes at distances up to $566 \mathrm{~m}(1,857 \mathrm{ft}$.). 


\section{ACKNOWLEDGEMENTS}

I sincerely thank Dr. Quaranta for the continuous support and supervision he has provided throughout the course of this research. The personal insight that was provided by Dr. Quaranta was critical for my success in completing this dissertation. The personal experiences which led to my professional development under the supervision of Dr. Quaranta during my graduate career at West Virginia University were difficult and invaluable.

I wish to thank Dr. Thomas Wachtel and Mr. Jeffrey Stevens for assistance and advice with this research.

I also wish to thank Dr. John Quaranta, Dr. Hema Siriwardane, Dr. Keith Heasley, Dr. Joseph Donovan, and Dr. Avinash Unnikrishnan for their participation on my committee; offering support, time, and insight into this research.

I would like to dedicate this dissertation to my family and friends for the support and encouragement they have provided throughout my academic career. 


\section{TABLE OF CONTENTS}

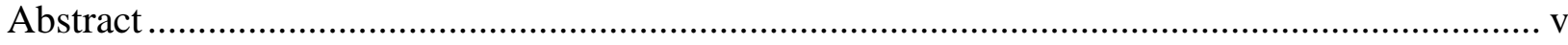

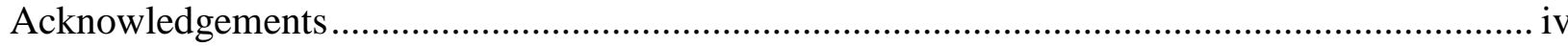

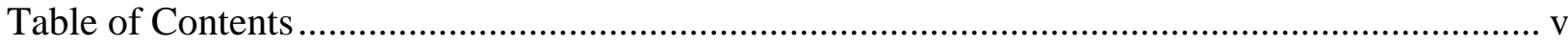

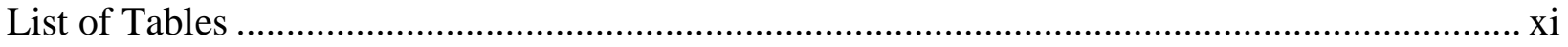

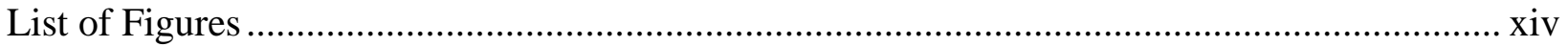

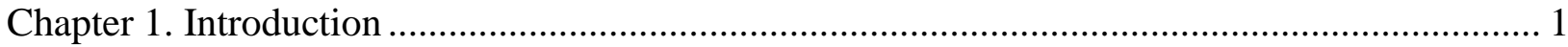

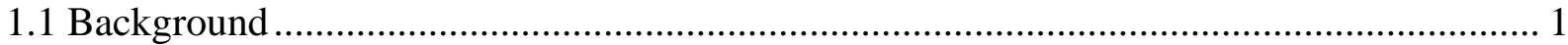

1.1.1 Research Motivation .................................................................................................. 3

1.2 Potential Hazard Assessment for Mineral Extraction Affecting Dams ............................ 5

1.2.1 Hazard Contributors and Identification ............................................................. 5

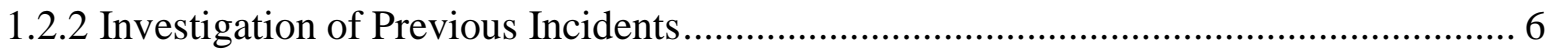

1.2.3 Hazard Assessment Conclusions ...................................................................... 7

1.2.4 Determination of Research Focus ........................................................................ 7

1.3 Research Purpose, Objectives, \& Contributions ........................................................ 7

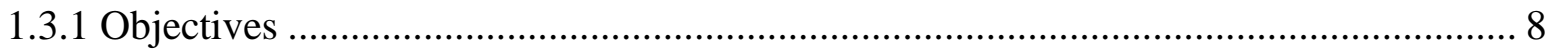

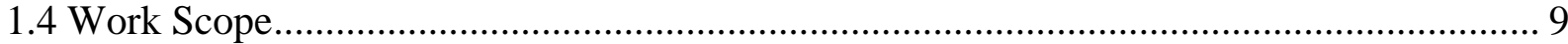

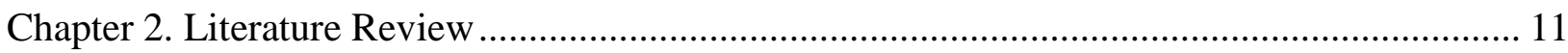

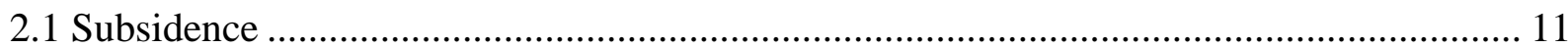

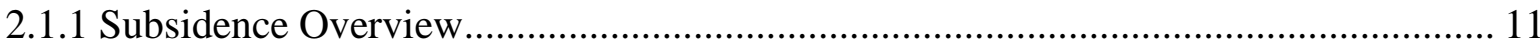

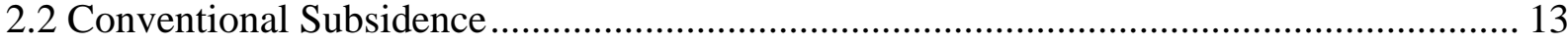

2.2.1 Mechanisms of Conventional Subsidence ............................................................. 17

2.3 Conventional Mine Subsidence: Regulatory Authority .............................................. 18

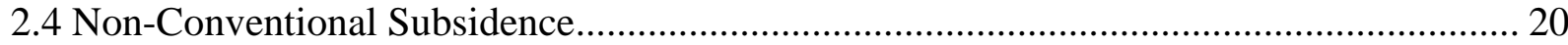

2.4.1 In-situ Horizontal Stress .................................................................................... 21

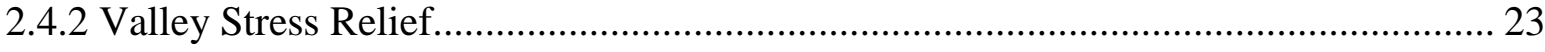

2.4.2.1 Valley Stress Relief Surface Effects ............................................................. 24

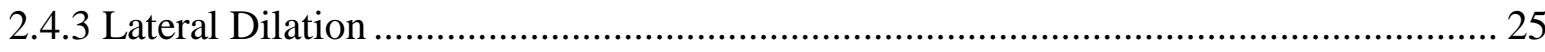

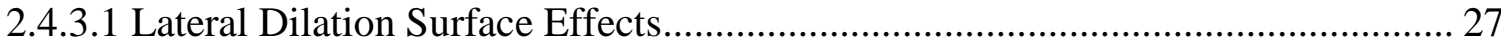

2.5 Summary of Identified Factors Affecting Area of Influence ........................................ 29

2.6 Non-conventional Mine Subsidence: Regulatory Authority......................................... 29

2.7 Case Studies of Non-Conventional Subsidence in Eastern U.S. Coalfields ...................... 31 


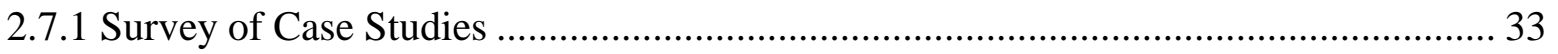

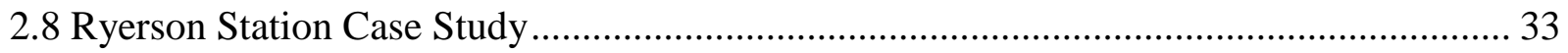

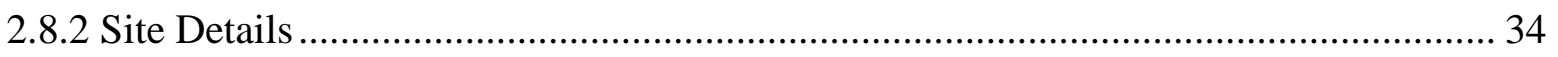

2.8.3 Pre-Mining Performance....................................................................................... 34

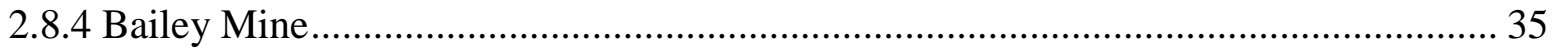

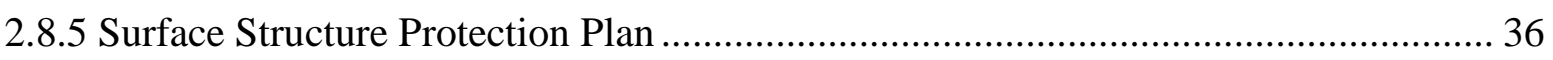

2.8.6 Concurrent and Post Mining Site observations........................................................... 37

2.8.6.1 Increased Seepage at the Ryerson Station Dam................................................... 37

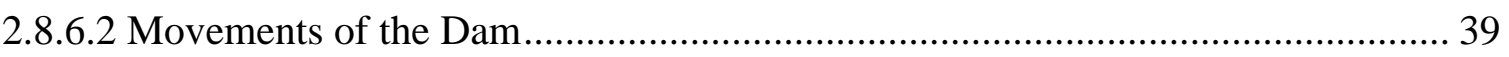

2.8.6.3 Movements in the Surrounding Area ................................................................... 39

2.8.7 Insights from the Ryerson Station Case Study ........................................................... 43

Chapter 3. Extent of Potential Far-Field Ground Strain Scenarios................................................ 46

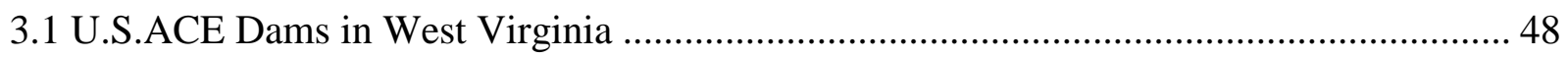

3.1.1 East Lynn Dam ……......................................................................................... 49

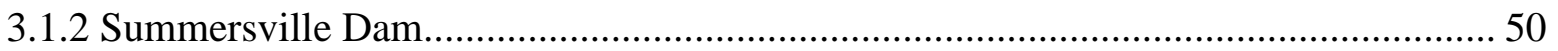

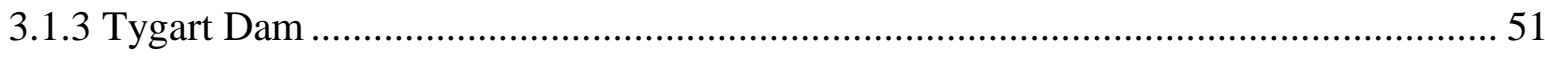

3.1.4 NID Locations in West Virginia ......................................................................... 52

3.2 Ryerson Station Dam and Tygart Dam Mapping …………............................................. 55

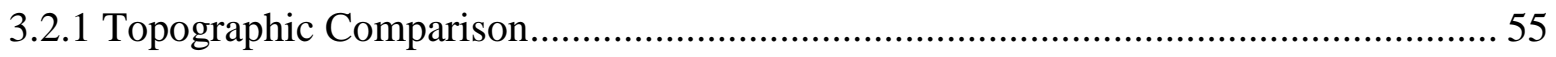

3.2.2 Slope Severity Comparison.................................................................................. 57

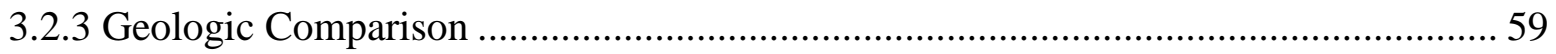

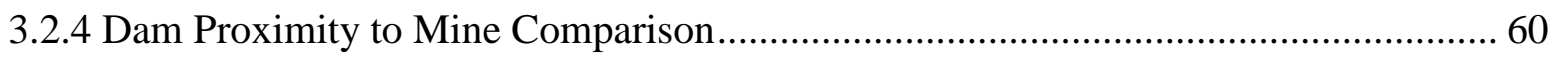

3.3 Discussion of Mapping Comparison and Study Findings................................................... 62

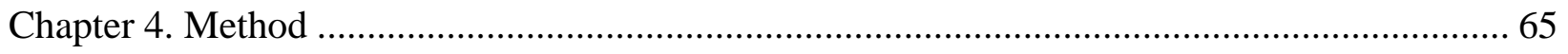

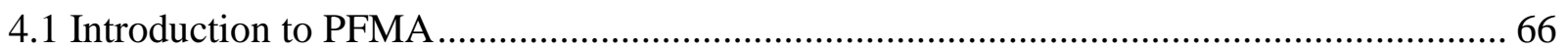

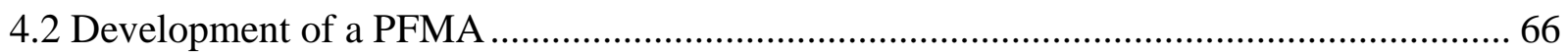

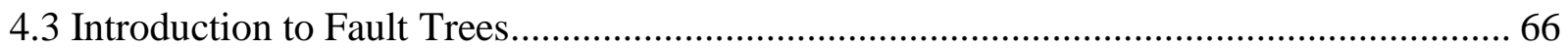

4.4 Development of a Fault Tree for Far-Field Ground Strain .............................................. 67

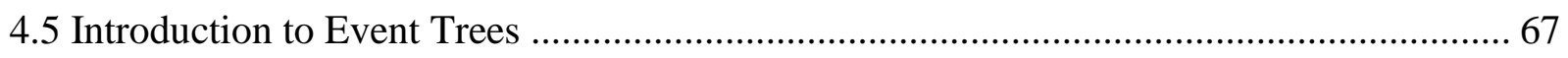

4.6 Development of Event Tree for Far-Field Ground Strain Affecting Seepage Rates at a

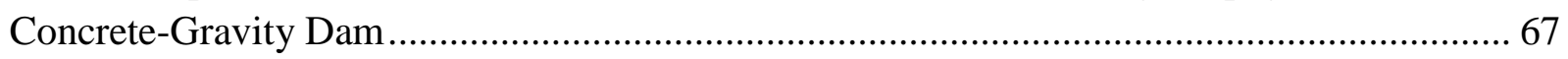


4.7 Development of Semi-Quantitative Potential Failure Mode Analysis (SQPFMA) ........... 68

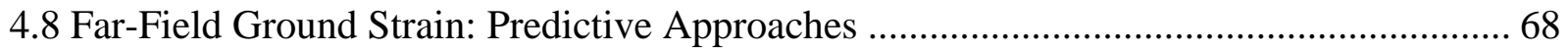

Chapter 5. Potential Failure Mode Analysis (PFMA) for Far Field Ground Strain at a Dam ...... 69

5.1 PFMA Background: Ryerson Station Dam Event Sequence ........................................... 69

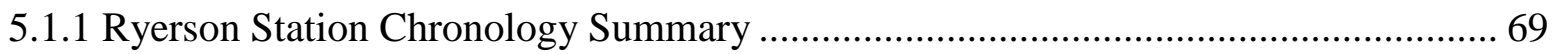

5.1.2 Failure Mode Identification (FMI) ..................................................................... 74

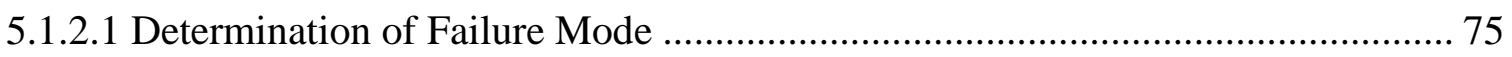

5.3 PFMA Development: Far-Field Ground Strain at a Concrete-Gravity Dam ..................... 76

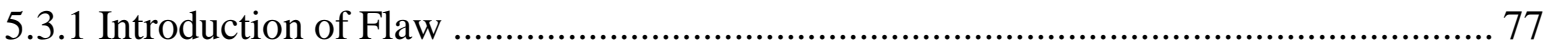

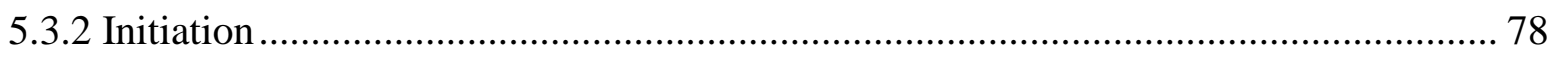

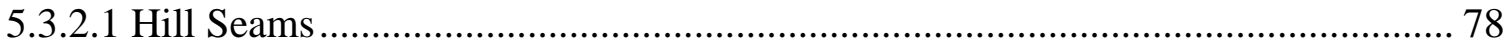

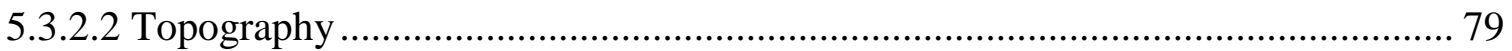

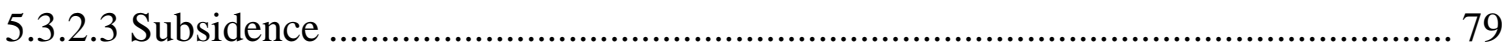

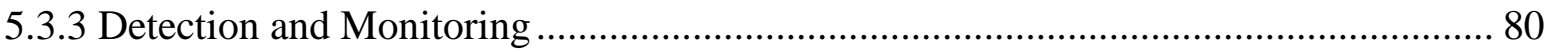

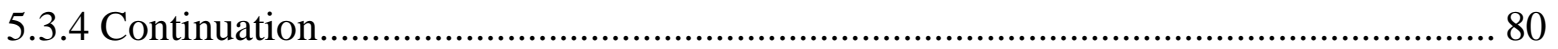

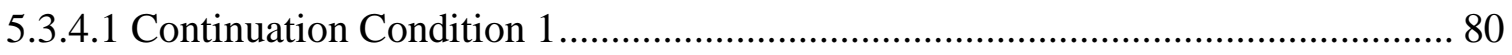

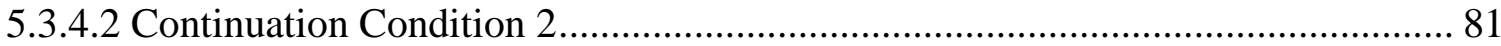

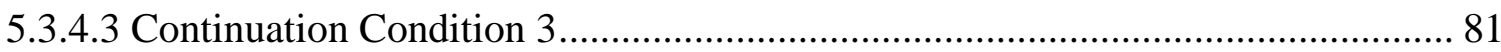

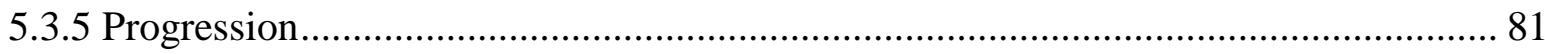

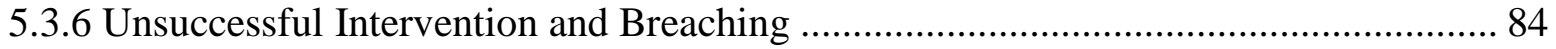

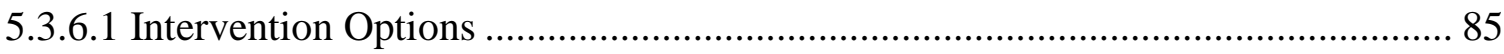

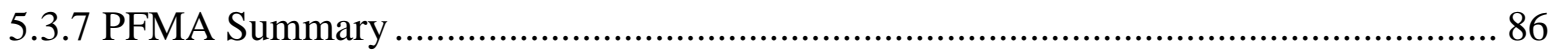

5.4 Development of Conceptual Fault Tree for Far-Field Ground Strain Leading to a Dam

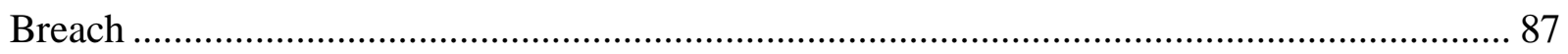

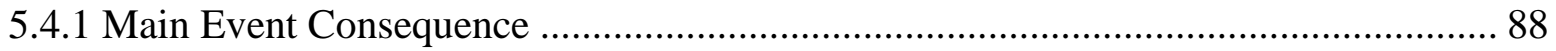

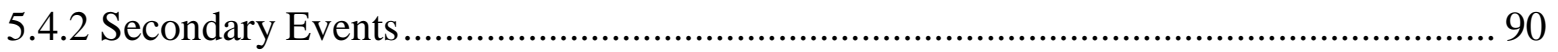

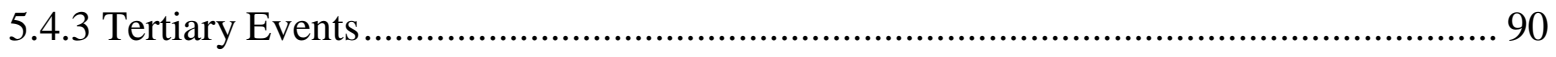

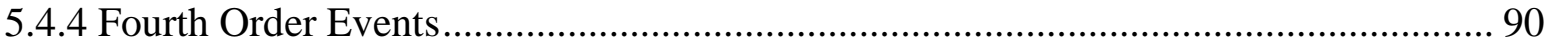

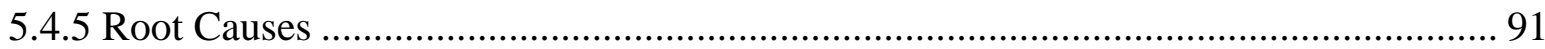

5.5 Development of Conceptual Event Tree for Far-Field Ground Strain Leading to a Dam Breach 
5.5.1 Description of Significant Factors

5.5.2 Sequence of Events and Worsening Factors which Lead to the Breaching of a Dam

Due to Far-Field Ground Strain ............................................................................. 92

5.5.3 Potentially Worsening Factors for Strain and Seepage ......................................... 96

Chapter 6. Numerical Modeling ....................................................................................... 100

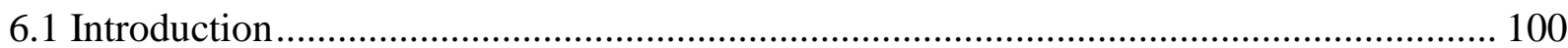

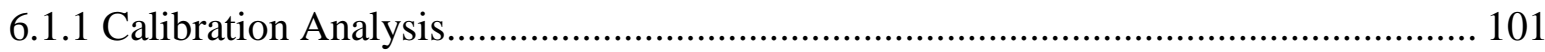

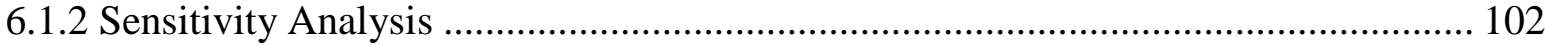

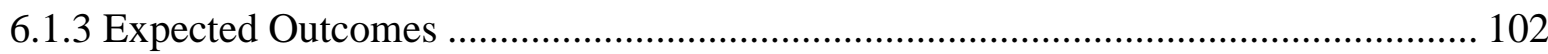

6.2 Determination of Appropriate Quantification Software Tool for Far-Field Ground Strain 103

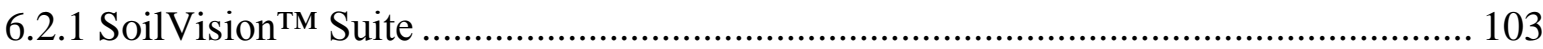

6.3 Finite Element Modeling at Ryerson Station Dam ................................................... 104

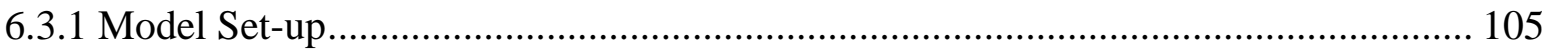

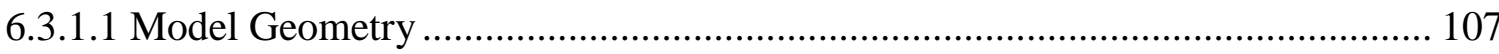

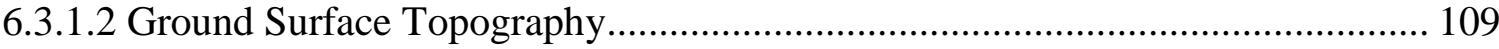

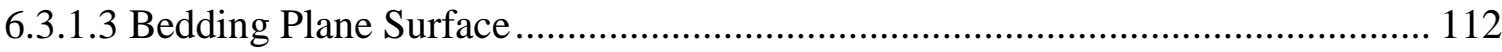

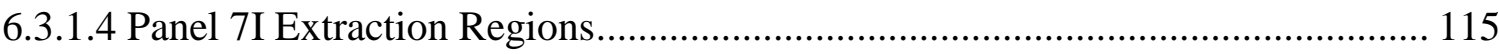

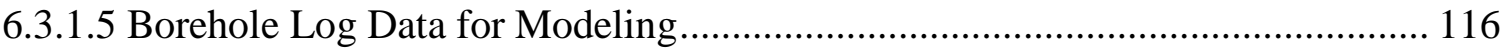

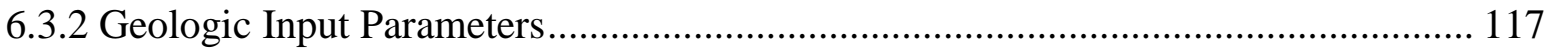

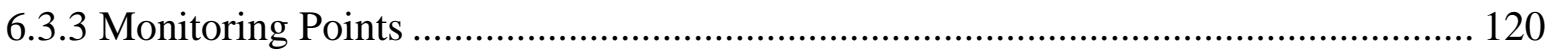

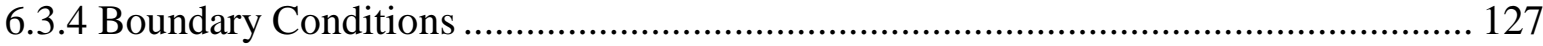

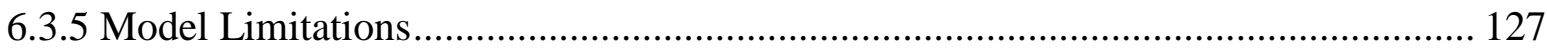

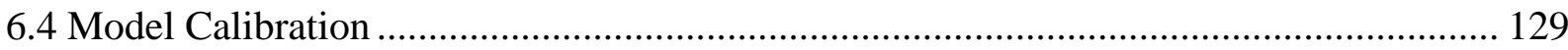

6.4.1 Bulk Analysis (3 Layer Model) .................................................................... 131

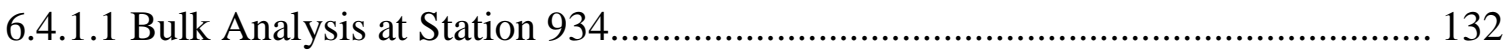

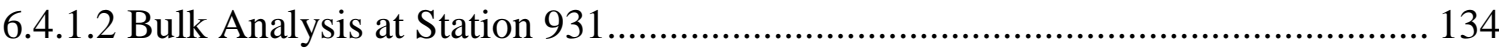

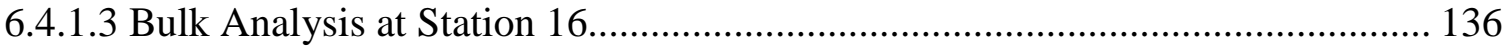

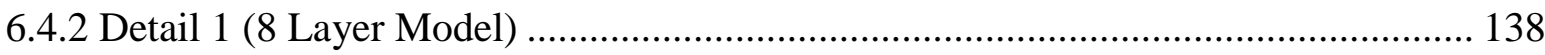

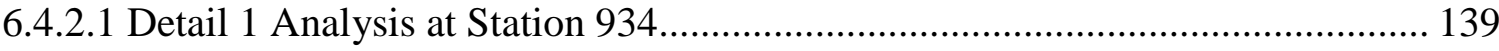

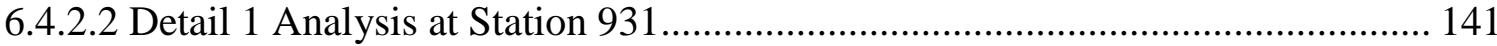




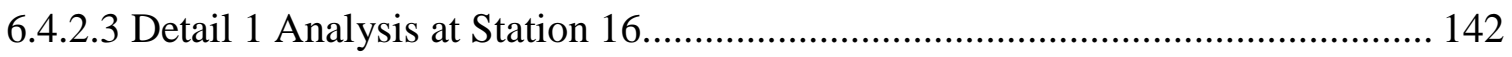

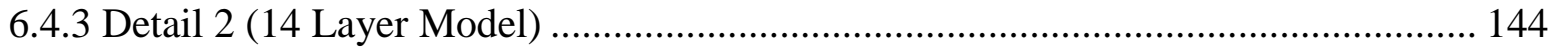

6.4.3.1 Detail 2 Analysis at Station 934................................................................. 145

6.4.3.2 Detail 2 Analysis at Station 931..................................................................... 147

6.4.3.3 Detail 2 Analysis at Station 16................................................................... 148

6.4.4 Calibration Result and Summary …………….............................................. 150

6.5 Parameter Correlation and Sensitivity: Stress and Displacement Analysis ...................... 153

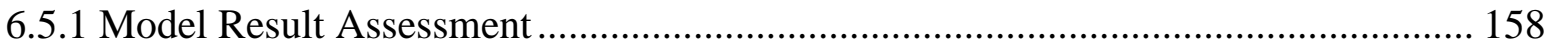

6.5.2 Sensitivity Analysis of Stress and Displacement .................................................... 163

6.5.2.1 Station 922.1 Model Result............................................................................... 168

6.5.2.2 Station 921 Model Result......................................................................... 172

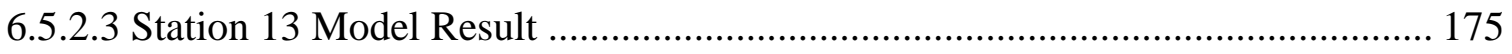

6.6 Parameter Correlation and Sensitivity Result Summary …………………………........ 177

Chapter 7. Root Cause Analysis for Far-Field Ground Strain ................................................. 180

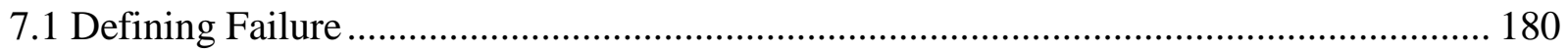

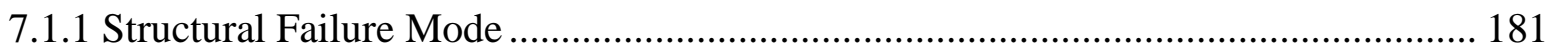

7.1.2 Foundation Rock Failure Mode ………………………………………………….... 183

7.1.3 Failure Mode Occurrence Potential ........................................................................... 184

7.2 Event and Causal Factor Tree for Far-Field Ground Strain Affecting Dams ................... 197

7.2.1 Event and Causal Factor Tree (ECFT) ................................................................... 198

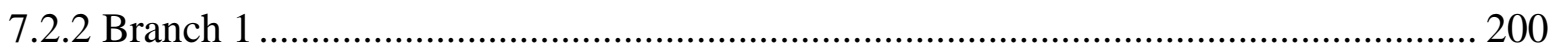

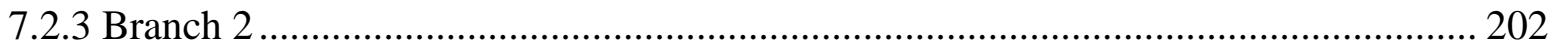

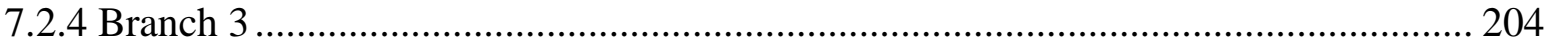

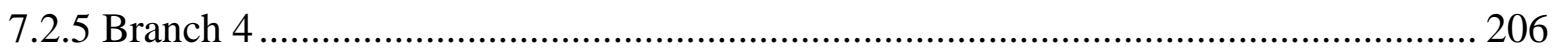

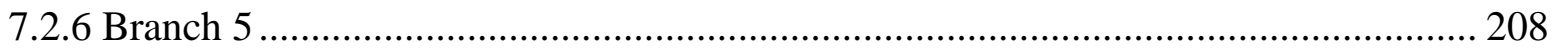

7.3 Recommendations to Prevent Recurrence ......................................................................... 211

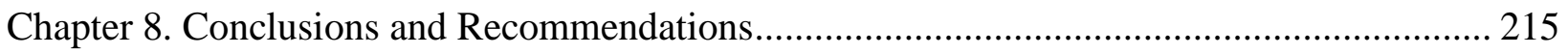

8.1 Conclusions from Extent and Potential for Far-Field Ground Strain Assessment ........... 216

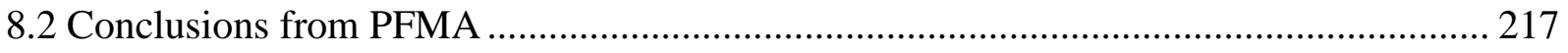

8.3 Numerical Modeling Conclusions .............................................................................. 218

8.3.1 Recommendations from Model Set-Up ……………......................................... 219 
8.3.2 Conclusions from 3D Numerical Modeling Calibration....................................... 220

8.3.3 Conclusions from Parameter Correlation and Sensitivity Analysis........................ 222

8.4 Conclusions from SQPFMA-RCA ECFT .................................................................. 224

8.4.1 Failure Mode (FM) Occurrence Potential........................................................... 224

8.4.2 Recommendations for Prevention...................................................................... 225

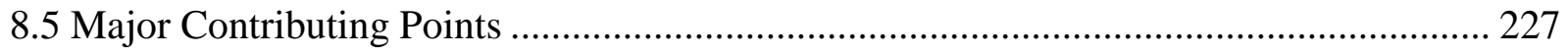

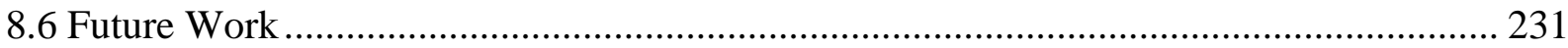

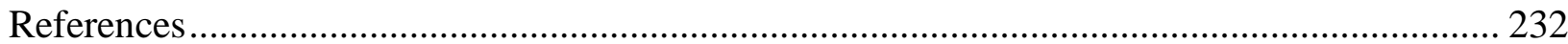

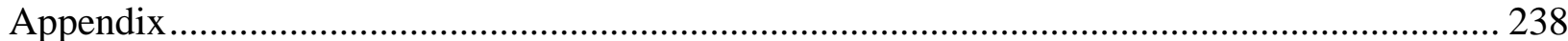




\section{LIST OF TABLES}

Table 1.1 U.S.ACE projects located in WV in close proximity to permitted mining 6

Table 2.1 Types of subsidence, correlated parameters, surface effects, and remedial measures . 17 Table 2.2 Cover ranges for longwall panels nearby to the Ryerson Station Dam (PADEP, 2010)

Table 2.3 Major seepage rate measurements (pre-breach) 37

Table 2.4 Site and description of some additionally reported movements in the Ryerson Station Dam vicinity. 43

Table 3.1 Dam safety statistics for the U.S. (FEMA, 2012) ................................................. 46

Table 3.2 Pool levels and lake area for Tygart Lake (U.S.ACE, 2014).................................. 51

Table 3.3 NID dams in WV with underground mine permits in their vicinity .......................... 54

Table 3.4 Overview of parameters for comparison of Ryerson Station Dam and Tygart Dam ... 63 Table 3.5 Total number of dams and frequency of occurrence for mine permits within the vicinity of U.S.ACE dams in WV. 64

Table 3.6 Total number of dams and frequency of occurrence for mine permits within the

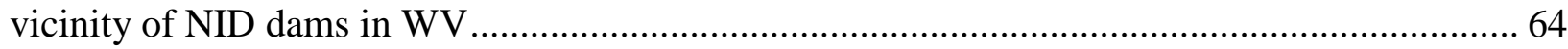

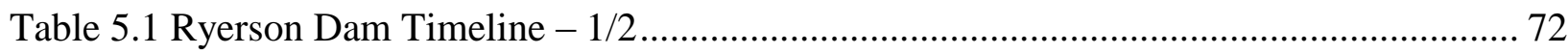

Table 5.2 Ryerson Dam Timeline $-2 / 2$......................................................................... 73

Table 5.3 Hillside stability model cases and resulting factors of safety (PADCNR, 2007) ........ 75

Table 5.4 Gantt chart for sequence of PFMA related events ................................................ 86

Table 5.5 PFMA components and associated parameters ................................................... 87

Table 5.6 Authorized uses of reservoirs (U.S.ACE, 1994) ..................................................... 88

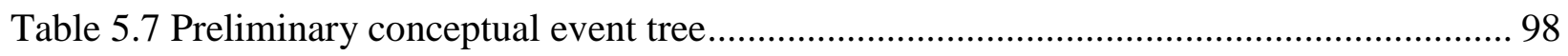

Table 6.1 Bedding plane angle calculation .......................................................................... 112

Table 6.2 Extraction region information............................................................................. 116

Table 6.3 Layering for model detail levels ........................................................................ 117

Table 6.4 Best Case (BC) and Worst Case (WC) parameters................................................. 119

Table 6.5 Best Case (BC) and Worst Case (WC) parameter rationale ................................... 120

Table 6.6 Survey monitoring points along western rim of Duke Lake.................................. 122

Table 6.7 Calibration modeling matrix ............................................................................... 130

Table 6.8 Overall BC and WC properties for the Bulk Analysis.......................................... 131

Table 6.9 Rock layering, type, and thickness for Bulk Analysis modeling ........................... 131

Table 6.10 Station 934 Bulk model and field data............................................................... 134

Table 6.11 Station 931 Bulk model and field data.................................................................. 135

Table 6.12 Station 16 Bulk and Field data, linear offset, and extraction region ...................... 137

Table 6.13 Rock layering, type, and thickness for Detail 1 modeling .................................... 138

Table 6.14 Station 934 Detail 1 calibration data.................................................................... 140

Table 6.15 Station 931 Detail 1 data, field data, region extracted, and linear offset................. 142

Table 6.16 Station 16 Detail 1 calibration data, extraction region, and linear offset ............... 143 
Table 6.17 Rock layering, type, and thickness for Detail 2 modeling .................................. 144

Table 6.18 Station 934 Detail 2 calibration data, extraction region, and linear offset .............. 146

Table 6.19 Station 931 calibration data, extraction region, and linear offset .......................... 148

Table 6.20 Station 16 Detail 2 calibration data, extraction region, and linear offset ............... 149

Table 6.20 PCC and maximum error for each level of detail .............................................. 152

Table 6.21 Monitoring station ranking for differential depth with respect to stress (X,Y,Z).... 154

Table 6.22 Station ranking for maximum stress impact and offset ..................................... 158

Table 6.23 Station Coordinates ........................................................................................... 159

Table 6.24 Station 922.1 model resultant data assessment .................................................... 170

Table 6.25 Station 921 model resultant data.................................................................... 174

Table 6.26 Station 13 model resultant data.................................................................... 176

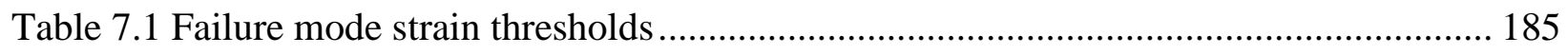

Table 7.2 Failure mode summary for foundation rock assessment ...................................... 187

Table 7.3 Foundation rock strain failure modes and linear offset per station per region ........... 188

Table 7.4 Failure mode summary for concrete joint stress assessment ................................... 189

Table 7.5 Concrete joint stress failure modes and linear offset per station per region .............. 190

Table 7.6 Failure mode summary for concrete compressive and tensile strain assessment ....... 191

Table 7.7 Concrete strain failure modes and linear offset per station per region ..................... 192

Table 7.8 Frequency of occurrence for failure modes ......................................................... 195

Table 7.9 Summary of failure modes at linear offset........................................................... 196

Table 7.10 ECFT - Branch 1 composition ........................................................................ 201

Table 7.11 ECFT - Branch 2 composition ......................................................................... 203

Table 7.12 ECFT - Branch 3 composition ........................................................................... 205

Table 7.13 ECFT - Branch 4 composition ............................................................................. 207

Table 7.14 ECFT - Branch 5 composition ........................................................................... 209

Table 7.15 Situational causal factors developed from the ECFT ........................................ 210

Table 7.16 Monitoring recommendations ........................................................................ 212

Table 5.5 PFMA components and associated parameters ................................................. 218

Table A1 Summary table of studies performed for numerical modeling in mountainous

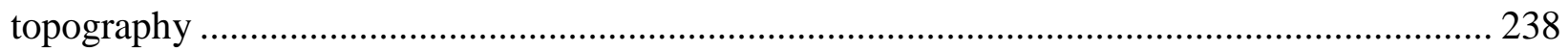

Table A2 Summary table of studies performed for numerical modeling in mountainous topography (continued) .......................................................................................... 239

Table A3 Summary table of studies performed for numerical modeling in mountainous

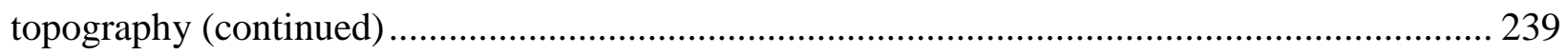

Table A4 Bottom of Pittsburgh coal seam elevation data................................................... 240

Table A4 Continued (1) .................................................................................................. 241

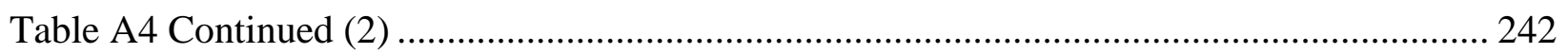

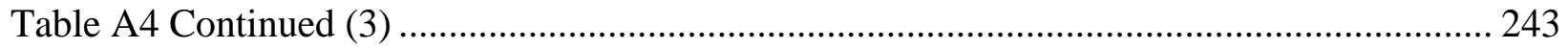

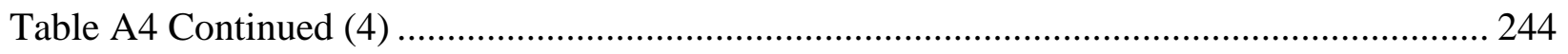

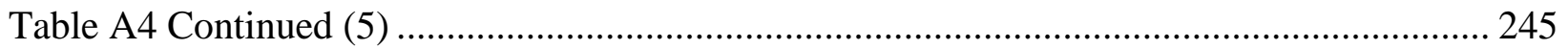


Table A5 Ground surface topographic data ...................................................................... 246

Table A5 Continued (1) ................................................................................................. 247

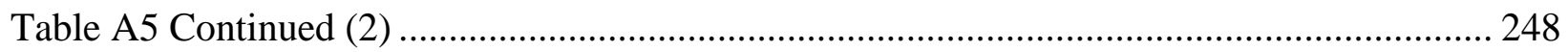

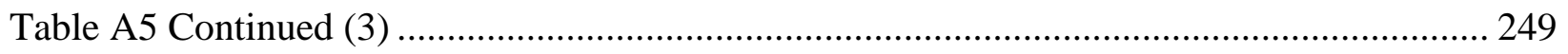

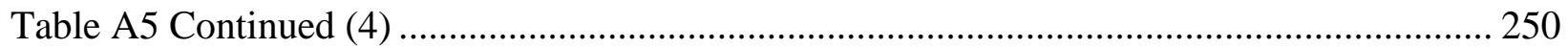

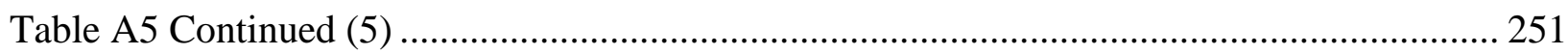

Table A6 Compiled borehole logs for geologic detail ...................................................... 252

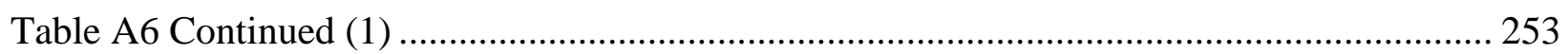

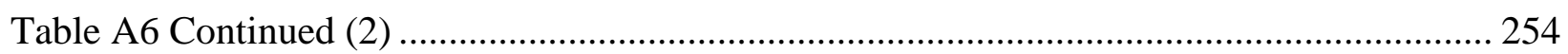

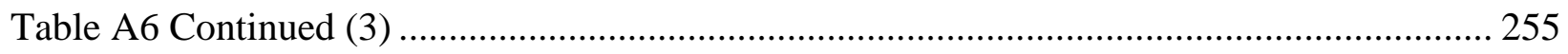

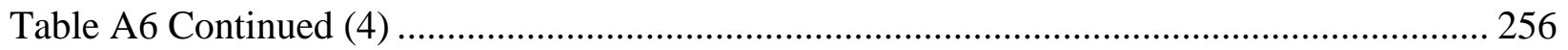

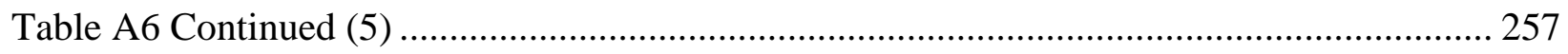

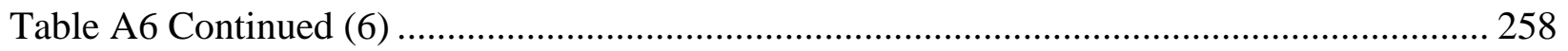

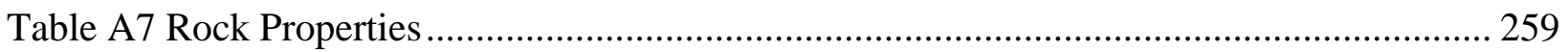

Table A7 Continued (1) ................................................................................................... 260

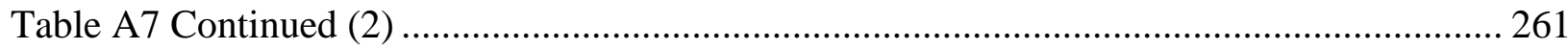

Table A7 Continued (3) .................................................................................................. 262

Table A7 Continued (4) ................................................................................................... 263

Table A8 Ryerson Station Dam dimensions (PADCNR, 2007) ............................................. 267

Table A9 (1) Station 934 Details ......................................................................................... 268

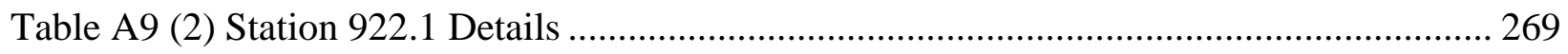

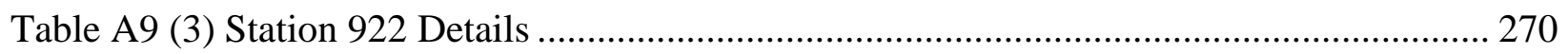

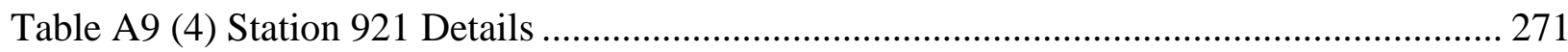

Table A9 (5) Station 926 Details ........................................................................................ 272

Table A9 (6) Station 17 Details ....................................................................................... 273

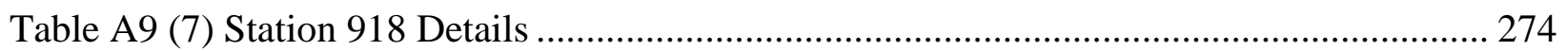

Table A9 (8) Station 14 Details ........................................................................................... 275

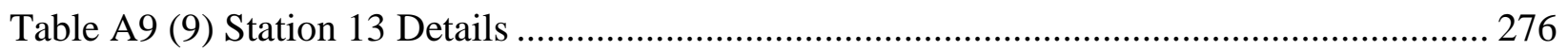

Table A9 (10) Station 931 Details ................................................................................... 277

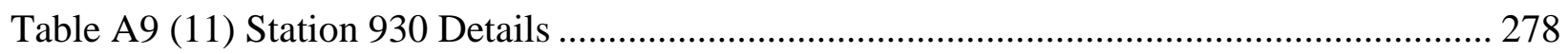

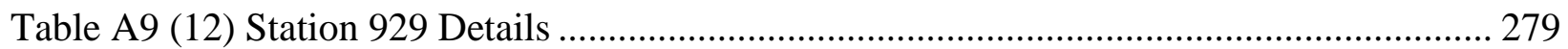

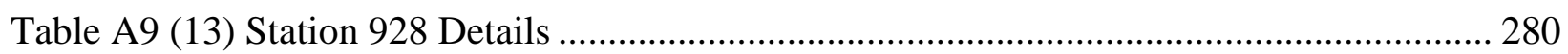

Table A9 (14) Station 927 Details ....................................................................................... 281

Table A9 (15) Station 16 Details ..................................................................................... 282

Table A9 (16) Summary station and Panel 7I profile relative model coordinates.................... 283

Table A10 (1) WC Detail 1 (R11-R8) 3D model stress results ............................................... 284

Table A10 (2) WC Detail 1 (R7-R5) 3D model stress results ............................................. 285

Table A10 (3) WC Detail 1 (R4-R2) 3D model stress results .............................................. 286

Table A11 Initial model stresses................................................................................ 287 


\section{LIST OF FIGURES}

Figure 1.1 U.S.ACE Dam Safety Portfolio Risk Management Process (U.S.ACE, 2014)........... 4 Figure 2.1 Illustration of ground movements due to subsidence according to Grond, 1957 (Singh, 1992) 12

Figure 2.2 Area of influence (a) Effect propagated to surface by mining (b) Maximum subsidence at a point $\mathrm{P}^{\prime}$ by mining entire area of influence (Singh, 1992) ............................... 12

Figure 2.3 Overlying strata disturbance (Singh, 1992) ......................................................... 13 Figure 2.4 Subsidence profiles for subcritical, critical, and supercritical mine widths (Singh,

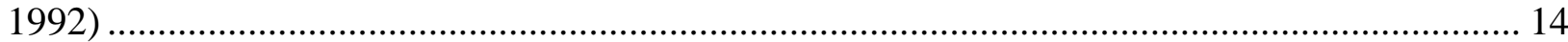

Figure 2.5 Safety zone beneath dam and impounded body of surface water (Babcock \& Hooker,

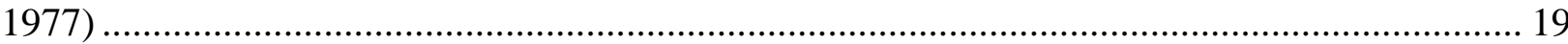

Figure 2.6 Stress field effects due to longwall mining disturbances (Zhang et al., 2012)........... 22

Figure 2.7 In Situ principal stress direction ................................................................... 23

Figure 2.8 Zones of extension and compression in a valley (Zhang et al., 2012) ..................... 24

Figure 2.9 Valley stress relief physical manifestation as an upward deformation at a valley bottom due to an increase in horizontal stresses (lateral compression) (Zhang et al., 2012) ...... 25

Figure 2.10 Valley stress relief surface effects ................................................................ 25

Figure 2.11 General illustration of hill seams created by valley stress relief (Sames \& Moebs,

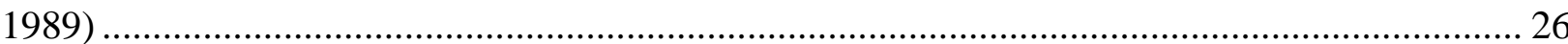

Figure 2.12 Block movement in a sagging subsidence wave .............................................. 27

Figure 2.13 Block movement in a hogging subsidence wave.............................................. 27

Figure 2.14 Lateral Dilation Mechanism (Mills, 2011 as cited in Zhang et al., 2012)............... 28

Figure 2.15 Restriction zones for mining near to a reservoir (Sydney, 2007) .......................... 30

Figure 2.16 Restriction zone for mining near to a dam (Sydney, 2007) ................................. 31

Figure 2.17 Ryerson Station Dam and surrounding longwall panels of the Bailey Mine (PADEP,

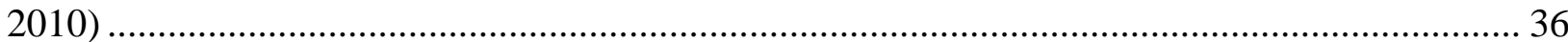

Figure 2.18 Right (east) side drain where the major seepage rate measurements were taken

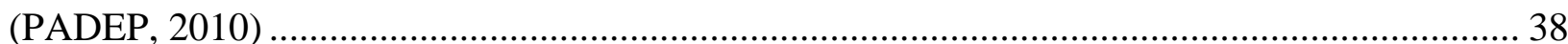

Figure 2.19 New seepage from the right (east) side wall drain (PADEP, 2010) ...................... 38

Figure 2.20 Opened vertical structural crack (PADEP, 2010) ............................................... 39

Figure 2.21 Vector plot of post-breaching movements in Duke Lake Valley (PADEP, 2007)... 41

Figure 2.22 Mapped locations of landslides and tension cracks (PADEP, 2007) ..................... 42

Figure 3.1 Valley closure versus longitudinal distance from goaf end (Waddington \& Kay, 2003)

Figure 3.2 U.S.ACE dams and mine permit areas for WV ............................................... 48

Figure 3.3 East Lynn Dam and underground coal mine permitted area ................................... 50

Figure 3.4 Summersville Dam and nearby underground mine permit area ............................ 51

Figure 3.5 Tygart Dam and nearby underground mine permits............................................ 52 
Figure 3.6 NID locations in northern WV and current underground coal mine permit area

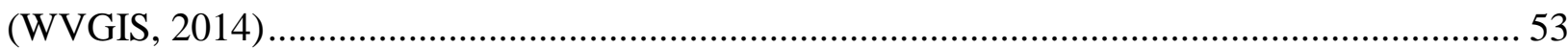

Figure 3.7 NID locations in southern WV and current underground coal mine permit area

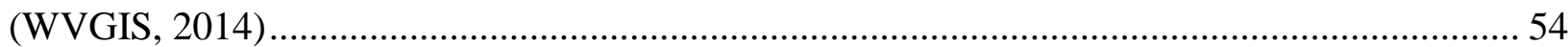

Figure 3.8 Topography and contours at the Ryerson Station Dam and nearby area (USGS, 2014)

Figure 3.9 Topography and contours at the Tygart Dam and nearby area ............................. 57

Figure 3.10 Slope severity at Ryerson Station Dam and nearby area..................................... 58

Figure 3.11 Slope severity at Tygart Dam and nearby area................................................59

Figure 3.12 Bedrock geology for the Ryerson Station Dam and Tygart Dam .......................... 60

Figure 3.13 Proximity of longwall mining to the Ryerson Station Dam ............................... 61

Figure 3.14 Tygart Lake and Dam with nearby underground longwall mine permit area .......... 62

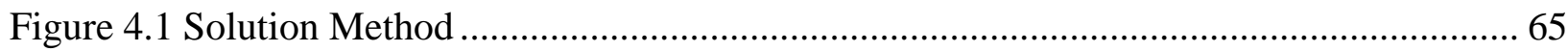

Figure 5.1 Ryerson Station Dam with superimposed mine panels (PADEP, 2010) ................... 71

Figure 5.2 Illustration of PFMA for Ryerson Station Dam ..................................................... 76

Figure 5.3 Angles from Bailey Mine Longwall Panel 4I East to Ryerson Station Dam ............. 77

Figure 5.4 Idealized hill seams (Sames \& Moebs, 1989) ....................................................... 78

Figure 5.5 Continuation Condition 1: Mining continues in a panel closer to the dam ................ 80

Figure 5.6 Continuation Condition 2: Mining initiates and continues surface effects in the same

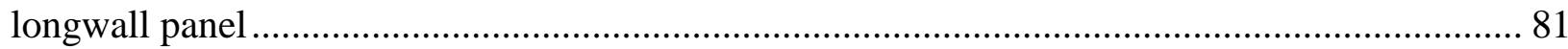

Figure 5.7 Generalized force regimes in the valley of the dam ......................................... 83

Figure 5.8 Downstream face displacement direction at Ryerson Station Dam (PADCNR, 2007)

Figure 5.9 Upstream face displacement direction at Ryerson Station Dam (PADCNR, 2007) ... 83

Figure 5.10 Mechanics of Ryerson Station Dam displacement due to valley stress relief.......... 84

Figure 5.11 Decision tree for far-field strain near to a dam................................................... 85

Figure 5.12 Summary of far-field ground strain PFMA timeline ......................................... 86

Figure 5.13 Conceptual fault tree for far-field ground strain leading to loss of authorized purpose

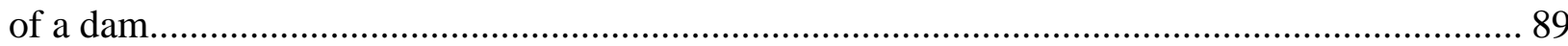

Figure 5.14 General statics of force proportions on a valley slope .................................... 93

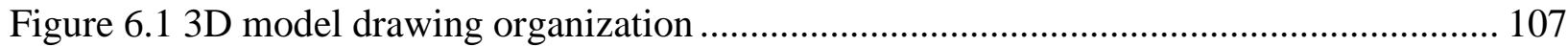

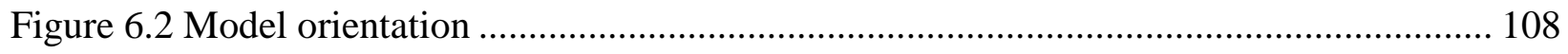

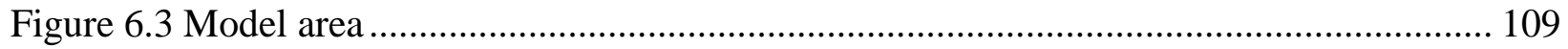

Figure 6.4 Final model geometry with elevation contours ................................................. 110

Figure 6.5 3D final model geometry with elevation contours ............................................... 111

Figure 6.6 Coal bed structure $50 \mathrm{ft}$. contours at Ryerson Station State Park............................ 112

Figure 6.7 Bedding plane angle and major geologic formations at the Ryerson Station Dam

valley (PADCNR, 2007) ................................................................................................ 113

Figure 6.8 Pittsburgh coal bed thickness (USGS, 2000) ................................................... 114

Figure 6.9 Panel 7I coal extraction regions ................................................................... 115 


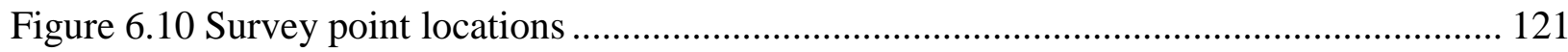

Figure 6.11 2D representation of survey monitoring points ................................................ 123

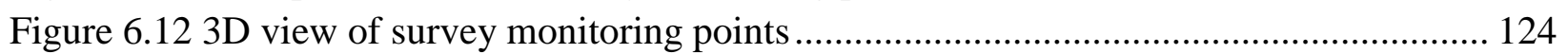

Figure $6.13(\mathrm{X}, \mathrm{Y})$ vector data plots for Duke Lake western rim survey points (PADCNR, 2007)

Figure 6.14 Elevation (Z) change data for Duke Lake western rim survey points (PADCNR,

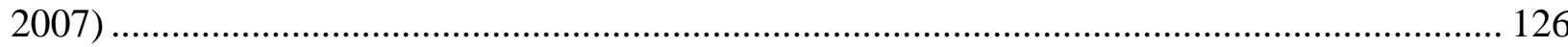

Figure 6.15 3D sidewall and surface boundary conditions .................................................... 129

Figure 6.16 Linear correlations of two data sets (LeBlanc, 2004)............................................. 131

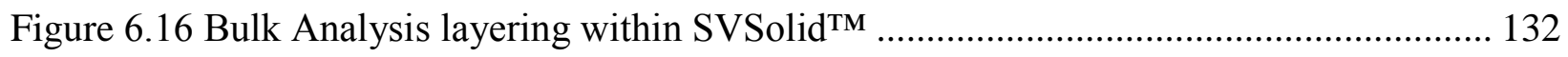

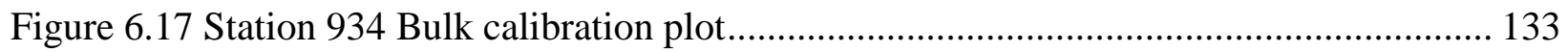

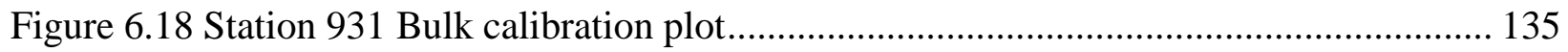

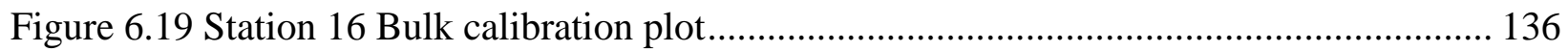

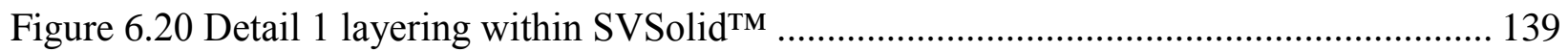

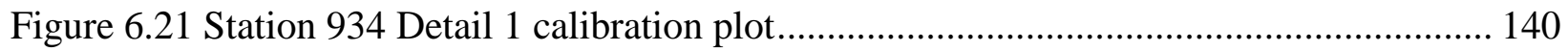

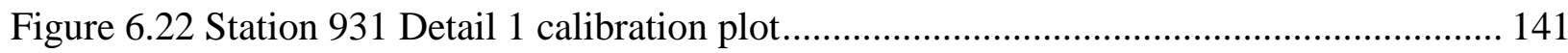

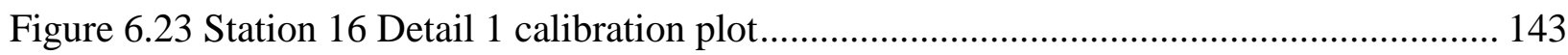

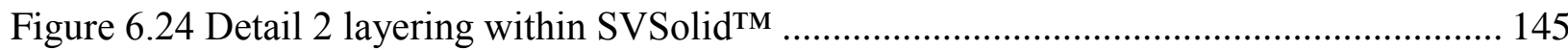

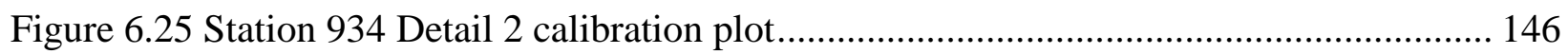

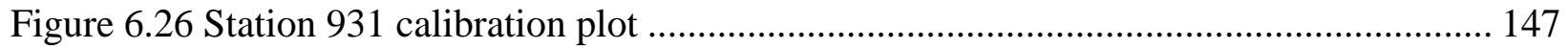

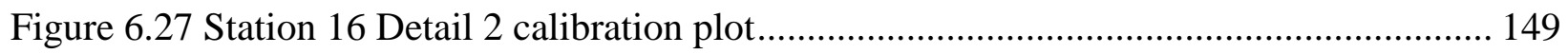

Figure 6.28 Pearson's Correlation Coefficient (PCC) for each level of model detail ................ 152

Figure 6.29 All model stations (15x) X stress versus Linear Offset to Panel 7I ........................ 155

Figure 6.30 All model stations (15x) Y stress versus Linear Offset to Panel 7I ....................... 156

Figure 6.31 All model stations (15x) Z stress versus Linear Offset to Panel 7I......................... 157

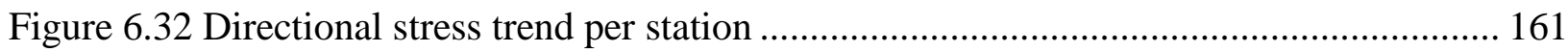

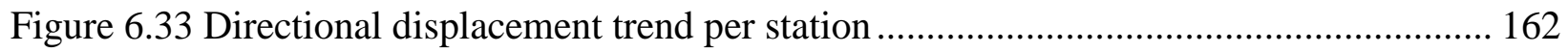

Figure 6.34 X Stress (psf) versus Linear Offset distance (ft.) ................................................ 163

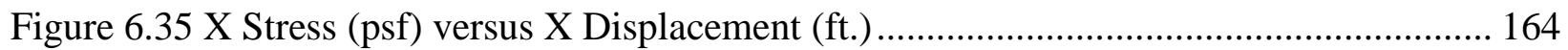

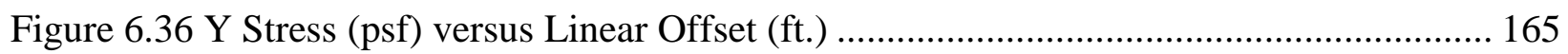

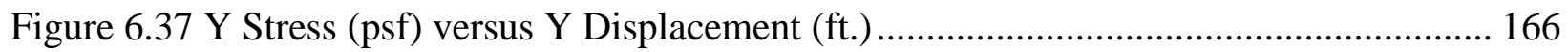

Figure 6.38 Z Stress (psf) versus Linear Offset (ft.) ............................................................. 167

Figure 6.39 Z Stress (psf) versus Z Displacement (ft.) …….............................................. 168

Figure 6.40 2D displacement vectors (a)Left: All coal removed; (b)Right: Coal removed to R7

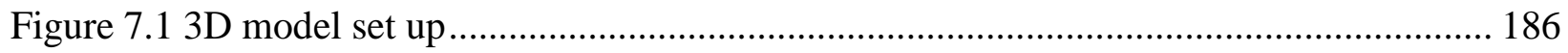

Figure 7.2 3D plot of extraction regions, stations, and associated strain rates for foundation rock

Figure 7.3 3D plot of extraction regions, stations, and associated strain rates for reinforced concrete 
Figure 7.4 ECFT for far-field ground strain affecting dams. 199

Figure 7.4 Idealized monitoring scheme for far-field ground strain propagation..................... 213

Figure A1 Elevation (Z) change data for Duke Lake western rim survey points (PADCNR, 2007)

Figure A2 Elevation $(Z)$ change data for Duke Lake western rim survey points (PADCNR, 2007)

Figure A3 (x,y) vector data plots for Duke Lake western rim survey points (PADCNR, 2007) 266

Figure A4 Total results for X stress versus depth............................................................... 287

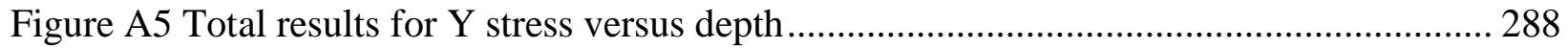

Figure A6 Total results for $\mathrm{Z}$ stress versus depth .......................................................... 289 


\section{CHAPTER 1. INTRODUCTION}

There are many dams in the United States that are used for recreation, flood control, transportation, and to provide reservoirs for drinking water. The United States Army Corps of Engineers (U.S.ACE) owns 23 dams in West Virginia amongst the Huntington, Pittsburgh, and Baltimore districts, and 694 dams nationwide and in Puerto Rico (U.S.ACE, 2014). West Virginia has 609 dams listed in the National Inventory of Dams (NID) (U.S.ACE, 2014).

West Virginia's economy has been fortunate to have such an abundant natural resource like coal, however the extraction of coal has resulted in some adverse effects on the land and watershed areas. As energy demands push hydrocarbon extraction technologies to their limits, public safety and the competency of our infrastructure become topics of great significance as the areas of influence of these extraction areas encroach on more highly populated regions. It is well documented and understood that longwall coal mining causes subsidence resulting in measurable vertical as well as horizontal ground displacements. Methods to quantify and predict these ground movements have been developed (Peng \& Luo, 1993; Agioutantis \& Karmis, 2013). The prediction methods are traditionally based on conventional subsidence mechanisms and do not consider variations in topography which are known to have an influence on the magnitude of subsidence induced ground movements (Khair, Quinn, \& Chaffins, 1988; Zhang, Mitra, \& Hebblewhite 2013; Hebblewhite, Waddington, \& Wood, 2000).

Traditional engineering design commonly incorporates Factor of Safety calculations to ensure that a structure is stable. Modern engineering design integrates numerical methods which incorporate reliability, probabilistic, finite-element, and statistical methods to ensure design criteria are met and to confirm structure stability. These types of methods are becoming a more popular approach to engineering design in lieu of the factor of safety approach because they have the capacity and capability to incorporate and quantify anisotropic material properties, variability, and randomness (Haldar \& Mahadevan, 2000). Governmental entities such as the U.S.ACE as well as the private sector have begun to include risk assessment into their design protocols for protecting dams.

\subsection{Background}

Rock displacement due to subsidence can propagate to the ground surface and manifest as vertical and horizontal deformation. This rock displacement in the proximity of the mine void is an expected result of subsidence caused by longwall mining operations. The surface effects of subsidence generate tensile as well as compressive forces on the overburden strata. 
Subsidence effects can be localized or can extend over large areas. The issues that arise due to subsidence have been traditionally analyzed by using empirical approaches. These approaches generated databases from field data gathered with the intent to protect structures and agricultural lands. These traditional approaches are referred to as conventional subsidence theory and utilize an angle of draw to define perimeter boundaries of effects (Singh, 1992). Additional attempts to protect surface structures have been developed as the angle of damage (Karmis, Mastoris, \& Agioutantis, 1994), and the angle of critical deformation (Peng \& Geng, 1982). The angle of draw is defined as the angle between the extent of the mine workings and the point of zero movement at the ground surface (Singh, 1992). The angle of damage is defined as the acute angle existing between the line connecting the point with the allowable value of surface deformation and panel edge (Peng \& Geng, 1982).

Studies in Australia indicate that horizontal displacements due to underground mining have the potential to propagate large distances further than the traditionally suggested distances within the angle of draw. These effects can cause significant movements in sloped topography, among other factors (Hebblewhite et al., 2000). These far-field ground movements outside of the angle of draw are commonly referred to as non-conventional subsidence.

In the United States, the guidance document that provides coal mining companies with allowable offset distances from structures retaining water is Information Circular 8741 (IC 8741) (Babcock \& Hooker, 1977). This document suggests minimal offset distances which are based on field evidence of common surface effects due to coal mining. Observation of longwall coal mine arrangements seem to usually be significantly conservative in this matter and stay many times further away from high risk and high cost structures than the regulations require, however this approach is not always sufficient. The Ryerson Station Dam was breached in 2005 in order to protect the safety of the downstream population. In this case the dam was well outside of the area traditionally predicted to be affected by the mine subsidence (Hebblewhite \& Gray, 2014).

Similar scenarios exist in Appalachia which may require in-depth analyses to ensure the safety and security of downstream populations, property, investments, and ecology. In West Virginia, for example, cases which may fall in this category are the Tygart Dam, Summersville Dam, and the East Lynn Dam; all owned by the United States Army Corps of Engineers (U.S.ACE). Current to July, 2014, the U.S.ACE also lists 609 dam in West Virginia on the National Inventory of Dams (NID) 79 of which are within 1 mile of permitted underground mines, and 45 have permits directly underneath.

Spatial maps were created using Geographic Information System GIS software that show a number of dams which are within proximity of underground longwall operations. In many cases, permitted mine areas are directly underneath of dams listed in the National Inventory of Dams (NID). Although specific exclusion zones may be implemented for these cases following IC 
8741. This is the reality of the extent of the problem, although little evidence has been collected which conclude that problems frequently or infrequently occur in the United States due to nonconventional subsidence theory.

Software has been developed which quantify underground coal mine subsidence such as Surface Deformation Prediction System (SDPS), and Comprehensive and Integrated Subsidence Prediction Model (CISPM). Several programs exist, each of which are based on their own empirical data bases; many upon the angle of draw. These programs have proven to be sound and are commonly used in the mining industry. Numerical computer modeling is extraordinarily useful, although oftentimes ideal models are generated which do not incorporate all of the significant practical variables. In non-conventional subsidence theory, factors such as the severity of sloped topography are critical. Modern traditional subsidence analysis approaches do not employ such factors (PADEP, 2010).

\subsubsection{Research Motivation}

The breaching of the Ryerson Station Dam in Greene County, Pennsylvania in August, 2005 reportedly due to far-field ground strain phenomena illustrates that the conventional engineering analysis methods to predict subsidence to protect structures may be incomplete. It is theorized that the mechanisms that led to the failure of the Ryerson Dam could pose a hazard to other dams in Appalachia and other locations in the United States. Concerns from the effects of mineral extraction are mounting as an increasing number of non-traditional subsidence case studies arise (Hebblewhite \& Gray, 2014).

A large number of investments into large scale critical infrastructure in the United States were made within the twentieth century. These components of critical infrastructure are expensive and difficult to replace. As a consequence, many of these components, such as large dams, have not been replaced and continue to age beyond their intended service life.

As a result of the increasing need to manage assets, and ensure their durability, the United States Army Corps of Engineers (U.S.ACE) began the development of a risk based management program in 2009. The U.S.ACE utilizes the "Safety of Dams - Policy and Procedures" document as an approach for risk management decision making policy (U.S.ACE, 2011). This document offers a flowchart for action to be taken in risk management. This flowchart is shown in Figure 1.1. Following the flowchart in Figure 1.1 to "All Dams," the subsequent two decision nodes depend on "periodic assessment," "periodic inspections," "assessment findings," and "lessons learned." As a result of incidents such as Ryerson Station, PA, Electric Lake, UT, and Interstate70 in PA; there is a demand for a forward-looking procedure for predictive methods to be incorporated into the U.S.ACE decision making process. This research provides the 
incorporation of predictive methods to identify and mitigate the root causes of far-field ground strain.

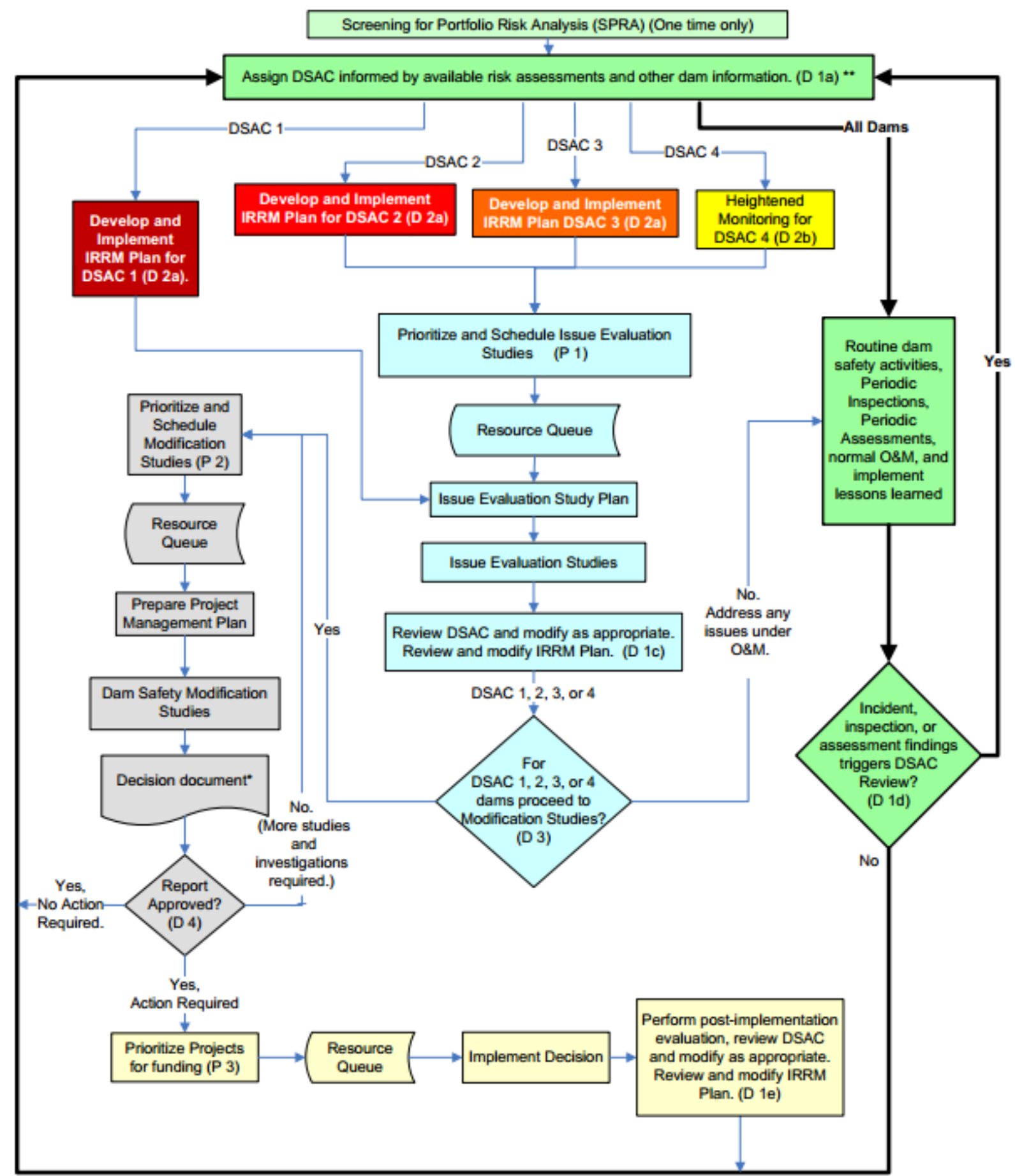

Decision Points are label as (D 1a), Prioritization Points are labeled as (P 1), and the details for each point is explained in Chapter 3. * Independent External Peer Review requirements are to be addressed per guidance in Chapter 9.

* Regardless of DSAC classification, dams with insignificant or no consequences should they fail are considered exceptions; will be so tagged, and are exempt from the dam safety portfolio management process depicted here in Figure 3.1.

Figure 1.1 U.S.ACE Dam Safety Portfolio Risk Management Process (U.S.ACE, 2014) 


\subsection{Potential Hazard Assessment for Mineral Extraction Affecting Dams}

This assessment includes context for the hazard identification associated with mineral extraction affecting dam structures and reservoirs. The purpose of this assessment is to present known information pertaining to the extents of U.S.ACE dams and reservoir sites located in West Virginia in close proximity to mining operations. Background information and mapping results are presented to support the assessment of potential mineral extraction hazards. Conclusions of the assessment are intended to define the focus of this research.

Studies such as from Booth, Curtiss, Demaris, \& Bauer, 2000; and Zhang, Roegiers, Bai, \& Zhang, 2001, have shown that stresses and strains induced by vertical ground subsidence initiated by underground mining can cause changes in regional groundwater flow. The increased seepage into subsurface soil and rock may lead to soil particle transport and ultimately increase hazard to the integrity of reservoirs and dams. Additionally, vertical and horizontal movements resulting from far-field ground strain accentuated by steeply sloped topography are hypothesized to have the potential to cause damage to a dam structure and develop or worsen seepage. These adverse conditions resulting from longwall coal mining near to U.S.ACE dams may affect the authorized purpose of a dam or reservoir (i.e. flood control, navigation, recreation, etc. (U.S.ACE, 1994)).

\subsubsection{Hazard Contributors and Identification}

Underground longwall mining produces subsurface voids that lead to subsidence effects in the overlying strata. Consequences of strain effects induced by mining reaching a dam or reservoir include altering the material properties of foundation rock and may increase and develop pathways for flow through or around the dam.

Far-field ground strain is a newly realized potential hazard contributor to dams where subsidence related movements can occur well outside the traditional subsidence angle of draw. These movements are typically observed in valleys. The consensus among experts in the field of Subsidence Engineering suggests that the severity of sloped topography as well as already high in situ stresses can have significant influences on the effects of subsidence deformation in valleys (Ferguson \& Hamel, 1981; Zhang et al., 2013; Singh, 1992; Hebblewhite et al., 2000). The effects of topography and stresses combine with movement due to vertical mine subsidence to cause valley closure and upsidence, where the valley sides move inwards and the valley floor heaves upward. These subsidence related movements can lead to structural damage to dams, change hydraulic conductivity of local strata, and alter groundwater flow around the dam leading to severe increases in seepage rates. 


\subsubsection{Investigation of Previous Incidents}

An investigation was performed into case studies involving mining that resulted in far-field ground strain at dams. Insight into the events which may occur as a result of extracting minerals via mining can assist in the development of a Potential Failure Mode Analyses (PFMA) which is intended to contribute to the protection of dams.

The Ryerson Station Dam is an example of the impacts that far-field ground strain effects can have on a dam. Beginning in April 2005, ground movements led to an increase in seepage and structural cracking of the concrete gravity dam. During a six-week period from June to July, 2005, seepage at a wall drain increased from 20 gallons per minute to 80 gallons per minute. This seepage, along with severe cracking, necessitated the breaching of the dam for safety purposes. During this time, longwall mining activities were located well outside of the traditional subsidence zone with the closest approach at a horizontal offset of approximately 900 $\mathrm{ft}$. This distance would have been at a draw angle in excess of 50 degrees which is well outside the typical range of 15-25 degrees (PADEP, 2010).

Following an investigation by the Pennsylvania Department of Environmental Protection (PA DEP), non-conventional mine subsidence behavior (valley closure and upsidence) was cited as the cause of seepage and structural cracking. This conclusion was the result of site specific field monitoring program from March to November 2006 after the dam was breached. This was the first widely reported case of valley closure behavior outside of Australia, where it has been documented since the 1990's. This indicates that valley closure and upsidence can occur in Appalachia.

GIS mapping identified three U.S.ACE dams in West Virginia as being within a potential zone of hazard for damage as a result of nearby mining activities. This zone of hazard was based on the documented case of damage at the Ryerson Station Dam where impacts were first noted when mining was approximately 6,000 feet away. The dams were denoted as the epicenter of a set of circles indicating $0.25, .050,0.75$, and 1 mile. If the dam had been digitized into the mapping, the distances would be somewhat different as some large dams can be much larger than $1,000 \mathrm{ft}$. in length, although the mapping that was performed does provide some indication of the proximity of mining to dams in West Virginia. These sites are identified in Table 1.1.

Table 1.1 U.S.ACE projects located in WV in close proximity to permitted mining

\begin{tabular}{|c|c|c|}
\hline Project & Location & $\begin{array}{c}\text { Nearest permitted mining } \\
\text { approach }\end{array}$ \\
\hline East Lynn Lake Dam & Wayne County, WV & Between 0.25 and 0.50 mile \\
\hline Summersville Dam & Nicholas County, WV & Between 0.25 and 0.50 mile \\
\hline Tygart Dam & Taylor County, WV & $\begin{array}{c}\text { Between } 0.75 \text { and } 1.0 \text { mile } \\
\text { (approximately 3,600 feet) }\end{array}$ \\
\hline
\end{tabular}




\subsubsection{Hazard Assessment Conclusions}

Far-field ground strain induced by mining operations poses a potential hazard to nearby dams.

- Mine subsidence can combine with topographic and geologic conditions to produce valley closure and upsidence movements that have been shown to cause structural damage and lead to increased seepage rates by changing the hydraulic conductivity of local soil and rock, and alter or exacerbate rock fracturing.

The hazard is further demonstrated by case studies.

- The Ryerson Station Dam breach provides evidence that mining induced far-field ground strain can occur in Northern Appalachian geology and that the movements are potentially damaging for dams.

- Three sites were identified in the West Virginia areas that exist in close proximity to underground mining.

\subsubsection{Determination of Research Focus}

A significant case has been documented where the effects of mineral extraction caused severe damage to the Ryerson Station State Park Dam case in Greene County, Pennsylvania.

The objective of this research is to identify and investigate potential failure modes resulting from far-field ground strain. This has been determined since a case study exists, measurements have been taken at the site of the case study, and other dams in the investigated sample area of West Virginia appear to be potentially at risk of a similar result.

\subsection{Research Purpose, Objectives, \& Contributions}

The research purpose is to develop a root cause based solution relating far-field ground strain to offset distances from critical infrastructure. Potential failure modes were identified having the greatest significance along with the development of an analytical method for analyzing far-field ground strain. A cause-and-effect analysis was investigated focusing on strain related failure modes propagated in soil and rock bearing formations supporting a water retention dam structure. 


\subsubsection{Objectives}

The objectives of this research are arranged to develop of a Semi-Quantitative Potential Failure Mode Analysis - Root Cause Analysis (SQPFMA-RCA) for a dam structure due to the effects of underground mineral extraction induced far-field ground strain. The SQPFMA-RCA will be developed in correlation with a far-field ground strain related case study to provide insight for hazard reduction opportunities.

\section{Objective 1}

Develop a Potential Failure Mode Analysis (PFMA) for a water reservoir dam from initiation to breach due to a mining induced far-field ground strain scenario within the proximity of a dam. This consists of a conceptual fault tree and event tree failure analysis. Topics included in the conceptual fault tree and conceptual event tree will be determined via case study investigation of the events leading to the Ryerson Station Dam breach.

\section{Contribution}

Introduce and apply a hazard assessment for preservation of the authorized purpose of dams due to far-field ground strain related phenomena following similar methods incorporated by the U.S.ACE.

\section{Objective 2}

Utilize finite element analysis to determine altered shallow near-surface ground deformations and stress field changes which ensued at the Ryerson Station Dam. This analysis includes:

2.1 Calibration to Ryerson Station State Park monitoring field data and verification of model precision

2.2 Parametric sensitivity study

\section{Contribution}

Develop a reliable finite element method (FEM) model to predict far-field ground strains, identify the potential for propagation, and quantify disrupted in situ stresses, strains, and deformations due to the introduction of underground mine voids.

The numerical modeling results will be used to determine the sensitivity of critical parameters pertinent to far-field ground deformations. Parameter significance will assist in the final Event and Causal Factor Tree (ECFT) development. 


\section{$\underline{\text { Objective } 3}$}

Utilize model results to acquire insight into ground behavior and establish the SQPFMA-RCA. The SQPFMA-RCA will be developed in collaboration with model results and case history PFMA outcomes to make recommendations to prevent recurrence of potential far-field ground strain. This investigation will include:

3.1 Practical and effective use of model results to populate Event and Causal Factor Tree (ECFT)

3.2 Identify most significant contributors to an undesirable outcome

3.3 Develop recommendations for the mitigation of root causes

\section{Contribution}

The populated ECFT will be used to organize failure mode sequences and identify causal factors which lead to far-field ground strain. The SQPFMA-RCA will be utilized to determine intervention opportunities and make recommendations to mitigate hazard potential for events which have the potential to lead to far-field ground strain.

\subsection{Work Scope}

The work scope for this research is comprised of the following work elements.

Section 1: Literature Review) Perform a literature review of related dam failures or problems associated with mining induced deformations. Identify case studies where dam abutments and structural appurtenances experienced problems from mining outside of the angle of draw.

Section 1.1) Assessment of empirical and analytical studies:

- Address aspects of the problems that have already been solved.

- Review the method of approach to problem solving criteria.

Section 1.2) Identify current methodologies regarding the protection of dams to nearby mineral extraction.

Section 2: Ryerson Station Dam Case Study) Investigate the events leading to Ryerson Station Dam breaching as a case study.

Section 2.1) Provide descriptions on the mechanisms of ground movement for far-field ground strain phenomena based on historic observational evidence. Identify and develop failure mode methodology and develop a PFMA based on the Ryerson Station case study.

Section 2.2) Develop a listing of critical conditions under which far-field ground strain occurs 
Section 2.3) Acquire and superimpose data into Geographic Information Systems (GIS) for the Ryerson Station Dam area (PA) and WV for comparing and contrasting the conditions at Ryerson Station Dam to WV dams to determine the potential extent of the problem.

Section 3: Event Tree) Construct a conceptual fault tree and conceptual event tree following the hypothesized mechanisms and critical conditions of far-field ground strain leading to the breaching of the dam structure

Section 4: Finite Element Modeling) Develop a 3-dimensional Finite Element Method (FEM) model using SoilVision ${ }^{\mathrm{TM}}$ for the Ryerson Station Dam. Calibrate SoilVision ${ }^{\mathrm{TM}}$ modules to deformation measurements acquired by survey monitoring instruments installed at the site.

Section 4.1) Generate a numerical modeling matrix from which results will provide insight into the protection of dams by in situ stress disruptions resulting in far-field ground strain.

Section 5: Sensitivity Analysis) Perform a sensitivity FEM study specific to far-field ground strain failure modes to aid in the identification of root cause parameters for the construction of the final ECFT.

Section 5.1) Utilize modeling information to identify parameters which have the significant effects on undesirable conditions. Draw conclusions specific to the mitigation of significant parameters to reduce the hazard of the recurrence of these phenomena.

\section{Section 6: Semi-Quantitative Potential Failure Mode Analysis - Root Cause Analysis)}

Develop a SQPFMA-RCA including the final development of the ECFT to organize failure sequences and identify causal factors

Section 6.1) Apply ECFT, numerical modeling results, and case history insights to develop recommendations to prevent the occurrence of failure mode sequences 


\section{CHAPTER 2. LITERATURE REVIEW}

This chapter provides an overview of relevant topics involved with coal mining induced ground subsidence. Topics involving mine subsidence due to coal extraction have been studied extensively. The mechanisms of movement and predictability of deformations have been historically established according to empirical evidence. Subsidence has been largely addressed utilizing databases to develop analytical tools.

\subsection{Subsidence}

Subsidence is described by the National Coal Board Subsidence Engineer's Handbook as an inevitable consequence of underground mining; small and localized or extending over large areas; immediate or delayed for many years (Singh, 1992). The motivation for initial studies was largely due to severe damage to structures, communications infrastructure, and agricultural lands. The owners of the affected properties filed claims against mine operators and demanded compensation. In order to defend against unjustified claims, studies ensued which developed into the scientific field of mine subsidence engineering (Singh, 1992). As mining continues in our modern times, so do subsidence phenomena.

\subsubsection{Subsidence Overview}

When coal is extracted from interbedded subsurface rock, a void is created which disrupts the stress field in the interlaying strata. This disruption in in situ stress causes strain deformations to occur in the surrounding rock; the extent of which largely depends on the magnitude of the stresses and the mine void dimensions (Singh, 1992). Over some period of time which depends on the type of mining, mine design, and geologic factors, instability occurs which induces overlying stratum to move into the mine void. The movements of the overlying stratum works its way to the ground surface, resulting in three major manifestations: (1) cracks, fissures, or step fractures; (2) pits or sinkholes; (3) troughs or sags. Surface subsidence includes both vertical as well as horizontal movements (Singh, 1992). Subsidence causes overburden strata to fill in the mine void and cause deformations and disturbances propagating to the ground surface and may manifest as bed separation and surface cracks. Figure 2.1 shows that mine subsidence results in deformation of the overburden vertically downward, vertically upward, and horizontally. 


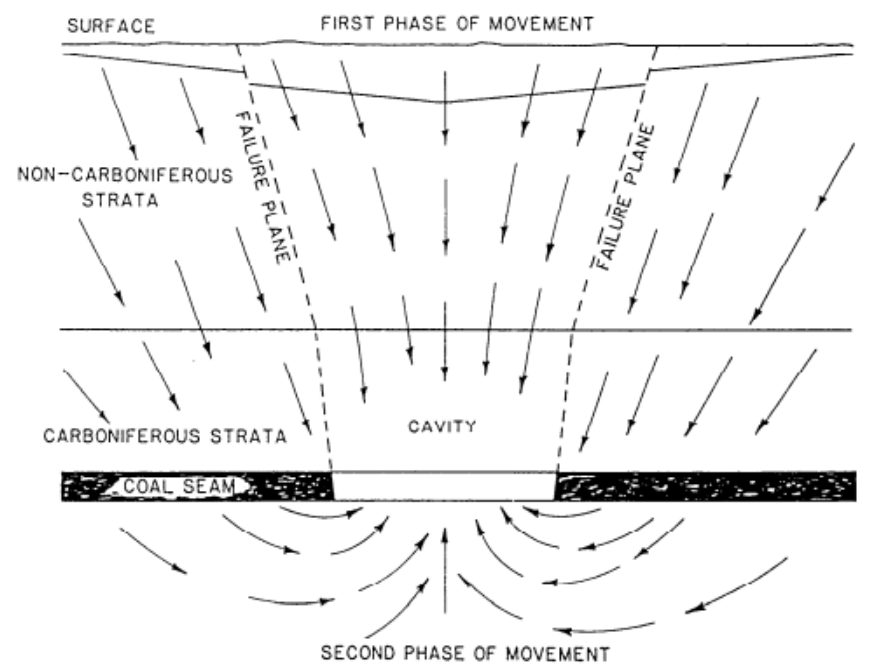

Figure 2.1 Illustration of ground movements due to subsidence according to Grond, 1957 (Singh, 1992)

According to subsidence theory, the largest ground effects occur within a subsidence angle of draw. The angle is an empirically derived dimension which creates a cone of disturbance above the mine void. Figure 2.2 illustrates the angle of draw and area of influence propagating from a point $\mathrm{P}$ to the surface (a) and from a point $\mathrm{P}$ ' at the surface to the depth of the mine void (b) (Singh, 1992).

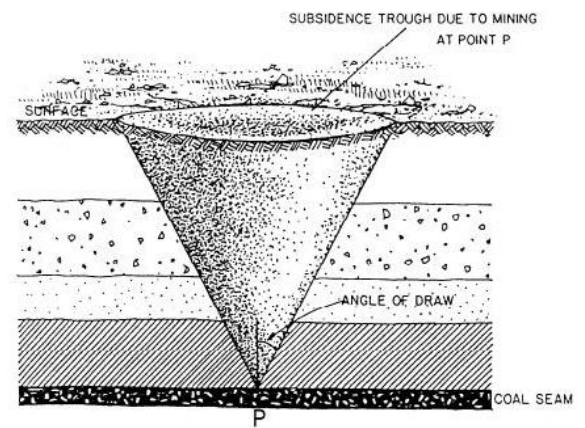

(a)

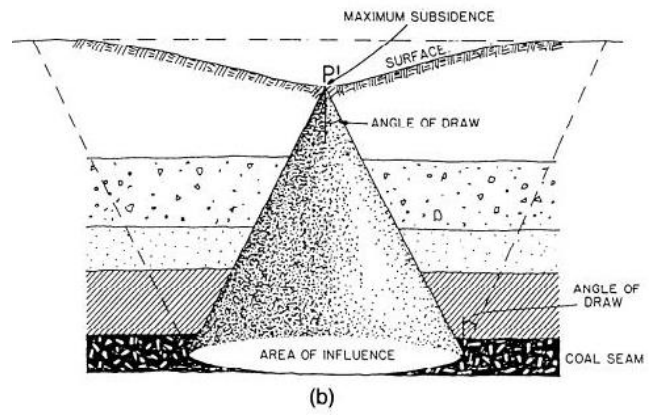

Figure 2.2 Area of influence (a) Effect propagated to surface by mining (b) Maximum subsidence at a point $P^{\prime}$ by mining entire area of influence (Singh, 1992) 
Figure 2.3 demonstrates subsidence as the overburden strata fill the mine void and causes deformations and disturbances propagating to the ground surface and manifesting themselves as bed separation, surface cracks, and other deformation.

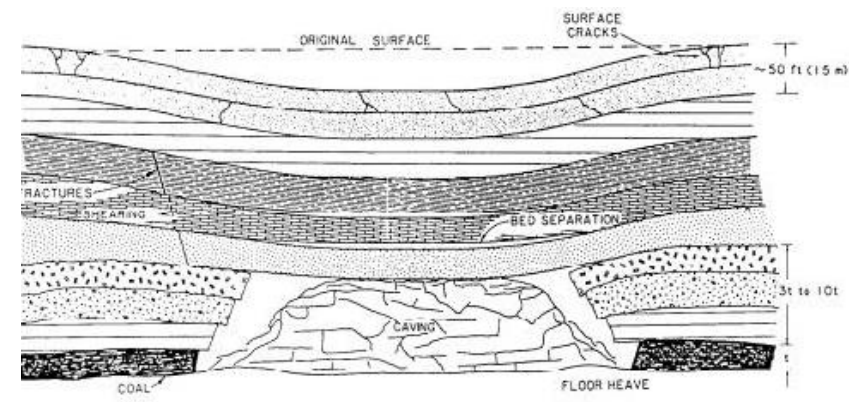

Figure 2.3 Overlying strata disturbance (Singh, 1992)

\subsection{Conventional Subsidence}

Subsidence profiles, horizontal strain curves, and horizontal displacement curves vary with changing mine widths. Figure 2.4 illustrates that regardless of the mine width and depth; subcritical, critical, or supercritical, the effects of subsidence continue to remain within the angle of draw. As a result of variability, methods to predict conventional subsidence have been established, and are commonly used throughout the mining industry, including SDPS, CISPM, LaModel, finite element, and finite difference software 


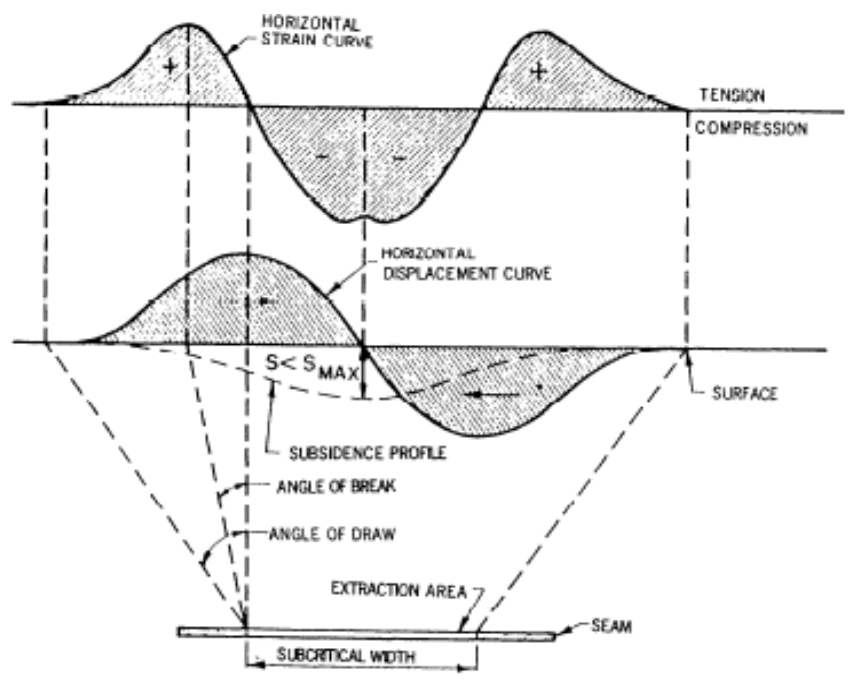

(a)

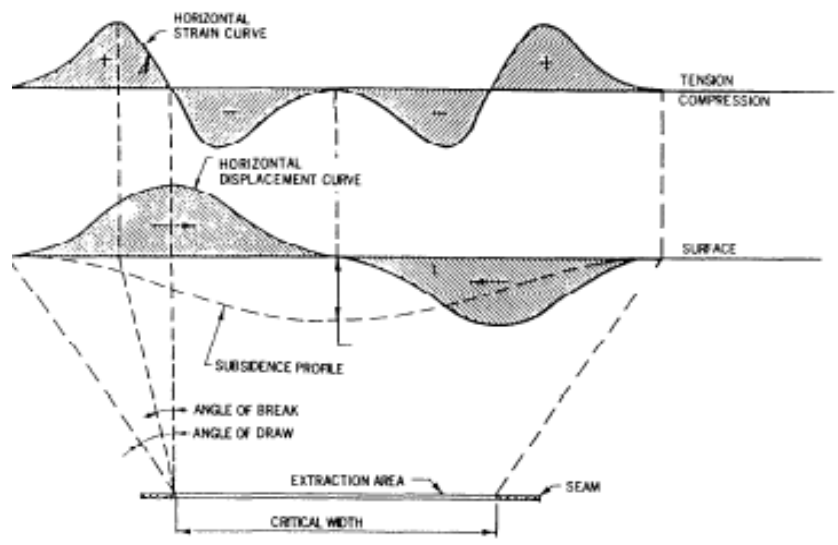

(b)

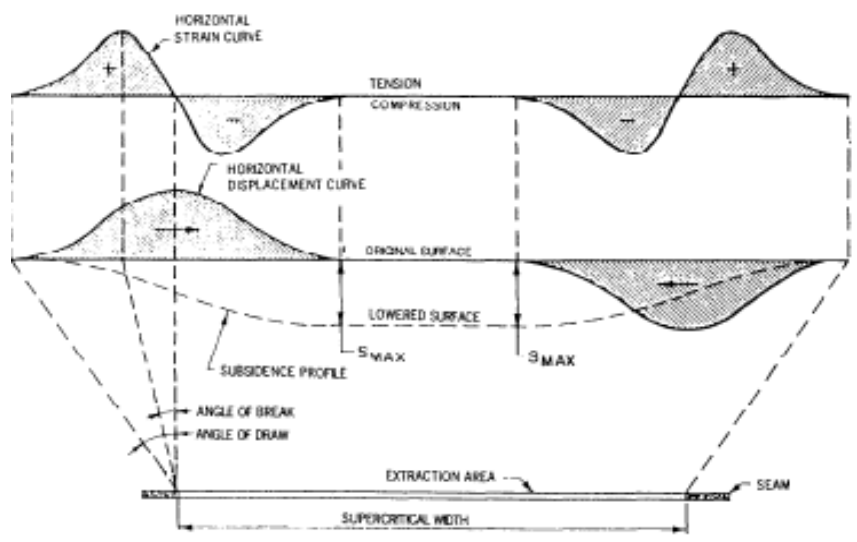

(c)

Figure 2.4 Subsidence profiles for subcritical, critical, and supercritical mine widths (Singh, 1992) 
The measurement of subsidence can be taken with instruments. The types of measuring instruments that are used depend on the objectives of the study, surface topography, area where measurements will be taken, profiles along which the monuments are installed, spacing and number of monuments or observation stations, total cost that can be tolerated, duration of the investigation; survey frequency, and labor requirements for surveying and data reduction (Singh, 1992).

Subsidence prediction techniques are predominately determined by empirical or phenomenological categories. The empirical theories are primarily based on observations and field experience from subsidence studies. Phenomenological techniques are based on idealized mathematical models that obey the laws of continuum mechanics. Some empirical methods for subsidence prediction are graphical methods, profile functions, and influence functions (Singh, 1992).

There are several factors that are thought to directly affect the magnitude and extent of mine subsidence. A complete description is provided for each of these subsidence factors in the National Coal Board's Subsidence Engineer's Handbook in Chapter 10, Section 10.6.2.4 (Singh, 1992). These factors are listed as:

- Effective Seam Thickness: In general, the thicker a coal seam is, the greater the subsidence that will result. In some cases, the entire seam is not extracted as pillars or non-minable coal is left in place.

- Multiple Seams: In some underground mine scenarios, multiple seams overlay each other. When collapses are initiated in multiple seams, the likelihood of subsidence events increases.

- Seam Depth: Subsidence is independent of the seam depth; meaning that the amount of subsidence does not change with varying depths, all else equal. Varying depths may result in prolonged surface effects.

- Dip of Seam: For an inclined coal seam, an asymmetric subsidence trough is formed that is skewed toward the rise; meaning that the limit angle is greater on the dip side of the mine workings. The strains are generally of smaller magnitude toward the dip direction.

- Competence of Mine Roof and Floor: The mine roof and floor initiate subsidence. The stronger the roof and floor, the more delayed the subsidence. The bulk volume of the collapsed material depends on the type of material of which the roof and floor are comprised. 
- Nature of Overburden: Strong massive overburden can delay the occurrence of subsidence

- Near-Surface Geology: The soil and rock near to the ground surface can accentuate the nature of subsidence effects

- Geologic Discontinuities: Faults, fissures, and folds may increase the potential for subsidence. Disruption of stress fields can trigger movements along fault planes.

- Fractures and Lineaments: Natural fractures and lineaments are known to adversely affect subsidence effects on the ground surface

- In situ Stresses: High horizontal stresses can cause mine roofs to fail violently

- Degree of Extraction: The time it takes for subsidence to develop can be delayed with lower extraction ratios

- Surface Topography: Sloped ground can cause down-hill movements as a result of gravity. Tensile strains may be increased at hilltops and decreased in valleys.

- Groundwater: The movement of strata can alter drainage gradients and change or create aquifers. Groundwater can infiltrate into mine voids.

- Water Level Elevation and Fluctuations: Structural elements in mines can be significantly weakened by saturation.

- Mined Area: The critical width needs to be exceeded along the lateral and longitudinal axes to achieve maximum subsidence.

- Method of Working: The type of subsidence that occurs is predominately a result of the type of mine workings causing the subsidence.

- Rate of Face Advance: The rate of face advance influences the fluctuation of propagating strains, and differential settlement results.

- Backfilling of Gob: The partial backfilling of gob reduces, but does not eliminate subsidence. 
- Time Elapse: The time it takes for subsidence to fully develop depends on a number of factors for specific scenarios. It may be either increased or decreased depending on these factors.

- Structural Characteristics: The damage incurred on surface structures depends on the size, shape, age, foundation design, construction materials and techniques used, standards of maintenance and repair, and purpose of the structure. Large structures are more likely to crack as a result of the strains and curvature induced by subsidence.

\subsubsection{Mechanisms of Conventional Subsidence}

Methods of underground coal mining primarily include the longwall method and the room and pillar method. Room and pillar mining induces subsidence in a much slower manner compared to longwall mining (Dyne, 1998). There are four types of subsidence. These include room subsidence, pit subsidence, sag subsidence, and beam subsidence, however the main two types of subsidence are trough (sag) and chimney (pit) (Dyne, 1998). These types of subsidence occur due to specific scenarios which include the geologic setting, type of mining, topography, and the depth and design of the mine.

Dams are susceptible to damage by ground movements, even from small movements at large distances. Concrete-gravity dams are especially sensitive to movements as concrete cannot attenuate much strain without fracturing. Remedial measures may assist stabilizing subsidence effects at a dam, however little remedial measures are possible at a dam once significant fracturing occurs. Table 2.1 shows the types of subsidence and when they occur with related parameters and remedial measures.

Table 2.1 Types of subsidence, correlated parameters, surface effects, and remedial measures

\begin{tabular}{|c|c|c|c|c|c|c|c|}
\hline \multirow{2}{*}{$\begin{array}{c}\text { Types of } \\
\text { Subsidence }\end{array}$} & \multirow{2}{*}{\multicolumn{3}{|c|}{ Pit }} & \multirow{2}{*}{ Room } & \multirow{2}{*}{ Sag } & \multicolumn{2}{|c|}{ Beam } \\
\hline & & & & & & Arch & Cantilever \\
\hline Overburden & Shale & $\begin{array}{l}\text { Unconsolidated } \\
\text { sediments - Dry }\end{array}$ & \begin{tabular}{|l|} 
Unconsolidated \\
sediments - \\
Wet
\end{tabular} & \begin{tabular}{|l} 
Shale with \\
interbedded \\
siltstone \\
\end{tabular} & \begin{tabular}{|l} 
Shale with \\
limestone and \\
siltstone
\end{tabular} & $\begin{array}{l}\text { Predominately siltstone } \\
\text { and sandstone }\end{array}$ & $\begin{array}{l}\text { Predominately sandstone } \\
\text { with interbedded } \\
\text { siltstone }\end{array}$ \\
\hline Topography & \multicolumn{2}{|c|}{$\begin{array}{l}\text { Flat to rolling } \\
\text { overburden less than } \\
100 \text { feet }\end{array}$} & \begin{tabular}{|l|} 
Generally flat \\
overburden any \\
thickenss
\end{tabular} & $\begin{array}{l}\text { Flat to rolling } \\
\text { overburden } \\
\text { less than } 150\end{array}$ & \begin{tabular}{|l|} 
Flat to rolling \\
overburden over \\
150 feet
\end{tabular} & $\begin{array}{l}\text { Flat to rolling and valley } \\
\text { bottoms overburden } \\
\text { any thickness }\end{array}$ & $\begin{array}{l}\text { Steep hillsides, high } \\
\text { relief, overburden any } \\
\text { thickness }\end{array}$ \\
\hline $\begin{array}{c}\text { Surface } \\
\text { Expression }\end{array}$ & \multicolumn{2}{|c|}{ Steep sided pit } & $\begin{array}{l}\text { Surface sag } \\
\text { indefinite size }\end{array}$ & $\begin{array}{l}\text { Depression } \\
\text { mimics room in } \\
\text { the mine }\end{array}$ & $\begin{array}{l}\text { Depression } \\
\text { larger than room } \\
\text { in mine }\end{array}$ & $\begin{array}{l}\text { Surface cracks with } \\
\text { graben type block } \\
\text { depressions. Water } \\
\text { loss from streams }\end{array}$ & $\begin{array}{l}\text { Large surface cracks, no } \\
\text { depres sion }\end{array}$ \\
\hline Depth & \multicolumn{2}{|c|}{$\begin{array}{l}\text { Generally only a few feet } \\
\text { can extend to the mine } \\
\text { level }\end{array}$} & $\begin{array}{l}\text { Generally less } \\
\text { than two feet }\end{array}$ & \multicolumn{2}{|c|}{$\begin{array}{l}\text { Generally less than } 1 / 2 \text { coal seam } \\
\text { thickness }\end{array}$} & $\begin{array}{l}\text { Tension cracks over } \\
\text { coal in place, shallow } \\
\text { depression over panels }\end{array}$ & $\begin{array}{l}\text { Crack width and depth } \\
\text { depends on overburden } \\
\text { thickness, relief and } \\
\text { thickness of beam }\end{array}$ \\
\hline \multicolumn{8}{|c|}{ Remedial Measures } \\
\hline Emergency & \multicolumn{2}{|c|}{$\begin{array}{l}\text { Excavation and backfill } \\
\text { with stable material }\end{array}$} & \multicolumn{4}{|c|}{ Temporary stabilization of structures to prevent further damage } & $\begin{array}{l}\text { Build fence around larger } \\
\text { cracks }\end{array}$ \\
\hline Long Term & \multicolumn{2}{|c|}{$\begin{array}{l}\text { Excavation and backfill } \\
\text { with stable material }\end{array}$} & $\begin{array}{l}\text { Identify piping } \\
\text { zone and grout } \\
\text { fractures in } \\
\text { bedrock }\end{array}$ & \multicolumn{2}{|c|}{$\begin{array}{l}\text { backfill void or build column } \\
\text { support systems in mine to stop } \\
\text { further failure }\end{array}$} & $\begin{array}{l}\text { Identify Compression } \\
\text { area, build support in } \\
\text { mine, grout cracks in } \\
\text { stream bed }\end{array}$ & Backfill crack \\
\hline
\end{tabular}




\subsection{Conventional Mine Subsidence: Regulatory Authority}

There are few regulations providing guidelines for mining in the vicinity of structures retaining water. The Federal regulations for the scenario of mining near to a dam are provided by "Results of Research to Develop Guidelines for Mining Near Surface and Underground Bodies of Water," and were developed with the compiled works of K. Wardell and Skelly and Loy. The objective of the document was specifically to provide "...maximum efficient utilization of underground coal resources consistent with minimizing inundation hazards" (Babcock \& Hooker, 1977). The perspective of the study was to protect the mine from inundation and provide safety to miners, not to provide the stability of a reservoir or dam. The document was authored by Clarence $\mathrm{O}$. Babcock and Verne E. Hooker. IC 8741 was developed for the United States Department of Interior Bureau of Mines (Babcock \& Hooker, 1977). The development of the document was undertaken due to the need of guidelines for mining near water and the increasing number of inundations near mining activities.

The approach to IC 8741 was empirical with databases collected worldwide as well as mining experience and was developed to be conservative, however further research should be considered to refine the conditions on which the recommendations are based (Babcock \& Hooker, 1977).

Further recommendations are provided for pillar dimensions, and safety zones for surface bodies of water; however, for the purposes of this research, only the guidance recommendations given for dams is presented. The following list outlines the recommendations for mining near to structures retaining water with respect to safety zones as provided by IC 8741 . Preceding the recommendations is a note that states "...no mining should be done in a safety zone beneath and around a structure where its failure would cause loss of life, property damage, or damage to water supplies needed for the public welfare. If the consequences of structural failure are not severe, mining may be undertaken."

Guideline 1. Where any surface structure is impounding a substantial body of surface water and damage to that structure by mine subsidence effects could lead to a risk of structural failure and prejudice to public safety, no mining should be permitted within the safety zone of such a structure.

Guideline 2. The perimeter of the structure requiring protection should be established by those responsible for its maintenance and safety. The safety zone around the perimeter of protection should extend outward 200 feet in all directions, then downward for 350 feet, and then outward at a dip of 65 from the horizontal. This safety zone is designated as a zone of extraction. 
- A greater or lesser distance than that specified in paragraph 2 may be used where local observations and/or experience indicate (Babcock \& Hooker, 1977).

Figure 2.5 presents the restriction zone for mining beneath impounded water as described in Guideline 2.

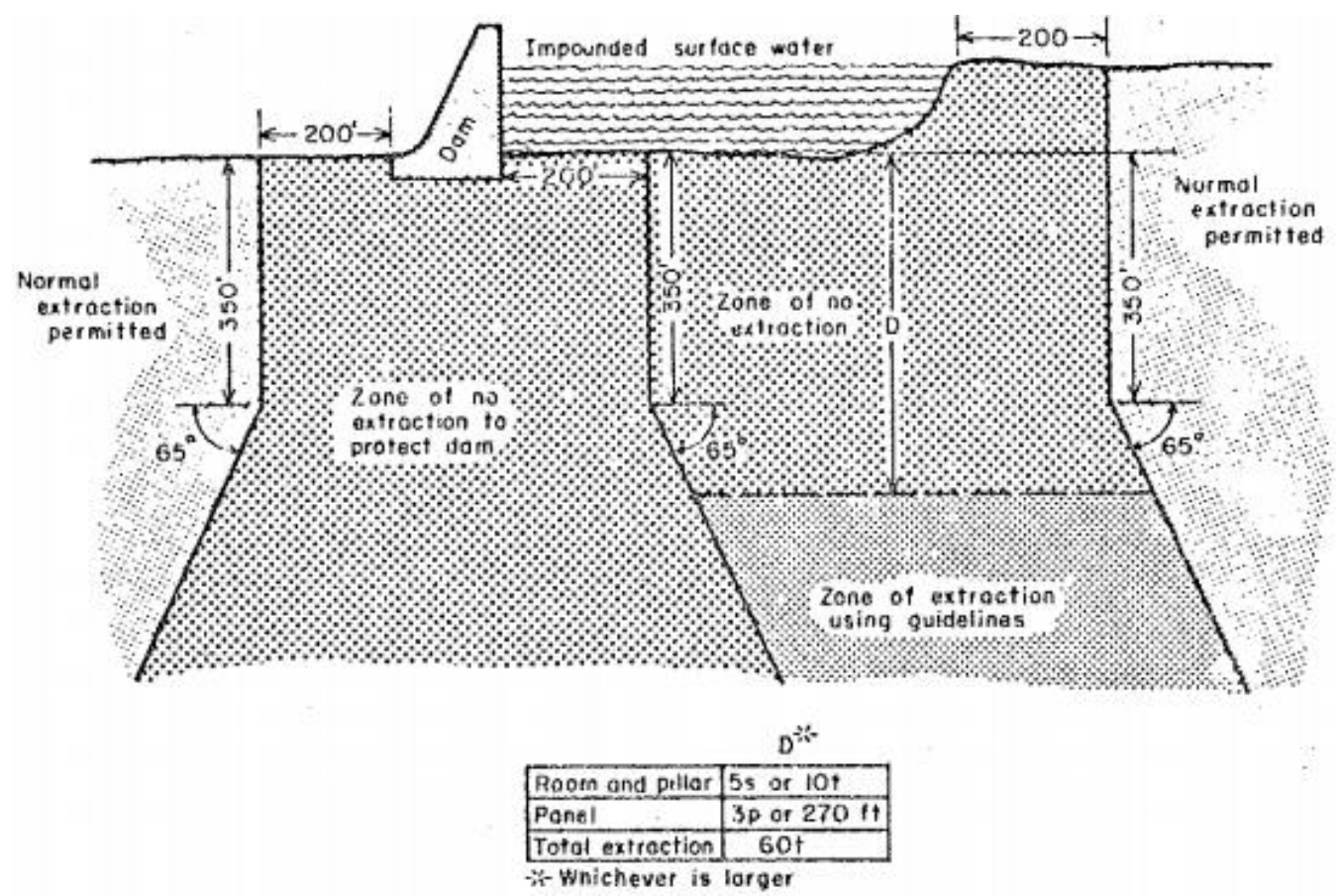

Figure 2.5 Safety zone beneath dam and impounded body of surface water (Babcock \& Hooker, 1977)

IC 8741 recommends a minimum distance to structures retaining bodies of water, modern subsidence prediction software such as the commonly used Surface Deformation Prediction System (SDPS) developed by Dr. Michael Karmis at Virginia Polytechnical Institute provide more realistic representations of nature, which typically set offset distances much greater than 200 feet. The costs associated with damaging an impounding structure of any great size are very high, including property damage, life loss, or monetary cost such as repair or replacement. Since the costs of affecting a large dam are high, mining companies have an incentive to stay far enough away from them that they will not be damaged. Understandably, mining companies also have incentive to extract as much coal as possible. The compromise of these two realities along with subsidence results provided by computer programs like SDPS determines where a mine plan will be located in proximity to dams, as long as the distance meets or exceeds the guidelines presented in IC 8741. 


\subsection{Non-Conventional Subsidence}

Non-conventional subsidence has been defined by the New South Wales Department of Planning in 2008 as a set of conditions varying from conventional subsidence. The term 'nonconventional subsidence' implies valley closure and far-field horizontal ground strains in steep topography which are induced by underground mining operations. The mention of 'far-field' implies that the movements are outside of the traditional angle of draw limits (Hebblewhite \& Gray, 2014). The phenomenon of non-conventional subsidence is identified to result in 'upsidence' and 'valley closure.' Valley closure occurs when the walls of the valley move toward each other downslope as a result of relief of gravity load stress. The definition is as follows:

"The conventional or general model of surface subsidence, which finds worldwide acceptance, is based on assuming the following site conditions:

- the surface topography is flat;

- the seam is level;

- the surrounding rock mass is relatively uniform and free of major geological disturbances or dissimilarities;

- the surrounding rock mass does not contain any extremely strong or extremely weak strata; and

- $\quad$ the mine workings are laid out on a regular pattern.

Where these conditions are not met, surface subsidence effects vary from those that would be predicted using the conventional model. Such subsidence effects are generally known as "nonconventional” (Hebblewhite \& Gray, 2015).

It is known in the field of Subsidence Engineering that topography and in situ stresses can have a substantial influence on the effects of subsidence (Singh, 1992). Large magnitude in situ stress can exacerbate valley bulging and upsidence. Upsidence occurs when the measured subsidence at the base of a valley is less than what would be expected in flat terrain, and is similar to observations for valley stress relief (Hebblewhite \& DiGiolia, Gray \& Associates, n.d.). Valley closure and upsidence occur naturally, but are thought to be largely accelerated in steep, irregular topography near to mining activities (Zhang et al., 2013). These phenomena are known to occur in the New South Wales (NSW) Southern Coalfield, but have not been confirmed as applicable in U.S. geology (Zhang et al., 2013; Waddington \& Kay, 2003). 


\subsubsection{In-situ Horizontal Stress}

In situ stress is a result of plate tectonics. In general, horizontal in situ stress is greater than vertical in situ stress. This determination and the magnitudes of stress are determined by the location on the plate. This scenario is not uncommon and has been observed to be the predominate condition in the Southern Coalfields in New South Wales where a great deal of nonconventional subsidence phenomena occur (Keilich, Lee, Aziz, \& Baafi, 2005). When a mine void is introduced under a valley, three events occur which describe the redistribution of in situ stresses:

i.) The stress field which existed before the void was excavated will redistribute above and below the opening.

ii.) The redistribution of in situ stress creates an unstable condition for the roof and floor, and they fail.

iii.) After the roof and floor collapse, the in situ stress field is redistributed further as subsidence propagates to the surface. The stresses progress upward from the void until they reach strata that has enough strength to take on the load. This location is generally between the caved zone and the surface (Keilich et al., 2005).

The strata directly above the void will experience a reduction in stress as a result of the rock collapsing into the void. The trajectory of the stress magnitude will sharply increase above the collapsed zone, then decrease to a degree. Stress magnitudes increase once again near the surface at the valley, then are relieved as buckled rock in the valley bottom and heave as an upsidence phenomenon. Horizontal deformation tends to move toward the valley in surrounding strata. Figure 2.6 illustrates conceptually how the in situ stress field is disrupted in a valley by the introduction of mine voids (Zhang, Mitra, \& Hebblewhite, 2012). 


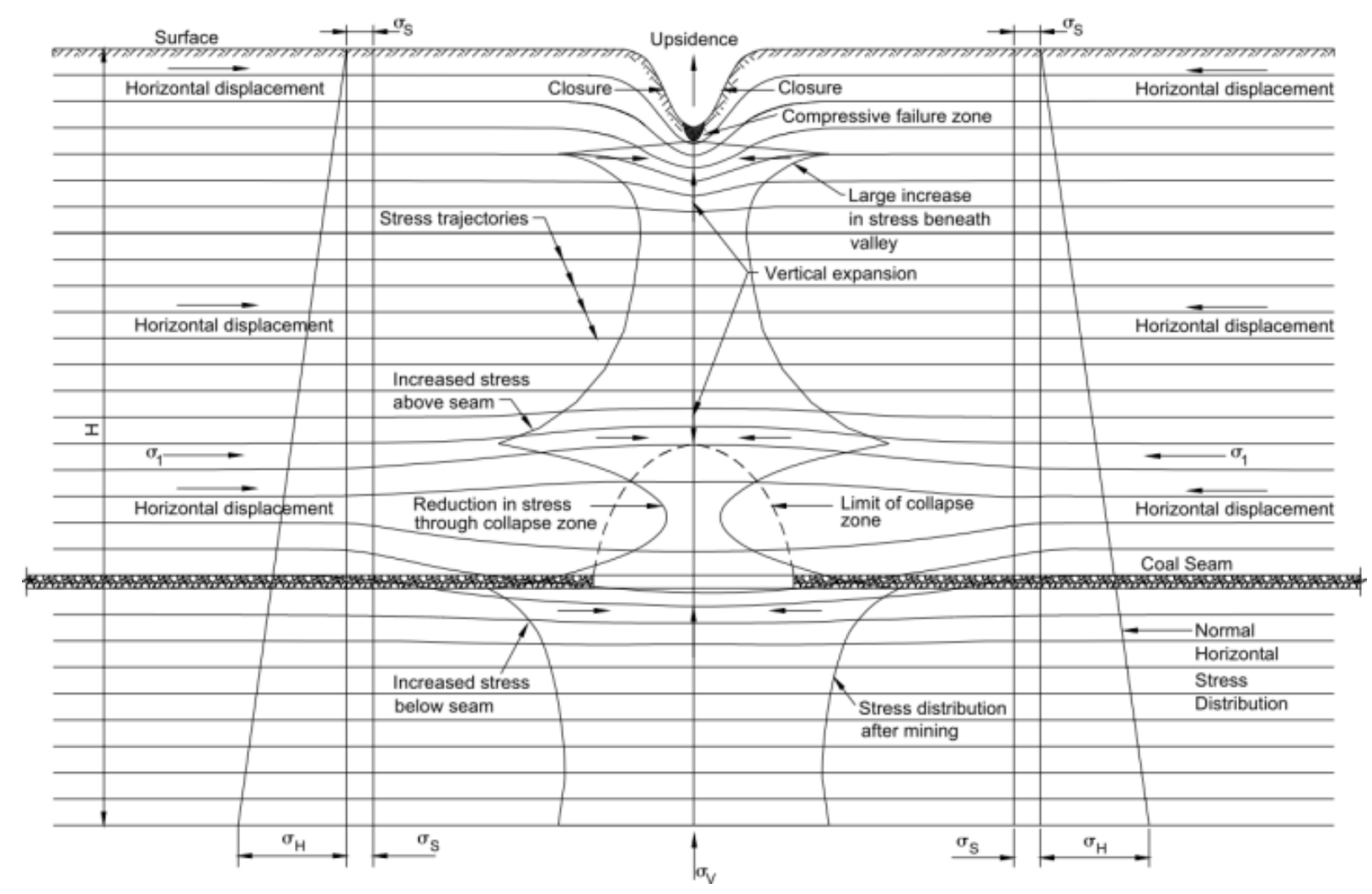

Figure 2.6 Stress field effects due to longwall mining disturbances (Zhang et al., 2012)

The caved zone is defined by Kendorski, et al., 1993 as the zone of complete disruption, at a thickness of approximately six times the coal seam thickness by Bai, Kendorski, \& Roosendaal, 1995; and 2 to 8 times the coal seam thickness by Booth, 2002. The zone directly above the caved zone is comprised of strata which do not fall and detach, but crack and settled instead. This zone is termed the 'Fractured Zone' (Kendorski, 1993).

As a result of the redistribution of stresses above the void, the in situ stresses near to the ground surface will be greatly increased. The change in horizontal stress is generally due to the change in curvature. Therefore, strata near to the surface will be compressed horizontally and may expand vertically (valley stress relief) due to a lack of confinement at the surface.

It has been suggested that the lateral direction of the horizontal stresses be taken into account as well. The effects of valley stress relief will be more pronounced if the directions of the horizontal stresses are more perpendicular to the flow of the channel than parallel to it (Gray, 1982). Additionally, residual-type shear strength may exist in strata with stress relief discontinuities and will manifest in roughly perpendicular in reference with the valley. This implies that foundation stability against sliding is more critical for longitudinal structures like dams which are underlain with stress relief discontinuities (Ferguson \& Hamel, 1981). With respect to valley geometry, greater upsidence is expected in more deep and narrow valleys, 
although the geologic discontinuities will be unaffected in varying valley geometry (Zhang et al., 2012; Ferguson \& Hamel, 1981).

Principal stresses are the normal stresses that act on the principal planes. Principal planes are two planes 90 degrees apart where the shear stress is zero (Das, 2006). The direction of the principal stress vectors tends to follow the ground surface. Figure 2.7 illustrates how the principal stress vector direction shifts to follow the ground surface at the depth of the stress is decreased.

When in situ stress is coupled with an increase in stress due to a redistribution of the stress field in subsidence propagation toward the ground surface; valley stress relief can manifest physically in the valley bottom. The surface effects of increased in situ stress are the effects of valley stress relief, and are presented in Section 2.4.2.

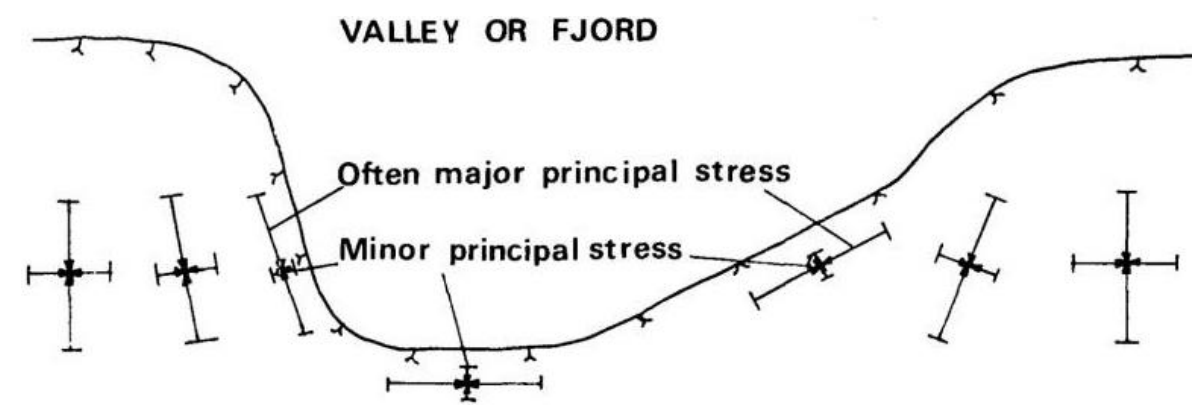

Figure 2.7 In Situ principal stress direction

\subsubsection{Valley Stress Relief}

One theorized mechanism of non-conventional subsidence is valley stress relief. Valley stress relief occurs naturally, but can be accelerated by mining activities unbalancing the in situ stress field (Zhang et al., 2012). This phenomenon is thought to occur as a result of a removal or decrease in the horizontally resistive forces in the valley walls (in a state of extension), and a decrease or removal of vertical resistance from the valley floor (in a state of compression). Following the disturbance in the tensile and compressive zones of the stress field, the valley walls can no longer remain static and deform as a result, moving down slope and inward (valley closure). Figure 2.8 illustrates the zones of extension and compression for a valley due to valley stress relief induced by longwall mining. 


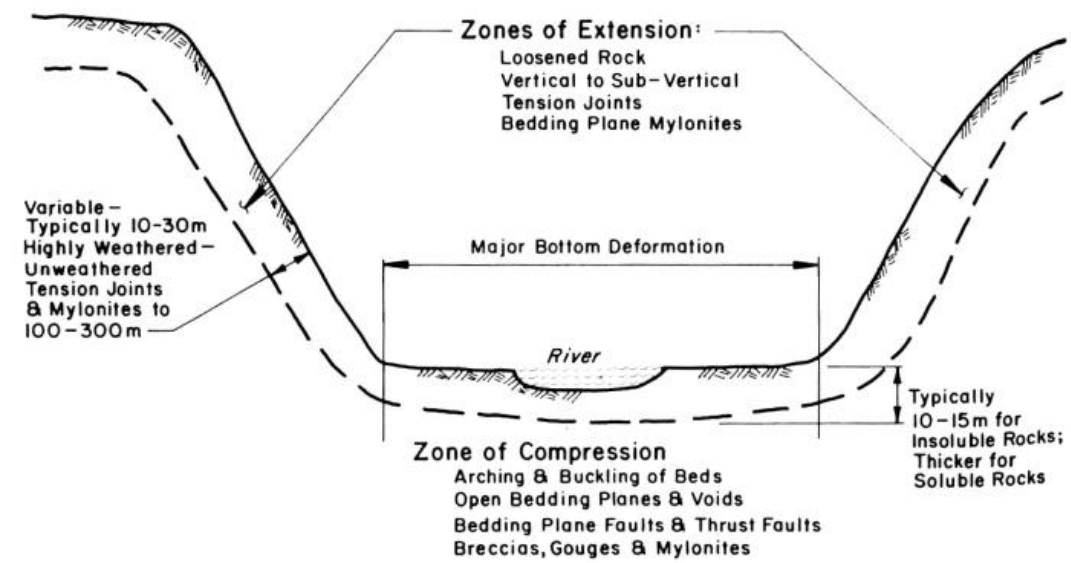

Figure 2.8 Zones of extension and compression in a valley (Zhang et al., 2012)

\subsubsection{Valley Stress Relief Surface Effects}

Research published by Ferguson \& Hamel, 1981 studied the phenomena involved with valley stress relief in flat-lying sedimentary rocks. The results concluded that valley stress relief concentrates in weaker, more deformable strata. Sometimes, diagonal and curved shear joints develop in shear zones at the interface of weaker layers with stiffer layers. The stiffer layers develop vertical to sub-vertical tension joints which do not propagate through the weaker beds. Bed buckling occurs at the valley bottom as it is horizontally compressed. Thrust faults, tension cracks, local voids, and bed separation may also occur in the compression zone at the valley bottom (Ferguson \& Hamel, 1981).

Foundation and abutment permeability is of critical importance for embankment and concrete gravity dams (Ferguson \& Hamel, 1981). At some point near to the surface, the vertical gravity load becomes low enough that equilibrium can no longer be maintained and the near-surface beds buckle upward (Zhang et al., 2012). Ferguson \& Hamel, 1981 reported that geologic discontinuities pertinent to valley stress relief exist at a depth in the order of 10-15m (32-49ft), regardless of valley geometry. Ground water flow through stress relief fractures can contribute to weathering as well as colluvium development (Ferguson \& Hamel, 1981). Figure 2.9 illustrates the mechanics of the buckling phenomenon. Figure 2.10 presents an idealization of the surface effects of valley stress relief. 


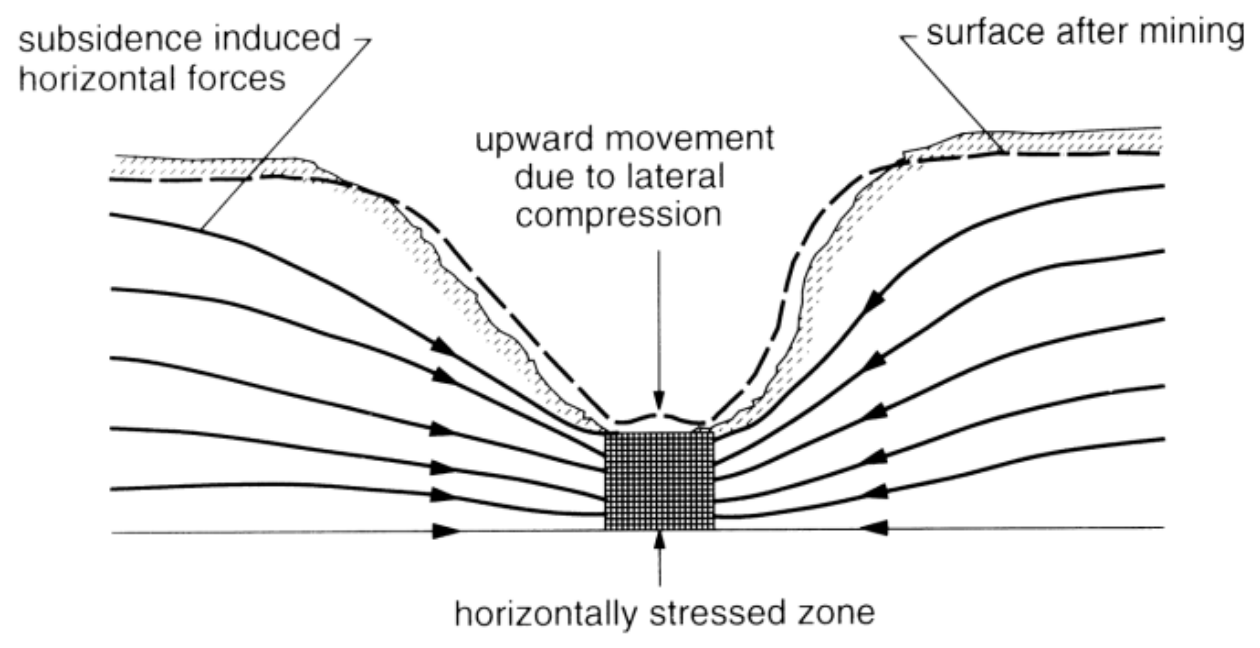

Figure 2.9 Valley stress relief physical manifestation as an upward deformation at a valley bottom due to an increase in horizontal stresses (lateral compression) (Zhang et al., 2012)

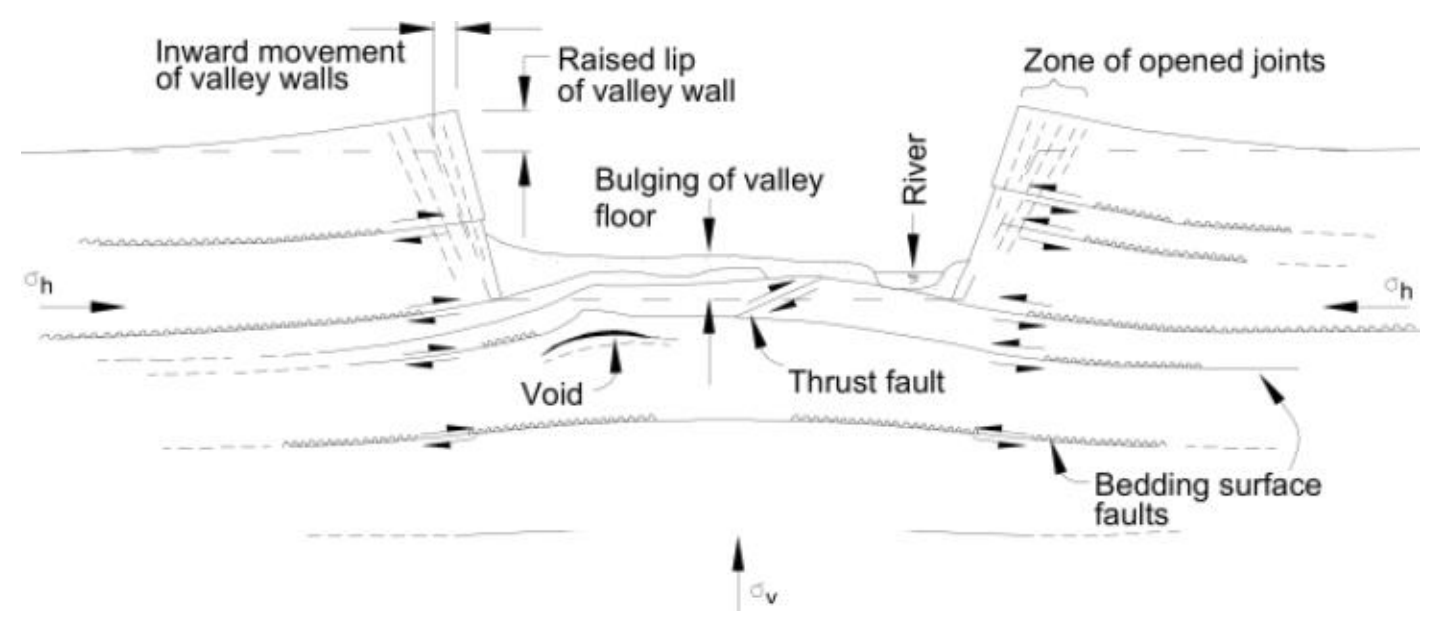

Figure 2.10 Valley stress relief surface effects

\subsubsection{Lateral Dilation}

Lateral dilation has been reported as a mechanism of valley closure and upsidence by Mills, 2011. In this scenario of valley closure, horizontal stresses are of relatively low magnitude and do not induce deformations, but the deformations are direct results of differential block movement and rotation across vertical joints. These vertical joints in the stratification of a hillside can be caused by valley stress relief, which occurs naturally. When a mine void is introduced near to these discontinuities, the natural rate of valley closure is accelerated. Shallow discontinuities, fractures, or joints which are formed parallel to valleys which are created by valley stress relief are sometimes referred to as "hill seams" or "mountain breaks." These hill seams generally occur vertically and are closely spaced and weathered (Sames \& Moebs, 1989). Figure 2.11 presents an illustration of hill seams. The term "hill seams" can be used synonymously with "tension cracks," "vertical joint," or "tension joint." 


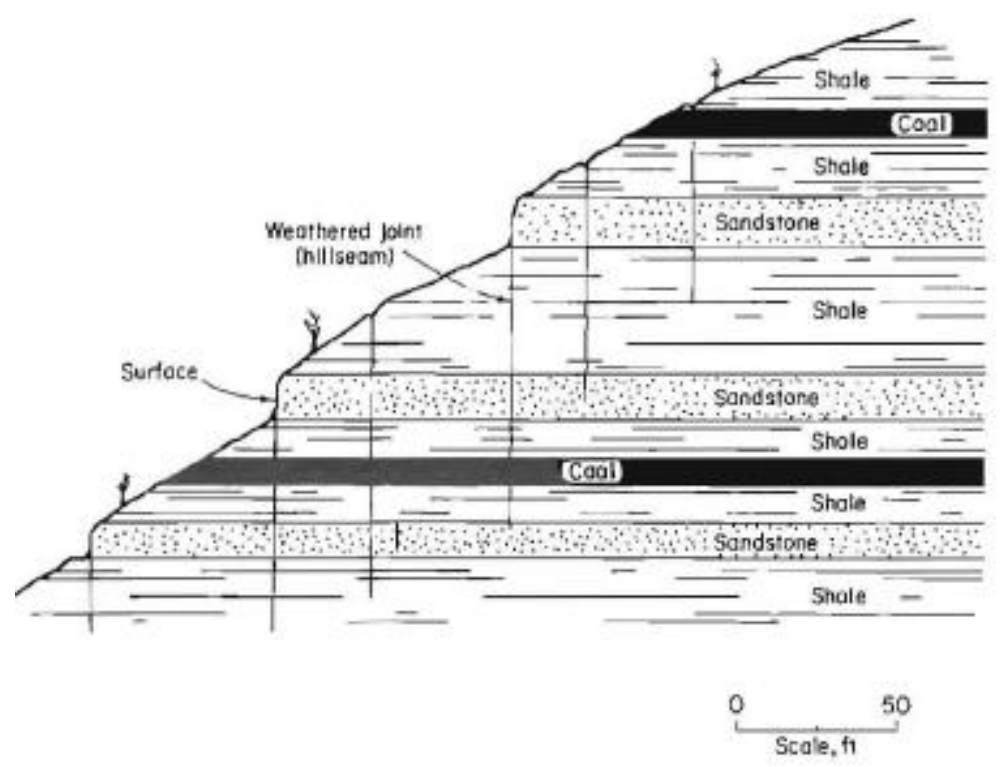

Figure 2.11 General illustration of hill seams created by valley stress relief (Sames \& Moebs, 1989)

Mills, 2011 found that downslope movements occur in valleys regardless of the direction of mining, and regardless of the direction of cliff lines. The presence of bedding planes allows for freedom of lateral movement in a downslope direction. The behavior of lateral dilation is amplified in steep terrain as there is no confining stress on the face of a hill or mountain in a valley as there would be in flat-lying terrain. The movements involved with lateral dilation can be large, and can sometimes be even greater than the magnitude of vertical subsidence, and much greater than horizontal deformations in flat terrain (Zhang et al., 2012). As a result, downslope movements govern horizontal subsidence behavior in steep terrain. Valley stress is a natural phenomenon, where the strata are at a critical stress state. Disturbances by nearby longwall mining can result in additional movement as a result of this critical stress state.

Seedsman \& Dawkins, 2006 proposed rigid block model to explain the lateral dilation phenomenon. In this idealized model, hogging and sagging modes of subsidence are interrelated to the block movement. The second derivative of subsidence is curvature. Curvature is 'hogging' over goaf edges and 'sagging' near the bottom of the subsidence trough (Subsidence Engineering, 2007). In the sagging phase, the sagging wave will induce lateral stresses on each block, which are resisted by adjacent blocks. In the presence of a valley, no adjacent block exists to resist the induced lateral stresses (Block B in Figure 2.12 and Figure 2.13). In the absence of a reaction block in the valley, unrecoverable translation of Block B occurs downslope into the valley as a result of the interaction of the induced stresses of Block A on Block B. 

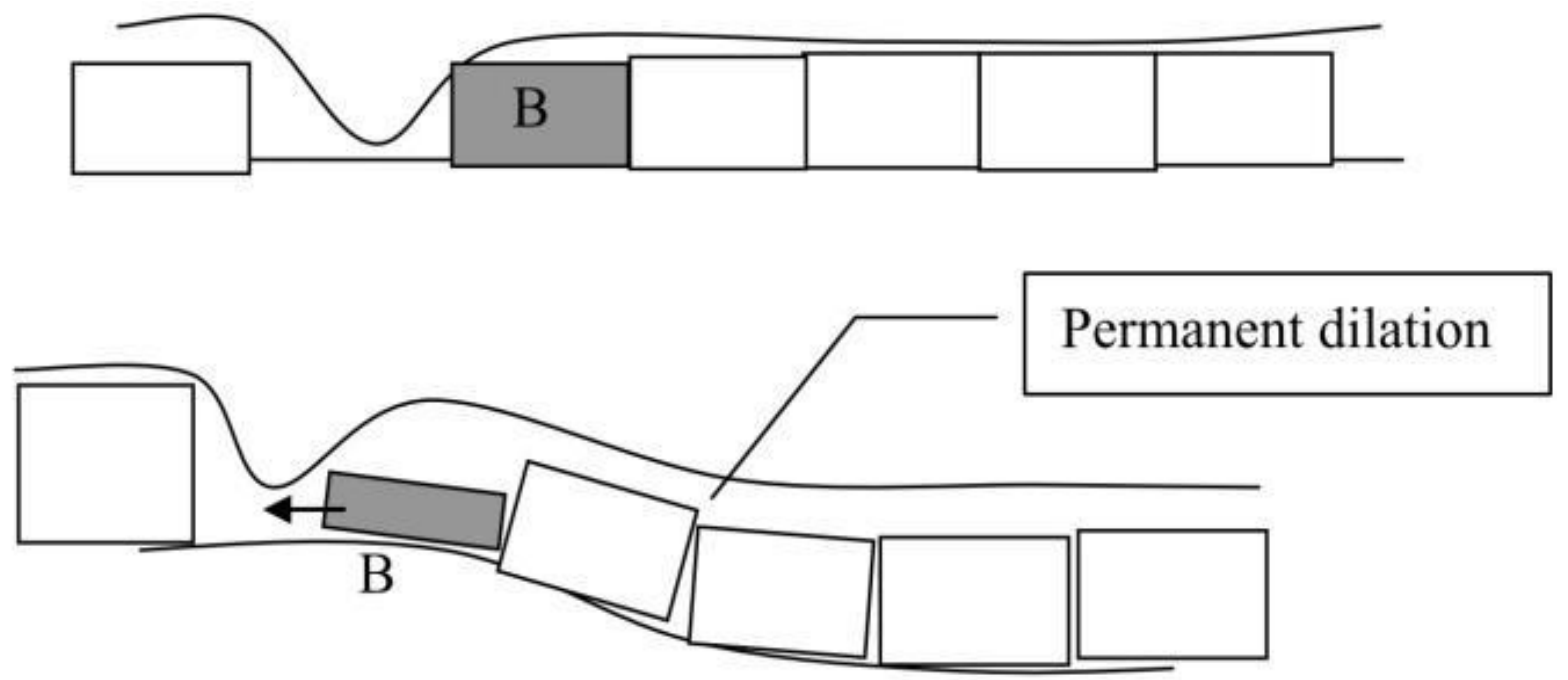

Figure 2.12 Block movement in a sagging subsidence wave
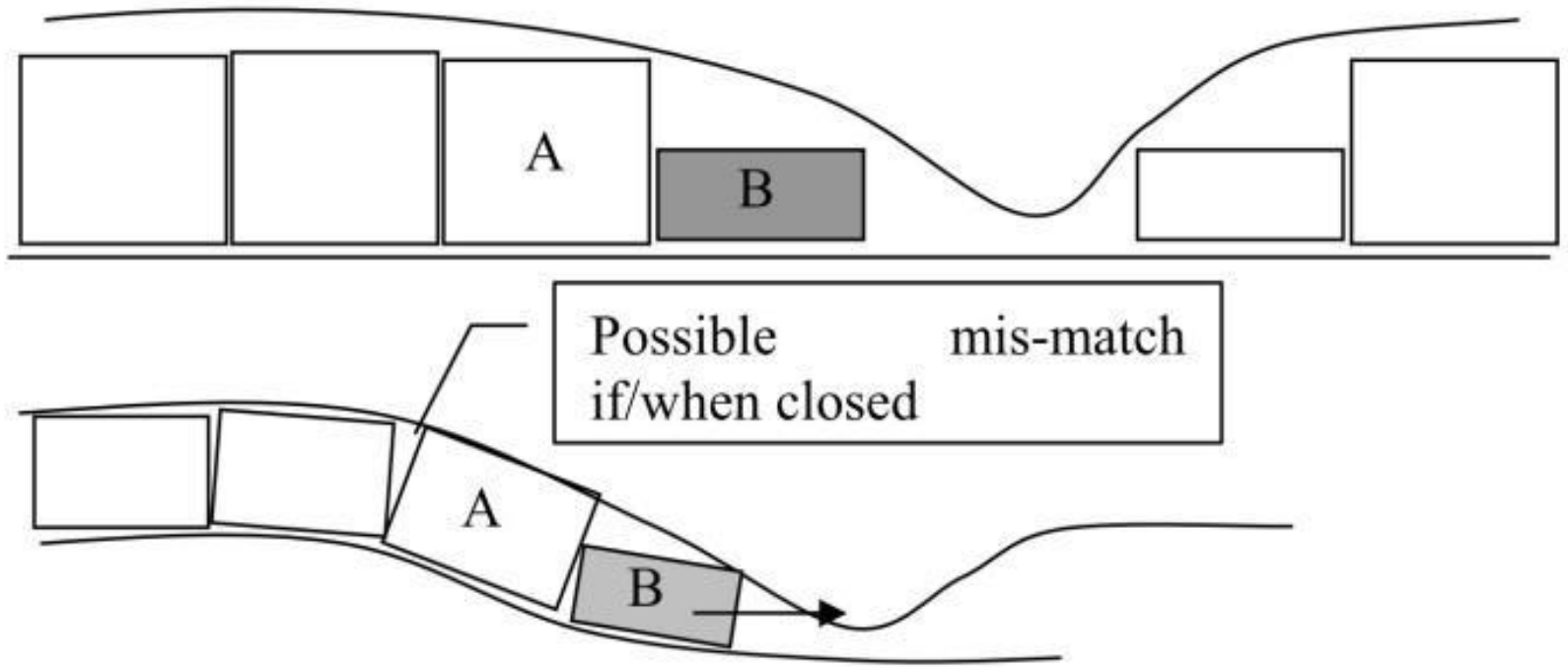

Figure 2.13 Block movement in a hogging subsidence wave

\subsubsection{Lateral Dilation Surface Effects}

Lateral dilation occurs when the ground is in a tensile phase. During the tensile phase, fractures open and deformation ensues. In later compression stages of subsidence, lateral dilation ceases to occur.

In the rigid block theory, if the translation plane exists above the valley floor, only valley closure takes place. If the translation plane is located beneath the valley floor, the base of the valley may not have the capacity to resist the translational movement, resulting in upward deformation of the valley floor or 'upsidence' (Zhang et al., 2012). Figure 2.14 illustrates the mechanics of lateral dilation as a cause for valley closure for block theory. 


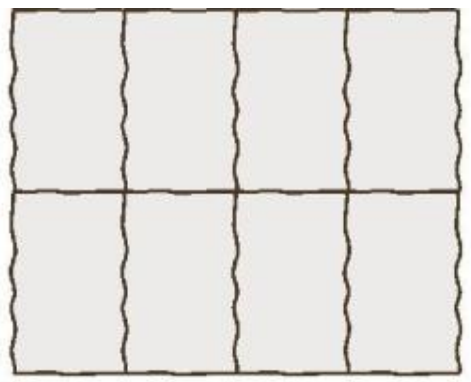

Prior to SUbSidence

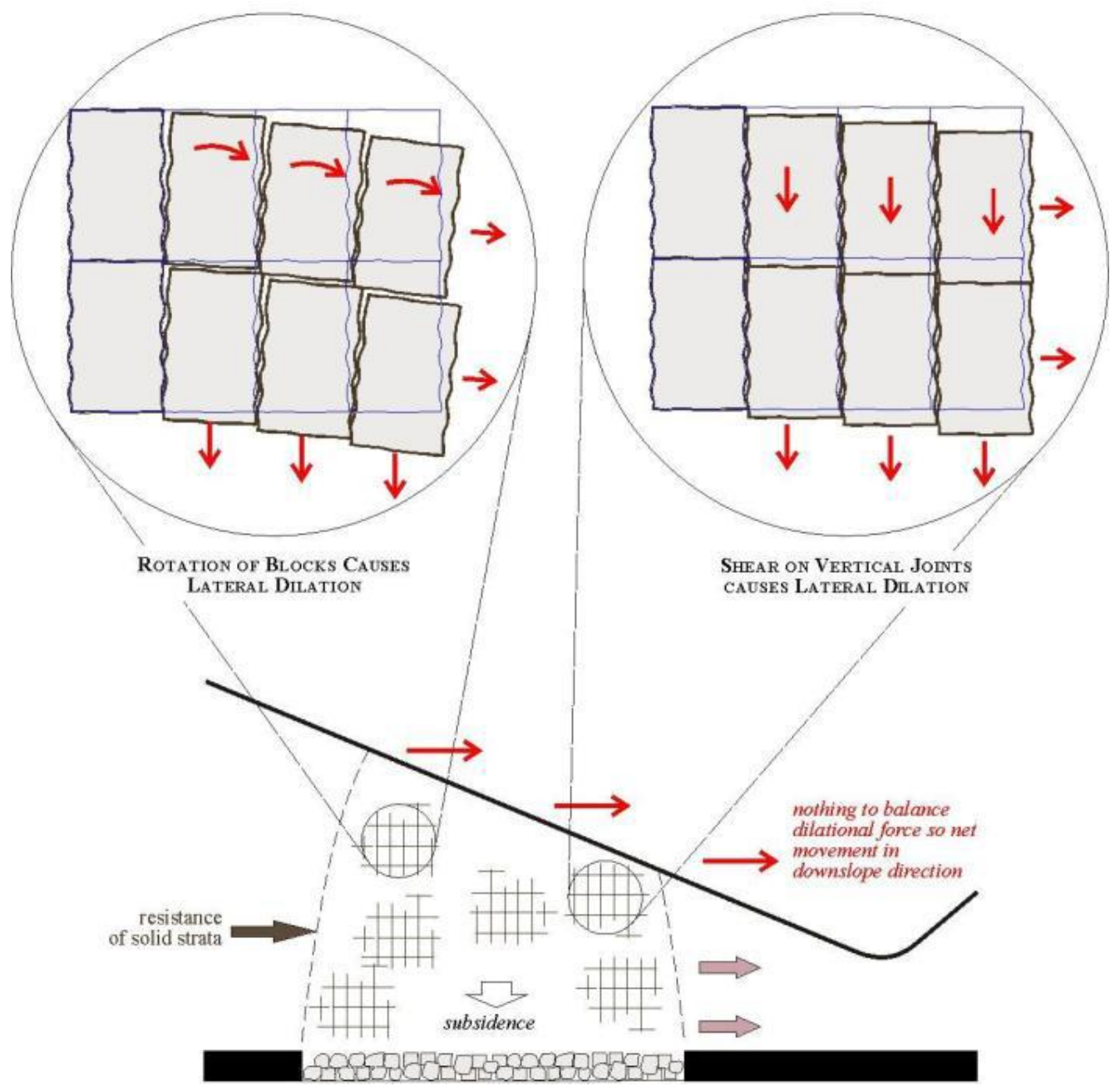

Figure 2.14 Lateral Dilation Mechanism (Mills, 2011 as cited in Zhang et al., 2012) 


\subsection{Summary of Identified Factors Affecting Area of Influence}

Valley closure and upsidence due to non-conventional subsidence outside of the angle of draw is affected by a number of factors. These include factors in relation to mining activities, topography, and geology. The identified factors contribute to the alteration of the in situ strain profile, magnitude of strains, upsidence effects including bulging at the valley bottom, extent of valley closure, and distance of propagation. The factors have been identified as:

- Valley geometry:

- the depth,

- width and

- shape of valleys,

- The direction and magnitude of pre-mining in situ horizontal stress (Zhang et al., 2012),

- The width of the longwall and its position relative to the valley,

- Near-surface rock characteristics,

- local geology,

- joint sets,

- Factors relative to the mining induced stresses:

- depth of cover,

- thickness of seam and

- width of the pillars

- Distance between the longitudinal end of the longwall and the valley,

- Distance between the maingate edge of the longwall and the valley,

- Depth of the valley, and

- Maximum predicted incremental subsidence over the longwall, (Zhang et al., 2013)

\subsection{Non-conventional Mine Subsidence: Regulatory Authority}

For the past 16 years, the phenomenon of non-conventional subsidence has been investigated in Australia (Zhang et al., 2013). This phenomenon is thought to have been at work at the Ryerson Station Dam in Pennsylvania, USA when mining occurred near to it in 2005. The United States mining industry and regulatory efforts have not incorporated non-conventional effects to date. As a result, Section 2.6 provides a brief review of regulations that have been developed in New South Wales, Australia.

In 1961, the Australian government enacted the Mine Subsidence Compensation Act. This act was the first act created to regulate longwall coal mining. The act requires that property owners be compensated for damage to structures that were built before mining began, or for structures that were built with the approval of the Mine Subsidence Board after mining. The act only 
compensates for damage to structures due to settlement, not vibration, and does not provide any compensation for economic losses that may result (Sydney, 2007).

The Dams Safety Committee was created by the Dams Safety Act in 1978 to undertake the responsibility of protection dams by declaring a Notification Area under the Mining Act of 1992. The Notification Area is the prescribed area around a dam where there is interest in the protection of the dam due to the effects of longwall mining. This area provides restriction zones which provide enough distance between the mine and the dam that the risk to the dam is negligible. The storage restricted zone protects the reservoir by establishing a zone at an angle of draw of 35 degrees. Figure 2.15 illustrates this restricted zone for mining near to reservoirs.

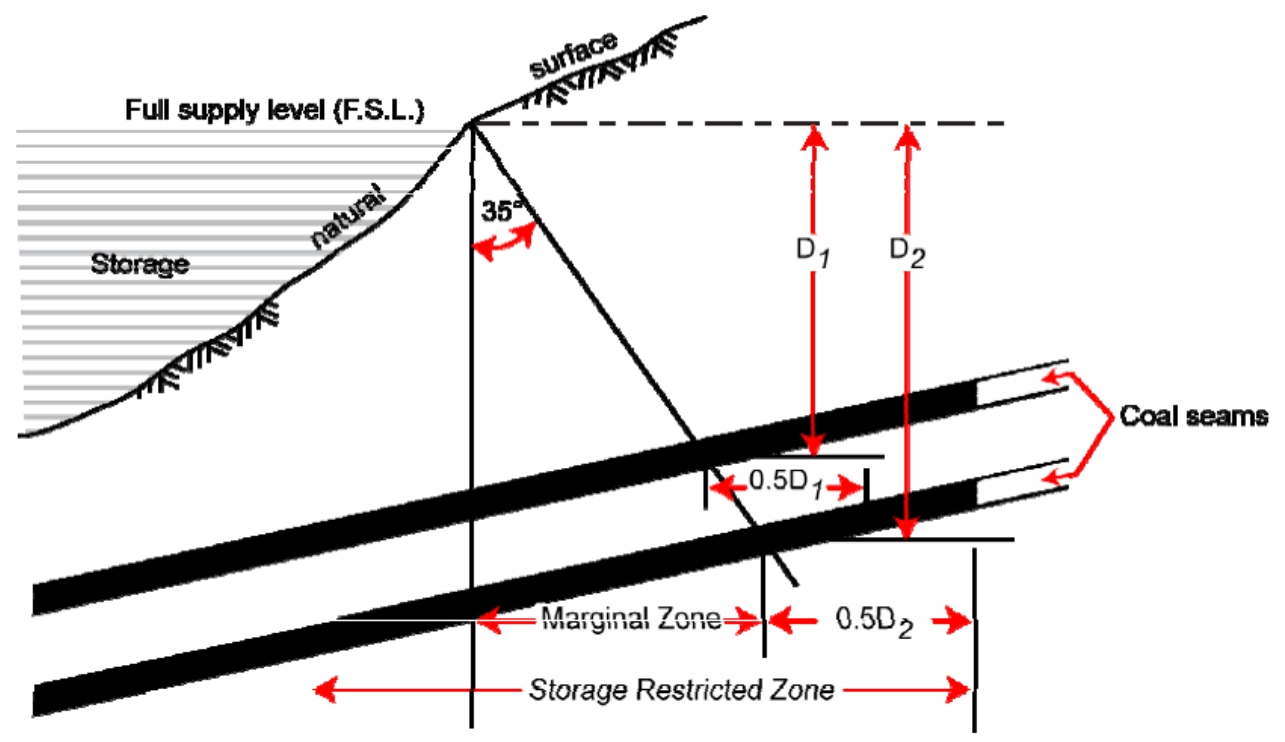

Figure 2.15 Restriction zones for mining near to a reservoir (Sydney, 2007)

The structure restricted zone which provides protection to the dam is established by extending an area of 1.2 times the depth of the mine from the structure for non-rigid dams and 1.7 times the depth of the mine from the structure for rigid dams (Sydney, 2007). Figure 2.16 illustrates the restricted zone for mining near to a dam in New South Wales. 


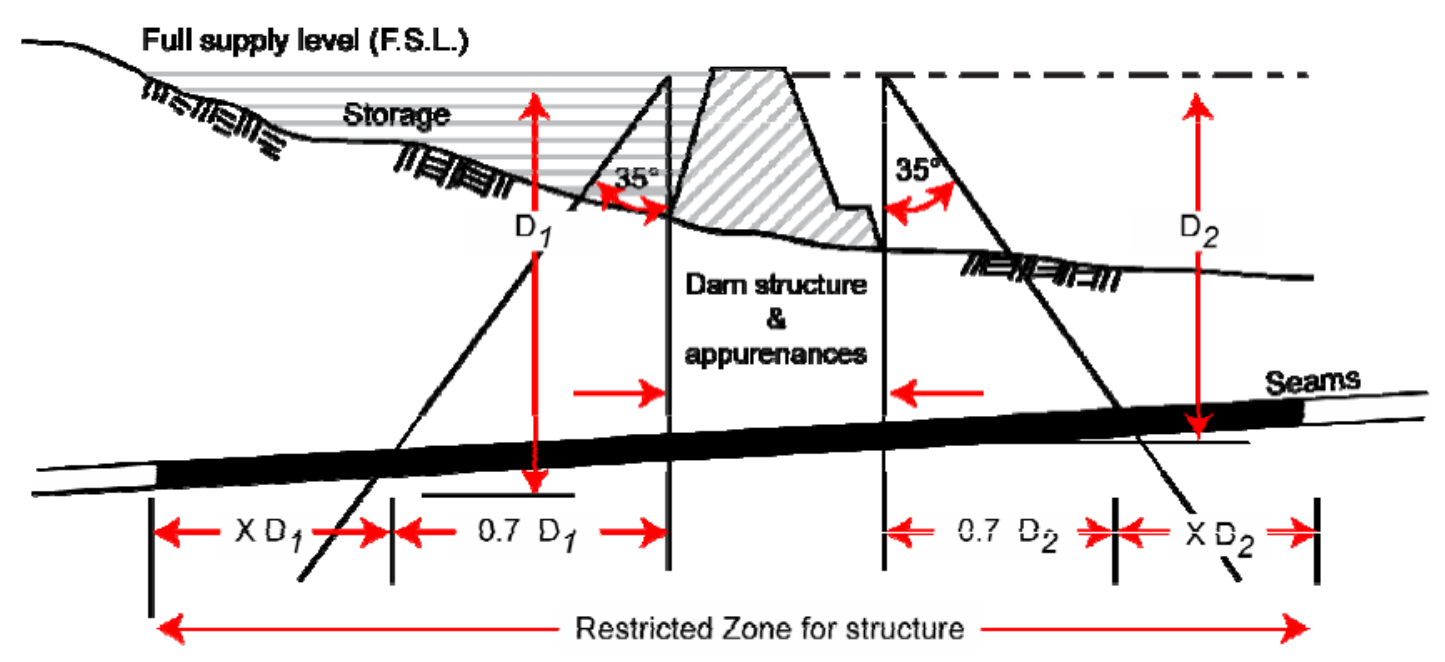

Figure 2.16 Restriction zone for mining near to a dam (Sydney, 2007)

\subsection{Case Studies of Non-Conventional Subsidence in Eastern U.S. Coalfields}

Non-conventional mine subsidence phenomena have only been documented in one case in the U.S.A. as being the cause of dam related issues. In this case, it was concluded by researchers that non-conventional subsidence movements were the cause of movements at the dam, but the case was settled in court with no conclusion to the official cause.

Non-conventional subsidence has not been widely accepted in the U.S., but valley stress relief is known to occur. These two concepts are very similar, sharing the same phenomena, but are induced by different means. These concepts can be thought of together as mine voids are thought to exacerbate valley stress relief and induce its occurrence much more rapidly than it would occur in nature. Case studies for valley stress relief abound in surface mining, underground mining, and geologic observation in the U.S.

Interstate I70 was thought to have undergone non-conventional subsidence effects by some experts. Longwall mining occurred $510 \mathrm{ft}$. below Interstate 70 in Washington County, Pennsylvania (O'Connor, Clark, Whitlatch, \& Dowding, 2001). Phenomena consistent with nonconventional movements were observed, causing lane closures and remedial construction work.

A few other cases were reported by the PADEP to have had movements outside of the traditional area of influence for CPCC longwall coal mining, but none were confirmed to be due to nonconventional subsidence. None of the cases were confirmed to be due to non-conventional phenomena, however none were investigated in great depth, and shared similar characteristics to the events at the Ryerson Station State Park. These events were only reported by the CPCC for 2005 and 2006 and are listed as reported in the PADEP report (PADEP, 2010). 


\section{Case 1: Loveridge Mine, Northern West Virginia}

CPCC reported that monitoring indicated movements at a 49-degree angle of draw, which is greater than the generally accepted angle of draw for that area. The data was collected to monitor potential impacts on an earthen impoundment. CPCC stated the earthen impoundment was not damaged "despite the apparent presence of ground movement at an anomalous location." Additional information provided for this case indicated the furthest monitoring point to experience movement was $936 \mathrm{ft}$. from the longwall stop point.

\section{Bailey Mine, Pennsylvania:}

\section{- Case 2: Bailey Mine, 9C Panel, Pennsylvania}

CPCC reported monitoring in connection with the mining of the $9 C$ panel at the Bailey Mine detected small ground movements at 43 degrees from the panel edge. It indicated no damage was reported.

\section{- Case 3: Bailey Mine, 2I Panel, Pennsylvania}

CPCC reported monitoring in connection with the mining of the 2I panel at the Bailey Mine detected small ground movements at 39 degrees from the panel edge. It indicated no damage was reported.

\section{- Case 4: Bailey Mine, 5I Panel, Pennsylvania}

$C P C C$ reported monitoring at the request of DEP related to the $5 I$ panel indicated possible movement of 40 to 49 degrees which was beyond the anticipated angle of draw. This movement was along State Route 21. They stated the movements were mostly horizontal, were erratic, were not consistent in direction or with vertical movement, and were recorded after mining within Panel 5 I was completed.

\section{Case 5: Buchanan Mine, Panel 11-NE, Southwest Virginia}

CPCC reported monitoring in connection with the mining of Panel 11-NE indicated movements at an angle of draw of 37 degrees, which was beyond the generally accepted angle of draw for that area. The movement was attributed to a thick sandstone unit which cantilevered over the panel, with very deep overburden of approximately 1,370 ft.

While CPCC's written response indicated no visible evidence of surface movement or damage was observed in the area where movement was detected, the report provided for this case indicated otherwise. The report describes a gradually progressing heave of approximately 0.28 ft. (3.36 inches) developed $630 \mathrm{ft}$. from the panel. The report states there may have been several contributing factors to the development of this heave, with the valley bottom location and a thick near surface sandstone unit mentioned specifically.

The discussion section of the report states, "Since both the level and the transit data indicate the presence of a gradually progressing heave zone beyond the 11-NE headgate-side panel edge, the event cannot be explained as being due to measurement error. However, the presence of such 
heave beyond panel edge is site-specific and depends on many factors, among them: the thickness of surface soil, the proximity to the toe of a slope, and the presence and thickness of near surface units. The heave-related results of this survey should not be extrapolated to other areas. In this particular instance, the relatively close proximity to the hillside combined with the presence of relatively thick sandstone near the surface may have contributed to the heave" (PADEP, 2010).

\subsubsection{Survey of Case Studies}

All of these cases are examples of instances where subsidence effects occurred outside of the expected area of influence for each site specific scenario. Additionally, these cases represent instances where the mined areas are within hill and ridge topography; where the movements were associated with valleys. The PADEP recalled these cases to argue that ground movements do occur outside of the traditional subsidence trough, and that current subsidence prediction software cannot adequately address these movements (PADEP, 2010).

Despite cases such as those listed above, subsidence due to underground longwall coal mining has been conventionally dealt with by implementing an empirically acquired angle of draw (Singh, 1992). Within the zone of the angle of draw, subsidence engineering has identified, described, and quantified to a great deal of accuracy, the extent and magnitude of predicted subsidence curves. The methods involved are capable of being implemented at unique and sitespecific cases, however these methods do not always accurately predict movements. In Greene County, Pennsylvania, a dam exists which required breaching due to significant movements in and around the dam area. These movements induced high seepage rates, and were concluded to be a result of non-conventional far-field subsidence movements (Hebblewhite \& Gray, 2014). These types of movements have been researched and documented for the New South Wales Southern Coalfields in Australia, but have not largely been considered for the United States. If one capitulates to this concept, then it is also possible that these movements have been taking place in the U.S.A., but have not been measured or mentioned as they have not been earnestly considered. If non-conventional movements are possible and have occurred in the U.S.A., then the potential exists for them to recur at other sites.

\subsection{Ryerson Station Case Study}

In August 2005, the Ryerson Station Dam in Greene County Pennsylvania was breached as a result of structural instability and uncontrollable increasing seepage rates. The draining of the impounded reservoir, Duke Lake, led to litigation between the management of the Ryerson Station State Park, the Pennsylvania Department of Conservation and Natural Resources (PADCNR) and the owner of the nearby Bailey coal mine, Consol Energy. Consol settled to pay to rebuild the dam but claimed the fault was not due to subsidence, however others argued that 
the movements at the dam were a direct result of the nearby longwall mining activities in the Bailey Mine. In the summer of 2015, lake bed silt removal resulted in further ground movements in the area. The ground has since been deemed too unstable to rebuild the dam; therefore, funds are being used for alternative facility development at the Ryerson Station State Park (PADCNR, 2016). This observation indicates that the landforms are in a critically stressed state.

\subsubsection{Site Details}

The Ryerson Station Dam is located within the Ryerson Station State Park in Greene County, Pennsylvania. The dam is owned and was managed by the Pennsylvania Department of Conservation and Natural Resources (PADCNR). The dam was designed by the SwindellDressler Corporation of Pittsburgh, PA. The construction of the dam was completed in 1960. The dam was a $515 \mathrm{ft}$. long concrete-gravity structure. The maximum height of the dam was 30 $\mathrm{ft}$. for the spillway and $42 \mathrm{ft}$. for the non-overflow section measured from the foundation grade at the downstream toe of the dam. The width of the dam varied from a minimum of $6 \mathrm{ft}$. at the crest of the non-overflow section to about $30 \mathrm{ft}$. at the base of the dam. The classification of the dam before it was breached was a Class B-1 by the Pennsylvania Department of Environmental Protection (PADEP) and was of intermediate size and high hazard. The reservoir covered 62 acres at normal pool level (PADEP, 2010). Additional dimensions and specifications pertaining to the Ryerson Station Dam can be found in Table A8.

\subsubsection{Pre-Mining Performance}

During the 45-year lifetime of the structure up to the breach in August, 2005, annual and semiannual inspections were performed by PADCNR engineers and maintenance staff, DEP Division of Dam Safety, as well as consultants (PADEP, 2010).

In 2000, the Annual Inspection Report (AIR) indicated 10 areas of concern on or around the Ryerson Station Dam. Between 2000 and 2004, minor spalling of concrete was noted at the spillway, abutment walls, downstream face of the left abutment walls, and ogee section. There was a vertical structural crack that had opened and the ground next to it was wet and spongy. Seepage had begun in the 12-inch corrugated metal pipe on the outside spillway wall and joints of the spillway wall. An eroded area of the upstream bank was also reported. The 2003 AIR noted new developments, including seepage from a plastic tube near the bottom of the downstream face of the structural crack as well as an increase in wetness of the spongy area near the left abutment wall, and further erosion of the upstream bank. Despite these issues, the 2004 inspection report stated that the dam "appears to be generally in good condition and well maintained" (PADEP, 2010). 
Nearby mining of the Bailey Mine Panel 3I began on December 7, 2004. A severe increase in damage to the Ryerson Station Dam and seepage around and through the dam began to be observed during the period of time when Panel 3I was being mined (PADEP, 2010).

\subsubsection{Bailey Mine}

The Bailey Mine is a large underground coal mine owned and operated by Consol Pennsylvania Coal Company (CPCC). It is located in portions of Washington and Greene counties in Pennsylvania. The mine extracts the Pittsburgh coal seam using longwall coal mining processes. The mine was first permitted in 1984, and has had numerous revisions (PADEP, 2010).

The Baily Mine consisted of a series of panels in the vicinity of the Ryerson Station State Park Dam. These panels were numbered from 1I to 8I and were mined from north to south, east to west; starting at $1 \mathrm{I}$ and finishing at $8 \mathrm{I}$. The panels were rectangular in shape, at 1,100 ft. wide and 10,000 ft. long. The mining in $1 \mathrm{I}$ began in November, 2003. The dam was breached in August, 2005 at approximately the same time that mining finished in the nearest panel to the mine, the 4I East panel. Mining finished in the 4I East panel on August 1, 2005. The Ryerson Station Dam completed breaching on August 10, 2005 (PADEP, 2010). The Ryerson Station State Park is situated within the rolling hills of the western edge of the Appalachian Mountains; therefore, the depth of cover varied over the panels. Table 2.2 presents the reported ranges of depth of cover for the longwall panels in the vicinity of Ryerson Station Dam. Figure 2.17 shows mapping of the Baily Mine longwall panels in the vicinity of the Ryerson Station Dam. Mine progression occurred north to south and east to west.

Table 2.2 Cover ranges for longwall panels nearby to the Ryerson Station Dam (PADEP, 2010)

\begin{tabular}{|c|c|}
\hline Panel & Depth (ft) \\
\hline 3I & $350-750$ \\
\hline 4I & $335-715$ \\
\hline 5I & $320-720$ \\
\hline 7I & $345-845$ \\
\hline
\end{tabular}




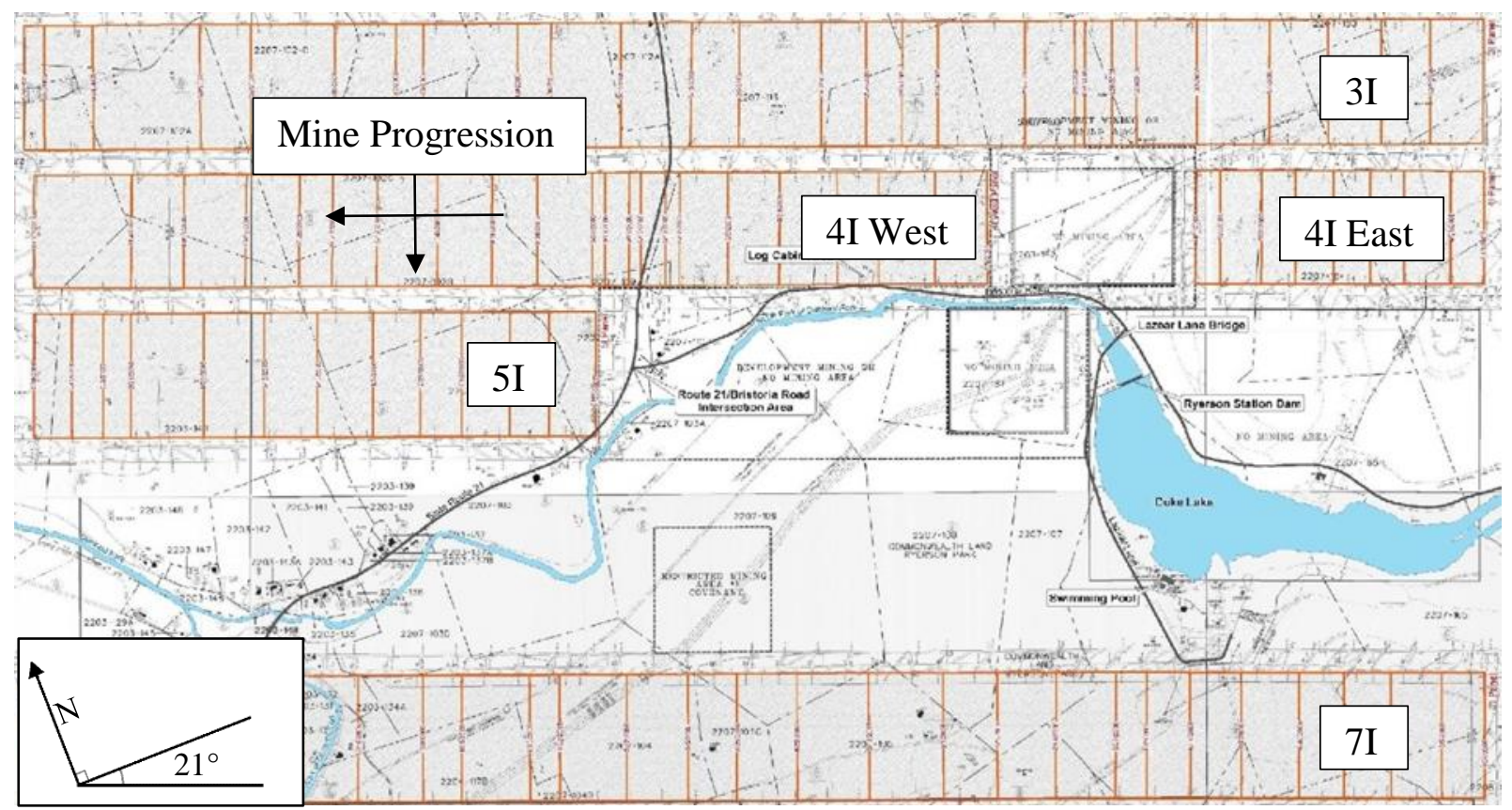

Figure 2.17 Ryerson Station Dam and surrounding longwall panels of the Bailey Mine (PADEP, 2010)

The seam height in the Bailey Mine is 96 inches ( $8 \mathrm{ft}$.) on average (MSHA, 2009). As is common throughout northern Appalachian basin, the coal seam is overlain by various sedimentary deposits, including limestone, shale, and sandstone

\subsubsection{Surface Structure Protection Plan}

The most important structure within the subsidence control plan area for R71 of the Bailey Mine was the Ryerson Station Dam. The PADEP used a method to protect structures based on the typically used angle of draw range for Appalachia between 15 and 25 degrees. This angle is from the top of the coal seam to a $15 \mathrm{ft}$. offset to the structure. If a structure is on a slope greater than 5 percent, the support area on the down-slope side of the structure is extended by multiplying the thickness of the overburden by the percentage (expressed as a decimal) of the surface slope. The PADEP method to protect structures against subsidence using an angle of draw between 15 and 25 degrees has proved to be effective in past cases (PADEP, 2010).

Structures retaining water are protected by IC 8741. IC 8741 defines safety zones for water bodies and structures retaining water. This zone is defined as the area contained in a $200 \mathrm{ft}$. radius around the structure at a depth of $350 \mathrm{ft}$. This area is extended at depths greater than 350 $\mathrm{ft}$. by an outward angle at 65 degrees from the horizontal. This zone is illustrated in Figure 2.5. Since the offset distances necessary to protect the Ryerson Station Dam and nearby highpressure gas lines, the Bailey Mine removed the 6I panel and more than half of the 5I panel from the mining projections. The 4I panel was split into two sections; 4I East and 4I West, for 
additional support area for the Ryerson Station Dam and Duke Lake reservoir. These mine projection changes resulted in offset distances that were greater than what was required. The closest approach to the dam was projected to be $900 \mathrm{ft}$., at an angle of draw of greater than 50 degrees. This angle of draw was twice as much as the greatest projected angle of draw for Appalachia that was used to establish minimum offset distances (PADEP, 2010; Hebblewhite \& Gray, 2014).

\subsubsection{Concurrent and Post Mining Site observations}

Several phenomena occurred during and after the extraction of the 3I, 4I East, 4I West, 7I, and 8I panels in the Bailey Mine. These phenomena include heaving in valleys, heaved pipes, landslides, valley closure, and greatly increased seepage rates due to structural damage at the Ryerson Station Dam. In July, 2005, the seepage through and around the dam had reached critical flow rates. At this time, the decision to breach the dam was made. This section presents the events which led to the breaching of the Ryerson Station Dam as well as some events in the nearby area.

\subsubsection{Increased Seepage at the Ryerson Station Dam}

The PADCNR began reporting increasing seepage rates in April, 2005 at approximately 3-5

gpm. By the end of July, 2005 the seepage rate was measured to be approximately $80 \mathrm{gpm}$. This rate was a large and rapid increase from $60 \mathrm{gpm}$, measured only days earlier. At the time of the seepage increase to $80 \mathrm{gpm}$, mining was commencing in the 4I East panel of the Bailey Mine (PADEP, 2010). The major seepage rate increases are given in Table 2.3.

Table 2.3 Major seepage rate measurements (pre-breach)

\begin{tabular}{|c|c|}
\hline Date of Measurement & Seepage Rate (gallons per minute, gpm) \\
\hline April 21, 2005 & $3-5$ \\
\hline June 15, 2005 & 20 \\
\hline July 13, 2005 & 35 \\
\hline July 18, 2005 & 45 \\
\hline July 26, 2005 & 60 \\
\hline July 28, 2005 & 80 \\
\hline
\end{tabular}

The seepage rate measurements reported in Table 2.3 were taken on the right (east) side of the dam as reported by the Gannett Fleming, Inc. timelines. Figure 2.18 shows the location of the east side drain. 


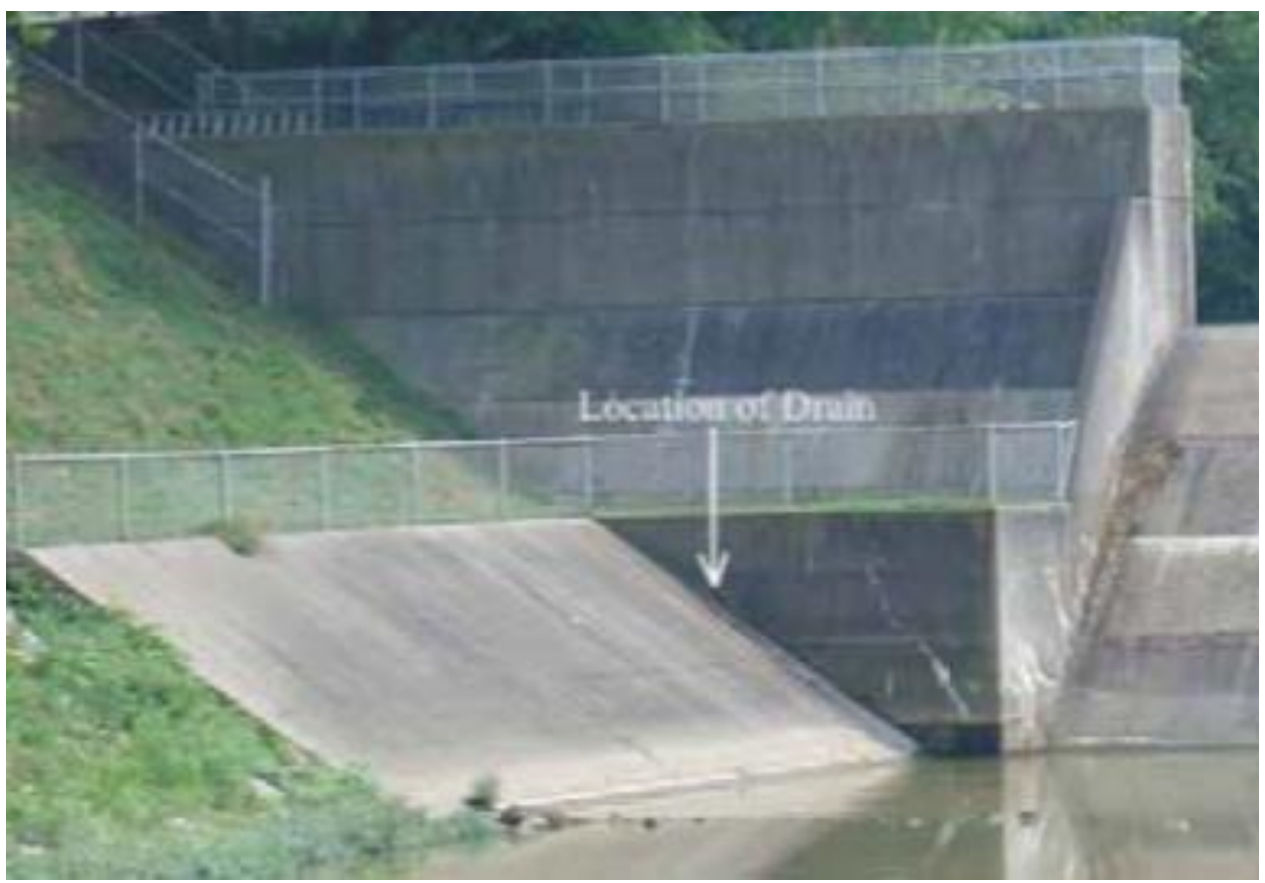

Figure 2.18 Right (east) side drain where the major seepage rate measurements were taken (PADEP, 2010)

Additional issues were reported in the historical performance of the dam, but none were noted as significant until April, 2005. At this time, evidence of new seepage was reported on the left (west) side of the dam, and through the joints on the right (east) side. The wall drain shown in Figure 2.18 also had increased to $10 \mathrm{gpm}$, and was unusual. At this time, mining activities were in the 3I panel, more than 6,000 feet away, but had been closer, 2,100 feet to the north at its closest approach (PADEP, 2010). Figure 2.19 shows seepage occurring through the right (east) side wall drain on July 12, 2005, when seepage rates were measured to be about $35 \mathrm{gpm}$.

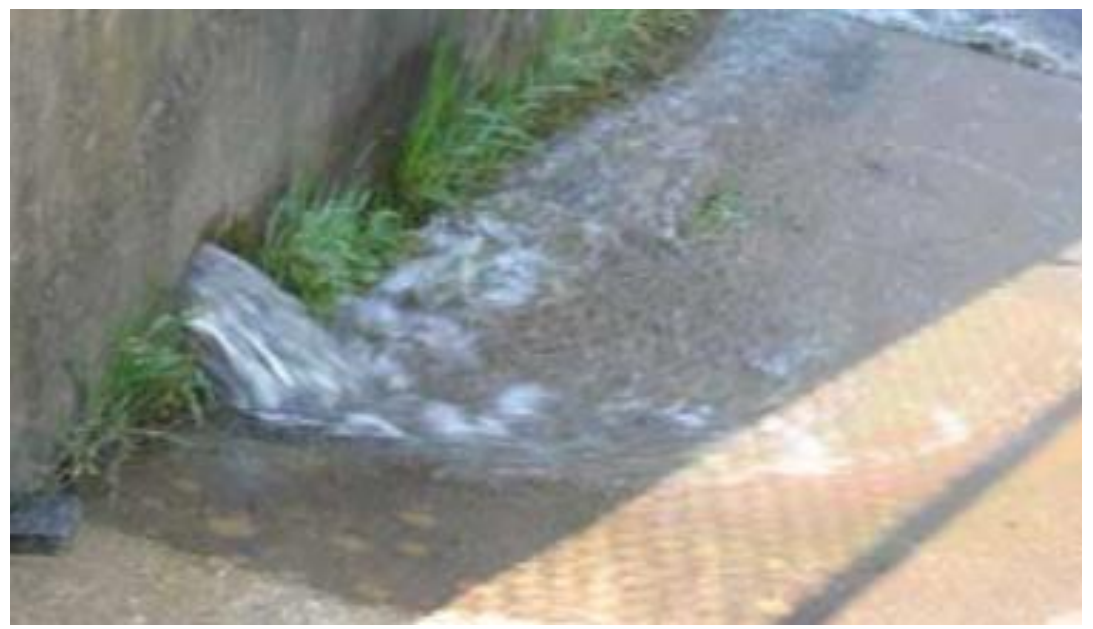

Figure 2.19 New seepage from the right (east) side wall drain (PADEP, 2010) 
Seepage rates were actively increasing in August, 2005, but no further seepage rates were available past July 28,2005 as the lake was drained, and the dam was breached soon afterward.

\subsubsection{Movements of the Dam}

In the annual inspection report of 1970, a vertical structural crack was noted on the right (east) side of the Ryerson Station Dam which propagated down the upstream and downstream faces, as well as across the top of the dam. This structural crack was reported to have opened on July 13, 2005. Figure 2.20 shows an image of the opened structural crack on July 30, 2005.

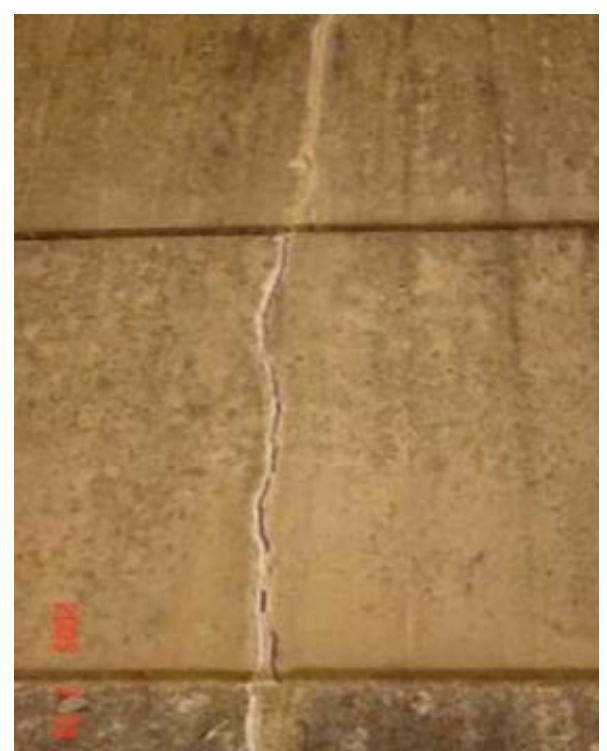

Figure 2.20 Opened vertical structural crack (PADEP, 2010)

After the breaching of the dam, Gannett Fleming, Inc. was contracted by the PADCNR to monitor and measure any additional movements which may occur at the dam and in the surrounding area. Several notable deformations of the dam were notable from August, 2005 to November, 2005.

\subsubsection{Movements in the Surrounding Area}

In addition to the dam structure movements, a study by Gannett Fleming, Inc. engineering consultants tracked displacements of the area surrounding the dam after the dam was breached. One of the studies was conducted along a portion of State Route 21 which was located primarily south of the 5I panel with a small portion crossing over the panel. Most of the monitored area was located outside of the traditional area of influence for subsidence related movements. The points located near the corner of the panel tended to act as customary subsidence theory predicted, but those away from the corner did not. Rather than experiencing no movement as points outside of the angle of draw would be expected to do in traditional mine subsidence 
theory, the points had measurable displacement away from the panel. Five points which were located away from panel 5I by distances ranging from $650 \mathrm{ft}$. to $1,250 \mathrm{ft}$; all of which underwent horizontal movement ranging from 1.2 to 2.1 inches (DEP, 2010). Figure 2.21 shows a vector plot provided by Volume I of the Gannett Fleming, Inc. investigative report (PADCNR, 2007). The vectors in Figure 2.21 show movements in the valley exceeding 2 inches in the downhill direction (away from mining) within the valley where Duke Lake and the Ryerson Station Dam were located.

Other monitoring studies conducted by Gannett Fleming, Inc. during the mining of the 7I panel produced similar results (PADCNR, 2007). Monitoring points above and within close proximity to the panel generally moved in accordance to what would be expected in traditional subsidence theory. The points experienced the varying downward displacement seen in the subsidence trough and horizontal displacement towards the center of the panel. Points away from this zone, such as those located near the swimming pool area of Ryerson State Park, consistently showed horizontal movement away from the panel. This movement exceeded 3 inches for some points. Additionally, vertical uplift occurred, ranging between 1 and 2 inches in some cases (DEP, 2010). This movement was sub-parallel to the principal horizontal stress.

During the field reconnaissance contracted to be performed by Gannett Fleming Inc., 11 landslides were also identified. The largest of the landslides is denoted as the orange area approximately $800 \mathrm{ft}$. downstream of the Ryerson Station Dam in Figure 2.22. All of the landslides were in the soil overburden. The large landslide appeared to have occurred relatively recent to the investigation, but others may have been up to 30 years old (PADEP, 2010).

Tension cracks were also observed near the ridge line of the hill adjacent to the valley which the Ryerson Station Dam is situated. These cracks measured approximately 50 to $100 \mathrm{ft}$. long and were located near to the edge of panel 4I East. Figure 2.22 shows the mapped locations of the landslides reported in Volume I of the Gannett Fleming, Inc. Ryerson investigation denoted as red polygons. Figure 2.22 also includes tension crack locations denoted as the yellow lines on the ridge to the east of the dam. 


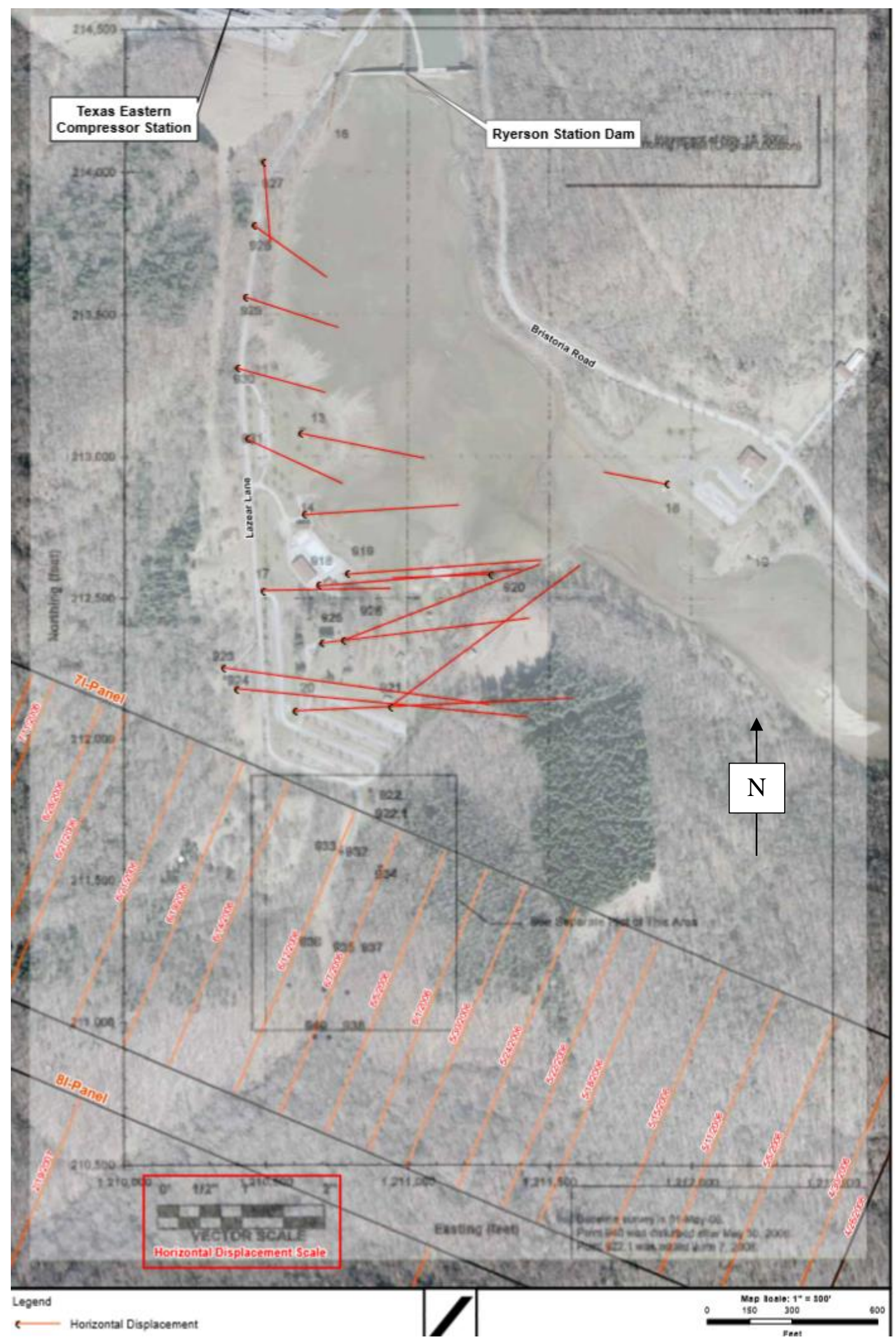

Figure 2.21 Vector plot of post-breaching movements in Duke Lake Valley (PADEP, 2007) 


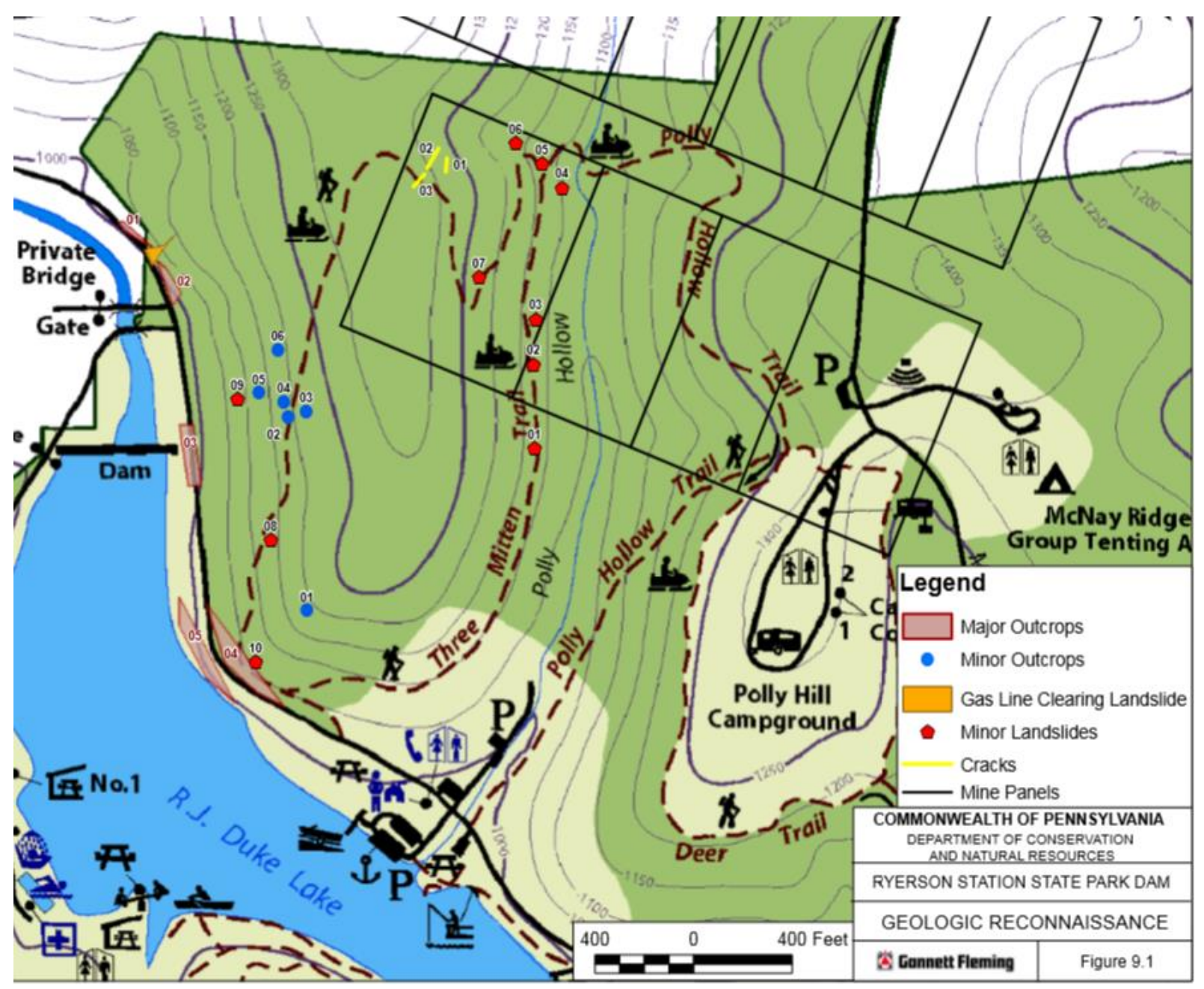

Figure 2.22 Mapped locations of landslides and tension cracks (PADEP, 2007)

The PADEP performed a comprehensive investigation which discovered heaving pipelines, and roadway movements. Most of these events occurred outside of the traditional subsidence trough expected for an angle of draw of 15 to 25 degrees. Table 2.4 presents a summary of the observed effects of ground movements as recorded by the PADEP; events which were all outside of the traditional subsidence trough. The furthest observed effects from mining were bumps in Bristoria Road at nearly 4,000 ft. Three other movement observations were made when mining was upwards of 3,000 ft. from mining activities. 
Table 2.4 Site and description of some additionally reported movements in the Ryerson Station Dam vicinity

\begin{tabular}{|c|c|c|}
\hline Site & Description & Observation timing and relationship to mining \\
\hline 1 & Road bumps in Bristoria Road & $\begin{array}{l}\text { Jan. } 31,2005 \text { when mining was } 2,150 \text { feet } \mathrm{NE} \text { in the } 3 \mathrm{I} \\
\text { panel } \\
\text { April 14, } 2005 \text { when mining was } 3,980 \text { feet } \mathrm{NW} \text { in the } 3 \mathrm{I} \\
\text { panel } \\
\text { August } 15,2005 \text { when mining was } 580 \text { feet East in the } 4 \mathrm{I} \\
\text { panel }\end{array}$ \\
\hline 2 & $\begin{array}{l}\text { Evidence of movement in the Bristoria } \\
\text { Road bridge }\end{array}$ & $\begin{array}{l}\text { August 17, } 2005 \text { when mining was } 480 \text { feet East in the } 4 \mathrm{I} \\
\text { panel }\end{array}$ \\
\hline 3 & Gas Line heave & $\begin{array}{l}\text { August 17, } 2005 \text { when mining was } 515 \text { feet East in the } 4 \mathrm{I} \\
\text { panel } \\
\text { August 19, } 2005 \text { when mining in the } 4 \mathrm{I} \text { panel was } 350 \text { feet } \\
\text { East of site }\end{array}$ \\
\hline 4 & Ground heave & $\begin{array}{l}\text { August 17, } 2005 \text { when mining was } 515 \text { feet East in the 4I } \\
\text { panel }\end{array}$ \\
\hline 5 & $\begin{array}{l}\text { Movement in guide rail moorings on the } \\
\text { Eastern end of the Lazear Lane Bridge }\end{array}$ & $\begin{array}{l}\text { September 8, } 2005 \text { when mining was } 3,400 \text { feet } \mathrm{NW} \text { in the } \\
\text { 4I panel }\end{array}$ \\
\hline 6 & Road bump in Route 21 eastbound lane & $\begin{array}{l}\text { September 12, } 2005 \text { when mining was } 740 \text { feet NE in the } 4 \mathrm{I} \\
\text { panel }\end{array}$ \\
\hline 7 & Road bump in Route 21 westbound lane & $\begin{array}{l}\text { September 13, } 2005 \text { when mining was } 730 \text { feet NE in the } 4 \mathrm{I} \\
\text { panel }\end{array}$ \\
\hline 8 & $\begin{array}{l}\text { Fresh cracks and movement at Route } 21 \\
\text { and Bristoria Road intersection }\end{array}$ & $\begin{array}{l}\text { September 15, } 2005 \text { when mining was } 780 \text { feet NE in } 4 \mathrm{I} \\
\text { panel }\end{array}$ \\
\hline 9 & Minor damage to a residence & $\begin{array}{l}\text { September 15, } 2005 \text { when mining was } 630 \text { feet North in the } \\
\text { 4I panel }\end{array}$ \\
\hline 10 & $\begin{array}{l}\text { Movement of guide rail mooring along } \\
\text { eastbound lane of Route } 21\end{array}$ & $\begin{array}{l}\text { September 16, } 2005 \text { when mining was 1,950 feet NE in the } \\
\text { 4I panel }\end{array}$ \\
\hline 11 & $\begin{array}{l}\text { Streambed heave in the North Fork of } \\
\text { Dunkard Fork }\end{array}$ & $\begin{array}{l}\text { Observed on September 16, } 2005 \text { when mining was 1,030 } \\
\text { feet North in the } 4 \text { I panel }\end{array}$ \\
\hline 12 & $\begin{array}{l}\text { Pipeline crossing North Fork of Dunkard } \\
\text { Fork heaved out of stream channel } \\
\text { Cracking and heaving of stream banks and } \\
\text { sagging of pipeline marker cable also } \\
\text { observed }\end{array}$ & $\begin{array}{l}\text { September 19, } 2005 \text { when mining was } 2,760 \text { feet } \mathrm{NW} \text { in the } \\
\text { 4I panel }\end{array}$ \\
\hline 13 & $\begin{array}{l}\text { Horizontal movements of pipelines at } \\
\text { compressor station }\end{array}$ & $\begin{array}{l}\text { September 20, } 2005 \text { when mining was } 3,800 \text { feet NW in the } \\
4 \mathrm{I} \text { panel }\end{array}$ \\
\hline 14 & $\begin{array}{l}\text { Pipeline located along the North Fork of } \\
\text { Dunkard Fork heaving from ground }\end{array}$ & $\begin{array}{l}\text { September 26, } 2005 \text { when mining was } 2,300 \text { feet NE in the } \\
\text { 4I panel }\end{array}$ \\
\hline
\end{tabular}

\subsubsection{Insights from the Ryerson Station Case Study}

The Ryerson Station Dam was breached in August 2005 due to the damages caused by in situ stress disruptions and ground shifting. Mine workings were located at an angle in excess of 51 degrees from the dam at their closest approach to the mine. This is far beyond the typical angle of draw for conventional mine subsidence in the area. It was argued that the effects of subsidence would not propagate to this distance (Hebblewhite \& Gray, 2014). 
Dr. Bruce Hebblewhite research has included "far-field movements" caused by longwall mining in New South Wales, Australia. It has been suggested that when longwall mining takes places in areas with steep hills and high horizontal stresses. Changes in the stress develop which can cause valley closure at significant distances from the longwall panel extent (Hebblewhite \& Gray, 2015). It was concluded that the valley closure phenomenon observed in New South Wales existed at the Ryerson Station Dam, which resulted in structural damage. Ground heaves, pipeline buckling, road bumps, and stream heaves were consistent with the compressive forces caused in valleys by closure movements (Hebblewhite \& Gray, 2014).

Richard E. Gray determined that it is his "...opinion within a reasonable degree of scientific certainty that mining increased the risk of and is the cause of the sudden increase in leakage of the Ryerson Station State Park Dam in July, 2005” (PADEP, 2010).

The PADCNR determined that non-conventional mine subsidence had occurred at Ryerson State Park as a result of the surface topography in the area. The geologic and topographic features at Ryerson were identified as similar to those in Australia where non-conventional mine subsidence movements have been observed and studied. These features include steep slopes, similar rock strata such as sandstones, bedded shales and mudstones, and high in situ horizontal stresses. (Hebblewhite \& Gray, 2014).

The PADCNR also contacted the Mine Subsidence Engineering Consultants from New South Wales, Australia to review the Ryerson Station Dam case to determine whether or not the movements and events leading to the breaching of the dam were attributable to mining activities. Observations and records were reviewed and compared to New South Wales observations. The consultants concluded that the movements which damaged the dam were the result of valley bulging, high horizontal strains, and valley closure caused by longwall mining (PADCNR, 2007).

The Ryerson Station Dam had been "competent and serviceable" for its lifespan and was in good condition into early 2005. Dam inspection reports into 2004 had given favorable findings to support this statement. Significant movements began in early 2005 and while no quantitative monitoring was available, visible cracking in the structure and a dramatic increase in seepage indicated that the dam and surrounding ground was shifting. After the breaching of the dam, a new subsidence monitoring program conducted by Gannett Fleming, Inc. indicated movements were ongoing. These movements coincided in timing with longwall mining operations in panels 3I, 4I, 5I, and 7I at the Bailey longwall mine (PADEP, 2010).

Historic inspection reports ruled out significant structural issues. Ryerson's geological and topographical profiles were similar to those in which this type of subsidence phenomena had been monitored in Australia. The damages observed at and around the dam were consistent with 
what would be expected with this type of subsidence. This behavior is not predicted by standard U.S. mine subsidence models, such as the SDPS model. The resultant horizontal displacements of the SDPS model differed with observations (PADEP, 2010).

The PADEP determined that the failure of the Ryerson Station Dam was the result of ground movements from longwall mining in the Bailey Mine's 3I and 4I East panels. 


\section{CHAPTER 3. EXTENT OF POTENTIAL FAR-FIELD GROUND STRAIN SCENARIOS}

There are tens of thousands of dams in the United States. Many of these dams are owned and managed by the Bureau of Reclamation (USBR), Natural Resources Conservation Service (NRCS), and the United States Army Corps of Engineers (U.S.ACE). A large number of these dams were built more than 50 years ago and are experiencing deterioration effects. Weathering of concrete will alter the ability of the material to withstand tensile and compressive stresses (Wang, Jin, \& Zhang, 2011). The deterioration effects of aging can cause a loss in strength in concrete, steel, and if seepage is present, foundations. Table 3.1 shows the hazard potential of dams listed in the U.S.ACE's NID database.

Table 3.1 Dam safety statistics for the U.S. (FEMA, 2012)

\begin{tabular}{|c|c|c|}
\hline Hazard Potential & $\begin{array}{c}\text { State Regulated Dams } \\
\text { Listed in the NID }\end{array}$ & Total State Regulated Dams \\
\hline High & 10,856 & 10,993 \\
\hline Significant & 11,163 & 10,931 \\
\hline Low & 45,142 & 66,112 \\
\hline Total & 67,161 & 88,036 \\
\hline
\end{tabular}

As coal mine permit area expands, it inevitably encroaches on communities and their infrastructure. Dams are highly important aspects of infrastructure as they provide flood protection for downstream populations. Active mining is known to cause surface effects, in some cases, at unanticipated distances and magnitudes. As mine permit areas and active mining processes begin to approach dams, it becomes increasingly important to protect downstream communities and their properties by ensuring that the dam will not be affected.

Section 2.8 outlines an important case study in this study at Ryerson Station Dam State Park Dam in Greene County, Pennsylvania. The work performed for Chapter 3 sought to determine whether or not major parameters listed in literature pertinent to the events leading to the Ryerson Station Dam breach were prevalent in the sample area of West Virginia. The work included overview mapping of important parameters listed in Zhang et al., 2012, Zhang et al., 2013, Hebblewhite et al., 2000, and others as controlling factors for far-field ground strain phenomena. Among the parameters mapped were:

- Dam proximity to underground coal mine permit area

- Geology

- Topography 
The mapping in Chapter 3 includes several circles surrounding each dam idealized as a point. Idealizing each dam as a point at the center of the dam provides some spatial understanding of the proximity of each dam to a mine permit, although these points lead to inaccuracies in distances from the mine to the dam as some dams are hundreds, even thousands of feet wide. As such, the mapping was intended to provide an overview of sites in West Virginia to determine whether or not similar scenarios existed in the sample area as at Ryerson Station State Park. The mapping does not provide accurate offset distances to the abutments, but does provide information about the number of dams in proximity to mine permits.

A buffer radius of 1 mile, $3 / 4 \mathrm{mi}, 1 / 2$ mile, and 1/4 mile were included around the idealized dam point coordinates. The maximum distance of a 1-mile buffer radius was determined to be an easily perceived value as a compromise between what was observed in a study by Waddington \& Kay, 2003 as $4921 \mathrm{ft}$. (1500 m) longitudinal distance from the incremental mine panel where valley closure was observed (Figure 3.1) and 6,000 ft.; as this was the approximate distance where increases in seepage were observed at the Ryerson Station State Park Dam. This 1-mile buffer offset distance is not intended to be a defining criterion for real in-field determination of whether or not a dam is susceptible to non-conventional subsidence, but rather was used as a filtering mechanism for dams which are in proximity of historic observed far-field ground strain effects.

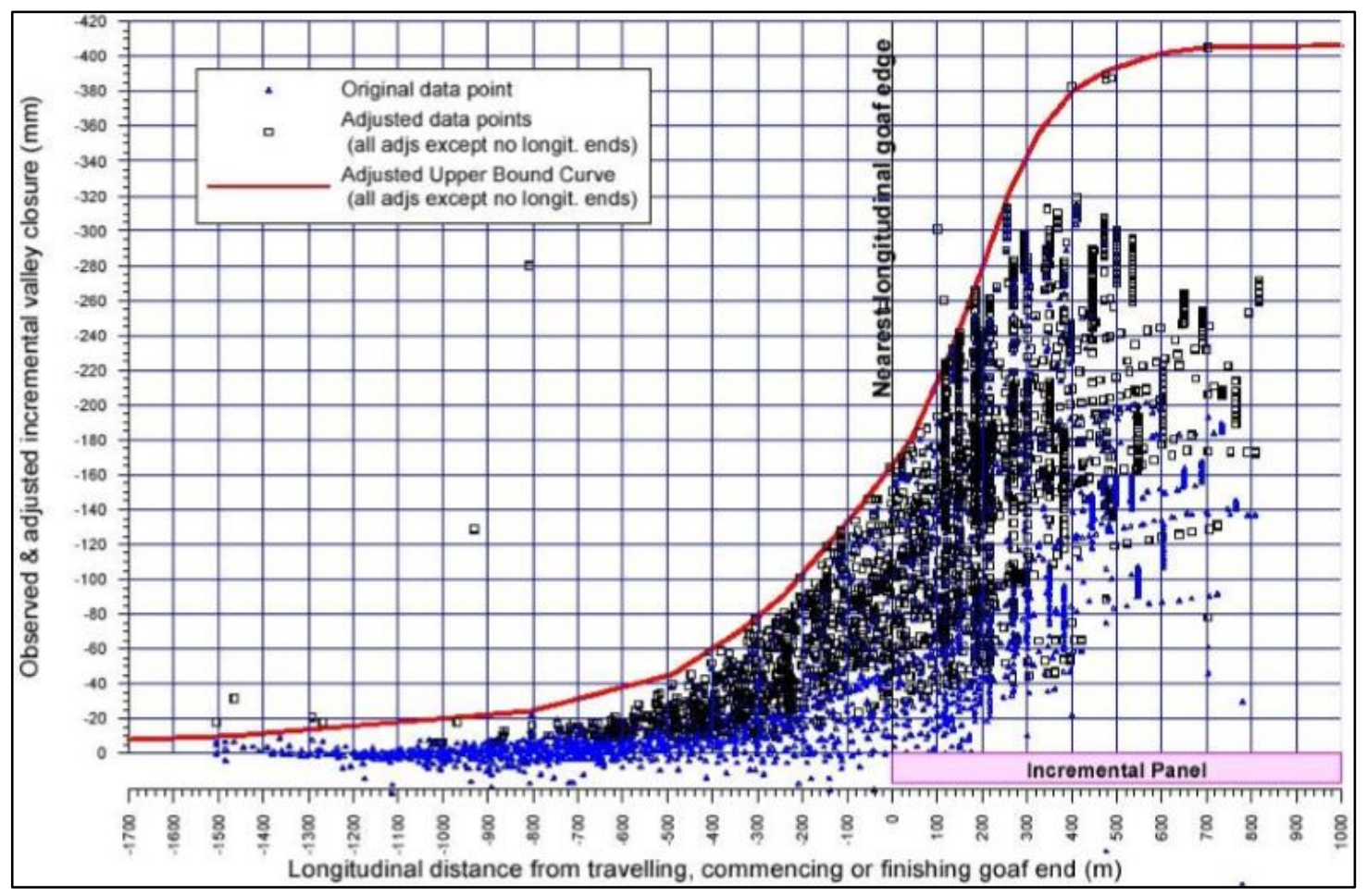

Figure 3.1 Valley closure versus longitudinal distance from goaf end (Waddington \& Kay, 2003) 


\subsection{U.S.ACE Dams in West Virginia}

Mapping was performed for West Virginia that included U.S.ACE dam locations as coordinate points. These points included four buffer radii at $1 \mathrm{mi}, 3 / 4 \mathrm{mi}, 1 / 2 \mathrm{mi}$, and $1 / 4 \mathrm{mi}$. Underground mine permit information was obtained from WVDEP shapefiles. Any dams where underground mines were nearby to the proximity of the buffer radius of any dam were highlighted as areas of potential concern. Figure 3.2 presents the mapping of the spatial locations of underground coal mine permit areas and U.S.ACE dams in WV.

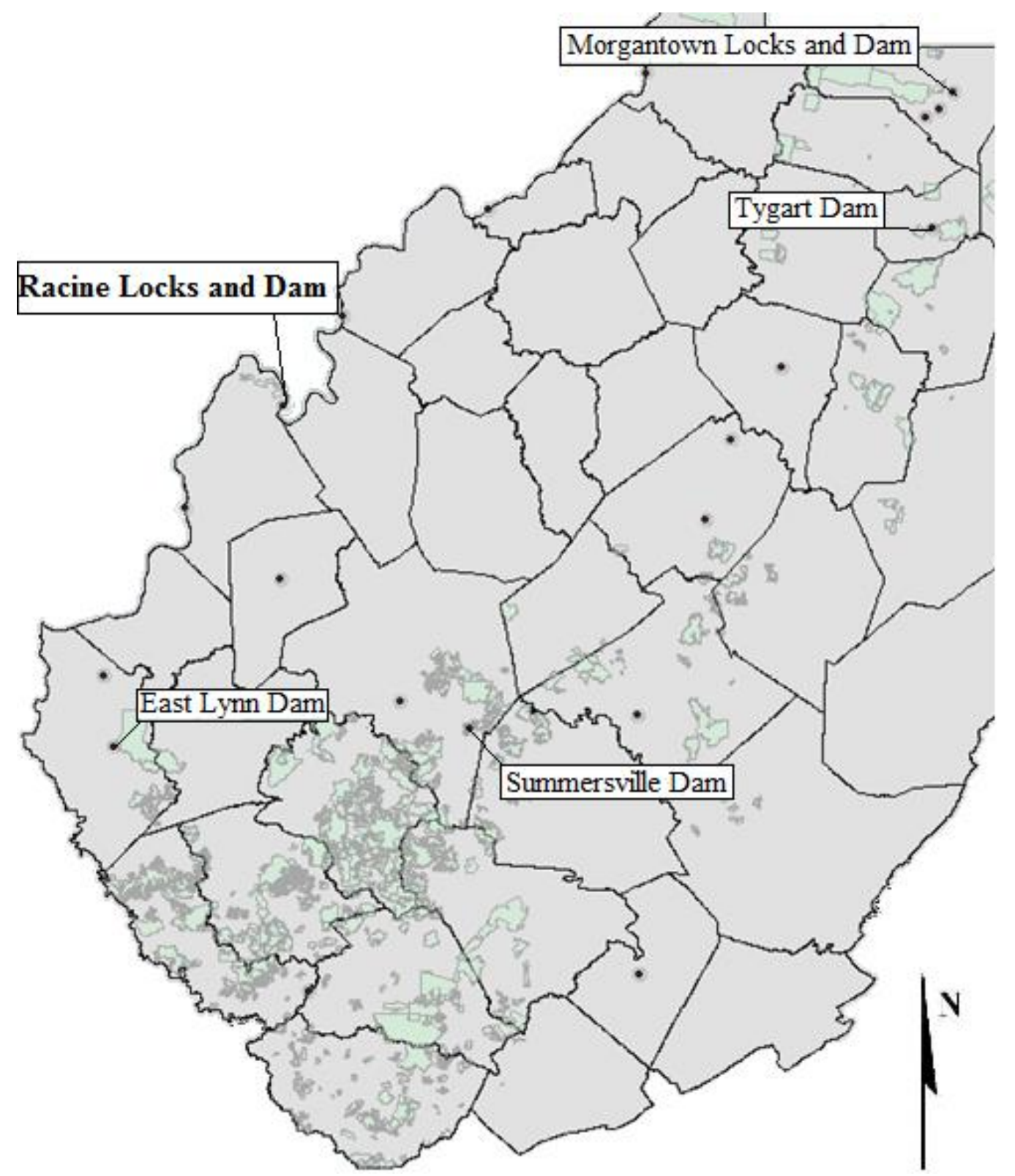

Figure 3.2 U.S.ACE dams and mine permit areas for $W V$ 


\section{Dams within the 1 mi buffer radius:}

- $\quad$ East Lynn Dam (0.311 mi.)

- Summersville Dam (West: 0.370 mi.; East: 0.440 mi.)

- $\quad$ Tygart Dam (West: 0.994 mi.; East: 0.801 mi.)

\section{Dams that were considered nearby to the buffer radius:}

- Morgantown Locks and Dam (1.656 mi.)

- Racine Locks and Dam (1.558 mi.)

- Hildebrand Locks and Dam (2.678 mi.)

- Opekiska Locks and Dam (2.248 mi.)

Morgantown Locks and Dam, Racine Locks and Dam, Hildebrand Locks and Dam, and Opekiska Locks and Dam were all relatively near to the buffer radius but still outside of it. As a result, they have only been noted and were not investigated further. The distances noted for these dams were measured from points, not at the extent of the structures; therefore, the distances would change somewhat due to the length of the dam which can be over $1 / 4 \mathrm{mi}$.

\subsubsection{East Lynn Dam}

The East Lynn Dam is located near East Lynn West Virginia in Wayne County. It is 1 of 3 dams located near to an underground mine permit in West Virginia. East Lynn has the closest approach of an underground mine permit than any other major dam owned by the U.S.ACE in WV. This dam is an earthen rolled fill dam. The structure is owned and managed by the U.S.ACE. The dam's primary authorization is flood control. It is $133 \mathrm{ft}$. high and $652 \mathrm{ft}$. long. East Lynn Lake is 12 miles long with 44 miles of shoreline. It holds 1005 acres of water at summer pool level (U.S.ACE, 2014). Figure 3.4 shows the proximity that was found in the mapping study for East Lynn Dam. The underground mine permit encroaches within the $1 / 2$ mile buffer zone, and nearly reaches the $1 / 4$ mile buffer zone. This offset distance is approximate as the dam is idealized as a point and is $652 \mathrm{ft}$. long. The geology in this area is Paleozoic - Pennsylvanian (299-318 mil. yrs. ago). This geology is comprised of cyclic sequences of sandstone, shale, clay, coal, and limestone. Coal, gas, oil, and brine exist within this geology (WVGES, 2011). 


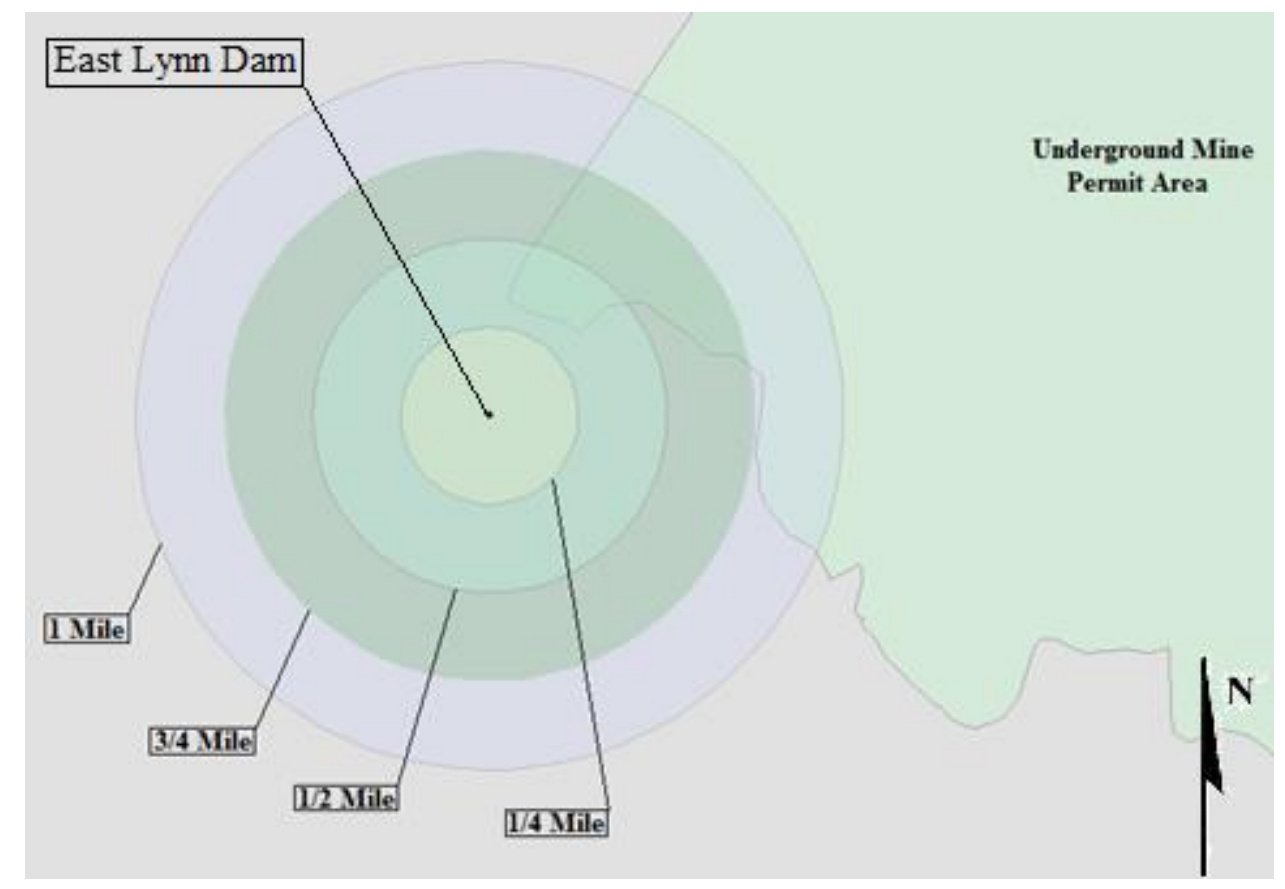

Figure 3.3 East Lynn Dam and underground coal mine permitted area

\subsubsection{Summersville Dam}

The Summersville Dam resides on the Gauley River, near to Summersville in Nicholas County, WV. This dam is 1 of only 3 dams owned by the U.S.ACE which have nearby underground coal mines near to them in WV. There are two underground mine permit areas that encroach within the 1-mile buffer radius for the dam. Each of these two mine permit areas are within $1 / 2$ mile from the dam. The dam is idealized as a point, and affects the offset distance to the mine as the dam is $2280 \mathrm{ft}$. long, well over $1 / 4$ mile. The dam was completed in 1966 , and was initially intended to be a flood control structure for the downstream communities for the Gauley and Kanawha Rivers. The watershed for Summersville Lake is 803 square miles. The dam is the second largest rock-fill dam in the eastern United States. According to the U.S.ACE, the dam is about as tall as a 40 story building at $390 \mathrm{ft}$. tall, is 2,280 ft. long, and is comprised of 12 million $\mathrm{yd}^{3}$ of earth and rock materials. The reservoir includes 2,790 acres of water at an elevation of 1,652 above sea level at the summer pool level. Winter pool level is lower, at an elevation of 1,575 to help attenuate flood waters. The geology is described as Paleozoic - Pennsylvanian (299-318 mil. yrs ago). This geology includes cyclic sequences of sandstone, shale, clay, coal, and limestone. Coal, gas, oil, and brine are also found within this geology (WVGES, 2011). Figure 3.4 shows the mapping for the Summersville Dam with $1 \mathrm{mi}, 3 / 4 \mathrm{mi}, 1 / 2 \mathrm{mi}$, and $1 / 4 \mathrm{mi}$ buffer zones and nearby underground mine permit areas. 


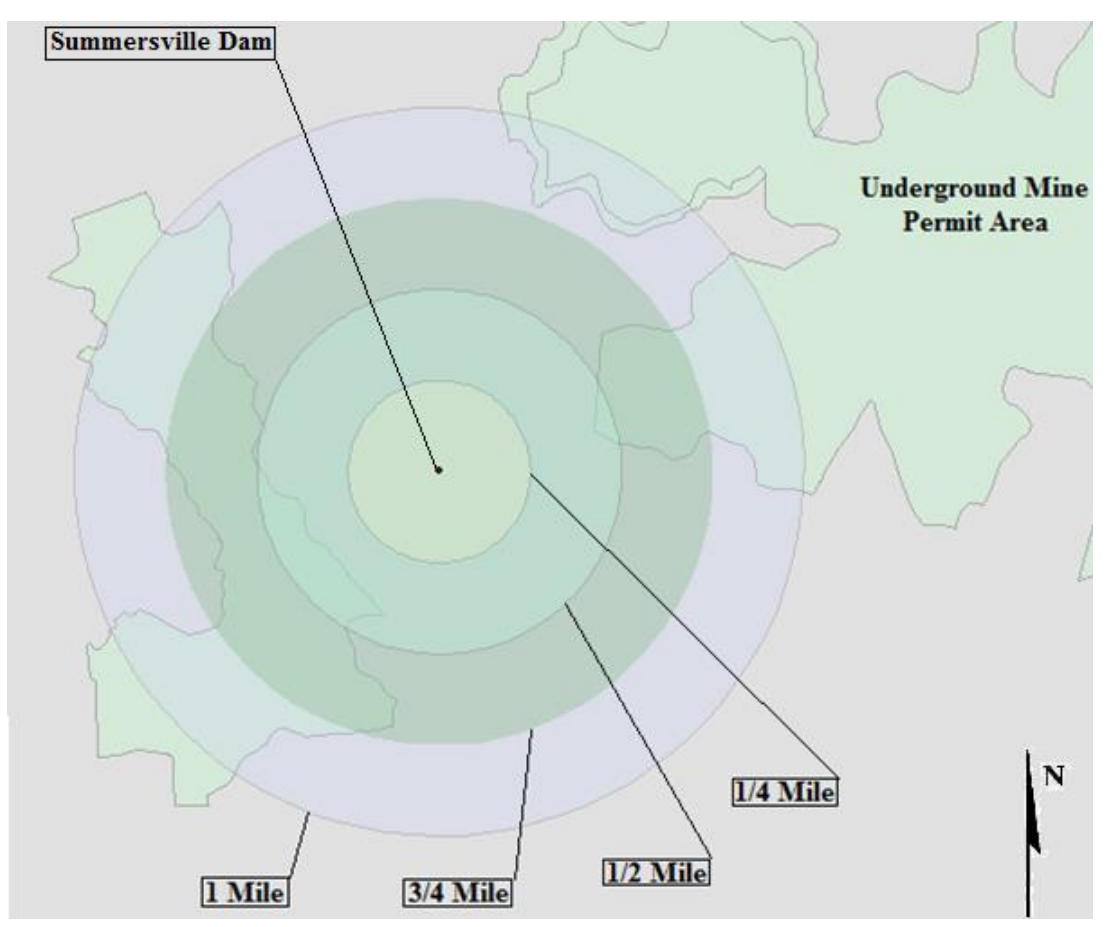

Figure 3.4 Summersville Dam and nearby underground mine permit area

\subsubsection{Tygart Dam}

Tygart Dam resides near Grafton in Taylor County, West Virginia on the Tygart Valley River. The construction of the dam was completed in 1938. The dam structure type is a concretegravity dam with an uncontrolled spillway. Tygart Lake resides in Taylor and Barbour Counties. The drainage area for the watershed is 1,184 square miles. The dam is comprised of 1,251,550 $\mathrm{yd}^{3}$ of concrete. The dam is $230 \mathrm{ft}$. tall from the streambed, $1,921 \mathrm{ft}$. long, and $207 \mathrm{ft}$. wide. The streambed rests at $960 \mathrm{ft}$. above sea level. The lake is 10 miles long at normal pool. Pool levels and lake areas are summarized in Table 3.2.

Table 3.2 Pool levels and lake area for Tygart Lake (U.S.ACE, 2014)

\begin{tabular}{|c|c|}
\hline Pool Level & Area of Lake (acres) \\
\hline Summer Pool & 1,750 \\
\hline Maximum Pool & 3,440 \\
\hline Pool Level & Elevation above sea level (ft) \\
\hline Maximum Pool & 1,167 \\
\hline Summer Pool & 1,094 \\
\hline Minimum Pool & 1,010 \\
\hline
\end{tabular}

The geology is described by the West Virginia Geologic and Economic Survey (WVGES) as Paleozoic - Pennsylvanian (299-318 mil. yrs. ago). This geology includes cyclic sequences of 
sandstone, shale, clay, coal, and limestone. Coal, gas, oil, and brine are also found within this geology (WVGES, 2011). Figure 3.5 shows the mapping for the Tygart Dam with $1 \mathrm{mi}, 3 / 4 \mathrm{mi}, 1 / 2$ $\mathrm{mi}$, and $1 / 4 \mathrm{mi}$ buffer zones and nearby underground mine permit areas. There are two underground mine permit areas within proximity of the dam. The dam is idealized as a point; therefore, if the total length of the dam $(1,921 \mathrm{ft}$.) was taken into account, the offset distance would differ greatly as the dam is well over $1 / 4 \mathrm{mi}$ long. Nonetheless, the mine permits each reside within about 1 mile or less from the dam structure.

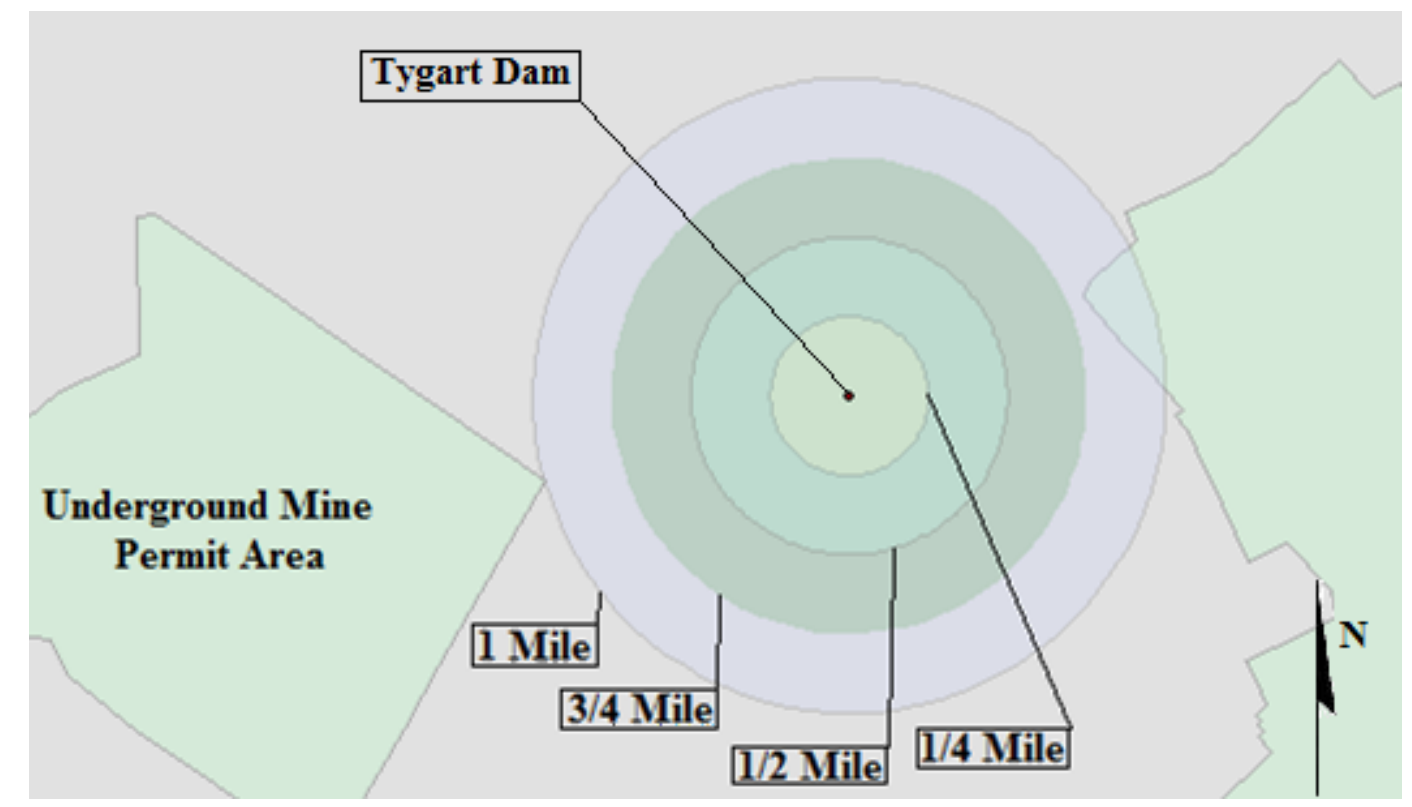

Figure 3.5 Tygart Dam and nearby underground mine permits

\subsubsection{NID Locations in West Virginia}

All dams in West Virginia are not owned and managed by the U.S.ACE. Many other dams exist that are owned by many entities throughout the state. The National Inventory of Dams (NID) is a database of dams established by the U.S.ACE. For a dam to be included in this inventory of dams it must meet certain criteria, these are listed below. This list of criteria is current to July, 2014 and is specific to the catastrophic failure of the structure.

- High hazard classification - Loss of one human life is likely if the dam fails

- Significant hazard classification - Possible loss of human life and likely significant property or environmental destruction:

- Equal to or exceeds 25 feet in height and exceed 15 acre-feet in storage

○ Equal to or exceeds 50 acre-feet storage and exceed 6 feet in height (U.S.ACE, 2014) 
There are 609 dams in WV listed in the NID database. Out of these 609, many are directly undermined or may be in the future by permitted underground coal mines. Many others have mining within the 1-mile buffer zone. Figure 3.6 shows the NID locations for the northern half of WV, and Figure 3.7 shows the NID locations for the southern half of WV. Table 3.3 presents the number of NID locations that had mine permits inside their buffer radius, directly undermined, or nearby to the buffer radius. Nearby mine permits were considered to be equal to or less than the maximum distance considered for U.S.ACE dams at $2.7 \mathrm{mi}$.

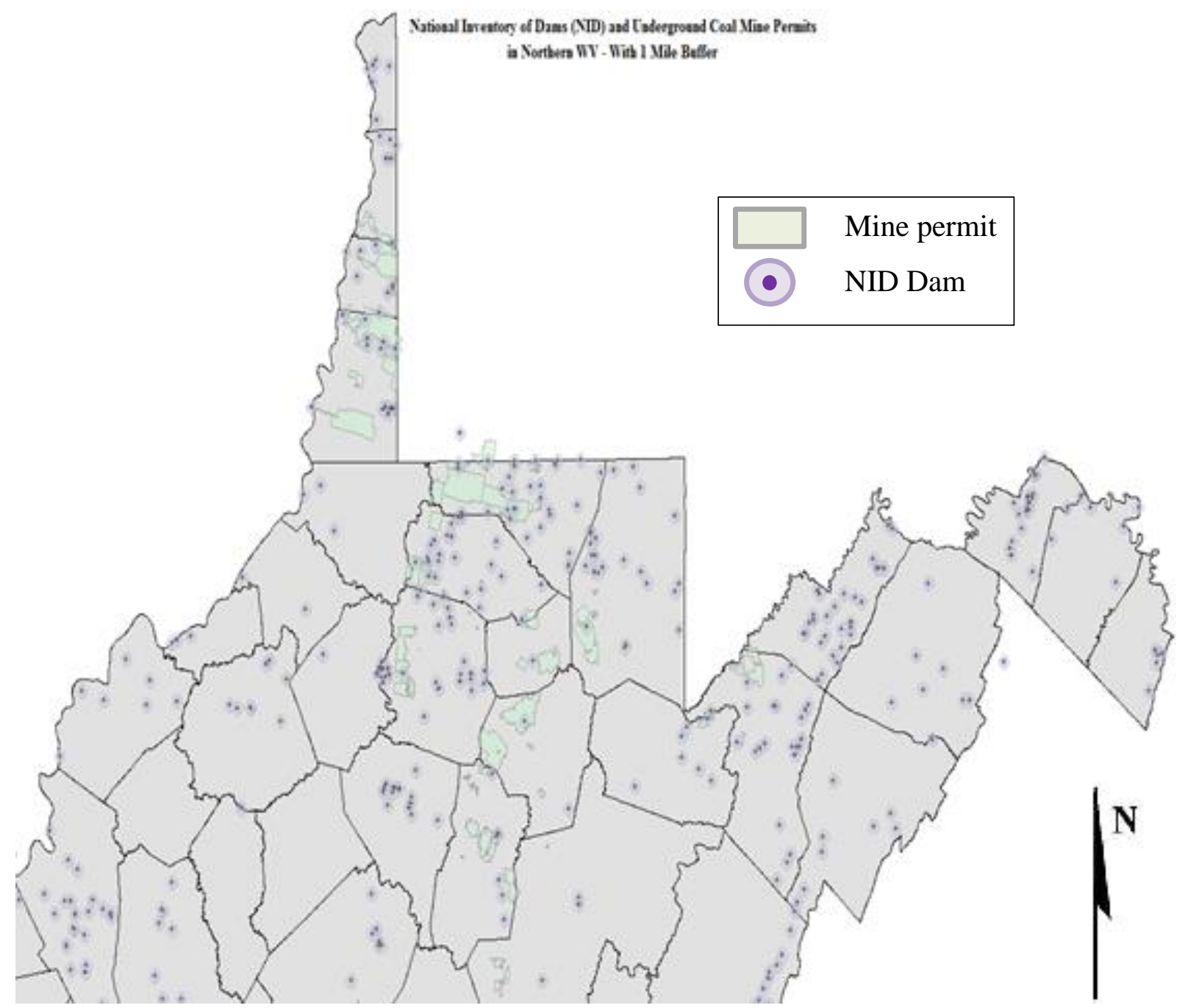

Figure 3.6 NID locations in northern $W V$ and current underground coal mine permit area (WVGIS, 2014) 


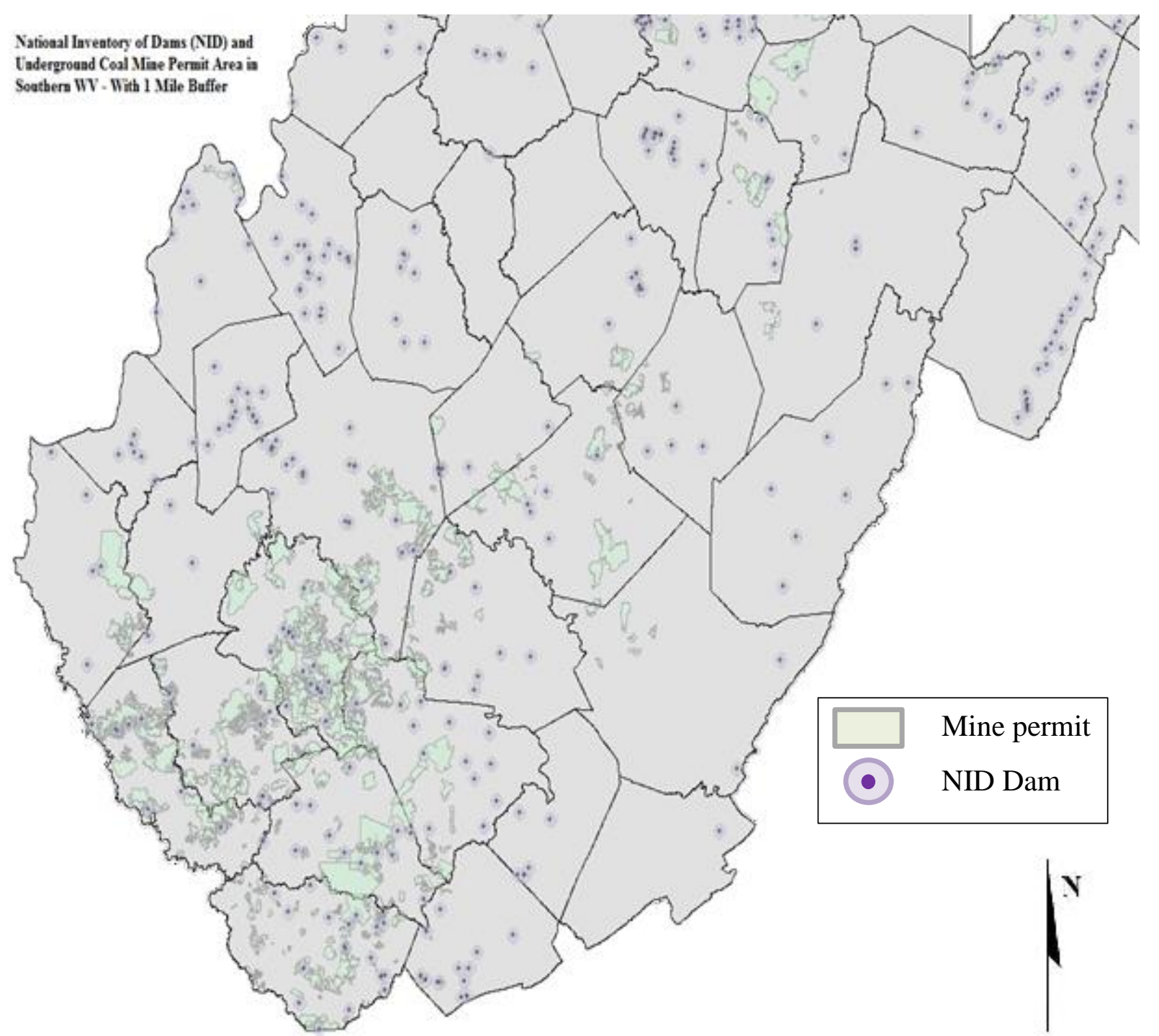

Figure 3.7 NID locations in southern WV and current underground coal mine permit area (WVGIS, 2014)

Table 3.3 NID dams in WV with underground mine permits in their vicinity

\begin{tabular}{|c|c|c|c|}
\hline & Within $2.7 \mathrm{mi}$. & Within $1 \mathrm{mi}$. & Directly Undermined \\
\hline NID & 115 & 79 & 45 \\
\hline
\end{tabular}




\subsection{Ryerson Station Dam and Tygart Dam Mapping}

There are thousands of dams across the United States, many of which are considered high hazard. It is important to protect these structures to ensure the safety of people and property. The Ryerson Station Dam case study has shown that non-conventional subsidence phenomena that are prevalent in New South Wales are also possible in Appalachia.

Out of the three U.S.ACE owned dams which have underground mine permits located within the 1 mile buffer zone, only Tygart Dam was investigated further to compare site specific conditions to those at Ryerson Station State Park. For this study, mapping was performed to see if comparable conditions existed at the dam, within the valley, and between the dam and the mine that existed at the Ryerson Station Dam case study. Some of the most important parameters according to Zhang et al., 2012 and Hebblewhite et al., 2000 were mapped for both sites, which included topography, geology, and dam proximity to underground coal mine permit area.

\subsubsection{Topographic Comparison}

The Ryerson Station Dam lies within the Appalachian Mountain chain. The topography in the area is comprised of hilly terrain. Mining in the 4I East Panel occurred to the east of the dam. Additional mining occurred to the south and south east after the dam was breached. The landform from the valley bottom at the downstream toe of the Ryerson Station dam to Ridgeline 1 East approximately perpendicular to it to the east is an elevation change of $360 \mathrm{ft}$. Figure 3.8 shows the topography at the Ryerson Station Dam as a surface with $20 \mathrm{ft}$. contours obtained from a USGS interactive mapping tool. 


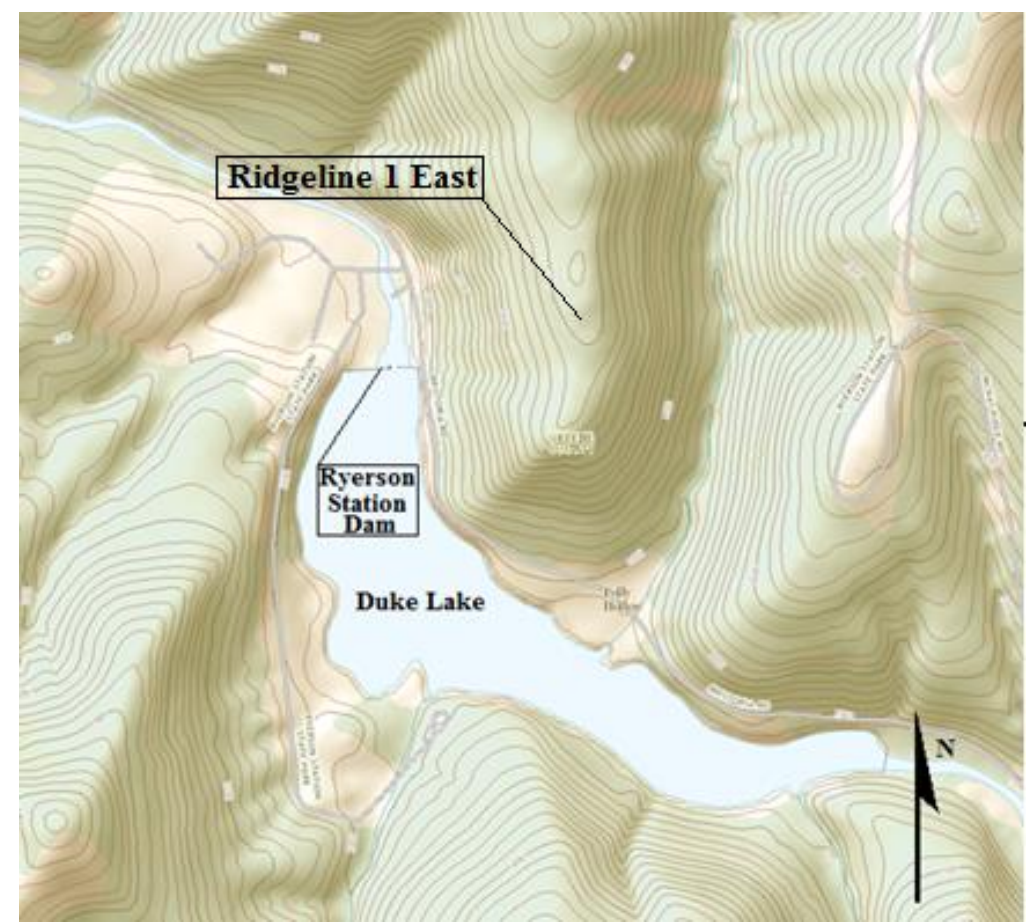

Figure 3.8 Topography and contours at the Ryerson Station Dam and nearby area (USGS, 2014)

The topography at and around Tygart Dam is similar to that of Ryerson Station Dam. The site also lies within the Appalachian Mountains and includes a deep valley with steep slopes from nearly flat to rock outcrops at 87 degrees. The landform to the east of the dam has a slope of about 46 degrees. Mine permits in the vicinity of the Tygart Dam exist to the east as well as to the west of the dam. The topographic elements around the dam are labeled in Figure 3.9. The image in Figure 3.9 was acquired from a USGS interactive mapping tool with $20 \mathrm{ft}$. contours. Ridgeline 1 East has an elevation change of $240 \mathrm{ft}$. from the valley bottom elevation at the downstream toe of the dam. The second ridgeline to the east of the dam (Ridgeline East 2) has an elevation of $1520 \mathrm{ft}$., which if taken from the downstream toe of the dam is an elevation change of $540 \mathrm{ft}$. The elevation difference taken from the bottom of the valley between Ridgeline 1 East and Ridgeline 2 East to the top of the hill at Ridgeline 2 East is $400 \mathrm{ft}$. From the top of Ridgeline 1 West to the downstream toe of the dam is also an elevation difference of $400 \mathrm{ft}$. 


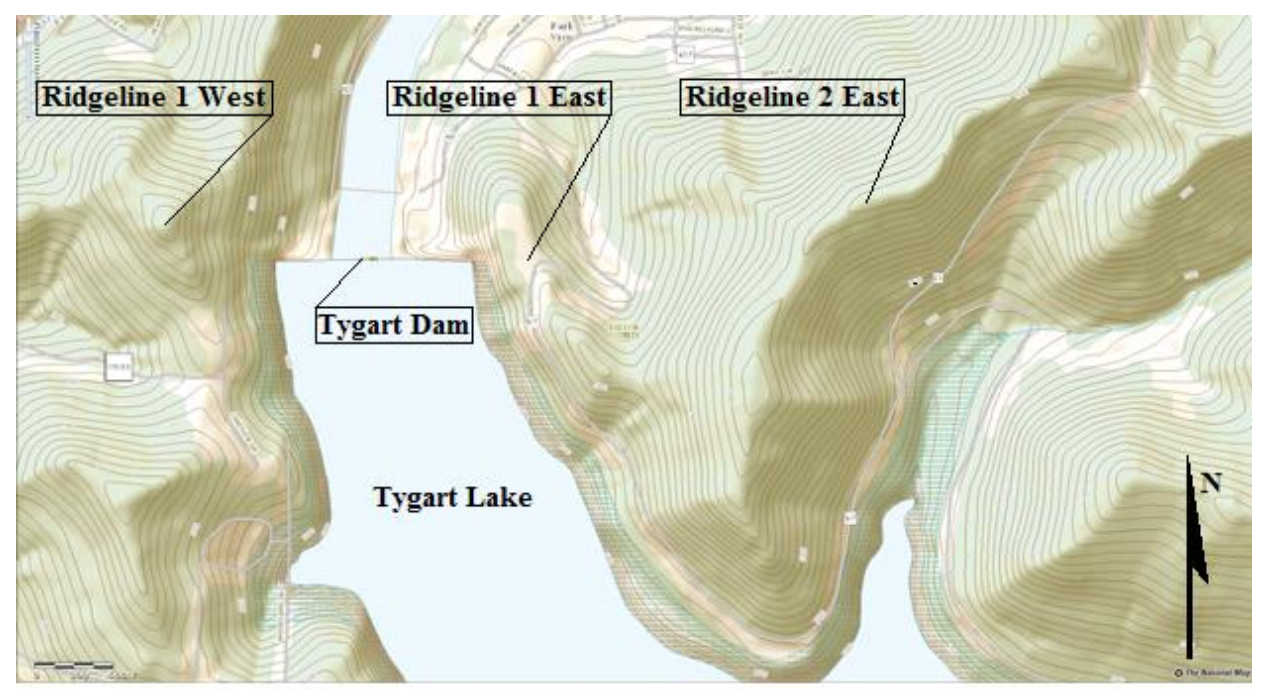

Figure 3.9 Topography and contours at the Tygart Dam and nearby area

\subsubsection{Slope Severity Comparison}

Khair et al., 1988 and others have determined that slope angles have an influence on the magnitude of subsidence effects. Slope angle mapping was performed in ESRI GIS ${ }^{\text {TM }}$ for both the Ryerson Station Dam site and the Tygart Dam site to compare the two site conditions.

The slope directly to the east of the Ryerson Station Dam was determined to be 26 degrees from the contour mapping in Figure 3.8. Figure 3.11 presents the slope severity mapping that was performed at the Ryerson Station Dam area. Figure 3.11 was developed from a 10-meter resolution digital elevation model acquired from the WV GIS Technical Center's data clearinghouse online (WVGIS, 2014). The mapping used a color scale from green to red to visually represent steeper slopes. As slopes became steeper, their color increased from green toward the red end of the spectrum. The slope angles ranged from 0 degrees to 61 degrees. The slope directly to the east of the dam is rather steep as presented in Figure 3.10. This steep slope was thought to have contributed to the non-conventional subsidence related events leading to the breaching of the dam (Hebblewhite \& Gray, 2014). 


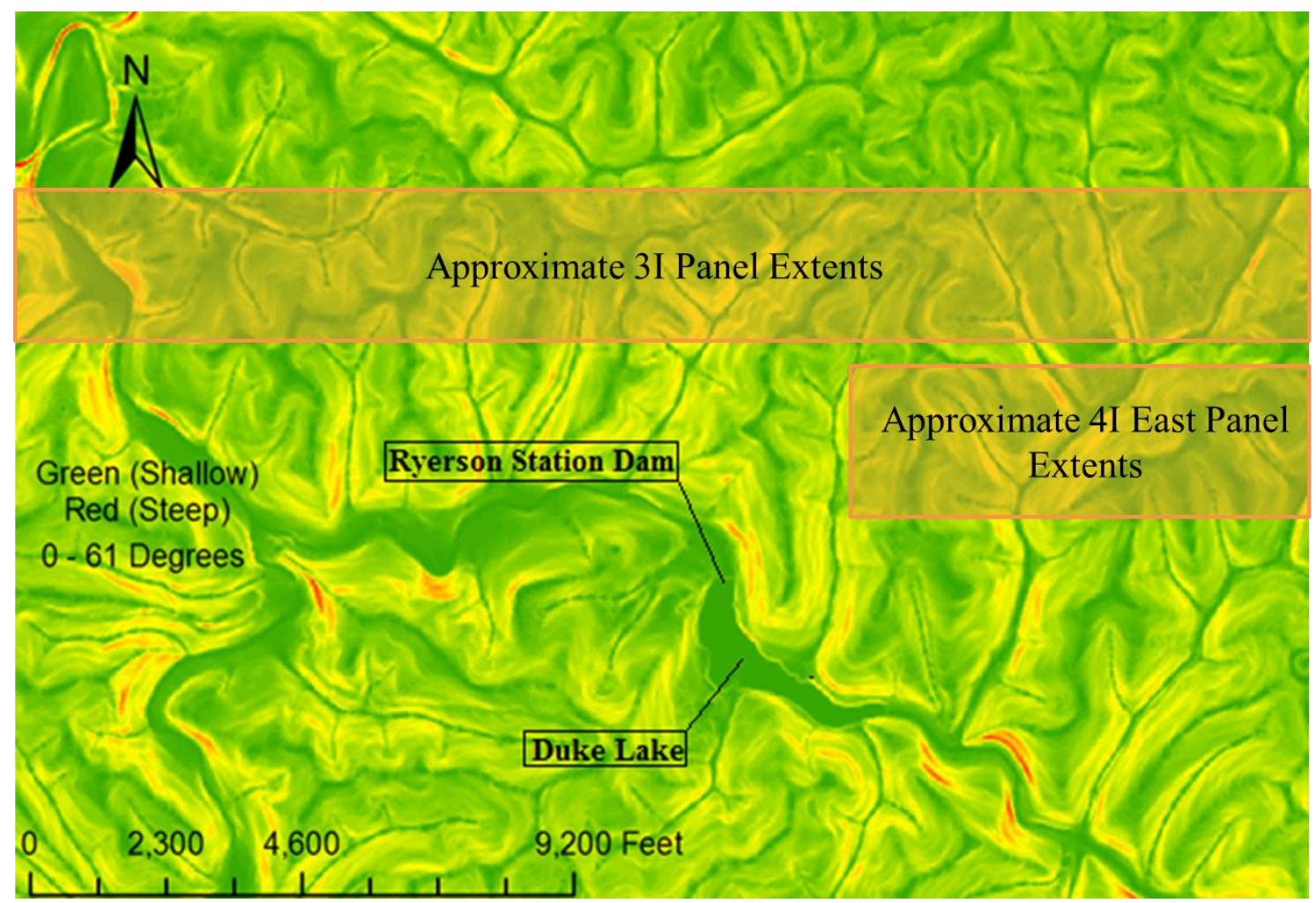

Figure 3.10 Slope severity at Ryerson Station Dam and nearby area

Slope severity modeling was also performed for the Tygart Dam and surrounding area. The color scheme represents slope angles from 0 degrees to 87 degrees which is shown as from green to red. The slope angle against the eastern side of the dam was taken from contour information to be 46 degrees, which is higher than the slope angle at Ryerson Station by 20 degrees. The mapping shown in Figure 3.11 revealed angles toward the maximum of the spectrum for the DEM for the area directly next to the dam. The slope on the western edge of the dam appears to be just as steep as the eastern slope. Both the eastern and western side of the dam has permitted underground mines within less than 1 mile from them as shown in Figure 3.5. 


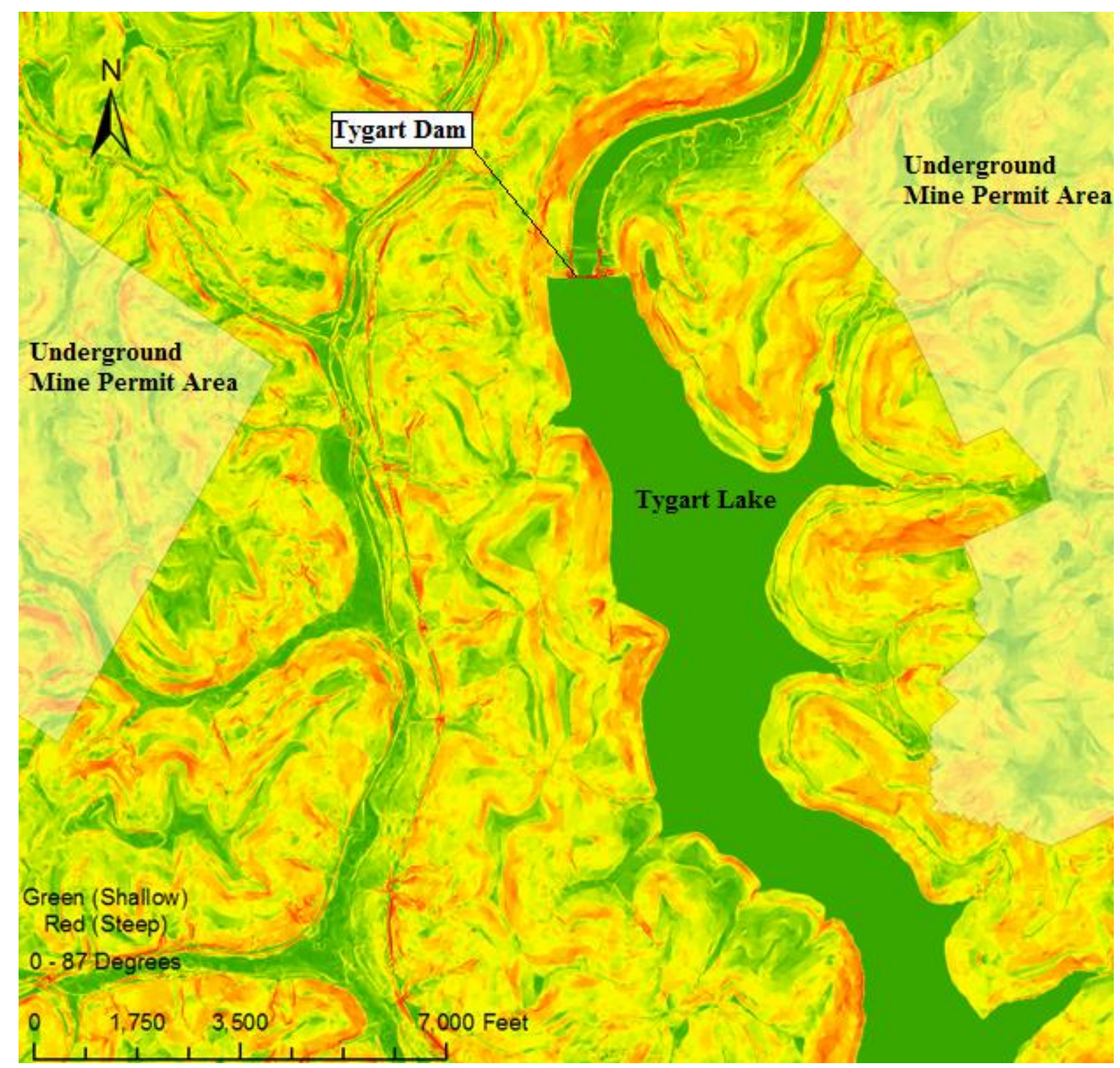

Figure 3.11 Slope severity at Tygart Dam and nearby area

\subsubsection{Geologic Comparison}

A brief geologic study was performed on GIS ${ }^{\text {TM }}$. Bedrock geology was acquired from a USGS database. Figure 3.12 shows the mapped bedrock geology for the Ryerson Station Dam and the Tygart Dam. The geologic zones differ, but are quite similar in composition. Each has cyclic sequences of sandstone, shale, limestone, clay, and shale. Through this determination, although it is not yet entirely clear what specific mechanism caused the large magnitude movements at the Ryerson Station site, it can be suspected that similar movements may be possible at the Tygart Dam site through similar mechanisms as what occurred at the Ryerson Station Dam. 


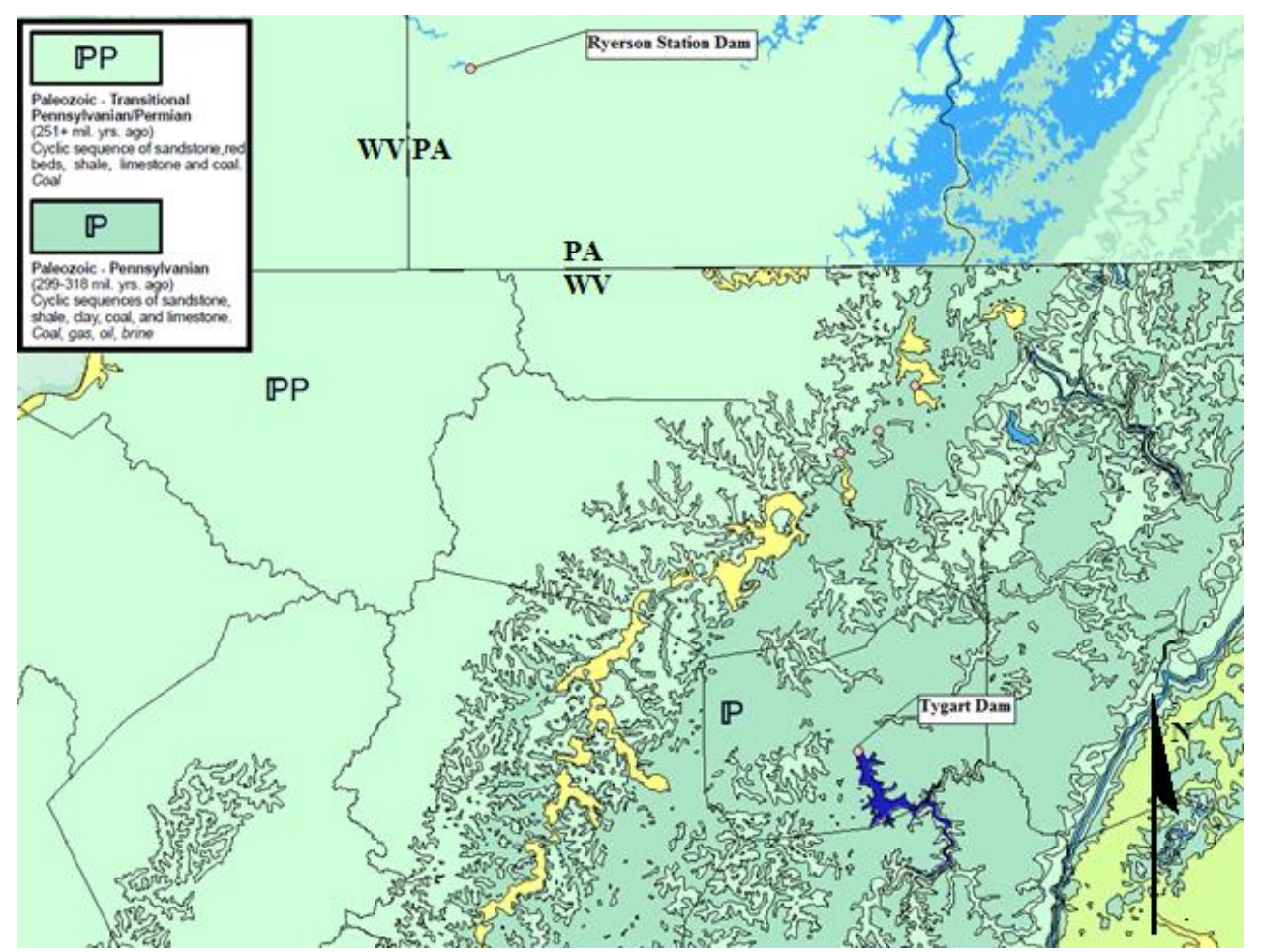

Figure 3.12 Bedrock geology for the Ryerson Station Dam and Tygart Dam

\subsubsection{Dam Proximity to Mine Comparison}

Information was obtained from mine permits to determine the proximity of the extents of mining for both the Ryerson Station Dam and the Tygart Dam sites. The furthest distance where changes in seepage were first noticed at the Ryerson Station Dam was more than 6,000 ft., however this distance was taken for the 3I Panel as mining was progressing away from the location of the dam. The mechanism which caused changes in the valley where the Ryerson Station Dam was situated was likely created when mining was closer to the dam. Regardless of this fact, the closest approach of the 3I panel to the Ryerson Station Dam was 2,100 ft. Figure 3.13 shows the proximity of the Bailey Mine panels to the Ryerson Station Dam. Figure 3.14 presents the proximity of longwall coal mine permit area to the east side of the Tygart Dam. Table 3.4 shows the points of extent of mining at the closest distances to the Ryerson Station Dam and the Tygart Dam. Extent of mining from the east side of Tygart Dam was determined to be 3,200 ft., and the west side of the dam was found to be 5,250 ft. These values are greater than the values for the 4I East Panel, but less than the distance of the 3I Panel at the time damages were noticed at the Ryerson Station Dam at about 6,000 ft. The orientation of the longwall panels and stress field are also significant factors which should be incorporated in the case of a thorough assessment. 


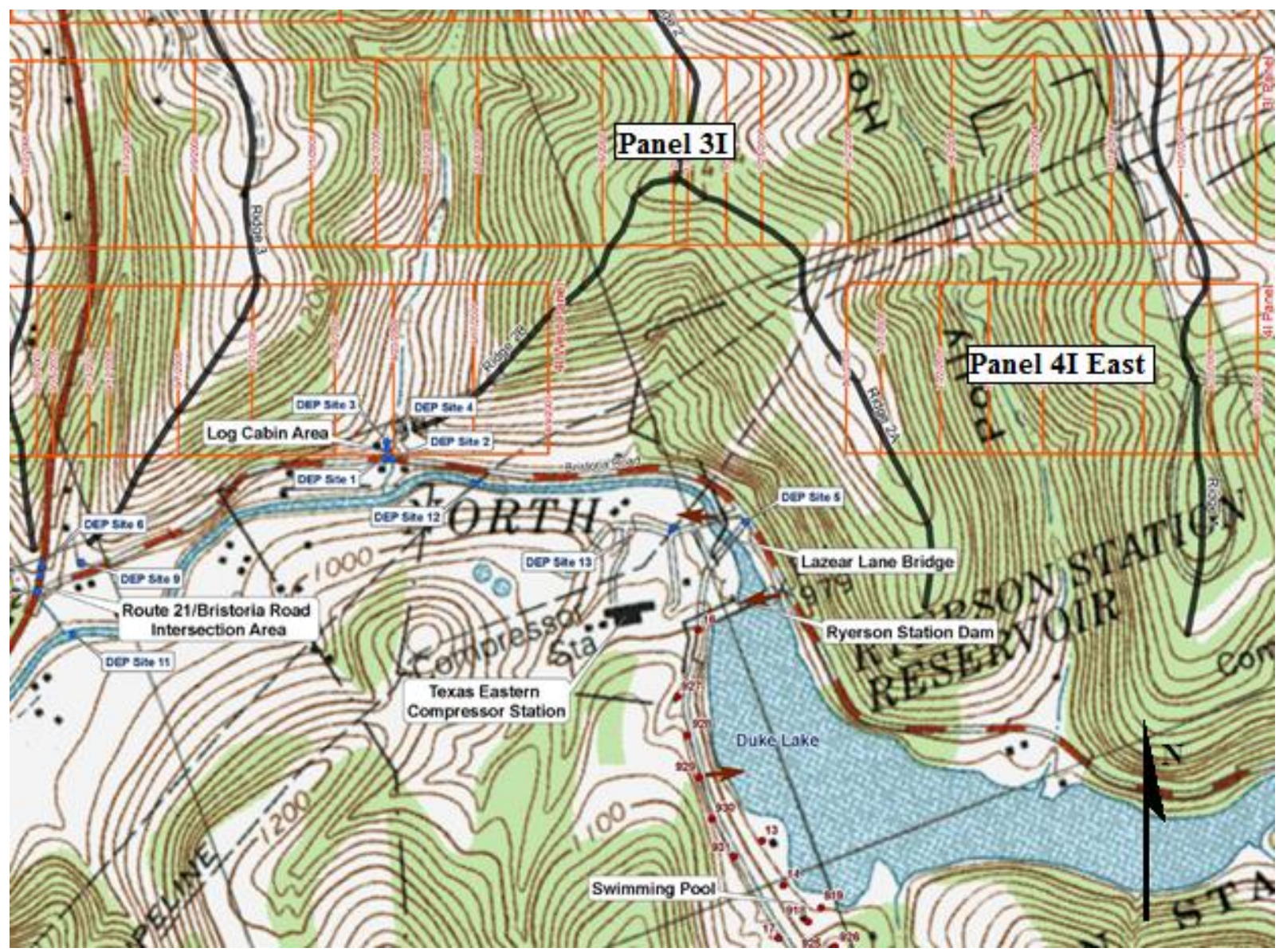

Figure 3.13 Proximity of longwall mining to the Ryerson Station Dam 


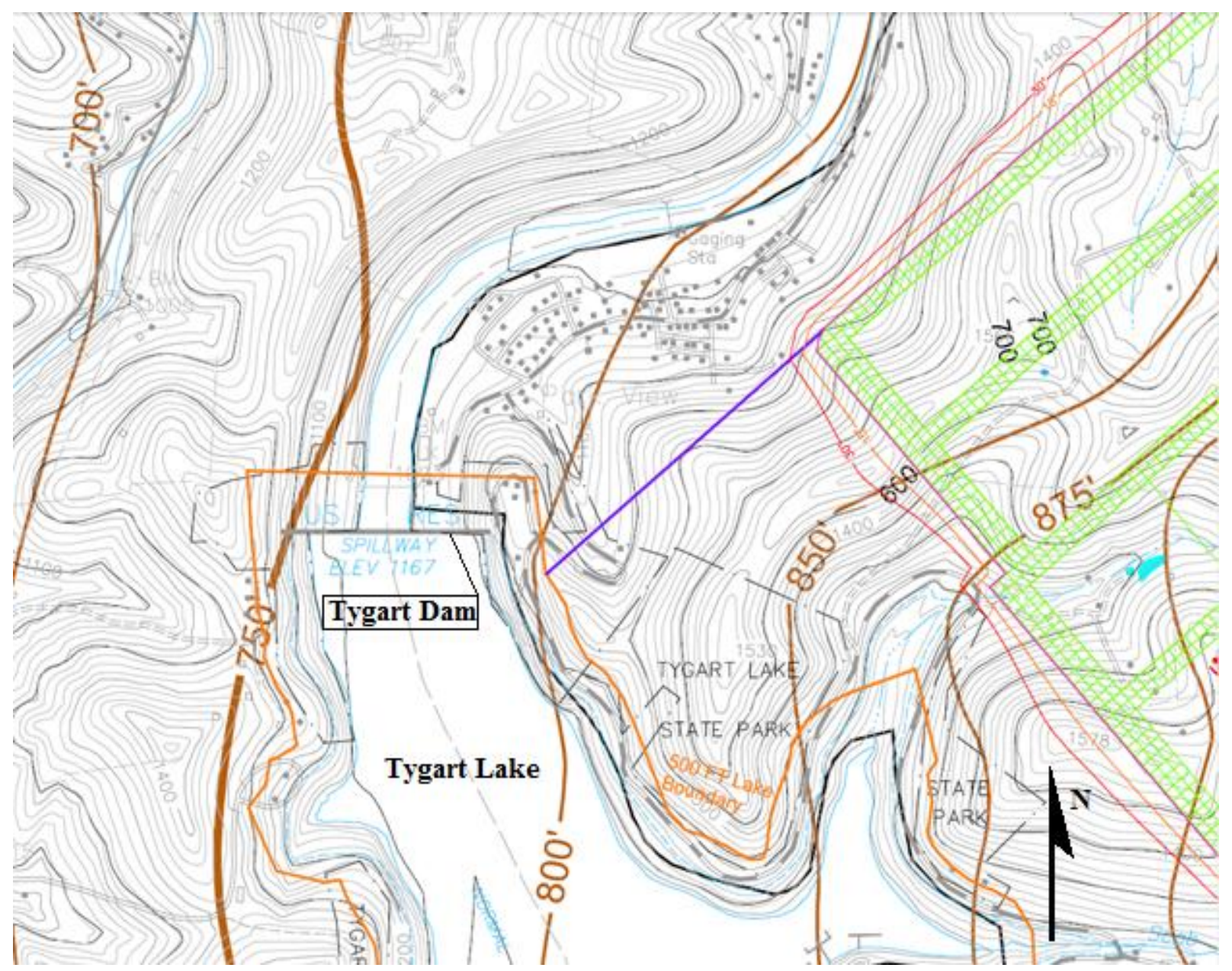

Figure 3.14 Tygart Lake and Dam with nearby underground longwall mine permit area

\subsection{Discussion of Mapping Comparison and Study Findings}

The mapping study performed in Chapter 3 has given insight into the potential for future valley closure and upsidence phenomena to occur in valleys nearby to dams in WV, especially for many NID sites. The Tygart Dam was investigated further, and it was found that similar characteristics existed at the site which also existed at the Ryerson Station Dam site. It was found that the investigated parameters suggested to have had an influence on the magnitude of valley closure and upsidence were even more critical for the Tygart Dam location than existed at the Ryerson Station Site, with the possible exception of mine offset distance. The downstream population of Tygart Dam is also much greater than what was at Ryerson Station Dam. The City of Grafton, WV rests just below the Tygart Dam, and has a population of 5,164 current to the 2010 census; which does not include nearby populations within the river valley and other downstream cities such as Fairmont, WV and Morgantown, WV which would likely also experience the effects of a catastrophic failure of the Tygart Dam (U.S. Census, 2010). Effects from mining may be attenuated in the valley between what has been labeled as Ridgeline 1 East and Ridgeline 2 East; 
as stresses tend to not propagate much of their magnitude past valley bottoms as presented in Figure 2.6.

The Tygart Dam is much larger and somewhat older than the Ryerson Station Dam. It is 22 years older, 1,400 ft. longer, $200 \mathrm{ft}$. taller, and $160 \mathrm{ft}$. wider at the base. The reservoir size of Tygart Lake is 1,700 - 3,380 acres larger than was Duke Lake. The bedrock geology for both sites, which has been hypothesized as a major contributing factor, is very similar in their sequences of strata. The adjacent slope angle is about 20 degrees steeper at Tygart's eastern slope than it was at Ryerson Station. The coal seam thickness in the area around the Tygart Dam is comparable but perhaps somewhat thinner than it was at Ryerson Station. The offset distance from the closest mining operations to the Tygart Dam is about 3,200 ft., which is within the range of when seepage changes were first noticed at Ryerson Station. Table 3.4 provides a brief summary of facts discovered in this study pertinent to the Ryerson Station Dam and the Tygart Dam.

Table 3.4 Overview of parameters for comparison of Ryerson Station Dam and Tygart Dam

\begin{tabular}{|c|c|c|}
\hline & Duke Lake and Ryerson Station Dam & Tygart Lake and Dam \\
\hline Dam Construction & Concrete Gravity (1960) & Concrete Gravity (1938) \\
\hline Dam Size & $\begin{array}{l}\text { - } 515 \text { feet long with } 200 \text {-foot spillway } \\
\text { - } 30 \text { feet high at spillway } \\
\text { - } \quad 42 \text { feet high at non-overflow } \\
\text { - } 6 \text { feet wide at crest } \\
\text { - } \quad 30 \text { feet wide at base }\end{array}$ & $\begin{array}{l}\text { - } 1,921 \text { feet long } \\
\text { - } 230 \text { feet high } \\
\text { - } 207 \text { feet wide at base }\end{array}$ \\
\hline Reservoir Size & 62 acres & $\begin{array}{l}1,750 \text { acres at summer pool } \\
3,440 \text { acres at maximum pool }\end{array}$ \\
\hline Bedrock Geology & $\begin{array}{l}\text { Paleozoic - Transitional } \\
\text { Pennsylvanian/Permian } \\
\text { Includes: Cyclic sequences of sandstone, red } \\
\text { beds, shale, limestone and coal }\end{array}$ & $\begin{array}{l}\text { Paleozoic - Pennsylvanian } \\
\text { Includes: Cyclic sequences of } \\
\text { sandstone, shale, clay, coal, and } \\
\text { limestone }\end{array}$ \\
\hline $\begin{array}{l}\text { Approximate Valley } \\
\text { Slope } \\
\end{array}$ & $26^{\circ}$ & $46^{\circ}$ \\
\hline Seam Thickness & - 36 in - 104 in (Pittsburgh Seam) & $\begin{array}{l}-\quad 4.07 \mathrm{ft} .-5.95 \mathrm{ft} \text {. (Lower } \\
\text { Kittanning) }\end{array}$ \\
\hline $\begin{array}{l}\text { Closest Approach of } \\
\text { Longwall mining to } \\
\text { Dam }\end{array}$ & $\begin{array}{l}\text { - } \\
\text { - } \\
\text { Damproximately } 900 \text { feet } \\
\text { panel which had a closest approach of } \\
\text { approximately } 1,900 \text { feet (potential } \\
\text { deformation lag from further panels) }\end{array}$ & $\begin{array}{l}\text { - } \quad \text { Approximately } 3200 \text { feet } \\
\text { No current measurements } \\
\text { nor monitoring for } \\
\text { prevention }\end{array}$ \\
\hline $\begin{array}{c}\text { Longwall Mining } \\
\text { Depth } \\
\end{array}$ & Approximately $300-850 \mathrm{ft}$. & Approximately 400-725 ft. \\
\hline
\end{tabular}


This mapping study revealed that for the sample area of WV, many dams exist which have mining nearby to them, and even directly underneath. Table 3.5 and Table 3.6 show the results of the proximity mapping that was performed for WV for the NID database and a subset of that with U.S.ACE dams in WV (3.8\% of nationwide NID). A frequency of occurrence was calculated to give perspective into the percentage of dams which may have the potential to be influenced by far field movements associated with non-conventional subsidence phenomena. Each dam was idealized as a point with buffer areas drawn around them at a radius. The 1-mile buffer radius was selected since it is a commonly known unit of measure (5280 ft.), and is approximately the distance at which seepage changes were first noticed at Ryerson Station Dam. The 2.7-mile buffer radius was selected because that distance encapsulated all nearby U.S.ACE dams to underground mine permits in WV. Three U.S.ACE owned and operated dams were found to be within the 1-mile buffer radius, and four within the 2.7-mile buffer radius. Some U.S.ACE dams can be very large in their length, changing the offset distances noted here significantly. There were zero U.S.ACE dams found to have any underground mine permit directly underneath their location. The total frequency of occurrence for U.S.ACE dams considered nearby to underground mine permits in WV was $17.4 \%$.

Table 3.5 Total number of dams and frequency of occurrence for mine permits within the vicinity of U.S.ACE dams in WV

\begin{tabular}{|l|c|c|}
\hline \multirow{2}{*}{ WV Dams } & U.S.ACE & Frequency of Occurrence (\%) \\
\cline { 2 - 3 } & 23 & - \\
\hline Dams with nearby mine permit areas: 1-mile buffer & 3 & 13.0 \\
\hline Dams with nearby mine permit areas: 2.7-mile buffer & 4 & 17.4 \\
\hline Dams directly undermined & 0 & 0 \\
\hline
\end{tabular}

Table 3.6 Total number of dams and frequency of occurrence for mine permits within the vicinity of NID dams in WV

\begin{tabular}{|l|c|c|}
\hline \multirow{2}{|c|}{ WV Dams } & NID & Frequency of Occurrence (\%) \\
\cline { 2 - 3 } & 609 & - \\
\hline Dams with nearby mine permit areas: 1-mile buffer & 79 & 13.0 \\
\hline Dams with nearby mine permit areas: 2.7-mile buffer & 115 & 18.9 \\
\hline Dams directly undermined & 45 & 7.39 \\
\hline
\end{tabular}

There are many more dams considered in the NID than U.S.ACE dams alone. The same buffer radii were chosen to assess the offset distances of NID dams to underground mine permits as were used for the U.S.ACE dam assessment. There were found to be 115 NID dams within the 2.7-mile buffer radius with 79 of those within 1 mile, and 45 directly undermined. The total frequency of occurrence for NID dams existing nearby to permitted underground mines was found to be $18.9 \%$. 


\section{CHAPTER 4. METHOD}

A multistep solution method was chosen for this research. This method has major components which are listed as they were used in the solution process.

1. Establishment of knowns and background

a. Literature review

2. Potential Failure Mode Analysis (PFMA)

a. PFMA development

i. Conceptual fault tree

ii. Conceptual event tree

3. Ryerson Station Dam modeling

a. Calibration

b. Parametric sensitivity modeling

i. Correlation plots

4. SQPFMA-RCA

a. Failure mode assessment

b. Event and Causal Factor Tree (ECFT)

i. Recommendations for the mitigation of root causes

These steps and their intended purposes are outlined in Chapter 4. Detailed descriptions are included for each topic. Figure 4.1 shows an illustrative example of the planned course of work for this research.

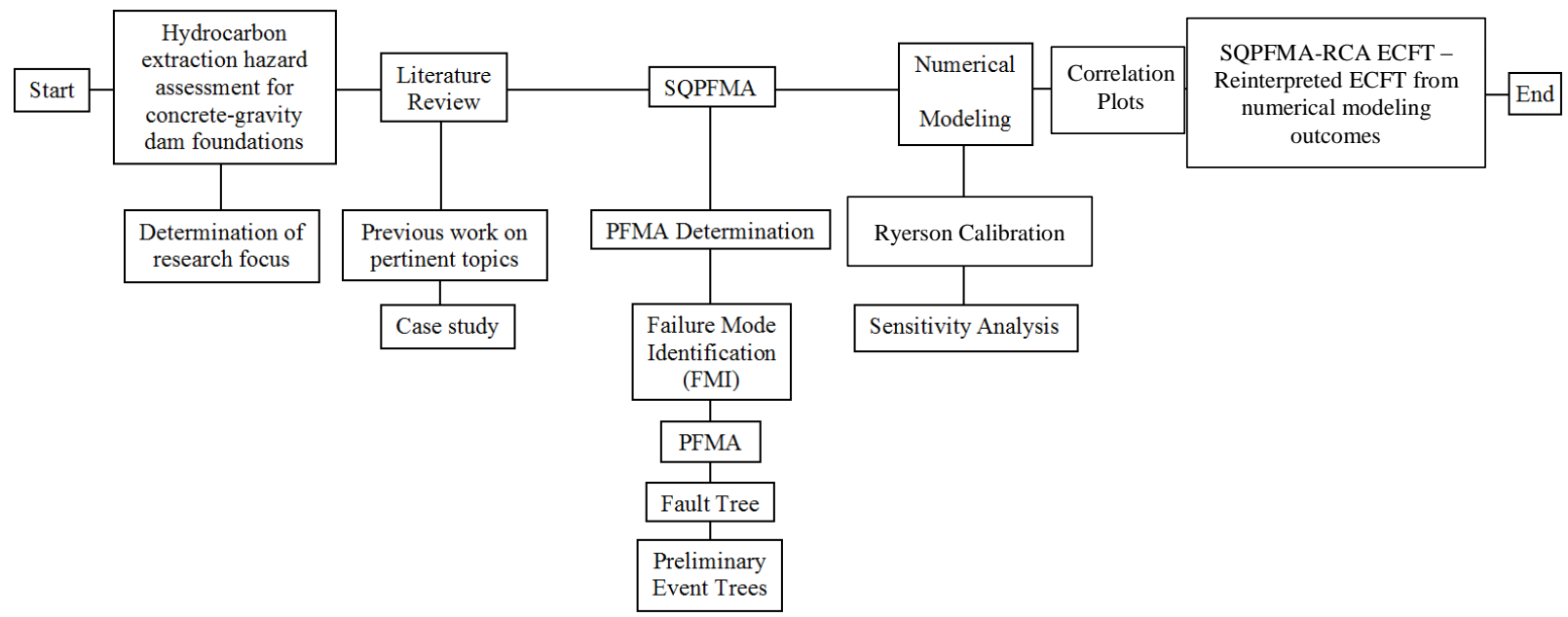

Figure 4.1 Solution Method 


\subsection{Introduction to PFMA}

The infrastructure in the United States is extensive and involves an interconnected system of dams, interstate highways, and other systems. Many components of this large system are aging to the state of required replacement or maintenance. The U.S.ACE is responsible for many of the large dams in the United States. Of these, some are in dire need of repair, while others maintain a good working condition. It is essential to assign risk appropriately to allocate the necessary funds to repair or replace high hazard dams in order to ensure the safety of the public and the durability of assets. To accommodate this need, the U.S.ACE developed a method of assigning risk to individual dams. Many scenarios exist where action through time by nature or humans can affect the long-term durability of a dam, or risk its compromise. A comprehensive assessment technique was devised by the U.S.ACE to identify these scenarios. This assessment technique is termed Potential Failure Mode Analysis (PFMA). When aspects of an engineering problem are quantified for a particular scenario, it is termed Semi-Quantitative Potential Failure Mode Analysis (SQPFMA). Risk probabilities are acquired by the utilization of event trees and fault trees, which are described in Section 4.3 and Section 4.5 (Scott, 2011). Risk probabilities were not utilized for the purposes of this research. Instead, Root Cause Analysis (RCA) was adopted to identify causal factors using numerical modeling. RCA was chosen since limited field data and only one significant case study in the U.S. has been identified. As a result, the reliability of a probabilistic approach would be uncertain.

\subsection{Development of a PFMA}

The hazard assessment that performing a PFMA provides allows U.S.ACE to better manage their large inventory of dams. The PFMA process was used to identify the most concerning failure mode pertinent to the events that occurred at the Ryerson Station Dam. Performing a thorough investigative PFMA for the scenario is a critical step in the determination of causal factors that this research has pursued. The PFMA is the foundation for the determination of key factors and parameters that were used in fault trees, event trees, and numerical modeling.

\subsection{Introduction to Fault Trees}

A fault tree is an analysis tool that can be used by engineers to decompose a failure event into subevents or combinations of subevents (Haldar \& Mahadevan, 2000). This decomposition of the failure event works backwards in time from the failure event and includes the events that led to the failure, or potential causes. The approach to creating a fault tree is the inverse of an event tree, which begins with an initiating event and leads to failure. 


\subsection{Development of a Fault Tree for Far-Field Ground Strain}

Fault trees are a tool to decipher the events which may lead to a predefined failure. It can be used to begin the process of defining specific phenomena or potential subevents for the preliminary construction of an event tree. The fault tree was built from the Ryerson Station Dam failure case study investigation. The events which were presumed to be the cause of the uncontrolled seepage at the Ryerson Station Dam in literature were used to build the conceptual fault tree.

\subsection{Introduction to Event Trees}

An event tree is an analysis tool which systematically defines subevents and possible scenarios which delineate important failure sequences (Haldar \& Mahadevan, 2000). Sequences within the same failure mode can have different final probabilities. Each topical instance is referred to as a node. There are 4 different types of nodes available in the software, each with different mathematical purpose to calculate the probability at that point in the tree. The nodes are chance, decision, logic, and reference. Custom probabilities can be assigned to each chance node. A decision node is a "yes/no" condition. A logic node is similar to a decision node but evaluates to "True/False" as the optimum condition for the scenario. Reference nodes are used to reference other event trees. They can be used to simplify large event trees by referencing smaller sections of the tree in separate sheets. An initial conceptual event tree was constructed without quantifying probabilities. Nodes decided as testable were analyzed in numerical modeling. The results of the modeling were used along with all background information and problem development to construct an ECFT. This final event tree was used to identify causal factors.

\subsection{Development of Event Tree for Far-Field Ground Strain Affecting Seepage Rates at a Concrete-Gravity Dam}

This research includes event trees as a tool to organize data in subevent categories. The outcomes of the event tree analysis are expected to provide insight into the mitigation of causal factors leading to far-field ground strain at dam foundations. The analysis began as a conceptual event tree based on the fault tree developed from the events leading to the breaching of the Ryerson Station Dam. A parametric numerical modeling study was performed to populate the final ECFT. RCA methods were employed for the development of the ECFT as well. 


\subsection{Development of Semi-Quantitative Potential Failure Mode Analysis (SQPFMA)}

A Potential Failure Mode Analysis (PFMA) is a thorough evaluation technique to bring a dam's vulnerabilities to light. The PFMA is the first and most critical step of a Semi-Quantitative Potential Failure Mode Analysis (SQPFMA). This step must be thorough and specific including pictures and diagrams detailing each matter within the analysis (Scott, 2011).

There is one documented case study of far-field ground strain affecting a dam in the United States. The case was Ryerson Station Dam at the Ryerson Station State Park in Green County, Pennsylvania. The entity possessing ownership of the Ryerson Station Dam, the Pennsylvania Department of Conservation and Natural Resources (PADCNR) hired Gannett Fleming, Inc. to perform an extensive study on the area including monitoring and instrumentation using inclinometers, extensometers, surveying, and strain gauges to record movements due to the nearby mining activities.

The data contained in the Gannett Fleming, Inc. reports (Volumes I-V) was extracted to assist in the development of the SQPFMA. Data from the monitoring instrumentation at the Ryerson Station Dam and the surrounding area was extracted to calibrate the modeling.

\subsection{Far-Field Ground Strain: Predictive Approaches}

There are two approaches which can be taken to predict valley closure. There are databases of information that were recorded in Australia from which an empirical approach to predict valley closure was developed (Zhang et al., 2013). The approach used in this research was prediction of far-field ground strain by numerical modeling techniques. 


\section{CHAPTER 5. POTENTIAL FAILURE MODE ANALYSIS (PFMA) FOR FAR FIELD GROUND STRAIN AT A DAM}

The events that led to the breaching of the Ryerson Station Dam were documented in chronologies by the Pennsylvania Department of Environmental Protection (PADEP). These events were used in this chapter establish a sequence of events to assist in the development of a PFMA. The PFMA provides a method of evaluation and risk assessment for civil engineers. The method was first developed by the U.S.ACE. Despite engineers' intentions to design conservatively, failure events still occur. All failure events are not catastrophic, but are generally defined as a loss of a system's function in some manner. As a result of the need to quantify risk, analysis techniques have become increasingly popular method of ensuring reliability of geotechnical design (Baecher \& Christian, 2005). A PFMA has been developed in Chapter 5 for far-field ground strain resulting from underground mining based on the Ryerson Station Dam case study.

\subsection{PFMA Background: Ryerson Station Dam Event Sequence}

The phenomena which resulted in dangerously high seepage rates and instability at the Ryerson Station Dam were thought to be the manifestation of longwall mine subsidence related mechanisms by the Pennsylvania Department of Conservation and Natural Resources (PADCNR). This chapter employs the perspective of longwall mining induced movements at the dam, and focuses on the strain induced seepage rate increases which were documented in the chronology and details of the Gannett Fleming, Inc. report Volumes I-V and the PADEP Damage Claim Report.

\subsubsection{Ryerson Station Chronology Summary}

The construction of the Ryerson Station Dam was completed in 1960. From 1960-2005, only minor seepage and cracks were detected (PADCNR, 2007). The reservoir at normal pool contained 62 acres of water. The height of the spillway was $30 \mathrm{ft}$. (Load).

Minor issues occurred throughout the dam's functioning lifetime, although additional reports indicate that the dam may have been predisposed to high in situ stresses (Flaw). Evidence of seepage around the dam and possible piping of upstream soil also was indicated in inspection reports.

From 2000 to 2004, there were about 10 areas of concern on or around the dam. Minor spalling of the concrete on the spillway, abutment walls, and downstream face of the left abutment wall was noted. A vertical structural crack had opened and the ground to the right of the crack was reported to be soft and spongy. A 12-inch corrugated metal pipe on the outside spillway wall 
and joints of the spillway wall was reported to have seepage occurring. Also, there was an eroded section of the upstream bank. In 2004, conditions remained unchanged except for some observed cracks along the downstream face of the left abutment wall. Despite of these minor issues, the dam was reported to be in good condition and well maintained. The inspection reports from 2005 were made by the same engineer as in previous years and stated that the dam was in serious condition and the conditions were worsening rapidly beginning in April 2005.

On December 7, 2004, mining began in the Bailey Mine in panel 3I (Flaw). Mining continued in Panel 3I until June 6, 2005. During this time, significant changes were noted at the Ryerson Station Dam. First, on January 31, 2005, bumps were noticed on Bristoria Road. On April 13, 2005, an increase in seepage was noted when mining was 5,937 ft. away from the dam. Seepage was then measured on April 21, 2005 to be 3-5 gpm (Initiation), but was disregarded as being due to heavy rains and saturated ground conditions. Park officials measured the seepage at 15 gpm and realized that there was a problem at the dam around the end of April, 2005 (Detection). At the end of April, 2005, provisions were made to monitor seepage volumes (Monitoring). Monitoring continued until the call was made to drain the lake on July 28, 2005.

Seepage volumes increased from $5 \mathrm{gpm}$ to $20 \mathrm{gpm}$ from April 21, 2005 to June 15, 2005, although the mining distance from the dam increased from 6,344 $\mathrm{ft}$. to the termination of Panel 3I at 8,188 ft. (Continuation). Mining began closer to the dam in Panel 4I on June 13, 2005 through August 1, 2005. During this time, seepage rates increased from $20 \mathrm{gpm}$ to $80 \mathrm{gpm}$ (Progression).

The circumstances of severe seepage rates as well as presumed structural instability of the dam resulted in the decision to drain the lake on July 28, 2005 (Intervention). At this point, the dam was deemed unsafe and the order was given to breach the dam (Unsuccessful Intervention). The instruction to drain the lake consequently led to the breaching of the dam on August 10, 2005 (Breach) (PADEP, 2010).

Table 5.1 and Table 5.2 provide a tabulated summary of the Ryerson Station Dam timeline. Figure 5.1 presents the Bailey Mine Panels that were near to the Ryerson Station Dam as well as the orientation of the dam to the mine. The mine progression was from east to west. The panels were installed north to south. 


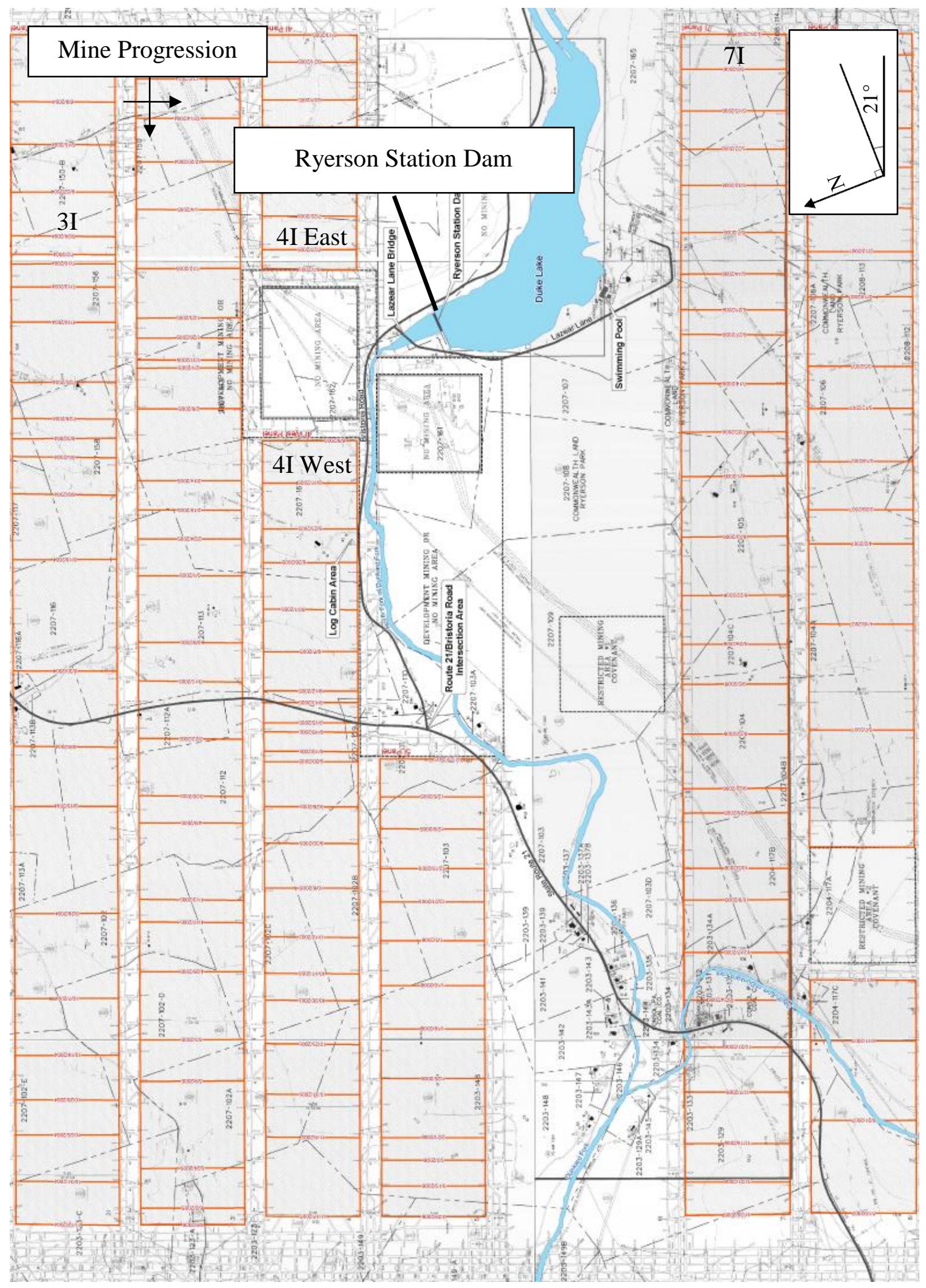

Figure 5.1 Ryerson Station Dam with superimposed mine panels (PADEP, 2010) 
Table 5.1 Ryerson Dam Timeline - 1/2

\begin{tabular}{|c|c|c|c|c|c|c|c|c|c|c|c|c|c|c|}
\hline 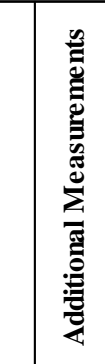 & 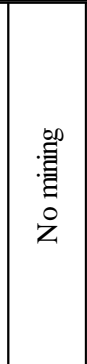 & \multicolumn{13}{|c|}{ 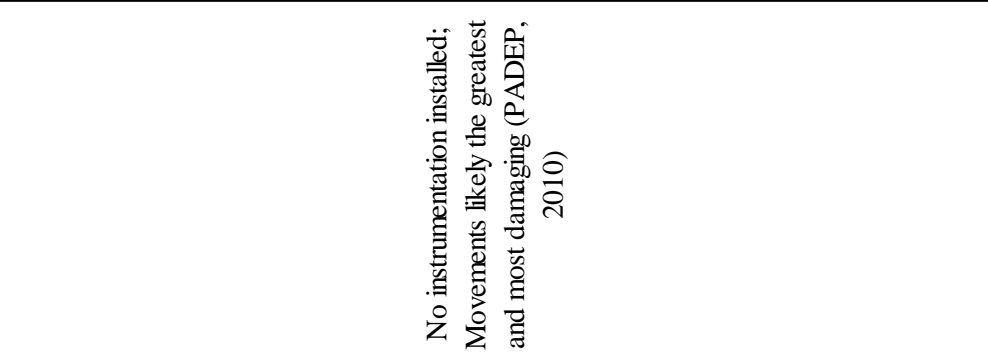 } \\
\hline 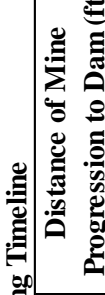 & 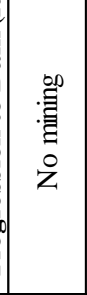 & : & 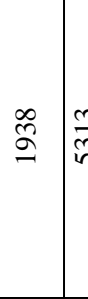 & & 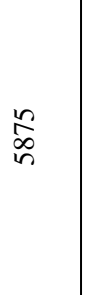 & ڤ్ & \&్ర & 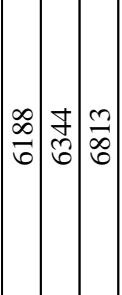 & 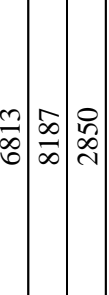 & 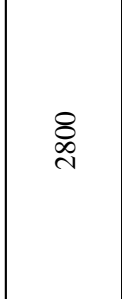 & 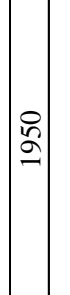 & 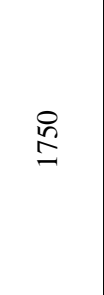 & & 응 \\
\hline 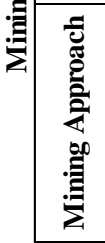 & 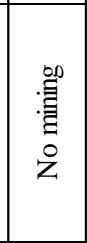 & $\mid$ & 密 & & 焉 & 蛋 & 焉 & 意部 & & 丞 & 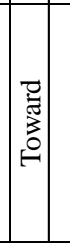 & 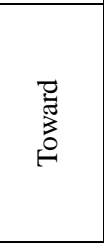 & & 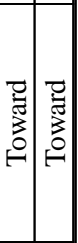 \\
\hline 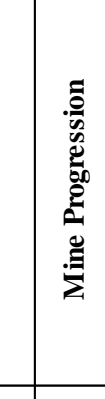 & 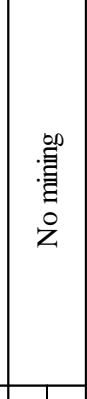 & 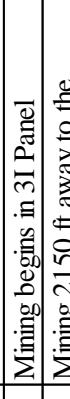 & 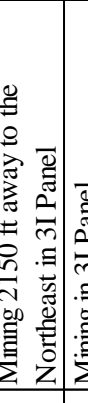 & & 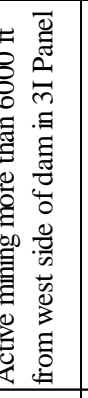 & 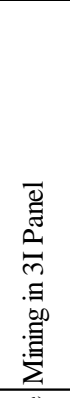 & 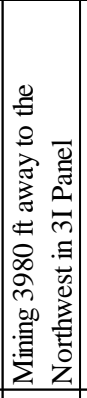 & 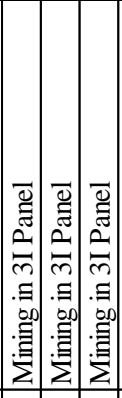 & 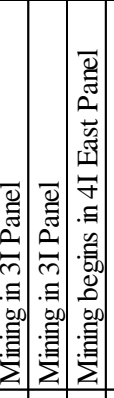 & 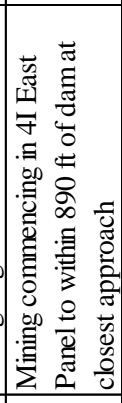 & 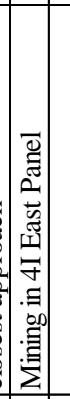 & 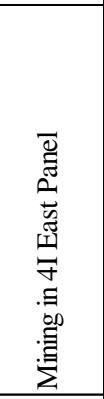 & & 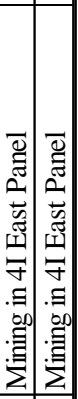 \\
\hline 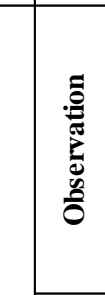 & 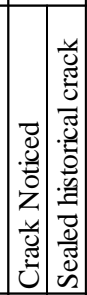 & & 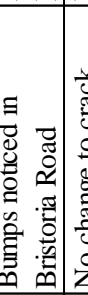 & & & 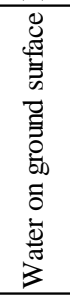 & 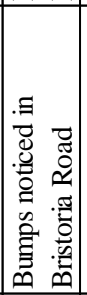 & 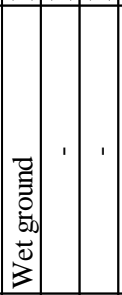 & & 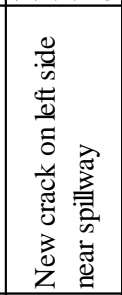 & & 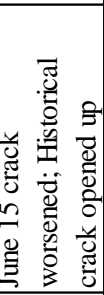 & & \\
\hline 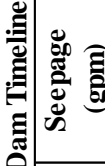 & 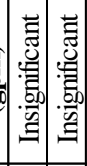 & & & & 总 & 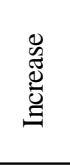 & & 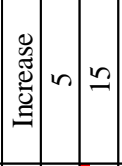 & 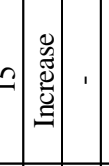 & i & 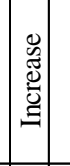 & $m$ & & $8 \approx$ \\
\hline 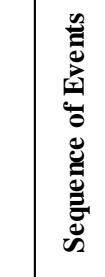 & 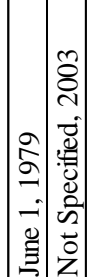 & & 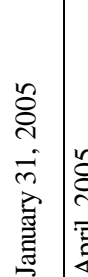 & & 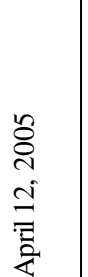 & 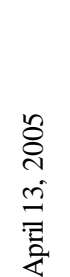 & 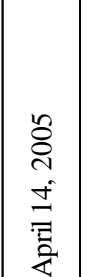 & 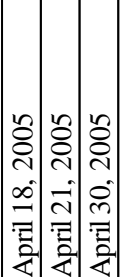 & 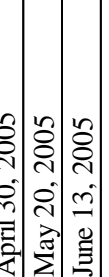 & 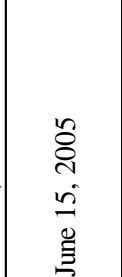 & $\left|\begin{array}{l}\mid \\
0 \\
0 \\
\vdots \\
\vdots \\
\vdots\end{array}\right|$ & $\begin{array}{l}\text { 品 } \\
\text { m } \\
\text { 交 }\end{array}$ & & 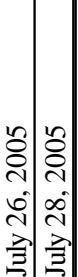 \\
\hline
\end{tabular}


Table 5.2 Ryerson Dam Timeline - 2/2

\begin{tabular}{|c|c|c|c|c|c|}
\hline August 1,2005 & \multirow{19}{*}{ 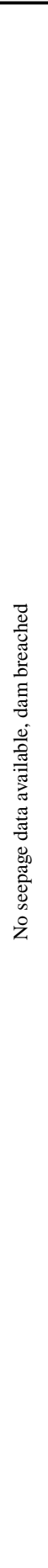 } & - & Mining finishes in 4I East Panel & Toward & 850 \\
\hline August 2, 2005 & & \begin{tabular}{|l|} 
Cracks form overnight; \\
Heave forms on Bristoria \\
Road at the right \\
abutment at 9 in to $1 \mathrm{ft}$ in \\
vertical relief \\
\end{tabular} & No mining & No mining & No mining \\
\hline August 5, 2005 & & $\begin{array}{l}\text { Minor Movement of the } \\
\text { dam }\end{array}$ & No mining & No mining & No mining \\
\hline August 9, 2005 & & - & $\begin{array}{l}\text { Mining Commences in 4I West } \\
\text { Panel; Nearest point to mine } \\
\text { entryway is } 565 \mathrm{ft} \text { at an angle of } \\
\text { draw of } 57.1 \text { degrees; Nearest } \\
\text { point to longwall mining is } 890 \mathrm{ft} \\
\text { at an angle of draw of } 57.6 \\
\text { degrees; well above typical } 15-25 \\
\text { degrees }\end{array}$ & Away & 890 \\
\hline August 10, 2005 & & \begin{tabular}{|l|} 
Movement in vertical \\
crack at right end of the \\
dam that opened after \\
the dam was drained
\end{tabular} & Mining in 4I West Panel & Away & 1350 \\
\hline August 15, 2005 & & \begin{tabular}{|l|} 
Bumps noticed in \\
Bristoria Road \\
\end{tabular} & $\begin{array}{l}\text { Mining } 580 \mathrm{ft} \text { away to the East in } \\
\text { 4I Panel }\end{array}$ & Away & \\
\hline August 17, 2005 & & \begin{tabular}{|l|} 
Evidence of movement in \\
Bristoria Road Bridge; \\
gas line heave; ground \\
heave
\end{tabular} & $\begin{array}{l}\text { Bridge movement }=480 \mathrm{ft} \text { East in } \\
\text { 4I Panel; Gas line heave }=515 \mathrm{ft} \\
\text { East in } 4 \mathrm{I} \text { Panel; } 515 \mathrm{ft} \text { East in } 4 \mathrm{I} \\
\text { Panel }\end{array}$ & Away & \\
\hline August 19, 2005 & & Gas line heave & Mining $350 \mathrm{ft}$ East & Away & - \\
\hline September 8, 2005 & & $\begin{array}{l}\text { Guiderail movement on } \\
\text { eastern end of Lazear } \\
\text { Lane Bridge }\end{array}$ & $\begin{array}{l}\text { Mining } 3400 \mathrm{ft} \text { Northwest in 4I } \\
\text { Panel }\end{array}$ & Away & - \\
\hline September 12, 2005 & & $\begin{array}{l}\text { Road bump in Rt. } 21 \\
\text { eastbound lane }\end{array}$ & $\begin{array}{l}\text { Mining } 740 \mathrm{ft} \text { Northeast in 4I } \\
\text { Panel }\end{array}$ & Away & - \\
\hline September 13, 2005 & & \begin{tabular}{|l|} 
Road bump in Rt. 21 \\
westbound lane
\end{tabular} & $\begin{array}{l}\text { Mining } 730 \mathrm{ft} \text { Northeast in 4I } \\
\text { Panel }\end{array}$ & Away & - \\
\hline September 15, 2005 & & \begin{tabular}{|l|} 
Cracks and movement at \\
Rt. 21 and Bristoria Rd. \\
intersection; minor \\
damage to residence \\
\end{tabular} & $\begin{array}{l}\text { Cracks }=780 \mathrm{ft} \text { Northeast 4I } \\
\text { Panel; Residence = Mining } 630 \mathrm{ft} \\
\text { North in 4I Panel }\end{array}$ & Away & - \\
\hline September 16, 2005 & & \begin{tabular}{|l|} 
Movement of guiderail \\
eastbound lane Rt. 21; \\
stream bed heave in \\
North Fork of Dunkard \\
Fork \\
\end{tabular} & $\begin{array}{l}\text { Guide rail = Mining } 1950 \mathrm{ft} \\
\text { Northeast in 4I Panel; Stream bed } \\
=1030 \mathrm{ft} \text { North in 4I Panel }\end{array}$ & Away & - \\
\hline September 19, 2005 & & $\begin{array}{l}\text { Pipeline heave in North } \\
\text { Fork of Dunkard Fork; } \\
\text { Cracking and heaving of } \\
\text { stream banks and } \\
\text { sagging of pipeline } \\
\text { marker cable }\end{array}$ & $\begin{array}{l}\text { Mining } 2760 \mathrm{ft} \text { Northwest in 4I } \\
\text { Panel }\end{array}$ & Away & - \\
\hline September 20, 2005 & & \begin{tabular}{|l|} 
Horizontal movements of \\
pipelines at compressor \\
station
\end{tabular} & $\begin{array}{l}\text { f Mining } 3800 \mathrm{ft} \text { Northwest in 4I } \\
\text { Panel }\end{array}$ & Away & - \\
\hline September 26, 2005 & & \begin{tabular}{|l|} 
Pipeline located along \\
North Fork of Dunkard \\
Fork heaving out of \\
ground
\end{tabular} & $\begin{array}{l}\text { Mining } 2300 \mathrm{ft} \text { Northeast in 4I } \\
\text { Panel }\end{array}$ & Away & - \\
\hline September 29, 2005 & & $\begin{array}{l}\text { Pipe lines buckle out of } \\
\text { the ground in the area }\end{array}$ & Mining in 4I West Panel & Away & - \\
\hline October 1, 2005 & & $\begin{array}{l}\text { Hillside and pipe } \\
\text { movement across from } \\
\text { entrance bridge }\end{array}$ & Mining in 4I West Panel & Away & - \\
\hline November 15, 2005 & & & Mining finishes in 4I West Panel & - & - \\
\hline
\end{tabular}

The west non-overflow section of the Ryerson Station Dam experienced vertical movement. This portion of the dam rose $0.3 \mathrm{in}$. at the far edge, transitioning to $1.2 \mathrm{in}$. near the spillway. At the same time, the east non-overflow section experienced both horizontal and vertical movement. The far easternmost portion experience vertical uplift of $1.2 \mathrm{in}$. which transitioned to $1.7 \mathrm{in}$. near the spillway. This portion of the dam also moved to the west approximately $2 \mathrm{in}$. These 
recorded movements generally occurred during two periods: August through September, 2005 and July through September 2006. During these time periods, mining was progressing in the 4I West and 7I panels, respectively (DEP, 2010). The Ryerson Station Dam was well outside the area that would be traditionally though to experience mine subsidence from these panels. Figure 5.1 shows the locations of the 4I West and 7I panels.

\subsubsection{Failure Mode Identification (FMI)}

A study on the events leading to the breach of the Ryerson Station Dam was contracted by the PADCNR to Gannett Fleming, Inc. to determine the cause(s) of the disruption of in situ conditions around the dam. The analyses for the determination of the root cause of the movements at the dam were essentially a failure mode identification. The analyses that were performed by Gannett Fleming, Inc. to deduce the cause of the deformation and seepage at the Ryerson Station Dam are summarized in this section. The approach to create the FMI involved literature pertinent to far-field subsidence induced by coal mining.

\section{Dam Stability Analysis}

Volume III of the PADCNR report provides analyses and conclusions related to the stability of the dam based on historical loading conditions. The intent of these analyses was to determine whether the damage to the dam could have been caused by external loading undergone in historically normal operating conditions. The conditions assessed by Gannett Fleming, Inc. were normal pool with ice loading, record flood pool, and record seismic loading

Several loads were applied to the dam, including the self-weight, hydrostatic pressure due to the reservoir and tail water pool, earth pressure both upstream and downstream for the overflow section, ice loading at normal pool elevation, seismic loading, and full uplift acting on the entire base of the section (PADCNR, 2007).

Based on the analyses that were considered for the dam stability assessment, Gannett Fleming, Inc. determined that the dam's resistive capacity far exceeded the loading conditions. Further, the three loading cases assessed could not have caused the movements because the observed movements were not consistent in direction or timing to what would have occurred under the loading conditions. Based on these results, Gannett Fleming, Inc. concluded that the deformation and disruption of the Ryerson Station Dam since April, 2005 were not caused by historical loadings of the dam, nor the capacity of the dam to resist them (PADCNR, 2007). 


\section{Hillside Stability Analysis}

The stability of the hillside at the right abutment of the Ryerson State Park Dam was analyzed. Six cases were modeled to calculate a factor of safety for the pre-breach in situ conditions. Landslides in the soil overburden are common in this region, however the resulting factors of safety indicated that the hillside rock mass is naturally stable. Table 5.3 presents the 6 model cases and resulting factors of safety Gannett Fleming, Inc. performed for the Ryerson Station Dam hillside stability analysis. GeoStudio's SLOPE/W module was used along with PCSTABL to determine factors of safety for the models.

Only the saturated overburden soil in the Case 6 models yielded failure planes on the slope with factors of safety below 1.0, the lowest being 0.87 . All factors of safety less than 1.0 were shallow failures. Despite the low factors of safety for this case, there were no reported recent earth flows in the vicinity (PADCNR, 2007).

Table 5.3 Hillside stability model cases and resulting factors of safety (PADCNR, 2007)

\begin{tabular}{|c|l|c|c|}
\hline Case & Description & Shear Strength & $\begin{array}{c}\text { Factor of } \\
\text { Safety }\end{array}$ \\
\hline 1 & $\begin{array}{l}\text { Simple sliding block(assume } \\
\text { vertical joint) }\end{array}$ & $\begin{array}{c}\text { Analysis Friction } \\
\text { Angle }\end{array}$ & 2.17 \\
\hline 2 & $\begin{array}{l}\text { Potential Sliding Surface at El. } \\
955 \text { and along 81 }{ }^{\circ} \text { joint }\end{array}$ & $\begin{array}{c}\text { Analysis Friction } \\
\text { Angle }\end{array}$ & 1.56 \\
\hline 3 & $\begin{array}{l}\text { Case 2 with seismic coefficient } \\
\text { of 0.01g. }\end{array}$ & $\begin{array}{c}\text { Analysis Friction } \\
\text { Angle }\end{array}$ & 1.52 \\
\hline 4 & $\begin{array}{l}\text { Potential Sliding Surface at El. } \\
840 \text { and along 81 } \text { joint }^{-}\end{array}$ & $\begin{array}{c}\text { Analysis Friction } \\
\text { Angle }\end{array}$ & 2.11 \\
\hline 5 & $\begin{array}{l}\text { Search for critical surface with } \\
\text { the Rock Mass Strength }\end{array}$ & $\begin{array}{c}\text { Rock Mass } \\
\text { Strength }\end{array}$ & 2.18 \\
\hline 6 & Saturated overburden soil & $\varnothing=30$ & 0.87 \\
\hline
\end{tabular}

Since the factors of safety for the model cases other than the overburden soil were all significantly greater than 1.0, Gannett Fleming, Inc. concluded that the movements at Ryerson Station Dam were not have a result of inherent hillside instability or natural geologic conditions (PADCNR, 2007).

\subsubsection{Determination of Failure Mode}

Following a study on the publications by Hebblewhite \& Gray, 2014; Zhang et al., 2012; Zhang et al., 2013; and the extensive Gannett Fleming, Inc. reports on the Ryerson Station Dam, the failure mode for the historical Ryerson Station Dam breach in 2005 has been concluded to be a result of far-field ground strain phenomena manifesting at the valley bottom where the Ryerson Station Dam resided. 


\subsection{PFMA Development: Far-Field Ground Strain at a Concrete-Gravity Dam}

This section describes the development of the PFMA for the events that occurred at the Ryerson Station Dam. This potential failure mode is introduced for far-field ground strain leading to uncontrolled seepage at a concrete-gravity dam. Figure 5.2 provides a summary of the chronology given in Section 5.1. The topical points in this section are logically deduced from the Gannett Fleming, Inc. reports which are cited throughout this research, published works from Dr. Bruce Hebblewhite, Dr. Zhang, Australian Coal Association Research Program (ACARP), among others.

A PFMA is comprised of multiple components. These components are Flaw, Initiation, Continuation, Progression, and Breach. Additional components incorporate Load conditions and Intervention. This section describes each component of the PFMA as it correlates with the failure mode for the Ryerson Station Dam. The development of the PFMA provided information to create a conceptual fault tree and event tree for the failure mode scenario.

Figure 5.2 presents the Bailey Mine Panels that were near to the Ryerson Station Dam, spatial timeline, and the orientation of the dam to the mine. The mine progression was from east to west. The panels were installed north to south. Significant points are numbered. Numbered point descriptions are provided in the following listing 1-5. The flow rates in the listing refer to the measured seepage occurring at the dam.

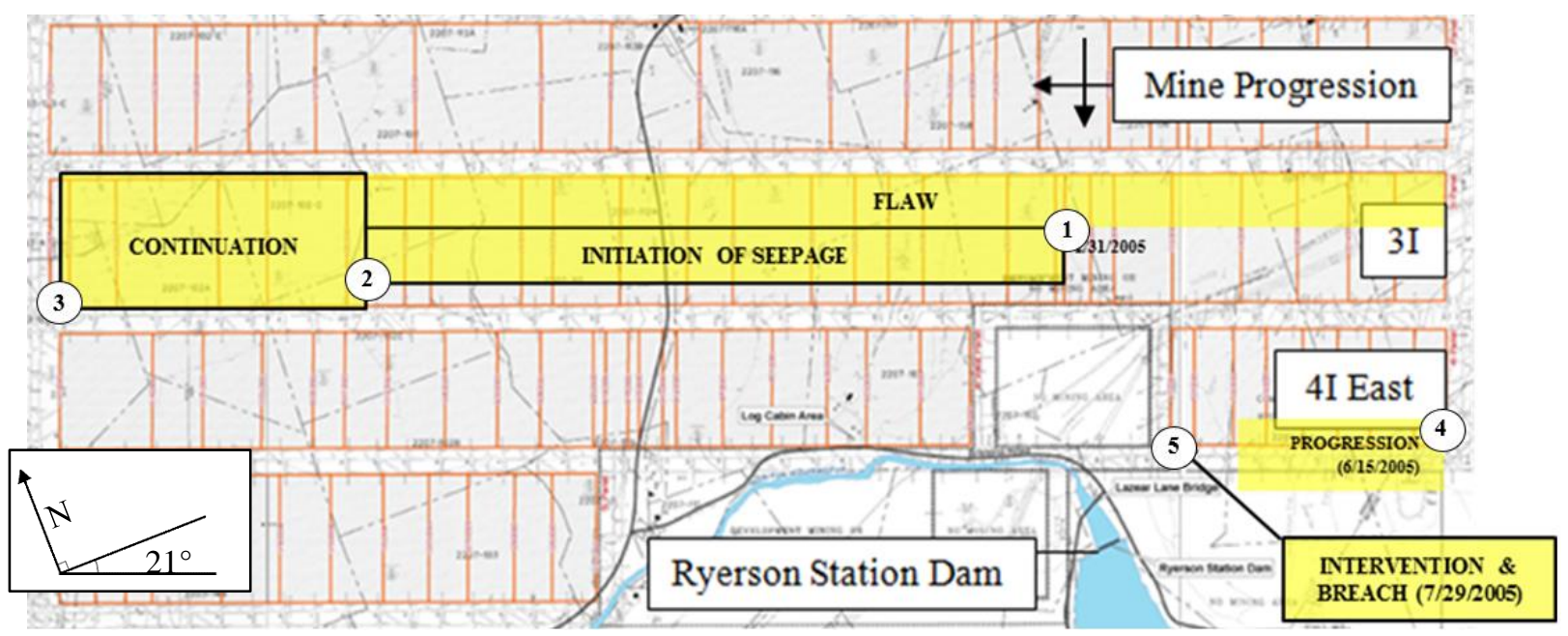

Figure 5.2 Illustration of PFMA for Ryerson Station Dam

1. December $7^{\text {th }}, 2004$ - January 31,$2005 ; 10-100$ gpd at 1,940 ft. from dam (Flaw)

2. January 31,2005 - April 21, 2005; 0-5 gpm at 6,300 ft. (Initiation)

3. April 21, 2005 - April 30, 2005; 5-15 gpm at 6,800 ft. in 3I (Continuation)

4. April 30, 2005 - June 15, 2005; 15-20 gpm at 2,800 ft. in 4I East (Progression)

5. June 15, 2005 - July 28, 2005; 20-80 gpm at $950 \mathrm{ft}$. (Intervention and Breach) 


\subsubsection{Introduction of Flaw}

Intended for the purposes of a PFMA, a "Flaw" is defined as an unfavorable condition in the engineered system (e.g. stress or strain change resulting in ground movement) (Scott, 2011). A conventional subsidence scenario is understood to be when underground longwall coal mining causes stress and strain changes in the vicinity of the mine void at some angle of draw, typically between 15-25 degrees in Appalachia (PADCNR, 2007). In the case of far-field subsidence, ground deformation occurs well outside the limits of the angle of draw, suggesting that other factors influence the distance of propagation of the stress and strain disruptions induced by the mine void.

At the Ryerson Station State Park, the angle of draw was nearly 60 degrees, if the angle of draw is considered to include the entire 'cone' of ground movement. Figure 5.3 shows the topographic 2D profile and varying levels of angle of draw from the mine extents of Panel 4I East. At this point, the surface effects were well underway at the dam.

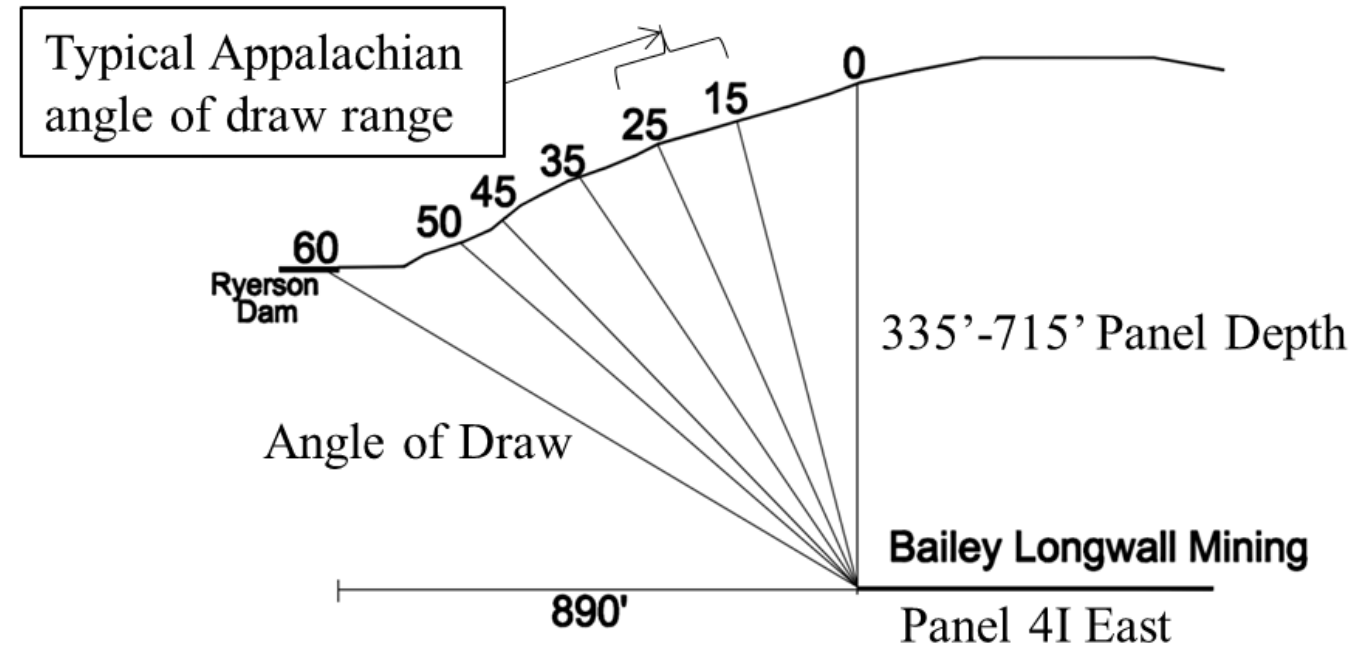

Figure 5.3 Angles from Bailey Mine Longwall Panel 4I East to Ryerson Station Dam

The Ryerson Station Dam began to show signs of movement due to seepage manifestation on April 21, 2005. The dam was built in 1960, and showed no significant signs of cracking or seepage until this point. Coincidentally, the Bailey mine's Panel 3I had begun operations about 4 months prior on December $7^{\text {th }}, 2004$. As a result, it is concluded that the creation of the mine void acts as the flaw for this PFMA scenario.

- Flaw: Underground mine void 


\subsubsection{Initiation}

The initiation step in a PFMA is defined as the loading or change in condition that may begin a chain of events. The change of conditions at the Ryerson Station State Park included stress field changes which started a chain of events including valley closure phenomena and far-field ground movement well outside the predicted SDPS analysis with an angle of draw of 15 degrees. If these horizontal strains appear in the valley where a dam is situated, they could cause:

- Cracks in concrete due to loading or unloading of in situ or dead load stresses

- Tilting or twisting of the dam (buckling)

- Cracks in dam foundation

- Seepage pathways around or through grout curtains

\subsubsection{Hill Seams}

Hill seams, or weather enlarged tension joints, occur parallel to topographic contours and ridges. These joints do intersect at varying angles, especially at the points or noses or ridges (Sames \& Moebs, 1989). These joints are known to sometimes propagate naturally to the depth of the coal seam being mined. Normally, these joints are considered for their tendency to cause roof falls in mines, which causes a significant safety concern, however for this research, hill seams were considered for their potential to influence stress/strain effects from the mine void to valleys. Figure 5.4 shows idealized hill seams.

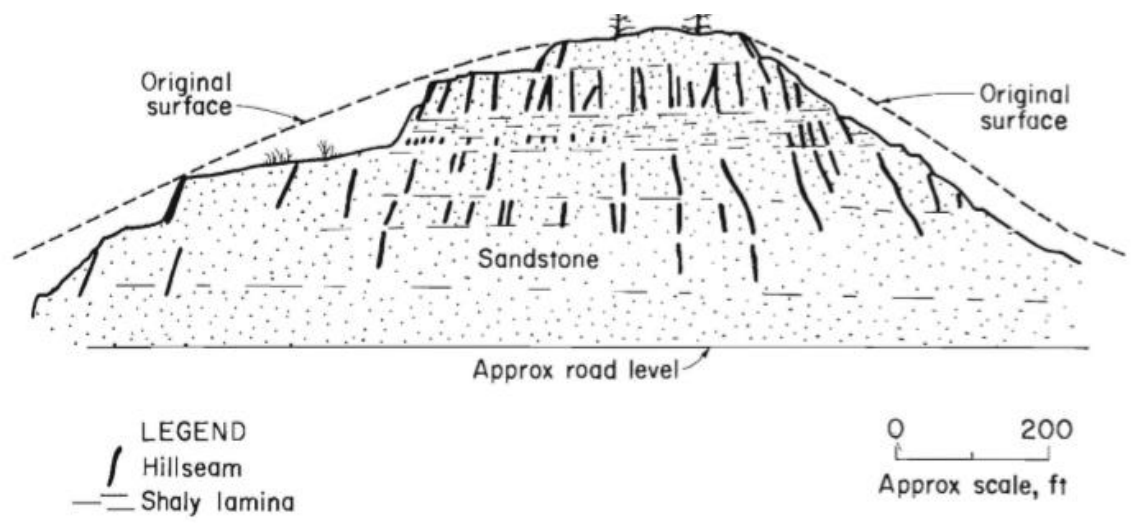

Figure 5.4 Idealized hill seams (Sames \& Moebs, 1989)

In situ stress magnitudes and direction could have influence on the distance of propagation of the disruptions. The magnitude of residual tectonic stresses in a valley could exacerbate the failure or assist in reaching critical stresses which perpetuate valley effects.

Stress concentrations may result as induced variations in the subsurface stress field are not applied into massive rock units, but fractured ones. Stress concentrations may be accentuated by weak layer failure and down ridge fractures. Stress changes will likely occur down ridge, not perpendicular. Stress is relieved perpendicular to the topography contours. Vertical joints or hill 
seams assist stress relief by decreasing resistive forces. Additionally, progressive failure may initiate at very low strains before movements are observed. Cohesive layering may fail suddenly and transfer loads to weak deformable strata (Peck, 1969).

The failure of rock is a brittle failure where, under increasingly large stresses, small strains are observed until failure occurs, and then large movements will be observed in a sudden manner. At Ryerson Station, movements occurred suddenly, followed by periods of stability (PADCNR, 2010). Weak rock layers tend to fail first under increased stresses, transferring their load to stronger strata. As a result of this assessment of stress migration amongst varying strengths of strata, the loads on the strongest strata cannot be linearly increasing and must; therefore, follow some other distribution of stepwise increasing load.

\subsubsection{Topography}

As discussed in Section 5.2.4, topography plays an important role in valley closure phenomena, which were observed at the Ryerson Station Park (Hebblewhite \& Gray, 2014; Zhang et al., 2013; Holla, 1997). As a result of GIS mapping shown in Figure 3.11 and summarized Table 3.4 , it is clear that steep valley walls exist adjacent to the Ryerson Station Dam at approximately 46 degrees. Consequently, topography quantified as maximum elevation change from valley bottom to ridgeline and slope angle were included as contributing parameters to the initiation of far-field ground strain.

\subsubsection{Subsidence}

Non-conventional subsidence is oftentimes misconstrued as being within a large angle of draw. Observations tend to indicate that subsidence within the common angle of draw, which may be typical for the region, may initiate enough tensile stress in landforms to propagate along ridgelines of high relief topography by concentrating in connected rock between fractures. This disruption in stress may be enough to cause the gravity load of the landform to initiate down-hill movements perpendicular to the slope.

- Initiator: Hill seams/weathered joints

- Initiator: Mountainous topography (elevation change/slope angle)

- Initiator: Subsidence due to coal mining

- Load (deformation): Adjacent landform weight (with respect to valley bottom)

- Load (deformation): In situ stress

- Load (seepage): Pore pressure in compression regime

- Load (seepage): Lake hydraulic head 


\subsubsection{Detection and Monitoring}

Detection and monitoring of flaw effects can occur if they are observed early on in the failure mode. Occasionally this monitoring may be able to provide management of the effects by an observational approach technique, first proposed by Peck, 1969. The observational technique is essentially the mitigation of unfavorable effects in real time. In other words, to understand how movements may or may not be propagating to make decisions as needed. This approach may be an option to impede ground movements from ever reaching the infrastructure needing protection, or halt elements of the initiator to not exacerbate the effects which may lead to a failure condition.

\subsubsection{Continuation}

Continuation as an element of a PFMA can be defined as an event or set of events which allow the initiating event to continue. The far-field ground strain scenario, following the events at the Ryerson Station State Park has provided insight into the continuation of the failure mode.

\subsubsection{Continuation Condition 1}

Mining continues beyond initiating longwall panel, to the subsequent longwall panel, situated closer to the proximity of the valley of the dam, enabling the disruptive initiating effects to worsen in the valley of the dam. Figure 5.5 shows the scenario that occurred at the Ryerson Station Dam, referred to as Continuation Condition 1.

The valley effects worsen as a result of the proximity of subsidence to already disturbed valley fractures. The observations at Ryerson Station suggest that the ground disturbance magnitude decreases with distance from the mine panel.

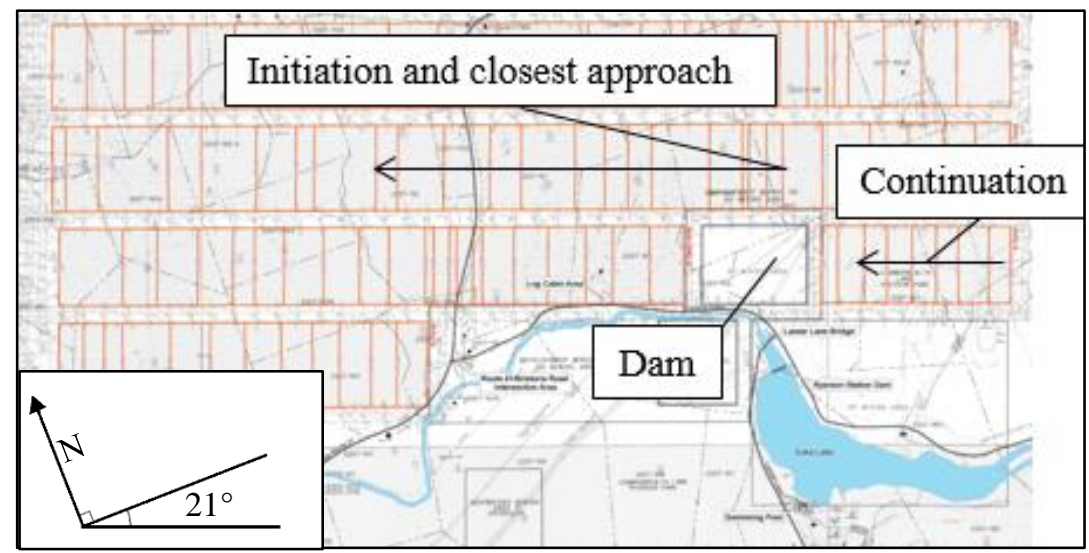

Figure 5.5 Continuation Condition 1: Mining continues in a panel closer to the dam 


\subsubsection{Continuation Condition 2}

Mining continues in initiating longwall panel, encroaching further toward the dam, enabling the disruptive initiating effects to worsen in the valley of the dam. Figure 5.6 shows this scenario, referred to Continuation Condition 2.

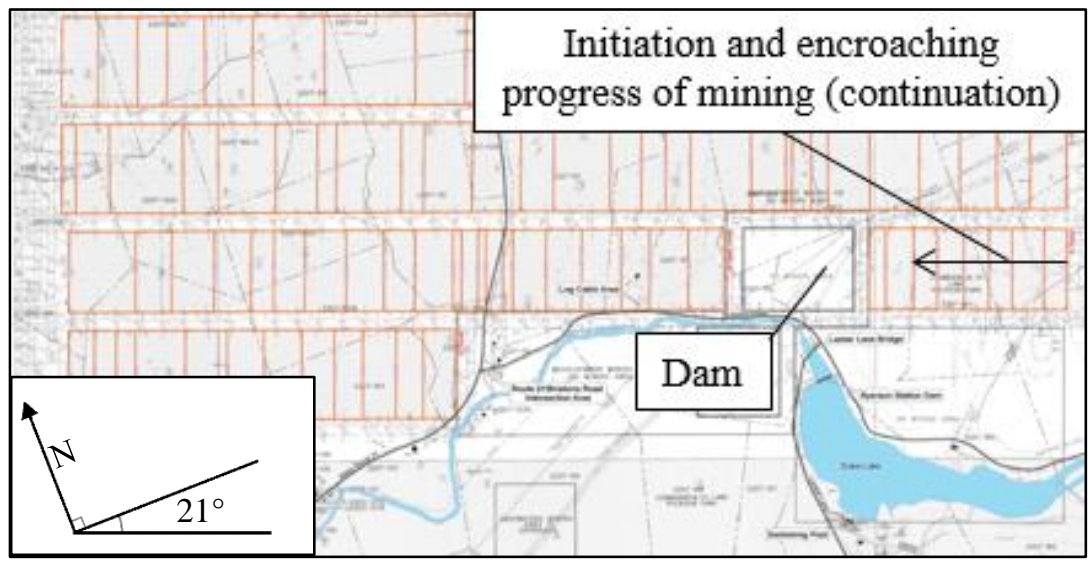

Figure 5.6 Continuation Condition 2: Mining initiates and continues surface effects in the same longwall panel

\subsubsection{Continuation Condition 3}

Alternatively, if mining does not continue toward the dam, observations have shown that the initiating far-field effects may be enough alone to induce a progressive seepage failure mode since existing seepage pathways were already disrupted. The seepage rates for the Ryerson Station case increased with time as mining was moving further from the dam. The seepage progression curve reveals that the seepage pathways did not self-heal, as seepage flows increased continuously. This could have been due to piping of small gradation particles, further opening seepage pathways or due to additional small magnitude movements. This scenario has been referred to as Continuation Condition 3.

- Continuation: Mining continues beyond initiating longwall panel, closer to the dam

- Continuation: Seepage increases due to disturbed natural fractures (seepage pathway)

\subsubsection{Progression}

Progression as a component of a PFMA is defined as the movement of failure within the system. At Ryerson Station, this occurred when mining became closest to the dam. Significant valley movements occurred within a few hours, rapidly degrading the stability of the dam, and exponentially increasing seepage rates. These observations, including broken pipelines and stream bedding, as well as other effects provide evidence that valley closure effects did take 
place. Figure 2.10 shows the valley effects due to non-conventional subsidence, many of which were also observed at Ryerson Station Dam.

The progression of the valley effects occurred as a result of mining encroaching near enough to the dam for stress disruptions to induce valley closure/lateral dilation, and upsidence/valley bulging phenomena to ensue, including:

- thrust faults

- bedding surface slippage

- localized void spaces

- fracturing of compressed strata

- further disruption of existing fractures and geologic discontinuities

These effects are a result of the exceedance of the capacity of the unrestrained rock strata in the valley bottom to attenuate stress. At some point, the mining became close enough to cause the stresses in the valley to exceed their ability to resist brittle fracturing, and upward movements occurred in the critically stressed valley bottom. The upward force is due to stress relief. Surface and near surface strata do not have sufficiently constraining gravity loads to restrict deformation, and valley heaving occurs. As depth from the valley bottom ground surface increases, the constraining gravity loads (normal stresses) increase and uplift magnitudes decrease. As a result of decreased thrust faults and heaving at increasing depth, seepage magnitudes, or fluid movement in saturated zones also are expected to decrease. At some depth, the flow changes from a fracture-flow dominated regime to a conductive flow regime (Lee, 1990). At the Ryerson Station Dam, the flow was rapid, high volume fracture-flow seepage resulting from the valley heaving and other valley deformation effects.

The forces acting on the dam included horizontal compression at the abutments and an upward force beneath the dam. Tension cracks were observed at the ridge between the dam and Panel 4I East. Figure 2.22 shows the location of the tension cracks. The interpretation of these observations is presented in Figure 5.7. The movement scenario is dynamic; therefore, the location of the tensile zone regime and compression zone regime will vary as the movements ensue. The tensile zone may be a temporary condition, where tensile stresses develop along the slope during the stress wave propagation. This disrupts resistive forces of the slope against its weight, movement occurs, and then a compressive condition reinstates. This compressive condition would be at maximum magnitudes at the valley bottom and at minimum magnitudes along the adjacent ridges. Figure 5.7 expands on the concepts presented in Figure 2.9 from Zhang et al., 2012 by including a dam at the valley bottom. 


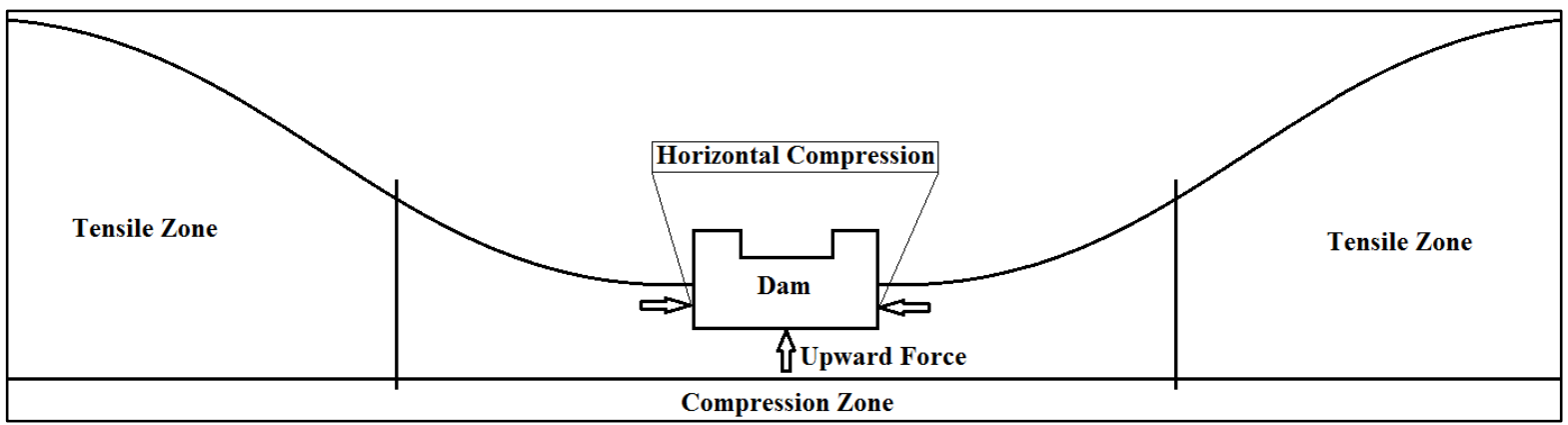

Figure 5.7 Generalized force regimes in the valley of the dam

Figure 5.8 and Figure 5.9 show the direction of movement of the top and bottom portions of the Ryerson Station Dam as reported by the PADCNR. The top portion of the dam and the bottom portion moved in opposing directions. This observation of dam movement is consistent with dam beam bending due to valley uplift.

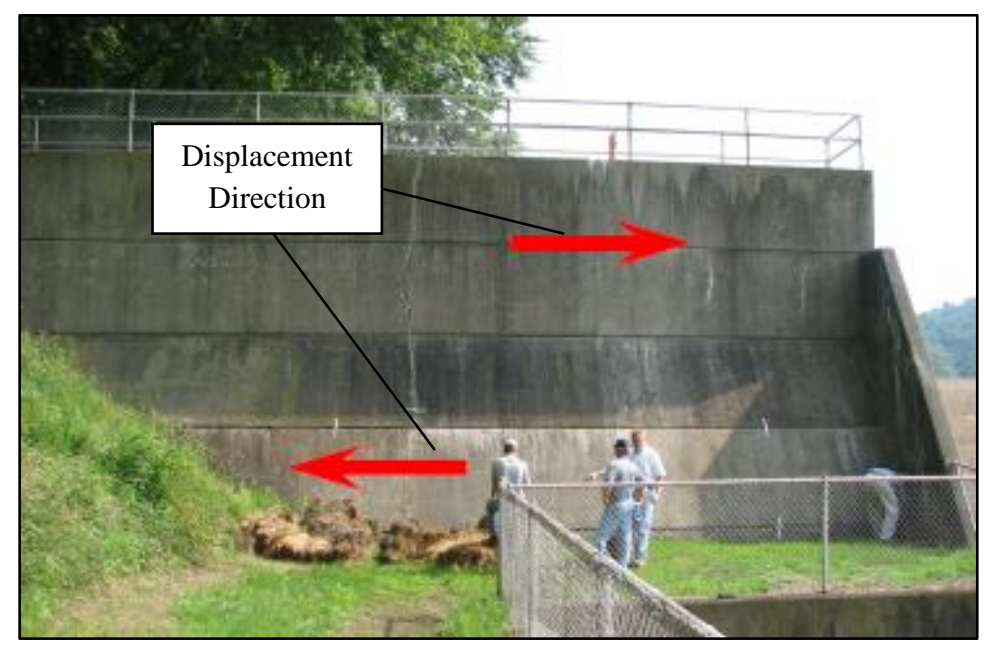

Figure 5.8 Downstream face displacement direction at Ryerson Station Dam (PADCNR, 2007)

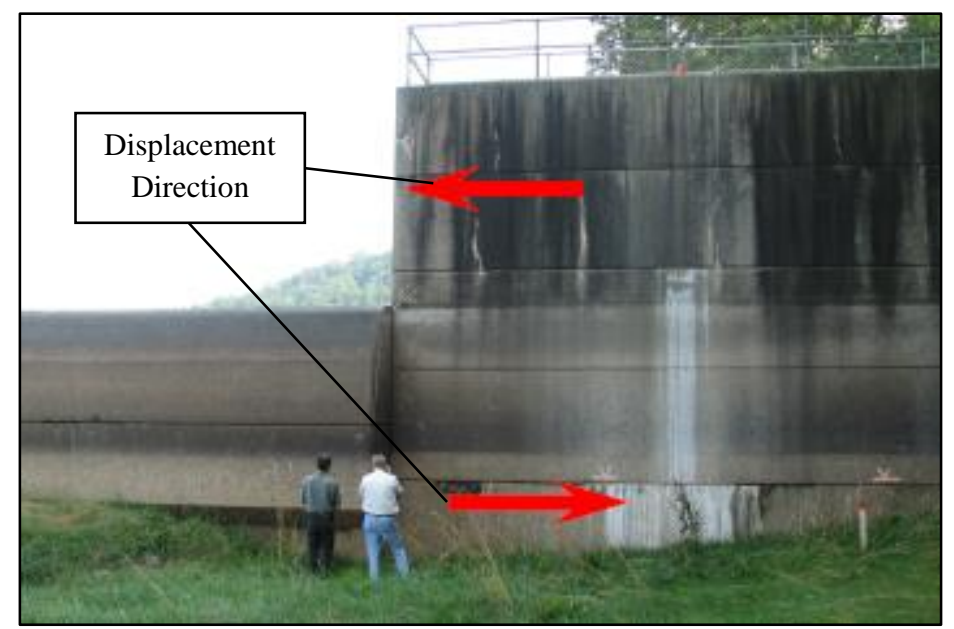

Figure 5.9 Upstream face displacement direction at Ryerson Station Dam (PADCNR, 2007) 
Observations at the Ryerson Station Dam indicate valley bottom heaving, leaving the rigid concrete dam to act as a bending beam. As the upward force beneath the dam is imposed on the structure, the top of the dam is in tension, and the bottom of the dam is in compression. The concrete joints in the dam allow the top and bottom of the dam to move independent of one another, acting as a multi-layered bending beam scenario. Figure 5.10 presents the mechanics of the dam failure resulting from upward forces beneath it. These mechanics are consistent with observations of movement within the Ryerson Station Dam.

Fixed beam shearing due to upward force $(\mathrm{F})$
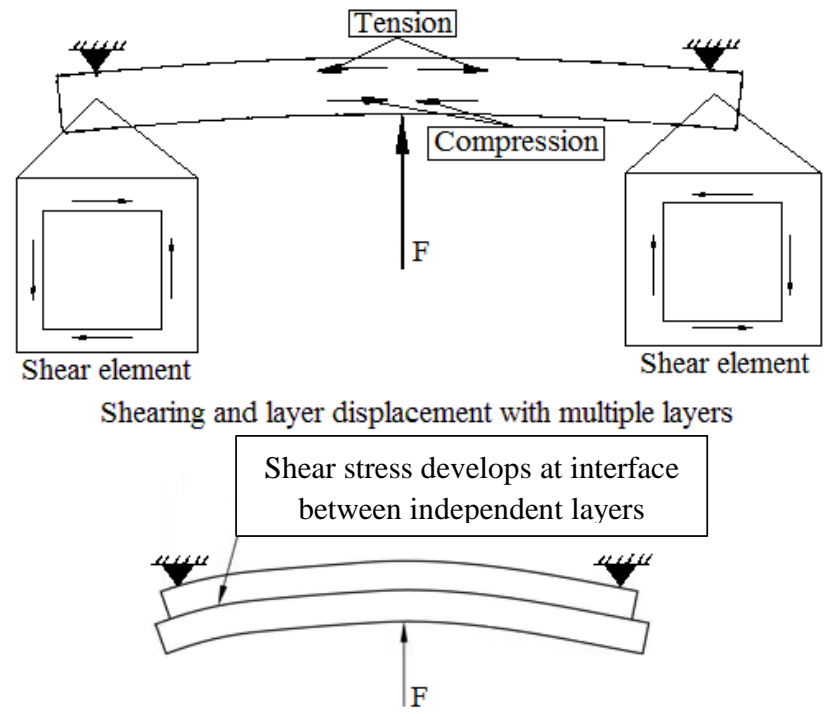

Shearing and layer displacement with multiple layers

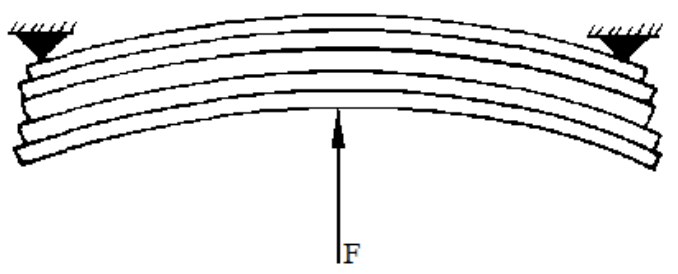

Figure 5.10 Mechanics of Ryerson Station Dam displacement due to valley stress relief

- Progression: Mining progresses to panel closer to the dam, increasing stresses in the valley and dam to the point of structural failure

\subsubsection{Unsuccessful Intervention and Breaching}

In 2005, the Ryerson Station Dam was breached due to unsuccessful intervention of valley closure and upsidence phenomena resulting from nearby longwall mining. Intervention can be possible when the failure progression is able to be identified early enough to prevent a failure. A failure of a dam can be defined as a breach or failure in system, including the loss of the authorized purpose for a dam. 


\subsubsection{Intervention Options}

Options to intervene in this scenario are few, but some decisions can be made. Decisions may be implemented sequentially or simultaneously. If there is concern for far-field ground strain to result in valley closure and upsidence phenomena, then monitoring instruments should be installed between the mine panel and the valley of the dam. Detection of a change in stress/strain will enable management personnel to make further decisions. Once strains are detected which may cause damage to the dam, then the load on the dam can be decreased by lowering the reservoir level. Also, monitoring ground movement beyond adjacent connected landforms could allow management to utilize the observational method. The mine plan could be altered to avoid areas which may induce ground strain to propagate to dam. If intervention is unsuccessful, it may be necessary to drain the reservoir and breach the dam, as was the case at Ryerson Station. In this case, seepage rates through joints and cracks, drains, at surface/dam interface, and at observed downstream seepage outlet areas have increased to levels concerning the dam management due to significant increased risk for loss of authorized purpose or:

- Dam structure instability

- Uncontrollable reservoir level

Observed/measured effects result in the decision to breach. Figure 5.11 shows a decision tree outlining intervention options.

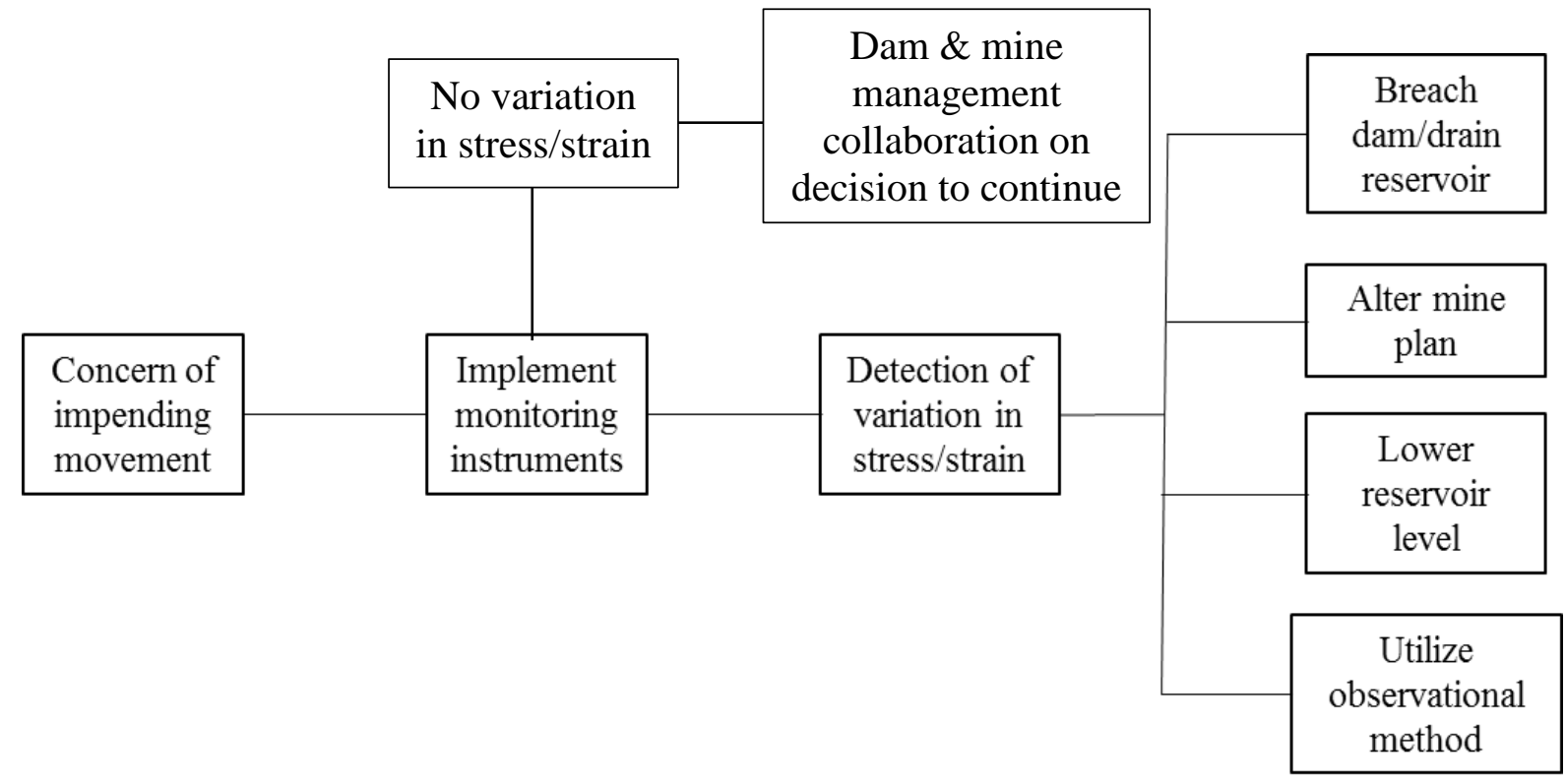

Figure 5.11 Decision tree for far-field strain near to a dam 


\subsubsection{PFMA Summary}

This section summarizes the components of the developed PFMA for the events that occurred at the Ryerson Station Dam. This potential failure mode is introduced for far-field ground strain leading to uncontrolled seepage at a dam. Figure 5.12 provides an illustrative summary of the chronology given in Section 5.1. The information is organized as a graphical sequence for a seepage related PFMA. This breakdown of the PFMA was used to assist in identifying key parameters. Table 5.4 provides a Gantt chart breaking down the overlapping timeline of the components of the PFMA.

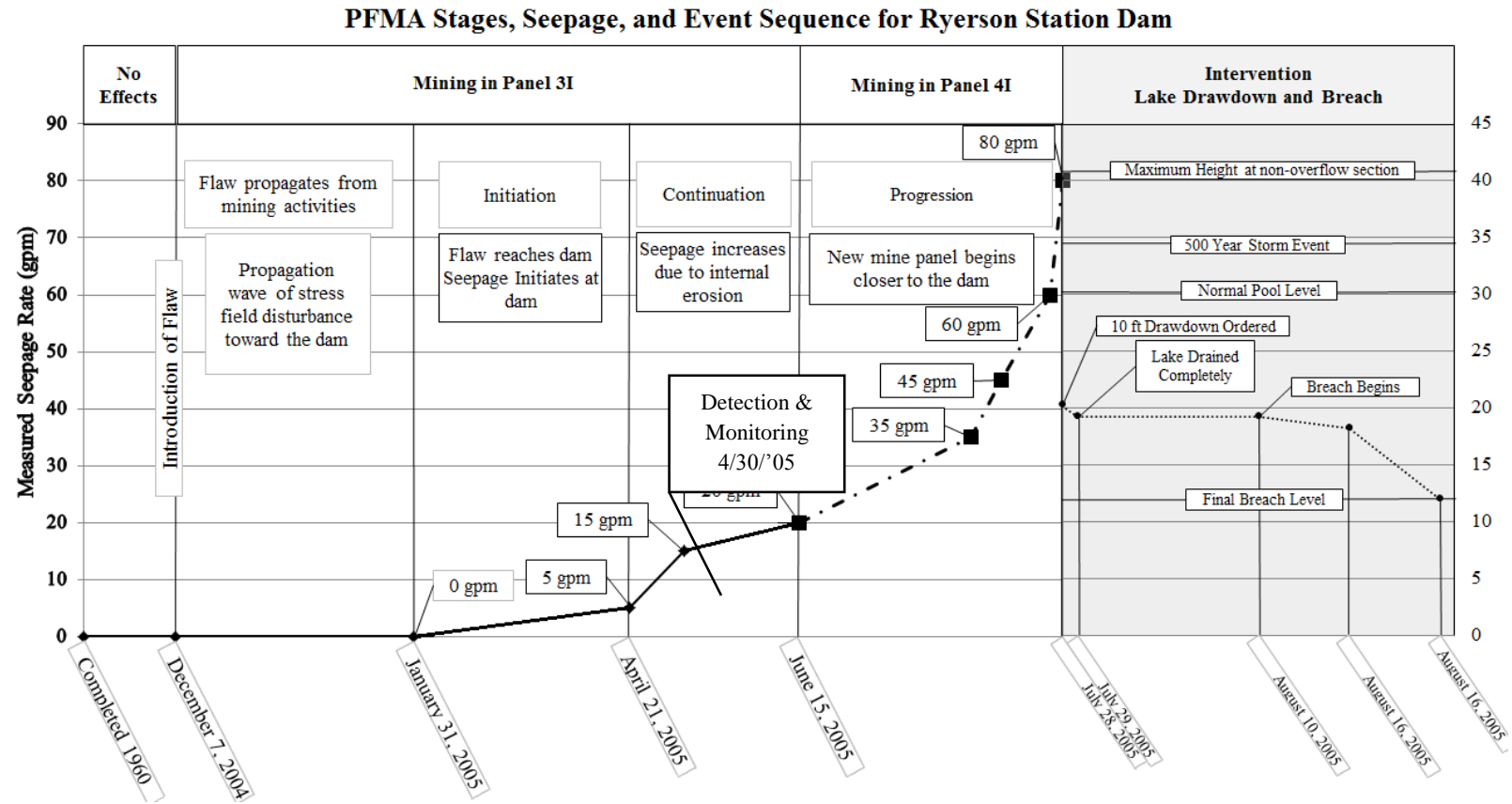

Figure 5.12 Summary of far-field ground strain PFMA timeline

Table 5.4 Gantt chart for sequence of PFMA related events

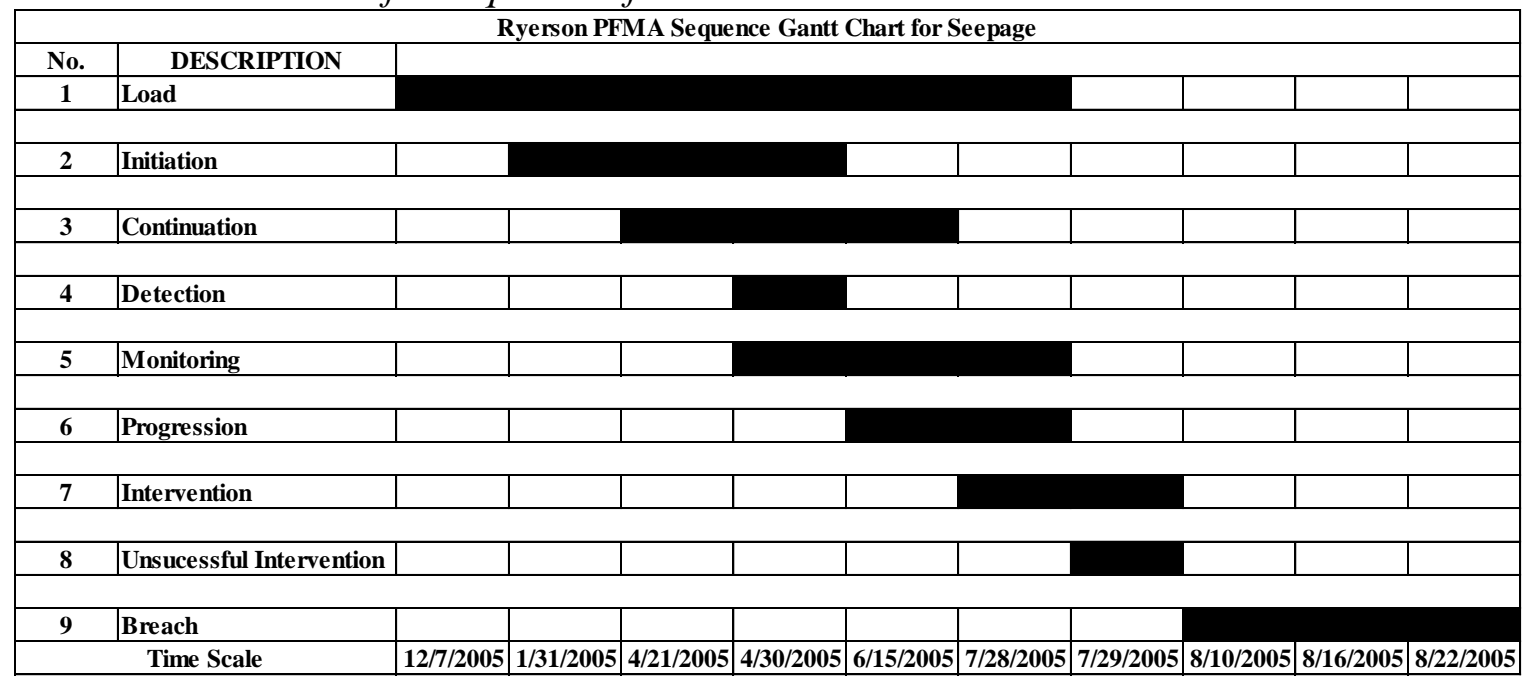


The key factors that have been identified in the PFMA process are shown in Table 5.5. The table links the identified mechanisms (flaw, initiation, continuation, and progression) to quantifiable parameters to allow event tree representation of the PFMA components.

Table 5.5 PFMA components and associated parameters

\begin{tabular}{|c|c|c|}
\hline PFMA Component & Description & Parameter \\
\hline Flaw & $\begin{array}{l}\text { Underground mine void } \\
\text { installment (<6000 ft.) }\end{array}$ & Prerequisite Assumption \\
\hline Load (deformation) & Adjacent landform weight & Height/Slope \\
\hline Load (deformation) & Tectonic stress & In situ stress magnitude (range) \\
\hline Load (seepage) & $\begin{array}{l}\text { Pore pressure in compression } \\
\text { regime }\end{array}$ & Pore pressure, $\mathrm{u}$ \\
\hline Load (seepage) & Lake hydraulic head & Seasonal lake elevation \\
\hline Initiation & Hill seams/weathered joints & Prerequisite Assumption \\
\hline Initiation & $\begin{array}{l}\text { Topography (elevation } \\
\text { change/slope angle) }\end{array}$ & Height/Slope \\
\hline Initiation & Subsidence due to coal mining & Coal seam thickness \\
\hline Continuation & $\begin{array}{l}\text { Mining continues beyond } \\
\text { initiating longwall panel, closer } \\
\text { to the dam }\end{array}$ & $\begin{array}{l}\text { Mine offset distance from point of } \\
\text { interest }\end{array}$ \\
\hline Continuation & $\begin{array}{l}\text { Seepage increases due to } \\
\text { disturbed natural fractures } \\
\text { (seepage pathway) }\end{array}$ & Hydraulic conductivity, $\mathrm{k}$ \\
\hline Progression & $\begin{array}{l}\text { Mining progresses to panel } \\
\text { closer to the dam, increasing } \\
\text { stresses in the valley and dam to } \\
\text { the point of failure }\end{array}$ & $\begin{array}{l}\text { Valley strata strength parameters, } \\
\text { UCS, E, } v\end{array}$ \\
\hline
\end{tabular}

\subsection{Development of Conceptual Fault Tree for Far-Field Ground Strain Leading to a Dam Breach}

A fault tree was created with the information contained within the PFMA to show the possible sequences of events that may have taken place to further organize the events that led to the farfield ground strain damage and failure at the Ryerson Station Dam. The subevents presented were not necessarily direct causes in the Ryerson Station Dam case. These topics were considered to illustrate potential major causes of failure to be used to build an event tree for farfield ground strain affecting a dam. 


\subsubsection{Main Event Consequence}

The main consequence considered was the loss of dam function. This loss of function is defined as the condition under which a dam can no longer maintain its authorized purpose. These purposes and their supporting legislation are summarized in Table 5.6.

Table 5.6 Authorized uses of reservoirs (U.S.ACE, 1994)

\begin{tabular}{|l|l|}
\hline Authorized Use & Supporting Legislation \\
\hline Flood Control & Flood Control Act of 1944 \\
\hline Recreation & Flood Control Act of 1944 \\
\hline Municipal and Industrial Water Supply & Title III, Water Supply Act of 1958 \\
\hline Wildlife and fish conservation & Fish and Wildlife Coordination Act of 1958 \\
\hline
\end{tabular}

The complete fault tree for this case is given in Figure 5.13. There are several pathways in which far-field ground strain behavior were determined to have the potential to lead to a dam failure. 


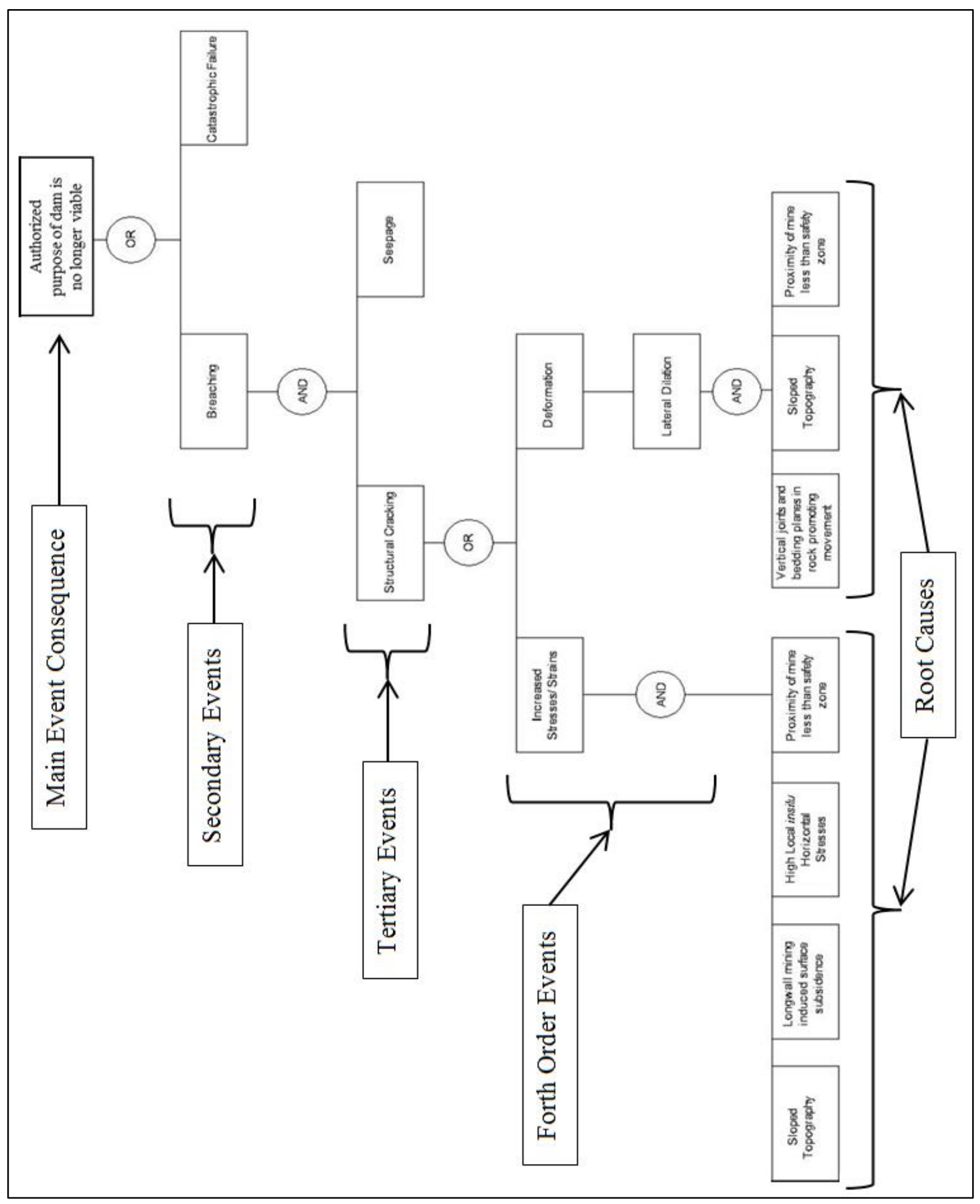

Figure 5.13 Conceptual fault tree for far-field ground strain leading to loss of authorized purpose of a dam 


\subsubsection{Secondary Events}

Two secondary events have been identified as causes of a dam losing its ability to maintain a reservoir that fulfills its authorized purposes. These include both a catastrophic failure case, and a dam breach event. In a catastrophic failure case, the dam would fail in an uncontrolled manner. This is a worst-case scenario as it would likely lead to significant flooding downstream and potential loss of life and property. A breaching event would include the intentional draining of the reservoir and removal of part or the entire impounding structure to prevent a catastrophic failure case.

\subsubsection{Tertiary Events}

Since the secondary events occur due to the same causes, one branch was used to describe the tertiary events. The tertiary events were determined to be structural cracking and seepage. These events became critical in the summer of 2005 when seepage rates reached $80 \mathrm{gpm}$. Together, these events signaled that the dam was in poor condition and that uncontrolled failure could occur if actions were not taken.

\subsubsection{Fourth Order Events}

There are three potential causes for the two tertiary events which included structural cracking and seepage. Evidence from the investigation by Gannett Fleming, Inc. monitoring suggests that ground movements were a result of nearby mining. The introduction of a void (Panel 4I East) resulted in lateral dilation, and vertical deformation. Increased stresses and strains also could exist under these conditions without the occurrence of lateral dilation and the types of deformation that occurred at the Ryerson Station site. These mechanisms are described in Section 4.4.

Increased stresses and strains at valley due to far-field ground movement are thought to be the result of the high relief topography losing its ability to maintain stable in situ conditions. Large enough magnitudes of increased stresses and strains could lead to the structural cracking, and an increase in seepage around dam structures due to a disruption of the soil and rock matrix around the structure.

Lateral dilation is a more severe manifestation of the topography losing its ability to remain stable. Under this mechanism, the vertical jointing in weathered sedimentary geology along with the tensile stresses induced by mining allow the landform to dilate (expand), and the valley bottom to relieve stress by breaking and heaving upward. This occurs in 'block-like' movements and could result in a failure to maintain the authorized purpose of a dam structure. 


\subsubsection{Root Causes}

The hypothesized root causes of this potential failure mode scenario include the specific properties and circumstances at the site which result in structural cracking and increased seepage at a dam due to far-field ground movement induced by coal mining. These root causes have been identified to include:

- Proximity of mining (horizontal distance/depth)

- Topography (relief and slope)

- Mine subsidence (magnitude due to void thickness)

- Geology (hill seams/tension cracks, rock strength properties)

- In situ horizontal stress

\subsection{Development of Conceptual Event Tree for Far-Field Ground Strain Leading to a Dam Breach}

A conceptual event tree was created based on the findings included in Section 5.3 and Section 5.4. This section presents the conceptual preliminary event tree for far-field ground strain leading to the inability to maintain the authorized purpose of a dam.

\subsubsection{Description of Significant Factors}

This section provides a description of each topic of focus found in literature and the Ryerson Station case study which may be considered for the development of event trees and PFMA for far-field ground strain adversely affecting a dam.

The major parameters affecting valley closure and upsidence were identified through studies by the Australian Coal Association Research Program (ACARP) Waddington \& Kay, 2003, Zhang et al., 2012; Zhang et al., 2013; and Holla, 1997. Some parameters were identically reported and are not repeated per study. These parameters are as follows:

- Waddington \& Kay, 2003:

- Distance between the longitudinal end of the longwall and the valley

- Distance between the maingate edge of the longwall and the valley

- Depth of the valley

- Maximum predicted incremental subsidence over the longwall

- Zhang et al., 2013:

- Direction and magnitude of in-situ horizontal stress 
- Zhang et al., 2012:

- Valley geometry (depth, width, shape)

- Width of longwall and position relative to the valley

- Near-surface rock characteristics, local geology, joint sets

- Holla, 1997:

- Slope of terrain

- Mining thickness

- Mining depth

\subsubsection{Sequence of Events and Worsening Factors which Lead to the Breaching of a Dam Due to Far-Field Ground Strain}

In order for far-field mine subsidence to adversely affect a dam enough that it must be breached to ensure the safety and security of society and property, a general sequence of events and conditions must occur. This section provides a sequence of events and conditions which must occur for far-field ground strain to result. The sequence is numbered from the initial event to the final event.

\section{Longwall coal mining}

- A longwall coal mine is permitted to extract coal according to the bounds imposed by IC 8741 .

\section{Traditional Subsidence Analysis}

- The mine will stay at least far enough away that conventional subsidence effects will not have a reasonable chance of causing harm to the dam according to the results of a Surface Deformation Prediction System (SDPS) analysis.

- SDPS does not currently take in to account varying topography to a significant degree, which is a critical factor in the severity of far-field ground strain. Therefore, the SDPS analysis is insufficient to account for far-field strain effects, leaving the dam potentially vulnerable to unforeseen disturbances. 


\section{Geologic Conditions}

- The dam is situated in geologic conditions similar to the geologic conditions found at Ryerson Station Dam (Pennsylvanian Age), where the circumstances are possible to have far-field strain phenomena occur. This may include large geostatic stress magnitude and direction intersecting the dam location from the mine voids.

\section{Topography}

- The dam is located within a valley where the slopes are as steep as or steeper than the slopes along the valley at Ryerson Station Dam.

- It has been found in studies by Hebblewhite et al., 2000; Zhang et al., 2013; Khair et al., 1988; and others, that the severity of the topography with respect to slope angle has a profound influence on the degree of valley deformation phenomena induced by far-field ground strain effects.

- Principal stresses become increasingly parallel to the ground surface with decreasing depth (Figure 2.7). Figure 5.14 shows the statics and vector triangle that describes the increase in the vertical stress vector along the slope surface as the slope angle $(\beta)$ increases. This increase in the proportion of the vertical force to the horizontal force causes a concentration of stress at the valley bottom. This may lead to upsidence phenomena as stress is relieved through the deformation of rigid horizontal rock layering whose strength cannot withstand the imposed forces.
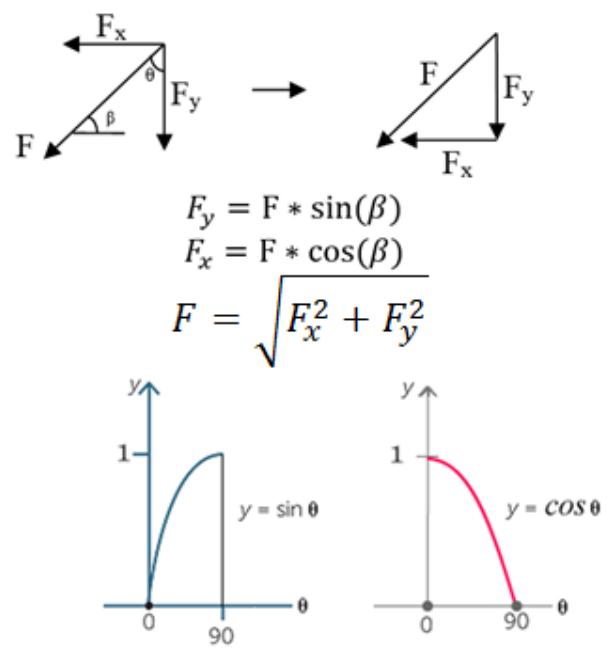

Figure 5.14 General statics of force proportions on a valley slope 


\section{Valley Movements at the Dam}

i. The dam must be located within 6,000 ft. (1.14 miles) of the closest approach of the mining operations.

- It was found at Ryerson Station Dam, an increase in seepage was realized when the approach of the mining activities was approximately 6,000 ft. away.

- It is a likely condition that the cause of the movements inducing an increase in seepage at the dam did not occur instantaneously, but took some time to propagate to the dam. This fact implies that the distance of propagation is likely less than 6,000 ft., at an unknown magnitude which should be researched further. Distance versus effect analyses were performed in Australia under an Australian Coal Association Research Program (ACARP) project, however these relationships have not been verified in U.S. geology.

\section{Mechanisms which are known to cause far-field ground strain exist at the site}

ii. At least 1 of 4 mechanisms must exist at the site to induce far-field ground strain effects; these are:

i. Disturbances in the stress field near to the dam are induced by mining. These disturbances develop strains in the foundation rock, near surface soils (<100 ft.), and surrounding strata within the valley.

- Increasing stresses and strains within the valley could induce upsidence phenomena (heaving at the valley bottom).

ii. Already high in situ stresses in the valley

- Increasing stresses and strains within the valley could induce upsidence phenomena; especially if the in situ stresses are already high perpendicular to the valley channel.

iii. Hill seams (vertical joints) within the topography adjacent to the dam

- According to Zhang et al., 2013, vertical joints (termed "hill seams" in the mining industry) play a key role in inducing lateral dilation and valley closure. 
- Hill seams decrease the ability of the hill sides to remain static as their resistive horizontal forces are decreased by a loss of contact in massive rock strata. This can cause bed shearing, and expansion of the hill, greatly increasing the compressive stresses at the valley bottom.

iv. Sloped topography

- Slope severity assists far-field ground strain as the vertical downhill forces take on an increasingly greater proportion to the horizontal forces within the mass of the rock under gravity (transition in principle stress) with an increasing slope angle.

\section{Far-field ground strain occurs at the dam}

iii. At least 1 mechanism which is known to cause far-field ground strain exists at the dam site and the valley movement phenomena ensue.

\section{Disturbances develop new seepage pathways or worsen already existing ones}

- The effects of far-field ground strain have the potential to produce local voids from bed separation.

- Thrust faults may occur, changing existing seepage pathways and creating new ones.

- Bulging of the valley floor (upsidence) disrupts the stability of the dam structure itself, which could lead to (Figure 2.10):

- The opening of seepage pathways in construction joints or in new or historic cracks in the dam.

- Disturbance of the dam-foundation rock interface in the form of fracturing or separation; ultimately creating potential seepage pathways.

iv. As may be expected, different rock types generate different fracture densities and fracture lengths when exposed to an adequate magnitude of stress (Lee, 1990). The disruption of pre-existing natural stress fractures around the dam could increase seepage and piping. Also, the disruption of horizontally lain strata or porous strata could potentially increase seepage rates. 


\section{Seepage pathways cause piping erosion}

v. Piping erosion occurs around the dam foundation. New seepage pathways carry small particles through them, further increasing the void ratio and the hydraulic conductivity in mudstone, siltstone, and shale.

- Historic evidence, via dam inspection logs, suggests that some existing seepage pathways existed, and perhaps, were causing erosion upstream and downstream of the dam (PADCNR, 2007).

\section{Breaching of the dam}

vi. As a result of unstable, worsening seepage conditions, the dam is breached in order to maintain the safety of downstream populations and property.

\subsubsection{Potentially Worsening Factors for Strain and Seepage}

The listing (1-10) in Section 5.5.2 is based on the events at Ryerson Station as well as findings in pertinent literature. Some factors could worsen the scenarios listed in Section 5.5.2. Some of the potentially worsening factors for far-field ground strain effects are:

- Aged dam materials

- Concrete and steel are known to degrade with time. Dams which were constructed many years ago could consist of degraded materials. These degraded materials could have less capacity to maintain their designed purpose.

- Design of the dam

- Different dam designs could cause stress concentrations in different locations. Some dams could have a better chance at maintaining stability and low seepage rates under varying applied strains.

- Siltstone/mudstone/horizontally bedded shale within the disturbed area of effect

- Strata around the dam which contact the reservoir when disturbed by a change in the in situ stress field could increase seepage rates and develop a seepage pathway to bypass the dam.

- Existing seepage pathways before far-field ground strain effects ensue which could worsen when disturbed.

- If cracks or joints in the surrounding rock exist before far-field strains are induced within them, then their movement may have the potential to increase seepage rates. 
- Near surface weathered rock fracturing along with vertical joints decrease the ability for topographic features to remain stationary when in situ stress disruptions occur.

- Landform orientation is hypothesized to influence the propagation of far-field ground strain. The orientation of a landform whose stress field is influence by mine subsidence may act as a conduit for far-field ground strains.

Table 5.7 provides a summary the significant factors from Section 5.5.2 and Section 5.5.3 organized into an event tree structure. This conceptual event tree is expected to change due to identified causal factors in numerical modeling. The event tree assisted the development of an Event and Causal Factor Tree (ECFT) in a Root Cause Analysis (RCA) . 
Table 5.7 Preliminary conceptual event tree

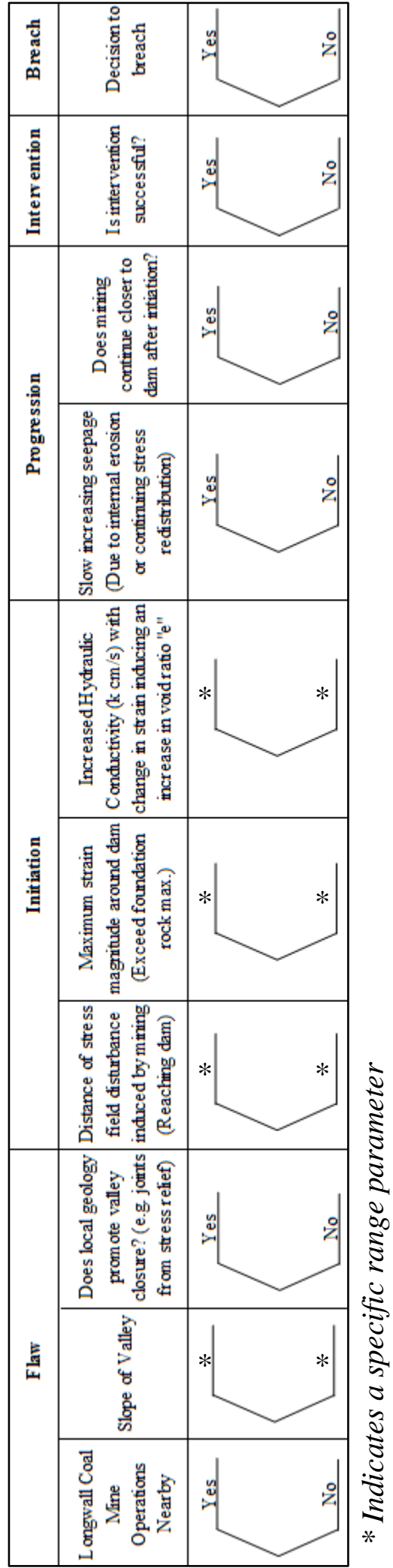


These results of the conceptual event tree and fault tree fulfill the intent of Objective \#1 from Section 1.3.1:

Objective 1: Develop a Potential Failure Mode Analysis (PFMA) for a water reservoir dam from initiation to breaching due to a mining induced far-field ground strain scenario within the proximity of a dam including conceptual fault tree and event tree failure analysis. Topics included in the conceptual fault tree and conceptual event tree will be determined via case study investigation of the events leading to the Ryerson Station Dam breach. 


\section{CHAPTER 6. NUMERICAL MODELING}

Since this case study was well documented, site-specific data exists, and far-field ground strains occurred which resulted in the breaching of a dam, the Ryerson Station State Park Dam has been chosen as the site to be modeled. Monitoring studies were performed after the breach to acquire near surface ground movement data for Bailey Mine's Panel 5I and Panel 7I.

Numerical finite element modeling was performed to simulate stress deformation responses in the valley of the Ryerson Station Dam due to the introduction of nearby underground mine voids. Parameters have been quantified so that relationships can be inferred and input into an ECFT to organize a failure progression. The modeling was performed to identify the significance of parameters with respect to the far-field surface deformation caused by an introduction of mine voids. A 3-Dimensional SVSolid ${ }^{\mathrm{TM}}$ model was utilized to quantify stresses and resulting deformation induced by nearby mining operations. Increased hydraulic conductivity is expected if the in situ stress field local to the dam is disrupted by mining, and especially if valley closure due to lateral dilation of the valley walls and upsidence effects occur. Seepage occurred as a result of ground movement at the dam, but quantifying seepage does not answer the primary research question and can only assist in defining a failure condition. As a result, seepage modeling was not performed. Seepage responses were addressed as a failure mode which would occur at very low strains in accordance with research by Bai et al., 1995.

Two modeling analyses were performed:

1. Site-specific model calibration to slope deformation recorded by field measurements (Ryerson Station Dam and Bailey Mine - Greene County, PA)

2. Parametric sensitivity analysis

\subsection{Introduction}

It is hypothesized that topography plays an important role in the propagation of far-field ground strains induced by mine voids. Unless restricting models to ridgeline profiles, adjacent loading of 2D profiles by surrounding topography, which would otherwise not be included, could cause 2D models to be inaccurate. Additionally, empirical studies have accumulated a range of field responses to account for subsidence propagation. Although useful, these empirical approaches are not capable of incorporating site specific topography. Therefore, 3D numerical modeling was chosen as the most appropriate approach to quantifying the complex geometry of mountainous terrain at Ryerson Station State Park. 


\subsubsection{Calibration Analysis}

Site-specific data from the monitoring project funded by the Pennsylvania Department of Conservation and Natural Resources (PADCNR) and performed by Gannett Fleming, Inc. at the Ryerson Station State Park was used for model calibration. Inclinometers, extensometers, surveying points, and strain gauges on the dam were used to obtain data at the site. Pertinent information for the monitoring project is available in five published volumes which were used to assist in the modeling approach (PADCNR, 2007). All instruments were installed just after the Ryerson Station Dam was breached; therefore, no seepage data from the dam is available in correlation with measured ground movement. The $\mathrm{X}, \mathrm{Y}$, and $\mathrm{Z}$ movement data were obtained by the survey points along the western rim of Duke Lake. This data was used for model calibration since it was the most extensively recorded available information. Data readings were taken over an extended period of time as the mine operations progressed to provide a dynamic view of the phenomena. Deformations were graphed and tabulated per location vs. time. Site and time specific conditions were considered for each data set such as the slope angle, distance from mining, and depth of mining. Figure 6.1 shows the area of interest for the numerical modeling calibration. The majority of the survey points resided along the west rim of the reservoir, between Panel 7I and the Ryerson Station Dam.

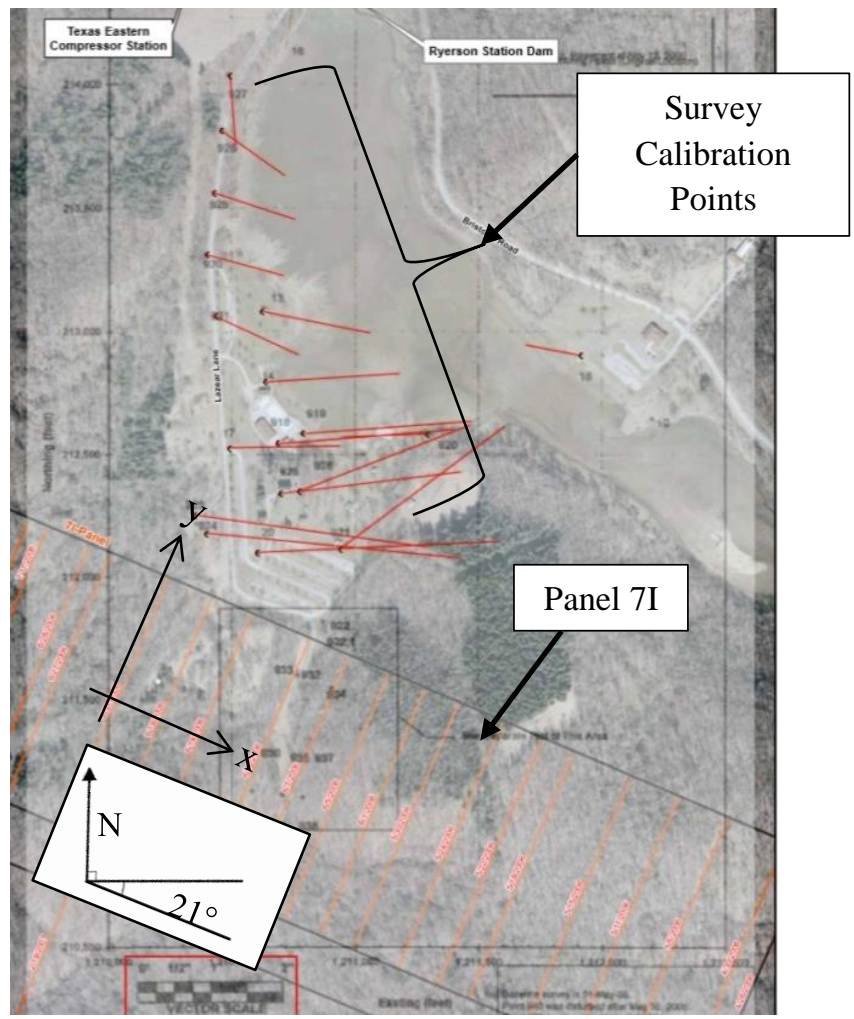

Figure 6.1 Plan view of Gannett Fleming, Inc. survey points and translation vectors at Ryerson Station State Park (PADCNR, 2007) 
Model cases were calibrated with a specific time of propagation of the mine void with respect to multiple survey stations. An initial case was performed as a zero movement condition for premining conditions.

\subsubsection{Sensitivity Analysis}

The sensitivity analysis was intended to provide clarity for the ECFT parameters. Models were conducted to identify the sensitivity of far-field ground strain and deformation responses to varying input parameters. The preliminary conceptual event tree was refined in accordance with the results of this sensitivity analysis. Data trends identified in correlation plots were used to assist the quantification of significant parameters for developing a RCA.

Input parameters were organized to have the greatest (Worst Case) and least (Best Case) deformation effects. These parameters were defined to find the full range of model responses. The resultant data was tracked to identify trends. The parametric sensitivity analysis models were built with respect to the progression of mining in Panel 7I to assist in the identification of parameter values which had the greatest influence on the model response. The identification of these parameter values was sought by measuring multiple survey point responses and graphing them in correlation plots. The modeling was approached with intent to identify the significance of each parameter on the model response, including:

- Slope angle

- Strata orientation and detail

- Rock properties:

○ Poisson's Ratio

- Young's Modulus

○ Void Ratio

○ Unit Weight

- Mine void orientation:

- Linear offset distance

- Depth of overburden

\subsubsection{Expected Outcomes}

The potential for far-field ground strain to adversely affect dams has become a concern for some dams which have nearby mining operations occurring or permitted. The intent of this research is to develop a Semi-Quantitative Potential Failure Mode Analysis - Root Cause Analysis (SQPFMA-RCA) for far-field ground strain effecting seepage at a dam as a first attempt to organize and quantify the problem. A fault tree based on the Ryerson Station case study is to be 
utilized to develop a preliminary conceptual event tree for the scenario. Sensitivity modeling results will be used to finalize the ECFT.

The main objective is to provide insight into significant parameters having the greatest influence on the ground responses through this analysis method. Final ECFT results are anticipated to provide insight into the protection of dams from far-field ground strain by mitigating the effects of the most significant parameters which lead to an undesired outcome.

\subsection{Determination of Appropriate Quantification Software Tool for Far-Field Ground Strain}

Several software programs were assessed before determining which code would be the most appropriate to utilize for this research. These are summarized in Table A1, Table A2, and Table A3 in the Appendix. The goal of the numerical modeling is to determine and quantify significant parameters which influence surface deformation and associated stress. Different approaches could be taken to solve specific questions about the influence of fracturing, in situ stress, angle of draw, and zones of subsidence, however the scope of this research has been established as a macrospective surface deformation by the introduction of a subsurface void.

SVOffice ${ }^{\mathrm{TM}}$ utilizes a module called SVSolid ${ }^{\mathrm{TM}}$ which determines stress, shear stress, and deformation. The module has $2 \mathrm{D}$ and 3D capabilities. The software can compute these stresses and deformations from linear elastic or nonlinear elastic material definitions. Von Mises, and Drucker-Prager failure criteria are also available options. SoilVision ${ }^{\mathrm{TM}}$ is capable of solving complex elastic deformation models for soil and rock (Fredlund, 2009). SVSolid ${ }^{\mathrm{TM}}$ is not the only approach which could be utilized to answer questions about the far-field ground movement phenomena that sometimes results due to mine voids in mountainous topography, however it has been determined to be adequate for the scope of this research. Smaller scale models may consider Fast Lagrangian Analysis of Continua (FLAC) for fracture simulation, or other methods summarized in the Appendix whose strengths would accentuate other analysis approaches.

\subsubsection{SoilVision ${ }^{\mathrm{TM}}$ Suite}

The software utilized for this research was SVOffice 2009'TM. SVOffice2009 ${ }^{\mathrm{TM}}$ is a geotechnical finite element modeling software package. The modules consist of SVSolid ${ }^{\mathrm{TM}}$, SVSlope ${ }^{\circledR}$, SVFlux $^{\mathrm{TM}}$, SVChemflux ${ }^{\mathrm{TM}}$, SVHeat ${ }^{\mathrm{TM}}$, and SVAirflow ${ }^{\mathrm{TM}}$. This research only utilized the SVSolid $^{\mathrm{TM}}$ module. 
SVSolid ${ }^{\mathrm{TM}}$ limitations to this problem solution include the inability to model rock fracturing, and model run times that can exceed practical wait times when model complexity is increased with the introduction of small regions. The auto-refined finite element mesh tends to refine around comparatively small regions within the model and exponentially increase run times.

The benefits of using SVSolid ${ }^{\mathrm{TM}}$ include the 3D modeling capability as well as the ability to choose analysis points, incorporate up to 14 layers of rock, and measure model output to high precision. Model regions can be run as void space or as a material layer.

\subsection{Finite Element Modeling at Ryerson Station Dam}

Finite Element Method (FEM) computer modeling at the Ryerson Station Dam was performed via SVOffice ${ }^{\mathrm{TM}}$. The SVSolid ${ }^{\mathrm{TM}}$ module was chosen to simulate ground movement induced by the introduction of subsurface mine voids using a linear elastic model. Both 2-Dimensional and 3-Dimensional modeling is possible with SVSolid ${ }^{\mathrm{TM}}$. A 3D modeling approach was chosen to encapsulate the effects of hypothesized causal factors that include hillside loading magnitudes and landform orientation. The results of the modeling were graphed to focus on the sensitivity or correlation that each parameter had with the subsequent movement. The parameter sensitivity was developed to identify priority causal factors of far-field ground movement due to the introduction of subsurface voids.

Preliminary modeling was organized to reach a level of model detail that was considered to most precisely simulate the field data. A number of geometric and situational decisions are presented to determine the appropriate level of detail. Best Case "BC" (strong rock case) and Worst Case "WC" (weak rock case) parameters were chosen at 3 levels of detail for 11 models each, totaling 66 model cases. Eleven of these models were selected after calibration to be used in the causal factor sensitivity analysis. Horizontal stresses were calculated using the relationship of Poisson's Ratio (v) to the Passive Earth Pressure Coefficient at Rest $\left(\mathrm{K}_{\mathrm{o}}\right)$. Equation 6.1 through Equation 6.4 present the general method for the calculation of horizontal stress used in the numerical modeling. A prime indicates that the stresses are effective since no piezometric surface was incorporated into the models. The earth pressure coefficient at rest $\left(\mathrm{K}_{\mathrm{o}}\right)$ was calculated in the model set up based on the site-specific laboratory tested Poisson's Ratio for each model layer.

Equation 6.1 (Fredlund, Gitirana, \& Thode, 2013)

$$
\begin{aligned}
K_{o} & =\frac{v}{(1-v)} \\
K_{o} & =\frac{\sigma_{h}}{\sigma_{v}} \\
\sigma_{h}^{\prime} & =K_{o} \sigma_{v}^{\prime} \\
\sigma_{v} & =\sigma_{v}^{\prime}=\gamma Z
\end{aligned}
$$$$
\text { Equation } 6.2 \text { (Holtz \& Kovacs, 2011) }
$$$$
\text { Equation } 6.3 \text { (Holtz \& Kovacs, 2011) }
$$$$
\text { Equation } 6.4 \text { (Holtz \& Kovacs, 2011) }
$$ 
where,

- $\quad v$ is Poisson's Ratio (unitless)

- $\quad \mathrm{K}_{\mathrm{o}}$ is the earth pressure coefficient at rest (unitless)

- $\quad \sigma_{\mathrm{h}}$ is the horizontal stress $\left(\mathrm{lb} / \mathrm{ft}^{3}\right)$

- $\sigma_{\mathrm{v}}$ is the vertical stress $\left(\mathrm{lb} / \mathrm{ft}^{3}\right)$

- $\quad \gamma$ is the unit weight of model materials $\left(\mathrm{lb} / \mathrm{ft}^{3}\right)$

- $\quad \mathrm{z}$ is the thickness of each model layer (ft)

\subsubsection{Model Set-up}

The Ryerson Station Dam post-breach case study was modeled. The most extensive field data reported in the PADCNR reports was for 30 survey points that were installed after the Ryerson Station Dam breach. Directional X, Y, and Z data was taken from May 1, 2006 to November 15, 2006 for these points. Fifteen of 30 survey points were determined to be significantly dissimilar enough to be considered. The calibration of a 3-Dimensional modeling approach was required to answer the following fundamental questions about the scenario:

i. At what level of rock layering detail does the range of deformation at a survey station become precise enough so that it can be determined to be adequate for prediction?

a. Addressed by graphing the range of best case (BC) and worst case (WC) model deformation results versus the field resultant deformation as the target for precision. Best Case (BC) parameters were selected to minimize model deformations (strong case). Worst Case (WC) parameters were selected to maximize model deformations (weak case). Material properties were held constant as model detail varied in 3 cases: 3 layers, 8 layers, and 14 layers.

ii. What level of detail is required on the surface layer to define the topography?

a. An irregular surface grid following the mine progression maps for panel 7I of the Bailey mine was created. The grid consists of 11 vertical profiles with points every $125 \mathrm{ft}$. in the $\mathrm{Y}$ direction. The model dimensions were 4,000 ft. (X) by $5,500 \mathrm{ft}$. (Y) by 1,000 ft. (Z) at a total of 495 surface points.

b. Typical 3D Cartesian coordinates were used to define the model. The X and $\mathrm{Y}$ coordinates defined a 2-Dimensional plane, with the $\mathrm{Z}$ coordinate defining the vertical relief of the model. Linear interpolation was performed to establish a surface consisting of 65,011 points, providing a surface point for each $1 \mathrm{ft}$. in the Y direction. This step was performed to allow for surface layer precision in the $3 \mathrm{D}$ model, however it was found to be too cumbersome for the computing ability even when reduced to $25 \%$ at 16,250 points. Additionally, the complexity of geologic features such as rock layers intercepting topographic structures is not 
sufficiently supported in SVOffice2009 $9^{\mathrm{TM}}$. A more basic 3D model or a 2D model could be run to simulate topographic interception of rock layers.

It was hypothesized that the post modeling result range would decrease and become more precise with respect to field data as model detail increased. Once an adequate level of detail was reached, a causal factor sensitivity analysis was performed.

The modeling was approached with the insights that resulted from research on the pre-breach events at the Ryerson Station Dam. The Potential Failure Mode Analysis (PFMA) with the developed conceptual event tree and fault tree were used to identify key parameters to quantify in the numerical modeling.

A total of eleven cross sections were taken in line with the mine progression maps. The borehole logs at this site showed that there were many layers of rock from the ground surface to the mine elevation, with intermittent massive sandstone strata. For model simplicity, layering increased in detail with the assistance of borehole log data from a most basic case to the most complex 3D case possible. Additionally, it is known that induced stresses on a mass of comparatively weak laminated rock, upon exceeding their capacity for strain, will distribute stresses to stronger, more massive strata. As a result, massive rock layers have a significant role in accumulating stress at dam abutments as a subsurface response to far-field mining induced strain.

The 2D model geometry was taken from topographic ESRI ${ }^{\mathrm{TM}}$ GIS generated profiles. Mine panel geometry was taken from mine maps provided in the Gannett Fleming, Inc. investigative report (PADCNR, 2007). 3D model geometry may also be taken from triangulated irregular network (TIN) surfaces generated in AutoCAD®, from digital elevation model (DEM) files, or topographic data. A level of surface precision should be sought which does not drastically increase run times but also encapsulates major topographic features. The model area extends from the eastern edge of Bailey Mine's Panel 7I development to the western ridge of the landform adjacent to the survey monitoring stations to capture the majority of the field measured effects. The top edge of the model includes the distance north to the highest elevation of the landform bordering the north-eastern valley wall as shown in Figure 6.4.

FEM elements were tetrahedrons and used auto-refinement for the complex geometry. FEM mesh refinement was such that less complex model regions required fewer, larger elements, while more complex geometry was refined to many smaller elements. The convergence error limit was \pm 0.01 with threshold values for incremental displacement of (u, v, w: $0.001 \mathrm{ft}$.) and incremental total stress (sx, sy, sz: $0.1 \mathrm{psf}$ ). The element interpolation was set to quadratic. The number of iterations per model was set to 1,000 in order to achieve a high level of precision. Model displacements are reported in feet by SVOffice ${ }^{\mathrm{TM}}$, and are presented in feet for consistency since some displacements are in the order of feet and some are in inches. 
There are many model options regarding near surface rock degradation due to weathered fracturing, boundary condition options for loading and degrees of freedom, and forced movement along a surface, however the most reasonable combination showing the greatest precision of model data to field measured data was used. The model calibration approach is discussed in Section 6.4.

\subsubsection{Model Geometry}

SVOffice ${ }^{\mathrm{TM}}$ has a unique way to define $3 \mathrm{D}$ geometry. The geometry consists of $2 \mathrm{D}$ regions and 3D surfaces. Surfaces act as interfaces between model layers. A maximum of 15 surfaces (14 layers) can be input into a 3D model in SVSolid ${ }^{\mathrm{TM}}$. A minimum of 2 surfaces (1 layer) must be delineated to define a 3D model. There is no limit to the number of regions, although computation times drastically increase with increasing regions. Regions are drawn in 2 dimensions and are extruded throughout the entirety of the 3D surfaces. Each time a region intersects a layer, material properties, sidewall boundary conditions, and surface boundary conditions must be defined. Each surface has an (X, Y) Cartesian grid. Grids can be defined regularly (square elements) or irregularly (rectangular elements). Each (X, Y) point requires an elevation magnitude, denoted as 'Z.' Figure 6.1 shows an illustration of how SVSolid' organizes 3D elements of a numerical model.

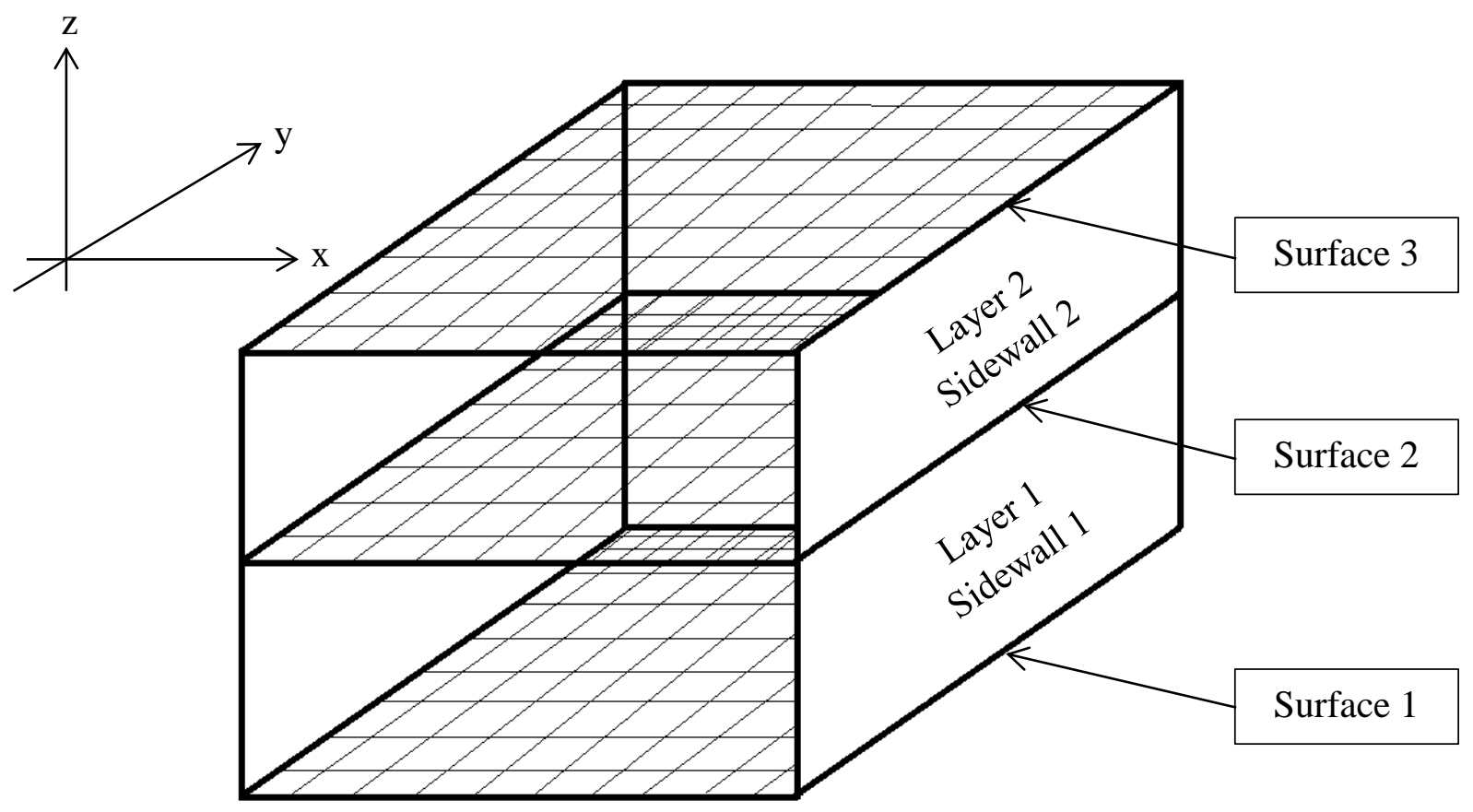

Figure 6.1 3D model drawing organization 
Numerical modeling was performed at the Ryerson Station State Park to analyze far-field ground movements due to the introduction of a subsurface void resulting from mining activities. The model consisted of the rock layering, topography, and a portion of Panel 7I. The Ryerson Station Dam was not included in the modeling since the intent was to calibrate to survey points, and not to perform a structural assessment of the breached dam. Four surface geometries had to be defined to build the model:
i. Ground surface topography
ii. Bedding plane surfaces
iii. Panel 7I extraction regions
iv. Levels of detail in stratigraphy

The model area was determined to encapsulate the majority of the displacement effects on the survey monitoring points. Since it has been hypothesized that topography plays a significant role in far-field ground movements, adjacent landforms to the ridgelines were included to incorporate valley loading effects. Known progression times of longwall mining in Panel 7I were incorporated to define model edges. The model was oriented rectangular with Panel 7I, which is 21 degree offset from an East-West configuration (Figure 6.2). Figure 6.3 provides the area determined to be included in the modeling. Final model dimensions were 4,000 ft. (X) x 5,500 ft. (Y) x 1,000 ft. (Z).

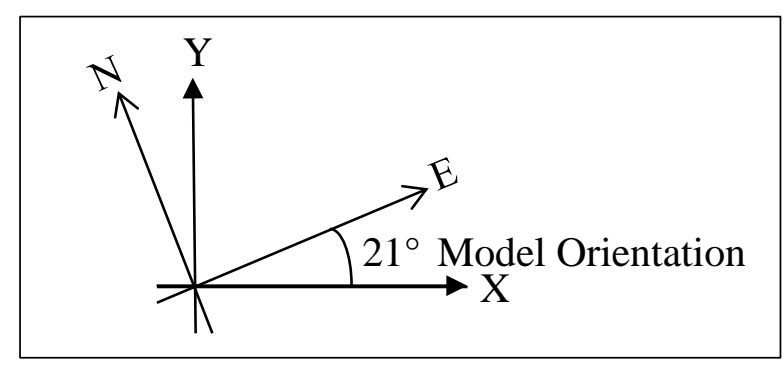

Figure 6.2 Model orientation 


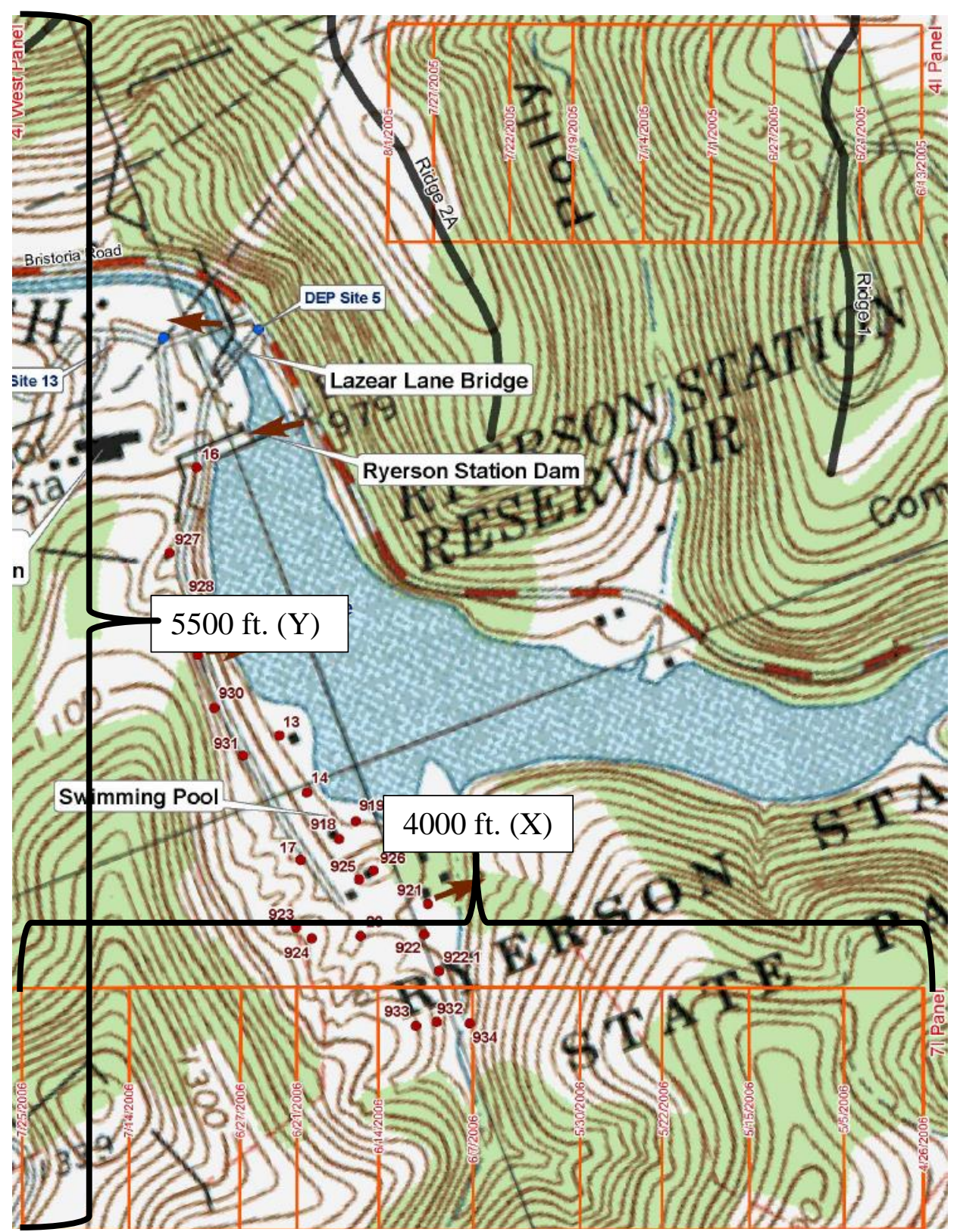

Figure 6.3 Model area

\subsubsection{Ground Surface Topography}

ESRITM GIS mapping was performed at the Ryerson Station State Park site. This mapping included digital elevation model (DEM) data for the topography as well as structure contours of the coal bed. Elevation contours were used to define 11 profiles which made up the 3D ground surface. The elevation points were taken every $125 \mathrm{ft}$. in the Y direction $(5,500 \mathrm{ft}$.) and irregularly following the 7I Panel extraction progression in the $\mathrm{X}$ direction (4,000 ft.), totaling 605 points. Lake bed elevation data files were not found. The absence of lake bed data was 
addressed by calculating a linear stream channel angle by taking the elevation just below the dam and above the reservoir. This resulted in a channel angle of 0.82 degrees.

The 3D approach angles from the adjacent valley walls also had to be calculated for each profile. The lake bed elevations were calculated by using the valley approach angles to extrapolate an elevation down to the channel angle elevation. This was performed for both sides of the lake for each profile. A 2D plan view of the final model geometry with elevation contours is provided in Figure 6.4. Figure 6.5 presents a 3D view of the model with elevation contours. Table A5 in the Appendix provides topographic data. Extraction regions were located on two landforms. These landforms are referred to in a general manner as the "eastern landform" and the "western landform." These landforms are distinguished around $\mathrm{X}=2000 \mathrm{ft}$. and are denoted in Figure 6.5.

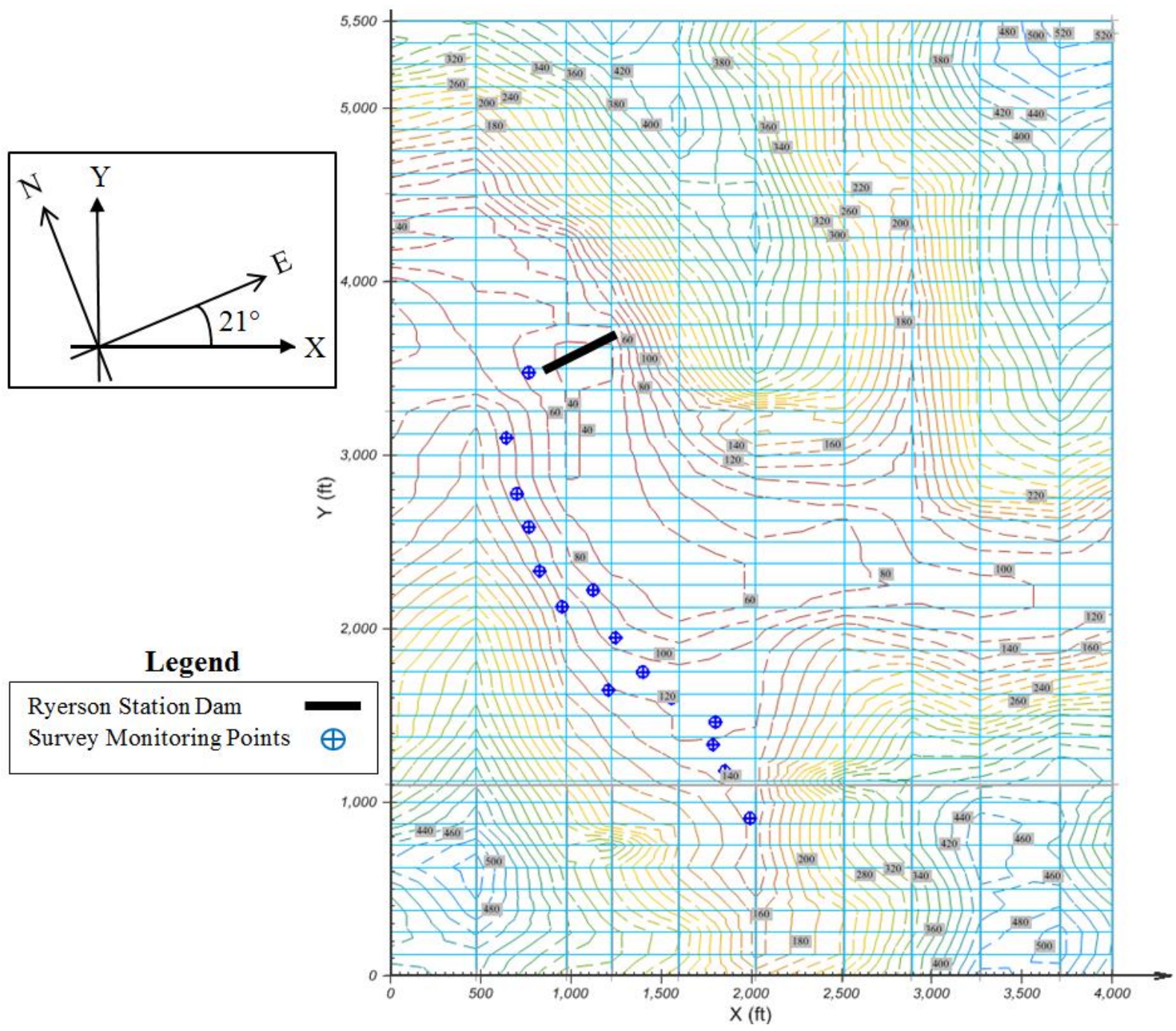

Figure 6.4 Final model geometry with elevation contours 

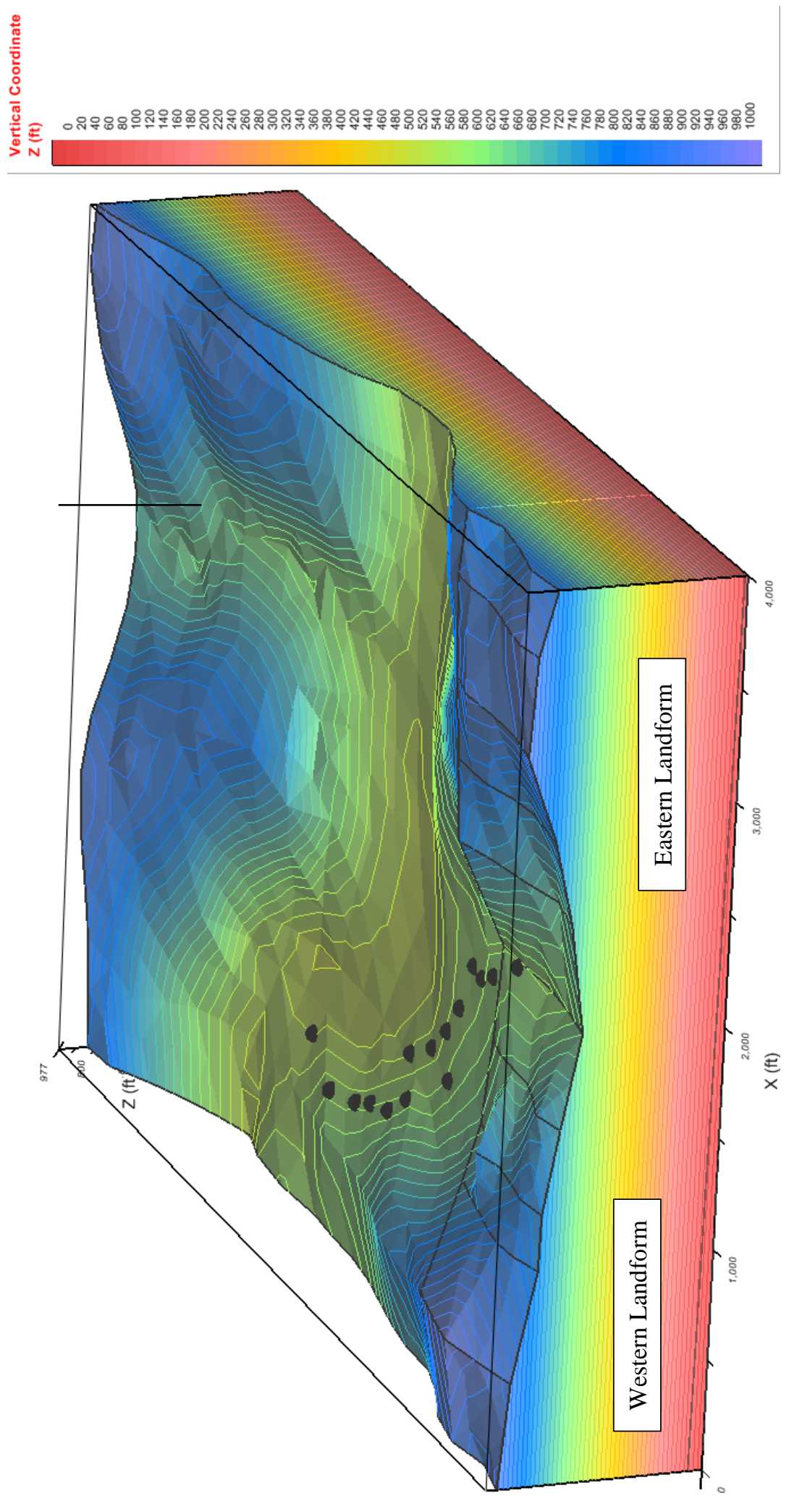

Figure 6.5 3D final model geometry with elevation contours 


\subsubsection{Bedding Plane Surface}

The angle of the coal bed was calculated to be only 0.72 degrees following Table 6.1. This angle was taken into account since the model is very large. The angle was calculated using coal structure contour data in GIS as shown in Figure 6.6. This is the same angle that Gannett Fleming, Inc. found for the other bedding planes in approximately the same orientation as extrapolated from borehole logs as shown in Figure 6.7.

Table 6.1 Bedding plane angle calculation

\begin{tabular}{|l|c|c|c|}
\hline \multicolumn{4}{|c|}{ Coal Seam Angle - Cross Section A-A' } \\
\hline \multicolumn{1}{|c|}{ Pt. Description } & Length (Miles) & Length (ft) & Z (ft) \\
\hline East Pt. 1 & 0.753 & 3975.84 & 450 \\
\hline West Pt. 2 & & & 500 \\
\hline Approx. Seam Angle (Degrees) & \multicolumn{3}{|c|}{0.72} \\
\hline
\end{tabular}

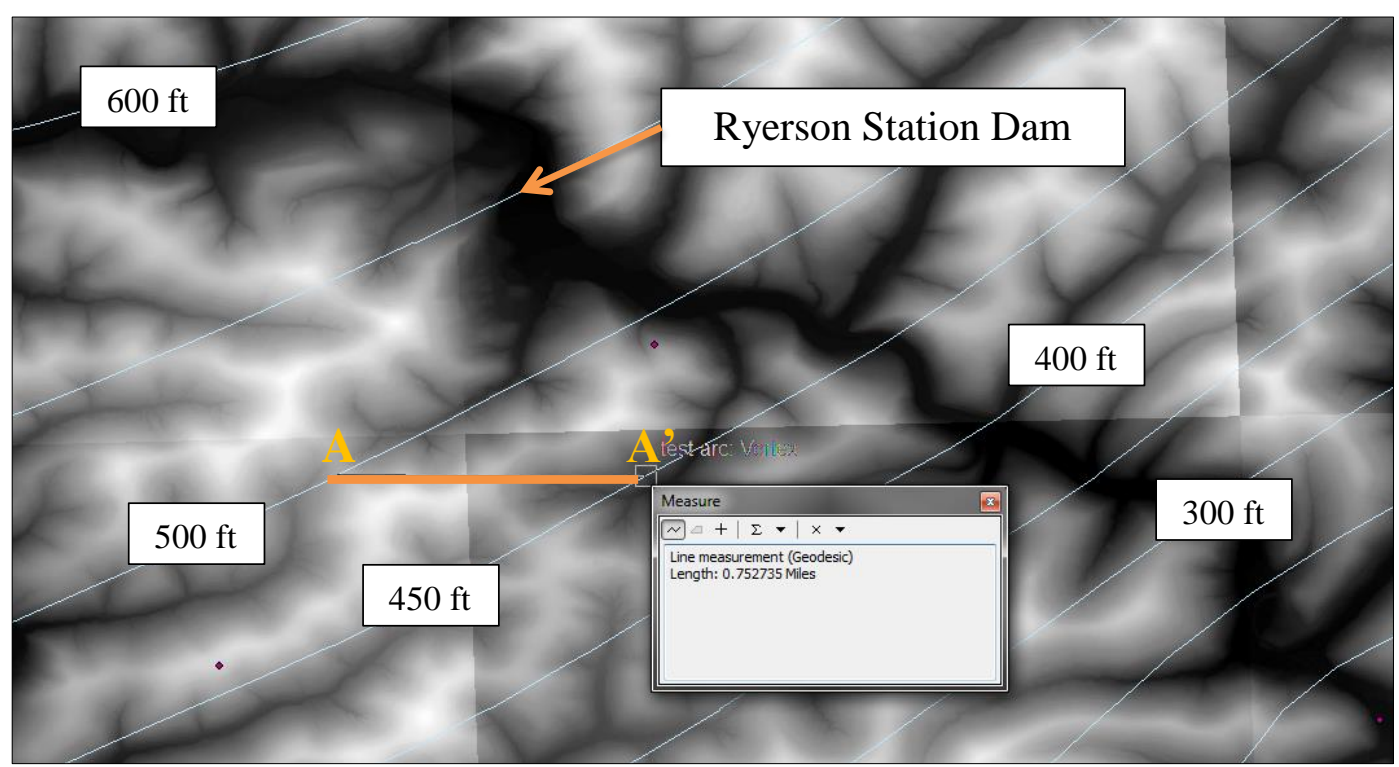

Figure 6.6 Coal bed structure 50 ft. contours at Ryerson Station State Park 


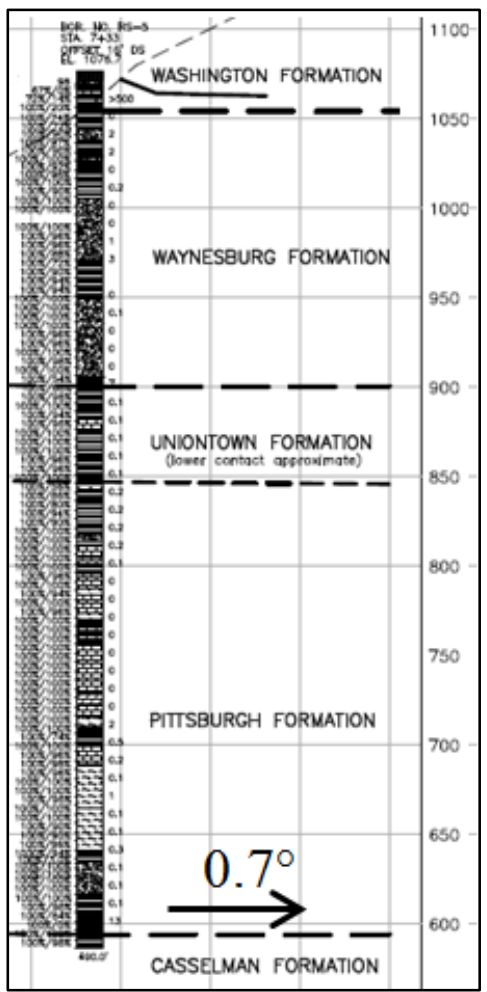

Figure 6.7 Bedding plane angle and major geologic formations at the Ryerson Station Dam valley (PADCNR, 2007)

The bedding plane angle of the coal had to be incorporated into the irregular grid that was established for the model. This was determined by calculating elevation offsets at 0.72 degrees over the width of the model. Table A4 in the Appendix presents the elevation data for the bottom surface of the Pittsburgh coal seam. All dimensions within the model were relative to the model space. Therefore, the bottom of the model was taken as zero elevation, and origin at ( $0 \mathrm{ft}$., $0 \mathrm{ft}$., $0 \mathrm{ft}$.). To avoid pinch-out finite element mesh generation errors, $10 \mathrm{ft}$. was added to the bottom of the model below the coal seam. The coal seam thickness was $>5-6 \mathrm{ft}$. in the area of the Ryerson Station State Park as acquired by USGS mapping. Figure 6.8 shows the regional coal seam thickness. 


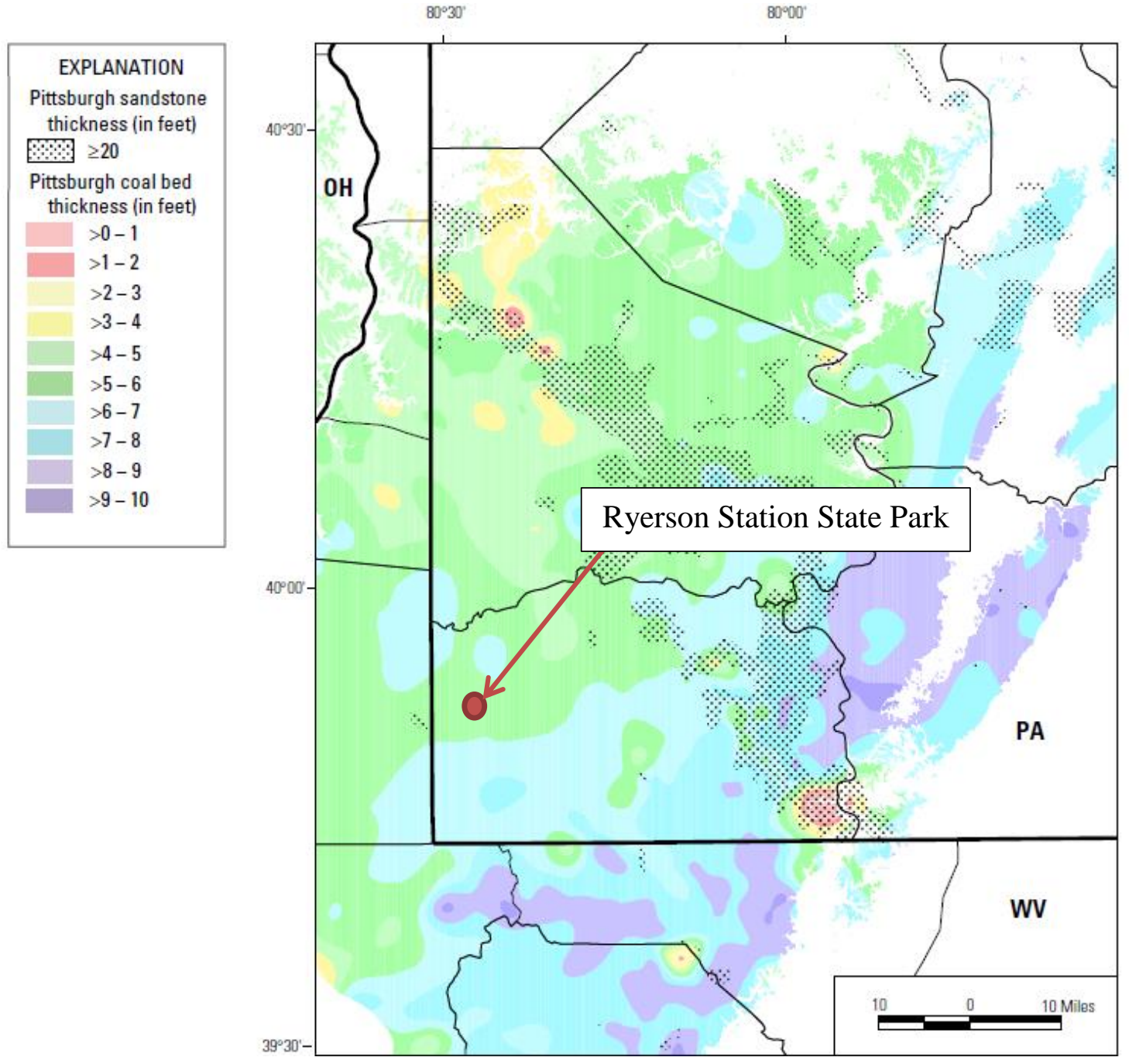

Figure 6.8 Pittsburgh coal bed thickness (USGS, 2000)

The PADEP reported that the maximum extraction thickness at the Bailey Mine was $8.5 \mathrm{ft}$., with an average of $5.8 \mathrm{ft}$. These values were consistent with borehole logs reported by Gannett Fleming, Inc. (PADEP, 2007). The mine void thickness was set to $8.5 \mathrm{ft}$. to simulate the largest seam extraction height. A larger void will result in a greater magnitude of expected ground movement. The extraction height was set to simulate the worst case for ground strain. 


\subsubsection{Panel 7I Extraction Regions}

The modeling approach was to progressively remove coal in the 7I Panel at known times to calibrate to field survey monitoring data. To accomplish this, each time increment of Panel 7I's progression was drawn into the model as a region which could be incorporated as a void space. For model simplicity, each spatial time increment was taken as a model profile along the $\mathrm{X}$ direction of the model. The regions are numbered according to their organization within the model matrix as shown in Figure 6.9. Coal sections are numbered as Region 11 - Region 2, and were removed from right to left (R11 to R2). Table 6.2 provides information regarding the time increments between each extraction region and their associated dates of progression. The total time of simulation was 90 days.

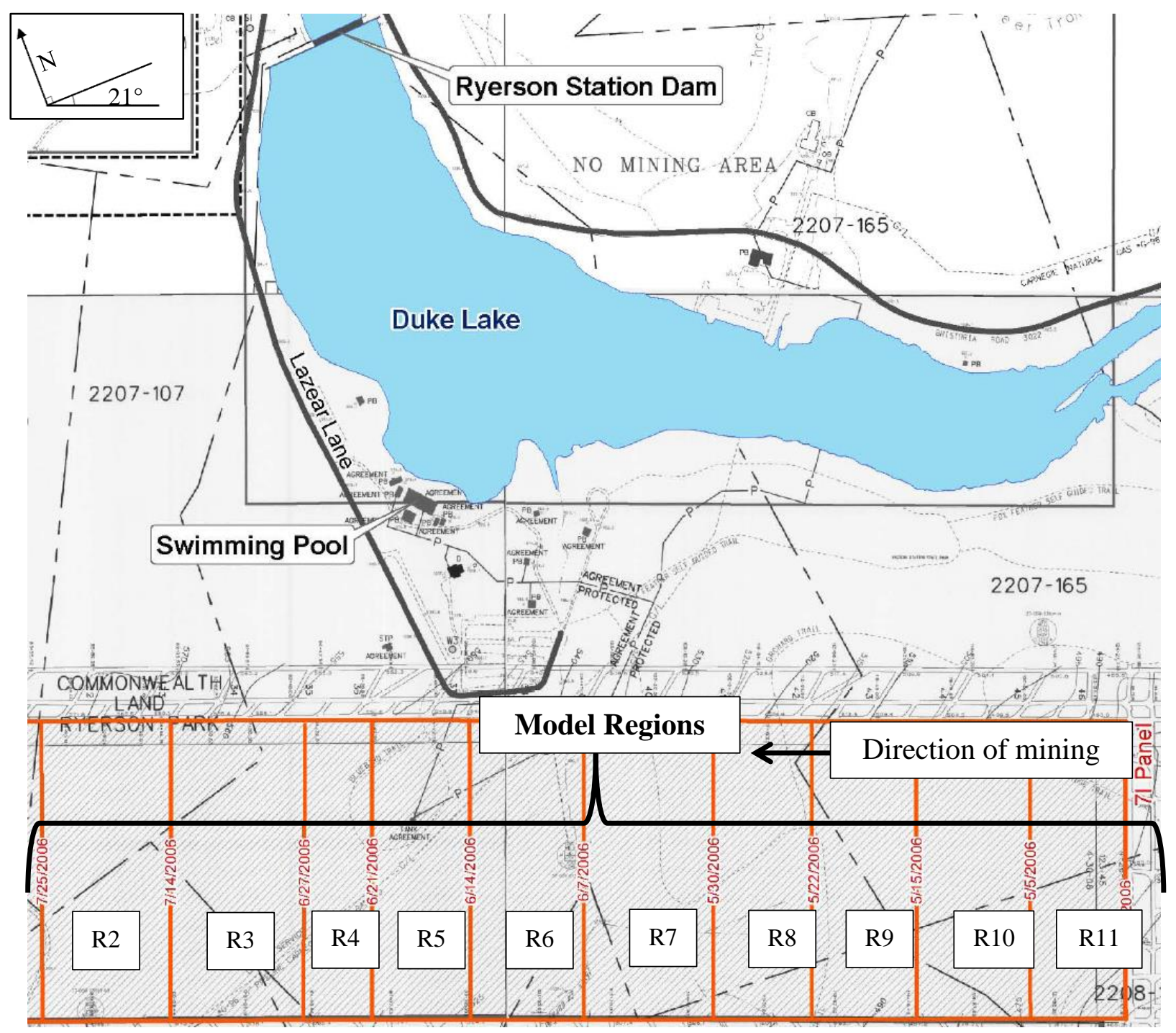

Figure 6.9 Panel 7 I coal extraction regions 
Table 6.2 Extraction region information

\begin{tabular}{|c|c|c|c|}
\hline $\begin{array}{c}\text { Profile } \\
\#\end{array}$ & $\begin{array}{c}\text { Date of Mine } \\
\text { Progress }\end{array}$ & $\begin{array}{c}\text { Distance Between } \\
\text { Progress Points (ft) }\end{array}$ & $\begin{array}{c}\text { Time Between } \\
\text { Progress Points (days) }\end{array}$ \\
\hline $\mathbf{1 1}$ & $4 / 26 / 2006$ & 0 & 0 \\
\hline $\mathbf{1 0}$ & $5 / 5 / 2006$ & 475 & 9 \\
\hline $\mathbf{9}$ & $5 / 15 / 2006$ & 975 & 10 \\
\hline $\mathbf{8}$ & $5 / 22 / 2006$ & 1225 & 7 \\
\hline $\mathbf{7}$ & $5 / 30 / 2006$ & 1600 & 8 \\
\hline $\mathbf{6}$ & $6 / 7 / 2006$ & 2025 & 8 \\
\hline $\mathbf{5}$ & $6 / 14 / 2006$ & 2515 & 7 \\
\hline $\mathbf{4}$ & $6 / 21 / 2006$ & 2890 & 6 \\
\hline $\mathbf{3}$ & $6 / 27 / 2006$ & 3270 & 17 \\
\hline $\mathbf{2}$ & $7 / 14 / 2006$ & 3710 & 11 \\
\hline $\mathbf{1}$ & $7 / 25 / 2006$ & 4000 & $\mathbf{9 0}$ \\
\hline & Total & $\mathbf{4 0 0 0}$ & 7 \\
\hline
\end{tabular}

\subsubsection{Borehole Log Data for Modeling}

The five borehole logs were taken in the area near to the Ryerson Station Dam and Bailey Mine by L.G. Hetager Drilling in 2006 (PADCNR, 2007). These boreholes are labeled RS-1 through RS-6 and their logs are provided in Volume I of the PADCNR reports prepared by Gannett Fleming, Inc. Borehole RS-5 was the highest elevation borehole which included the most rock layers, and was used to establish the strata layering up to elevation $1064.3 \mathrm{ft}$. Since modeling included strata up to the ridgelines, additional borehole logs were needed. The California District Office for the Pennsylvania Department of Environmental Protection provided Revision 71 of the Bailey Mine permit which included the panels that led to the breaching at the Ryerson Station Dam. This document included borehole logs in the area, including Drill Hole DD95 15 which had a top elevation of $1425 \mathrm{ft}$. This borehole was linked to RS-5 at an elevation of 1064.3 $\mathrm{ft}$. and was used to account for the top $361 \mathrm{ft}$. of rock strata.

Layers with the most similar descriptions were combined from compiled borehole log data. The rock layering was simplified to be the most basic while including the coal layer (Bulk -3 layers) stepwise to the most complex that SoilVision ${ }^{\mathrm{TM}}$ would allow (Detail $2-14$ layers). The first iteration of simplicity was approached by combining regions of layering with a detail of minimum thickness of $40 \mathrm{ft}$. for Detail 1. Detail 2 sought to find the most complex geology at the maximum possible 14 layers. The minimum thickness of layering for Detail 2 was $21 \mathrm{ft}$. with the goal of a $20 \mathrm{ft}$. minimum. These layering methods exempted the coal layer which was set to $8.5 \mathrm{ft}$. for all detail levels, the bottom of the model which was set from 10-60.3 ft. at a bedding angle of 0.72 degrees down to a uniform elevation of $0 \mathrm{ft}$., and the topographic layer 
which varied from 11.8-496.8 ft. in thickness. The compiled borehole log data is provided in the Appendix in Table A6.

Table 6.3 Layering for model detail levels

\begin{tabular}{|c|c|c|c|c|c|c|}
\hline \multirow{2}{*}{$\begin{array}{c}\text { Number } \\
\text { of } \\
\text { Layers }\end{array}$} & \multicolumn{2}{|c|}{ Bulk } & \multicolumn{2}{|c|}{ Detail 1} & \multicolumn{2}{|c|}{ Detail 2} \\
\hline & $\begin{array}{l}\text { Rock } \\
\text { Type }\end{array}$ & $\begin{array}{c}\text { Thickness } \\
\text { (ft) }\end{array}$ & $\begin{array}{l}\text { Rock } \\
\text { Type }\end{array}$ & $\begin{array}{c}\text { Thickness } \\
\text { (ft) }\end{array}$ & $\begin{array}{l}\text { Rock } \\
\text { Type }\end{array}$ & $\begin{array}{c}\text { Thickness } \\
\text { (ft) }\end{array}$ \\
\hline 1 & $\begin{array}{l}\mathrm{BC} / \mathrm{WC} \\
\text { Overall }\end{array}$ & 416-901 & Shale & $12-497$ & Shale & $12-497$ \\
\hline 2 & Coal & 8.5 & Sandstone & 105 & Sandstone & 35 \\
\hline 3 & $\begin{array}{l}\mathrm{BC} / \mathrm{WC} \\
\text { Overall }\end{array}$ & 10 & Limestone & 40.3 & Siltstone & 21.3 \\
\hline 4 & - & - & Siltstone & 50.8 & Sandstone & 43.8 \\
\hline 5 & - & - & Limestone & 95.8 & Siltstone & 22.6 \\
\hline 6 & - & - & Siltstone & 112.5 & Limestone & 22.6 \\
\hline 7 & - & - & Coal & 8.5 & Siltstone & 50.8 \\
\hline 8 & - & - & Sandstone & $10-60$ & Limestone & 55.3 \\
\hline 9 & - & - & - & - & Limestone & 40.5 \\
\hline 10 & - & - & - & - & Siltstone & 27.4 \\
\hline 11 & - & - & - & - & Siltstone & 53.6 \\
\hline 12 & - & - & - & - & Sandstone & 31.5 \\
\hline 13 & - & - & - & - & Coal & 8.5 \\
\hline 14 & - & - & - & - & Siltstone & $10-60$ \\
\hline
\end{tabular}

\subsubsection{Geologic Input Parameters}

Laboratory testing for rock parameters were provided in Volume I of the PADCNR reports investigating the events leading to the Ryerson Station Dam breach. Compressive strength and direct shear strength tests were conducted on representative samples of rock taken from rock corings. These tests were performed on the predominant rock types found in the borehole including coal, sandstone, shale, siltstone, and limestone. Unconfined compressive strength was determined via ASTM D3148 on 21 rock samples. Direct shear testing was determined on 27 samples in accordance with the International Society for Rock Mechanics (ISRM) Suggested Method for Determining Shear Strength.

Geologic parameters reported for the rock and overburden soil included modulus of elasticity $(E)$, volumetric unit weight $(\gamma)$ and Poisson's Ratio $(v)$, unconfined compressive strength, peak friction angle, and residual friction angle. The thickness of each bed was modeled with uniform thickness. Model materials were incorporated to be homogeneous and isotropic. SVSolid ${ }^{\mathrm{TM}}$ required only the input of the modulus of elasticity, unit weight, Poisson's ratio, and void ratio. 
The void ratio was determined from the mathematical relationship to porosity. Equation 6.1 provides the relationship that was used to calculate the void ratio from porosity.

Equation $6.1 \quad e=\frac{n}{1-n}$

where,

$\mathrm{n}$ is porosity

e is void ratio

Porosity values were determined from literature for each rock type since site specific laboratory testing for porosity was not available. These values were obtained from McWhorter \& Sunada, 1977; Freeze \& Cherry, 1979; Jaeger, Cook, \& Zimmerman, 2009; and Mastalerz, He, Melnichenko, \& Rupp, 2012.

Parameters were selected depending on the maximum or minimum of each parameter; whichever would yield the greatest/least deformation. Best Case (BC) parameters were selected to simulate a strong rock case based on their potential to minimize model resultant deformations. Worst Case (WC) parameters were selected as a weak rock case based on their potential to maximize model resultant deformations. This concept constitutes the Best Case (BC) and Worst Case (WC) for each rock type. Table 6.4 provides the BC and WC input parameters. These parameters were summarized from laboratory testing reports provided in the PADCNR Volume I Investigative Report and from literature. Table A7 in the Appendix provides the compiled data. The Poisson's Ratio for shale was determined by laboratory testing to be 0.51 . SVSolid ${ }^{\mathrm{TM}}$ allows for a maximum of 0.495 , which was the applied input value. Best Case (BC) porosity for limestone and shale was found to be 0.00 , however SVSolid ${ }^{\mathrm{TM}}$ does not allow this value to be input for void ratio. The value used was selected as a small value of $0.01(1 \%)$. All other values fell within the acceptable range allowed in SVSolid ${ }^{\mathrm{TM}}$. 
Table 6.4 Best Case (BC) and Worst Case (WC) parameters

\begin{tabular}{|c|c|c|c|c|c|c|}
\hline \multicolumn{2}{|c|}{ Input Parameters } & Sandstone & Siltstone & Limestone & Shale & Coal \\
\hline \multirow{5}{*}{$\begin{array}{c}\text { Best } \\
\text { Case } \\
\text { Value } \\
\text { (BC) }\end{array}$} & $\begin{array}{l}\text { Poisson's } \\
\text { Ratio, v }\end{array}$ & 0.05 & 0.25 & 0.19 & 0.24 & 0.30 \\
\hline & $\begin{array}{c}\text { Modulus } \\
\text { of } \\
\text { Elasticity, } \\
\text { E (psf) }\end{array}$ & $8.00640 \mathrm{E}+08$ & $3.51360 \mathrm{E}+08$ & $1.35072 \mathrm{E}+09$ & $3.26880 \mathrm{E}+08$ & $1.03680 \mathrm{E}+08$ \\
\hline & Porosity, n & $0.05(5 \%)$ & $0.21(21 \%)$ & $0.01(1 \%)$ & $0.01(1 \%)$ & $0.10(10 \%)$ \\
\hline & $\begin{array}{c}\text { Initial } \\
\text { Void } \\
\text { Ratio, e }\end{array}$ & 0.05 & 0.27 & 0.01 & 0.01 & 0.11 \\
\hline & $\begin{array}{c}\text { Unit } \\
\text { Weight, } \gamma \\
\left(\mathbf{l b} / \mathbf{f t}^{3}\right)\end{array}$ & 146.50 & 166.60 & 166.30 & 136.90 & 98.80 \\
\hline \multirow{5}{*}{$\begin{array}{l}\text { Worst } \\
\text { Case } \\
\text { Value } \\
\text { (WC) }\end{array}$} & $\begin{array}{l}\text { Poisson's } \\
\text { Ratio, v }\end{array}$ & 0.16 & 0.26 & 0.30 & 0.51 & 0.30 \\
\hline & $\begin{array}{c}\text { Modulus } \\
\text { of } \\
\text { Elasticity, } \\
\text { E (psf) }\end{array}$ & $1.72800 \mathrm{E}+08$ & $1.09440 \mathrm{E}+08$ & $5.14080 \mathrm{E}+08$ & $1.33920 \mathrm{E}+08$ & $1.03680 \mathrm{E}+08$ \\
\hline & Porosity, n & $0.49(49 \%)$ & $0.41(41 \%)$ & $0.30(30 \%)$ & $0.24(24 \%)$ & $0.11(11 \%)$ \\
\hline & $\begin{array}{c}\text { Initial } \\
\text { Void } \\
\text { Ratio, e }\end{array}$ & 0.96 & 0.69 & 0.43 & 0.32 & 0.13 \\
\hline & $\begin{array}{c}\text { Unit } \\
\text { Weight, } \gamma \\
\left(\mathbf{l b} / \mathbf{f t}^{3}\right)\end{array}$ & 161.40 & 169.30 & 170.70 & 165.10 & 98.80 \\
\hline
\end{tabular}

SVSolid ${ }^{\mathrm{TM}}$ does not require a preset decrease in material strengths within the angle of draw nor account for the zones of fracturing including caved, fractured, dilated, and surface following the North American method (Kendorski, 1993). SVSolid ${ }^{\mathrm{TM}}$ acts to respond to a load on a mass of material. The mine void is the stimulus for the material to have a stress and deformation response. The best and worst case parameters in Table 6.4 contain the field measured deformations within the model response range. Table 6.5 provides organized rationale for the selection of $\mathrm{BC}$ and $\mathrm{WC}$ parameters. 
Table 6.5 Best Case (BC) and Worst Case (WC) parameter rationale

\begin{tabular}{|c|c|c|c|}
\hline \multicolumn{2}{|c|}{ Input Parameters } & Choice & Reasoning \\
\hline \multirow{5}{*}{$\begin{array}{l}\text { Best } \\
\text { Case } \\
\text { Value } \\
(\text { BC) }\end{array}$} & $\begin{array}{l}\text { Poisson's } \\
\text { Ratio, v }\end{array}$ & $\begin{array}{l}\text { Lowest } \\
\text { Value }\end{array}$ & $\begin{array}{l}v \text { is (lateral strain/axial strain). Lower } v \text { means higher } \\
\text { proportion of axial strain to lateral strain. This would result in } \\
\text { lower magnitude downhill movements }\end{array}$ \\
\hline & $\begin{array}{l}\text { Modulus of } \\
\text { Elasticity, E } \\
\quad(\text { psf })\end{array}$ & $\begin{array}{l}\text { Highest } \\
\text { Value }\end{array}$ & $\begin{array}{l}\mathrm{E} \text { is (stress/strain). Higher value will result in higher resistance } \\
\text { of material to strain under applied stress. This will result in } \\
\text { lower magnitudes of deformation. }\end{array}$ \\
\hline & Porosity, n & $\begin{array}{l}\text { Lowest } \\
\text { Value }\end{array}$ & $\begin{array}{l}\text { Porosity is the (volume of voids/total volume). The lower } n \text {, the } \\
\text { smaller proportion of voids to the total volume. This would } \\
\text { result in lower deformation magnitudes. }\end{array}$ \\
\hline & $\begin{array}{l}\text { Initial Void } \\
\text { Ratio, e }\end{array}$ & $\begin{array}{l}\text { Lowest } \\
\text { Value }\end{array}$ & $\begin{array}{l}\text { Void ratio is the (volume of voids/volume of solids). The lower } \\
\text { e, the smaller the proportion of voids to the volume of solids. } \\
\text { This would result in lower deformation magnitudes. }\end{array}$ \\
\hline & $\begin{array}{c}\text { Unit Weight, } \\
\gamma\left(\mathbf{l b} / \mathbf{f t}^{3}\right)\end{array}$ & $\begin{array}{l}\text { Lowest } \\
\text { Value }\end{array}$ & $\begin{array}{l}\text { Lower value of unit weight would result in lower stresses } \\
\text { induced on the landform. This would result in lower } \\
\text { magnitudes of deformation. }\end{array}$ \\
\hline \multirow{5}{*}{$\begin{array}{l}\text { Worst } \\
\text { Case } \\
\text { Value } \\
\text { (WC) }\end{array}$} & $\begin{array}{c}\text { Poisson's } \\
\text { Ratio, v }\end{array}$ & $\begin{array}{l}\text { Highest } \\
\text { Value }\end{array}$ & $\begin{array}{l}v \text { is (lateral strain/axial strain). Higher } v \text { means lower } \\
\text { proportion of axial strain to lateral strain. This would result in } \\
\text { higher magnitude downhill movements }\end{array}$ \\
\hline & $\begin{array}{l}\text { Modulus of } \\
\text { Elasticity, E } \\
\quad(\text { psf })\end{array}$ & $\begin{array}{l}\text { Lowest } \\
\text { Value }\end{array}$ & $\begin{array}{l}\mathrm{E} \text { is (stress/strain). Lower value will result in lower resistance } \\
\text { of material to strain under applied stress, increasing ground } \\
\text { movement. }\end{array}$ \\
\hline & Porosity, n & $\begin{array}{l}\text { Highest } \\
\text { Value }\end{array}$ & $\begin{array}{l}\text { Porosity is the (volume of voids/total volume). The higher } n \text {, } \\
\text { the larger proportion of voids to the total volume. This would } \\
\text { result in higher deformation magnitudes. }\end{array}$ \\
\hline & $\begin{array}{c}\text { Initial Void } \\
\text { Ratio, e }\end{array}$ & $\begin{array}{l}\text { Highest } \\
\text { Value }\end{array}$ & $\begin{array}{l}\text { Void ratio is the (volume of voids/volume of solids). The higher } \\
\text { e, the larger the proportion of voids to the volume of solids. } \\
\text { This would result in higher deformation magnitudes. }\end{array}$ \\
\hline & $\begin{array}{l}\text { Unit Weight, } \\
\gamma\left(\mathbf{l b} / \mathbf{f t}^{3}\right)\end{array}$ & $\begin{array}{l}\text { Highest } \\
\text { Value }\end{array}$ & $\begin{array}{l}\text { Higher value of unit weight would result in higher stresses } \\
\text { induced on the landform. This would result in higher } \\
\text { magnitudes of deformation. }\end{array}$ \\
\hline
\end{tabular}

\subsubsection{Monitoring Points}

The most complete long term data that was recorded at the Ryerson Station State Park site near the dam were survey points along the western rim of the empty reservoir. These points are presented in Figure 6.10. These survey points were installed as punch marks set in concrete and steel rods set throughout Ryerson Station State Park. The equipment used for monitoring had a tolerance of $\pm 0.015 \mathrm{ft}$. for vertical movements. 


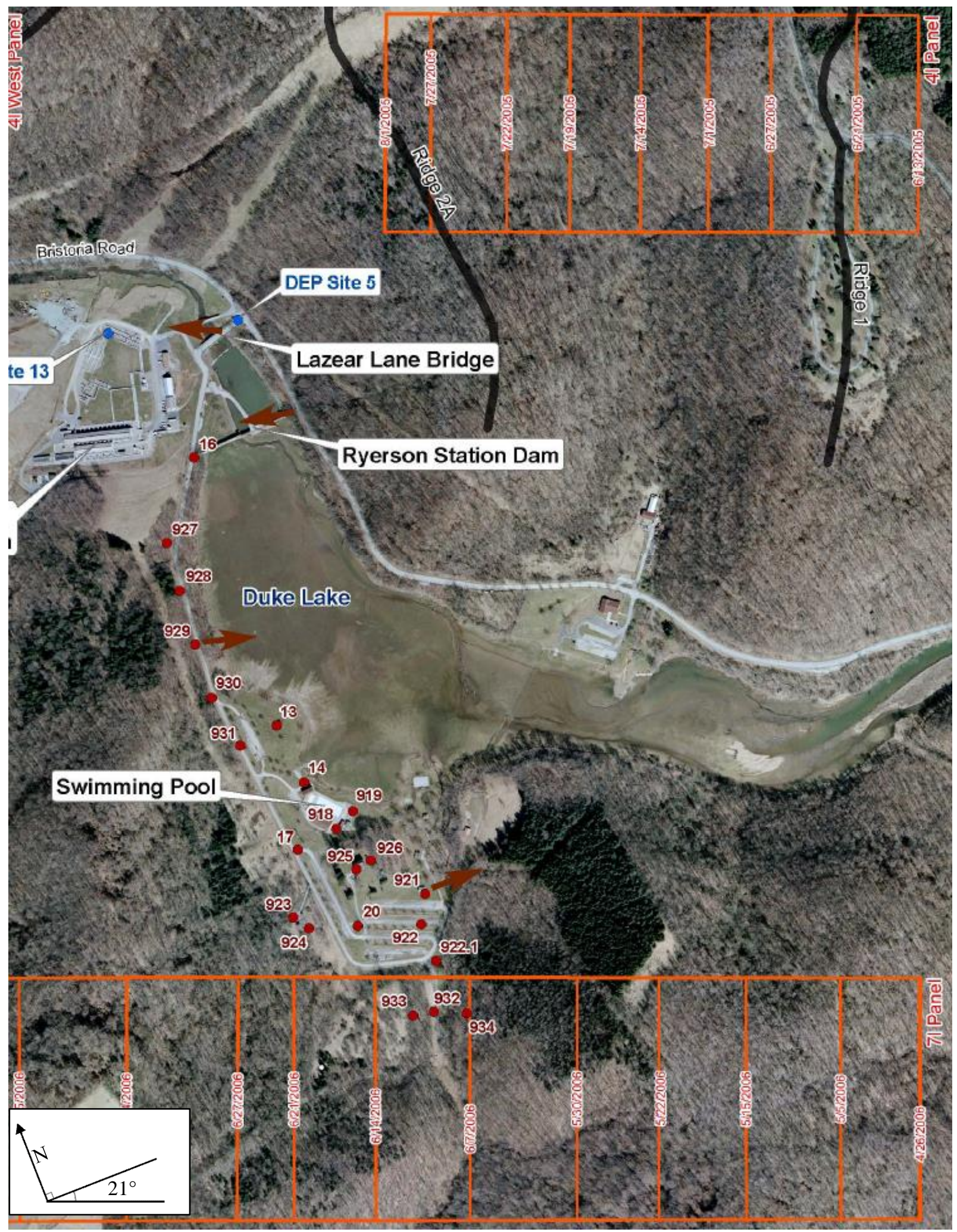

Figure 6.10 Survey point locations 
A subset of survey monitoring points was investigated depending on their uniqueness with respect to slope angle and point-to-ridge distance. These two survey point characteristics were thought to have influence on the loading at each point. The characteristics were found for each of 22 survey monitoring stations. Additionally, this subset of points represents the nearest point to the panel and the furthest as well as 13 points between the extents. Table 6.6 presents the determination of survey stations to be considered for calibration and sensitivity analysis denoted by an " $\mathrm{X}$ " selection in the left column. Colors were included to easily determine likeness and differences for each survey monitoring point.

Table 6.6 Survey monitoring points along western rim of Duke Lake

\begin{tabular}{|c|c|c|c|}
$\begin{array}{c}\# \\
\text { Graphs }\end{array}$ & Point ID & $\begin{array}{c}\text { Avg. Slope } \\
\text { (degrees) }\end{array}$ & $\begin{array}{c}\text { Point-to-Ridge } \\
\text { (ft) }\end{array}$ \\
\hline$X$ & 934 & 14 & 345 \\
\hline & 932 & 14 & 340 \\
\hline$X$ & 933 & 14 & 340 \\
\hline$X$ & 922.1 & 13 & 315 \\
\hline & 922 & 13 & 380 \\
\hline$X$ & 20 & 13 & 420 \\
\hline & 921 & 13 & 430 \\
\hline & 923 & 13 & 430 \\
\hline & 924 & 13 & 430 \\
\hline$X$ & 925 & 13 & 430 \\
\hline$X$ & 926 & 13 & 430 \\
\hline$X$ & 17 & 15 & 350 \\
\hline & 918 & 15 & 350 \\
\hline$X$ & 919 & 15 & 350 \\
\hline$X$ & 14 & 16 & 290 \\
\hline$X$ & 13 & 17 & 230 \\
\hline$X$ & 931 & 17 & 230 \\
\hline$X$ & 930 & 18 & 160 \\
\hline$X$ & 929 & 15 & 100 \\
\hline$X$ & 928 & 10 & 90 \\
\hline$X$ & 927 & 8 & 70 \\
\hline & 16 & 5 & \\
\hline & & & 40 \\
\hline
\end{tabular}

All geometry within the model was derived to be relative to the model with a Cartesian $(0,0,0)$ coordinate as the origin. The survey point data was also derived into relative coordinates for the model to be input into SVSolid ${ }^{\mathrm{TM}}$. This means that although each geometric point within the model was relative to the $(0,0,0)$ origin rather than defined by its coordinates, Northing and Easting, etc. Figure 6.11 presents a 2D illustration of the survey points as they were input into the modeling. Figure 6.12 presents a 3D image of the survey points. The 3D points are 
represented as spheres. Each sphere's midpoint was adjusted manually to be just below the ground surface as it was interpolated between grid points.

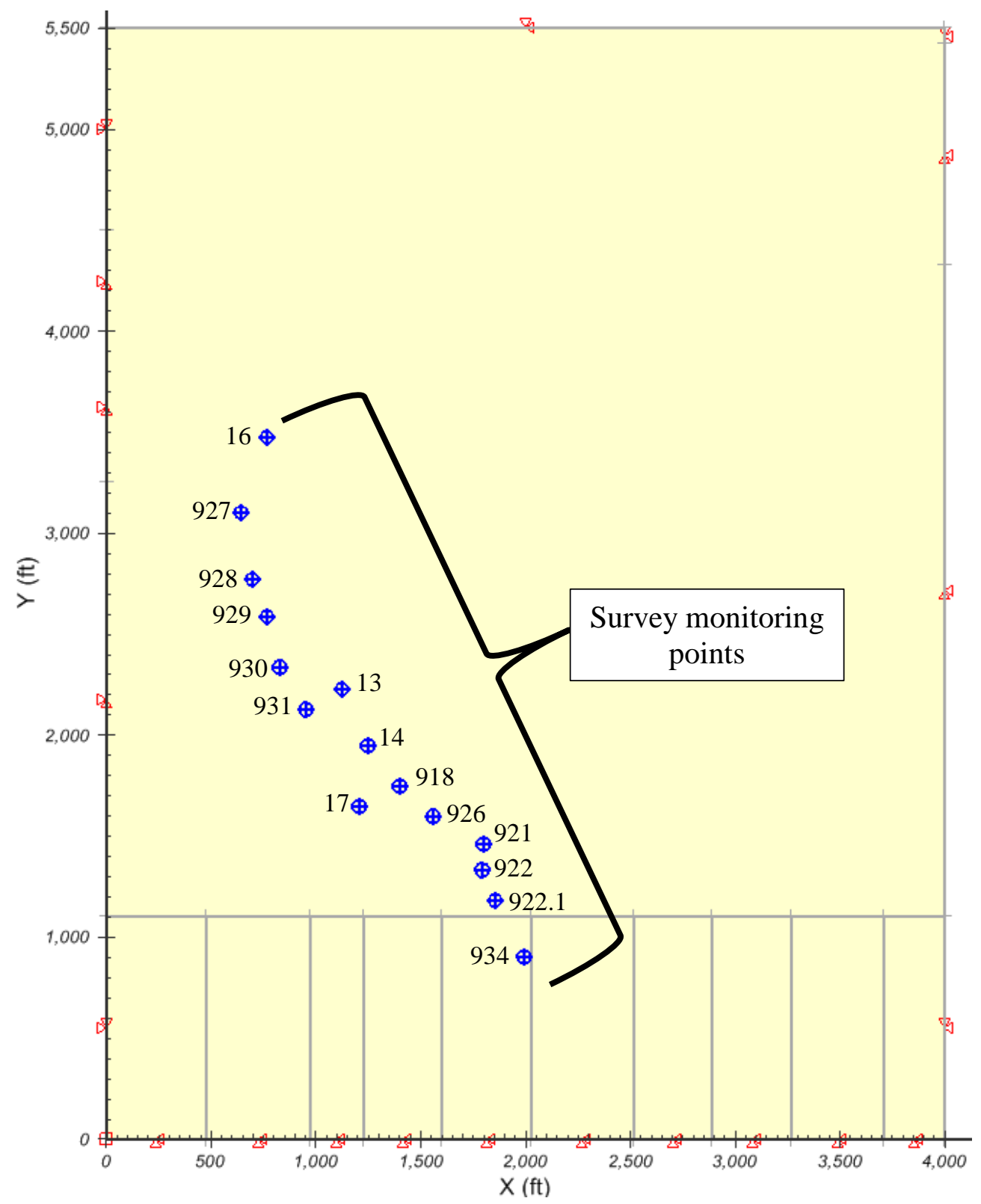

Figure $6.112 \mathrm{D}$ representation of survey monitoring points 


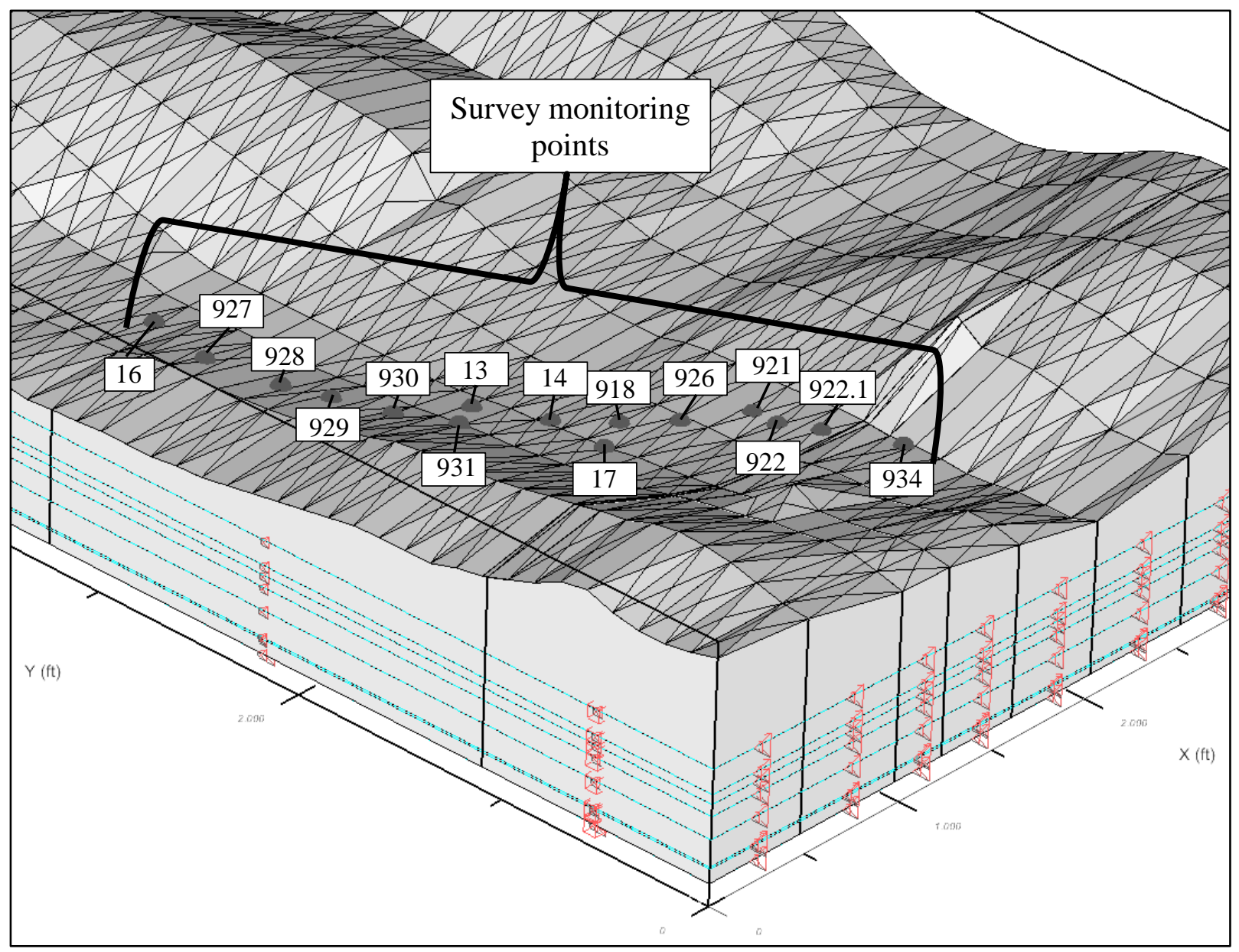

Figure $6.123 D$ view of survey monitoring points

Gannett Fleming, Inc. implemented extensometers, inclinometers, and survey gauges on the dam in the monitoring and instrumentation plan at the Ryerson Station Dam site. Those instruments had plots available, but no raw data was able to be acquired neither by the PADEP nor Gannett Fleming, Inc. for use in this research. Since the survey point data plots were decipherable within a high level of precision, data was available in the $\mathrm{X}, \mathrm{Y}$, and $\mathrm{Z}$ direction at varying distances from the mine, and data was recorded over a significant amount of time, they were used in lieu of the other instrument data. Figure 6.13 and Figure 6.14 show two of the plots that were used to extract field recorded data for calibration. The remainder of the plots that were used can be found in the Appendix in Figure A1, Figure A2, and Figure A3. The X and Y data were measured with an Engineer's scale with precision at one-tenth of an inch. The map used to acquire surface data used a scale of $1{ }^{\prime \prime}=500$ '. Since the vector plots were geosynchronous, the measurements were corrected to the 21 degree offset of the modeling. This step was important to correctly orient $\mathrm{X}$ and $\mathrm{Y}$ vectors with resultant model stress and deformation. 


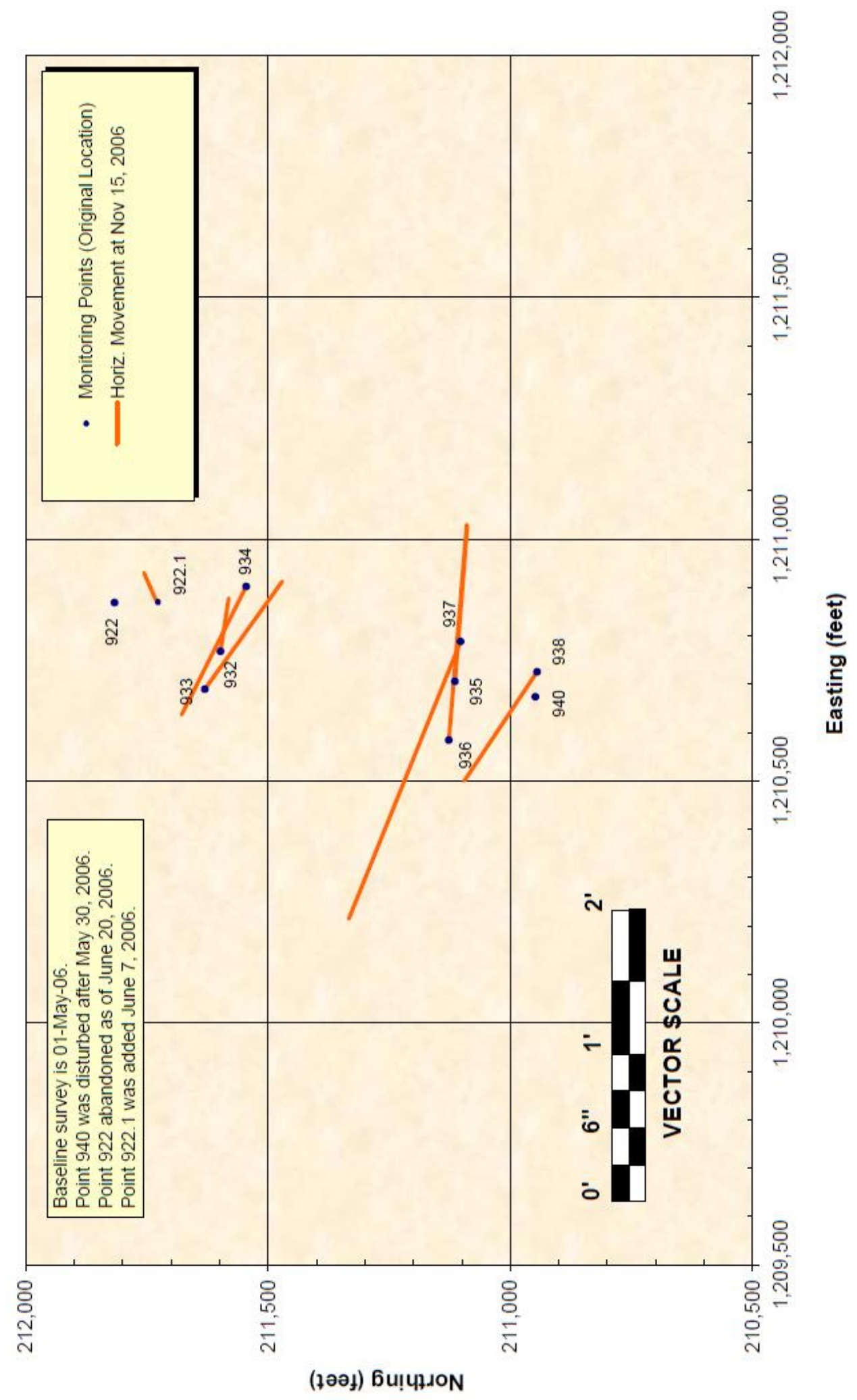

Figure $6.13(X, Y)$ vector data plots for Duke Lake western rim survey points (PADCNR, 2007) 


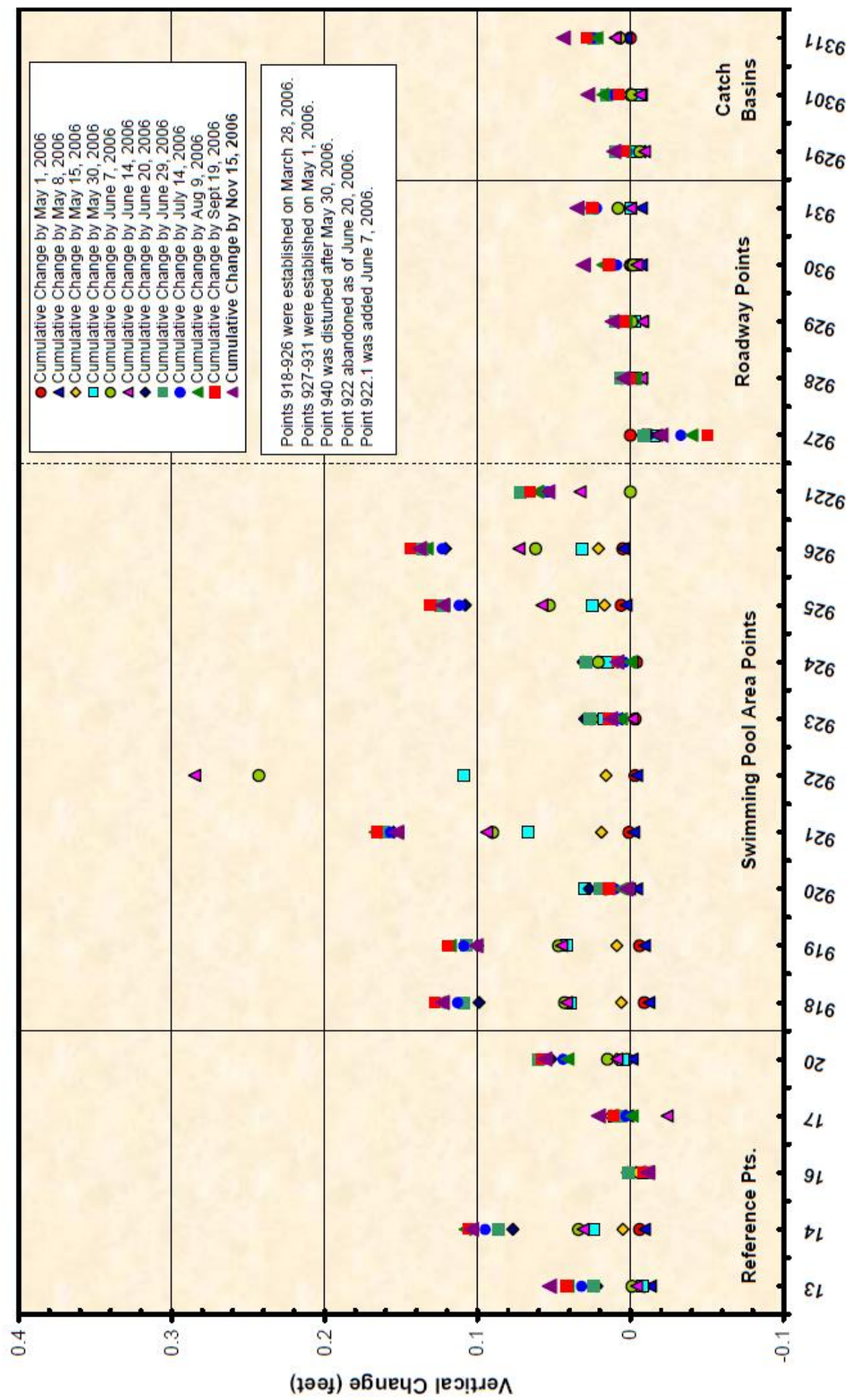

Figure 6.14 Elevation (Z) change data for Duke Lake western rim survey points (PADCNR, 2007) 


\subsubsection{Boundary Conditions}

SVSolid ${ }^{\text {TM }}$ 3D modeling required a number of boundary conditions to be defined in the modeling. These consisted of surface deformation boundary conditions in the $\mathrm{X}, \mathrm{Y}$, and $\mathrm{Z}$ direction as well as sidewall deformation boundary conditions in the $\mathrm{X}, \mathrm{Y}$, and $\mathrm{Z}$ directions for each region. The modeling for Panel 7I consisted of 11 regions at 3 levels of detail including 3 layer, 8-layer, and 14-layer model cases. Each region boundary within the model was set to free on all sides and surface except for those sidewalls of the region which shared a common boundary with the entire model. Additionally, the bottom surface of the model was fixed in the $\mathrm{Z}$ direction everywhere to simulate a no-movement condition with adjacent strata. All other surface boundary conditions were set as free in the $X, X$, and $Z$ directions. Sidewall boundary conditions were fixed in the $\mathrm{X}$ and $\mathrm{Y}$ directions and free in the $\mathrm{Z}$ direction. The $\mathrm{Z}$ direction was fixed on R2 (Figure 6.9) along the left model edge to simulate the adjacent strata that exists in the field which would resist some movement in the $\mathrm{Z}$ direction. Without this fixed condition in $\mathrm{R} 2$, model results were overestimated as the mine roof acted as a cantilever beam with no resistance along its edges to displacement in the $\mathrm{Z}$ direction. No stress boundary conditions were defined. In general, model stresses resulted from the geometry of the topography and the unit weight of each layer. Figure 6.15 shows the model set up with respect to 3D boundary conditions.

\subsubsection{Model Limitations}

Numerical modeling was used as a mathematical idealization to simulate far-field ground strain. Thus, limitations are necessary to be addressed which may affect model results. The major limitations of the numerical modeling method are listed and discussed in this section.

1. Residual tectonic in situ stress causes landforms to be stressed in their natural state, perhaps to critical magnitude. Strains in Appalachia ranges from 300 to 550 micro strains, but have been measured locally from 700 to 1000 micro strains (Dolinar, 2003). Valley movements would be exacerbated in cases where in situ stresses are of significant magnitude.

- The model approach did not incorporate stress boundary conditions to simulate in situ stress conditions. Rather, in situ stresses were simulated by initial gravity body load stresses. These initial stresses were included as the in situ stress condition. Initial deformations were subtracted from subsequent model runs.

2. A linear elastic model was used. The mechanisms that lead to valley closure appear to be brittle rock failure on a local scale. Dilatancy of valley walls has been cited as a mechanism of valley closure (Mills, 2011). Dilatancy is defined by Mills, 2011 as a volume increase observed in the elastic range prior to rock failure, but also refers to macroscale ground movements on irregular fracture surfaces, and is sensitive to confining 
pressure. In sloping terrain, there is no confinement in the direction of the valley, and result in downhill movements.

3. The model approach was to use a very large model (5,500 ft. x 4,000 ft. x $1000 \mathrm{ft}$.$) and$ define stratigraphy as linear elastic following the testing method (ASTM D 3148) to establish the modulus of elasticity (E) and Poisson's Ratio (v) of rock using site bore hole $\operatorname{logs}$.

4. The linear elastic model was not able to accommodate some field effects that occur in valleys due to far-field ground strain. These include:

i. Bedding plane slippage

ii. Bedding plane separation

iii. Thrust faults

iv. Stratigraphic interface interactions

v. Rock fracture networks

5. The model approach was to select input parameters which simulate a weak rock case and a strong rock case. The intent was to calibrate the linear elastic strata to its weakened state using a range of site specific input parameters. Acquisition of parameters and the outcomes are discussed in Section 6.4. 


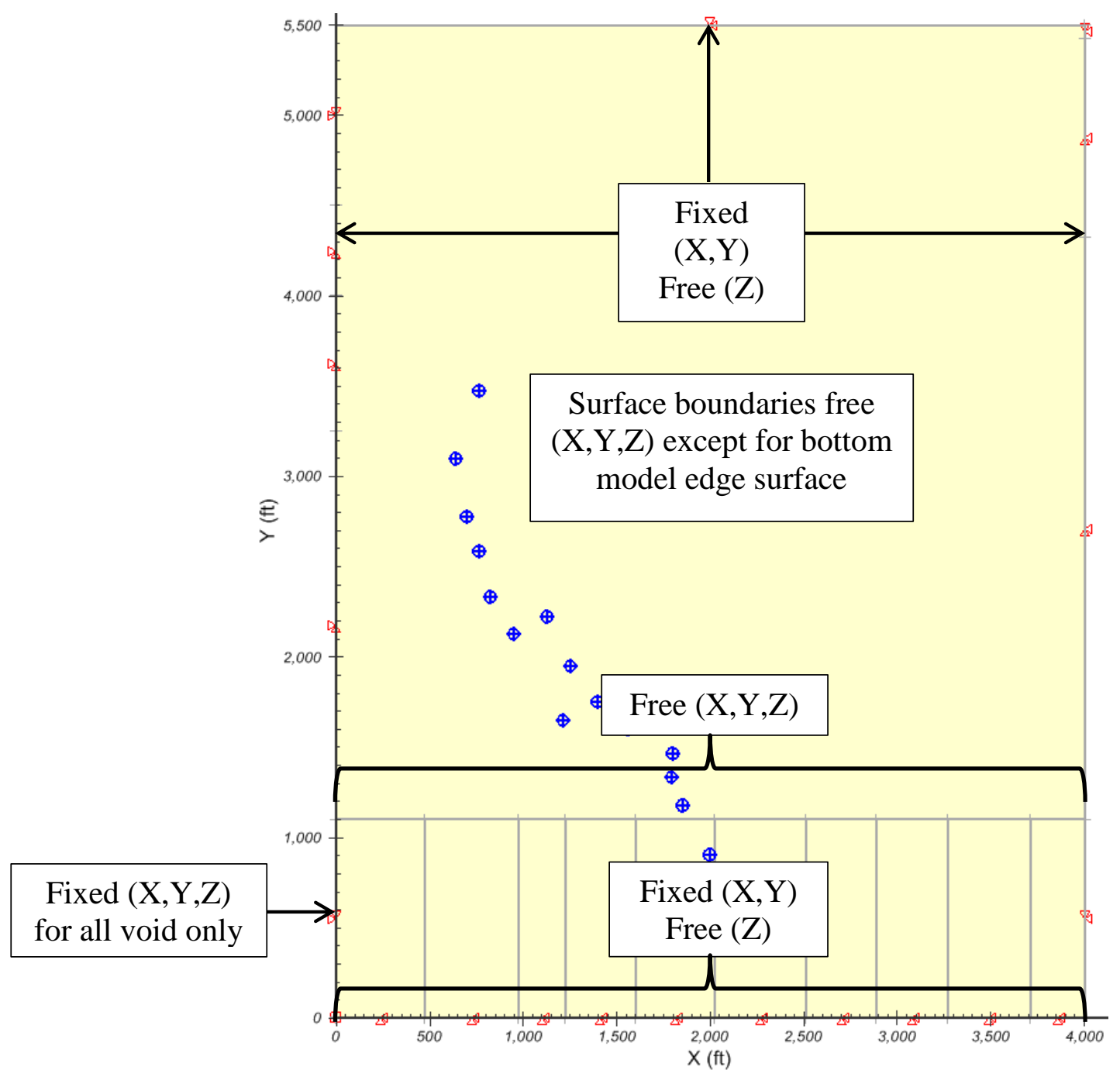

Figure $6.153 D$ sidewall and surface boundary conditions

\subsection{Model Calibration}

Calibration of the numerical modeling was imperative to validate the solution approach, and to answer key questions about what is required to achieve meaningful modeling results. SVSolid ${ }^{\mathrm{TM}}$ allows the freedom to create 3D models with high complexity. A balance of model precision, software capability, and reasonable model run times needed to be known to carry out the modeling analyses. Three levels of detail were chosen, including the most basic case (Bulk Analysis), and 2 progressively complex levels of detail, up to the software maximum. All three levels of detail had an identical topographic surface, but varied in stratigraphy. Monitoring points of interest discussed in Section 6.3.3 were utilized to calibrate model data to field measured data. Field measured data in the $\mathrm{Z}$ direction was available for several recording times while $\mathrm{X}$ and $\mathrm{Y}$ data were only available for 2 points. As a result, only $\mathrm{Z}$ data was used for calibration. Three monitoring points were investigated for calibration. Stations 934, 931, and 16 were investigated as 934 resides over Panel 7I, station 931 is approximately at the midpoint in 
offset distance to the maximum offset at Station 16. Best case (BC) and worst case (WC) input parameters were chosen for each of the 10 coal regions. Table 6.7 provides the modeling matrix that was used to perform the calibration.

\section{Table 6.7 Calibration modeling matrix}

\begin{tabular}{|l|c|c|}
\hline \multicolumn{1}{|c|}{ Bulk Model/Detail 1/Detail 2 } & Profiles & Number of Models \\
\hline No Void Calibration - In situ/Best Case Properties & - & 3 \\
\hline No Void Calibration - In situ/Worst Case Properties & - & 3 \\
\hline Best Case Properties Coal Removal 7I & 11 & 30 \\
\hline Worst Case Properties Coal Removal 7I & 11 & 30 \\
\hline \multicolumn{2}{|r|}{ Total Model Cases: } & $\mathbf{6 6}$ \\
\hline
\end{tabular}

Once an adequate level of detail was reached, correlation plots of important parameters were graphed versus stress in the $\mathrm{X}, \mathrm{Y}$, and $\mathrm{Z}$ directions. Closest point offsets per 7I increment and slope angles were calculated. Determination of root causes through a sensitivity analysis is intended to provide insight into a RCA development and provide calibrated stress/strain/deformation results in the $\mathrm{X}, \mathrm{Y}$, and $\mathrm{Z}$ direction for the 15 survey monitoring stations.

A measure of correlation between the sets of data needed to be satisfied to determine how well the model data matched the field data. Pearson's Correlation Coefficient (PCC) was chosen to represent the relationship in the data sets due to the convenience of interpretation of the range $(-1$ to +1$)$. PCC is a measure of the linear relationship between two variables and is denoted by the lowercase ' $r$.' This value ranges between -1 and +1 . An $r$ value of -1 indicates a perfect negative linear relationship while a value of +1 indicates a positive perfectly linear relationship. An $r$ value of 0 indicates no linear relationship between the two variables or data sets (LeBlanc, 2004). Figure 6.16 shows illustrations of the degree of correlation in two sets of data. Equation 6.2 was used to calculate PCC.

\section{Equation 6.2}

$$
r=\frac{\left(\sum n \sum x y\right)-\left(\sum x \sum y\right)}{\left(\sqrt{\sum n \sum x^{2}-\left(\sum x\right)^{2}}\right) *\left(\sqrt{\sum n \sum y^{2}-\left(\sum y\right)^{2}}\right)}
$$

where,

$\mathrm{n}$ is the number of data points

$\mathrm{x}$ is the field data values

$\mathrm{y}$ is the model data values 

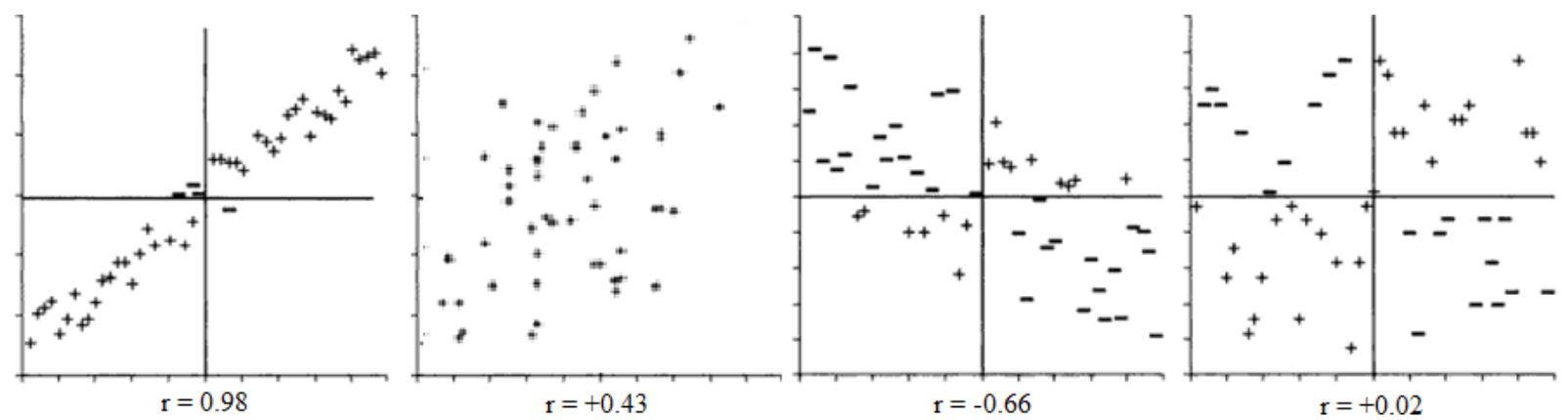

Figure 6.16 Linear correlations of two data sets (LeBlanc, 2004)

\subsubsection{Bulk Analysis (3 Layer Model)}

A three-layer model was chosen as the first calibration modeling suite to be run. This case was the least complex, and included Best Case and Worst Case overall properties, rather than the selection of specific rock properties for each layer. Table 6.8 presents the $\mathrm{BC}$ and $\mathrm{WC}$ properties taken from Table 6.4. Three stations $(934,931$, and 16$)$ were chosen to be investigated using the Bulk Analysis layering scheme. Table 6.9 provides the layer thickness and number of layers for the Bulk Analysis. Figure 6.16 shows the layering within the Bulk Analysis models.

Table 6.8 Overall BC and WC properties for the Bulk Analysis

\begin{tabular}{|c|c|c|c|}
\hline \multicolumn{4}{|c|}{ Overall Best/Worst for Bulk Analysis } \\
\hline \multicolumn{2}{|c|}{ Input Parameters } & Rock & Choice \\
\hline \multirow{5}{*}{$\begin{array}{c}\text { Best Case Value } \\
\text { (BC) }\end{array}$} & Poisson's Ratio, v & 0.05 & Lowest Value \\
\hline & Modulus of Elasticity, E (psf) & $1.35072 \mathrm{E}+09$ & Highest Value \\
\hline & Porosity, n & 0.01 & Lowest Value \\
\hline & Initial Void Ratio, e & 0.01 & Lowest Value \\
\hline & Unit Weight, $\gamma\left(\mathbf{l b} / \mathbf{f t}^{3}\right)$ & 98.80 & Lowest Value \\
\hline \multirow{5}{*}{$\begin{array}{c}\text { Worst Case Value } \\
\text { (WC) }\end{array}$} & Poisson's Ratio, v & 0.50 & Highest Value \\
\hline & Modulus of Elasticity, E (psf) & $1.03680 \mathrm{E}+08$ & Lowest Value \\
\hline & Porosity, n & 0.49 & Highest Value \\
\hline & Initial Void Ratio, e & 0.96 & Highest Value \\
\hline & Unit Weight, $\gamma\left(\mathbf{l b} / \mathbf{f t}^{3}\right)$ & 170.70 & Highest Value \\
\hline
\end{tabular}

Table 6.9 Rock layering, type, and thickness for Bulk Analysis modeling

\begin{tabular}{|c|c|c|}
\hline \multirow{2}{*}{ Number of Layers } & \multicolumn{2}{|c|}{ Bulk } \\
\cline { 2 - 3 } & Rock Type & Thickness (ft) \\
\hline $\mathbf{1}$ & BC/WC Overall & $416-901$ \\
\hline $\mathbf{2}$ & Coal & 8.5 \\
\hline $\mathbf{3}$ & BC/WC Overall & 10 \\
\hline
\end{tabular}




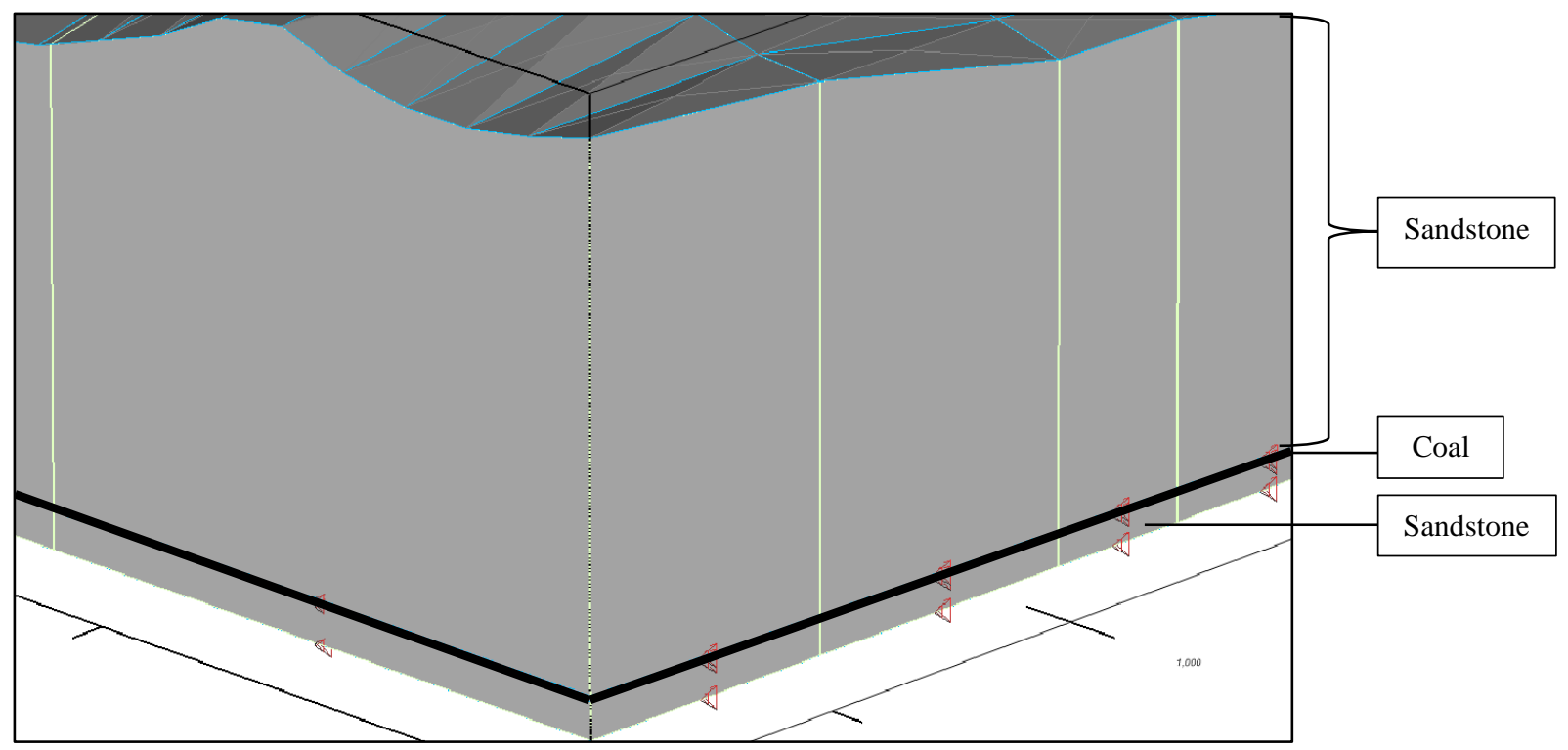

Figure 6.16 Bulk Analysis layering within SVSolid ${ }^{\mathrm{TM}}$

\subsubsection{Bulk Analysis at Station 934}

Overall Best Case (BC) model results, Worst Case (WC) model results, and actual field measurements were graphed versus time to observe the data trends. Best Case (BC) model results were not included further since the values differed greatly from the field data. Figure 6.17, Figure 6.18, and Figure 6.19 show clearly that the BC model results do not provide data which correlate with the field data. BC parameter models simulated intact rock resistant to deformation. Pearson's Correlation Coefficient (PCC) was calculated to be 0.97 for the WC versus Field data. A PCC value of $r \geq 0.9$ is considered perfect linear correlation.

Regardless, the WC model data differed significantly from the field data for some points. The maximum difference in WC model results and Field data was $0.825 \mathrm{ft}$. Figure 6.17 shows the plotted model and field data. The vertical dotted line identifies 6/7/2006 when the landform that the monitoring stations were oriented upon was encroached. Since the data sets were not identical in time, interpolation was performed to match the data points in time and to match the two sample sizes. Model data extrapolation is not a viable strategy in this case. Data trends may exist which would fit a regression equation for the current data, but the use of such a strategy for extrapolation would not be accurate due to highly variable model geometry and nonsymmetrical landforms. 


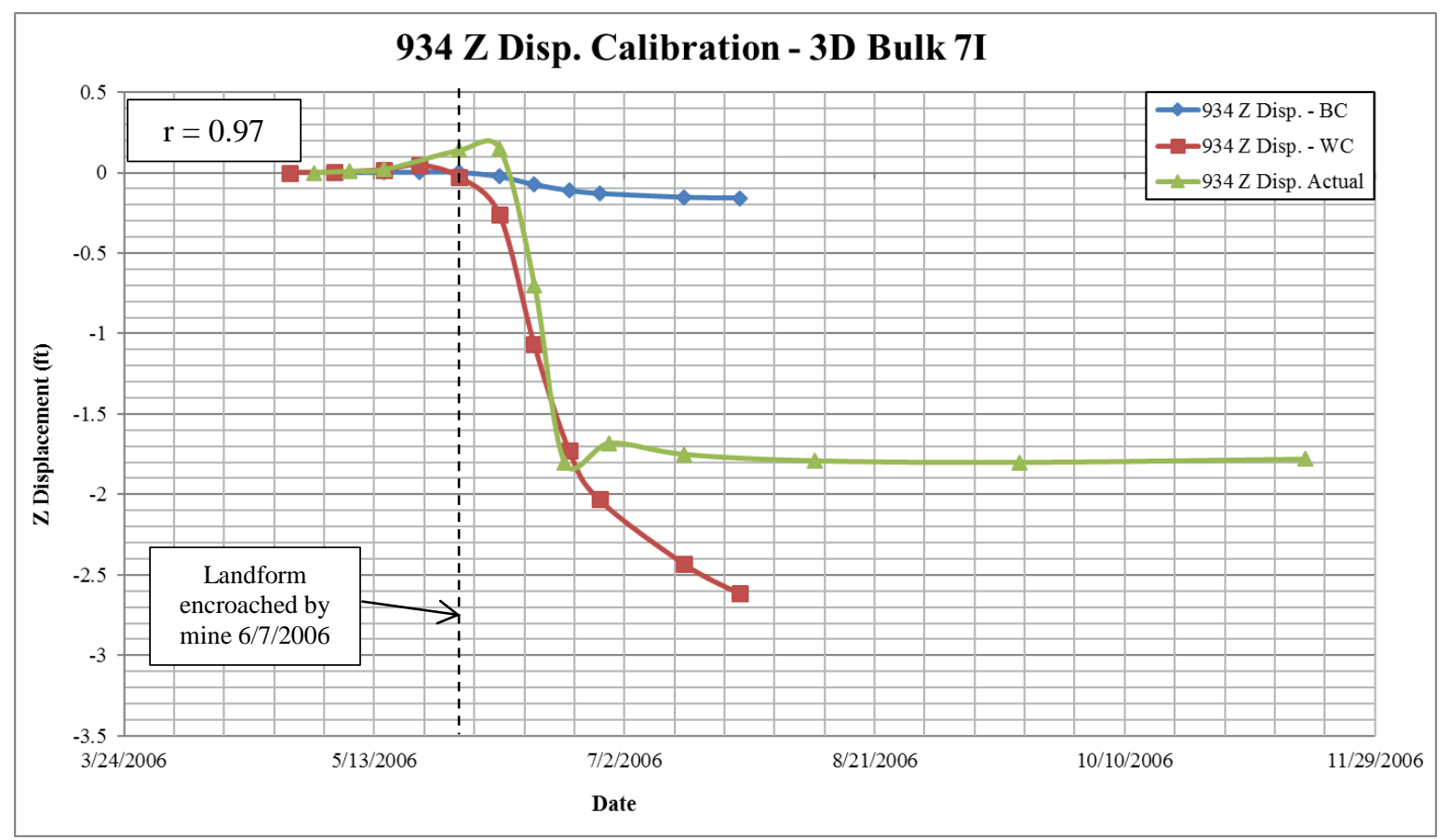

Figure 6.17 Station 934 Bulk calibration plot

Table 6.10 presents WC model data and Field curve data with associated model extraction regions and linear offset for each point in Figure 6.17. Dark gray rows specify the regions at which the landform was encroached by the Panel 7I mine area. Station 934 was also directly undermined approximately during the end of mining in R7 and the beginning of mining in R6. 
Table 6.10 Station 934 Bulk model and field data

\begin{tabular}{|c|c|c|c|}
\hline \multicolumn{4}{|c|}{ Station 934 Bulk Analysis } \\
\hline Region Extracted & Field (ft) & Model (ft) & Linear xy Offset (ft) \\
\hline$-*$ & 0 & 0 & $-*$ \\
\hline R11 & 0 & 0 & 1726 \\
\hline$-*$ & 0 & 0 & $-*$ \\
\hline R10 & 0 & 0 & 1290 \\
\hline$-*$ & 0.025 & 0.025 & $-*$ \\
\hline R9 & 0.070 & 0.050 & 916 \\
\hline R8 & 0.150 & -0.025 & 555 \\
\hline R7 & 0.150 & -0.250 & 197 \\
\hline R6 & -0.710 & -1.075 & 441 \\
\hline R5 & -1.800 & -1.625 & 794 \\
\hline$-*$ & -1.85 & -1.750 & $\sim 794$ \\
\hline R4 & -1.725 & -2.050 & 1038 \\
\hline$-*$ & -1.700 & -2.100 & $\sim 1038$ \\
\hline R3 & -1.750 & -2.450 & 1532 \\
\hline R2 & -1.775 & -2.600 & 2005 \\
\hline
\end{tabular}

*Hashed cells (-) indicate that data was interpolated from field data, where the linear offset is not known, but is between the adjacent offsets for known extraction regions

\subsubsection{Bulk Analysis at Station 931}

Station 931 was graphed similarly to Station 934 for best case (BC) model results, worst case (WC) model results, and actual field measurements were graphed versus time to observe the data trends. The $\mathrm{BC}$ model results were not included further since the values differed greatly from the field data. Pearson's Correlation Coefficient (PCC) was calculated to be 0.86 for the WC versus Field data. A PCC value of $r \geq 0.9$ shows strong linear correlation in data.

The model data still varied somewhat from the field data for some points. The maximum difference in WC model results and Field data was $0.033 \mathrm{ft}$., which is about the magnitude of total observed movement in the field. Figure 6.18 shows the plotted model and field data. The vertical dotted line identifies 6/7/2006 when the landform that the monitoring stations were oriented upon was encroached. The model did not reflect a significant displacement upon the encroachment of mining on the landform.

Since the data sets were not identical in time, interpolation was performed to match the data points in time and to match the two sample sizes. Table 6.11 presents the data for WC and Field curves as well as the model extraction region and linear offset for each point. Station 931 was oriented further from the mine panel than Station 934 at a maximum offset of nearly 3,000 ft. 


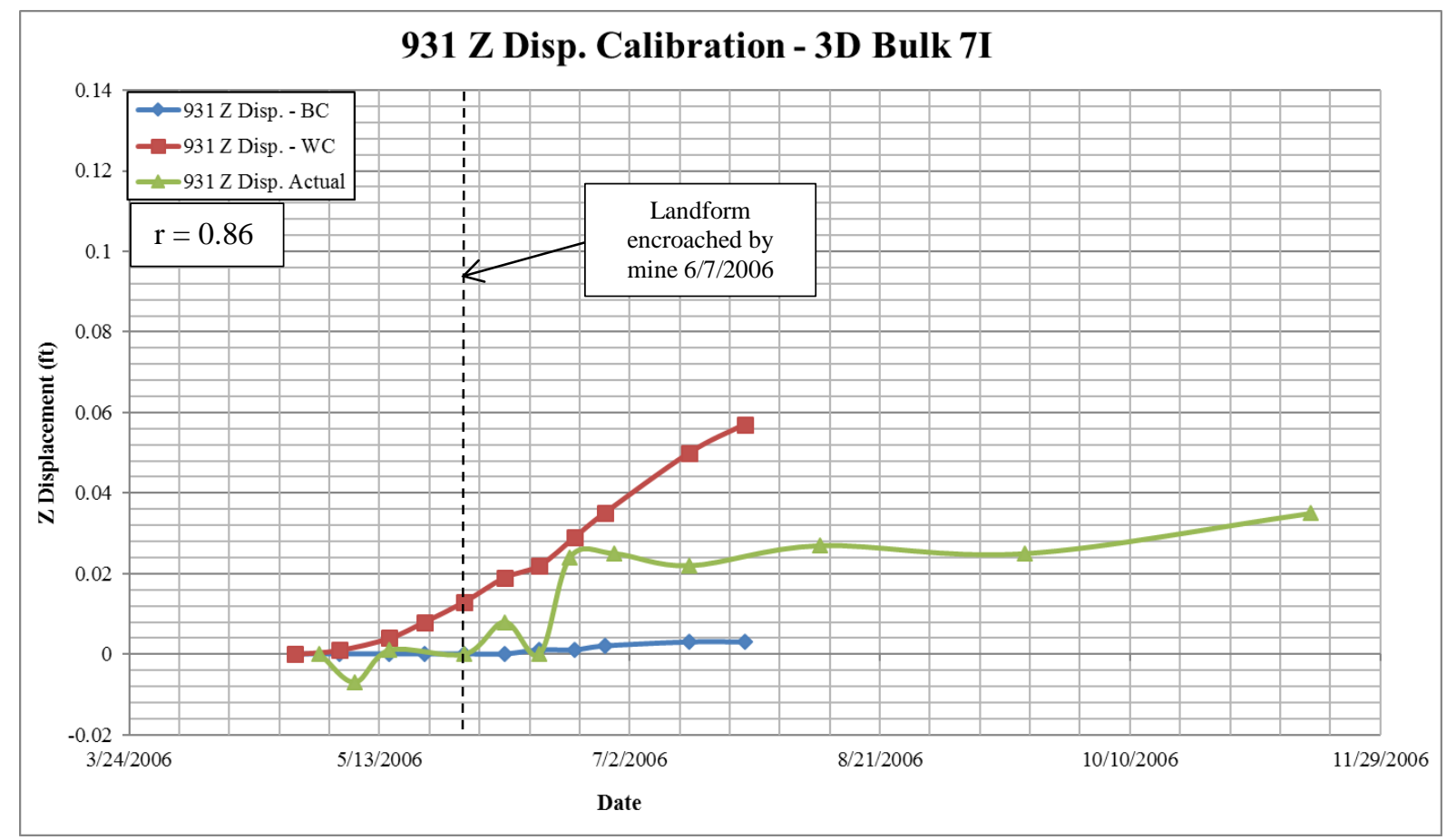

Figure 6.18 Station 931 Bulk calibration plot

Table 6.11 Station 931 Bulk model and field data

\begin{tabular}{|c|c|c|c|}
\hline \multicolumn{4}{|c|}{ Station 931 Bulk Analysis } \\
\hline Region Extracted & Field (ft) & Model (ft) & Linear xy Offset (ft) \\
\hline$-*$ & 0 & 0 & $-*$ \\
\hline R11 & 0 & 0 & 2944 \\
\hline$-*$ & -0.006 & 0.001 & $-*$ \\
\hline R10 & -0.007 & 0.002 & 2536 \\
\hline$-*$ & 0.001 & 0.004 & $-*$ \\
\hline R9 & 0.001 & 0.008 & 2194 \\
\hline R8 & 0 & 0.014 & 1871 \\
\hline R7 & 0.008 & 0.019 & 1485 \\
\hline R6 & -0.001 & 0.022 & 1214 \\
\hline R5 & 0.022 & 0.024 & 1061 \\
\hline$-*$ & 0.026 & 0.03 & $\sim 1061$ \\
\hline R4 & 0.025 & 0.035 & 1025 \\
\hline$-*$ & 0.023 & 0.036 & $\sim 1025$ \\
\hline R3 & 0.022 & 0.05 & 1130 \\
\hline R2 & 0.024 & 0.057 & 1398 \\
\hline
\end{tabular}

*Hashed cells (-) indicate that data was interpolated from field data, where the linear offset is not known, but is between the adjacent offsets for known extraction regions 


\subsubsection{Bulk Analysis at Station 16}

Station 16 was positioned further from Panel 7I than any other monitoring station. The furthest offset distance from the extraction regions was approximately 3,800 ft. The magnitude of movements was small, but did occur. The model data showed similar order of magnitude movements between $-0.005 \mathrm{ft}$. for the field data and up to 0.01 for model data. The calculated PCC was $r=0.17$. This indicates little linear correlation between the model data and field data. The model data did trend in a similar manner to the field data, loosely having the same shape displacement curve. BC data showed essentially zero movement for all model results. There was no significant model response for Bulk Analysis for Station 16 for the time at which the landform was intercepted by the mine void area. Figure 6.19 shows the graphed WC, BC, and Field displacement data versus time for Bulk model conditions. Table 6.12 presents the curve data, associated extraction regions, and offset distance per point. It is important to consider that at such small movements human error and perhaps model surface resolution could have a significant influence on these data readings.

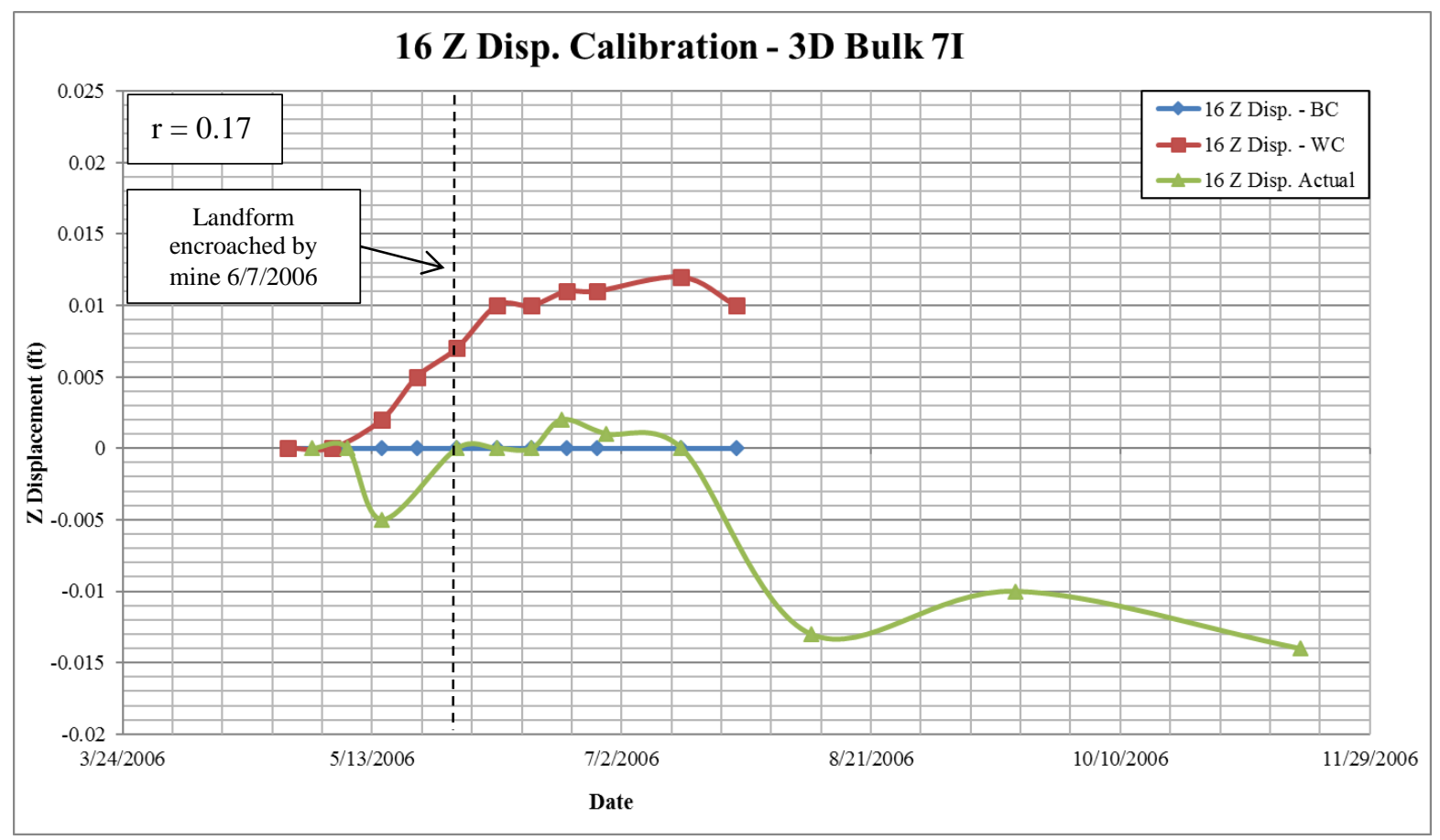

Figure 6.19 Station 16 Bulk calibration plot 
Table 6.12 Station 16 Bulk and Field data, linear offset, and extraction region

\begin{tabular}{|c|c|c|c|}
\hline \multicolumn{4}{|c|}{ Station 16 Bulk Analysis } \\
\hline Region Extracted & Field (ft) & Model (ft) & Linear xy Offset (ft) \\
\hline$-*$ & 0 & 0 & $-*$ \\
\hline R11 & 0 & 0 & 3783 \\
\hline$-*$ & 0.00025 & 0 & $-*$ \\
\hline R10 & 0 & 0.0005 & 3452 \\
\hline$-*$ & -0.005 & 0.002 & $-*$ \\
\hline R9 & -0.002 & 0.005 & 3187 \\
\hline R8 & 0 & 0.007 & 2950 \\
\hline R7 & 0 & 0.01 & 2689 \\
\hline R6 & 0 & 0.01 & 2518 \\
\hline R5 & 0.002 & 0.0105 & 2419 \\
\hline$-*$ & 0.002 & 0.011 & 2419 \\
\hline R4 & 0.00125 & 0.011 & 2384 \\
\hline$-*$ & 0.001 & 0.01125 & $\sim 2384$ \\
\hline R3 & 0 & 0.012 & 2393 \\
\hline R2 & -0.007 & 0.01 & 2495 \\
\hline
\end{tabular}

*Hashed cells (-) indicate that data was interpolated from field data, where the linear offset is not known, but is between the adjacent offsets for known extraction regions

Station 934 was located approximately at the interface of the extraction regions R7 and R6 of Panel 7I. This station was the closest in proximity to the mine void and was situated in a small valley between two landforms. The WC model data and field data matched well for the Bulk Analysis 3D modeling of Station 934 with a PCC of $r=0.97$. This high degree of linear correlation in the model data is surprising given that the model consists of three layers and overall WC rock properties. The $\mathrm{BC}$ properties resulted in very low displacements for all stations and did not correlate with the field data. The model data did not match the field data exactly and diverged from the field data for the last few data points. The landform influence cannot be distinguished since the station was directly undermined.

Station 931 was situated approximately in the middle of the other two calibration stations (Station 934 and Station 16). The perpendicular offset distance of Station 931 was approximately $1,000 \mathrm{ft}$. but reached up to almost 3,000 ft. linear offset. The PCC was calculated to be 0.86 for Station 931 Bulk Analysis data. This result implies a significant linear correlation in the data. The interception of the landform at R7 did not produce any significant change in the trend of the model data.

Station 16 was the furthest station considered for the modeling analysis. The perpendicular distance to Panel 7I was approximately 2,400 ft., and reached up to 3,800 ft. linear offset for R11. The PCC was calculated to be $r=0.17$. There was little linear correlation in the data, 
however the results were similar in magnitude. The range of field and model data was from $0.005 \mathrm{ft}$. to $0.01 \mathrm{ft}$. No significant change in the model data occurred at the point at which the landform was encroached by the mine void. At such distances and small magnitude displacements human error could affect field measurements, and model results could be influenced by surface resolution. Although the PCC was low indicating little linear correlation between the field data and the model resultant data, the order of magnitude for both data sets was the same. Additionally, the model data fell well within survey tolerances $( \pm 0.015 \mathrm{ft}$.).

\subsubsection{Detail 1 (8 Layer Model)}

An eight-layer model was chosen as the second calibration modeling suite to be run. This case was the second most complex, and included Best Case (BC) and Worst Case (WC) properties specific to each rock type in each layer. BC and WC properties can be viewed via Table 6.4. This eight-layer model is denoted as "Detail 1." Three stations $(934,931,16)$ were chosen to be investigated at Detail 1 layering and properties. Table 6.13 provides the layer thickness and number of layers for the Detail 1 Analysis. Figure 6.20 shows the layering within the Detail 1 Analysis models. All layers were oriented similarly as the coal seam with an east-west inclination of 0.72 degrees as discussed in Section 6.3.1.3.

Table 6.13 Rock layering, type, and thickness for Detail 1 modeling

\begin{tabular}{|c|c|c|}
\hline \multirow{2}{*}{$\begin{array}{c}\text { Number of } \\
\text { Layers }\end{array}$} & \multicolumn{2}{|c|}{ Detail 1 } \\
\cline { 2 - 3 } & Rock Type & Thickness (ft) \\
\hline $\mathbf{1}$ & Shale & $12-497$ \\
\hline $\mathbf{2}$ & Sandstone & 105 \\
\hline $\mathbf{3}$ & Limestone & 40.3 \\
\hline $\mathbf{4}$ & Siltstone & 50.8 \\
\hline $\mathbf{5}$ & Limestone & 95.8 \\
\hline $\mathbf{6}$ & Siltstone & 112.5 \\
\hline $\mathbf{7}$ & Coal & 8.5 \\
\hline $\mathbf{8}$ & Sandstone & $10-60$ \\
\hline
\end{tabular}




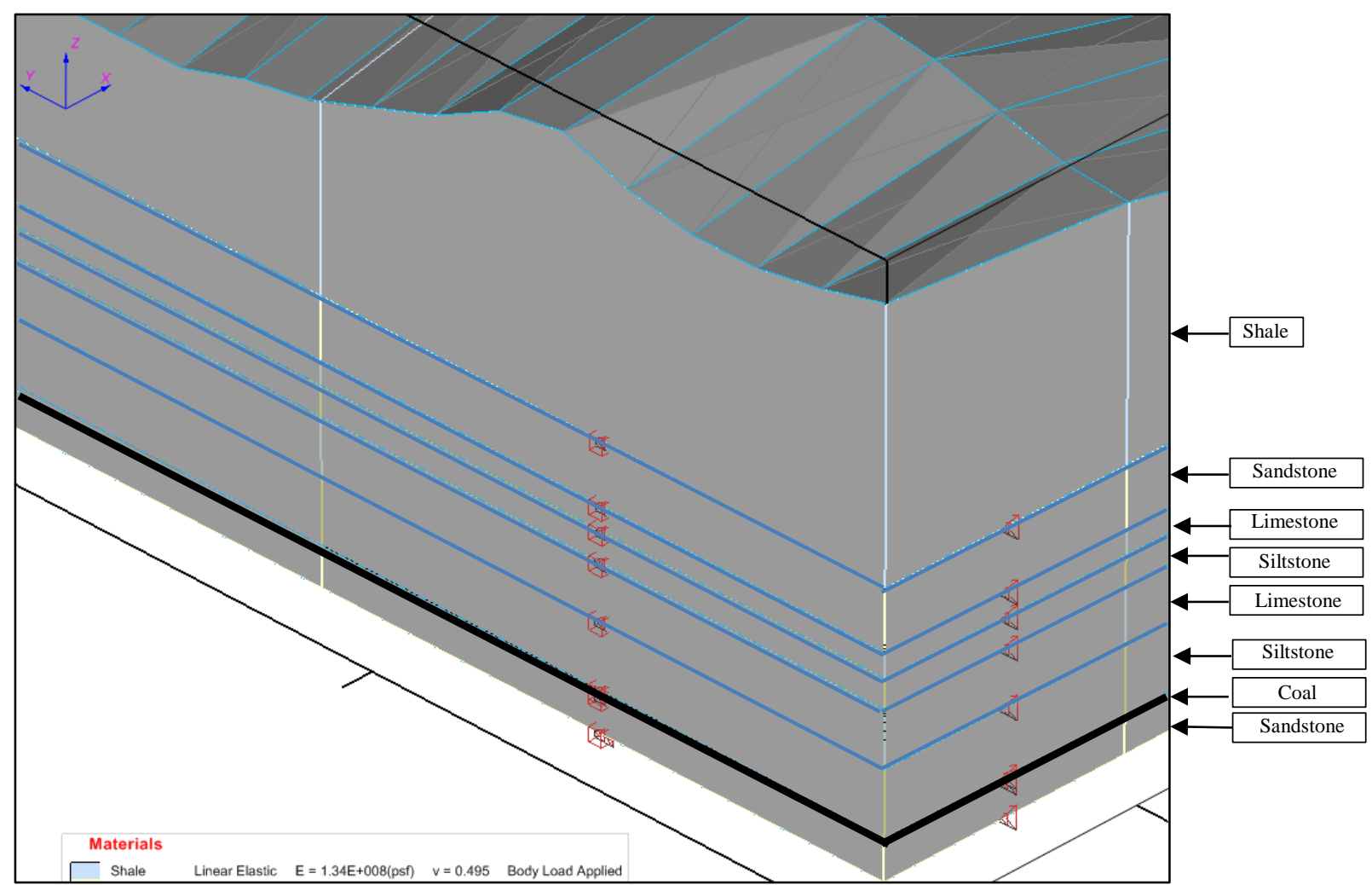

Figure 6.20 Detail 1 layering within SVSolid ${ }^{\mathrm{TM}}$

\subsubsection{Detail 1 Analysis at Station 934}

Station 934 was graphed similarly for Detail 1 model results with best case (BC) model results, worst case (WC) model results, and actual field measurements to observe data trends. As before, $\mathrm{BC}$ model results were not studied further since the values differed greatly from the field data. Pearson's Correlation Coefficient (PCC) was calculated to be 0.96 for the WC versus Field data. A PCC value of $r \geq 0.9$ is considered perfect linear correlation. The model data still varied from the field data for some points with a maximum difference in WC model results and Field data at $0.65 \mathrm{ft}$. Figure 6.21 shows the plotted model and field data. The vertical dotted line identifies $6 / 7 / 2006$ when the landform that the monitoring stations were oriented upon was encroached. Since the data sets were not identical in time, interpolation was performed to match the data points in time and to match the two sample sizes. Table 6.14 presents the data for WC and Field curves as well as the model extraction region and linear offset for each point. Hashed cells indicate that the data was interpolated from the field data, where the linear offset is not known, but is between the adjacent offsets for the known extraction regions. Station 934 was oriented the closest to the mine panel of the three monitoring stations. 


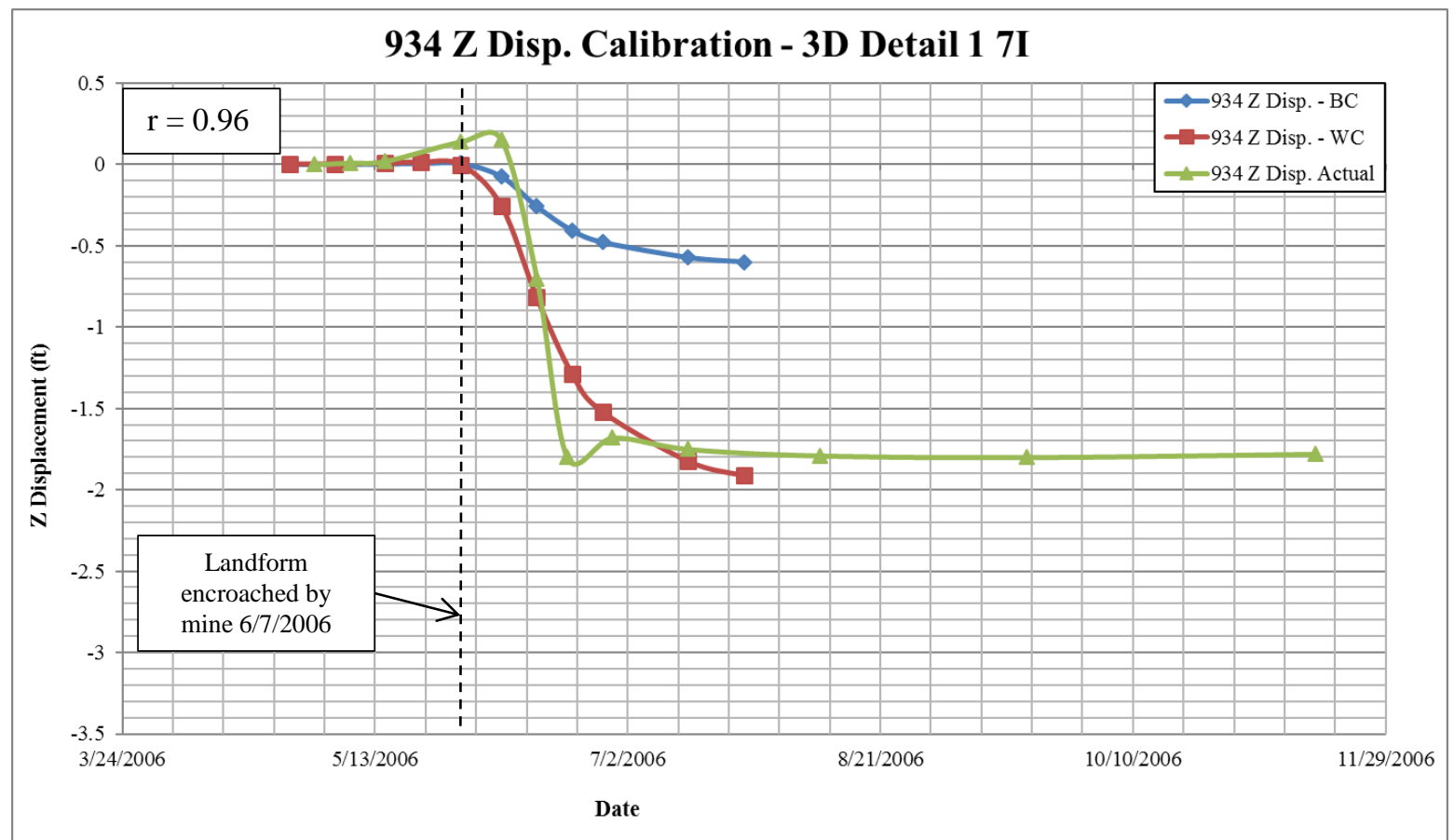

Figure 6.21 Station 934 Detail 1 calibration plot

Table 6.14 Station 934 Detail 1 calibration data

Station 934 Detail 1

\begin{tabular}{|c|c|c|c|}
\hline Region Extracted & Field (ft) & Model (ft) & Linear xy Offset (ft) \\
\hline$-*$ & 0 & 0 & $-*$ \\
\hline R11 & 0 & 0 & 1726 \\
\hline$-*$ & 0 & 0 & $-*$ \\
\hline R10 & 0 & 0 & 1290 \\
\hline$-*$ & 0 & 0 & $-*$ \\
\hline R9 & 0.075 & 0 & 916 \\
\hline R8 & 0.150 & 0 & 555 \\
\hline R7 & 0.160 & -0.250 & 197 \\
\hline R6 & -0.725 & -0.825 & 441 \\
\hline R5 & -1.800 & -1.150 & 794 \\
\hline R4 & -1.850 & -1.275 & 1038 \\
\hline$-*$ & -1.725 & -1.525 & $\sim 1038$ \\
\hline R3 & -1.675 & -1.550 & 1532 \\
\hline$-*$ & -1.750 & -1.825 & $\sim 1532$ \\
\hline R2 & -1.775 & -1.900 & 2005 \\
\hline
\end{tabular}

*Hashed cells (-) indicate that data was interpolated from field data, where the linear offset is not known, but is between the adjacent offsets for known extraction regions 


\subsubsection{Detail 1 Analysis at Station 931}

Station 931 model results were plotted for BC and WC scenarios versus the field monitoring data. The PCC was $r=0.84$ for the WC data and field data, indicating a strong correlation in the two data sets. $\mathrm{BC}$ results showed some displacement, but did not match the field data. The linear offset of mining to Station 931 ranged from about 1,000 ft. to about 3,000 ft. The maximum error for Detail 1 at Station 931 was $0.016 \mathrm{ft}$. Figure 6.22 shows the model results plotted against the field data. Table 6.15 presents the data associated with Figure 6.22 as well as the extraction regions and linear offset data.

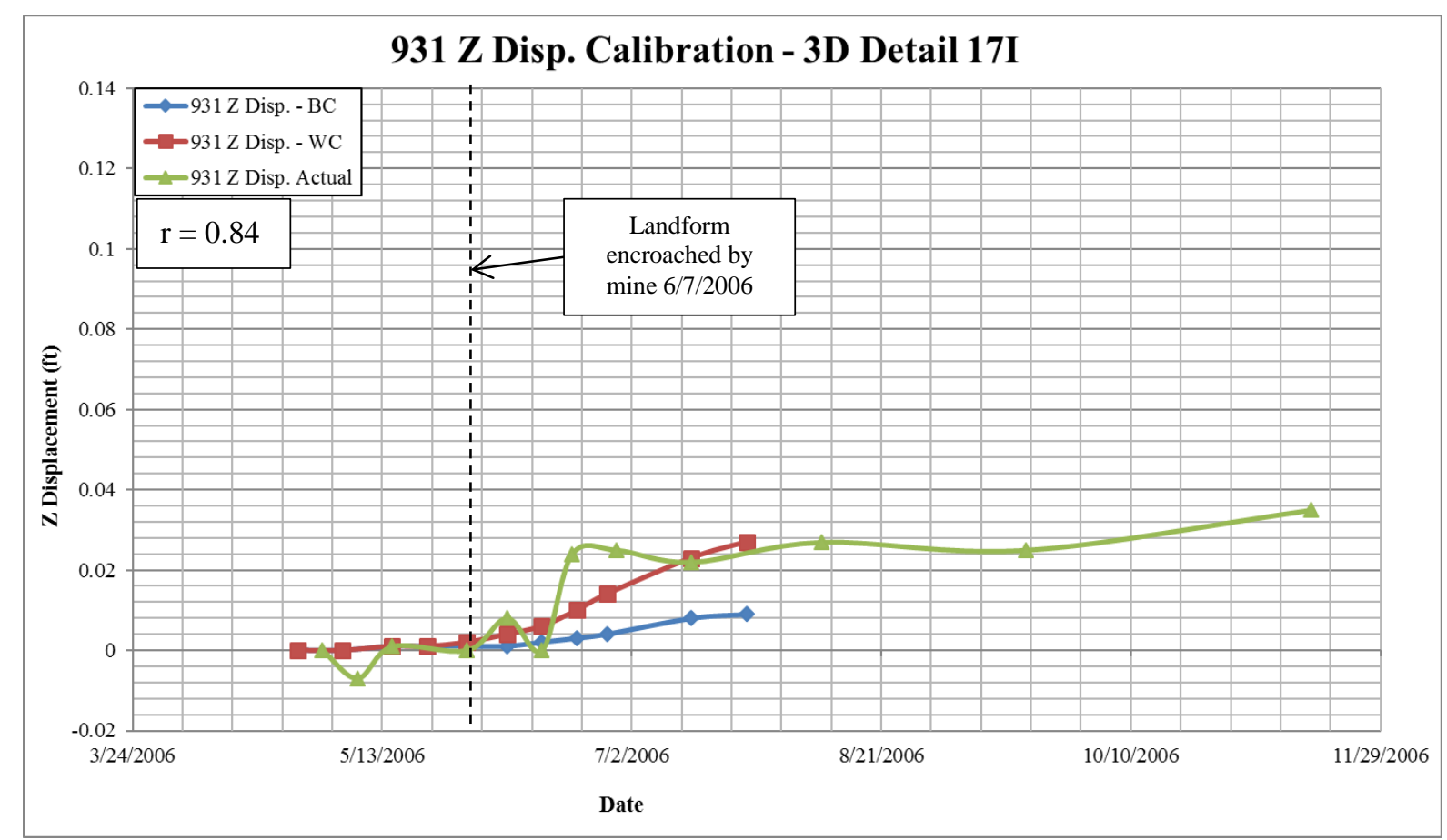

Figure 6.22 Station 931 Detail 1 calibration plot 
Table 6.15 Station 931 Detail 1 data, field data, region extracted, and linear offset

\begin{tabular}{|c|c|c|c|}
\hline \multicolumn{4}{|c|}{ Station 931 Detail 1 } \\
\hline Region Extracted & Field (ft) & Model (ft) & Linear xy Offset (ft) \\
\hline$-*$ & 0 & 0 & $-*$ \\
\hline R11 & 0 & 0 & 2944 \\
\hline$-*$ & -0.006 & 0 & $-*$ \\
\hline R10 & -0.007 & 0 & 2536 \\
\hline$-*$ & 0.001 & 0.001 & $-*$ \\
\hline R9 & 0.001 & 0.001 & 2194 \\
\hline R8 & 0 & 0.002 & 1871 \\
\hline R7 & 0.008 & 0.004 & 1485 \\
\hline R6 & -0.001 & 0.006 & 1214 \\
\hline R5 & 0.022 & 0.009 & 1061 \\
\hline R4 & 0.026 & 0.01 & $\sim 1061$ \\
\hline$-*$ & 0.025 & 0.014 & 1025 \\
\hline R3 & 0.023 & 0.015 & $\sim 1025$ \\
\hline$-*$ & 0.022 & 0.023 & 1130 \\
\hline R2 & 0.024 & 0.026 & 1398 \\
\hline * Hashed cells (-) indicate that data was interpolated from field data, where the \\
\hline $\begin{array}{l}\text { linear offset is not known, but is between the adjacent offsets for known } \\
\text { extraction regions }\end{array}$
\end{tabular}

\subsubsection{Detail 1 Analysis at Station 16}

Station 16 was located at the west abutment of the Ryerson Station Dam. The offset distance ranged from about 2,300 ft. to 3,800 ft. The PCC was calculated to be $\mathrm{r}=0.33$, which indicates some correlation in the WC and Field data. This case showed the strongest correlation between WC and the Field data for Station 16, but still did not achieve considerable linear correlation. The model results show a conservative prediction of the displacement, acting almost as a limiting bound to the field data for this case. The PCC was low compared to the other two closer stations 931 and 934, although the model results are within the same order of magnitude as the field results, and trend similarly. The maximum error was $0.009 \mathrm{ft}$. Field data shows that the majority of the movement occurred after the model period ended; therefore, it would have been beneficial to model further removal of coal affecting the landform where Station 16 was located. Figure 6.23 shows the data for Detail $1 \mathrm{WC}, \mathrm{BC}$, and Field monitoring data. Table 6.16 shows the raw data for the curves in Figure 6.23, extraction region, and linear offset distance per point. 


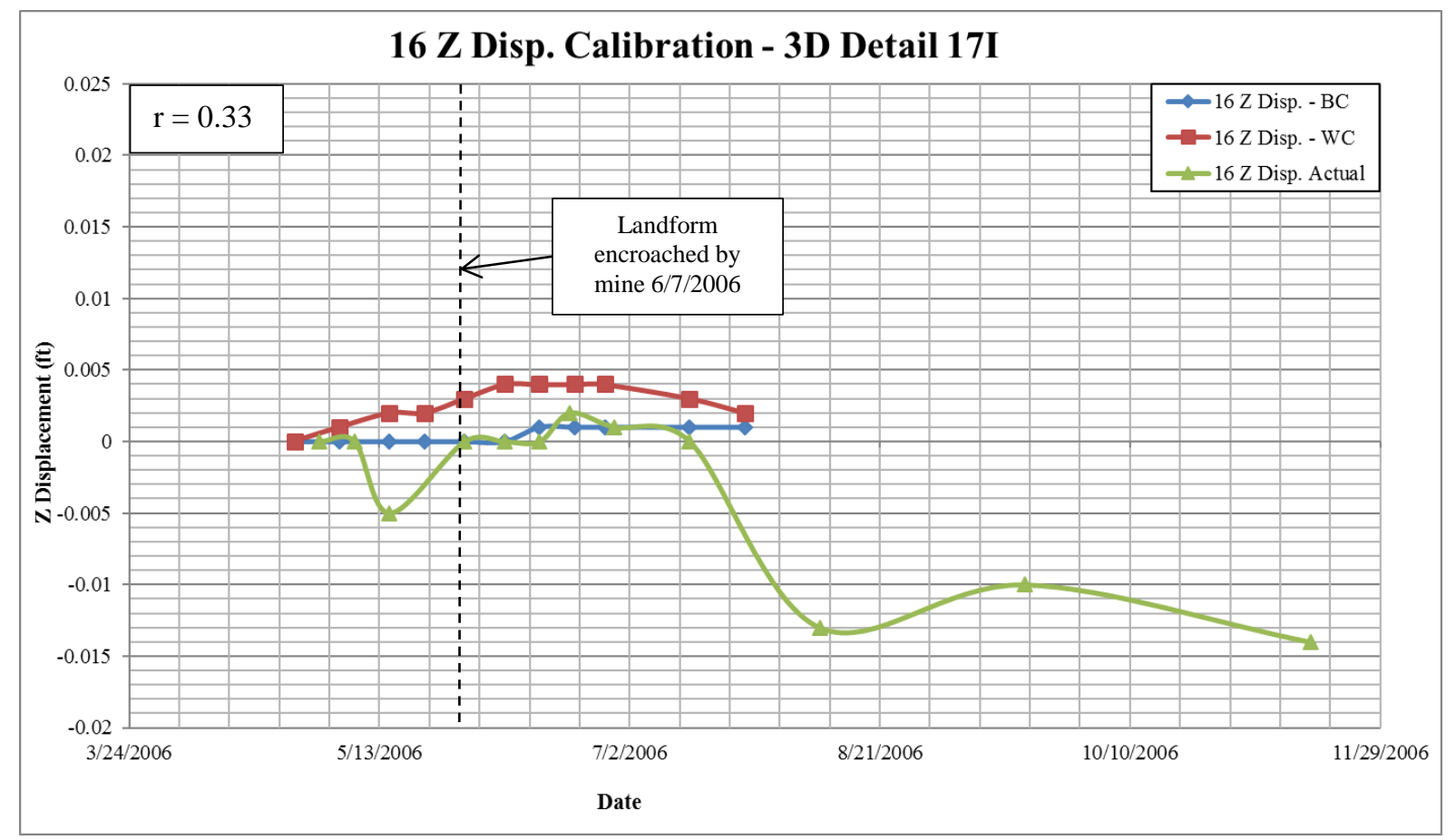

Figure 6.23 Station 16 Detail 1 calibration plot

Table 6.16 Station 16 Detail 1 calibration data, extraction region, and linear offset Station 16 Detail 1

\begin{tabular}{|c|c|c|c|}
\hline Region Extracted & Field (ft) & Model (ft) & Linear xy Offset (ft) \\
\hline$-^{*}$ & 0 & 0 & $-*$ \\
\hline R11 & 0 & 0.0005 & 3783 \\
\hline$-*$ & 0.00025 & 0.001 & $-*$ \\
\hline R10 & 0 & 0.00125 & 3452 \\
\hline$-*$ & -0.005 & 0.002 & $-*$ \\
\hline R9 & -0.002 & 0.002 & 3187 \\
\hline R8 & 0 & 0.003 & 2950 \\
\hline R7 & 0 & 0.004 & 2689 \\
\hline R6 & 0 & 0.004 & 2518 \\
\hline R5 & 0.002 & 0.004 & 2419 \\
\hline R4 & 0.002 & 0.004 & 2419 \\
\hline$-*$ & 0.00125 & 0.004 & 2384 \\
\hline R3 & 0.001 & 0.00375 & $\sim 2384$ \\
\hline$-*$ & 0 & 0.003 & 2393 \\
\hline R2 & -0.007 & 0.002 & 2495 \\
\hline
\end{tabular}

*Hashed cells (-) indicate that data was interpolated from field data, where the linear offset is not known, but is between the adjacent offsets for known extraction regions 
Detail 1 was an 8 layer set of 22 models. Eleven models were run at Worst Case and eleven at Best Case. Station 934, Station 931, and Station 16 were selected to investigate further as each represented a different offset distance to Panel 7I. In comparison with the Bulk Analysis (3 layers), Station 934 and Station 931 performed approximately the same with respect to the PCC. Station 934 yielded a PCC of $r=0.96$ and Station 931 at $r=0.84$. Despite these numbers, the visual comparison of the curves in Figure 6.21 and Figure 6.22 show that data trends were very similar for field and model data. Station 16 yielded a much higher PCC of $r=0.33$ than the Bulk Analysis which yielded $r=0.17$.

\subsubsection{Detail 2 (14 Layer Model)}

Detail 2 was an attempt to push the software to its limit in complexity without crashing the system. The model consisted of the software maximum 15 surface and 14 layers. This was the most complex possible orientation of stratigraphy. The model included Best Case (BC) and Worst Case (WC) properties specific to each rock type in each layer. Input parameters for the modeled rock materials can be reviewed in Table 6.4. This fourteen-layer model is denoted as "Detail 2" and was the final level of detail in this analysis, totaling 6 variations. Three stations $(934,931,16)$ were chosen to be investigated at Detail 2 layering and properties. Table 6.17 provides the layer thickness and number of layers for the Detail 2 Analysis. Figure 6.24 shows the layering within the Detail 2 Analysis models. All layers were oriented similarly as the coal seam with an east-west inclination of 0.72 degrees as discussed in Section 6.3.1.3. Coal thickness was held constant at $8.5 \mathrm{ft}$. for all analyses.

Table 6.17 Rock layering, type, and thickness for Detail 2 modeling

\begin{tabular}{|c|c|c|}
\hline Number of & \multicolumn{2}{|c|}{ Detail 2 } \\
\cline { 2 - 3 } Layers & Rock Type & Thickness (ft) \\
\hline $\mathbf{1}$ & Shale & $12-497$ \\
\hline $\mathbf{2}$ & Sandstone & 35 \\
\hline $\mathbf{3}$ & Siltstone & 21.3 \\
\hline $\mathbf{4}$ & Sandstone & 43.8 \\
\hline $\mathbf{5}$ & Siltstone & 22.6 \\
\hline $\mathbf{6}$ & Limestone & 22.6 \\
\hline $\mathbf{7}$ & Siltstone & 50.8 \\
\hline $\mathbf{8}$ & Limestone & 55.3 \\
\hline $\mathbf{9}$ & Limestone & 40.5 \\
\hline $\mathbf{1 0}$ & Siltstone & 27.4 \\
\hline $\mathbf{1 1}$ & Siltstone & 53.6 \\
\hline $\mathbf{1 2}$ & Sandstone & 31.5 \\
\hline $\mathbf{1 3}$ & Coal & 8.5 \\
\hline $\mathbf{1 4}$ & Siltstone & $10-60$ \\
\hline
\end{tabular}




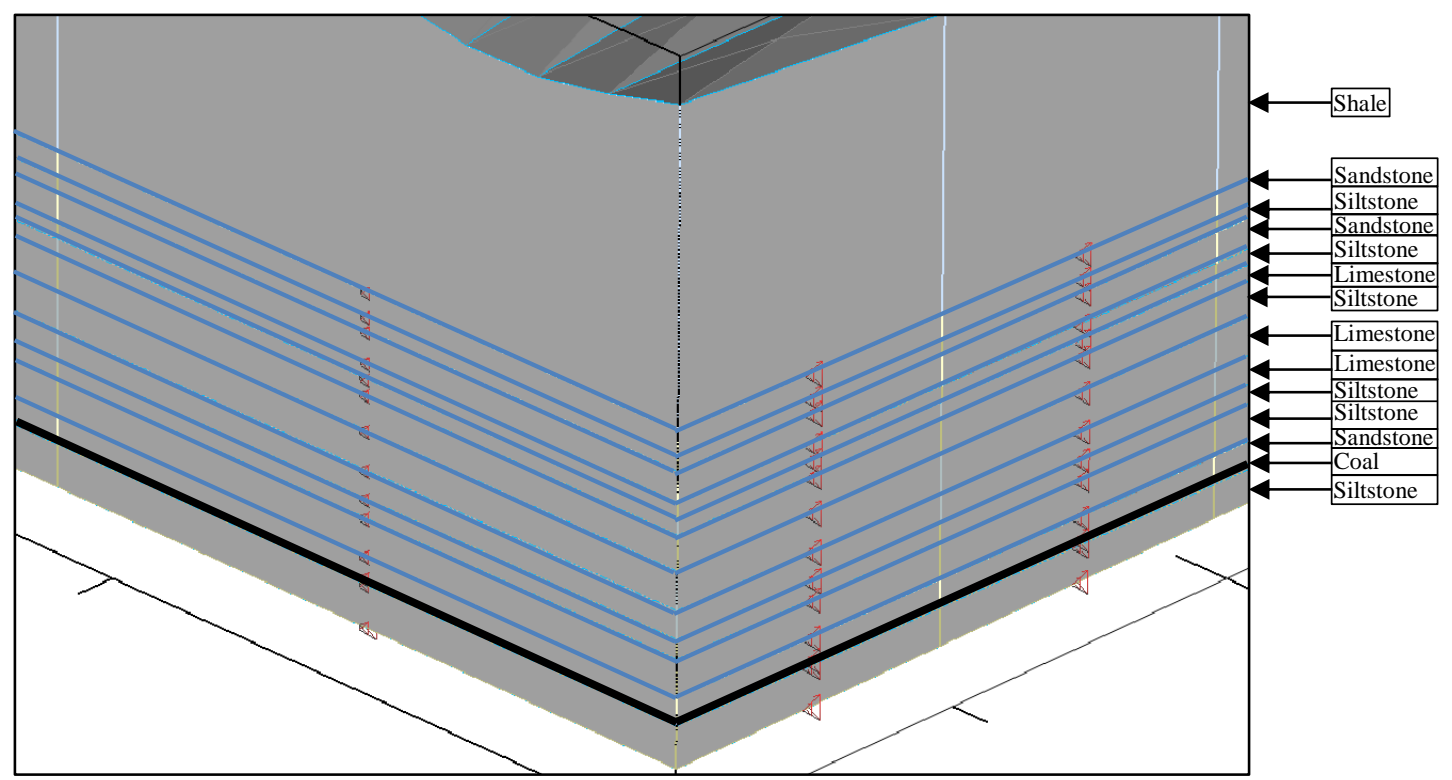

Figure 6.24 Detail 2 layering within SVSolid ${ }^{\mathrm{TM}}$

\subsubsection{Detail 2 Analysis at Station 934}

Detail 2 model results at 934 produced a PCC of $r=0.96$. This PCC was no different than for Detail 1, but the maximum error was less at $0.55 \mathrm{ft}$. The results were graphed according to the most meaningful data, which was WC data. BC data varied much more in Detail 2 models than in Bulk or Detail 1, but still did not match the Field data. Figure 6.25 shows the calibration plot for Station 934. Table 6.18 presents the data, extraction regions, and linear offset for Station 934 per point. 


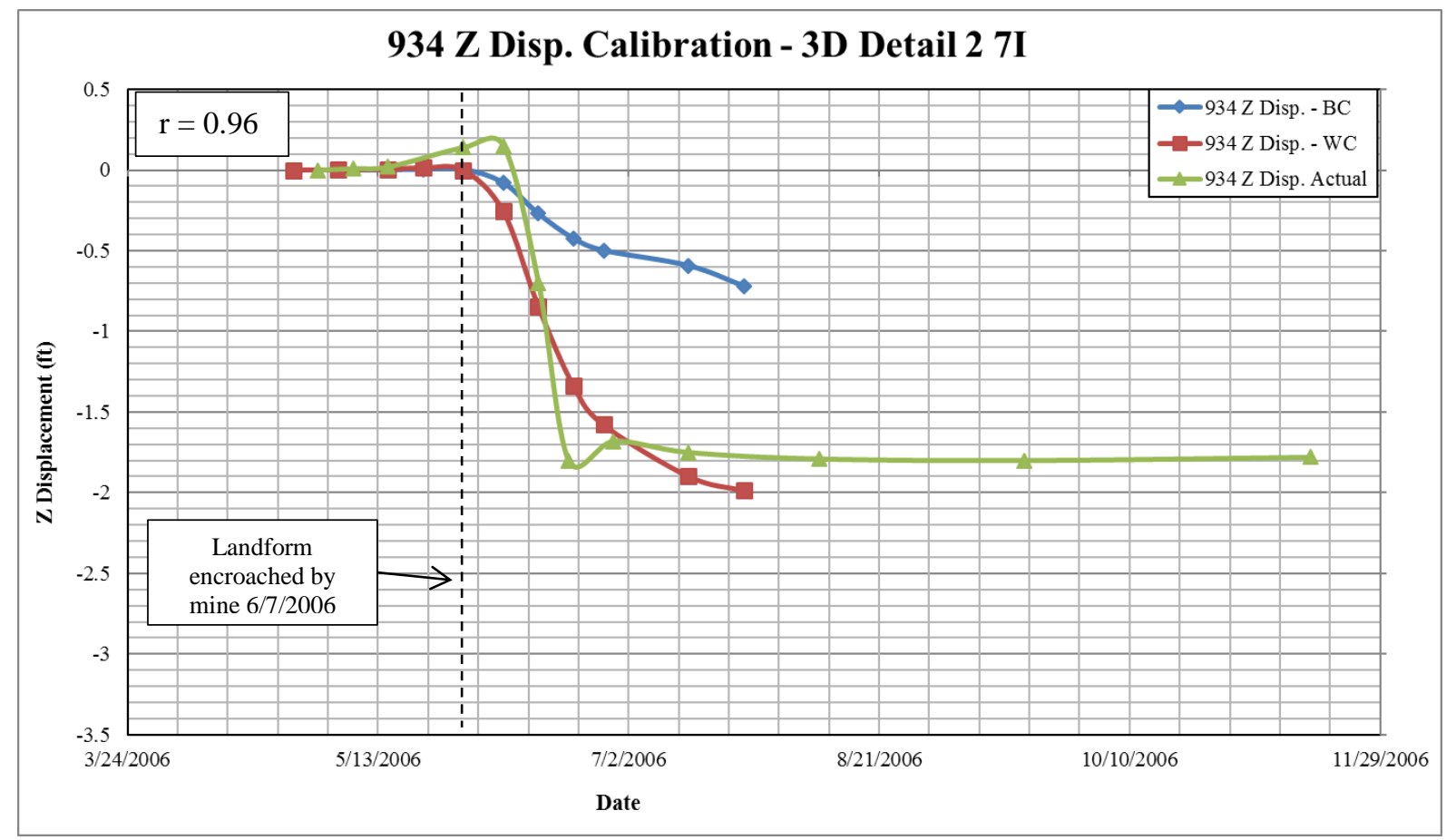

Figure 6.25 Station 934 Detail 2 calibration plot

Table 6.18 Station 934 Detail 2 calibration data, extraction region, and linear offset Station 934 Detail 2

\begin{tabular}{|c|c|c|c|}
\hline Region Extracted & Field (ft) & Model (ft) & Linear xy Offset (ft) \\
\hline$-*$ & 0 & 0 & $-*$ \\
\hline R11 & 0 & 0 & 1726 \\
\hline$-^{*}$ & 0 & 0 & $-*$ \\
\hline R10 & 0 & 0 & 1290 \\
\hline$-*$ & 0 & 0 & $-*$ \\
\hline R9 & 0.075 & 0 & 916 \\
\hline R8 & 0.15 & 0 & 555 \\
\hline R7 & 0.16 & -0.25 & 197 \\
\hline R6 & -0.725 & -0.85 & 441 \\
\hline R5 & -1.8 & -1.25 & 794 \\
\hline R4 & -1.85 & -1.325 & $\sim 794$ \\
\hline$-*$ & -1.725 & -1.575 & 1038 \\
\hline R3 & -1.675 & -1.625 & $\sim 1038$ \\
\hline$-*$ & -1.75 & -1.9 & 1532 \\
\hline R2 & -1.775 & -1.975 & 2005 \\
\hline
\end{tabular}

*Hashed cells (-) indicate that data was interpolated from field data, where the linear offset is not known, but is between the adjacent offsets for known extraction regions 


\subsubsection{Detail 2 Analysis at Station 931}

Station $931 \mathrm{BC}$ and WC model results were graphed versus the field monitoring data. BC results did not match the data and were not investigated further. WC results matched the field data well with a PCC of $r=0.84$. This value indicates a strong correlation in the two sets of data. The maximum error was 0.016 , which was the same as in Detail 1 . The majority of the movement for this station occurred after the landform was encroached by Panel 7I. Figure 6.26 shows the Station 931 calibration plot. Table 6.19 provides the data for Figure 6.26, extraction region, and linear offset per point.

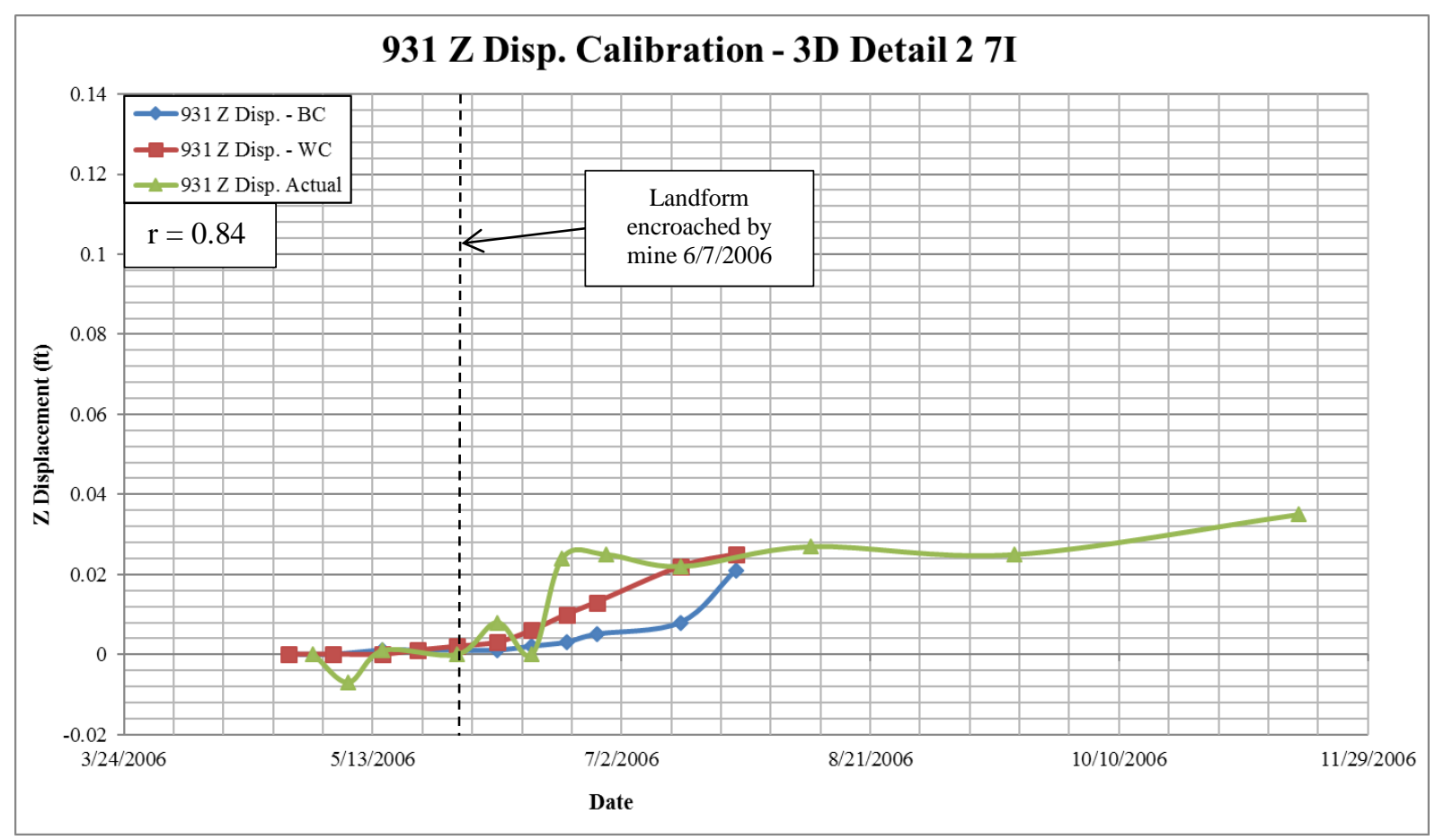

Figure 6.26 Station 931 calibration plot 
Table 6.19 Station 931 calibration data, extraction region, and linear offset

\begin{tabular}{|c|c|c|c|}
\hline \multicolumn{4}{|c|}{ Station 931 Detail 2 } \\
\hline Region Extracted & Field (ft) & Model (ft) & Linear xy Offset (ft) \\
\hline$-*$ & 0 & 0 & $-*$ \\
\hline R11 & 0 & 0 & 2944 \\
\hline$-*$ & -0.006 & 0 & $-*$ \\
\hline R10 & -0.007 & 0 & 2536 \\
\hline$-*$ & 0.001 & 0 & $-*$ \\
\hline R9 & 0.001 & 0.001 & 2194 \\
\hline R8 & 0 & 0.002 & 1871 \\
\hline R7 & 0.008 & 0.003 & 1485 \\
\hline R6 & -0.001 & 0.006 & 1214 \\
\hline R5 & 0.022 & 0.009 & 1061 \\
\hline R4 & 0.026 & 0.01 & $\sim 1061$ \\
\hline -* & 0.025 & 0.013 & 1025 \\
\hline R3 & 0.023 & 0.015 & $\sim 1025$ \\
\hline -* & 0.022 & 0.022 & 1130 \\
\hline R2 & 0.024 & 0.025 & 1398 \\
\hline
\end{tabular}

*Hashed cells (-) indicate that data was interpolated from field data, where the linear offset is not known, but is between the adjacent offsets for known extraction regions

\subsubsection{Detail 2 Analysis at Station 16}

Detail 2 model results for Station 16 did not trend well with the field data. The PCC was calculated to be $r=0.18$, which indicates very little correlation in the data. The maximum error was calculated to be 0.009 , the same error as in Detail 1 modeling. The data did not correlate according to a PCC; however, the resulting values were in the same order of magnitude. Figure 6.27 shows the calibration plot for Station 16. Table 6.20 presents the data for Figure 6.27 as well as extraction region, and linear offset per point. 


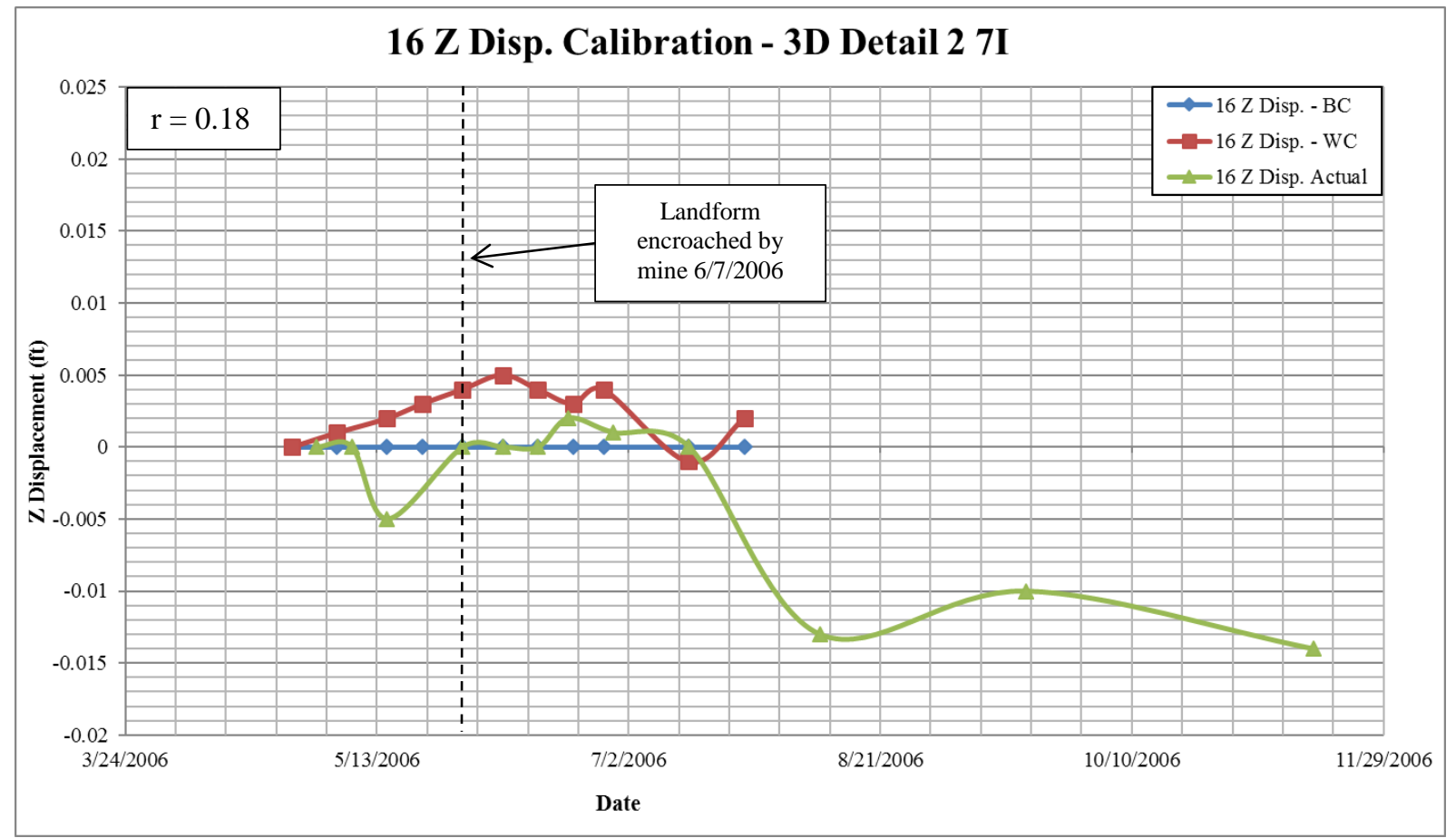

Figure 6.27 Station 16 Detail 2 calibration plot

Table 6.20 Station 16 Detail 2 calibration data, extraction region, and linear offset Station 16 Detail 2

\begin{tabular}{|c|c|c|c|}
\hline Region Extracted & Field (ft) & Model (ft) & Linear xy Offset (ft) \\
\hline -* $^{*}$ & 0 & 0 & $-*$ \\
\hline R11 & 0 & 0.005 & 3783 \\
\hline * $^{*}$ & 0.00025 & 0.001 & $-*$ \\
\hline R10 & 0 & 0.00125 & 3452 \\
\hline$-*$ & -0.005 & 0.002 & $-*$ \\
\hline R9 & -0.002 & 0.003 & 3187 \\
\hline R8 & 0 & 0.004 & 2950 \\
\hline R7 & 0 & 0.005 & 2689 \\
\hline R6 & 0 & 0.004 & 2518 \\
\hline R5 & 0.002 & 0.003 & 2419 \\
\hline R4 & 0.002 & 0.003 & 2419 \\
\hline$-*$ & 0.00125 & 0.004 & 2384 \\
\hline R3 & 0.001 & 0.0035 & $\sim 2384$ \\
\hline$-*$ & 0 & -0.001 & 2393 \\
\hline R2 & -0.007 & 0.002 & 2495 \\
\hline
\end{tabular}

*Hashed cells (-) indicate that data was interpolated from field data, where the linear offset is not known, but is between the adjacent offsets for known extraction regions 
The Detail 2 models consisted of eleven BC and eleven WC models. The model increased in precision from Detail 1 (8 layers) to the software maximum 14 layers. This increase in detail did not yield more precise results as anticipated. Instead, model results were approximately the same for Station $934(\mathrm{r}=0.96)$ and Station $931(\mathrm{r}=0.84)$. The data remained to trend well, but Station 16 results varied from the Bulk Analysis and Detail 1 Analysis. The resulting PCC was calculated to be $r=0.18$, a decrease from the Detail 1 Analysis at $r=0.33$. Otherwise, the model performed generally well and did not experience significant jumps in data upon the landform encroachment by the mine, although the majority of displacement occurred after the landform was encroached.

\subsubsection{Calibration Result and Summary}

The range of results between $\mathrm{BC}$ input parameters and WC parameters (Table 6.4) was expected to decrease as the model detail increased. That was not the case; in fact, the increase in detail from 8 layers to 14 layers had little influence on the precision of the model. BC input parameters improved as the level of detail increased but did not match field data. It is hypothesized that the WC parameters more closely simulated the other factors at play which influenced the magnitude of displacement (i.e. fracturing, in situ stress).

The calibration plots show model data and field data. The model data tended to be a smooth line whereas the field data had more rapid jumps in displacement. This was expected as the model simulated an elastic deformation in its medium, incapable of failing in the same brittle manner as what is experienced in the field. The field data tended to rebound somewhat after each major displacement, but did not recover all of the incurred displacement. Also, the manner in which the field displacement was graphed may or may not necessarily represent the movement in the field. As previously mentioned, movements were likely sudden and brittle with possible periods of zero movement or some creep or settlement at some stations. It is difficult to know the exact shape of the curve with certainty without more frequent recordings. The model data trend was nearly identical to the field measurements as presented in Figure 6.17, Figure 6.21, and Figure 6.25, but was offset in time. Unfortunately, the lag time of the field movements are not known, which may have had an effect in this analysis, resulting in error. The model simulation reaches convergence criteria before producing a final movement condition. As a result, no lag time is associated with the stimulus (introduction of mine void) and the model response (stress and deformation).

Detail 1 (8 layers) and Detail 2 (14 layers) results were not significantly different for stations 934 and 931. The Bulk Analysis modeling showed a high amount of correlation with field data, but did not match the data as well as Detail 1 and Detail 2, despite the PCC values. This can be observed near the last few data points in the calibration plots in Section 6.4.1 - Section 6.4.3. 
This concludes that a high level of detail may not be required to obtain predictive approximate ground displacements.

Station 931 and Station 934 showed the most significant movement after the landform was affected on 6/7/2006, however no abrupt changes occurred at this point. This provides evidence that the landform encroachment may influence stress and deformation more significantly than the offset distance alone. The offset distance was equal to or greater than the distances upon which the greatest movements occurred.

The movements of each station were not always in the same direction. The further uphill from the bottom of the valley, the less likely it is that heaving will occur, and the movement expected would be in the $-Z$ direction. Station 934 moved down (-Z) since it was over the mine panel. Station 931 moved up $(+Z)$ since the ground heaved in this region. Station 16 moved downhill (Z) as would be expected if heaving does not occur.

It has been realized that an increase in surface resolution would likely increase the precision of model results which are of small magnitude like what ensued at Station 16. Additionally, inclinometer and extensometer data could be calibrated to a similar 3D SVSolid ${ }^{\mathrm{TM}}$ model if data sets were available. This could be accomplished by the incorporation of cylinders within SVSolid ${ }^{\mathrm{TM}}$ extended to a known depth. This option is available, but greatly increases model run times and can crash the model if computing power is not adequate. Increases in surface resolution is possible and can be accomplished using the AutoCADD Civil $3 \mathrm{D}^{\mathrm{TM}}$ grid feature. Future versions of SVSolid ${ }^{\mathrm{TM}}$ may allow the incorporation of additional layering. Greater model precision may result if layering possibilities include topographic intersection of surfaces.

Figure 6.28 shows the trend of PCC with increasing offsets. The offset distances graphed were taken to be the perpendicular distance from the station to the mine panel. The offset distances were calculated to be:

- Station 934: Over Panel 7I - Linear offset ranged (0 ft. - 2,000 ft.)

- Station 931: 1,125 ft. perpendicular distance - Linear offset ranged (1,000 ft. - 3,000 ft.)

- Station 16: 2,375 ft. perpendicular distance - Linear offset ranged (2,400 ft. $-3,800 \mathrm{ft}$.)

Table 6.20 presents the summary PCC values and associated maximum error and level of detail for each station. 


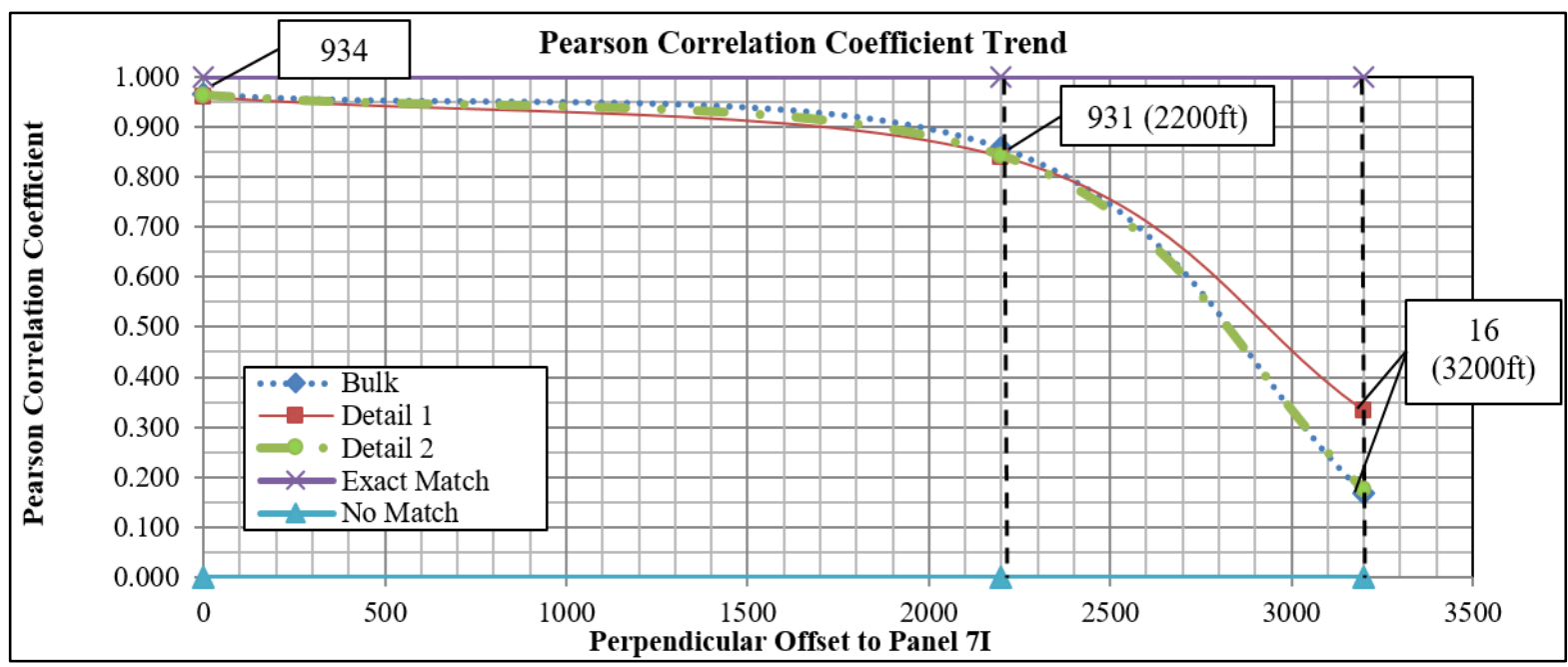

Figure 6.28 Pearson's Correlation Coefficient (PCC) for each level of model detail

It is important to recognize that the mine progress changed the offset distances per increment mined. These distances are listed in Table 6.18, Table 6.19, and Table 6.20 for the calibration of each of the three stations investigated. Possible reasons for the decrease in correlation with distance could be due to the decreasing distance between each station and the edge of the model, increasing chaos in the calculation at a distance, or a need of greater surface resolution.

Table 6.20 PCC and maximum error for each level of detail

\begin{tabular}{|c|c|c|c|c|c|c|}
\hline \multicolumn{7}{|c|}{ Pearson Correlation Coefficients \& Error } \\
\hline Station & Bulk, r & $\begin{array}{c}\text { Bulk } \\
\text { Maximum } \\
\text { Error (ft) }\end{array}$ & Detail 1, r & $\begin{array}{c}\text { Detail 1 } \\
\text { Maximum } \\
\text { Error (ft) }\end{array}$ & Detail 2, r & $\begin{array}{c}\text { Detail 2 } \\
\text { Maximum } \\
\text { Error (ft) }\end{array}$ \\
\hline $\mathbf{9 3 4}$ & 0.97 & 0.83 & 0.96 & 0.65 & 0.96 & 0.55 \\
\hline $\mathbf{9 3 1}$ & 0.86 & 0.03 & 0.84 & 0.02 & 0.84 & 0.02 \\
\hline $\mathbf{1 6}$ & 0.17 & 0.02 & 0.33 & 0.01 & 0.18 & 0.01 \\
\hline
\end{tabular}

Pearson's Correlation Coefficient (PCC) decreased with distance but maintained strong linear correlation for Station 931 which ranged in offset distance from 1,000 ft. to 3,000 ft. Detail 2 did not trend well for Station 16. Detail 1 provided the highest PCC for Station 16 by a factor of 2x. Detail 1 model data trended best over the course of the model calibration while maintaining the strongest linear correlation out of the 66 model runs (6 sets of 11 models). As a result, Detail 1 models were chosen to move forward with stress/strain analysis and sensitivity analysis. 
These conclusions fulfill Objective \#2.1 from Section 1.3.1:

Objective \#2: Utilize finite element analysis to determine altered shallow near-surface ground deformations and stress field changes which ensued at the Ryerson Station Dam. This analysis includes:

2.1 Calibration to Ryerson Station State Park monitoring field data and verification of model precision.

\subsection{Parameter Correlation and Sensitivity: Stress and Displacement Analysis}

Model results were compiled for all eleven 3D Detail 1 models. These results included stresses (psi) and displacements (ft.) in the $\mathrm{X}, \mathrm{Y}$, and $\mathrm{Z}$ directions with respect to the model orientation for each of 15 monitoring stations. Each survey monitoring station was idealized as a point. Each point had independent X-Y offset distances from directly over the panel at Station 934 to a maximum of 3,800 ft. at Station 16. Each station was located on the same face and similar orientation on a single landform. Linear offsets were planar (X-Y) but can be calculated using data from Table A9 (16). Graphs were created from these data with stress versus displacement and linear offset. This generated 6 independent graphs for each survey monitoring point totaling 90 graphs. These graphs were compiled into 6 summary graphs to better observe trends in the data.

The differential depth from the monitoring point to the mining was tracked but was not investigated further. Conventional subsidence theory considers depth to delay the final magnitude of subsidence (Singh, 1992). Table 6.21 provides ranking for the differential depth of mining with respect to maximum resultant stress in the $\mathrm{X}, \mathrm{Y}$, and $\mathrm{Z}$ (ft.) directions. Light gray cells indicate equal elevation. Dark gray cells indicate small insignificant differences in the station stress result. Depth did not have an apparent significant effect on model results; however, may have played a role in the correlation of data in the calibration study. Future studies may benefit from further investigation of depth in association with other governing factors that influence stresses. Figure A4, Figure A5, and Figure A6 present the total results of stress versus depth. 
Table 6.21 Monitoring station ranking for differential depth with respect to stress $(X, Y, Z)$

\begin{tabular}{|c|c|c|c|c|}
\hline \multicolumn{5}{|c|}{ Maximum Stress Impact } \\
\hline Relative Elevation (ft) & $\begin{array}{c}\text { Depth from Elevation: } \\
\text { Least to Greatest }\end{array}$ & $\mathbf{X}$ & $\mathbf{Y}$ & $\mathbf{Z}$ \\
\hline 540 & 13 & 922.1 & 922.1 & 922.1 \\
\hline 545 & 14 & 922 & 922 & 922 \\
\hline 550 & 918 & 926 & 921 & 926 \\
\hline 555 & 921 & 921 & 926 & 921 \\
\hline 560 & 922 & 17 & 17 & 918 \\
\hline 560 & 16 & 918 & 918 & 13 \\
\hline 570 & 922.1 & 931 & 14 & 14 \\
\hline 580 & 17 & 13 & 931 & 931 \\
\hline 580 & 931 & 14 & 13 & 17 \\
\hline 580 & 927 & 928 & 928 & 927 \\
\hline 585 & 926 & 929 & 929 & 928 \\
\hline 590 & 930 & 16 & 16 & 929 \\
\hline 590 & 929 & 927 & 927 & 930 \\
\hline 590 & 928 & 930 & 930 & 16 \\
\hline
\end{tabular}

Fifteen survey monitoring stations were plotted versus displacement and linear offset in regards to Panel 7I. Each of the 3 parameters were broken into X, Y, and Z components for comparison. Six summary plots were created to better observe the data trends. These 6 summary plots were

- Stress vs. displacement in $\mathrm{X}, \mathrm{Y}$, and $\mathrm{Z}(3 \mathrm{x})$

- Stress vs. Linear Offset in X, Y, and Z (3x)

Calibrated model resultant stress data was used to create these graphs. A "No Void" case was first run to apply gravity to the model. These results were used as in situ stress for each subsequent model run to simulate an initial condition. The initial stresses are presented in Table A11. The primary objective of this analysis was to identify the primary causal factors that most significantly induce far-field ground strain.

Figure 6.29 shows the graph of all 15 stations for $\mathrm{X}$ stress versus linear offset to each time increment modeled for Panel 7I. Although this is a complex graph, some data trends can be observed. Initial in situ stresses were included in this analysis. Each station exhibited compressive initial stress conditions. Most resultant stresses had negative signage, indicating a tensile force in the $\mathrm{X}$ direction. Table A9 presents the calculated characteristics for each monitoring point. The largely noticeable trends are:

i. No large stress disruptions that significantly deviated from in situ stress conditions occurred until mining approached about 1,200 ft. from each monitoring station. 
ii. Maximum stress magnitudes were greatest for the stations nearest to mining.

iii. Station 934 was directly over Panel 7I and showed different behavior than the other stations

iv. As mining continued past each point, offset distances again increased causing the graph to rebound somewhat along the $\mathrm{X}$ axis.

v. Offset distances were the same at some points, although the $\mathrm{X}$ stress increased greatly for many of the stations after mining began to move past the point.

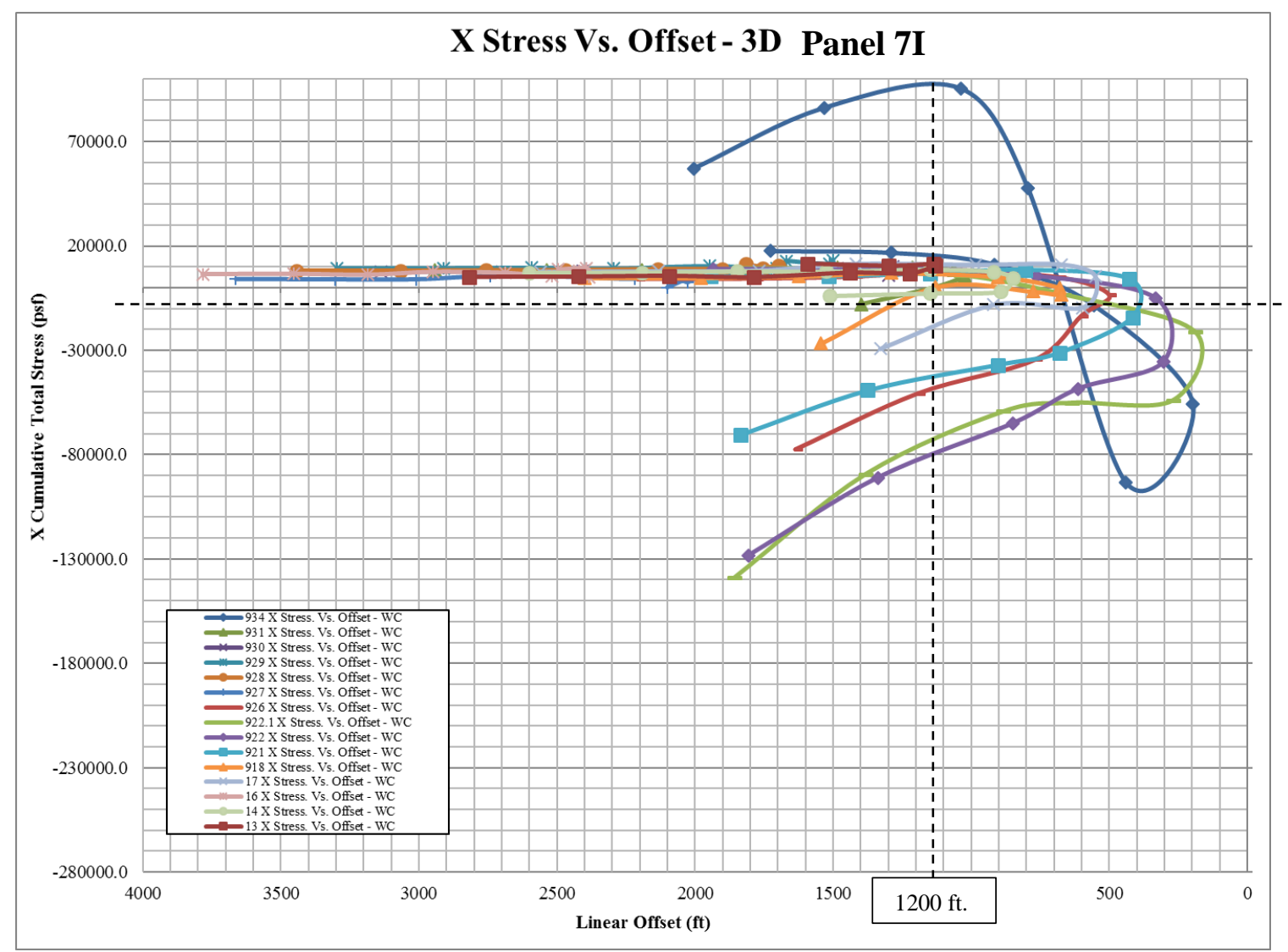

Figure 6.29 All model stations (15x) X stress versus Linear Offset to Panel 7I

Since all of the stations except for 927 and 16 were oriented similarly in the $\mathrm{X}$ and $\mathrm{Y}$ directions, the stress results broken into its components are comparable. Also, SVSolid ${ }^{\mathrm{TM}}$ does not produce resultant vector stresses, but reports on stresses in the $\mathrm{X}, \mathrm{Y}$, and $\mathrm{Z}$ directions. All 15 stations were also graphed with linear offset for stress in the $\mathrm{Y}$ direction. The noticeable data trends are similar to the results for $\mathrm{X}$ stress, except the stress magnitudes differ. Most stresses had negative signage, indicating a tensile stress in the Y direction. Figure 6.30 presents the model resultant $Y$ stress for each of the 15 stations. Table A9 shows the detailed calculations for each station. 


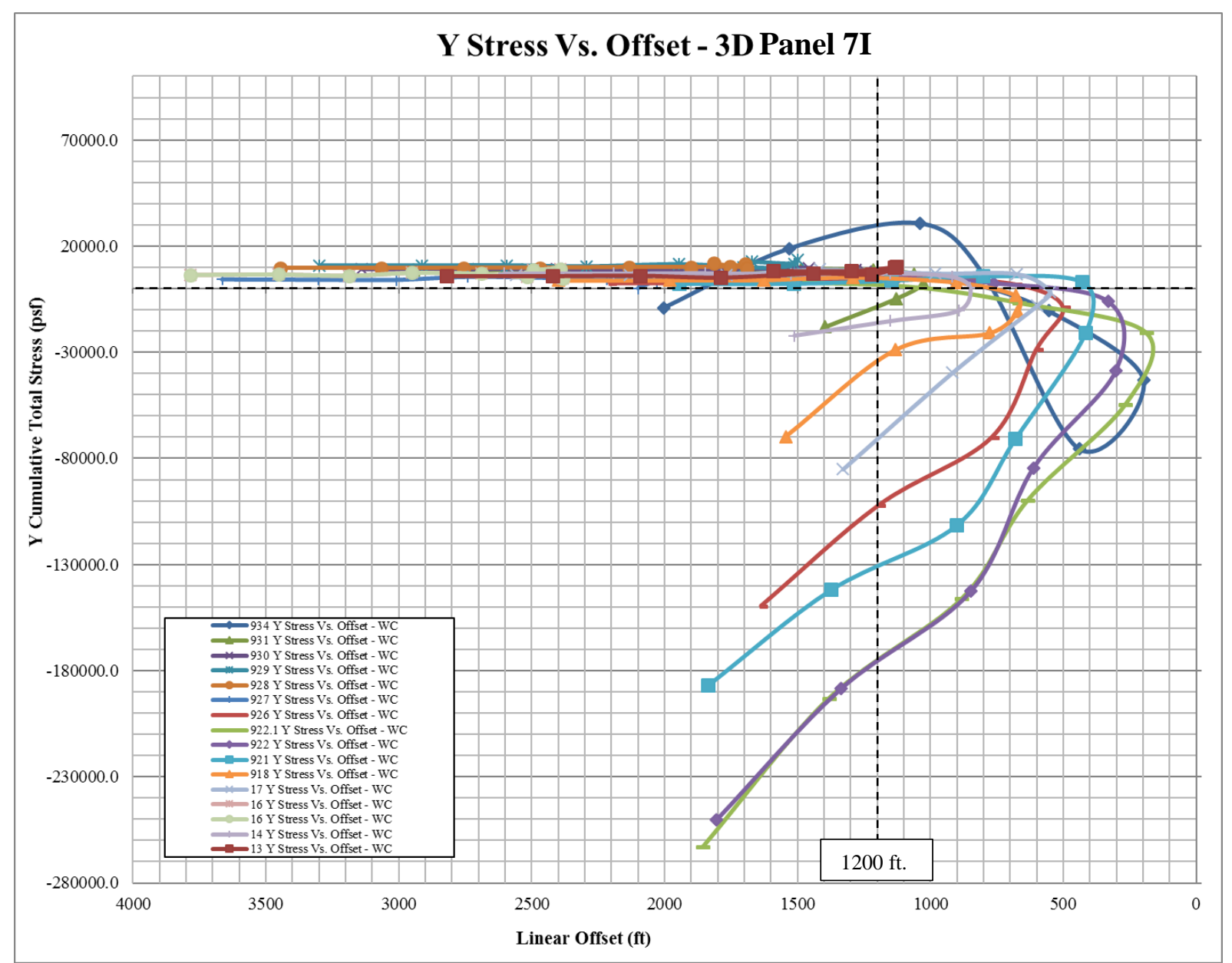

Figure 6.30 All model stations (15x) Y stress versus Linear Offset to Panel 7I

Stress versus linear offset was also graphed for the $\mathrm{Z}$ direction. Similar to the $\mathrm{X}$ and $\mathrm{Y}$ direction, stress changes begin to deviate from the initial stress state at 1,200-1,400 ft. The shape of the graph differs from the $\mathrm{X}$ and $\mathrm{Y}$ graphs, however as some of the stresses were positive and some were negative, indicating compressive stresses at some stations and tensile stresses at other stations in the $\mathrm{Z}$ direction. This result depends on where each station is oriented in the stress regime along the slope. Figure 6.31 provides the $\mathrm{Z}$ stress versus linear offset distance graph. Table A9 provides detailed information about each station. 


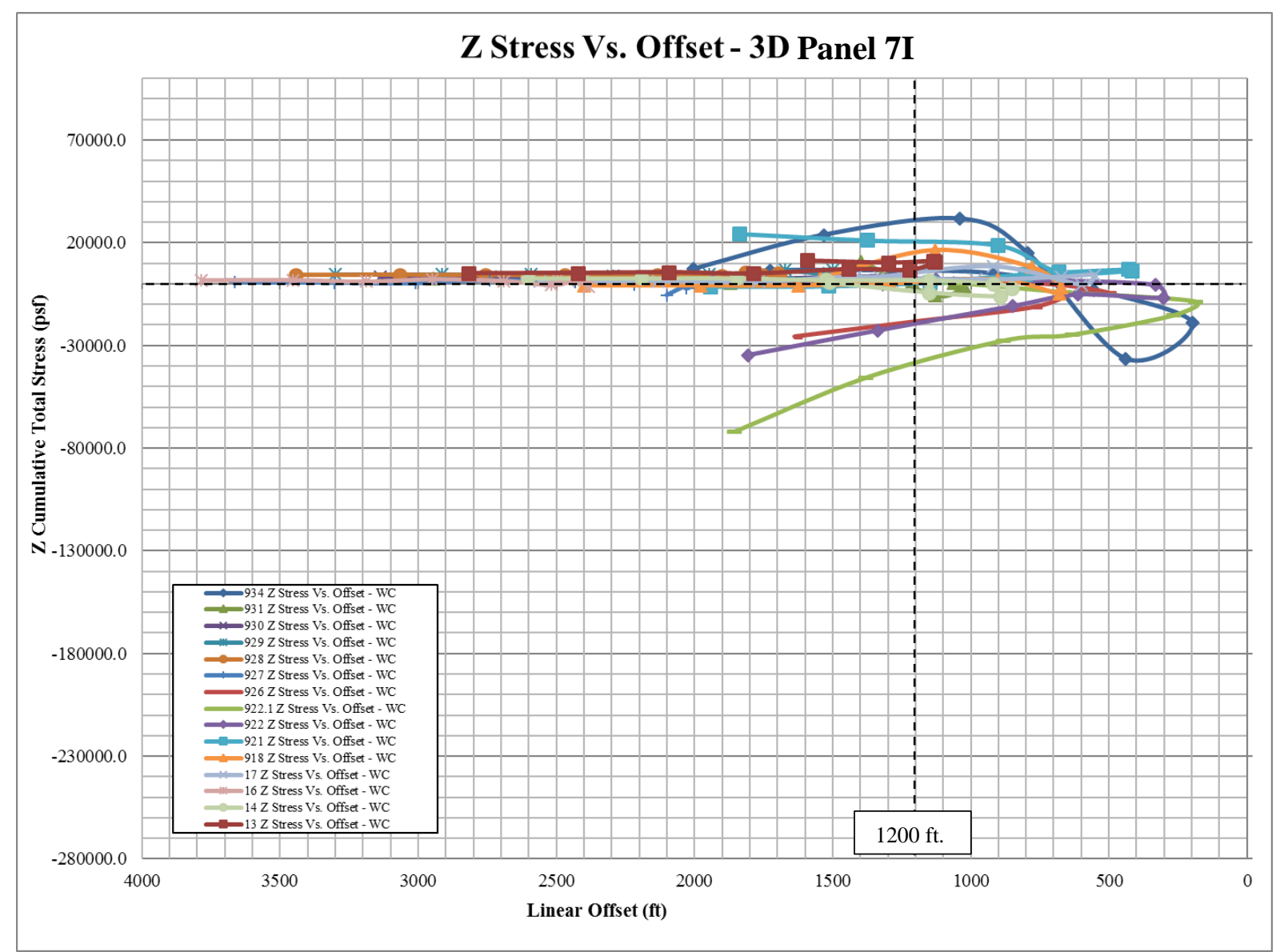

Figure 6.31 All model stations (15x) Z stress versus Linear Offset to Panel $7 I$

The maximum stress magnitude was ranked from the greatest to least (1-15) for each of the 3dimensional directions (X, Y, and Z) to identify any dissimilarity in data trends. In general, the maximum stress magnitude is expected to decrease with increasing offset distance. Therefore, any inconsistency in ranking would indicate that other factors are influencing the result. Table 6.22 shows the stress ranking.

Stations with stress ranking within 1 rank of the offset rank were considered as acceptable. Any station with inconsistent ranking greater than 1 place was highlighted as white. The dark gray cells were essentially equivalent small magnitude stresses with little deviation from the initial stress conditions in all directions. Light gray cells were acceptable rankings. 
Table 6.22 Station ranking for maximum stress impact and offset

\begin{tabular}{|c|c|c|c|c|c|}
\hline \multirow{2}{*}{ Coordinate } & Rank & $\mathbf{x}$ & $\mathbf{y}$ & $\mathbf{z}$ & Offset \\
\hline \multirow{4}{*}{} & 1 & 922.1 & 922.1 & 922.1 & 922.1 \\
\cline { 2 - 6 } & 2 & 922 & 922 & 922 & 922 \\
\cline { 2 - 6 } & 3 & 926 & 921 & 926 & 921 \\
\cline { 2 - 6 } & 4 & 921 & 926 & 921 & 926 \\
\cline { 2 - 6 } & 5 & 17 & 17 & 918 & 17 \\
\cline { 2 - 6 } & 6 & 918 & 918 & 13 & 918 \\
\cline { 2 - 6 } for stress & 7 & 931 & 14 & 17 & 14 \\
\cline { 2 - 6 } & 8 & 14 & 931 & 931 & 931 \\
\cline { 2 - 6 } & 9 & 927 & 930 & 14 & 13 \\
\cline { 2 - 6 } & 10 & 13 & 13 & 930 & 930 \\
\cline { 2 - 6 } & 11 & 930 & 929 & 929 & 929 \\
\cline { 2 - 6 } & 12 & 929 & 928 & 928 & 928 \\
\cline { 2 - 6 } & 13 & 928 & 927 & 927 & 927 \\
\cline { 2 - 6 } & 14 & 16 & 16 & 16 & 16 \\
\hline
\end{tabular}

Station 934 was excluded in the rankings as it was directly over Panel 7I for a portion of time and was expected to incur deformations. The behavior of the stresses and deformations at Station 934 was also not consistent with the behavior of the stations that were not over the mine panel; therefore, the results at Station 934 were not compared to the other 14 stations.

The stress rankings revealed that Station 17, Station 13, and Station 14 do not have a consistent ranking for stress in the $\mathrm{Z}$ direction. Each of these stations was located at the base of a gentle concavity between two landforms. It is suspected that stresses from each landform converged along this concavity, resulting in anomalously higher stresses than compared to stations along the hillside face.

Station 927 also had an inconsistent ranking. The geometric orientation of Station 927 was almost perfectly perpendicular to the $\mathrm{x}$-axis; therefore, any most all movement at this station would occur in the x direction, biasing the rank. All other stations follow approximately the same orientation to the hillside. The location of these stations can be observed in Figure 6.32 and Figure 6.33.

\subsubsection{Model Result Assessment}

The model results were investigated to understand the overall movement of the stations. Differences at each station were sought to gain insight into the dynamic nature of the 3D model scenario. The results of three stations $(922.1,921$, and 13) were isolated to assess their differences. Station 922.1 was selected since it was closest to the mine panel with the highest $-Z$ tensile stress overall. Station 921 had the highest compressive stress in the $\mathrm{Z}$ direction and was just downhill from Station 922.1. Station 13 was furthest away with anomalous offset distance 
ranking in $+Z$ compressive stress. Station 922.1, Station 922, and Station 13 are outside of the typical (15-30 degrees) angle of draw for this region. Additionally, each station was as close or closer to Panel 7I at a perpendicular distance than Station 931 which had a near perfect correlation of model result data at a PCC of $r \geq 0.84$ in the calibration model evaluation. As a result, the model produced stresses and displacements are expected to have a high linear correlation with field measurements.

Figure 6.32 and Figure 6.33 were developed to generalize the movements and stresses at each station. When inspecting Figure 6.32 and Figure 6.33 it is important to realize that the trend of the data was denoted with signage, but the entire data set is not represented in these figures. The overall final movement is denoted with a negative or positive signage for the $\mathrm{X}, \mathrm{Y}$, and $\mathrm{Z}$ directions. Heaving $(+Z)$ movement was expected at the lower stations. Upper stations were expected to move down-slope (-Z). The $\mathrm{X}$ and $\mathrm{Y}$ movements were expected to result as downhill movement consistent with the slope.

These assumptions did not hold true in all cases, in fact, most stations developed heaving $(+\mathrm{Z})$ after Station 921 (>365 ft. perpendicular distance from Panel 7I). The station coordinates are provided in Table 6.23 for understanding of the distances between each station relative to the model.

Table 6.23 Station Coordinates

\begin{tabular}{|c|c|c|c|}
\hline Point ID & $\mathbf{X}(\mathbf{f t})$ & $\mathbf{Y}(\mathbf{f t})$ & $\mathbf{Z}(\mathbf{f t})$ \\
\hline $\mathbf{9 3 4}$ & 1995 & 905 & 575 \\
\hline $\mathbf{9 2 2 . 1}$ & 1855 & 1180 & 575 \\
\hline $\mathbf{9 2 2}$ & 1790 & 1335 & 565 \\
\hline $\mathbf{9 2 1}$ & 1800 & 1465 & 555 \\
\hline $\mathbf{9 2 6}$ & 1560 & 1600 & 560 \\
\hline $\mathbf{1 7}$ & 1210 & 1650 & 575 \\
\hline $\mathbf{9 1 8}$ & 1400 & 1750 & 555 \\
\hline $\mathbf{1 4}$ & 1250 & 1950 & 540 \\
\hline $\mathbf{1 3}$ & 1125 & 2225 & 535 \\
\hline $\mathbf{9 3 1}$ & 950 & 2125 & 580 \\
\hline $\mathbf{9 3 0}$ & 825 & 2335 & 585 \\
\hline $\mathbf{9 2 9}$ & 765 & 2585 & 570 \\
\hline $\mathbf{9 2 8}$ & 700 & 2775 & 570 \\
\hline $\mathbf{9 2 7}$ & 640 & 3100 & 570 \\
\hline $\mathbf{1 6}$ & 765 & 3475 & 515 \\
\hline
\end{tabular}

The $\mathrm{Y}$ coordinate for the edge of Panel 7I was 1,100 ft. In general, the survey stations displaced in the negative $-\mathrm{X},+\mathrm{Y}$, and $+\mathrm{Z}$ after direct panel effects ceased beyond Station 921 . Some stations exhibited differing behavior which is a direct result of its position on the landform. 
There were tensile forces developed along the slopes and also due to the introduction of the mine void. Station 922.1, Station 921, and Station 13 results were isolated to investigate specific behavior of each point with time. 


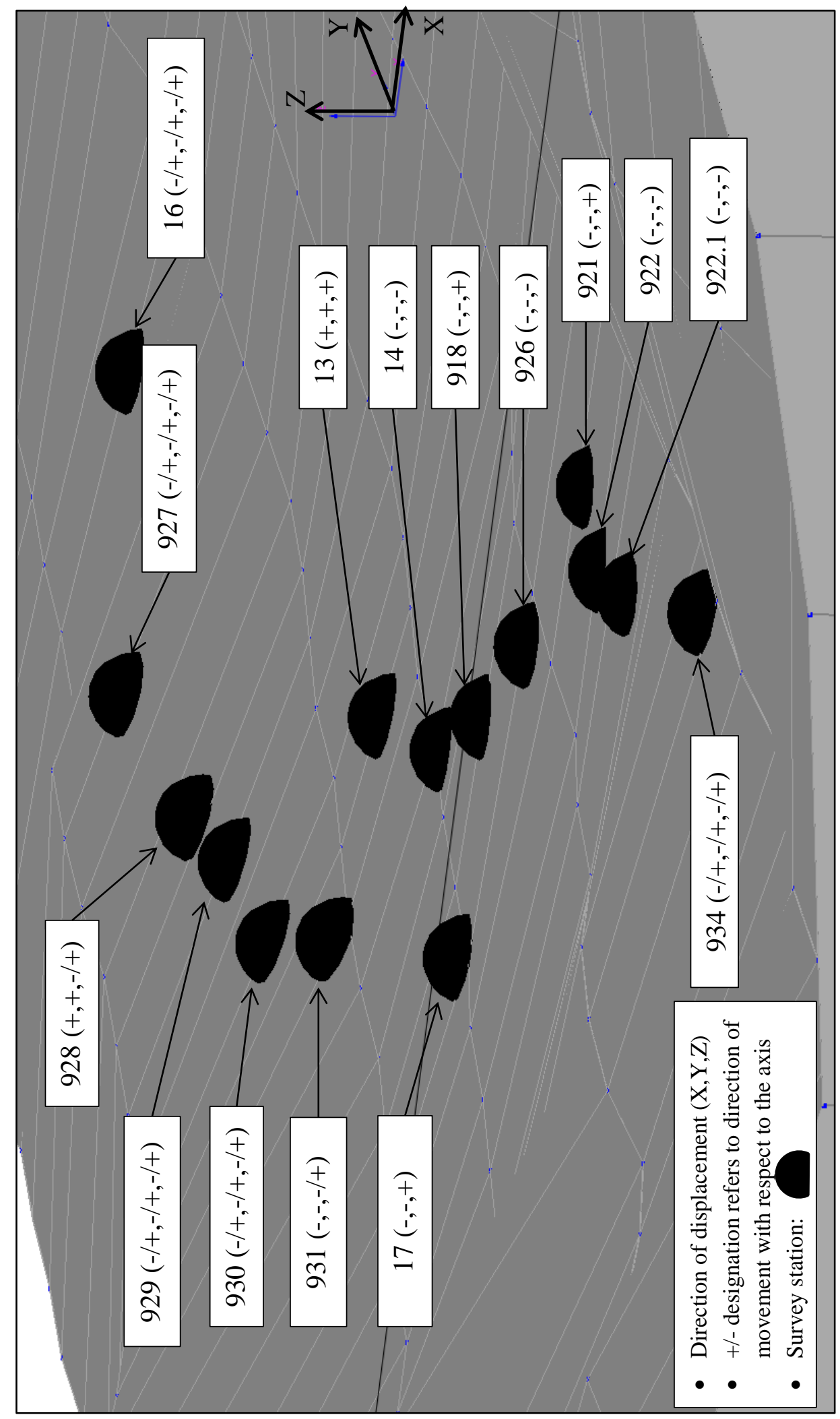

Figure 6.32 Directional stress trend per station 


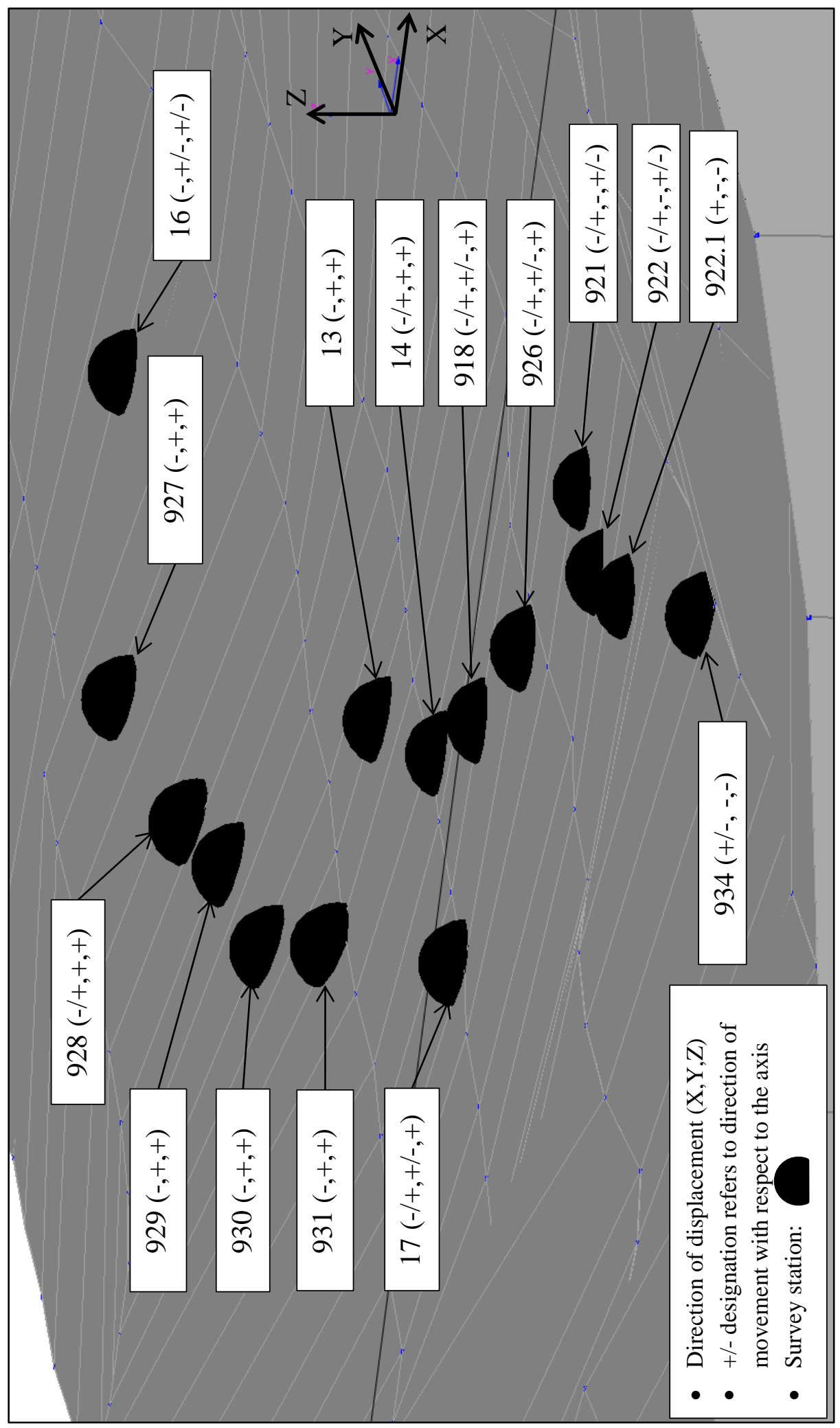

Figure 6.33 Directional displacement trend per station 


\subsubsection{Sensitivity Analysis of Stress and Displacement}

Figure 6.34 through Figure 6.39 are presented to show stress and displacement in the $\mathrm{X}, \mathrm{Y}$ and Z directions for Station 13, Station 922.1, and Station 921. The station selection for the sensitivity analysis was investigated in Section 6.5.1. The initial extraction region (R11), final extraction region (R2), and extraction region at which the landform was encroached (R7) are denoted. These curves were developed to observe stress and displacement data trends with respect to topographic influence and linear offset.

Figure 6.34 shows stress (psf) in the $\mathrm{X}$ direction versus linear offset for the ten extraction regions (R11-R2) for the Worst Case (WC) 3D stress/displacement modeling. Station 13 behaves differently than Station 922.1 and Station 921 . The stresses become increasingly compressive after the landform is encroached, and changes directions at R6 instead of R7 as is the case for Station 922.1 and Station 921. Stresses increase in magnitude after the landform is encroached for each station with increasing offset distances and increasing topographic relief.

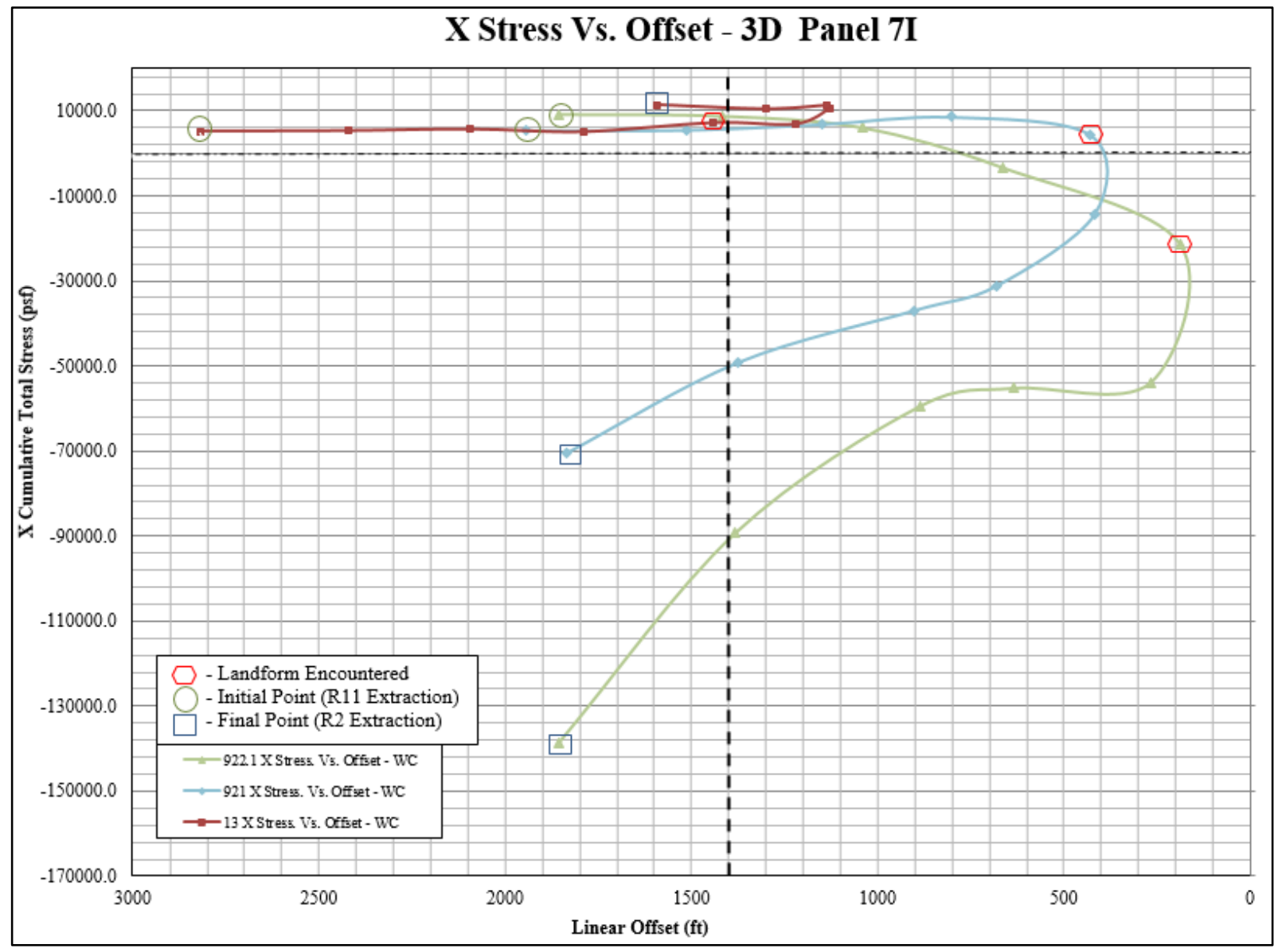

Figure 6.34 X Stress (psf) versus Linear Offset distance (ft.) 
Figure 6.35 presents stress versus displacement for the $\mathrm{X}$ direction. Each point on the curves represents stress and displacement results for one of the ten extraction region models. Station 13 did not experience large magnitude displacements in the X direction. Station 922.1 and Station 921 accrued proportionally larger displacements in the X direction than Station 13. Both Station 922.1 and Station $921 \mathrm{X}$ displacement data trends were in the positive, down-slope direction while experiencing large tensile stresses. The signage of each $\mathrm{X}$ displacement for all three stations changed during the modeling. Station 921 and Station 922.1 displacements moved toward the -X direction at R6. Tensile stresses for Station 921 and Station 922.1 continued to accrue as additional extraction regions were removed.

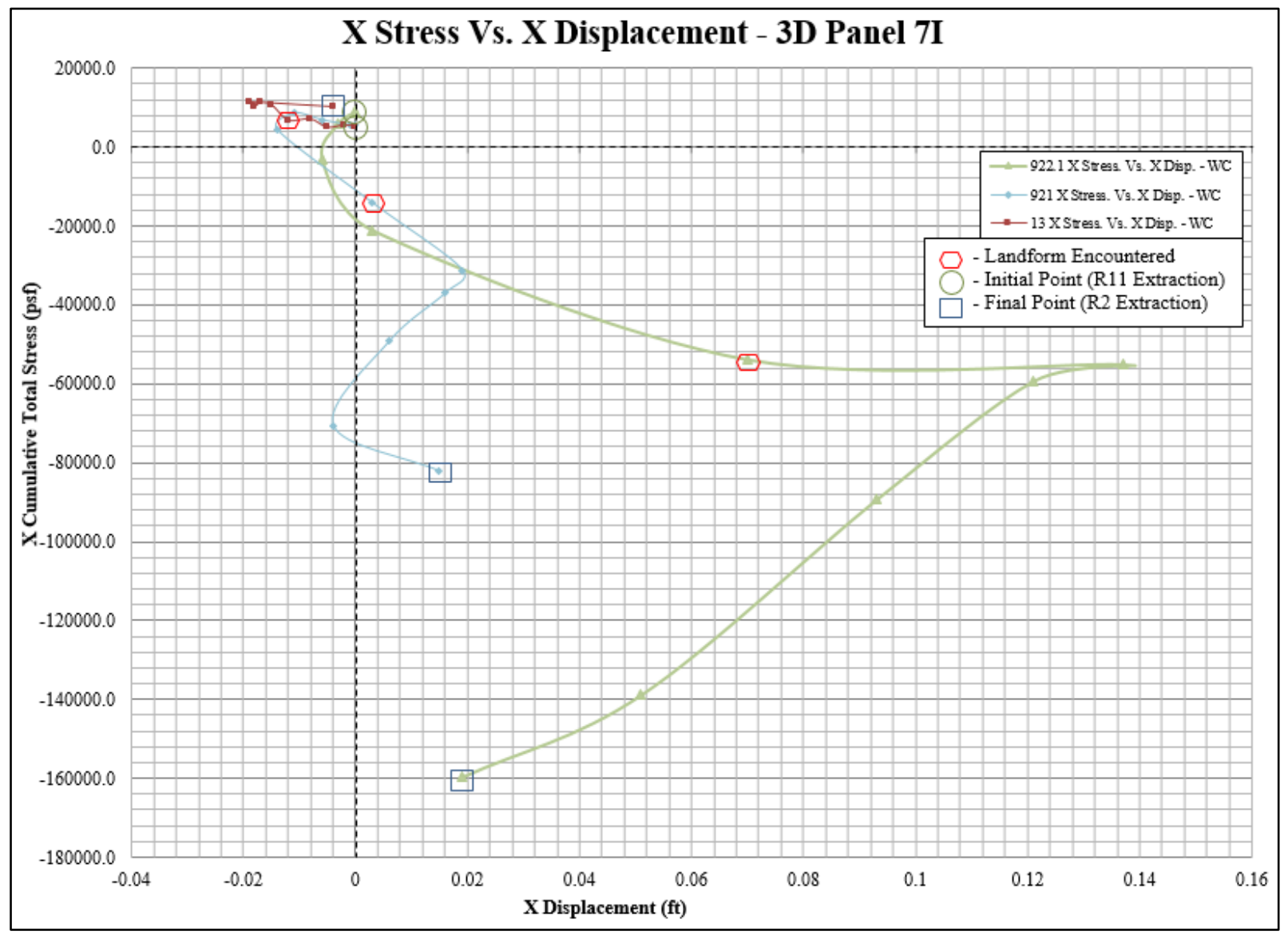

Figure 6.35 X Stress (psf) versus X Displacement (ft.)

Figure 6.36 presents model results for stresses in the Y direction versus linear offset for Station 921, Station 922.1, and Station 13. Station 13 did not experience large magnitude stresses, but did experience a small compression. Station 922.1 and Station 921 endured large magnitude tensile stresses in the $\mathrm{Y}$ direction. These stresses continued to increase in magnitude after the landform was encroached at R7. The linear offset increases toward the conclusion of the curves at R2. In this case the stresses would be expected to decrease, but increase instead. The topographic relief increased as extraction regions were removed past R7. 


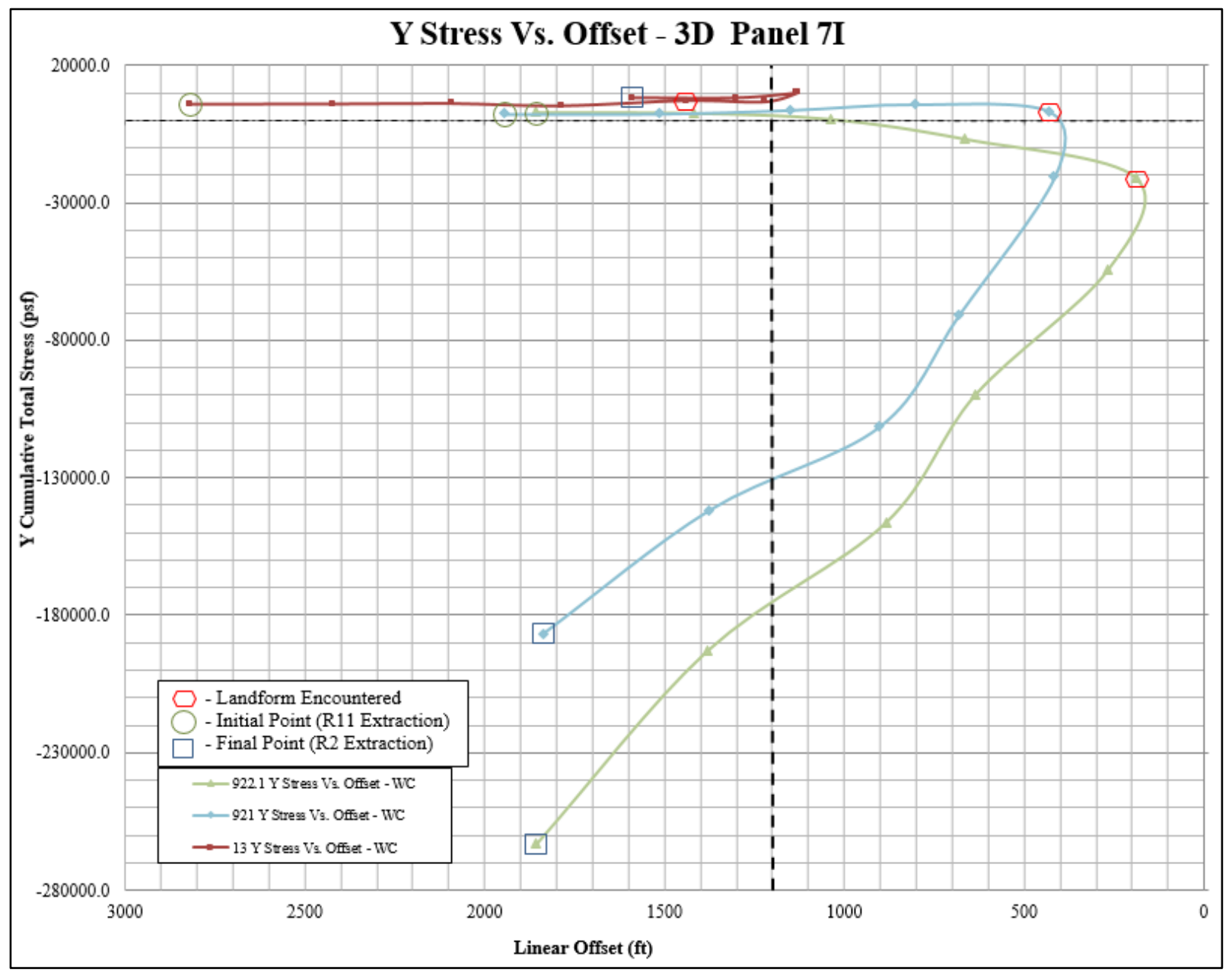

Figure 6.36 Y Stress (psf) versus Linear Offset (ft.)

Displacement versus stress in the $\mathrm{Y}$ direction was graphed and is presented in Figure 6.37. Station 13 moved about $0.08 \mathrm{ft}$. in the $+Y$ direction. Station 921 and Station 922.1 moved in the opposite direction. No noticeable change in direction or magnitude is shown upon the landform being influenced by the $\mathrm{R} 7$ extraction region. 


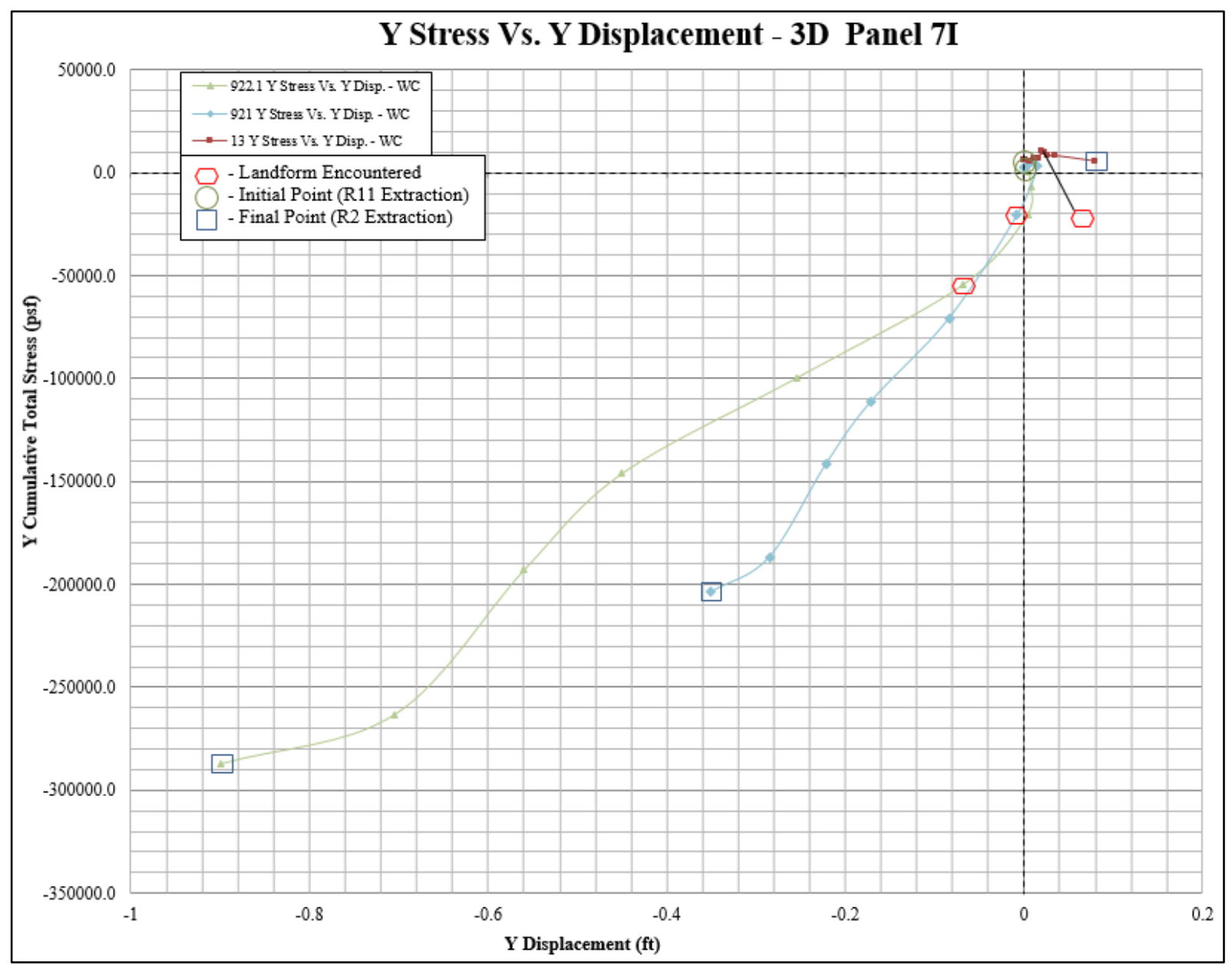

Figure 6.37 Y Stress (psf) versus Y Displacement (ft.)

Figure 6.38 presents model results for stress versus offset in the $\mathrm{Z}$ direction for Station 921 , Station 922.1, and Station 13. Station 13 and Station 921 yielded compressive stresses in the Z direction, while Station 921 experienced tensile stresses. The stresses at each station continued to increase in magnitude after R7 at increasing offset distance and topographic relief. Stress magnitudes increased predominantly after the landform was encroached at R7. 


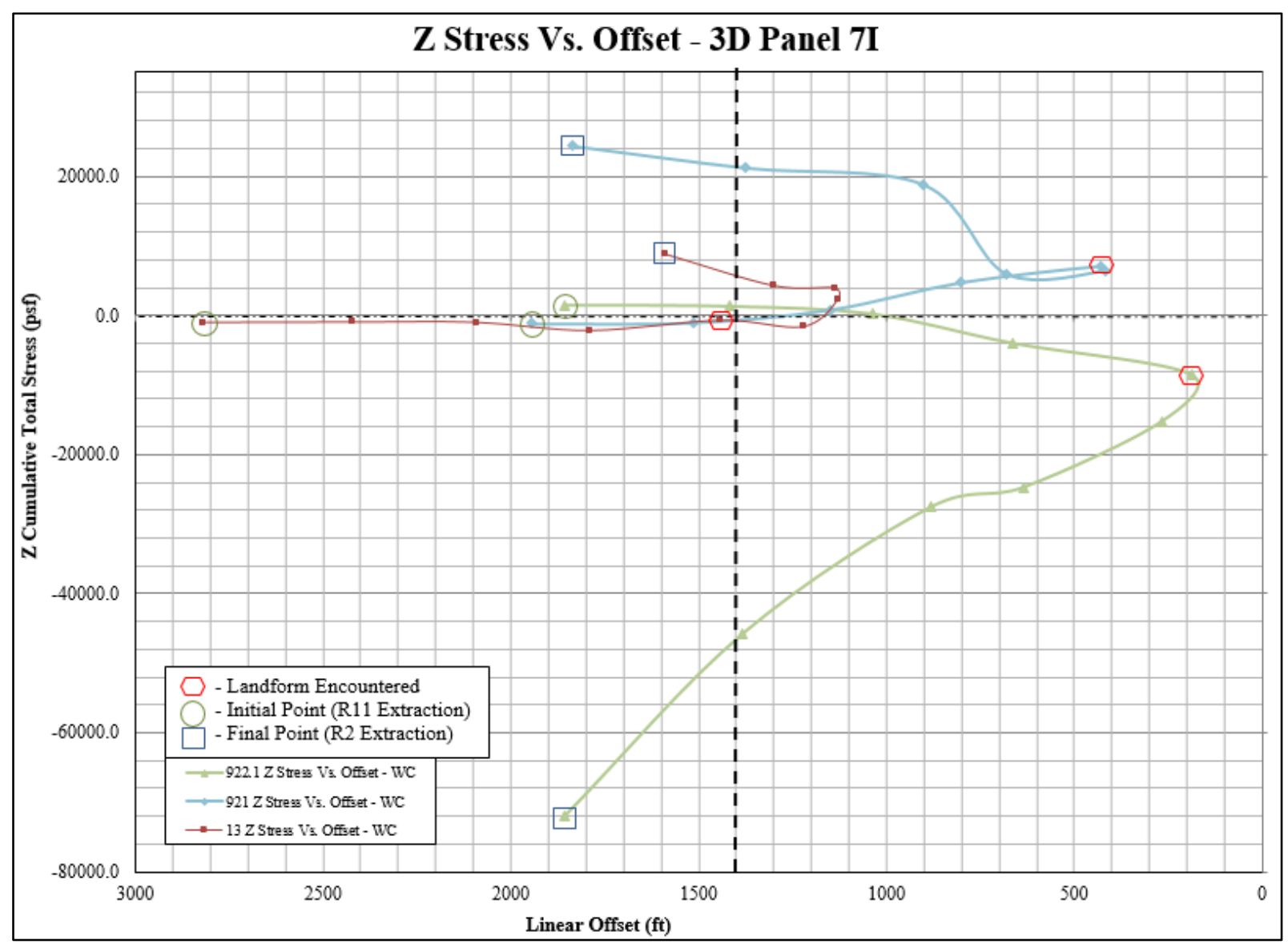

Figure 6.38 Z Stress (psf) versus Linear Offset (ft.)

Stress versus displacement was graphed for Station 921, Station 922.1, and Station 13 and is presented in Figure 3.39. All three stations behaved differently in Z displacement direction and magnitude. Station 13 experienced compression and a $+Z$ heave. Station 921 underwent constant and increasing compression and a change in direction of the displacement in the $\mathrm{Z}$ direction from $+Z$ (R11-R8) to $-Z$ (R7-R2). Station 922.1 endured large magnitude tensile stresses and displacement in the $-Z$ direction. Displacement and stress magnitudes continued to increase in the $\mathrm{Z}$ direction as extraction regions were removed from R11-R2. 


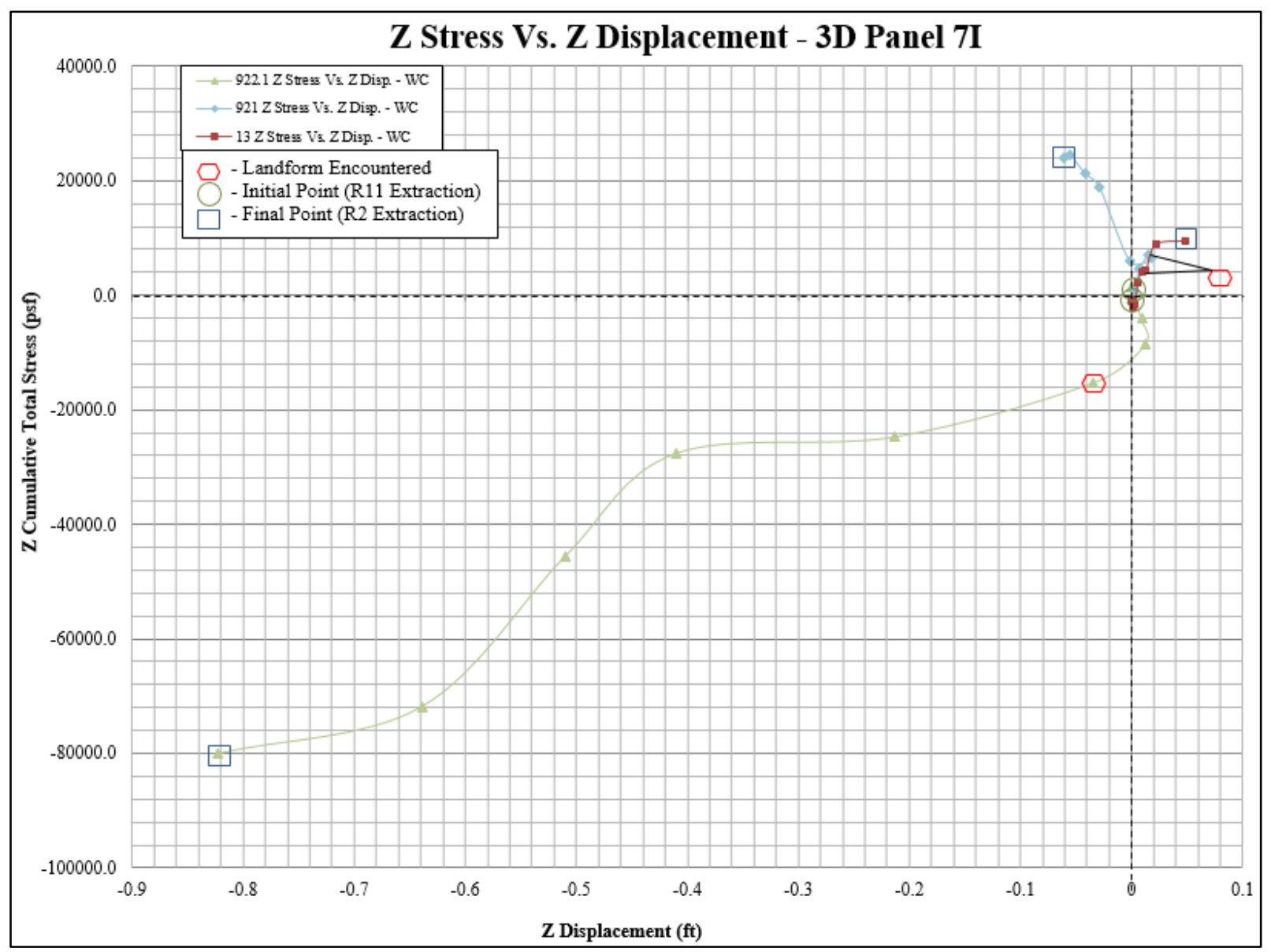

Figure 6.39 Z Stress (psf) versus Z Displacement (ft.)

\subsubsection{Station 922.1 Model Result}

Station 922.1 was chosen to investigate stress magnitudes in the $\mathrm{X}, \mathrm{Y}$, and $\mathrm{Z}$ directions since it had the closest perpendicular offset and largest magnitude stresses in each of the $\mathrm{X}, \mathrm{Y}$, and Z directions. This station was within the angle of draw during R7 (19 degrees) and R6 (27 degrees) region extraction. All other extraction region influences were outside of the angle of draw for Station 922.1. This station exhibited tensile stress components in the $\mathrm{X}, \mathrm{Y}$, and Z directions.

The direction of displacement was $(-,+,+)$ as mining approached the point and was within the initial landform along the eastern edge of the model extents. After mining passed the point, the displacement directions changed to $(+,-,-)$, directly opposite of the initial directions. This change occurred as a result of the location of the point in the topographic surface. Station 922.1 was located just between the western landform and the eastern landform. The observation of displacement direction change indicates that the movement at a specific time is dependent on the location of the point with respect to the surface features. 
The stress that accrued at Station 922.1 was always increasing for the duration of the modeling from R11 to R2. As extraction regions were removed, the vertical relief of the western landform increased. This disruption resulted in continually increasing stresses at Station 922.1. The displacement of 922.1 was away from the affected landform in the $\mathrm{X}$ direction, and toward the panel in the $\mathrm{Y}$ and $\mathrm{Z}$ directions. The displacement trends can be described as a down-slope (-X, $+Y)$ heave $(+Z)$ from the eastern landform from R11-R8, and a down-slope displacement of the western landform $(+X,-Y,-Z)$ from R7-R2.

Table 6.24 shows the model resultant data and assessment. The majority of the developed stress at Station 922.1 came after the landform was encroached at R7. The offset distances are nearly the same before and after R7, although the stress did not increase significantly until the void was introduced at the western landform. 


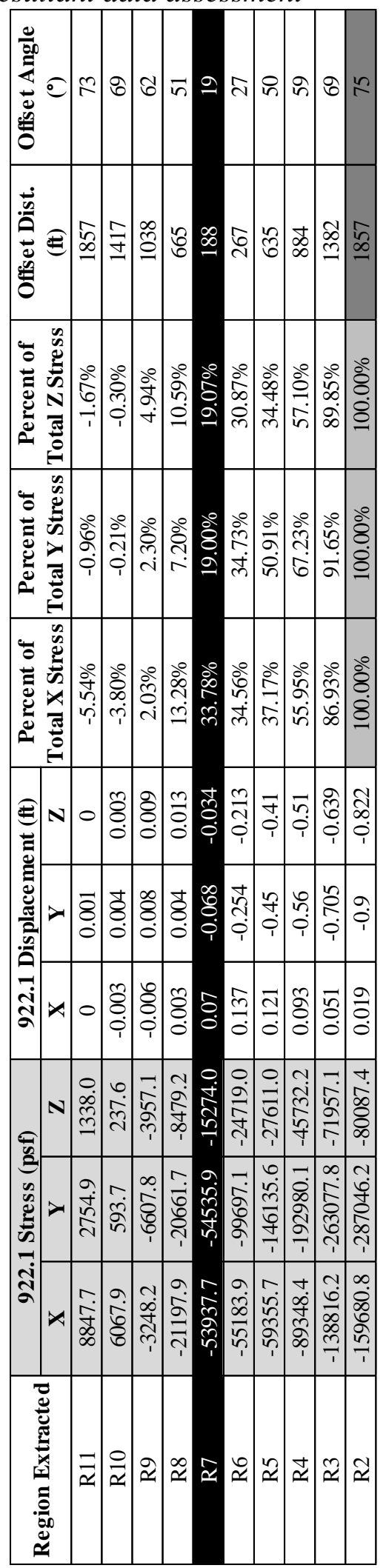


In this case, when mining came to a 19-degree offset angle, the stress began to increase significantly. Remaining stress percentages were $(66 \%, 81 \%, 81 \%)$ with respect to the total encountered stress at Station 922.1 upon reaching extraction region R7. This result is significant; however, the stress was at its greatest when mining was under the ridge of the western landform at an offset angle of 75 degrees. This observation indicates that the landform is of greater significance than the offset. Since a landform has more degrees of freedom than flat ground, effects on one part of the landform have the potential to affect the entire body.

Station 922.1 experienced a changing of direction of displacement, although the stress was continuously in tension in the $\mathrm{X}, \mathrm{Y}$, and $\mathrm{Z}$ directions. While the mining approached Station 922.1 (R11-R7), the displacement was what might be expected; a downhill movement with a slight heave in the $\mathrm{Z}$ direction. After mining passed its closest approach to Station 922.1, the displacement moved away from mining in the $\mathrm{X}$ direction, downhill from the western landform. As mining progressed further, however the displacement began to decrease in the $\mathrm{X}$ direction. The $\mathrm{Y}$ and $\mathrm{Z}$ movements moved toward the mine void. Figure 6.40 shows a $2 \mathrm{D}$ vector displacement trend of the entire model. Voids were introduced in the extraction regions from right (R11) to left (R2). Figure 6.40a shows the combined $x-y$ vectors along the surface after all coal was removed from R11-R2. Figure 6.40b shows the combined $x-y$ vectors along the ground surface for coal removed from R11-R7, when the western landform was encroached, just before the stations were passed by voided extraction regions. Black lines on both figures delineate the approximate region where the opposing forces from subsidence and topography change the $\mathrm{X}-\mathrm{Y}$ stress direction. The topographic lines have been shaded from highest elevation (blue) to lowest elevation (orange).

These differences in vector direction are being referred to as the "Direct mine influence regime" and the "Topographic influence regime." This region generally follows the lower third of the landform, loosely following the contours. The general stress direction follows the slope of the surface to the lowest point of the model. Vector magnitudes are not indicated in Figure 6.40, only $\mathrm{X}-\mathrm{Y}$ direction. All vector lengths were set to be equal for ease in observing stress direction. 

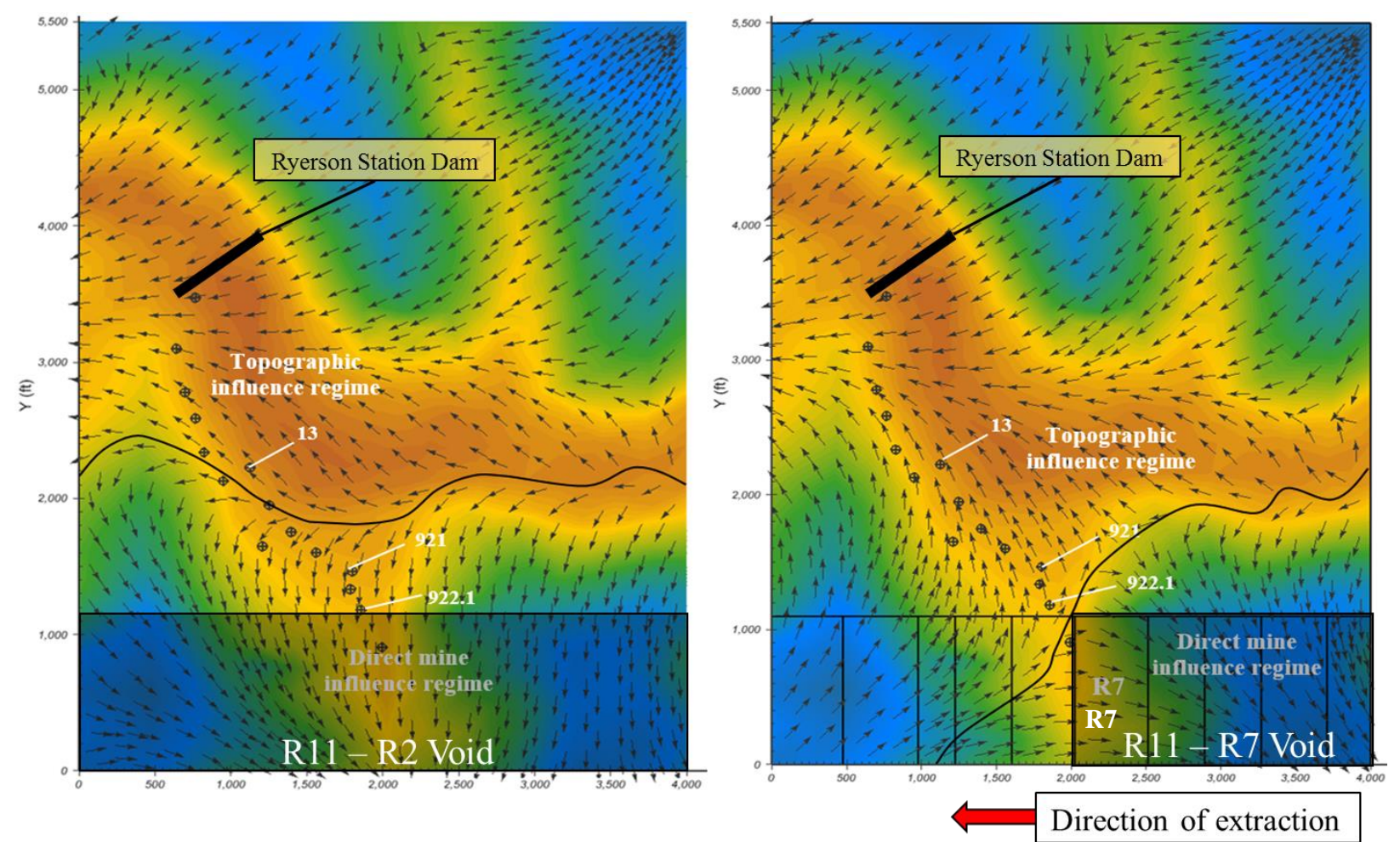

Figure $6.402 D$ displacement vectors (a)Left: All coal removed; (b)Right: Coal removed to $R 7$

\subsubsection{Station 921 Model Result}

Station 921 was similar to Station 922.1 for the $\mathrm{X}$ and $\mathrm{Y}$ stress and displacement but varied in the $\mathrm{Z}$ direction. Station 921 was about $135 \mathrm{ft}$. further away from Panel 7I that Station 922.1 at a perpendicular distance. This was a total perpendicular distance of about $365 \mathrm{ft}$. from Panel 7I. Panel 7I was located at $Y=1,100 \mathrm{ft}$. at its closest northern-most edge along its width. These determinations can be easily calculated from Table 6.23.

Table 6.25 presents the data summary for Station 921. Station 921 experienced compressive forces in the $\mathrm{Z}$ direction, which was different from Station 922.1, however the direction of movement was similar, but smaller magnitude. Comparable to Station 922.1, the direction of displacement changed signage from positive to negative or negative to positive after the landform was encroached (R7) for the X, Y, and Z directions. Also, the stresses did not increase significantly at comparable linear offset distances until the landform was disturbed. Figure 6.34 - Figure 6.39 show the stress and displacements for Station 921 in graphical format in the X, Y, and $\mathrm{Z}$ directions. The initial point (R11) final point (R2) and point at which the landform was encroached (R7) are denoted on the figures. 
Table 6.25 shows that a proportionally small percentage of the total stress encountered at Station 921 occurred up to the extraction region's closest approach at R7-R6. Upon the extraction of R7, about $17 \%$ of stress in the $\mathrm{X}$ direction, $10 \%$ in the $\mathrm{Y}$, and $27 \%$ in the $\mathrm{Z}$ had accrued of the total encountered stress over the course of the modeling. A rapid increase in stress percentage occurred at R6 in the $\mathrm{X}$ and $\mathrm{Y}$ directions occurred, indicating that the closest approach did have influence on the model result at a 39 degree offset angle. The majority of the stresses for Station 921 were encountered after R7 (83\%, 90\%, $73 \%)$.

The displacements and stresses at Station 921 are an example of the opposing near surface forces developed by the landform's mass and the tensile forces developed by the voided extraction regions. The displacements can be described as a down-slope $(-X,+Y)$ heave $(+Z)$ of the eastern landform from R11-R8, and a down-slope (+X, -Y) movement with no heave (-Z) approximately perpendicular to the surface contours from R7-R2. The complexity of the resultant compression at this point in the $\mathrm{Z}$ direction (Table 6.25) compared to tensile forces developed for Station 922.1 at only $135 \mathrm{ft}$. further distance (Table 6.24) accentuate the notion that site specific modeling needs performed to predict these types of stresses and displacements. 


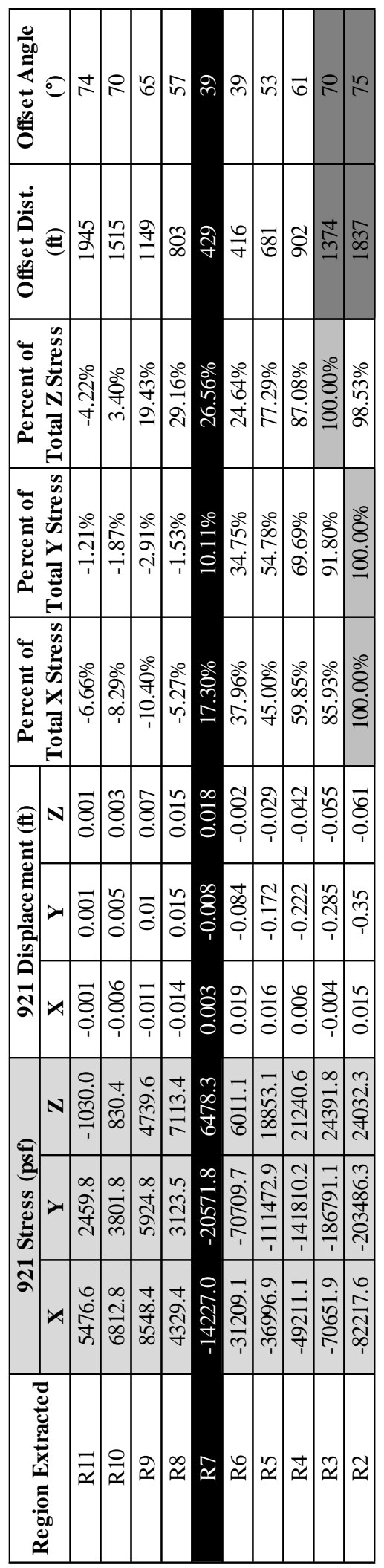




\subsubsection{Station 13 Model Result}

The model results for Station 13 were different than the results of Station 922.1 and Station 921. Station 13 lies between the western and eastern landforms as presented in Figure 6.32. Also, Figure 6.40 and Table 6.23, show that Station 13 had the lowest elevation than any other point other than Station 16. Figure 6.34 - Figure 6.39 show stress versus offset relationship and stress versus displacement for each station.

This location is on the lowest portion of the landform compared to the other stations. The location of Station 13 between the eastern and western landforms likely contributed to the resulting compressive stresses. The maximum stress magnitudes did not result at the end of the mining duration (R2) as expected. Consistent in comparison to Station 922.1 and Station 921, the stresses did not increase significantly until the landform was encroached, but somewhat further away at R8. The maximum compressive stress in the $\mathrm{Z}$ direction initiated after $\mathrm{R} 7$ and reach maximum at $\mathrm{R} 2$.

Table 6.26 presents the model resultant data summary and assessment for Station 13. Unlike Station 922.1 and Station 921, the signage on displacements in the X, Y, and Z directions did not change after the landform was encountered at R7. Displacement values all increased continuously for each extraction region with the exclusion of R2. The displacement trend was toward the lowest elevation of the landform $(-X)$ and downslope $(+Y)$ with a slight heave $(+Z)$.

The maximum stress occurrences were variable for the $\mathrm{X}, \mathrm{Y}$, and $\mathrm{Z}$ directions. All of the extraction regions at which $100 \%$ of the maximum stress was exhibited occurred after R7. Unlike Station 922.1 and Station 921, much of the total stress magnitude was exhibited by the in situ stress condition. Also, the majority of the available total stress magnitude was reached for each direction after R7 (40\%, 33\%, 83\%). This emphasizes that resultant stresses and displacements are highly dependent on the location and orientation of each station. Stresses increased significantly from R7 to R6, but did not reach the closest approach to the station until R5.

Figure 6.40 shows that Station 13 lies just below the break in stresses between the topographic influence regime and the mine influence regime. Station 922.1 and Station 921 lie within the direct mine influence regime. These stresses and displacements are difficult to predict without site specific modeling. 


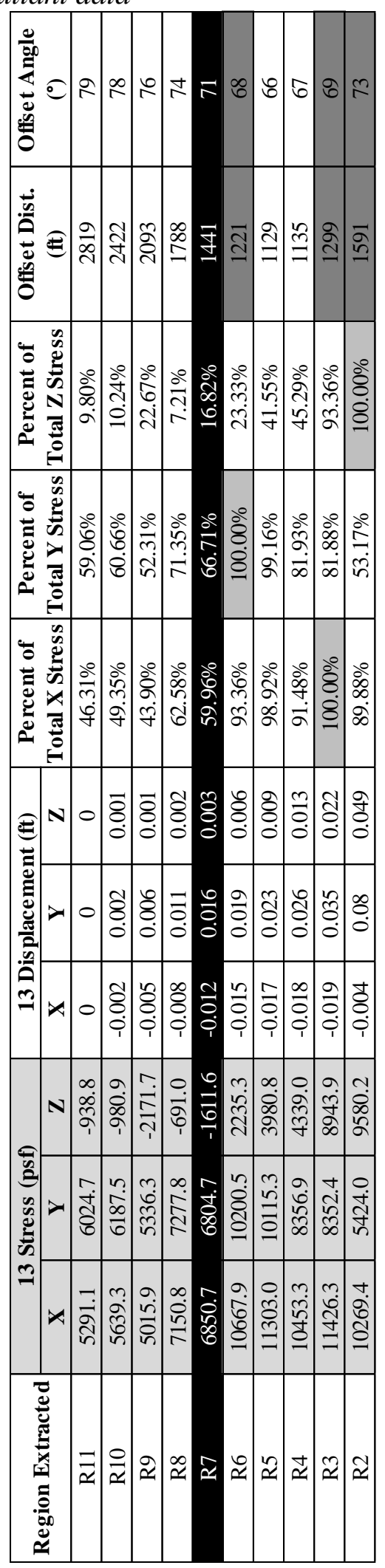




\subsection{Parameter Correlation and Sensitivity Result Summary}

The model results presented in Section 6.5 illustrate the difficulty in prediction of displacement magnitude and direction along a landform due to the introduction of nearby underground voids. The developed 3D model represents one case of a unique topographic feature and the stress and displacement relationship the ground surface has with an underground void.

Topography in Appalachia is highly variable. The influences of varying seam inclination, seam thickness, slope height, slope angle, multiple valley influence, and other specific landform characteristics are yet to be quantified in stress/deformation 3D modeling. This variability produces great difficulty in establishing specific inferences for topographic features. Therefore, case by case site specific model calibration and prediction is recommended in cases of concern for topographic influence of ground movement due to underground mine voids to ensure safety of critical infrastructure. Numerical 3D modeling provides clarity and ease in accounting for these variable parameters. Comparing Station 922.1, Station 921, and Station 13 showed that resulting stresses and displacements were highly sensitive to the orientation and location of each station.

\section{Model Calibration}

The initial step in data reduction after modeling is completed is to subtract a zero mine condition model results from all subsequent model results. This is recommended to calibrate the model to an initial condition. The deformation results from the zero mine void model should be subtracted from subsequent model results to simulate an initial ground response to the introduction of a subsurface void. Initial stresses should be included as the in situ stress condition for the model.

The correlation of the 3D data according to Pearson's Correlation Coefficient (PCC) showed near perfect results for field monitoring stations versus model calibration results for stations within 3,000 ft. linear offset. PCC decreased with distance from the mine void, but may have opportunities to increase by moving stations further from the model edge where the $\mathrm{Z}$ direction incorporated a fixed boundary condition. Geometric refinement could also increase the PCC as it has been found that model surface geometry is of great importance for model results. Model results still yielded values within the same order of magnitude for displacement, although the PCC decreased considerably.

Relative to final results, significant initiation of stresses occurred at a minimum 1,200 ft. and a maximum of 1,400-1,500 ft. in X, Y, and Z directions as presented in Figure 6.29, Figure 6.30, and Figure 6.31. Identical offset distances for each station did not yield the same stresses. In fact, similar offset yielded much higher stresses after the western landform was encroached where the stations investigated reside. Nearly all of the modeled movements were outside of the typical angle of draw. 
The depth of mining has been cited as an insignificant factor in the final magnitude of subsidence. The 3D modeling has shown agreement for this point. Depth may play a role in the calibration of the modeling. A field lag time is thought to occur between the initiator of stress and the final result for far-field ground strain. The Subsidence Engineer's Handbook mentions that the depth of mining can slow down the final manifestation of subsidence (Singh, 1992). As a result, trending model data may have more significance than time correlation with field measurements. This effect may be illustrated in Figure 6.17, Figure 6.21, and Figure 6.25 for the calibration of Station 934, and may inherently exist in all calibration plots. Additionally, this indicates that the layering may have little influence as well. If the number of layers of differing strengths does not decrease the final subsidence magnitude, then overall strength properties reduced due to fracturing could be the most important parameter in precision prediction of farfield ground strain. The comparison of 3, 8, and 14 layers showed that increasing layer detail may not increase model precision.

\section{Model Set-Up}

With regards to model development, geometric refinement of the ground surface should be enough to encapsulate major topographic features. High levels of detail such as LiDAR are not required, however high levels of topographical detail could increase the precision of the model. Irregular surface grids can be useful, although it is important to have a high enough refinement to encapsulate all major topographic features. SVSolid $2009^{\mathrm{TM}}$ currently allows for a maximum of 15 surfaces, 14 layers. High levels of detail in layering do not appear to be needed.

Representative rock parameter selection proved more valuable than the number of layers in the model.

Modeling should extend beyond the intended extraction of mining to decrease the impact of edge effects. Model edge effects were accommodated by fixing the model edge boundary condition in the $\mathrm{Z}$ direction. This boundary condition acted as adjacent strata to support the panel roof. It is expected that if the boundary were allowed to deform in accordance with the adjacent rock properties, the model results may be more precise. The model area was extended northward to the ridges of the landforms on the opposite side of the valley. This simulated a buttressing effect in the valley with rock properties rather than a rigid boundary condition. Also, the development of a very large model (4,000 ft. x 5,500 ft. x 1,000 ft.) intended to view material properties in a macrospective manner, where the overall influence of fracturing would act as one elastic material. 


\section{Geologic Input Parameters}

Site specific laboratory testing was available at the Ryerson Station site. Worst Case (WC) parameters were chosen as the values of each parameter which would simulate a worst case deformation response in the model. These worst case parameters more closely accounted for fracturing/in situ stress effects than best case parameters. The $\mathrm{WC}$ and $\mathrm{BC}$ properties can be reviewed in Table 6.4 and Table 6.8. Calibration results indicate that other influencing factors previously hypothesized to control the stress/deformation likely play a part in the final results.

Best Case (BC) properties simulated intact non-fractured rock. These parameters yielded unrealistic calibration results that were far smaller magnitude displacements than were measured in the field. The degree of fracturing and quantified overall reduction in strength cannot be thoroughly accounted for independently. A reduction in rock properties adequately accounted for these effects. As a result, rock properties $(E, \gamma, n, v)$ seem to have the greatest influence on the final model results. In situ horizontal stress has the potential to exacerbate far-field ground strains, but was not incorporated into this modeling approach.

\section{Parameter Correlation and Sensitivity: Stress and Displacement Analysis}

Model results showed that station behavior generally reversed after Station 921 at $365 \mathrm{ft}$. perpendicular to Panel 7I compared to the stations closer than Station 921. X-Y displacement vector plots were developed to identify these areas of opposing behavior. These two zones have been identified to be the topographic influence regime and direct mine influence regime. These two regimes can be easily delineated with the X-Y vector plots. Stations closer to the mine than Station 921 (365 ft.) tended to move toward the mine while stations further away moved in accordance with the landform as a result of the topographic influence. The majority of movement directions in the topographic influence regime were downhill toward the northern, lowest elevation of the landform.

These conclusions fulfill Objective\#2.2 from Section 1.3.1:

Objective \#2: Utilize finite element analysis to determine altered shallow near-surface ground deformations and stress field changes which ensued at the Ryerson Station Dam. This analysis includes:

2.2 Parametric sensitivity study 


\section{CHAPTER 7. ROOT CAUSE ANALYSIS FOR FAR-FIELD GROUND STRAIN}

Analytical modeling outcomes were organized into a causal analysis. The approach used is referred to as a Root Cause Analysis (RCA). A RCA is "a structured evaluation method that identifies the root causes of an undesired outcome and the actions adequate to prevent recurrence (BCMEM, 2015)." RCA has been used to investigate a variety of possible scenarios that might be encountered with systems which may lead to undesirable outcomes by the National Aeronautics and Space Administration (NASA) as well as the British Columbia Ministry of Energy and Mines (BCMEM). The events leading to an undesired outcome are referred to as root causes. The RCA is intended to result in recommendations which prevent the scenario to repeat (BCMEM, 2015). The resulting recommendations target root causes.

\subsection{Defining Failure}

Model results have been summarized to further investigate the ground strain that occurred at the Ryerson Station State Park due to the mining of Panel 7I. Thus far data trends and other relationships have been established on the behavior of ground movement in topography. General failure mode thresholds were incorporated in order to establish a reference frame for the results. Insights from this analysis were used to assist the Event and Causal Factor Tree (ECFT) development and provide visual interpretation of the summarized data. The case history and subsequent Semi-Quantitative Potential Failure Mode Analysis (SQPFMA) development have identified two failure modes for far-field ground strain. These occur at differing magnitudes of ground strain. Seepage issues around the dam foundation occur at lower strains while structural damage can result at larger strains.

Strains were calculated via a linear relationship for stress, modulus of elasticity, and strain. Input rock properties were defined in SVSolid ${ }^{\mathrm{TM}}$ as linear elastic. Additionally, rock layers were considered homogeneous and isotropic. Therefore, Hooke's Law applies appropriately to this scenario as its inherent assumptions are consistent with the model set up. Strains are presented as unitless, but are calculated using $(\mathrm{ft} / \mathrm{ft})$. Stresses used to calculate strains are presented in Table A10. Hooke's Law follows Equation 7.1 (Gere \& Goodno, 2009):

Equation $7.1 \quad E=\frac{\sigma}{\epsilon}$

where,

- $\quad$ E is the modulus of elasticity (psf)

- $\sigma$ is stress (psf)

- $\epsilon$ is strain $(\mathrm{ft} / \mathrm{ft})$ 
It was known from the PADCNR reports developed by Gannett Fleming, Inc. that the compressive stress for structural failure of the Ryerson Station Dam was 4,000 psi (576 ksf). This value was taken as the compressive strength for the concrete found from testing three large diameter (6.73 in) concrete core samples from the Ryerson Station Dam as a conservative estimate to account for the variability of the material (PADCNR, 2007).

In order to calculate the strain required to reach this threshold, the modulus of elasticity of the concrete must be known. The equation required $f_{c}{ }^{\prime}$ to be incorporated in psi. The final modulus of elasticity was converted to psf to be consistent with model resultant units. The American Concrete Institute (ACI) defines the modulus of elasticity for concrete to follow Equation 7.2 (ACI, 2008):

$$
\text { Equation } 7.2=57000 \sqrt{f_{c}{ }^{\prime}}
$$

where,

- $\quad f_{c}^{\prime}$ is the compressive strength of concrete (psi)

- $\quad$ E is the modulus of elasticity (psf)

The modulus of elasticity for reinforced concrete was found to be 5.19E+08. A foundation strain threshold was calculated from the modulus of elasticity of the modeled shale foundation rock and the allowable bearing capacity of the foundation at $14.2 \mathrm{ksf}$. The modulus of elasticity for the shale was calculated to be $1.34 \mathrm{E}+08$.

\subsubsection{Structural Failure Mode}

In order to determine whether a modeling result is satisfactory or undesirable, a failure condition must be defined and quantified. Gannett Fleming, Inc. performed several dam stability analyses on the Ryerson Station Dam. Through these analyses in collaboration with the PADCNR, it was determined that failure of the dam could be defined using the following criteria:

"A concrete gravity structure can be considered stable (i.e., immobile) if all of the following three conditions are met:

1. The vertical resultant location computed by summing all of the forces and moments acting on the dam is positioned within the base of the dam. 
2. The average base pressure does not exceed the allowable bearing capacity of the foundation, and the maximum stress does not exceed the compressive strength of the materials comprising the structure and its foundation. For Ryerson Station Dam, the compressive strength of the concrete and rock are 4,000 psi and 8,000 psi, respectively, and the allowable bearing capacity of the foundation is estimated to be approximately $100 \mathrm{psi}(14.2 \mathrm{ksf})$.

3. The computed safety factor against sliding is greater than 1.0." (PADCNR, 2007).

As a result of this determination by the PADCNR for the compressive strength of the concrete dam, the structural failure condition has been defined conservatively as a compressive stress which exceeds 4,000 psi (576 ksf). Using Hooke's Law, the strain threshold can be calculated using the modulus of elasticity for concrete $(5.19 \mathrm{E}+8)$

Three structural failure modes were defined for the reinforced concrete dam structure:

i. Compressive strength failure

ii. Tensile strength failure

iii. Joint strength failure

The compressive strength failure mode was determined using the conservative compressive strength of the concrete of which Ryerson Station was comprised and the calculated modulus of elasticity. The resultant strain threshold was determined to be 0.001 (3E-3) for compressive strength failure.

Tensile strength failure was a result of a calculation recommended by the American Concrete Institute (ACI) to be (ACI, 2008):

$$
\text { Equation } 7.2 \quad f_{t}=1.7 f_{c}^{2 / 3}
$$

where,

- $f_{t}=$ tensile strength of concrete

- $f_{c}=$ compressive strength of concrete

The United States Bureau of Reclamation (USBR) recommends that the tensile strength should be taken as $4 \%$ to $6 \%$ of the compressive strength. Using $4 \%$ of the compressive strength results in a tensile strength of 200 psi for intact concrete (PADCNR, 2007). This is the lowest most conservative value, therefore, it was chosen as the tensile strength threshold stress. The resultant strain threshold was calculated to be (6E-5) for the tensile strength of concrete at the Ryerson Station Dam. 
Concrete joint strength was also addressed. The strength of the joints in the dam would be up to the same strength as the tensile strength of the concrete depending on the methods used to construct the dam. The value chosen was conservative at 0.67 of the determined tensile strength of the concrete at a value of about 130 psi (PADCNR, 2007). Since the joint would likely not have the same deformation characteristics as the intact concrete, the joint failure threshold was determined using a stress analysis of 130 psi (18,720 psf).

\subsubsection{Foundation Rock Failure Mode}

Two failure modes were identified for the foundation rock. These were:

i. Seepage due to strain dependent permeability variations

ii. Foundation bearing capacity

The seepage strain threshold was defined by Bai et al., 1995 to be 0.001 for rock masses that are not disrupted significantly to increase permeability. This conclusion was based on research performed by the National Coal Board, Farmer, 1985, and Garrity, 1982 (Bai et al., 1995). Strain values greater than 0.001 were used to identify significant material property changes leading to permeability variations in fractured rock for this study. The threshold of 0.001 was set for rock which has not been sufficiently deformed or strained to significantly increase its storage potential (Bai et al., 1995). A seepage failure mode may likely be induced at different strain values than 0.001 for severely fractured strata.

A foundation bearing capacity failure mode was addressed. Average Uniaxial Compressive Strength (UCS) tests resulted in a compressive strength of about 8,000 psi for the foundation rock at the Ryerson Station Dam. Methods were incorporated following EM1110-1-2908 of the U.S.ACE Rock Foundations Engineer's Manual to estimate the bearing capacity of fractured bedrock (PADCNR, 2007). The manual recommends a minimum acceptable factor of safety for structural foundations of 3 for the full dead load and live load. The ultimate bearing capacity was calculated using the traditional Buisman-Terzaghi bearing capacity expression:

Equation 7.3

$$
q_{u l t}=c N_{c}+0.5 \gamma B N_{\gamma}+\gamma D N_{q}
$$

where,

- $\quad$ qult $=$ Ultimate bearing capacity (21.29 tsf)

- $\quad \gamma=$ Effective unit weight $\left(154 \mathrm{lb} / \mathrm{ft}^{3}\right)$

- $\quad$ B $=$ Width of foundation $(30.95 \mathrm{ft})$

- $\quad \mathrm{D}=$ Depth of foundation $(5 \mathrm{ft})$

- $\quad c=$ Cohesion intercepts for the rock mass

The terms of Equation 7.3 can be defined using the following equations: 
Equation 7.4

Equation 7.5

Equation 7.6

Equation 7.7

$$
\begin{aligned}
& N_{\gamma}=N \varphi^{1 / 2}\left(N_{\varphi}^{2}-1\right) \\
& N_{q}=N_{\varphi}^{2} \\
& N_{\varphi}=\tan (45+\varphi / 2)^{2} \\
& N_{c}=2 N \varphi^{1 / 2}(N \varphi+1)
\end{aligned}
$$

where,

- $\varphi=$ Angle of friction for the rock mass (36.5 degrees)

Parameters in each term were defined with drawings of the dam for the dimensions B. An eccentricity of $2 \mathrm{ft}$. was used. The depth $\mathrm{D}$ was assumed. Laboratory testing determined the friction angle. The resultant ultimate bearing capacity was calculated to be $7.1 \mathrm{tsf}$ ( $\mathrm{qult}_{\mathrm{u}} / \mathrm{FS}$ ) or 14,200 psf (100 psi) (PADCNR, 2007). The strain threshold was calculated using the modulus of elasticity of shale to be 1E-4 as determined from WC laboratory data.

\subsubsection{Failure Mode Occurrence Potential}

The failure mode occurrence potential was calculated as a frequency of occurrence for the 7I model stress vector resultant data. Failure modes were primarily based on strain since this parameter is a commonly referenced value with respect to dam safety and seepage disruptions. Also, calculating failure modes as a strain threshold provides ease in comparison of the results.

Station 934 yielded the greatest displacement, and was located over Panel 7I, therefore it should have produced failure conditions for many of the extraction regions. The local stresses from the removed coal regions to the east and west of Station 934 cancelled each other, resulting in a lower local strain value. This observation implies that Hooke's law does not provide an accurate failure mode assessment for stations directly over Panel 7I. Stress dependent strain at Station 934 does not represent the failure mode identification for Station 934. This is due to the void located directly below the station. This caused the majority of the movement to manifest as a vertical translation, not inducing high stresses to appropriately apply Hooke's Law to calculate strain. Hooke's Law applies to stations other than Station 934 since their strain is stress dependent.

Table 7.1 provides a summary of the calculated strain thresholds to define the failure modes. The strain values are color coded for easy identification in the failure mode tables. Stresses less than the dam joint threshold and strains less than the tensile strain threshold were shaded green to denote a "no failure" condition. These strains were calculated using a model convergence of 0.1 psf with stress values rounded to whole numbers. Model tolerances are discussed in Section 
6.3.1. Model resultant stress components were calculated as resultant stresses for each survey station. Figure 7.1 presents the model set up as a reference for the failure mode assessment.

Table 7.1 Failure mode strain thresholds

\begin{tabular}{|c|c|c|c|c|c|c|}
\hline $\begin{array}{c}\text { Threshold } \\
\text { Category }\end{array}$ & $\begin{array}{c}\text { Seepage } \\
\text { Strain }\end{array}$ & $\begin{array}{c}\text { Structural } \\
\text { Compressive } \\
\text { Strain }\end{array}$ & $\begin{array}{c}\text { Foundation } \\
\text { Strain }\end{array}$ & $\begin{array}{c}\text { Structural } \\
\text { Tensile Strain }\end{array}$ & Joint Stress & $\begin{array}{c}\text { Satisfactory } \\
\text { Stress/Strain }\end{array}$ \\
\hline Reference & Bai, 1992 & PADCNR, 2007 & PADCNR, 2007 & PADCNR, 2007 & PADCNR, 2007 & PADCNR, 2007 \\
\hline Value & $1.00 \mathrm{E}-03$ & $1.10 \mathrm{E}-03$ & $1.00 \mathrm{E}-04$ & $6.00 \mathrm{E}-05$ & $18,720 \mathrm{psf}$ & Strain $(\epsilon<6 \mathrm{E}-5)$ \\
\cline { 6 - 7 } & & & & &
\end{tabular}




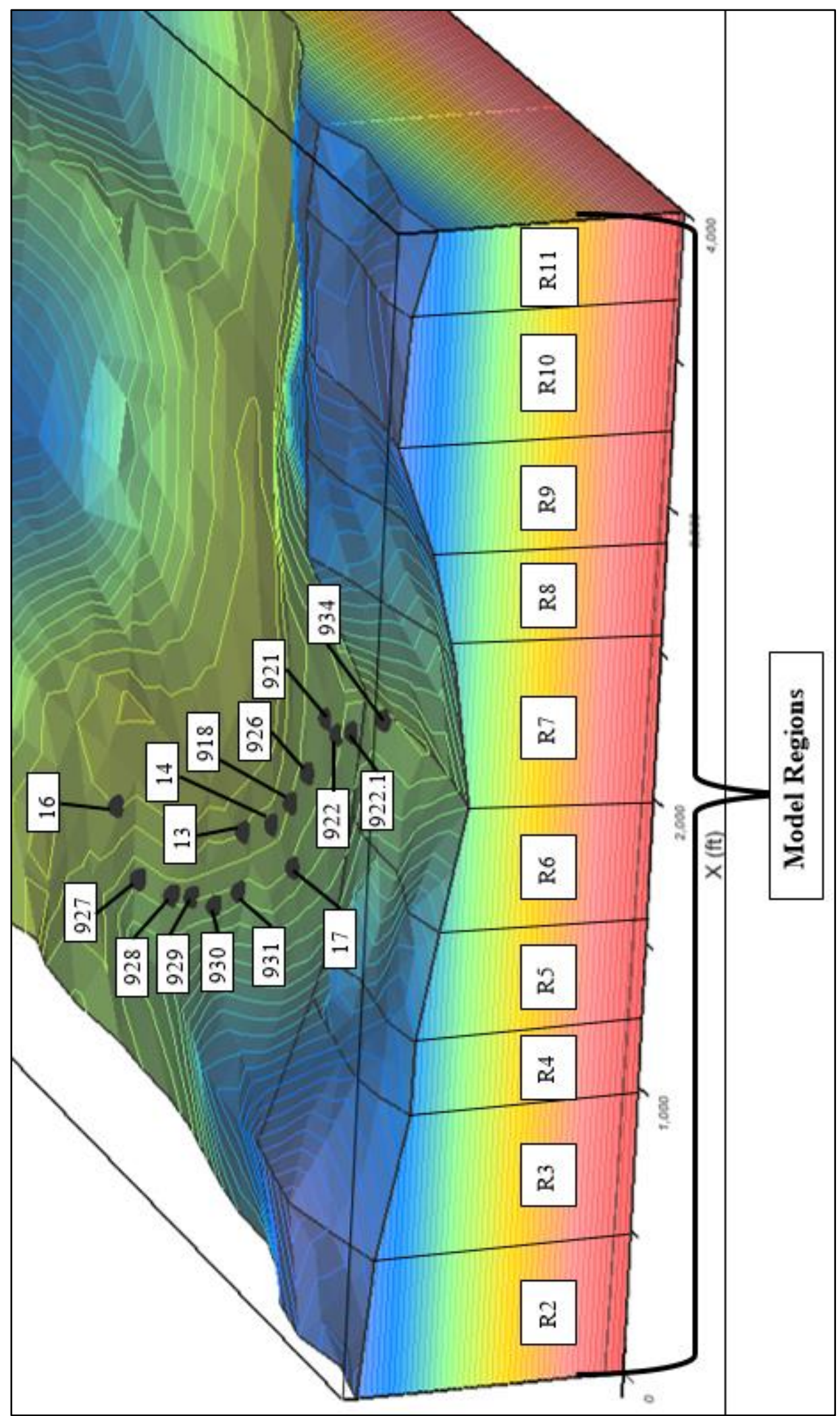

Figure $7.13 D$ model set up 
Table 7.2 provides a summary of the identified failure modes assessed for the foundation rock. The frequency of occurrence is reported for cases of only foundation bearing capacity or seepage threshold exceedance. Table 7.3 provides the calculated strain values at each station as well as the associated linear offset values. Data in Table 7.3 are presented from the closest station to Panel 7I (922.1) to the furthest left to right (16). Nearly 10\% of the 140 failure scenarios for foundation rock resulted in high enough magnitude strain to exceed limit to initiate seepage or foundation bearing capacity at offset distances up to 1,857 ft. Foundation bearing capacity thresholds were exceeded up to $3,298 \mathrm{ft}$. for $29 \%$ of the cases.

A continually decreasing amount of failure modes were identified at further offset distances from Panel 7I as is observed reading Table 7.3 from left to right. Station 929 and Station 928 had slightly higher stress magnitudes that allowed the failure strain threshold for foundation bearing capacity to be exceeded. This is due to the stresses generated at the location of the two stations in a dip along the landform.

Table 7.2 Failure mode summary for foundation rock assessment

\begin{tabular}{|c|c|c|c|c|}
\hline $\begin{array}{c}\text { Failure } \\
\text { Mode }\end{array}$ & $\begin{array}{c}\text { Identified } \\
\text { Cases }\end{array}$ & $\begin{array}{c}\text { Frequency of } \\
\text { Occurrence (\%) }\end{array}$ & $\begin{array}{c}\text { Min. Offset } \\
\text { (ft) }\end{array}$ & $\begin{array}{c}\text { Max. Offset } \\
\text { (ft) }\end{array}$ \\
\hline Satisfactory & 87 & $62.14 \%$ & 550 & 3783 \\
\hline Foundation & 40 & $28.57 \%$ & 188 & 3298 \\
\hline Seepage & 13 & $9.29 \%$ & 612 & 1857 \\
\hline
\end{tabular}


Table 7.3 Foundation rock strain failure modes and linear offset per station per region

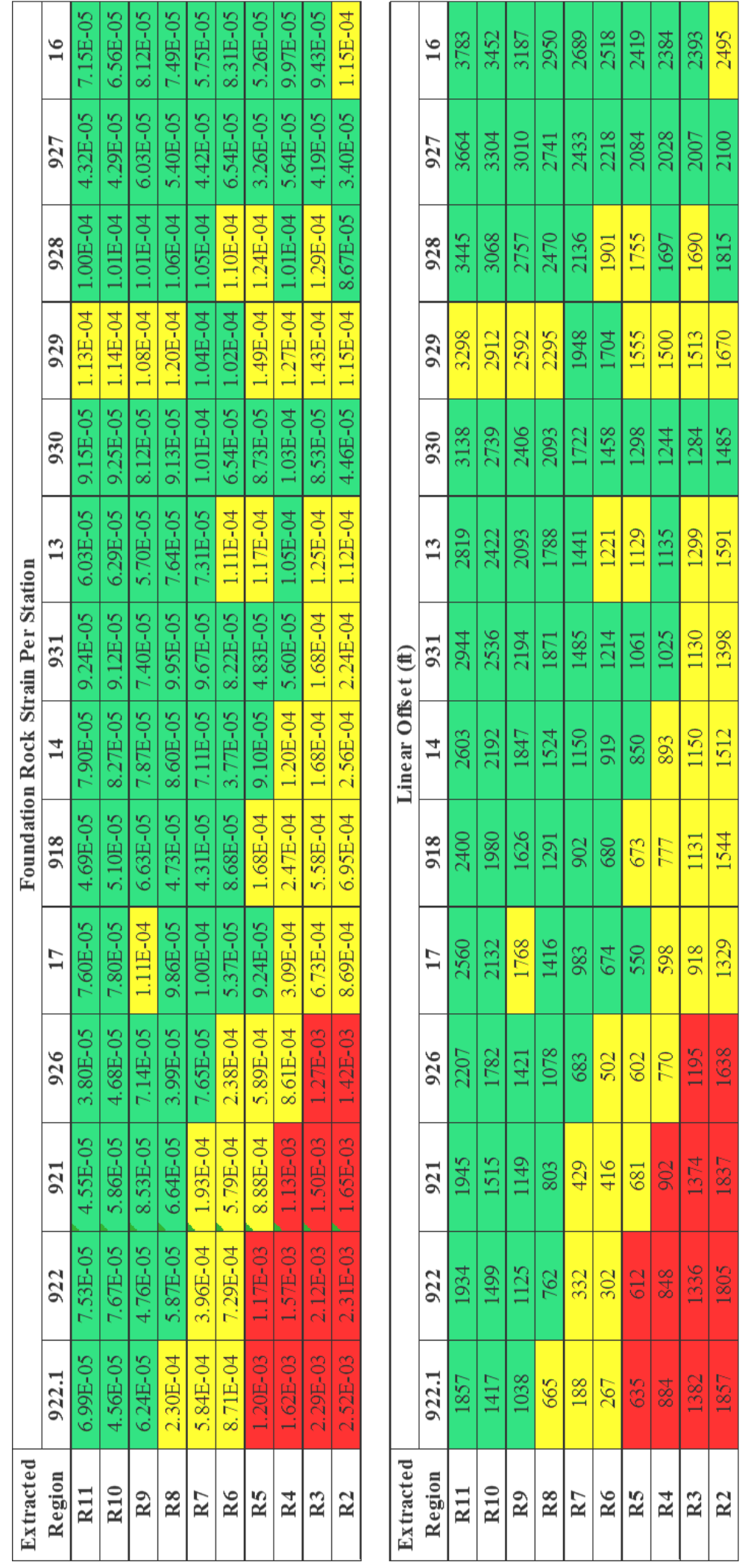


Table 7.4 provides a summary of the identified failure modes assessed for the joint stress assessment. Table 7.5 provides the calculated stress values at each station as well as the associated linear offset values. Data in Table 7.5 are presented from the closest station to Panel 7I (922.1) to the furthest left to right (16). Approximately $26 \%$ of the 140 failure scenarios for concrete joints resulted in large enough magnitude stress to exceed the threshold required to result in a failure condition. The offset distance for joint disruption occurred up to $1,857 \mathrm{ft}$. A continually decreasing amount of failure modes were identified at further offset distances from Panel 7I as is observed reading Table 7.5 from left to right. Station 929 reached the threshold for $\mathrm{R} 3$ and R5, which is due to its location in a dip along the landform.

Table 7.4 Failure mode summary for concrete joint stress assessment

\begin{tabular}{|c|c|c|c|c|}
\hline $\begin{array}{c}\text { Failure } \\
\text { Mode }\end{array}$ & $\begin{array}{c}\text { Identified } \\
\text { Cases }\end{array}$ & $\begin{array}{c}\text { Frequency of } \\
\text { Occurrence } \\
\text { (\%) }\end{array}$ & $\begin{array}{c}\text { Min. Offset } \\
\text { (ft) }\end{array}$ & $\begin{array}{c}\text { Max. Offset } \\
\text { (ft) }\end{array}$ \\
\hline Satisfactory & 103 & $73.57 \%$ & 550 & 3783 \\
\hline Joint Stress & 37 & $26.43 \%$ & 188 & 1857 \\
\hline
\end{tabular}


Table 7.5 Concrete joint stress failure modes and linear offset per station per region

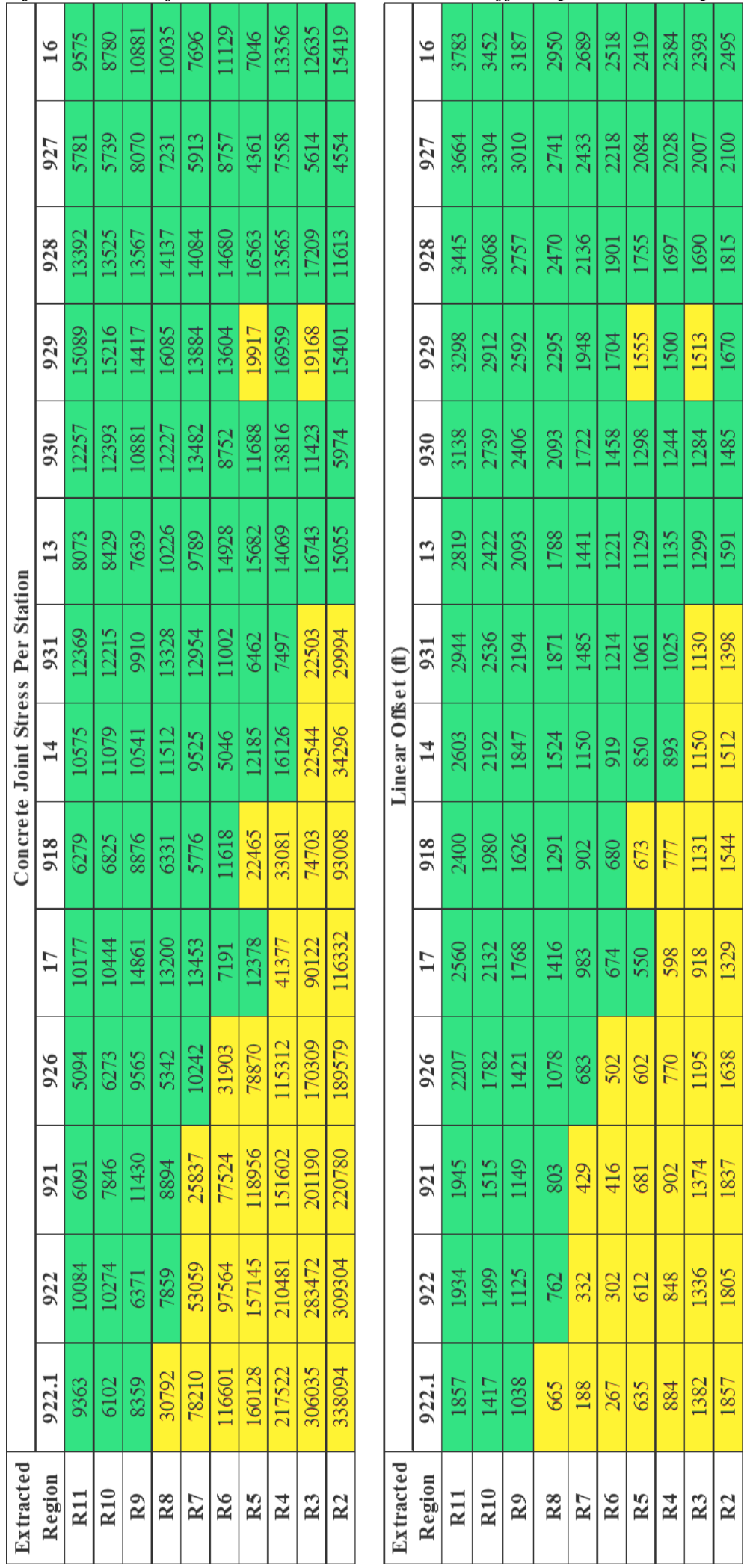


Table 7.6 provides a summary of the identified failure modes assessed for the tensile strain assessment. Table 7.7 provides the calculated strain values at each station as well as the associated linear offset values. Data in Table 7.7 are presented from the closest station to Panel 7I (922.1) to the furthest left to right (16). Approximately $23 \%$ of the 140 failure scenarios for reinforced concrete resulted in stresses great enough in magnitude to exceed the limit required to result in tensile failure. The offset distance for tensile failure occurred up to 2,093 ft. There were no failure modes identified to reach or exceed the required strain to produce a compressive failure mode. A continually decreasing amount of failure modes were identified for tensile strain at further offset distances from Panel 7I as is observed reading Table 7.7 from left to right.

Table 7.6 Failure mode summary for concrete compressive and tensile strain assessment

\begin{tabular}{|c|c|c|c|c|}
\hline $\begin{array}{c}\text { Failure } \\
\text { Mode }\end{array}$ & $\begin{array}{c}\text { Identified } \\
\text { Cases }\end{array}$ & $\begin{array}{c}\text { Frequency of } \\
\text { Occurrence } \\
(\%)\end{array}$ & $\begin{array}{c}\text { Min. Offset } \\
\text { (ft) }\end{array}$ & $\begin{array}{c}\text { Max. Offset } \\
\text { (ft) }\end{array}$ \\
\hline Satisfactory & 108 & $77.14 \%$ & 429 & 3783 \\
\hline Tensile & 32 & $22.86 \%$ & 188 & 2093 \\
\hline Compressive & 0 & 0 & n/a & n/a \\
\hline
\end{tabular}


Table 7.7 Concrete strain failure modes and linear offset per station per region

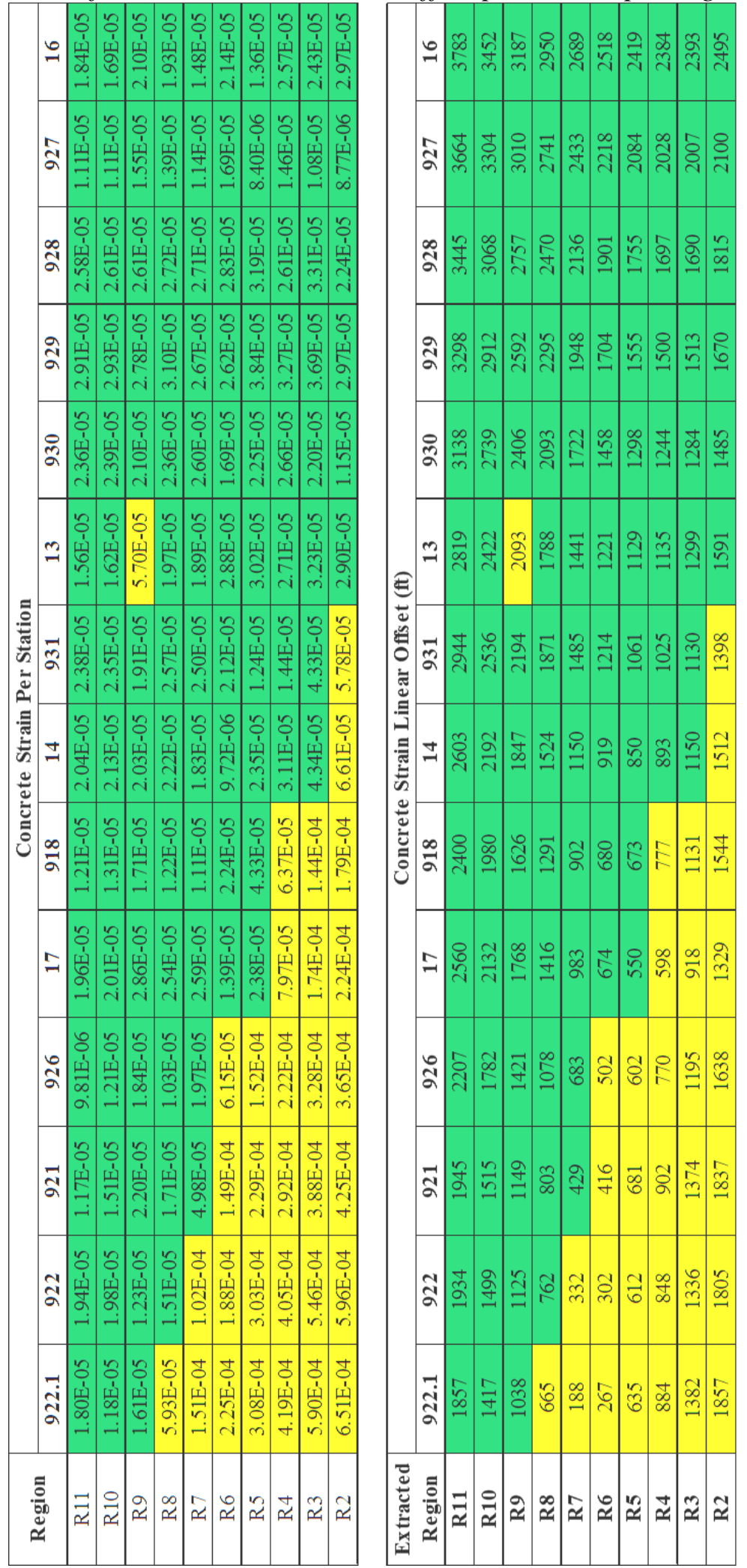


Figure 7.2 and Figure 7.3 present 3D histograms for all 14 stations, 10 extraction regions, and their associated strain magnitude. Stations are organized from closest to Panel 7I at Station 934 to furthest at Station 16. The histograms show that the majority of strains did not occur until R7 (teal) to R2, increased as extraction regions were removed under the western landform, and included a greater number of stations at further offset distances as extraction regions were removed. Comparing Figure 7.2 and Figure 7.3 reveals that the resultant strain for the foundation rock was approximately one order of magnitude greater (1E-3) than that calculated for the reinforced concrete (1E-4). This is due to the higher modulus of elasticity for concrete.

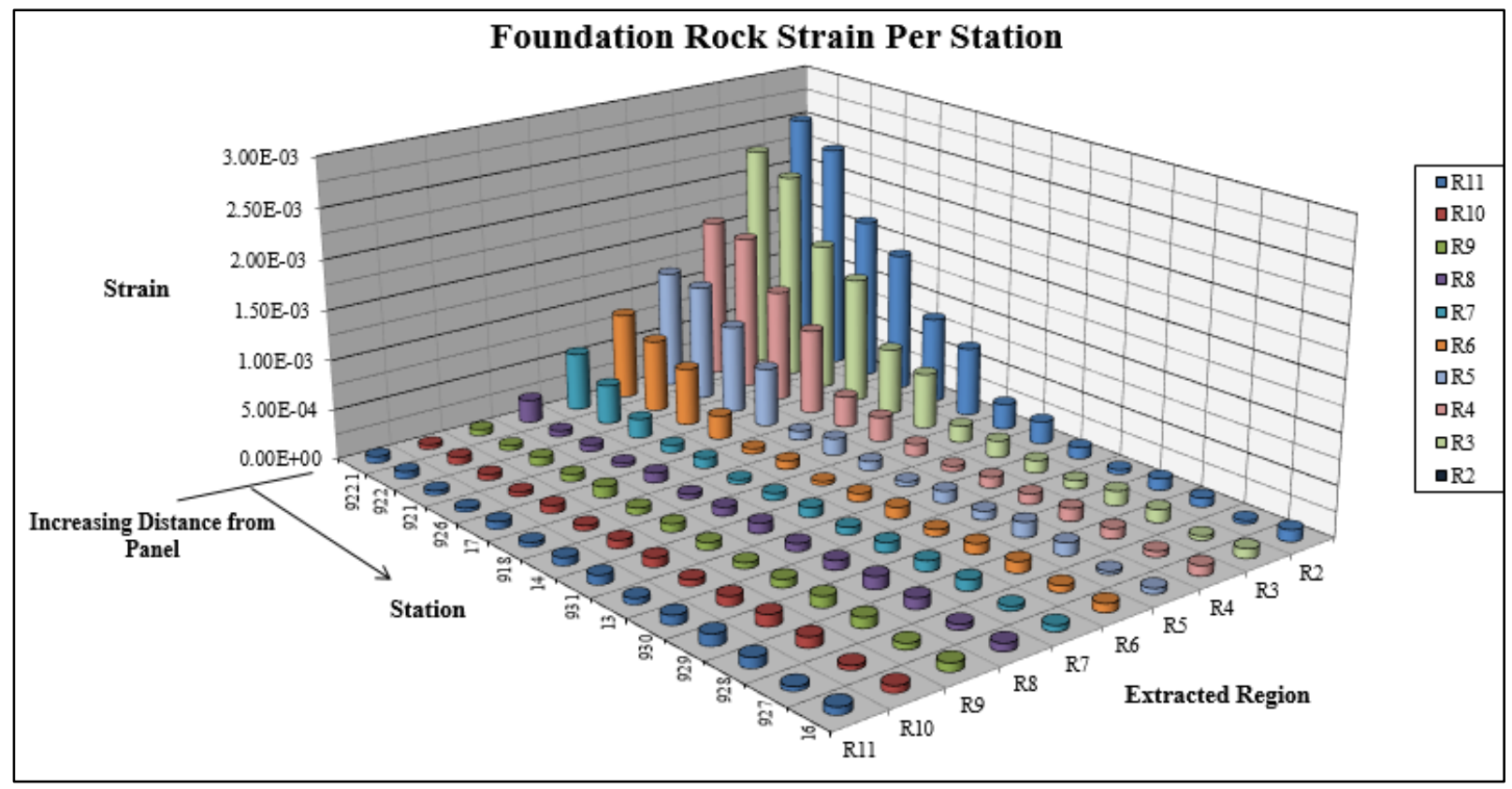

Figure 7.23 plot of extraction regions, stations, and associated strain rates for foundation rock 


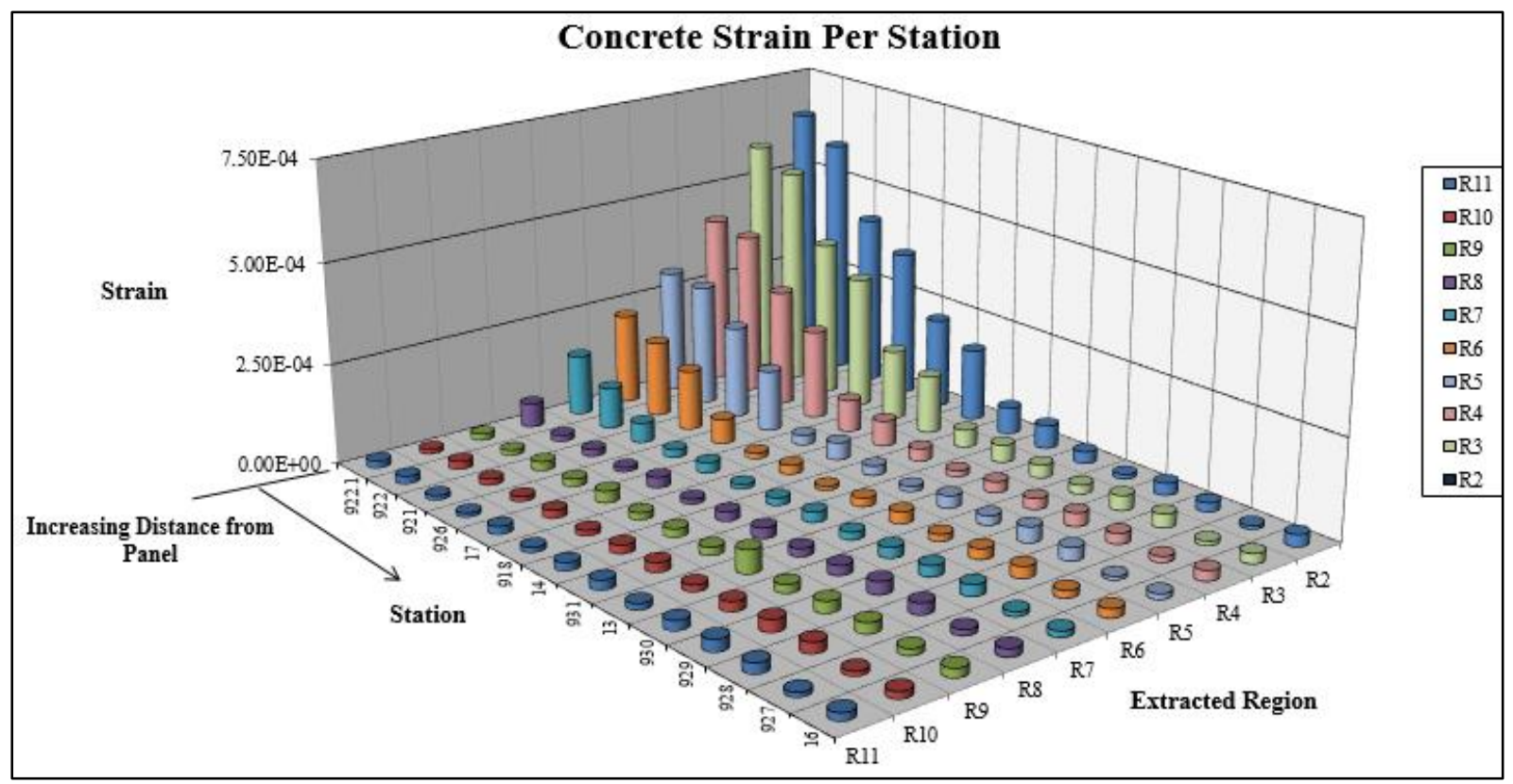

Figure 7.33 plot of extraction regions, stations, and associated strain rates for reinforced concrete

Table 7.8 presents the legend and frequency of occurrence for each strain threshold. The closest offset distance to mining without a failure mode was calculated to be $550 \mathrm{ft}$. Failure events were identified up to 3,298 ft. offset. All failures were included to determine a frequency of occurrence in Table 7.8. The cases calculated for a failure mode totaled to 420 cases. Most cases resulted in a no failure condition (60\%). Table 7.8 includes "Frequency of Occurrence" and "Total Occurrence." Approximately $12 \%$ of cases resulted in only foundation exceedance, and resulted in a total occurrence of $28.6 \%$ of the cases. Foundation bearing capacity and joint disruption only accounted for $5 \%$ of the cases, and resulted in a total occurrence of $27.1 \%$. Foundation bearing capacity, joint disruption, and tensile strain exceedance occurred for $12.9 \%$ of the cases, and resulted in a total occurrence of $22.1 \%$. Seepage variation, foundation bearing capacity, joint disruption, and tensile strain exceedance occurred for $9.3 \%$ of the cases.

Table 7.9 show that most of the failure modes reside within the region of the table past R8, when the western landform begun to be influenced by mining in Panel 7I. Approximately 86\% of all identified dam failure modes occurred in extraction regions beyond $\mathrm{R} 8$ which were the extraction regions within the western landform (R7-R2). 
Table 7.8 Frequency of occurrence for failure modes

\begin{tabular}{|l|c|c|c|c|c|}
\hline \multicolumn{1}{|c|}{ Failure Modes } & Legend & $\begin{array}{c}\text { Minimum } \\
\text { Offs et (ft) }\end{array}$ & $\begin{array}{c}\text { Maximum } \\
\text { Offs et (ft) }\end{array}$ & $\begin{array}{c}\text { Frequency of } \\
\text { Occurrence (\%) }\end{array}$ & $\begin{array}{c}\text { Total } \\
\text { Occurrence (\%) }\end{array}$ \\
\hline Seepage/Foundation/Joint/Tensile & & 612 & 1857 & $9.3 \%$ & $9.3 \%$ \\
\hline Foundation/Joint/Tensile & & 188 & 1544 & $12.9 \%$ & $22.1 \%$ \\
\hline Foundation/Joint & & 429 & 1555 & $5.0 \%$ & $27.1 \%$ \\
\hline Foundation & & 188 & 3298 & $12.1 \%$ & $28.6 \%$ \\
\hline Tensile & & 2093 & 2093 & $0.71 \%$ & $22.86 \%$ \\
\hline Satisfactory & & 550 & 3783 & $60.0 \%$ & $60.0 \%$ \\
\hline
\end{tabular}

* Frequency of occurrence implies that only the specific condition existed for a percentage of the cases.

*The total occurrence is where other failure modes also occurred for the same instance. 
Table 7.9 Summary of failure modes at linear offset

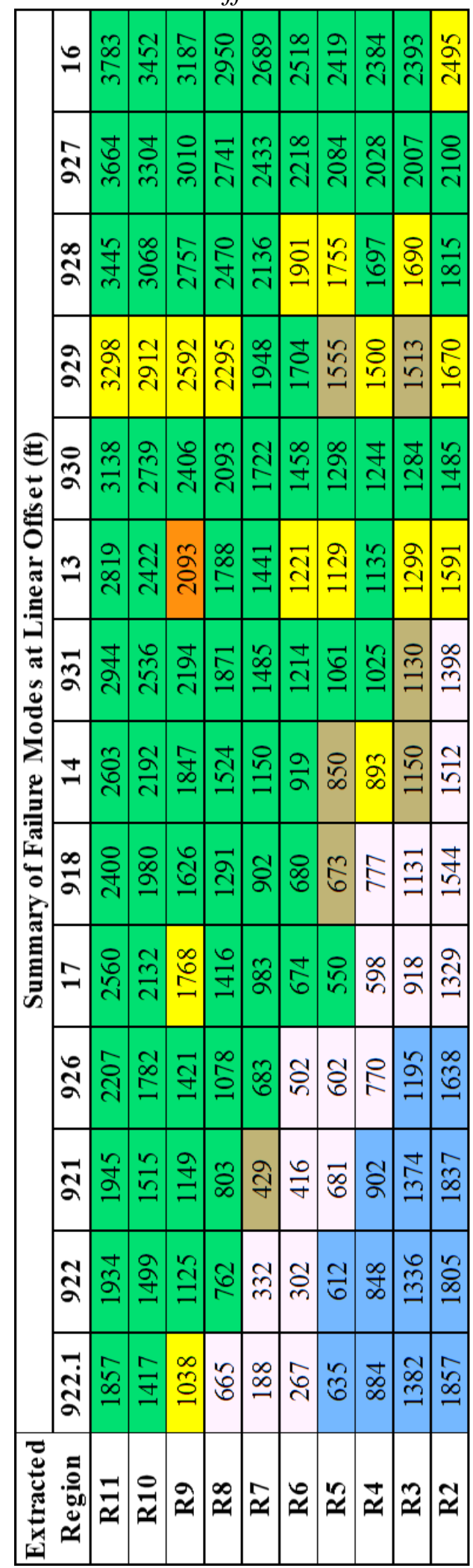




\subsection{Event and Causal Factor Tree for Far-Field Ground Strain Affecting Dams}

This research has implemented a RCA in collaboration with a PFMA and numerical modeling results (SQPFMA) that has a focus on analytically and historically determined events. This research employed the RCA to provide an organized synopsis of the events leading to far-field ground strain. Management problems, policy issues, and other personnel matters which may have contributed to the failure of the Ryerson Station Dam case study are not within the scope of this analysis. This SQPFMA-RCA is intended to objectively identify physical and situational elements of the ECFT.

An Event and Causal Factor Tree (ECFT) is an organizational flowchart developed to identify root causes of an undesired outcome. An undesired outcome is an unwanted event or result of a system that is different than the desired outcome. In the case of a dam, the desired outcome is maintaining working function to preserve the authorized purpose of the structure. An undesired outcome would be the loss of the authorized purpose of the structure. Undesired outcomes typically result from a sequence of events and actions under specific conditions. The causes of the undesired outcome must be investigated and understood to develop solutions to prevent the recurrence of the scenario (BCMEM, 2015).

The intent of the RCA is to exhaust all paths which could lead to the undesired outcome. These paths are incorporated into an ECFT with several components. The components are described as:

- Proximate Cause: A proximate cause is a branch of the ECFT. The branch is composed of events, conditions, and defeated defenses which lead to the occurrence of an undesired outcome.

- Root Cause: Root causes are major contributors to the proximate cause, but are different than contributing factors. A root cause is a cause of multiple factors that creates or can lead to a proximate cause. Multiple root causes can exist in an ECFT. In a pure RCA, a root cause would be organizational and could refer to a policy issue, management error, etc. A contributing factor is an event or condition which contributes to a proximate cause but, if removed from the proximate cause, would not prevent the occurrence of the undesired outcome.

- Defense: Defenses consist of barriers and controls that exist to prevent an undesired outcome.

- Barrier: A barrier is a passive intervention of the progression of a proximate cause which may prevent or reduce the likelihood of the undesired outcome. 
- Control: Controls are active mechanisms put in place intentionally to identify the initiation of an event within a known proximate cause (BCMEM, 2015).

\subsubsection{Event and Causal Factor Tree (ECFT)}

A SQPFMA-RCA based ECFT is presented based on the Ryerson Station case history, PFMA, and numerical modeling outcomes. Figure 7.4 presents the SQPFMA-RCA ECFT for far-field ground strain resulting in the loss of authorized purpose of a dam. Model verified causal factors and a synopsis of the events leading to the loss of authorized purpose were included. Situational conditions were included for the development of the flaw. Proximate causes (PC) were incorporated as contributing to the development of the flaw to allow initiation to occur. The ECFT approach was to remain in the scope of this research and focus on the analytical and quantitative factors leading to the undesired outcome rather than management and policy errors.

The development of the ECFT with the results from numerical modeling sensitivity and the PFMA fulfill the intent of Objective \#3.1 from Section 1.3.1:

Objective 3: Utilize model results to acquire insight into ground behavior and establish the SQPFMA-RCA. The SQPFMA-RCA will be developed in collaboration with model results and case history to make recommendations to prevent recurrence of potential far-field ground strain. This investigation will include:

3.1 Practical and effective use of model results to populate Event and Causal Factor Tree (ECFT) 


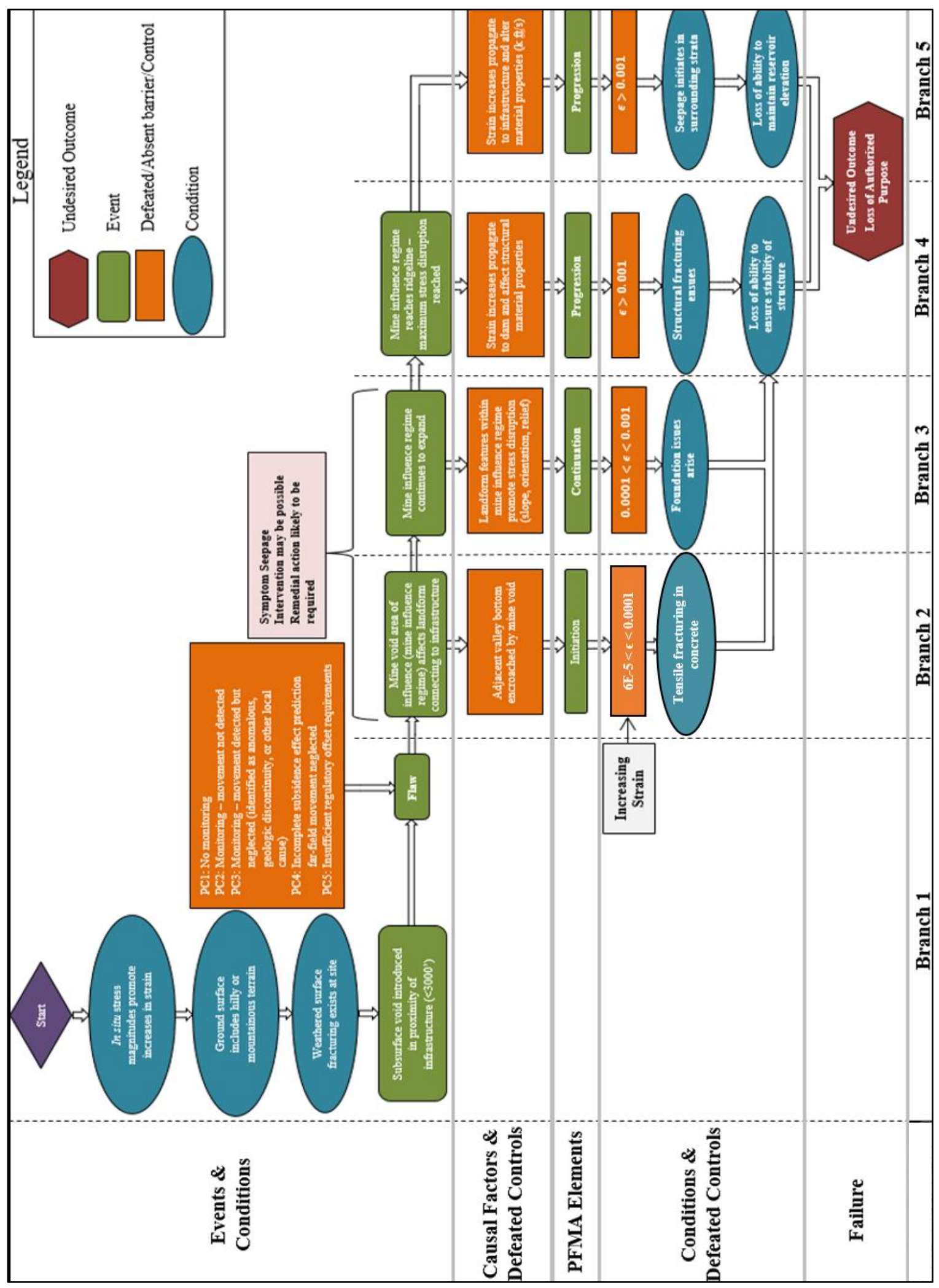

Figure 7.4 ECFT for far-field ground strain affecting dams 


\subsubsection{Branch 1}

Identification of early movement is of primary importance to avoid failure modes resulting from far-field ground strain. Branch 1 of the ECFT incorporates the conditions under which far-field ground strain manifested at Ryerson Station State Park in accordance with case history and modeling outcomes. A subsurface void proximity of 3,000 ft. was chosen as the area of concern for far-field ground strain following Section 7.1.3. Weathered surface fracturing, hilly or mountainous terrain, and in situ stress magnitudes are believed to contribute to the inability of landforms to remain static. Proximate Causes (PC) have been listed as paths/branches for the occurrence of the PFMA elements. Each PC presents an opportunity for a control to be in place as ground monitoring instrumentation. Table 7.10 presents Branch 1 in tabular format with associated relevance and recommendations. 
Table 7.10 ECFT - Branch 1 composition

\begin{tabular}{|c|c|c|}
\hline \multicolumn{3}{|c|}{ ECFT - Branch 1} \\
\hline Tree Element & Content & $\begin{array}{c}\text { Relevance \& } \\
\text { Recommendations }\end{array}$ \\
\hline Precursor Information & - None & - $\mathrm{n} / \mathrm{a}$ \\
\hline PFMA Element & - Flaw & $\begin{array}{l}\text { - The identification of the flaw } \\
\text { allows the failure modes to } \\
\text { be recognized and avoided. }\end{array}$ \\
\hline Events & $\begin{array}{l}\text { - Subsurface void introduced in } \\
\text { proximity of infrastructure } \\
\left(<3000^{\prime}\right)\end{array}$ & $\begin{array}{l}\text { Disruption of stress field by } \\
\text { mine influence regime at } \\
\text { connecting landforms to a } \\
\text { dam structure should be } \\
\text { avoided }\end{array}$ \\
\hline Defeated Controls & $\begin{array}{l}\text { - PC1: No monitoring } \\
\text { - PC2: Monitoring - movement } \\
\text { not detected } \\
\text { - PC3: Monitoring - movement } \\
\text { detected but neglected } \\
\text { - PC4: Incomplete subsidence } \\
\text { effect prediction for far-field } \\
\text { ground strain } \\
\text { - PC5: Insufficient regulatory } \\
\text { offset requirements }\end{array}$ & $\begin{array}{l}\text { - Monitoring in the area of } \\
\text { mining is of utmost } \\
\text { importance. Monitoring can } \\
\text { provide calibration data for } \\
\text { site specific numerical } \\
\text { modeling. }\end{array}$ \\
\hline Conditions & $\begin{array}{l}\text { - Weathered surface fracturing } \\
\text { exists at site } \\
\text { - Ground surface includes hilly } \\
\text { or mountainous terrain } \\
\text { - In situ stress magnitudes } \\
\text { promote increases in strain }\end{array}$ & $\begin{array}{l}\text { Surface fracturing, } \\
\text { mountainous terrain, and in } \\
\text { situ stress promote the } \\
\text { occurrence of far-field } \\
\text { ground strain }\end{array}$ \\
\hline Failure & - No failure & - $\mathrm{n} / \mathrm{a}$ \\
\hline Causal Factors & $\begin{array}{r}\text { - Far-field ground strain } \\
\text { neglected/not detected }\end{array}$ & $\begin{array}{l}\text { - Far-field ground strain } \\
\text { should be considered in these } \\
\text { conditions }\end{array}$ \\
\hline
\end{tabular}




\subsubsection{Branch 2}

Once the flaw occurs as the introduction of an underground mine void, the possibility exists for initiation of strain failure modes. The passive intervention of a valley to attenuate stress disruptions is valuable to prevent the progression of failure modes induced by far-field ground strains. Valleys provide a barrier to exposing the adjacent landform to far-field ground strain effects. Strains tend to not propagate significantly beyond valleys. After the adjacent landform valley has been surpassed by the mine influence regime, far-field ground strains will initiate. The Ryerson Station case study provides evidence that symptom seepage can occur at low initiating strains as well as concrete joint disruptions and tensile fracturing in the structure. Figure 7.11 presents the content pertinent to Branch 2 of the ECFT. 
Table 7.11 ECFT - Branch 2 composition

\begin{tabular}{|c|c|c|}
\hline \multicolumn{3}{|c|}{ ECFT - Branch 2} \\
\hline Tree Element & Content & $\begin{array}{c}\text { Relevance \& } \\
\text { Recommendations }\end{array}$ \\
\hline Precursor Information & - Flaw occurred & $\begin{array}{l}\text { - Flaw must occur for PFMA } \\
\text { to carry out }\end{array}$ \\
\hline PFMA Element & - Initiation & $\begin{array}{l}\text { - Identification of initiation } \\
\text { may allow intervention and } \\
\text { halt the FM }\end{array}$ \\
\hline Events & $\begin{array}{l}\text { - Mine void area of influence } \\
\text { (mine influence regime) } \\
\text { affects landform connecting } \\
\text { to infrastructure }\end{array}$ & $\begin{array}{l}\text { - Valleys tend to attenuate } \\
\text { propagating near surface } \\
\text { stress field disruptions }\end{array}$ \\
\hline Defeated Controls & $\begin{array}{l}\text { - Adjacent valley bottom } \\
\text { encroached by mine influence } \\
\text { regime } \\
\text { - Concrete tensile strain } \\
\text { threshold breached }(0.00006< \\
\epsilon 0.0001)\end{array}$ & $\begin{array}{l}\text { - Minimal disruption of } \\
\text { adjacent landforms to far- } \\
\text { field ground strains } \\
\text { - Monitoring instrumented } \\
\text { before strain thresholds } \\
\text { reached could help identify } \\
\text { FM and prevent occurrence }\end{array}$ \\
\hline Conditions & $\begin{array}{l}\text { - Concrete joints disrupted } \\
\text { - Loss of ability to ensure } \\
\text { stability of infrastructure } \\
\text { - Symptom seepage may result } \\
\text { through concrete joints and/or } \\
\text { fractured surrounding rock }\end{array}$ & $\begin{array}{l}\text { - Once strain threshold } \\
\text { surpassed, the FM is initiated. }\end{array}$ \\
\hline Failure & $\begin{array}{l}\text { - Loss of authorized purpose - } \\
\text { structural FM }\end{array}$ & $\begin{array}{l}\text { - Possibility of failure should } \\
\text { be considered at these low } \\
\text { strains }\end{array}$ \\
\hline Causal Factors & $\begin{array}{l}\text { - Adjacent valley bottom } \\
\text { encroached } \\
\text { - In situ stress field disrupted in } \\
\text { connecting landform to } \\
\text { infrastructure }\end{array}$ & $\begin{array}{l}\text { Evidence suggests that the } \\
\text { disruption of the adjacent } \\
\text { landform results in the } \\
\text { initiation of the FM. }\end{array}$ \\
\hline
\end{tabular}




\subsubsection{Branch 3}

In order for continuation to occur in the development of the FM, the flaw and initiation must first occur. Continuation occurs when the adjacent landform's surrounding valley is surpassed by mine void area allowing the mine influence regime to expand. This increase in the affected area of the stress field disruption increases strain magnitudes along the landform. Table 7.12 presents the composition of Branch 3 of the ECFT. 
Table 7.12 ECFT - Branch 3 composition

\begin{tabular}{|c|c|c|}
\hline \multicolumn{3}{|c|}{ ECFT - Branch 3} \\
\hline Tree Element & Content & Relevance \& Recommendations \\
\hline $\begin{array}{l}\text { Precursor } \\
\text { Information }\end{array}$ & - Flaw and initiation occurred & $\begin{array}{l}\text { - The development of the FM requires } \\
\text { that flaw and initiation occurred }\end{array}$ \\
\hline PFMA Element & - Continuation & $\begin{array}{l}\text { - Identification of continuation may allow } \\
\text { intervention to half development of FM } \\
\text { - Acknowledgement of FM of critical } \\
\text { importance to preserve infrastructure }\end{array}$ \\
\hline Events & $\begin{array}{l}\text { - Mine influence regime continues } \\
\text { to expand beyond initiating } \\
\text { strain effects }\end{array}$ & $\begin{array}{l}\text { - Continuing to mine underneath of the } \\
\text { adjacent connecting landform will result } \\
\text { in increasing strain magnitudes }\end{array}$ \\
\hline $\begin{array}{l}\text { Defeated } \\
\text { Controls }\end{array}$ & $\begin{array}{l}\text { - Landform features promote } \\
\text { strain magnitudes } \\
\text { - No current intervention for } \\
\text { incurred strain effects } \\
\text { - Rock foundation bearing } \\
\text { capacity strain threshold } \\
\text { breached } 0.0001<\epsilon<0.001\end{array}$ & $\begin{array}{l}\text { - Identification of the failure mode has } \\
\text { not been achieved or has been neglected } \\
\text { - Noticeable effects exist at the } \\
\text { infrastructure (symptom seepage, } \\
\text { structural disruptions) } \\
\text { - FM development ensues but may still } \\
\text { allow intervention to halt FM }\end{array}$ \\
\hline Conditions & $\begin{array}{l}\text { - Foundation issues arise } \\
\text { - Loss of ability to ensure } \\
\text { structural stability } \\
\text { - Symptom seepage may result } \\
\text { through and around } \\
\text { rock/structure interfaces }\end{array}$ & $\begin{array}{l}\text { - Foundation bearing capacity and } \\
\text { concrete joint strain thresholds } \\
\text { surpassed, FM continuation occurs }\end{array}$ \\
\hline Failure & $\begin{array}{l}\text { - Loss of authorized purpose - } \\
\text { structural FM }\end{array}$ & $\begin{array}{l}\text { - Resultant strain may continue to lead to } \\
\text { loss of authorized purpose at this stage }\end{array}$ \\
\hline Causal Factors & $\begin{array}{l}\text { - No intervention of strain effects } \\
\text { - Mine influence regime area } \\
\text { increases in adjacent landform } \\
\text { whose features promote far-field } \\
\text { strain propagation }\end{array}$ & $\begin{array}{l}\text { - Acknowledgement of far-field ground } \\
\text { strain effects from mining will allow the } \\
\text { understanding to halt FM through } \\
\text { intervention }\end{array}$ \\
\hline
\end{tabular}




\subsubsection{Branch 4}

The development of the failure mode to progression requires the occurrence of flaw, initiation, and continuation. If the mine influence regime is allowed to progress to its maximum potential area along the landform, then far-field ground strain magnitudes will also reach their maximum. At strains of 0.001, structural cracking in reinforced concrete occurs. At this stage according to this criterion, structural failure is inevitable. The available intervention is to breach and/or drain the reservoir. Table 7.13 presents the composition of Branch 4 of the ECFT. 
Table 7.13 ECFT - Branch 4 composition

\begin{tabular}{|c|c|c|}
\hline \multicolumn{3}{|c|}{ ECFT - Branch 4} \\
\hline Tree Element & Content & $\begin{array}{c}\text { Relevance \& } \\
\text { Recommendations }\end{array}$ \\
\hline Precursor Information & $\begin{array}{l}\text { - Flaw, initiation, and } \\
\text { continuation occurred }\end{array}$ & $\begin{array}{l}\text { - Flaw, initiation, and } \\
\text { continuation must occur in } \\
\text { the development of the FM }\end{array}$ \\
\hline PFMA Element & - Progression & $\begin{array}{l}\text { - Identification of progression } \\
\text { of utmost importance } \\
\text { - Consideration of downstream } \\
\text { consequences necessary }\end{array}$ \\
\hline Events & $\begin{array}{l}\text { - Mine influence regime } \\
\text { reaches ridgeline - maximum } \\
\text { stress disruption reached }\end{array}$ & $\begin{array}{l}\text { - Mine influence regime has } \\
\text { reached its maximum } \\
\text { potential affected area in } \\
\text { landform }\end{array}$ \\
\hline Defeated Controls & $\begin{array}{l}\text { - Mine influence regime area } \\
\text { progresses despite noticeable } \\
\text { strain effects } \\
\text { - Strain increases effect } \\
\text { structural material properties } \\
\text { - Compressive concrete } \\
\text { cracking strain threshold } \\
\text { breached } \epsilon>0.001\end{array}$ & $\begin{array}{l}\text { - Identification of the FM has } \\
\text { not been detected or has been } \\
\text { neglected, allowing FM to } \\
\text { develop } \\
\text { - Critical strains for structural } \\
\text { stability have been reached or } \\
\text { surpassed } \\
\text { - Intervention as breach and/or } \\
\text { reservoir drain }\end{array}$ \\
\hline Conditions & $\begin{array}{l}\text { - Structural cracking occurs } \\
\text { - Loss of ability to ensure } \\
\text { structural stability }\end{array}$ & $\begin{array}{l}\text { - Infrastructure composition } \\
\text { cannot sustain strains, and } \\
\text { becomes fractured } \\
\text { - Critical conditions for } \\
\text { structural stability exist }\end{array}$ \\
\hline Failure & $\begin{array}{l}\text { - Loss of authorized purpose - } \\
\text { Structural FM }\end{array}$ & $\begin{array}{l}\text { - Structural failure inevitable at } \\
\text { this stage }\end{array}$ \\
\hline Causal Factors & $\begin{array}{l}\text { - No intervention for strain } \\
\text { effects } \\
\text { - Mine influence regime } \\
\text { continues to expand up to the } \\
\text { ridgeline of adjacent landform }\end{array}$ & $\begin{array}{l}\text { Mine influence regime } \\
\text { allowed to reach its } \\
\text { maximum affected area, } \\
\text { increasing strains to critical } \\
\text { magnitudes }\end{array}$ \\
\hline
\end{tabular}




\subsubsection{Branch 5}

The development of the FM to progression requires that flaw, initiation, and continuation have occurred. At progression, the strain magnitudes have reached their maximum. This maximum magnitude is due to the mine influence regime reaching its maximum affected area at the landform ridgeline. At this stage, far-field ground strain magnitudes have reached critical levels where rock properties alter significantly enough to result in an increase in permeability. Failure

is likely to result from the inability to maintain the reservoir level. Table 7.14 presents Branch 5 of the ECFT. 
Table 7.14 ECFT - Branch 5 composition

\begin{tabular}{|c|c|c|}
\hline \multicolumn{3}{|c|}{ ECFT - Branch 5} \\
\hline Tree Element & Content & Relevance \& Recommendations \\
\hline Precursor Information & $\begin{array}{l}\text { - Flaw, initiation, and } \\
\text { continuation occurred }\end{array}$ & $\begin{array}{l}\text { - Flaw, initiation, and } \\
\text { continuation must occur in the } \\
\text { development of the FM }\end{array}$ \\
\hline PFMA Element & - Progression & $\begin{array}{l}\text { - Identification of progression is } \\
\text { of utmost importance } \\
\text { - Consideration of consequences } \\
\text { for loss of reservoir necessary }\end{array}$ \\
\hline Events & $\begin{array}{l}\text { - Mine influence regime } \\
\text { reaches ridgeline - maximum } \\
\text { stress disruption reached }\end{array}$ & $\begin{array}{l}\text { Mine influence regime has } \\
\text { reached its maximum potential } \\
\text { affected area in landform }\end{array}$ \\
\hline Defeated Controls & $\begin{array}{l}\text { - Strain increases result in } \\
\text { foundation rock material } \\
\text { property changes } \\
\text { - Seepage due to material } \\
\text { property change strain } \\
\text { threshold surpassed } \epsilon>0.001\end{array}$ & $\begin{array}{l}\text { - Identification of the FM has not } \\
\text { been detected or has been } \\
\text { neglected, allowing FM to } \\
\text { develop } \\
\text { - Critical strains for seepage have } \\
\text { been reached or surpassed } \\
\text { - Intervention possible as breach } \\
\text { and/or reservoir drain }\end{array}$ \\
\hline Conditions & $\begin{array}{l}\text { - Seepage initiates in } \\
\text { surrounding strata } \\
\text { - Loss of ability to maintain } \\
\text { reservoir level }\end{array}$ & $\begin{array}{l}\text { - Surrounding rock composition } \\
\text { cannot withstand additional } \\
\text { strains to maintain pre-mining } \\
\text { seepage rates } \\
\text { - Critical conditions exist for } \\
\text { seepage FM }\end{array}$ \\
\hline Failure & $\begin{array}{l}\text { - Loss of authorized purpose - } \\
\text { Seepage FM }\end{array}$ & $\begin{array}{l}\text { - Failure due to loss of ability to } \\
\text { maintain reservoir level } \\
\text { inevitable }\end{array}$ \\
\hline Causal Factors & $\begin{array}{l}\text { - No intervention for } \\
\text { propagating strain effects } \\
\text { - Mine influence regime } \\
\text { continues to expand up to the } \\
\text { ridgeline of adjacent landform }\end{array}$ & $\begin{array}{l}\text { Mine influence regime allowed } \\
\text { to reach its maximum affected } \\
\text { area, increasing strains to } \\
\text { critical magnitudes }\end{array}$ \\
\hline
\end{tabular}


Table 7.15 Situational causal factors developed from the ECFT

\begin{tabular}{|c|c|c|}
\hline Branches & Causal Factors & Relevance \\
\hline $\begin{array}{l}\text { Branch } 1 \\
\text { (Flaw) }\end{array}$ & $\begin{array}{l}\text { Far-field ground strain } \\
\text { neglected/not detected }\end{array}$ & $\begin{array}{l}\text { Far-field ground strain } \\
\text { should be considered in } \\
\text { some conditions }\end{array}$ \\
\hline $\begin{array}{c}\text { Branch } 2 \\
\text { (Initiation) }\end{array}$ & $\begin{array}{l}\text { - Adjacent valley bottom } \\
\text { encroached } \\
\text { - In situ stress field disrupted in } \\
\text { connecting landform to } \\
\text { infrastructure }\end{array}$ & $\begin{array}{l}\text { The disruption of the } \\
\text { adjacent landform results } \\
\text { in the initiation of the } \\
\text { FM. }\end{array}$ \\
\hline $\begin{array}{c}\text { Branch } 3 \\
\text { (Continuation) }\end{array}$ & $\begin{array}{l}\text { - No intervention of strain } \\
\text { effects } \\
\text { - Mine influence regime area } \\
\text { increases in adjacent landform } \\
\text { whose features promote far- } \\
\text { field strain propagation }\end{array}$ & $\begin{array}{l}\text { - Halt of FM through } \\
\text { intervention }\end{array}$ \\
\hline $\begin{array}{c}\text { Branch } 4 \\
\text { Structural FM } \\
\text { (Progression) }\end{array}$ & $\begin{array}{l}\text { - No intervention of strain } \\
\text { effects } \\
\text { - Mine influence regime } \\
\text { continues to expand up to the } \\
\text { ridgeline of adjacent landform }\end{array}$ & $\begin{array}{l}\text { Mine influence regime } \\
\text { allowed to reach its } \\
\text { maximum affected area, } \\
\text { increasing strains to } \\
\text { critical magnitudes }\end{array}$ \\
\hline $\begin{array}{c}\text { Branch 5 } \\
\text { Seepage FM } \\
\text { (Progression) }\end{array}$ & $\begin{array}{l}\text { No intervention for } \\
\text { propagating strain effects } \\
\text { Mine influence regime } \\
\text { continues to expand up to the } \\
\text { ridgeline of adjacent landform }\end{array}$ & $\begin{array}{l}\text { Mine influence regime } \\
\text { allowed to reach its } \\
\text { maximum affected area, } \\
\text { increasing strains to } \\
\text { critical magnitudes }\end{array}$ \\
\hline
\end{tabular}

The breakdown of the ECFT following Table 7.10 - Table 10.15 fulfills the intent of Objective \#3.2 from Section 1.3.1:

Objective 3: Utilize model results to acquire insight into ground behavior and establish the SQPFMA-RCA. The SQPFMA-RCA will be developed in collaboration with model results and case history to make recommendations to prevent recurrence of potential far-field ground strain. This investigation will include:

3.2 Identify most significant contributors to an undesirable outcome 


\subsection{Recommendations to Prevent Recurrence}

The ECFT provides an organized representation of the development of the SQPFMA in an approach similar to a brief RCA. The intention of the SQPFMA-RCA was to find order in the failure mode development. The outcomes of the SQPFMA-RCA include insights to provide an approach, method, and recommendations to prevent recurrence and predict potential occurrences. In order to halt or prevent the FM from carrying out, the root causes must be defended by controls. These controls have been incorporated into a four step approach. The steps for prevention are:
I. Acknowledgement
II. Monitoring
III. Identification
IV. Intervention

In order to prevent recurrence of a seepage and structural based failure mode due to far-field ground strain, the four steps aforementioned must be considered. These steps have been denoted as (AMII). First, acknowledgement of the potential for far-field ground strain must be considered. At Ryerson Station State Park, the FM was neglected for 5 months until downstream residents were evacuated, Duke Lake was drained, and the dam was breached. Consequently, it is imperative to acknowledge the potential for far-field ground strain following Branch 1 in the ECFT.

Once it is acknowledged that failure modes initiated by far-field ground strain are possible at the site under investigation, monitoring should be implemented in some form to measure ground movement with high precision and resolution. Monitoring should be installed far away from any adjacent landform to the protected infrastructure. This will provide time for intervention if farfield movements are observed. Instrumentation should be installed along slopes outside and inside of the expected subsidence trough. Predictive modeling and model calibration would benefit from field instrument data collection along the length of landforms and perpendicular to valley ridgelines in a grid.

Table 7.16 provides recommendations for the implementation of field monitoring for far-field ground strain. These recommendations are based on inferences from numerical modeling outcomes and are intended to identify ground movement before resulting in damaging effects at a dam. The offset of monitoring should be no closer than 3,000 ft. as a conservative estimate for strain propagation based on the ECFT. The chosen landform should be representative of the connecting landforms to the infrastructure, allowing for the identification of equally offset distances from proposed mining operations. The best case monitoring scheme would be oriented as similarly as possible to conditions (slope severity, topographic relief) adjacent to the dam. 
Monitoring instruments should be installed before mining approaches within 3,000 ft.

Recordings should be taken as frequently as possible for the X, Y, and Z directions. Figure 7.4 presents the recommendations from Table 7.16 for an idealized case. Hypothetical values were determined for the evaluation of landforms.

Table 7.16 Monitoring recommendations

\begin{tabular}{|c|c|c|c|c|c|}
\hline $\begin{array}{c}\text { Grid } \\
\text { Number }\end{array}$ & Location & $\begin{array}{c}\text { Instrument } \\
\text { Type }\end{array}$ & $\begin{array}{c}\text { Instrument } \\
\text { Precision }\end{array}$ & Orientation & Rele vance \\
\hline 1 & Slope Surface 1 & & $\begin{array}{l}\text { A ground monitoring scheme in a grid of } \\
\text { minimum 3x3 along the length of a slope } \\
\text { surface offers opportunities to identify } \\
\text { movement propagation. Monitoring on } \\
\text { extensometers, } \\
\text { opposing slope surfaces may provide }\end{array}$ \\
\cline { 1 - 2 } & Slope Surface 1.1 & Survey points, \\
Slope Surface 2 & or inclinometers & $\begin{array}{l}\text { Parallel and } \\
\text { perpendicular to } \\
\text { valley bottom } \\
\text { insight into the propagation or } \\
\text { dampening effect of a valley on stress } \\
\text { magnitudes. }\end{array}$ \\
\hline
\end{tabular}




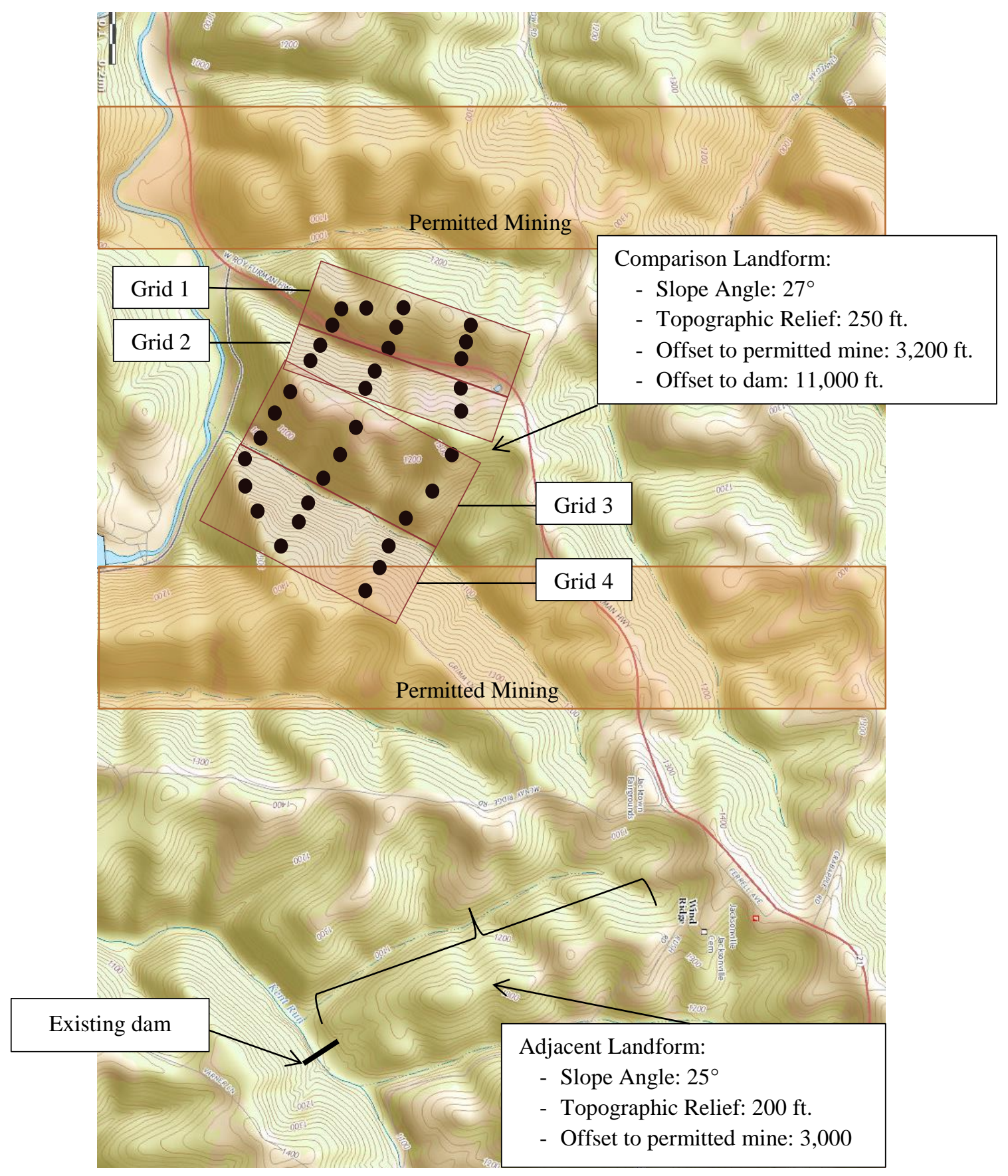

Figure 7.4 Idealized monitoring scheme for far-field ground strain propagation 
A maximum strain threshold was identified using Hooke's Law and the tensile strength of 4000 psi UCS concrete to be 6E-5. Strains exceeding this value using the modulus of elasticity of the site foundation rock and calibrated numerical modeling stresses indicate identification of potential initiation. Upon the identification of far-field ground strain from a monitoring scheme, numerical modeling should be calibrated. Due to the variability of landform characteristics and orientation, site specific 3D numerical modeling is recommended. An offset distance or zone of safety should be determined via predictive modeling. The zone of safety should incorporate a tolerance appropriate to the precision of the software and calibration results to preserve the infrastructure.

Intervention during failure mode development due to far-field ground strain is possible. These interventions include lowering the reservoir level, altering the mine plan, utilizing the observational method (Peck, 1969), and in the worst cases, draining of the lake and/or breaching of the dam. These intervening strategies are organized for review in Figure 5.19. Further intervention could be achieved by utilizing calibrated predictive numerical modeling to establish zones of safety around the infrastructure and its adjacent landforms.

These recommendations fulfill Objective\#3 from Section 1.3.1:

Objective 3: Utilize model results to acquire insight into ground behavior and establish the SQPFMA-RCA. The SQPFMA-RCA will be developed in collaboration with model results and case history to make recommendations to prevent recurrence of potential far-field ground strain. This investigation will include:

3.3 Develop recommendations for the mitigation of root causes 


\section{CHAPTER 8. CONCLUSIONS AND RECOMMENDATIONS}

Valley effects of subsidence are not unknown phenomena. The Subsidence Engineering Handbook cites surface topography as an influencing factor of underground mine subsidence (Singh, 1992). These types of movements may have little significance as a result of where they manifest. Narrow, steep valleys are typically not desirable locations for construction of homes and towns, but are sometimes desirable for the construction of cross valley dams. This may offer some insight into why the issue has not been researched further until the Ryerson Station Dam breach case occurred.

The mapping study revealed that three U.S.ACE owned and operated dams were within the 1mile buffer radius, and four within the 2.7-mile buffer radius of permitted mines in West Virginia. Some U.S.ACE dams can be very large in their length, changing the offset distances noted here significantly. There were zero U.S.ACE dams found to have any underground mine permit directly underneath their location. The total frequency of occurrence for U.S.ACE dams considered nearby to underground mine permits in WV was $17.4 \%$.

There are many more dams considered in the National Inventory of Dams (NID) than U.S.ACE dams alone. The same buffer radii were chosen to assess the offset distances of NID dams to underground mine permits as were used for the U.S.ACE dam assessment. There were found to be 115 NID dams within the 2.7-mile buffer radius with 79 of those within 1 mile, and 45 directly undermined. The total frequency of occurrence for NID dams existing nearby to permitted underground mines was found to be $18.9 \%$.

To date, much of the research involving far-field ground strain has been carried out in Australia and is referred to as non-conventional mine subsidence (Hebblewhite \& Gray, 2015). Many cases of valley closure and upsidence have been noted there and mechanisms that drive this process have been identified (Waddington \& Kay, 2003). This phenomenon has had limited attention in America in great depth. Studies conducted in the 1980's did indicate that subsidence behavior in mountainous terrain was different than what was predicted by traditional subsidence models. It was found that the topography alone determined the direction of horizontal displacements on steep slopes (Khair et al., 1988).

Lateral dilation is a more severe manifestation of the topography losing its ability to remain stable. Under this mechanism, the vertical jointing in weathered sedimentary geology along with the tensile stresses induced by mining allow the landform to dilate (expand), and the valley bottom to relieve stress by breaking and heaving upward. This occurs in 'block-like' movements and could result in a failure to maintain the authorized purpose of a dam structure.

In the modeled Ryerson Station case, when mining came to a 19-degree offset angle at Station 922.1, the stress began to increase significantly. Remaining stress percentages were $(66 \%, 81 \%$, $81 \%$ ) with respect to the total encountered stress at Station 922.1 upon reaching extraction region 
R7. This result is significant; however, the stress was at its greatest when mining was under the ridge of the western landform at an offset angle of 75 degrees. This observation indicates that the landform is of greater significance than the offset. Since a landform has more degrees of freedom than flat ground, effects on one part of the landform have the potential to affect the entire body.

Station 931 and Station 934 showed the most significant movement after the landform was affected on 6/7/2006, however no abrupt changes occurred at this point. This provides evidence that the landform encroachment may influence stress and deformation more significantly than the offset distance alone. The offset distance was equal to or greater than the distances upon which the greatest movements occurred.

Table 7.9 show that most of the failure modes reside within the region of the table past R8, when the western landform begun to be influenced by mining in Panel 7I. Approximately 86\% of all identified dam failure modes occurred in extraction regions beyond $\mathrm{R} 8$ which were the extraction regions within the western landform (R7-R2).

While evidence suggests that non-conventional subsidence does occur, the differences in the influencing factors between the United States and Australia may lead to different behavior. More research is necessary to determine the occurrence and scale of far-field ground strain in the United States.

\subsection{Conclusions from Extent and Potential for Far-Field Ground Strain Assessment}

There are many high hazard dams across the United States, and their protection is important to ensure the safety of people and property. The mapping study performed in Chapter 5 has given insight into the potential for future valley closure and upsidence phenomena to occur in valleys nearby to dams in WV, especially for many National Inventory of Dams (NID) sites. The Tygart Dam was investigated further, and it was found that many similar characteristics existed at the site which also existed at the Ryerson Station Dam site.

The overview study of key parameters for non-conventional subsidence at the Ryerson Station Dam and the Tygart Dam has given credence to the potential for further such events to occur in Appalachia. It has also been found that other sites such as East Lynn Dam, Summersville Dam, and many NID locations may meet the conditions under which far-field ground strain is possible. The mapping study revealed that for the sample area of West Virginia, dams exist which have mining nearby to them at less than 1 mile (3 U.S.ACE, 79 NID), and even directly underneath (0 U.S.ACE, 45 NID). Therefore, it is important that these phenomena be considered to ensure protection of infrastructure against far-field ground strain. 
Evaluation of the Ryerson Station case history determined that:

1. Far-field ground strains propagate large distances away from mining activities compared to conventional subsidence due to a lack of restraining adjacent land in high relief landforms. This lack of adjacent land provides little resistive forces to keep landforms from deforming under induced stresses which disrupt the static equilibrium state.

2. Observations of far-field ground strain phenomena from monitoring instruments such as strain gauges, extensometers, inclinometers, and survey stations indicate that the effects are a result of a stress/displacement induced dilation of hillside strata.

3. The PADEP requires an angle of draw of 15 to 25 degrees to evaluate support areas for structures that require protection from mine subsidence (PADEP, 2010). This angle appears to not be adequate in high relief landforms within sedimentary strata. Safety zones determined from site specific modeling may provide an alternative to an angle of draw where far-field ground strain may manifest.

\subsection{Conclusions from PFMA}

A Potential Failure Mode Analysis (PFMA) was developed for the events that occurred at the Ryerson Station Dam. This potential failure mode has been introduced for far-field ground strain leading to uncontrolled seepage at a dam. The key factors that have been identified in the PFMA process are shown in Table 5.5. The table links the identified mechanisms (flaw, initiation, continuation, and progression) to quantifiable parameters to allow event tree representation of the PFMA components. 
Table 5.5 PFMA components and associated parameters

\begin{tabular}{|c|c|c|}
\hline PFMA Component & Description & Parameter \\
\hline Flaw & $\begin{array}{l}\text { Underground mine void } \\
\text { installment (<6000 ft.) }\end{array}$ & Prerequisite Assumption \\
\hline Load (deformation) & Adjacent landform weight & Height/Slope \\
\hline Load (deformation) & Tectonic stress & In situ stress magnitude (range) \\
\hline Load (seepage) & $\begin{array}{l}\text { Pore pressure in compression } \\
\text { regime }\end{array}$ & Pore pressure, $\mathrm{u}$ \\
\hline Load (seepage) & Lake hydraulic head & Seasonal lake elevation \\
\hline Initiation & Hill seams/weathered joints & Prerequisite Assumption \\
\hline Initiation & $\begin{array}{l}\text { Topography (elevation } \\
\text { change/slope angle) }\end{array}$ & Height/Slope \\
\hline Initiation & Subsidence due to coal mining & Coal seam thickness \\
\hline Continuation & $\begin{array}{l}\text { Mining continues beyond } \\
\text { initiating longwall panel, closer } \\
\text { to the dam }\end{array}$ & $\begin{array}{l}\text { Mine offset distance from point of } \\
\text { interest }\end{array}$ \\
\hline Continuation & $\begin{array}{l}\text { Seepage increases due to } \\
\text { disturbed natural fractures } \\
\text { (seepage pathway) }\end{array}$ & Hydraulic conductivity, $\mathrm{k}$ \\
\hline Progression & $\begin{array}{l}\text { Mining progresses to panel } \\
\text { closer to the dam, increasing } \\
\text { stresses in the valley and dam to } \\
\text { the point of failure }\end{array}$ & $\begin{array}{l}\text { Valley strata strength parameters, } \\
\text { UCS, E, } v\end{array}$ \\
\hline
\end{tabular}

\subsection{Numerical Modeling Conclusions}

Site-specific data from the PADCNR monitoring project at the Ryerson Station State Park was used for model calibration. Model results were investigated in detail to understand the overall movement of the stations. Differences at each station were sought to gain insight into the dynamic nature of the 3D model scenario. The results of three stations $(922.1,921$, and 13) were isolated to more thoroughly assess their differences. 


\subsubsection{Recommendations from Model Set-Up}

SoilVision $^{\mathrm{TM}} 2009$ 3D Finite Element Method (FEM) stress/deformation modeling was performed for the Ryerson Station State Park site. Recommendations for the model set-up including geometry, model settings, and boundary conditions are listed 1-8.

1. Geometric refinement of the ground surface should be detailed enough to encapsulate major topographic features. High levels of detail such as LiDAR are not required, however high levels of topographical detail could increase the precision of the model. Irregular surface grids can be useful, although it is important to have a high enough refinement to encapsulate all major topographic features.

2. SVSolid2009 ${ }^{\mathrm{TM}}$ currently allows for a maximum of 15 surfaces, 14 layers. High levels of detail in layering do not appear to be needed. Accurate rock parameter selection proved more valuable than the number of layers in the model.

3. Modeling should extend beyond the intended extraction of mining to decrease the impact of edge effects. Model edge effects were accommodated by fixing the model edge boundary condition in the $\mathrm{Z}$ direction. This boundary condition acted as adjacent strata to support the panel roof. It is expected that if this were allowed to deform in accordance with the adjacent rock properties, the model results may be more precise.

4. The model area was extended northward to the ridges of the landforms on the opposite side of the valley. This simulated a buttressing effect in the valley with rock properties rather than a rigid boundary condition.

5. The development of a very large model $(4,000 \mathrm{ft}$. x 5,500 ft. x 1,000 ft.) intended to view material properties in a macrospective manner, where the overall influence of fracturing would act as one elastic material. A smaller model area may not encapsulate a landform movement, but would likely have greater influences from local fracturing. Far-field ground strain modeling could benefit from both large scale and small scale simulations.

6. Finite Element Method (FEM) elements were tetrahedral and used auto-refinement for complex geometry. FEM mesh refinement was such that less complex model regions required fewer, larger elements, while more complex geometry refined to many smaller elements. The convergence error limit was \pm 0.01 with threshold values for incremental displacement of (u, v, w: $0.001 \mathrm{ft} ., 0.01 \mathrm{in}$.) and incremental total stress (sx, sy, sz: 0.1 psf). The element interpolation was set to quadratic as the $3 \mathrm{D}$ modeling preference. The number of iterations per model was set to 1,000 in order to achieve a high level of precision while keeping model run times manageable. These settings provided model 
calibration results similar to field measured values, and were determined to be sufficient for this research.

7. The degree of local fracturing and quantified overall reduction in strength cannot be thoroughly accounted for independently due to field variability on a small scale;

however, a reduction in rock properties adequately accounted for these effects on a large scale. As a result, rock properties $(E, \gamma, n, v)$ seem to have the greatest influence on the final model results.

8. A zero mine void model must be run to calibrate the model to an initial gravity load condition. The deformation results from the zero mine void model should be subtracted from subsequent model results to simulate an initial ground response to the introduction of a subsurface void. Initial stresses from the zero mine void calibration should be used as the in situ stress condition.

\subsubsection{Conclusions from 3D Numerical Modeling Calibration}

Site specific model calibration was performed in SVSolid ${ }^{\mathrm{TM}}$. This process utilized laboratory testing results from on-site borehole materials. Parameters were summarized into Best Case (BC) and Worst Case (WC) for shale, limestone, siltstone, sandstone, and coal. BC and WC model parameters can be reviewed in Table 6.4 and Table 6.5. Conclusions from the calibration procedure are listed 1-13.

1. The range of results between $\mathrm{BC}$ input parameters and $\mathrm{WC}$ parameters was expected to decrease as the model detail increased. That was not the case; in fact, the increase in detail from 8 layers to 14 layers had little influence on the precision of the model.

2. BC input parameters improved as level of detail increased but did not match data. Best Case (BC) properties simulated intact non-fractured rock to minimize resultant deformation. These parameters yielded unrealistic calibration results, far smaller magnitude displacements than were measured in the field.

3. The WC parameters more closely simulated the other factors at play which influenced the magnitude of displacement (i.e. fracturing, in situ stress, and material properties).

4. Model data tended to be a smooth line whereas the field data had more rapid jumps in displacement. This was expected as the model simulated an elastic media, incapable of failing in the same brittle manner as what is experienced in the field. The field data tended to rebound somewhat after each major displacement, but did not recover all of the incurred displacement. 
5. The manner in which the field displacement was graphed may not necessarily represent the movement in the field. Movements were likely sudden and brittle with possible periods of zero movement or some creep or settlement. It is difficult to know the exact shape of the curve with certainty without more frequent recordings.

6. The model data trend was nearly identical to the field measurements, but was offset in time. Unfortunately, the lag time of the field movements are not known, which may have had an effect in this analysis, resulting in error. The model simulation reaches equilibrium before producing a final movement condition. This indicates that model data trends may be more important than time correlation.

7. Detail 1 (8 layers) and Detail 2 (14 layers) results were not significantly different for stations 934 and 931. The Bulk Analysis modeling showed a high amount of correlation with field data, but did not match the data as well as Detail 1 and Detail 2. This concludes that a high level of detail may not be required to obtain predictive approximate ground displacements.

8. Station 931 and Station 934 showed the most significant movement after the landform was affected on 6/7/2006. This provides evidence that the landform encroachment may be more important than the offset distance. The offset distance was equal to or greater than the distances upon which the greatest movements occurred.

9. The movements of each station were not always in the same direction. Station 934 moved down (-Z) as it was over the mine panel. Station 931 moved up $(+Z)$ as the ground heaved in this region. Station 16 moved downhill as would be expected if heaving does not occur. The further uphill from the bottom of the valley, the less likely it is that heaving would occur, and the movement expected would be in the $-\mathrm{Z}$ direction.

10. An increase in surface resolution would refine model results which are of small magnitude like those far from the mine void at Station 16 which ranged in offset from 3,200 ft. to 3,800 ft. This would decrease the influence of anomalous surface effects.

11. Inclinometer and extensometer data could be calibrated to a similar 3D SVSolid ${ }^{\mathrm{TM}}$ model if data sets were available. This could be accomplished by the incorporation of cylinders within SVSolid ${ }^{\mathrm{TM}}$ extended to a known depth. This option is available, but greatly increases model run times and can crash the model if computing power is not adequate. Increases in surface resolution is possible and can be accomplished using the AutoCADD Civil $3 \mathrm{D}^{\mathrm{TM}}$ grid feature. Future versions of SVSolid ${ }^{\mathrm{TM}}$ may allow the incorporation of 
additional layering. Greater model precision may result if layering possibilities include topographic intersection of surfaces.

12. Survey data in the $X$ and $Y$ directions were not calibrated as there were no frequent recordings of data available. Future studies would benefit from frequent and precise ground movement measurements in the $\mathrm{X}, \mathrm{Y}$, and $\mathrm{Z}$ directions.

13. Pearson's Correlation Coefficient (PCC) decreased with distance but maintained a high level of correlation for Station 931 which ranged in linear offset from 1,000 ft. to 3,000 ft. In general, the model data trends with the field data and PCC values are high. Possible reasons for the decrease in correlation with distance could be due to the decreasing distance between each station and the edge of the model, increasing chaos in the calculation at a distance, or a need for greater surface resolution. Despite the lack of linear correlation at great distances $(\mathrm{r}=0.33)$, model results produced the same order of magnitude movements ( $0.001 \mathrm{ft}$.) up to $3,800 \mathrm{ft}$. offset.

\subsubsection{Conclusions from Parameter Correlation and Sensitivity Analysis}

Model parameter relationships to final results and model behavior were assessed in the $\mathrm{X}, \mathrm{Y}$, and $\mathrm{Z}$ directions to gain insight into the phenomenon of far-field ground strain. Multiple survey stations were compared for linear offset and topographic orientation. Conclusions from this work are listed 1-6.

1. Topography in Appalachia is highly variable. The influences of varying seam inclination, seam thickness, slope height, slope angle, multiple valley influence, and other specific landform characteristics are yet to be quantified in stress/deformation 3D modeling. This variability produces great difficulty in establishing specific inferences for topographic features. Therefore, case by case site specific model calibration and prediction is recommended in cases of concern for topographic influence of ground movement due to underground mine voids to ensure safety of critical infrastructure. Numerical 3D modeling provides clarity and ease in accounting for these variable parameters. Comparing Station 922.1, Station 921, and Station 13 showed that resulting stresses and displacements were highly sensitive to the orientation and location of each station.

2. The calculated PCC for model and field data decreased with distance from the mine void, but may have opportunities to increase by moving stations further from the model edge where the $\mathrm{Z}$ direction incorporated a fixed boundary condition. 
3. Relative to final results, significant initiation of stresses occurred at a minimum 1,200 ft. and a maximum of 1,400-1,500 ft. in X, Y, and Z directions. Identical offset distances for each station did not yield the same stresses. In fact, similar offset yielded much higher stresses after the western landform was encroached where the stations investigated resided. Nearly all of the modeled movements were outside of the typical angle of draw.

4. Depth may play a role in the calibration of the modeling. A field lag time is thought to occur between the initiator of stress and the final result for far-field ground strain. The Subsidence Engineer's Handbook mentions that the depth of mining can slow down the final manifestation of subsidence. As a result, trending data may have more significance than time correlation.

5. Model results showed that station displacement and stress behavior generally reversed after Station 921 at $365 \mathrm{ft}$. perpendicular to Panel 7I compared to the stations closer than Station 921. X-Y displacement vector plots were developed to identify these areas of opposing behavior. These two zones have been identified to be the topographic influence regime and direct mine influence regime. These two regimes can be easily delineated with X-Y vector plots. Stations closer to the mine than Station 921 (365 ft.) tended to move toward the mine while stations further away moved in accordance with the landform as a result of the topographic influence. The majority of movement directions in the topographic influence regime trended downhill toward the northern, lowest elevation of the landform.

6. Smaller magnitude stresses resulted at stations that were located where topographic relief was less, but was also at greater distances from the mine void. As a result, it is uncertain the quantitative role that topographic relief plays in resultant strains. Topographic relief provides a loading condition for resulting surface strain along a landform. 


\subsection{Conclusions from SQPFMA-RCA ECFT}

An Event and Causal Factor Tree (ECFT) is an organizational flowchart that is developed to identify root causes of an undesired outcome. An undesired outcome is an unwanted event or result of a system that is different than the desired outcome. In the case of a dam, the desired outcome is maintaining working function to preserve the authorized purpose of the structure. An undesired outcome would be the loss of the authorized purpose of the structure. Undesired outcomes typically result from a sequence of events and actions under specific conditions. The causes of the undesired outcome must be investigated and understood to develop solutions to prevent the recurrence of the scenario (BCMEM, 2015).

\subsubsection{Failure Mode (FM) Occurrence Potential}

The failure mode occurrence potential was calculated as a frequency of occurrence for the 7I model stress vector resultant data. Failure modes were based on strain since this parameter is a commonly referenced value with respect to dam safety and seepage disruptions. Also, calculating all failure modes as a strain threshold provides ease in comparison of the results. Result conclusions for calculated failure mode occurrence potential are listed 1-7.

1. The seepage strain threshold to generate a significant material property change which induces permeability variations in fractured rock were taken to be strain values greater than 0.001 (Bai et al., 1995). A seepage failure mode may likely be induced at much lower strain values than 0.001 for severely fractured strata. The threshold of 0.001 was set for rock which has not been sufficiently deformed or strained to significantly increase its storage potential (Bai et al., 1995).

2. The dam joint stress threshold was utilized from the reported concrete joint strength at the Ryerson Station Dam of 130 psi. A foundation strain threshold was calculated from the modulus of elasticity of the modeled shale foundation rock and the allowable bearing capacity of the foundation (14.2 ksf).

3. Since Station 934 yielded the greatest displacement, and was located over Panel 7I, it should have produced failure conditions for R7 - R2. The local stresses from the removed coal regions to the east and west of Station 934 cancelled each other due to opposing signage, resulting in a lower local strain value. This observation implies that Hooke's law does not provide a realistic failure mode assessment for stations directly over the panel. Stress dependent strain at Station 934 does not represent the failure mode identification for Station 934. This is due to the void located directly below the station. This caused the majority of the movement to manifest as a vertical translation, not inducing high stresses to appropriately apply Hooke's Law. 
4. Results show that the majority of the failure modes reside after R8 extraction (R7-R2), when the western landform begun to be influenced by mining in Panel 7I. Up to 86\% of all identified breached failure modes occurred after R8.

5. Nearly $10 \%$ of the 140 failure scenarios resulted in high enough strain to result in significant seepage or structural failure at offset distances up to $1,857 \mathrm{ft}$.

6. Foundation bearing capacity strain thresholds were exceeded up to 3,298 ft. for $29 \%$ of the cases.

7. Dam joint stress thresholds were reached or surpassed at offsets up to $1,857 \mathrm{ft}$. for $26 \%$ of the cases

8. Concrete tensile strain thresholds were reached or exceeded up to $2,093 \mathrm{ft}$. for $23 \%$ of the cases.

\subsubsection{Recommendations for Prevention}

The ECFT provides an organized representation of the development of the SQPFMA in an approach similar to a brief RCA. The intention of the SQPFMA-RCA was to find order in the failure mode development. The outcomes of the SQPFMA-RCA include insights to provide an approach, method, and recommendations to prevent recurrence and predict potential occurrences. Recommendations for prevention determined from the SQPFMA-RCA are listed 1-10.

1. The steps for prevention are (AMII):
a. Acknowledgement
b. Monitoring
c. Identification
d. Intervention

2. Acknowledgement of the potential for far-field ground strain must be considered. At Ryerson Station State Park, the failure mode was neglected for 4 months until downstream residents were temporarily evacuated, Duke Lake was drained, and the dam was breached. Consequently, it is imperative to acknowledge the potential for far-field ground strain.

3. If acknowledgement occurs, monitoring should be implemented in some form to measure ground movement at high precision. 
4. Site specific 3D numerical modeling is recommended due to the variability of landform orientation and characteristics.

5. Monitoring should be installed far away from any adjacent landform to the protected infrastructure. This will provide time for intervention if far-field movements are observed.

6. Instrumentation should be installed along slopes outside and inside of the expected subsidence trough. Calibration and predictive modeling would benefit from instruments along the length of landforms and perpendicular to valley to ridgelines.

7. Identification of far-field ground strain from a monitoring scheme occurs when ground displacements outside of the expected subsidence trough exceed those required to initiate seepage or structural failure modes at the dam.

8. Upon the identification of far-field ground strain from a monitoring scheme, numerical modeling should be calibrated.

9. Tolerances of some magnitude should be incorporated in the predictive modeling to determine offset distances or zones of safety to preserve the infrastructure.

10. Possible interventions for a far-field ground strain based failure mode include lowering the reservoir level, altering the mine plan, utilizing the observational method (Peck, 1969), and in the worst cases, draining of the lake and/or breaching of the dam.

11. Further intervention could be achieved by utilizing calibrated predictive numerical modeling to establish zones of safety around the infrastructure and its adjacent landforms. 


\subsection{Major Contributing Points}

Ground movement leading to the Ryerson Station Dam breach has indicated the potential for farfield ground strain resulting from underground mine voids. This research provides an approach to predict and prevent the recurrence of such a scenario. Methods include a Semi-Quantitative Potential Failure Mode Analysis (SQPFMA), site specific 3D stress/deformation numerical modeling calibration, 3D stress result assessment via a parameter correlation and sensitivity analysis, and a subsequent modified Root Cause Analysis (RCA) including recommendations for prevention. The major contributing conclusions for this work are listed 1-24.

\section{Model Calibration and Set-Up}

1. Geometric refinement of the ground surface should be detailed enough to encapsulate major topographic features. High levels of detail such as LiDAR are not required, however high levels of topographical detail could increase the precision of the model. Irregular surface grids can be useful, although it is important to have a high enough refinement to encapsulate all major topographic features.

2. SVSolid2009TM currently allows for a maximum of 15 surfaces, 14 layers. High levels of detail in layering do not appear to be needed. Representative rock parameter selection proved more valuable than the number of layers in the model.

3. The Worst Case (WC) parameters more closely simulated the other factors at play which influenced the magnitude of displacement (i.e. fracturing, in situ stress, and material properties).

4. Station 931 and Station 934 showed the most significant movement after the landform was affected on $6 / 7 / 2006$. This provides evidence that the landform encroachment may be more important than the offset distance. The offset distance was equal to or greater than the distances upon which the greatest movements occurred.

5. Pearson's Correlation Coefficient (PCC) decreased with distance but maintained a high level of correlation for Station 931 which ranged in linear offset from 1,000 ft. to 3,000 $\mathrm{ft}$. In general, the model data trends with the field data and PCC values are high. Possible reasons for the decrease in correlation with distance could be due to the decreasing distance between each station and the edge of the model, increasing chaos in the calculation at a distance, or a need for greater surface resolution. Despite the lack of linear correlation at great distances $(\mathrm{r}=0.33)$, model results produced the same order of magnitude movements ( $0.001 \mathrm{ft}$.) up to $3,800 \mathrm{ft}$. offset. 


\section{$\underline{\text { Parameter Correlation and Sensitivity Analysis }}$}

6. The comparison of Station 922.1, Station 921, and Station 13 showed that resulting stresses and displacements were highly sensitive to the orientation and location of each station.

7. Relative to final results, significant initiation of stresses occurred at a minimum 1,200 ft. and a maximum of 1,400-1,500 ft. in X, Y, and Z directions. Identical offset distances for each station did not yield the same stresses. In fact, similar offset yielded much higher stresses after the western landform was encroached where the stations investigated resided. Nearly all of the modeled movements were outside of the typical angle of draw.

8. Depth may play a role in the calibration of the modeling. A field lag time is thought to occur between the initiator of stress and the final result for far-field ground strain. The Subsidence Engineer's Handbook mentions that the depth of mining can slow down the final manifestation of subsidence. As a result, trending data may have more significance than time correlation.

9. Model results showed that station behavior generally reversed after Station 921 at $365 \mathrm{ft}$. perpendicular to Panel 7I compared to the stations closer than Station 921. X-Y displacement vector plots were developed to identify these areas of opposing behavior. These two zones have been identified to be the topographic influence regime and direct mine influence regime. These two regimes can be easily delineated with $\mathrm{X}-\mathrm{Y}$ vector plots. Stations closer to the mine than Station 921 (365 ft.) tended to move toward the mine while stations further away moved in accordance with the landform contours as a result of the topographic influence. The majority of movement directions in the topographic influence regime trended downhill toward the northern, lowest elevation of the landform. 


\section{FM Occurrence Potential}

10. Since Station 934 yielded the greatest displacement, and was located over Panel 7I, it should have produced failure conditions for R7 - R2. The local stresses from the removed coal regions to the east and west of Station 934 cancelled each other due to opposing signage, resulting in a lower local strain value. This observation implies that Hooke's law does not provide a realistic failure mode assessment for stations directly over the panel. Stress dependent strain at Station 934 does not represent the failure mode identification for Station 934. This is due to the void located directly below the station. This caused the majority of the movement to manifest as a vertical translation, not inducing high stresses to appropriately apply Hooke's Law.

11. Results show that most of the failure modes reside after R8 extraction (R7-R2), when the western landform begun to be influenced by mining in Panel 7I. Up to $86 \%$ of all identified breached failure modes occurred after R8.

12. Nearly $10 \%$ of the 140 failure scenarios resulted in high enough strain to result in significant seepage or structural failure at offset distances up to $1,857 \mathrm{ft}$.

13. Foundation bearing capacity strain thresholds were exceeded up to $3,298 \mathrm{ft}$. for $29 \%$ of the cases.

14. Dam joint stress thresholds were reached or surpassed at offsets up to $1,857 \mathrm{ft}$. for $26 \%$ of the cases

15. Concrete tensile strain thresholds were reached or exceeded up to $2,093 \mathrm{ft}$. for $23 \%$ of the cases.

\section{SQPFMA-RCA ECFT}

16. The steps for prevention are (AMII):
a. Acknowledgement
b. Monitoring
c. Identification
d. Intervention 
17. Acknowledgement of the potential for far-field ground strain must be considered in appropriate scenarios. At Ryerson Station State Park, the failure mode was neglected for 5 months until downstream residents were temporarily evacuated, Duke Lake was drained, and the dam was breached. Consequently, it is imperative to acknowledge the potential for far-field ground strain.

18. Upon acknowledgement, field monitoring should be implemented to measure ground movement at high precision.

19. Site specific 3D numerical modeling is recommended due to the variability of landform orientation and characteristics.

20. Monitoring should be installed far away from any adjacent landform to the protected infrastructure. This will provide time for intervention if far-field movements are observed.

21. Instrumentation should be installed along slopes outside and inside of the expected subsidence trough. Calibration and predictive modeling would benefit from instruments along the length of landforms and perpendicular to valley to ridgelines.

22. Upon the identification of far-field ground strain from a monitoring scheme, numerical modeling should be calibrated.

23. Tolerances should be incorporated in the predictive modeling to determine offset distances or zones of safety to preserve the infrastructure.

24. Possible interventions for a far-field ground strain based failure mode include lowering the reservoir level, altering the mine plan, utilizing the observational method (Peck, 1969), and in the worst cases, draining of the lake and/or breaching of the dam.

25. Further intervention could be achieved by utilizing calibrated predictive numerical modeling to establish zones of safety around the infrastructure and its adjacent landforms. 


\subsection{Future Work}

There remains much information which could be added upon within the pertinent topics of this research, including:

1. Horizontal and vertical stress disruption dampening across multiple valley bottoms

2. Australian Coal Association Research Program (ACARP) database calibration to United States phenomena

3. If data at Ryerson can be argued as correlating with the Australian database, then the probability of deformation magnitude at a distance can be determined.

4. Further monitoring studies to find:

a. $\mathrm{X}$ and $\mathrm{Y}$ frequent readings for updated calibration for current model verification

b. Strain dampening effect of valleys on far-field ground strains induced by longwall mining

c. Elastic versus plastic strata absorbing strain

d. Rock layer interface/bedding plane behavior

e. Numerical modeling for fracture densities simulated for far-field ground strain disturbances adjacent to an idealized dam. Future models may benefit from utilizing fracture densities to emulate seepage effects due to thrust faults, bed separation, fracture generation, and worsening of existing fractures.

f. Incorporation of stress boundary conditions to account for in situ stress conditions.

5. SVSlope ${ }^{\mathrm{TM}}$ modeling utilizing Hoek-Brown or reduced Mohr-Coulomb failure criterion could be performed in lieu of SVSolid ${ }^{\mathrm{TM}}$ stress/deformation modeling to predict a probability of slope movement instead of resultant stress and displacement. The angle of draw, fracturing as a reduction in rock strength, and the North American zones (Bai \& Kendorski, 1995) of fracturing could be incorporated in 2D and 3D profiles.

6. Future modeling with increased surface resolution

7. Predictive modeling study on Ryerson Station Dam for Panel 3I and Panel 4I East 


\section{REFERENCES}

Agioutantis, Z.G. \& Karmis, M. (2013). Recent developments on surface ground strain calculations due to underground mining in Appalachia. In Proceedings of the 32nd International Conference on Ground Control in Mining. Morgantown, West Virginia, USA (pp. 214-219)

ACI Committee, American Concrete Institute, \& International Organization for Standardization. (2008). Building code requirements for structural concrete (ACI 318-08) and commentary. American Concrete Institute.

American Society of Civil Engineers (ASCE) (2013). 2013 Report Card for America's Infrastructure. Retrieved from http://www.infrastructurereportcard.org/

Babcock, C.O., and Hooker, V.E. (1977). Results of research to develop guidelines for mining near surface and underground bodies of water, IC 8741. [Washington, D.C] US Department of Interior, Bureau of Mines Circular.

Baecher, G. B., \& Christian, J. T. (2005). Reliability and Statistics in Geotechnical Engineering. John Wiley \& Sons.

Bai, M., Kendorski, F.S., Roosendaal, D. J. (1995). Chinese and North American HighExtraction Underground Coal Mining Strata Behavior and Water Protection Experience and Guidelines. 14th Conference on Ground Control in Mining. Morgantown, WV: 209-217.

Booth, C. J., Curtiss, A. M., Demaris, P. J., \& Bauer, R. A. (2000). Site-specific variation in the potentiometric response to subsidence above active longwall mining. Environmental \& Engineering Geoscience, 6(4), 383-394.

Booth, C. J. (2002). The effects of longwall coal mining on overlying aquifers. Mine Water Hydrogeology and Geochemistry. London, Geological Society. 198: 17-45.

British Columbia Ministry of Energy and Mines (BCMEM). (2015). Mount Polley Mine Tailings Storage Facility Breach: Investigation Report of the Chief Inspector of Mines.

Das, Braja M. (2006). Principles of Geotechnical Engineering ( $7^{\text {th }}$ ed.). Canada: Nelson Education Ltd.

Dolinar, D. R. (2003, August). Variation of horizontal stresses and strains in mines in bedded deposits in the eastern and midwestern United States. In Proceedings of the 22nd International Conference on Ground Control in Mining, Morgantown, WV (pp. 178-185). 
Dyne, L. A. (1998). The prediction and occurrence of chimney subsidence in southwestern Pennsylvania (Doctoral dissertation, Virginia Polytechnic Institute and State University).

Federal Emergency Management Agency (FEMA). (2012). Summary of Existing Guidelines for Hydrologic Safety of Dams.

Ferguson, H. F., \& Hamel, J. V. (1981, January). Valley stress relief in flat-lying sedimentary rocks. In ISRM International Symposium. International Society for Rock Mechanics.

Fredlund, M. D. (2009). SoilVision Systems Ltd. SVSolid User's Manual. Saskatoon, Saskatchewan, Canada.

Fredlund, M., Gitirana, P. G., \& Thode, R. (2013). SVSolid ${ }^{\mathrm{TM}}$ 2D/3D Stress Deformation Modeling Software Tutorial Manual.

Freeze, R. A., \& Cherry, J. A. (1979). Groundwater (No. 629.1 F7).

Geologic Map of West Virginia. (May 16, 2011). West Virginia Geologic and Economic Survey (WVGES). Retrieved from http://www.wvgs.wvnet.edu/www/maps/geomap.htm.

Gere, James M, \& Goodno, B. J. (2009). Mechanics of Materials. Cengage Learning.

Haldar, A., \& Mahadevan, S. Probability, reliability, and statistical methods in engineering design. 2000.

Hebblewhite, B., Digiolia, Gray \& Associates. n.d. Leakage Investigation of Ryerson Station State Park Dam, Greene County, Pennsylvania.

Hebblewhite, B. K., Waddington, A., \& Wood, J (2000). "Regional horizontal surface displacements due to mining beneath severe surface topography." In $19^{\text {th }}$ International Conference on Ground Control in Mining. Morgantown, West Virginia, USA (pp. 149157)

Hebblewhite, B. \&. Gray, R. (2014). "Non-Conventional Subsidence Behaviour and ImpactsRyerson State Park Dam, Pennsylvania USA Case Study," Proceedings, $9^{\text {th }}$ Triennial Conference on Mine Subsidence, Pokolbin, New South Wales, Australia.

Hebblewhite, B. \& Gray, R. (2015). "Non-Conventional Surface Ground Behaviour Induced by Underground Mining in Pennsylvania," Proceedings, SME Annual Meeting, Denver, Colorado, United States. 
Holtz, R. D., Kovacs, W. D., \& Sheahan, T. C. (2011). An introduction to geotechnical engineering.

Hopey, Don (2008). "Pennsylvania Says Mining destroyed lake dam in park

Consol Energy sued for \$58 million to fix Greene Co. damage,” Pittsburgh Post-Gazette, Friday, February 01, 2008.

Jaeger, J. C., Cook, N. G., \& Zimmerman, R. (2009). Fundamentals of rock mechanics. John Wiley \& Sons.

Karmis, M., Mastoris, J., \& Agioutantis, Z. "An Investigation into the Potential of the "Damage Angle" Concept for Assessing the Impacts of Underground Mining on the Surface." Preprints-Society of Mining, Metallurgy, and Exploration (1994).

Keilich, W., Lee, J. W., Aziz, N., \& Baafi, E. (2005). Numerical Modelling of Undermined River Valleys--A Case Study.

Kendorski, F. S. (1993). Effect of high-extraction coal mining on surface and ground waters. In Proceedings, 12 international conference on ground control in mining.

Khair, A.W., Quinn, M.K., \& Chaffins, R.D. (1988). Effect of topography on ground movement due to longwall mining. Mining Engineering (Littleton, Colorado); (United States), $40(8)$.

LeBlanc, D. C. (2004). Statistics: concepts and applications for science (Vol. 2). Jones \& Bartlett Learning.

Lee, Cheng-Haw (1990). Flow in Fractured Rock.

Mastalerz, M., He, L., Melnichenko, Y. B., \& Rupp, J. A. (2012). Porosity of coal and shale: insights from gas adsorption and SANS/USANS techniques. Energy \& Fuels, 26(8), 5109-5120.

McWhorter, D. B., \& Sunada, D. K. (1977). Ground-water hydrology and hydraulics. Water Resources Publication.

Mills, K. W. 2011. Developments in understanding subsidence with improved monitoring. In Proceedings of the 8th Triennial Conference on Mine Subsidence. Pokolbin. 
O'Connor, K. M., Clark, R. J., Whitlatch, D. J., \& Dowding, C. H. (2001). Real-time monitoring of subsidence along I-70 in Washington, Pennsylvania. Transportation Research Record: Journal of the Transportation Research Board, 1772(1), 32-39.

Peck, R. B. (1969). Advantages and limitations of the observational method in applied soil mechanics. Geotechnique, 19(2), 171-187.

Peng, S. S., \& Y. Luo. "A new method for designing support area to protect surface structures over underground coal mining areas." PREPRINTS-SOCIETY OF MINING ENGINEERS OF AIME (1993).

Peng, S. S., \& Geng, D. Y. (1982). Methods of Predicting the Subsidence Factors, Angle of Draw and Angle of Critical Deformation. Proceedings State-of-the-Art of Ground Control in Longwall Mining and Mining Subsidence, SME-AIME, Littleton, CO, 211-221.

Pennsylvania Department of Conservation and Natural Resources. (2007). Ryerson Station State Park Dam Greene County, Pennsylvania Volume I-V Data Report. California, PA: Gannett Fleming, Inc.

Pennsylvania Department of Conservation and Natural Resources (DCNR) (2013). DCNR and CONSOL Energy reach agreement related to Duke Lake in Ryerson Station State Park. [Press Release]. Retrieved from http://www.denr.state.pa.us/cs/groups/public/documents/news/dcnr_20026882.pdf

Pennsylvania Department of Convservation and Natural Resources (DCNR) (2016). Retrieved from http://www.denr.state.pa.us/stateparks/findapark/ryersonstation/dukelake/index.htm.

Pennsylvania Department of Environmental Protection. (n.d.) Retrieved from http://www.dep.state.pa.us/dep/deputate/minres/LongwallForestlandStudy/Table1.pdf.

Pennsylvania Department of Environmental Protection (DEP) (2010). Interim Report: Ryerson Station State Park, Ryerson Dam, Damage Claim Number SA1736.

Sames, G. P., and N. N. Moebs. Hill seam Geology and Roof Instability Near Outcrop in Eastern Kentucky Drift Mines. BuMines RI 9267, 1989, 32 pp.

Scott, G. A. (2011). The practical application of risk assessment to dam safety. GeoRisk 2011, (224), 129-168.

Seedsman, R. \& A. Dawkins. 2006. Techniques to Predict and Measure Subsidence and Its Impacts on the Groundwater Regime Above Shallow Longwalls. 
Singh, M. M. (1992). Mine Subsidence. In H.L. Hartman (Ed.), SME Mining Engineering Handbook (Vol.1) (pp. 939-971). Littleton, Colorado: Society for Mining, Metallurgy, and Exploration, Inc.

Sydney Catchment Authority (2007). Literature review on longwall mining.

United States Army Corps of Engineers (U.S.ACE). (1994). Authorized and operating purposes of Corps of Engineers reservoirs. Hydraulics and Hydrology Branch, PR-19.

United States Army Corps of Engineers (U.S.ACE) (2011). Engineering and Design. Safety of Dams - Policy and Procedures. ER 1110-2-1156.

United States Army Corps of Engineers (U.S.ACE) (2014). National Inventory of Dams. Retrieved from http://geo.U.S.ACE.army.mil/pgis/f?p=397:1:0::NO

United States Army Corps of Engineers (U.S.ACE) (2014). Program Activities. Retrieved from http://www.U.S.ACE.army.mil/Missions/CivilWorks/DamSafetyProgram/ProgramActivi ties.aspx

United States Army Corps of Engineers (U.S.ACE) (2014). Program Activities. Retrieved from http://www.U.S.ACE.army.mil

United States Department of Labor, Mine Safety and Health Administration (MSHA). (2009). Report of Investigation, Underground Coal Mine Fatal Fall of Roof Accident, June, 23, 2009, at Bailey Mine, Consol Pennsylvania Coal Company, Wind Ridge, Pennsylvania. District 2 office, Mt. Pleasant, Pennsylvania

United States Energy Information Administration. (2014, June). Quarterly Coal Report, 2014.

United States Geological Survey (USGS) (2000). U.S. Geological Survey Professional Paper 1625-C.

United States Geological Survey (USGS) (2014). The National Map Viewer. Retrieved from http://viewer.nationalmap.gov/viewer/

Waddington, A., \& Kay, D. (2003, January). The Impacts of Mine Subsidence on Creeks, River Valleys and Gorges Due to Underground Coal Mining Operations. In Coal Operators' Conference (p. 165). 
Wang J T, Jin F, Zhang C H. (2011, March). Seismic safety of arch dams with aging effects. Sci China Tech Sci, 2011, 54: 522-530, doi: 10.1007/s11431-010-4279-7.

West Virginia GIS Technical Center Data Clearinghouse. (2014). West Virginia State GIS Data Clearinghouse. Retrieved from http://wvgis.wvu.edu/data/data.php.

Zhang, C., Mitra, R., \& Hebblewhite, B. K. (2012, January). Review of Fundamental Geotechnical Mechanisms of Valley Closure Subsidence Effects. In 46th US Rock Mechanics/Geomechanics Symposium. American Rock Mechanics Association.

Zhang, C., Mitra, R, \& Hebblewhite, B (2013). Evaluation of valley closure subsidence effects under irregular topographic conditions. Mining Technology, 122(3), 172-183

Zhang, J., Roegiers, J. C., Bai, M., \& Zhang, Y. (2001, January). Stress-dependent permeability variation and mine subsidence. In DC Rocks 2001 The 38th US Symposium on Rock Mechanics (USRMS). American Rock Mechanics Association. 


\section{APPENDIX}

This appendix is provided to accompany information from this research.

Table A1, Table A2, and Table A3 provide a summary of the numerical modeling methods and their associated strengths and limitations that have been used for modeling the types of stresses and deformation involved in mining under varying topography.

Methods exist and software has been developed to predict and quantify aspects of nonconventional subsidence. Some commonly used software, such as SDPS, do not predict these potentially damaging movements as they do not significantly incorporate topography into the calculations. Numerical models such as FLAC and UDEC have proven to be effective means of quantifying aspects of non-conventional subsidence behavior.

Table A1 Summary table of studies performed for numerical modeling in mountainous topography

\begin{tabular}{|c|c|c|c|c|c|c|}
\hline $\begin{array}{l}\text { Method } \\
\text { Type }\end{array}$ & \begin{tabular}{|c|} 
Code \\
Computation \\
Technique \\
\end{tabular} & Software & Strengths & Limitations & Author & Description \\
\hline \multirow{7}{*}{$\begin{array}{l}\text { Continuum } \\
\text { Methods }\end{array}$} & DDM & - & $\begin{array}{l}\text { Conduct stress } \\
\text { analysis, fracture } \\
\text { growth simulation }\end{array}$ & $\begin{array}{l}\text { Limited flexibility in the } \\
\text { simulation of non- } \\
\text { homogeneous and } \\
\text { plasticity behavior }\end{array}$ & $\begin{array}{l}\text { Ahola, 1990; Wardle } \\
\text { and McNabb, } 1992\end{array}$ & $\begin{array}{l}\text { Placed along cliff } \\
\text { and valley regions }\end{array}$ \\
\hline & 2D FEM & - & \multirow{3}{*}{$\begin{array}{l}\text { Great flexibility in } \\
\text { addressing material } \\
\text { inhomogeneity, } \\
\text { anisotropy and } \\
\text { complex boundary } \\
\text { conditions }\end{array}$} & \multirow{3}{*}{$\begin{array}{l}\text { Difficulty in addressing } \\
\text { block rotation, fracture } \\
\text { growth, and mesh } \\
\text { generation for complex } \\
\text { 3D geometry }\end{array}$} & $\begin{array}{l}\text { Siriwardane and } \\
\text { Amanat, 1984; Franks } \\
\text { and Geddes, 1986; } \\
\text { Shu and } \\
\text { Bhattacharyya, } 1992\end{array}$ & $\begin{array}{l}\text { Longwall mining } \\
\text { induced subsidence } \\
\text { beneath sloped } \\
\text { surfaces }\end{array}$ \\
\hline & FEM & COSFLOW & & & Guo et al., 2004 & $\begin{array}{l}\text { Modeling } \\
\text { subsidence profiles } \\
\text { using a plasticity } \\
\end{array}$ \\
\hline & FEM & ABAQUS & & & $\begin{array}{l}\text { Capasso and Mantica, } \\
2006 \\
\end{array}$ & $\begin{array}{l}\text { Conventional } \\
\text { surface subsidence }\end{array}$ \\
\hline & Discrete FEM & - & $\begin{array}{l}\text { Enhanced } \\
\text { applicability of FEM } \\
\text { to the rock fracture }\end{array}$ & - & $\begin{array}{l}\text { Belytschko et al., } \\
\text { 2001; Stolarska } \text { et al., } \\
\text { 2001; Li et al., } 2001\end{array}$ & $\begin{array}{l}\text { Rock fracture } \\
\text { modeling }\end{array}$ \\
\hline & FDM & FLAC & $\begin{array}{l}\text { Improved prediction } \\
\text { of subsidence }\end{array}$ & $\begin{array}{l}\text { Grid system limits } \\
\text { application in } \\
\text { representing explicit } \\
\text { fractures associated } \\
\text { with subsidence } \\
\end{array}$ & $\begin{array}{l}\text { Kay et al. , 1991; } \\
\text { Molinda et al. , 1992; } \\
\text { Alejano et al, } 1999\end{array}$ & $\begin{array}{l}\text { Studies of irregular } \\
\text { surface subsidence } \\
\text { phenomena }\end{array}$ \\
\hline & FDM & FLAC-FISH & $\begin{array}{l}\text { Fracture network } \\
\text { geometry generation }\end{array}$ & $\begin{array}{l}\text { Discontinuous methods } \\
\text { may be more useful for } \\
\text { large fracture networks } \\
\text { with increasing model } \\
\text { size }\end{array}$ & $\begin{array}{l}\text { Gale }(2004,2006, \\
2008,2011) ; \mathrm{W} 2 \mathrm{CP}, \\
2010\end{array}$ & $\begin{array}{l}\text { Simulate } \\
\text { overburden } \\
\text { characteristics }\end{array}$ \\
\hline
\end{tabular}


Table A2 Summary table of studies performed for numerical modeling in mountainous topography (continued)

\begin{tabular}{|c|c|c|c|c|c|c|}
\hline $\begin{array}{l}\text { Method } \\
\text { Type }\end{array}$ & \begin{tabular}{|c|}
\multicolumn{1}{|c|}{ Code } \\
Computation \\
Technique \\
\end{tabular} & Software & Strengths & Limitations & Author & Description \\
\hline \multirow{5}{*}{$\begin{array}{c}\text { Discontinuous } \\
\text { Methods }\end{array}$} & $\begin{array}{l}\text { Rigid block } \\
\text { computer } \\
\text { code }\end{array}$ & - & - & - & O'Connor and Dowding, 1992 & $\begin{array}{l}\text { Addressed impacts } \\
\text { of rock } \\
\text { discontinuities on }\end{array}$ \\
\hline & - & UDEC & $\begin{array}{l}\text { Prediction of } \\
\text { convergence of valley } \\
\text { sides, maximum } \\
\text { bedding shear } \\
\text { displacement, and } \\
\text { expected subsidence }\end{array}$ & $\begin{array}{l}\text { Fails to depict the } \\
\text { development of mining } \\
\text { induced explicit fracture } \\
\text { networks around river } \\
\text { valleys }\end{array}$ & $\begin{array}{l}\text { Wold } \text { et al. , 1999; } \\
\text { Waddington and Kay (2001, } \\
\text { 2002) }\end{array}$ & $\begin{array}{l}\text { Undermining cliffs } \\
\text { and gorges in } \\
\text { Australia's Southern } \\
\text { Coalfield }\end{array}$ \\
\hline & - & PFC & $\begin{array}{l}\text { Fracture analysis } \\
\text { where rock is } \\
\text { represented as a } \\
\text { number of small, rigid, } \\
\text { spherical grains }\end{array}$ & $\begin{array}{l}\text { Restricted to modeling at } \\
\text { field scale and requires } \\
\text { high computational power. } \\
\text { Other limitations exist } \\
\text { (Cundall, 2004; Damjanac } \\
\text { et al, 2007) which may } \\
\text { be overcome (Cho et al., } \\
\text { 2007) }\end{array}$ & Cundall and Strack, 1979 & - \\
\hline & - & PFC2D & $\begin{array}{l}\text { Crack propagation and } \\
\text { explicit fracture }\end{array}$ & & Sainsbury, 2008 & $\begin{array}{l}\text { Riverbed and gorge } \\
\text { fracture simulation }\end{array}$ \\
\hline & $\begin{array}{c}\text { Voronio } \\
\text { Tessellation }\end{array}$ & UDEC & $\begin{array}{l}\text { Constructing } \\
\text { microstructures and } \\
\text { simulating crack } \\
\text { propgagation at lab } \\
\text { test scale }\end{array}$ & $\begin{array}{l}\text { Calibration of } \\
\text { microproperties to match } \\
\text { macroproperties }\end{array}$ & $\begin{array}{l}\text { Nygards and Gundmundson, } \\
\text { 2002; Zhang et al., 2005; Li } \\
\text { et al., 2006; Kazerani and } \\
\text { Zhao, 2010; Lan et al ., 2010; } \\
\text { Alzo'ubi, 2009; Alzo'ubi et }\end{array}$ & - \\
\hline
\end{tabular}

Table A3 Summary table of studies performed for numerical modeling in mountainous topography (continued)

\begin{tabular}{|c|c|c|c|c|c|c|}
\hline $\begin{array}{l}\text { Method } \\
\text { Type }\end{array}$ & $\begin{array}{c}\text { Code } \\
\text { Computation } \\
\text { Technique }\end{array}$ & Software & Strengths & Limitations & Author & Description \\
\hline \multirow{4}{*}{$\begin{array}{l}\text { Hybrid } \\
\text { Methods }\end{array}$} & FDM/FEM & FLOMEC & \multirow{4}{*}{$\begin{array}{l}\text { Coupled software } \\
\text { can model parts of } \\
\text { the solution, taking } \\
\text { advantage of each } \\
\text { code's strengths }\end{array}$} & \multirow{4}{*}{$\begin{array}{l}\text { Difficulty may be } \\
\text { experienced where } \\
\text { continuity conditions } \\
\text { exist at different } \\
\text { region boundaries, in } \\
\text { the mechanical } \\
\text { coupling scheme, } \\
\text { and in the } \\
\text { communication } \\
\text { between software } \\
\text { codes }\end{array}$} & Waddington and Kay, 2002 & $\begin{array}{l}\text { Strata movement } \\
\text { simulation in }\end{array}$ \\
\hline & BEM/DDM & - & & & Chugh et al., 1994 & $\begin{array}{l}\text { Mine induced } \\
\text { subsidence } \\
\text { modeling }\end{array}$ \\
\hline & FEM/DEM & ELFEN & & & Vyazmensky et al., 2007 & $\begin{array}{l}\text { Model with rock } \\
\text { mass represented } \\
\text { as an assembly of } \\
\text { spaced } \\
\text { discontinuities and } \\
\text { intervening regions } \\
\text { with reduced intact } \\
\text { properties }\end{array}$ \\
\hline & - & $\begin{array}{l}\text { FLAC, } \\
\text { UDEC, } \\
\text { PFC }\end{array}$ & & & $\begin{array}{l}\text { Sainsbury, 2008; Katsage } \\
\text { and Potyondy, } 2012\end{array}$ & $\begin{array}{l}\text { Coupled software } \\
\text { to investigate the } \\
\text { mining induced } \\
\text { fracture } \\
\text { development }\end{array}$ \\
\hline
\end{tabular}


Table A4 provides the surface geometry for the bottom surface of the Pittsburgh coal seam. All other layers were identical to this layer geometry other than the ground surface layer which included topographic features. The ground surface layer data is provided in Table A5. The coal seam was set to 0.72 degrees following both the conclusion of the PADCNR as well as GIS mapping of coal structure contours.

Table A4 Bottom of Pittsburgh coal seam elevation data

\begin{tabular}{|c|c|c|c|c|c|c|c|c|c|}
\hline \multirow{2}{*}{ Profile \# } & \multirow{2}{*}{ Point \# } & \multicolumn{3}{|c|}{ Bottom Pittsburgh Coal Surface } & \multirow{2}{*}{ Profile \# } & \multirow{2}{*}{ Point \# } & \multicolumn{3}{|c|}{ Bottom Pittsburgh Coal Surface } \\
\hline & & $\mathbf{X}(\mathbf{f t})$ & $Y(f t)$ & $\operatorname{Rel} \mathbf{Z}$ (ft) & & & $X(f t)$ & $Y(f t)$ & $\operatorname{Rel} \mathbf{Z}(\mathbf{f t})$ \\
\hline \multirow{45}{*}{1} & 1 & 0 & 0 & 60.3 & \multirow{45}{*}{2} & 1 & 475 & 0 & 54.3 \\
\hline & 2 & 0 & 125 & 60.3 & & 2 & 475 & 125 & 54.3 \\
\hline & 3 & 0 & 250 & 60.3 & & 3 & 475 & 250 & 54.3 \\
\hline & 4 & 0 & 375 & 60.3 & & 4 & 475 & 375 & 54.3 \\
\hline & 5 & 0 & 500 & 60.3 & & 5 & 475 & 500 & 54.3 \\
\hline & 6 & 0 & 625 & 60.3 & & 6 & 475 & 625 & 54.3 \\
\hline & 7 & 0 & 750 & 60.3 & & 7 & 475 & 750 & 54.3 \\
\hline & 8 & 0 & 875 & 60.3 & & 8 & 475 & 875 & 54.3 \\
\hline & 9 & 0 & 1000 & 60.3 & & 9 & 475 & 1000 & 54.3 \\
\hline & 10 & 0 & 1125 & 60.3 & & 10 & 475 & 1125 & 54.3 \\
\hline & 11 & 0 & 1250 & 60.3 & & 11 & 475 & 1250 & 54.3 \\
\hline & 12 & 0 & 1375 & 60.3 & & 12 & 475 & 1375 & 54.3 \\
\hline & 13 & 0 & 1500 & 60.3 & & 13 & 475 & 1500 & 54.3 \\
\hline & 14 & 0 & 1625 & 60.3 & & 14 & 475 & 1625 & 54.3 \\
\hline & 15 & 0 & 1750 & 60.3 & & 15 & 475 & 1750 & 54.3 \\
\hline & 16 & 0 & 1875 & 60.3 & & 16 & 475 & 1875 & 54.3 \\
\hline & 17 & 0 & 2000 & 60.3 & & 17 & 475 & 2000 & 54.3 \\
\hline & 18 & 0 & 2125 & 60.3 & & 18 & 475 & 2125 & 54.3 \\
\hline & 19 & 0 & 2250 & 60.3 & & 19 & 475 & 2250 & 54.3 \\
\hline & 20 & 0 & 2375 & 60.3 & & 20 & 475 & 2375 & 54.3 \\
\hline & 21 & 0 & 2500 & 60.3 & & 21 & 475 & 2500 & 54.3 \\
\hline & 22 & 0 & 2625 & 60.3 & & 22 & 475 & 2625 & 54.3 \\
\hline & 23 & 0 & 2750 & 60.3 & & 23 & 475 & 2750 & 54.3 \\
\hline & 24 & 0 & 2875 & 60.3 & & 24 & 475 & 2875 & 54.3 \\
\hline & 25 & 0 & 3000 & 60.3 & & 25 & 475 & 3000 & 54.3 \\
\hline & 26 & 0 & 3125 & 60.3 & & 26 & 475 & 3125 & 54.3 \\
\hline & 27 & 0 & 3250 & 60.3 & & 27 & 475 & 3250 & 54.3 \\
\hline & 28 & 0 & 3375 & 60.3 & & 28 & 475 & 3375 & 54.3 \\
\hline & 29 & 0 & 3500 & 60.3 & & 29 & 475 & 3500 & 54.3 \\
\hline & 30 & 0 & 3625 & 60.3 & & 30 & 475 & 3625 & 54.3 \\
\hline & 31 & 0 & 3750 & 60.3 & & 31 & 475 & 3750 & 54.3 \\
\hline & 32 & 0 & 3875 & 60.3 & & 32 & 475 & 3875 & 54.3 \\
\hline & 33 & 0 & 4000 & 60.3 & & 33 & 475 & 4000 & 54.3 \\
\hline & 34 & 0 & 4125 & 60.3 & & 34 & 475 & 4125 & 54.3 \\
\hline & 35 & 0 & 4250 & 60.3 & & 35 & 475 & 4250 & 54.3 \\
\hline & 36 & 0 & 4375 & 60.3 & & 36 & 475 & 4375 & 54.3 \\
\hline & 37 & 0 & 4500 & 60.3 & & 37 & 475 & 4500 & 54.3 \\
\hline & 38 & 0 & 4625 & 60.3 & & 38 & 475 & 4625 & 54.3 \\
\hline & 39 & 0 & 4750 & 60.3 & & 39 & 475 & 4750 & 54.3 \\
\hline & 40 & 0 & 4875 & 60.3 & & 40 & 475 & 4875 & 54.3 \\
\hline & 41 & 0 & 5000 & 60.3 & & 41 & 475 & 5000 & 54.3 \\
\hline & 42 & 0 & 5125 & 60.3 & & 42 & 475 & 5125 & 54.3 \\
\hline & 43 & 0 & 5250 & 60.3 & & 43 & 475 & 5250 & 54.3 \\
\hline & 44 & 0 & 5375 & 60.3 & & 44 & 475 & 5375 & 54.3 \\
\hline & 45 & 0 & 5500 & 60.3 & & 45 & 475 & 5500 & 54.3 \\
\hline
\end{tabular}


Table A4 Continued (1)

\begin{tabular}{|c|c|c|c|c|c|c|c|c|c|}
\hline \multirow{2}{*}{ Profile \# } & \multirow{2}{*}{ Point \# } & \multicolumn{3}{|c|}{ Bottom Pittsburgh Coal Surface } & \multirow{2}{*}{ Profile \# } & \multirow{2}{*}{ Point \# } & \multicolumn{3}{|c|}{ Bottom Pittsburgh Coal Surface } \\
\hline & & $X(f t)$ & $\mathbf{Y}(\mathbf{f t})$ & $\operatorname{Rel} Z(\mathbf{f t})$ & & & $X(f t)$ & $Y(f t)$ & $\operatorname{Rel} \mathbf{Z}(\mathbf{f t})$ \\
\hline \multirow{45}{*}{3} & 1 & 975 & 0 & 48.0 & \multirow{45}{*}{4} & 1 & 1225 & 0 & 44.9 \\
\hline & 2 & 975 & 125 & 48.0 & & 2 & 1225 & 125 & 44.9 \\
\hline & 3 & 975 & 250 & 48.0 & & 3 & 1225 & 250 & 44.9 \\
\hline & 4 & 975 & 375 & 48.0 & & 4 & 1225 & 375 & 44.9 \\
\hline & 5 & 975 & 500 & 48.0 & & 5 & 1225 & 500 & 44.9 \\
\hline & 6 & 975 & 625 & 48.0 & & 6 & 1225 & 625 & 44.9 \\
\hline & 7 & 975 & 750 & 48.0 & & 7 & 1225 & 750 & 44.9 \\
\hline & 8 & 975 & 875 & 48.0 & & 8 & 1225 & 875 & 44.9 \\
\hline & 9 & 975 & 1000 & 48.0 & & 9 & 1225 & 1000 & 44.9 \\
\hline & 10 & 975 & 1125 & 48.0 & & 10 & 1225 & 1125 & 44.9 \\
\hline & 11 & 975 & 1250 & 48.0 & & 11 & 1225 & 1250 & 44.9 \\
\hline & 12 & 975 & 1375 & 48.0 & & 12 & 1225 & 1375 & 44.9 \\
\hline & 13 & 975 & 1500 & 48.0 & & 13 & 1225 & 1500 & 44.9 \\
\hline & 14 & 975 & 1625 & 48.0 & & 14 & 1225 & 1625 & 44.9 \\
\hline & 15 & 975 & 1750 & 48.0 & & 15 & 1225 & 1750 & 44.9 \\
\hline & 16 & 975 & 1875 & 48.0 & & 16 & 1225 & 1875 & 44.9 \\
\hline & 17 & 975 & 2000 & 48.0 & & 17 & 1225 & 2000 & 44.9 \\
\hline & 18 & 975 & 2125 & 48.0 & & 18 & 1225 & 2125 & 44.9 \\
\hline & 19 & 975 & 2250 & 48.0 & & 19 & 1225 & 2250 & 44.9 \\
\hline & 20 & 975 & 2375 & 48.0 & & 20 & 1225 & 2375 & 44.9 \\
\hline & 21 & 975 & 2500 & 48.0 & & 21 & 1225 & 2500 & 44.9 \\
\hline & 22 & 975 & 2625 & 48.0 & & 22 & 1225 & 2625 & 44.9 \\
\hline & 23 & 975 & 2750 & 48.0 & & 23 & 1225 & 2750 & 44.9 \\
\hline & 24 & 975 & 2875 & 48.0 & & 24 & 1225 & 2875 & 44.9 \\
\hline & 25 & 975 & 3000 & 48.0 & & 25 & 1225 & 3000 & 44.9 \\
\hline & 26 & 975 & 3125 & 48.0 & & 26 & 1225 & 3125 & 44.9 \\
\hline & 27 & 975 & 3250 & 48.0 & & 27 & 1225 & 3250 & 44.9 \\
\hline & 28 & 975 & 3375 & 48.0 & & 28 & 1225 & 3375 & 44.9 \\
\hline & 29 & 975 & 3500 & 48.0 & & 29 & 1225 & 3500 & 44.9 \\
\hline & 30 & 975 & 3625 & 48.0 & & 30 & 1225 & 3625 & 44.9 \\
\hline & 31 & 975 & 3750 & 48.0 & & 31 & 1225 & 3750 & 44.9 \\
\hline & 32 & 975 & 3875 & 48.0 & & 32 & 1225 & 3875 & 44.9 \\
\hline & 33 & 975 & 4000 & 48.0 & & 33 & 1225 & 4000 & 44.9 \\
\hline & 34 & 975 & 4125 & 48.0 & & 34 & 1225 & 4125 & 44.9 \\
\hline & 35 & 975 & 4250 & 48.0 & & 35 & 1225 & 4250 & 44.9 \\
\hline & 36 & 975 & 4375 & 48.0 & & 36 & 1225 & 4375 & 44.9 \\
\hline & 37 & 975 & 4500 & 48.0 & & 37 & 1225 & 4500 & 44.9 \\
\hline & 38 & 975 & 4625 & 48.0 & & 38 & 1225 & 4625 & 44.9 \\
\hline & 39 & 975 & 4750 & 48.0 & & 39 & 1225 & 4750 & 44.9 \\
\hline & 40 & 975 & 4875 & 48.0 & & 40 & 1225 & 4875 & 44.9 \\
\hline & 41 & 975 & 5000 & 48.0 & & 41 & 1225 & 5000 & 44.9 \\
\hline & 42 & 975 & 5125 & 48.0 & & 42 & 1225 & 5125 & 44.9 \\
\hline & 43 & 975 & 5250 & 48.0 & & 43 & 1225 & 5250 & 44.9 \\
\hline & 44 & 975 & 5375 & 48.0 & & 44 & 1225 & 5375 & 44.9 \\
\hline & 45 & 975 & 5500 & 48.0 & & 45 & 1225 & 5500 & 44.9 \\
\hline
\end{tabular}


Table A4 Continued (2)

\begin{tabular}{|c|c|c|c|c|c|c|c|c|c|}
\hline \multirow{2}{*}{ Profile \# } & \multirow{2}{*}{ Point \# } & \multicolumn{3}{|c|}{ Bottom Pittsburgh Coal Surface } & \multirow{2}{*}{ Profile \# } & \multirow{2}{*}{ Point \# } & \multicolumn{3}{|c|}{ Bottom Pittsburgh Coal Surface } \\
\hline & & $X(f t)$ & $Y(f t)$ & Rel Z (ft) & & & $X(f t)$ & $Y(f t)$ & Rel Z (ft) \\
\hline \multirow{45}{*}{5} & 1 & 1600 & 0 & 40.2 & \multirow{45}{*}{6} & 1 & 2025 & 0 & 34.8 \\
\hline & 2 & 1600 & 125 & 40.2 & & 2 & 2025 & 125 & 34.8 \\
\hline & 3 & 1600 & 250 & 40.2 & & 3 & 2025 & 250 & 34.8 \\
\hline & 4 & 1600 & 375 & 40.2 & & 4 & 2025 & 375 & 34.8 \\
\hline & 5 & 1600 & 500 & 40.2 & & 5 & 2025 & 500 & 34.8 \\
\hline & 6 & 1600 & 625 & 40.2 & & 6 & 2025 & 625 & 34.8 \\
\hline & 7 & 1600 & 750 & 40.2 & & 7 & 2025 & 750 & 34.8 \\
\hline & 8 & 1600 & 875 & 40.2 & & 8 & 2025 & 875 & 34.8 \\
\hline & 9 & 1600 & 1000 & 40.2 & & 9 & 2025 & 1000 & 34.8 \\
\hline & 10 & 1600 & 1125 & 40.2 & & 10 & 2025 & 1125 & 34.8 \\
\hline & 11 & 1600 & 1250 & 40.2 & & 11 & 2025 & 1250 & 34.8 \\
\hline & 12 & 1600 & 1375 & 40.2 & & 12 & 2025 & 1375 & 34.8 \\
\hline & 13 & 1600 & 1500 & 40.2 & & 13 & 2025 & 1500 & 34.8 \\
\hline & 14 & 1600 & 1625 & 40.2 & & 14 & 2025 & 1625 & 34.8 \\
\hline & 15 & 1600 & 1750 & 40.2 & & 15 & 2025 & 1750 & 34.8 \\
\hline & 16 & 1600 & 1875 & 40.2 & & 16 & 2025 & 1875 & 34.8 \\
\hline & 17 & 1600 & 2000 & 40.2 & & 17 & 2025 & 2000 & 34.8 \\
\hline & 18 & 1600 & 2125 & 40.2 & & 18 & 2025 & 2125 & 34.8 \\
\hline & 19 & 1600 & 2250 & 40.2 & & 19 & 2025 & 2250 & 34.8 \\
\hline & 20 & 1600 & 2375 & 40.2 & & 20 & 2025 & 2375 & 34.8 \\
\hline & 21 & 1600 & 2500 & 40.2 & & 21 & 2025 & 2500 & 34.8 \\
\hline & 22 & 1600 & 2625 & 40.2 & & 22 & 2025 & 2625 & 34.8 \\
\hline & 23 & 1600 & 2750 & 40.2 & & 23 & 2025 & 2750 & 34.8 \\
\hline & 24 & 1600 & 2875 & 40.2 & & 24 & 2025 & 2875 & 34.8 \\
\hline & 25 & 1600 & 3000 & 40.2 & & 25 & 2025 & 3000 & 34.8 \\
\hline & 26 & 1600 & 3125 & 40.2 & & 26 & 2025 & 3125 & 34.8 \\
\hline & 27 & 1600 & 3250 & 40.2 & & 27 & 2025 & 3250 & 34.8 \\
\hline & 28 & 1600 & 3375 & 40.2 & & 28 & 2025 & 3375 & 34.8 \\
\hline & 29 & 1600 & 3500 & 40.2 & & 29 & 2025 & 3500 & 34.8 \\
\hline & 30 & 1600 & 3625 & 40.2 & & 30 & 2025 & 3625 & 34.8 \\
\hline & 31 & 1600 & 3750 & 40.2 & & 31 & 2025 & 3750 & 34.8 \\
\hline & 32 & 1600 & 3875 & 40.2 & & 32 & 2025 & 3875 & 34.8 \\
\hline & 33 & 1600 & 4000 & 40.2 & & 33 & 2025 & 4000 & 34.8 \\
\hline & 34 & 1600 & 4125 & 40.2 & & 34 & 2025 & 4125 & 34.8 \\
\hline & 35 & 1600 & 4250 & 40.2 & & 35 & 2025 & 4250 & 34.8 \\
\hline & 36 & 1600 & 4375 & 40.2 & & 36 & 2025 & 4375 & 34.8 \\
\hline & 37 & 1600 & 4500 & 40.2 & & 37 & 2025 & 4500 & 34.8 \\
\hline & 38 & 1600 & 4625 & 40.2 & & 38 & 2025 & 4625 & 34.8 \\
\hline & 39 & 1600 & 4750 & 40.2 & & 39 & 2025 & 4750 & 34.8 \\
\hline & 40 & 1600 & 4875 & 40.2 & & 40 & 2025 & 4875 & 34.8 \\
\hline & 41 & 1600 & 5000 & 40.2 & & 41 & 2025 & 5000 & 34.8 \\
\hline & 42 & 1600 & 5125 & 40.2 & & 42 & 2025 & 5125 & 34.8 \\
\hline & 43 & 1600 & 5250 & 40.2 & & 43 & 2025 & 5250 & 34.8 \\
\hline & 44 & 1600 & 5375 & 40.2 & & 44 & 2025 & 5375 & 34.8 \\
\hline & 45 & 1600 & 5500 & 40.2 & & 45 & 2025 & 5500 & 34.8 \\
\hline
\end{tabular}


Table A4 Continued (3)

\begin{tabular}{|c|c|c|c|c|c|c|c|c|c|}
\hline \multirow{2}{*}{ Profile \# } & \multirow{2}{*}{ Point \# } & \multicolumn{3}{|c|}{ Bottom Pittsburgh Coal Surface } & \multirow{2}{*}{ Profile \# } & \multirow{2}{*}{ Point \# } & \multicolumn{3}{|c|}{ Bottom Pittsburgh Coal Surface } \\
\hline & & $\mathrm{X}(\mathrm{ft})$ & $Y(f t)$ & $\operatorname{Rel} \mathrm{Z}(\mathbf{f t})$ & & & $X(f t)$ & Y (ft) & $\operatorname{Rel} Z(\mathbf{f t})$ \\
\hline \multirow{45}{*}{7} & 1 & 2515 & 0 & 28.7 & \multirow{45}{*}{8} & 1 & 2890 & 0 & 24.0 \\
\hline & 2 & 2515 & 125 & 28.7 & & 2 & 2890 & 125 & 24.0 \\
\hline & 3 & 2515 & 250 & 28.7 & & 3 & 2890 & 250 & 24.0 \\
\hline & 4 & 2515 & 375 & 28.7 & & 4 & 2890 & 375 & 24.0 \\
\hline & 5 & 2515 & 500 & 28.7 & & 5 & 2890 & 500 & 24.0 \\
\hline & 6 & 2515 & 625 & 28.7 & & 6 & 2890 & 625 & 24.0 \\
\hline & 7 & 2515 & 750 & 28.7 & & 7 & 2890 & 750 & 24.0 \\
\hline & 8 & 2515 & 875 & 28.7 & & 8 & 2890 & 875 & 24.0 \\
\hline & 9 & 2515 & 1000 & 28.7 & & 9 & 2890 & 1000 & 24.0 \\
\hline & 10 & 2515 & 1125 & 28.7 & & 10 & 2890 & 1125 & 24.0 \\
\hline & 11 & 2515 & 1250 & 28.7 & & 11 & 2890 & 1250 & 24.0 \\
\hline & 12 & 2515 & 1375 & 28.7 & & 12 & 2890 & 1375 & 24.0 \\
\hline & 13 & 2515 & 1500 & 28.7 & & 13 & 2890 & 1500 & 24.0 \\
\hline & 14 & 2515 & 1625 & 28.7 & & 14 & 2890 & 1625 & 24.0 \\
\hline & 15 & 2515 & 1750 & 28.7 & & 15 & 2890 & 1750 & 24.0 \\
\hline & 16 & 2515 & 1875 & 28.7 & & 16 & 2890 & 1875 & 24.0 \\
\hline & 17 & 2515 & 2000 & 28.7 & & 17 & 2890 & 2000 & 24.0 \\
\hline & 18 & 2515 & 2125 & 28.7 & & 18 & 2890 & 2125 & 24.0 \\
\hline & 19 & 2515 & 2250 & 28.7 & & 19 & 2890 & 2250 & 24.0 \\
\hline & 20 & 2515 & 2375 & 28.7 & & 20 & 2890 & 2375 & 24.0 \\
\hline & 21 & 2515 & 2500 & 28.7 & & 21 & 2890 & 2500 & 24.0 \\
\hline & 22 & 2515 & 2625 & 28.7 & & 22 & 2890 & 2625 & 24.0 \\
\hline & 23 & 2515 & 2750 & 28.7 & & 23 & 2890 & 2750 & 24.0 \\
\hline & 24 & 2515 & 2875 & 28.7 & & 24 & 2890 & 2875 & 24.0 \\
\hline & 25 & 2515 & 3000 & 28.7 & & 25 & 2890 & 3000 & 24.0 \\
\hline & 26 & 2515 & 3125 & 28.7 & & 26 & 2890 & 3125 & 24.0 \\
\hline & 27 & 2515 & 3250 & 28.7 & & 27 & 2890 & 3250 & 24.0 \\
\hline & 28 & 2515 & 3375 & 28.7 & & 28 & 2890 & 3375 & 24.0 \\
\hline & 29 & 2515 & 3500 & 28.7 & & 29 & 2890 & 3500 & 24.0 \\
\hline & 30 & 2515 & 3625 & 28.7 & & 30 & 2890 & 3625 & 24.0 \\
\hline & 31 & 2515 & 3750 & 28.7 & & 31 & 2890 & 3750 & 24.0 \\
\hline & 32 & 2515 & 3875 & 28.7 & & 32 & 2890 & 3875 & 24.0 \\
\hline & 33 & 2515 & 4000 & 28.7 & & 33 & 2890 & 4000 & 24.0 \\
\hline & 34 & 2515 & 4125 & 28.7 & & 34 & 2890 & 4125 & 24.0 \\
\hline & 35 & 2515 & 4250 & 28.7 & & 35 & 2890 & 4250 & 24.0 \\
\hline & 36 & 2515 & 4375 & 28.7 & & 36 & 2890 & 4375 & 24.0 \\
\hline & 37 & 2515 & 4500 & 28.7 & & 37 & 2890 & 4500 & 24.0 \\
\hline & 38 & 2515 & 4625 & 28.7 & & 38 & 2890 & 4625 & 24.0 \\
\hline & 39 & 2515 & 4750 & 28.7 & & 39 & 2890 & 4750 & 24.0 \\
\hline & 40 & 2515 & 4875 & 28.7 & & 40 & 2890 & 4875 & 24.0 \\
\hline & 41 & 2515 & 5000 & 28.7 & & 41 & 2890 & 5000 & 24.0 \\
\hline & 42 & 2515 & 5125 & 28.7 & & 42 & 2890 & 5125 & 24.0 \\
\hline & 43 & 2515 & 5250 & 28.7 & & 43 & 2890 & 5250 & 24.0 \\
\hline & 44 & 2515 & 5375 & 28.7 & & 44 & 2890 & 5375 & 24.0 \\
\hline & 45 & 2515 & 5500 & 28.7 & & 45 & 2890 & 5500 & 24.0 \\
\hline
\end{tabular}


Table A4 Continued (4)

\begin{tabular}{|c|c|c|c|c|c|c|c|c|c|}
\hline \multirow{2}{*}{ Profile \# } & \multirow{2}{*}{ Point \# } & \multicolumn{3}{|c|}{ Bottom Pittsburgh Coal Surface } & \multirow{2}{*}{ Profile \# } & \multirow{2}{*}{ Point \# } & \multicolumn{3}{|c|}{ Bottom Pittsburgh Coal Surface } \\
\hline & & $X(f t)$ & $Y(f t)$ & Rel Z (ft) & & & $X(f t)$ & $Y(f t)$ & Rel Z (ft) \\
\hline \multirow{45}{*}{9} & 1 & 3270 & 0 & 19.2 & \multirow{45}{*}{10} & 1 & 3710 & 0 & 13.6 \\
\hline & 2 & 3270 & 125 & 19.2 & & 2 & 3710 & 125 & 13.6 \\
\hline & 3 & 3270 & 250 & 19.2 & & 3 & 3710 & 250 & 13.6 \\
\hline & 4 & 3270 & 375 & 19.2 & & 4 & 3710 & 375 & 13.6 \\
\hline & 5 & 3270 & 500 & 19.2 & & 5 & 3710 & 500 & 13.6 \\
\hline & 6 & 3270 & 625 & 19.2 & & 6 & 3710 & 625 & 13.6 \\
\hline & 7 & 3270 & 750 & 19.2 & & 7 & 3710 & 750 & 13.6 \\
\hline & 8 & 3270 & 875 & 19.2 & & 8 & 3710 & 875 & 13.6 \\
\hline & 9 & 3270 & 1000 & 19.2 & & 9 & 3710 & 1000 & 13.6 \\
\hline & 10 & 3270 & 1125 & 19.2 & & 10 & 3710 & 1125 & 13.6 \\
\hline & 11 & 3270 & 1250 & 19.2 & & 11 & 3710 & 1250 & 13.6 \\
\hline & 12 & 3270 & 1375 & 19.2 & & 12 & 3710 & 1375 & 13.6 \\
\hline & 13 & 3270 & 1500 & 19.2 & & 13 & 3710 & 1500 & 13.6 \\
\hline & 14 & 3270 & 1625 & 19.2 & & 14 & 3710 & 1625 & 13.6 \\
\hline & 15 & 3270 & 1750 & 19.2 & & 15 & 3710 & 1750 & 13.6 \\
\hline & 16 & 3270 & 1875 & 19.2 & & 16 & 3710 & 1875 & 13.6 \\
\hline & 17 & 3270 & 2000 & 19.2 & & 17 & 3710 & 2000 & 13.6 \\
\hline & 18 & 3270 & 2125 & 19.2 & & 18 & 3710 & 2125 & 13.6 \\
\hline & 19 & 3270 & 2250 & 19.2 & & 19 & 3710 & 2250 & 13.6 \\
\hline & 20 & 3270 & 2375 & 19.2 & & 20 & 3710 & 2375 & 13.6 \\
\hline & 21 & 3270 & 2500 & 19.2 & & 21 & 3710 & 2500 & 13.6 \\
\hline & 22 & 3270 & 2625 & 19.2 & & 22 & 3710 & 2625 & 13.6 \\
\hline & 23 & 3270 & 2750 & 19.2 & & 23 & 3710 & 2750 & 13.6 \\
\hline & 24 & 3270 & 2875 & 19.2 & & 24 & 3710 & 2875 & 13.6 \\
\hline & 25 & 3270 & 3000 & 19.2 & & 25 & 3710 & 3000 & 13.6 \\
\hline & 26 & 3270 & 3125 & 19.2 & & 26 & 3710 & 3125 & 13.6 \\
\hline & 27 & 3270 & 3250 & 19.2 & & 27 & 3710 & 3250 & 13.6 \\
\hline & 28 & 3270 & 3375 & 19.2 & & 28 & 3710 & 3375 & 13.6 \\
\hline & 29 & 3270 & 3500 & 19.2 & & 29 & 3710 & 3500 & 13.6 \\
\hline & 30 & 3270 & 3625 & 19.2 & & 30 & 3710 & 3625 & 13.6 \\
\hline & 31 & 3270 & 3750 & 19.2 & & 31 & 3710 & 3750 & 13.6 \\
\hline & 32 & 3270 & 3875 & 19.2 & & 32 & 3710 & 3875 & 13.6 \\
\hline & 33 & 3270 & 4000 & 19.2 & & 33 & 3710 & 4000 & 13.6 \\
\hline & 34 & 3270 & 4125 & 19.2 & & 34 & 3710 & 4125 & 13.6 \\
\hline & 35 & 3270 & 4250 & 19.2 & & 35 & 3710 & 4250 & 13.6 \\
\hline & 36 & 3270 & 4375 & 19.2 & & 36 & 3710 & 4375 & 13.6 \\
\hline & 37 & 3270 & 4500 & 19.2 & & 37 & 3710 & 4500 & 13.6 \\
\hline & 38 & 3270 & 4625 & 19.2 & & 38 & 3710 & 4625 & 13.6 \\
\hline & 39 & 3270 & 4750 & 19.2 & & 39 & 3710 & 4750 & 13.6 \\
\hline & 40 & 3270 & 4875 & 19.2 & & 40 & 3710 & 4875 & 13.6 \\
\hline & 41 & 3270 & 5000 & 19.2 & & 41 & 3710 & 5000 & 13.6 \\
\hline & 42 & 3270 & 5125 & 19.2 & & 42 & 3710 & 5125 & 13.6 \\
\hline & 43 & 3270 & 5250 & 19.2 & & 43 & 3710 & 5250 & 13.6 \\
\hline & 44 & 3270 & 5375 & 19.2 & & 44 & 3710 & 5375 & 13.6 \\
\hline & 45 & 3270 & 5500 & 19.2 & & 45 & 3710 & 5500 & 13.6 \\
\hline
\end{tabular}




\begin{tabular}{|c|c|c|c|c|}
\hline \multirow{2}{*}{ Profile \# } & \multirow{2}{*}{ Point \# } & \multicolumn{3}{|c|}{ Bottom Pittsburgh Coal Surface } \\
\hline & & $X(f t)$ & $\mathbf{Y}(\mathbf{f t})$ & $\operatorname{Rel} \mathbf{Z}(\mathbf{f t})$ \\
\hline \multirow{45}{*}{11} & 1 & 4000 & 0 & 10.0 \\
\hline & 2 & 4000 & 125 & 10.0 \\
\hline & 3 & 4000 & 250 & 10.0 \\
\hline & 4 & 4000 & 375 & 10.0 \\
\hline & 5 & 4000 & 500 & 10.0 \\
\hline & 6 & 4000 & 625 & 10.0 \\
\hline & 7 & 4000 & 750 & 10.0 \\
\hline & 8 & 4000 & 875 & 10.0 \\
\hline & 9 & 4000 & 1000 & 10.0 \\
\hline & 10 & 4000 & 1125 & 10.0 \\
\hline & 11 & 4000 & 1250 & 10.0 \\
\hline & 12 & 4000 & 1375 & 10.0 \\
\hline & 13 & 4000 & 1500 & 10.0 \\
\hline & 14 & 4000 & 1625 & 10.0 \\
\hline & 15 & 4000 & 1750 & 10.0 \\
\hline & 16 & 4000 & 1875 & 10.0 \\
\hline & 17 & 4000 & 2000 & 10.0 \\
\hline & 18 & 4000 & 2125 & 10.0 \\
\hline & 19 & 4000 & 2250 & 10.0 \\
\hline & 20 & 4000 & 2375 & 10.0 \\
\hline & 21 & 4000 & 2500 & 10.0 \\
\hline & 22 & 4000 & 2625 & 10.0 \\
\hline & 23 & 4000 & 2750 & 10.0 \\
\hline & 24 & 4000 & 2875 & 10.0 \\
\hline & 25 & 4000 & 3000 & 10.0 \\
\hline & 26 & 4000 & 3125 & 10.0 \\
\hline & 27 & 4000 & 3250 & 10.0 \\
\hline & 28 & 4000 & 3375 & 10.0 \\
\hline & 29 & 4000 & 3500 & 10.0 \\
\hline & 30 & 4000 & 3625 & 10.0 \\
\hline & 31 & 4000 & 3750 & 10.0 \\
\hline & 32 & 4000 & 3875 & 10.0 \\
\hline & 33 & 4000 & 4000 & 10.0 \\
\hline & 34 & 4000 & 4125 & 10.0 \\
\hline & 35 & 4000 & 4250 & 10.0 \\
\hline & 36 & 4000 & 4375 & 10.0 \\
\hline & 37 & 4000 & 4500 & 10.0 \\
\hline & 38 & 4000 & 4625 & 10.0 \\
\hline & 39 & 4000 & 4750 & 10.0 \\
\hline & 40 & 4000 & 4875 & 10.0 \\
\hline & 41 & 4000 & 5000 & 10.0 \\
\hline & 42 & 4000 & 5125 & 10.0 \\
\hline & 43 & 4000 & 5250 & 10.0 \\
\hline & 44 & 4000 & 5375 & 10.0 \\
\hline & 45 & 4000 & 5500 & 10.0 \\
\hline
\end{tabular}


Table A5 Ground surface topographic data

\begin{tabular}{|c|c|c|c|c|c|c|c|c|c|}
\hline \multicolumn{5}{|c|}{ Ground Surface Data } & \multicolumn{5}{|c|}{ Ground Surface Data } \\
\hline Profile \# & Point \# & $X(\mathbf{f t})$ & $\mathbf{Y}(\mathbf{f t})$ & Relative $\mathbf{Z}$ (ft) & Profile \# & Point \# & $\mathbf{X}(\mathbf{f t})$ & $\mathbf{Y}(\mathbf{f t})$ & Relative $\mathbf{Z}$ (ft) \\
\hline \multirow{45}{*}{1} & 1 & 0 & 0 & 930 & \multirow{45}{*}{2} & 46 & 475 & 0 & 890 \\
\hline & 2 & 0 & 125 & 900 & & 47 & 475 & 125 & 900 \\
\hline & 3 & 0 & 250 & 880 & & 48 & 475 & 250 & 930 \\
\hline & 4 & 0 & 375 & 880 & & 49 & 475 & 375 & 960 \\
\hline & 5 & 0 & 500 & 900 & & 50 & 475 & 500 & 975 \\
\hline & 6 & 0 & 625 & 940 & & 51 & 475 & 625 & 980 \\
\hline & 7 & 0 & 750 & 920 & & 52 & 475 & 750 & 960 \\
\hline & 8 & 0 & 875 & 860 & & 53 & 475 & 875 & 920 \\
\hline & 9 & 0 & 1000 & 820 & & 54 & 475 & 1000 & 905 \\
\hline & 10 & 0 & 1125 & 780 & & 55 & 475 & 1125 & 880 \\
\hline & 11 & 0 & 1250 & 760 & & 56 & 475 & 1250 & 860 \\
\hline & 12 & 0 & 1375 & 725 & & 57 & 475 & 1375 & 835 \\
\hline & 13 & 0 & 1500 & 725 & & 58 & 475 & 1500 & 815 \\
\hline & 14 & 0 & 1625 & 725 & & 59 & 475 & 1625 & 800 \\
\hline & 15 & 0 & 1750 & 720 & & 60 & 475 & 1750 & 795 \\
\hline & 16 & 0 & 1875 & 700 & & 61 & 475 & 1875 & 780 \\
\hline & 17 & 0 & 2000 & 680 & & 62 & 475 & 2000 & 765 \\
\hline & 18 & 0 & 2125 & 660 & & 63 & 475 & 2125 & 730 \\
\hline & 19 & 0 & 2250 & 640 & & 64 & 475 & 2250 & 700 \\
\hline & 20 & 0 & 2375 & 620 & & 65 & 475 & 2375 & 670 \\
\hline & 21 & 0 & 2500 & 600 & & 66 & 475 & 2500 & 650 \\
\hline & 22 & 0 & 2625 & 595 & & 67 & 475 & 2625 & 635 \\
\hline & 23 & 0 & 2750 & 580 & & 68 & 475 & 2750 & 625 \\
\hline & 24 & 0 & 2875 & 580 & & 69 & 475 & 2875 & 615 \\
\hline & 25 & 0 & 3000 & 580 & & 70 & 475 & 3000 & 615 \\
\hline & 26 & 0 & 3125 & 570 & & 71 & 475 & 3125 & 610 \\
\hline & 27 & 0 & 3250 & $\begin{array}{l}565 \\
\end{array}$ & & 72 & 475 & 3250 & 600 \\
\hline & 28 & 0 & 3375 & 555 & & 73 & 475 & 3375 & 560 \\
\hline & 29 & 0 & 3500 & 570 & & 74 & 475 & 3500 & 550 \\
\hline & 30 & 0 & 3625 & 585 & & 75 & 475 & 3625 & 545 \\
\hline & 31 & 0 & 3750 & 585 & & 76 & 475 & 3750 & 535 \\
\hline & 32 & 0 & 3875 & 575 & & 77 & 475 & 3875 & 530 \\
\hline & 33 & 0 & 4000 & 560 & & 78 & 475 & 4000 & 525 \\
\hline & 34 & 0 & 4125 & 520 & & 79 & 475 & 4125 & 515 \\
\hline & 35 & 0 & 4250 & 505 & & 80 & 475 & 4250 & 510 \\
\hline & 36 & 0 & 4375 & 540 & & 81 & 475 & 4375 & 510 \\
\hline & 37 & 0 & 4500 & 560 & & 82 & 475 & 4500 & 550 \\
\hline & 38 & 0 & 4625 & 600 & & 83 & 475 & 4625 & 560 \\
\hline & 39 & 0 & 4750 & 630 & & 84 & 475 & 4750 & 600 \\
\hline & 40 & 0 & 4875 & 680 & & 85 & 475 & 4875 & 640 \\
\hline & 41 & 0 & 5000 & 720 & & 86 & 475 & 5000 & 670 \\
\hline & 42 & 0 & 5125 & 760 & & 87 & 475 & 5125 & 730 \\
\hline & 43 & 0 & 5250 & 830 & & 88 & 475 & 5250 & 770 \\
\hline & 44 & 0 & 5375 & 860 & & 89 & 475 & 5375 & 810 \\
\hline & 45 & 0 & 5500 & 840 & & 90 & 475 & 5500 & 850 \\
\hline
\end{tabular}


Table A5 Continued (1)

\begin{tabular}{|c|c|c|c|c|c|c|c|c|c|}
\hline \multicolumn{5}{|c|}{ Ground Surface Data } & \multicolumn{5}{|c|}{ Ground Surface Data } \\
\hline Profile \# & Point \# & $X(f t)$ & $\mathbf{Y}(\mathbf{f t})$ & Relative $\mathbf{Z}$ (ft) & Profile \# & Point \# & $X(f t)$ & $Y(f t)$ & Relative Z (ft) \\
\hline \multirow{45}{*}{3} & 91 & 975 & 0 & 790 & \multirow{45}{*}{ ค10 } & 136 & 1225 & 0 & 785 \\
\hline & 92 & 975 & 125 & 820 & & 137 & 1225 & 125 & 805 \\
\hline & 93 & 975 & 250 & 845 & & 138 & 1225 & 250 & 805 \\
\hline & 94 & 975 & 375 & 840 & & 139 & 1225 & 375 & 780 \\
\hline & 95 & 975 & 500 & 820 & & 140 & 1225 & 500 & 760 \\
\hline & 96 & 975 & 625 & 810 & & 141 & 1225 & 625 & 750 \\
\hline & 97 & 975 & 750 & 780 & & 142 & 1225 & 750 & 810 \\
\hline & 98 & 975 & 875 & 760 & & 143 & 1225 & 875 & 680 \\
\hline & 99 & 975 & 1000 & 740 & & 144 & 1225 & 1000 & 660 \\
\hline & 100 & 975 & 1125 & 710 & & 145 & 1225 & 1125 & 640 \\
\hline & 101 & 975 & 1250 & 680 & & 146 & 1225 & 1250 & 625 \\
\hline & 102 & 975 & 1375 & 650 & & 147 & 1225 & 1375 & 610 \\
\hline & 103 & 975 & 1500 & 640 & & 148 & 1225 & 1500 & 600 \\
\hline & 104 & 975 & 1625 & 620 & & 149 & 1225 & 1625 & 580 \\
\hline & 105 & 975 & 1750 & 605 & & 150 & 1225 & 1750 & 570 \\
\hline & 106 & 975 & 1875 & 590 & & 151 & 1225 & 1875 & 560 \\
\hline & 107 & 975 & 2000 & 585 & & 152 & 1225 & 2000 & 545 \\
\hline & 108 & 975 & 2125 & 575 & & 153 & 1225 & 2125 & 540 \\
\hline & 109 & 975 & 2250 & 560 & & 154 & 1225 & 2250 & 525 \\
\hline & 110 & 975 & 2375 & 545 & & 155 & 1225 & 2375 & 510 \\
\hline & 111 & 975 & 2500 & 540 & & 156 & 1225 & 2500 & 498 \\
\hline & 112 & 975 & 2625 & 525 & & 157 & 1225 & 2625 & 498 \\
\hline & 113 & 975 & 2750 & 510 & & 158 & 1225 & 2750 & 498 \\
\hline & 114 & 975 & 2875 & 498 & & 159 & 1225 & 2875 & 498 \\
\hline & 115 & 975 & 3000 & 498 & & 160 & 1225 & 3000 & 498 \\
\hline & 116 & 975 & 3125 & 498 & & 161 & 1225 & 3125 & 498 \\
\hline & 117 & 975 & 3250 & 498 & & 162 & 1225 & 3250 & 498 \\
\hline & 118 & 975 & 3375 & 498 & & 163 & 1225 & 3375 & 498 \\
\hline & 119 & 975 & 3500 & 495 & & 164 & 1225 & 3500 & 495 \\
\hline & 120 & 975 & 3625 & 495 & & 165 & 1225 & 3625 & 495 \\
\hline & 121 & 975 & 3750 & 520 & & 166 & 1225 & 3750 & 520 \\
\hline & 122 & 975 & 3875 & 520 & & 167 & 1225 & 3875 & 560 \\
\hline & 123 & 975 & 4000 & 520 & & 168 & 1225 & 4000 & 580 \\
\hline & 124 & 975 & 4125 & 530 & & 169 & 1225 & 4125 & 620 \\
\hline & 125 & 975 & 4250 & 550 & & 170 & 1225 & 4250 & 665 \\
\hline & 126 & 975 & 4375 & 630 & & 171 & 1225 & 4375 & 700 \\
\hline & 127 & 975 & 4500 & 680 & & 172 & 1225 & 4500 & 750 \\
\hline & 128 & 975 & 4625 & 705 & & 173 & 1225 & 4625 & 780 \\
\hline & 129 & 975 & 4750 & 740 & & 174 & 1225 & 4750 & 805 \\
\hline & 130 & 975 & 4875 & 760 & & 175 & 1225 & 4875 & 825 \\
\hline & 131 & 975 & 5000 & 770 & & 176 & 1225 & 5000 & 850 \\
\hline & 132 & 975 & 5125 & 810 & & 177 & 1225 & 5125 & 870 \\
\hline & 133 & 975 & 5250 & 855 & & 178 & 1225 & 5250 & 890 \\
\hline & 134 & 975 & 5375 & 880 & & 179 & 1225 & 5375 & 920 \\
\hline & 135 & 975 & 5500 & 900 & & 180 & 1225 & 5500 & 935 \\
\hline
\end{tabular}


Table A5 Continued (2)

\begin{tabular}{|c|c|c|c|c|c|c|c|c|c|}
\hline \multicolumn{5}{|c|}{ Ground Surface Data } & \multicolumn{5}{|c|}{ Ground Surface Data } \\
\hline Profile \# & Point \# & $\mathbf{X}(\mathbf{f t})$ & $\mathbf{Y}(\mathbf{f t})$ & Relative $\mathbf{Z}$ (ft) & Profile \# & Point \# & $X(f t)$ & $\mathbf{Y}(\mathbf{f t})$ & Relative Z (ft) \\
\hline \multirow{45}{*}{5} & 181 & 1600 & 0 & 720 & \multirow{45}{*}{6} & 226 & 2025 & 0 & 640 \\
\hline & 182 & 1600 & 125 & 750 & & 227 & 2025 & 125 & 600 \\
\hline & 183 & 1600 & 250 & 755 & & 228 & 2025 & 250 & 600 \\
\hline & 184 & 1600 & 375 & 700 & & 229 & 2025 & 375 & 600 \\
\hline & 185 & 1600 & 500 & 665 & & 230 & 2025 & 500 & 580 \\
\hline & 186 & 1600 & 625 & 640 & & 231 & 2025 & 625 & 570 \\
\hline & 187 & 1600 & 750 & 650 & & 232 & 2025 & 750 & 580 \\
\hline & 188 & 1600 & 875 & 645 & & 233 & 2025 & 875 & 580 \\
\hline & 189 & 1600 & 1000 & 630 & & 234 & 2025 & 1000 & 570 \\
\hline & 190 & 1600 & 1125 & 600 & & 235 & 2025 & 1125 & 580 \\
\hline & 191 & 1600 & 1250 & 590 & & 236 & 2025 & 1250 & 580 \\
\hline & 192 & 1600 & 1375 & 570 & & 237 & 2025 & 1375 & 570 \\
\hline & 193 & 1600 & 1500 & 570 & & 238 & 2025 & 1500 & 565 \\
\hline & 194 & 1600 & 1625 & 565 & & 239 & 2025 & 1625 & 560 \\
\hline & 195 & 1600 & 1750 & 560 & & 240 & 2025 & 1750 & 560 \\
\hline & 196 & 1600 & 1875 & 540 & & 241 & 2025 & 1875 & 555 \\
\hline & 197 & 1600 & 2000 & 520 & & 242 & 2025 & 2000 & 540 \\
\hline & 198 & 1600 & 2125 & 502 & & 243 & 2025 & 2125 & 510 \\
\hline & 199 & 1600 & 2250 & 502 & & 244 & 2025 & 2250 & 508 \\
\hline & 200 & 1600 & 2375 & 502 & & 245 & 2025 & 2375 & 510 \\
\hline & 201 & 1600 & 2500 & 510 & & 246 & 2025 & 2500 & 525 \\
\hline & 202 & 1600 & 2625 & 520 & & 247 & 2025 & 2625 & 540 \\
\hline & 203 & 1600 & 2750 & 530 & & 248 & 2025 & 2750 & 545 \\
\hline & 204 & 1600 & 2875 & 540 & & 249 & 2025 & 2875 & 570 \\
\hline & 205 & 1600 & 3000 & 550 & & 250 & 2025 & 3000 & 610 \\
\hline & 206 & 1600 & 3125 & 570 & & 251 & 2025 & 3125 & 650 \\
\hline & 207 & 1600 & 3250 & 580 & & 252 & 2025 & 3250 & 620 \\
\hline & 208 & 1600 & 3375 & 600 & & 253 & 2025 & 3375 & 770 \\
\hline & 209 & 1600 & 3500 & 640 & & 254 & 2025 & 3500 & 820 \\
\hline & 210 & 1600 & 3625 & 670 & & 255 & 2025 & 3625 & 830 \\
\hline & 211 & 1600 & 3750 & 690 & & 256 & 2025 & 3750 & 840 \\
\hline & 212 & 1600 & 3875 & 720 & & 257 & 2025 & 3875 & 840 \\
\hline & 213 & 1600 & 4000 & 740 & & 258 & 2025 & 4000 & 850 \\
\hline & 214 & 1600 & 4125 & 770 & & 259 & 2025 & 4125 & 865 \\
\hline & 215 & 1600 & 4250 & 795 & & 260 & 2025 & 4250 & 875 \\
\hline & 216 & 1600 & 4375 & 820 & & 261 & 2025 & 4375 & 870 \\
\hline & 217 & 1600 & 4500 & 840 & & 262 & 2025 & 4500 & 860 \\
\hline & 218 & 1600 & 4625 & 860 & & 263 & 2025 & 4625 & 840 \\
\hline & 219 & 1600 & 4750 & 880 & & 264 & 2025 & 4750 & 820 \\
\hline & 220 & 1600 & 4875 & 900 & & 265 & 2025 & 4875 & 810 \\
\hline & 221 & 1600 & 5000 & 900 & & 266 & 2025 & 5000 & 800 \\
\hline & 222 & 1600 & 5125 & 890 & & 267 & 2025 & 5125 & 790 \\
\hline & 223 & 1600 & 5250 & 875 & & 268 & 2025 & 5250 & 760 \\
\hline & 224 & 1600 & 5375 & 870 & & 269 & 2025 & 5375 & 720 \\
\hline & 225 & 1600 & 5500 & 880 & & 270 & 2025 & 5500 & 740 \\
\hline
\end{tabular}


Table A5 Continued (3)

\begin{tabular}{|c|c|c|c|c|c|c|c|c|c|}
\hline \multicolumn{5}{|c|}{ Ground Surface Data } & \multicolumn{5}{|c|}{ Ground Surface Data } \\
\hline Profile \# & Point \# & $X(f t)$ & $\mathbf{Y}(\mathbf{f t})$ & Relative $\mathbf{Z}$ (ft) & Profile \# & Point \# & $X(f t)$ & $\mathbf{Y}(\mathbf{f t})$ & Relative Z (ft) \\
\hline \multirow{45}{*}{7} & 271 & 2515 & 0 & 710 & \multirow{45}{*}{8} & 316 & 2890 & 0 & 800 \\
\hline & 272 & 2515 & 125 & 665 & & 317 & 2890 & 125 & 795 \\
\hline & 273 & 2515 & 250 & 665 & & 318 & 2890 & 250 & 770 \\
\hline & 274 & 2515 & 375 & 660 & & 319 & 2890 & 375 & 765 \\
\hline & 275 & 2515 & 500 & 700 & & 320 & 2890 & 500 & 770 \\
\hline & 276 & 2515 & 625 & 730 & & 321 & 2890 & 625 & 800 \\
\hline & 277 & 2515 & 750 & 750 & & 322 & 2890 & 750 & 825 \\
\hline & 278 & 2515 & 875 & 750 & & 323 & 2890 & 875 & 830 \\
\hline & 279 & 2515 & 1000 & 740 & & 324 & 2890 & 1000 & 830 \\
\hline & 280 & 2515 & 1125 & 820 & & 325 & 2890 & 1125 & 820 \\
\hline & 281 & 2515 & 1250 & 705 & & 326 & 2890 & 1250 & 800 \\
\hline & 282 & 2515 & 1375 & 685 & & 327 & 2890 & 1375 & 785 \\
\hline & 283 & 2515 & 1500 & 665 & & 328 & 2890 & 1500 & 755 \\
\hline & 284 & 2515 & 1625 & 655 & & 329 & 2890 & 1625 & 700 \\
\hline & 285 & 2515 & 1750 & 640 & & 330 & 2890 & 1750 & 660 \\
\hline & 286 & 2515 & 1875 & 625 & & 331 & 2890 & 1875 & 600 \\
\hline & 287 & 2515 & 2000 & 595 & & 332 & 2890 & 2000 & 560 \\
\hline & 288 & 2515 & 2125 & 540 & & 333 & 2890 & 2125 & 540 \\
\hline & 289 & 2515 & 2250 & 515 & & 334 & 2890 & 2250 & 521 \\
\hline & 290 & 2515 & 2375 & 515 & & 335 & 2890 & 2375 & 535 \\
\hline & 291 & 2515 & 2500 & 515 & & 336 & 2890 & 2500 & 540 \\
\hline & 292 & 2515 & 2625 & 520 & & 337 & 2890 & 2625 & 545 \\
\hline & 293 & 2515 & 2750 & 550 & & 338 & 2890 & 2750 & 545 \\
\hline & 294 & 2515 & 2875 & 570 & & 339 & 2890 & 2875 & 550 \\
\hline & 295 & 2515 & 3000 & 590 & & 340 & 2890 & 3000 & 550 \\
\hline & 296 & 2515 & 3125 & 630 & & 341 & 2890 & 3125 & 555 \\
\hline & 297 & 2515 & 3250 & 655 & & 342 & 2890 & 3250 & 560 \\
\hline & 298 & 2515 & 3375 & 690 & & 343 & 2890 & 3375 & 570 \\
\hline & 299 & 2515 & 3500 & 710 & & 344 & 2890 & 3500 & 575 \\
\hline & 300 & 2515 & 3625 & 720 & & 345 & 2890 & 3625 & 580 \\
\hline & 301 & 2515 & 3750 & 730 & & 346 & 2890 & 3750 & 580 \\
\hline & 302 & 2515 & 3875 & 730 & & 347 & 2890 & 3875 & 575 \\
\hline & 303 & 2515 & 4000 & 730 & & 348 & 2890 & 4000 & 590 \\
\hline & 304 & 2515 & 4125 & 725 & & 349 & 2890 & 4125 & 600 \\
\hline & 305 & 2515 & 4250 & 710 & & 350 & 2890 & 4250 & 605 \\
\hline & 306 & 2515 & 4375 & 690 & & 351 & 2890 & 4375 & 620 \\
\hline & 307 & 2515 & 4500 & 665 & & 352 & 2890 & 4500 & 625 \\
\hline & 308 & 2515 & 4625 & 640 & & 353 & 2890 & 4625 & 665 \\
\hline & 309 & 2515 & 4750 & 620 & & 354 & 2890 & 4750 & 700 \\
\hline & 310 & 2515 & 4875 & 620 & & 355 & 2890 & 4875 & 735 \\
\hline & 311 & 2515 & 5000 & 620 & & 356 & 2890 & 5000 & 760 \\
\hline & 312 & 2515 & 5125 & 620 & & 357 & 2890 & 5125 & 770 \\
\hline & 313 & 2515 & 5250 & 650 & & 358 & 2890 & 5250 & 785 \\
\hline & 314 & 2515 & 5375 & 660 & & 359 & 2890 & 5375 & 780 \\
\hline & 315 & 2515 & 5500 & 680 & & 360 & 2890 & 5500 & 760 \\
\hline
\end{tabular}


Table A5 Continued (4)

\begin{tabular}{|c|c|c|c|c|c|c|c|c|c|}
\hline \multicolumn{5}{|c|}{ Ground Surface Data } & \multicolumn{5}{|c|}{ Ground Surface Data } \\
\hline Profile \# & Point \# & $X(f t)$ & $\mathbf{Y}(\mathbf{f t})$ & Relative Z (ft) & Profile \# & Point \# & $X(f t)$ & $Y(f t)$ & Relative $\mathbf{Z}$ (ft) \\
\hline \multirow{45}{*}{9} & 361 & 3270 & 0 & 940 & \multirow{45}{*}{10} & 406 & 3710 & 0 & 915 \\
\hline & 362 & 3270 & 125 & 915 & & 407 & 3710 & 125 & 935 \\
\hline & 363 & 3270 & 250 & 900 & & 408 & 3710 & 250 & 935 \\
\hline & 364 & 3270 & 375 & 885 & & 409 & 3710 & 375 & 910 \\
\hline & 365 & 3270 & 500 & 890 & & 410 & 3710 & 500 & 890 \\
\hline & 366 & 3270 & 625 & 900 & & 411 & 3710 & 625 & 870 \\
\hline & 367 & 3270 & 750 & 910 & & 412 & 3710 & 750 & 860 \\
\hline & 368 & 3270 & 875 & 905 & & 413 & 3710 & 875 & 875 \\
\hline & 369 & 3270 & 1000 & 880 & & 414 & 3710 & 1000 & 865 \\
\hline & 370 & 3270 & 1125 & 840 & & 415 & 3710 & 1125 & 860 \\
\hline & 371 & 3270 & 1250 & 795 & & 416 & 3710 & 1250 & 850 \\
\hline & 372 & 3270 & 1375 & 760 & & 417 & 3710 & 1375 & 815 \\
\hline & 373 & 3270 & 1500 & 680 & & 418 & 3710 & 1500 & 770 \\
\hline & 374 & 3270 & 1625 & 640 & & 419 & 3710 & 1625 & 680 \\
\hline & 375 & 3270 & 1750 & 590 & & 420 & 3710 & 1750 & 630 \\
\hline & 376 & 3270 & 1875 & 560 & & 421 & 3710 & 1875 & 560 \\
\hline & 377 & 3270 & 2000 & 540 & & 422 & 3710 & 2000 & 540 \\
\hline & 378 & 3270 & 2125 & 526 & & 423 & 3710 & 2125 & 533 \\
\hline & 379 & 3270 & 2250 & 526 & & 424 & 3710 & 2250 & 533 \\
\hline & 380 & 3270 & 2375 & 540 & & 425 & 3710 & 2375 & 533 \\
\hline & 381 & 3270 & 2500 & 560 & & 426 & 3710 & 2500 & 565 \\
\hline & 382 & 3270 & 2625 & 580 & & 427 & 3710 & 2625 & 600 \\
\hline & 383 & 3270 & 2750 & 660 & & 428 & 3710 & 2750 & 665 \\
\hline & 384 & 3270 & 2875 & 680 & & 429 & 3710 & 2875 & 705 \\
\hline & 385 & 3270 & 3000 & 700 & & 430 & 3710 & 3000 & 735 \\
\hline & 386 & 3270 & 3125 & 710 & & 431 & 3710 & 3125 & 770 \\
\hline & 387 & 3270 & 3250 & 720 & & 432 & 3710 & 3250 & 800 \\
\hline & 388 & 3270 & 3375 & 720 & & 433 & 3710 & 3375 & 815 \\
\hline & 389 & 3270 & 3500 & 720 & & 434 & 3710 & 3500 & 825 \\
\hline & 390 & 3270 & 3625 & 740 & & 435 & 3710 & 3625 & 835 \\
\hline & 391 & 3270 & 3750 & 750 & & 436 & 3710 & 3750 & 850 \\
\hline & 392 & 3270 & 3875 & 765 & & 437 & 3710 & 3875 & 865 \\
\hline & 393 & 3270 & 4000 & 770 & & 438 & 3710 & 4000 & 880 \\
\hline & 394 & 3270 & 4125 & 780 & & 439 & 3710 & 4125 & 885 \\
\hline & 395 & 3270 & 4250 & 780 & & 440 & 3710 & 4250 & 885 \\
\hline & 396 & 3270 & 4375 & 780 & & 441 & 3710 & 4375 & 880 \\
\hline & 397 & 3270 & 4500 & 770 & & 442 & 3710 & 4500 & 870 \\
\hline & 398 & 3270 & 4625 & 760 & & 443 & 3710 & 4625 & 865 \\
\hline & 399 & 3270 & 4750 & 790 & & 444 & 3710 & 4750 & 865 \\
\hline & 400 & 3270 & 4875 & 830 & & 445 & 3710 & 4875 & 880 \\
\hline & 401 & 3270 & 5000 & 860 & & 446 & 3710 & 5000 & 900 \\
\hline & 402 & 3270 & 5125 & 885 & & 447 & 3710 & 5125 & 920 \\
\hline & 403 & 3270 & 5250 & 905 & & 448 & 3710 & 5250 & 935 \\
\hline & 404 & 3270 & 5375 & 900 & & 449 & 3710 & 5375 & 950 \\
\hline & 405 & 3270 & 5500 & 890 & & 450 & 3710 & 5500 & 965 \\
\hline
\end{tabular}




\begin{tabular}{|c|c|c|c|c|}
\hline \multicolumn{5}{|c|}{ Ground Surface Data } \\
\hline Profile \# & Point \# & $X(\mathbf{f t})$ & $\mathbf{Y}(\mathbf{f t})$ & Relative Z (ft) \\
\hline \multirow{45}{*}{11} & 451 & 4000 & 0 & 840 \\
\hline & 452 & 4000 & 125 & 860 \\
\hline & 453 & 4000 & 250 & 865 \\
\hline & 454 & 4000 & 375 & 850 \\
\hline & 455 & 4000 & 500 & 820 \\
\hline & 456 & 4000 & 625 & 790 \\
\hline & 457 & 4000 & 750 & 770 \\
\hline & 458 & 4000 & 875 & 780 \\
\hline & 459 & 4000 & 1000 & 815 \\
\hline & 460 & 4000 & 1125 & 840 \\
\hline & 461 & 4000 & 1250 & 835 \\
\hline & 462 & 4000 & 1375 & 805 \\
\hline & 463 & 4000 & 1500 & 760 \\
\hline & 464 & 4000 & 1625 & 700 \\
\hline & 465 & 4000 & 1750 & 645 \\
\hline & 466 & 4000 & 1875 & 600 \\
\hline & 467 & 4000 & 2000 & 560 \\
\hline & 468 & 4000 & 2125 & 537 \\
\hline & 469 & 4000 & 2250 & 537 \\
\hline & 470 & 4000 & 2375 & 537 \\
\hline & 471 & 4000 & 2500 & 537 \\
\hline & 472 & 4000 & 2625 & 545 \\
\hline & 473 & 4000 & 2750 & 580 \\
\hline & 474 & 4000 & 2875 & 640 \\
\hline & 475 & 4000 & 3000 & 690 \\
\hline & 476 & 4000 & 3125 & 730 \\
\hline & 477 & 4000 & 3250 & 740 \\
\hline & 478 & 4000 & 3375 & 760 \\
\hline & 479 & 4000 & 3500 & 780 \\
\hline & 480 & 4000 & 3625 & 800 \\
\hline & 481 & 4000 & 3750 & 820 \\
\hline & 482 & 4000 & 3875 & 835 \\
\hline & 483 & 4000 & 4000 & 840 \\
\hline & 484 & 4000 & 4125 & 830 \\
\hline & 485 & 4000 & 4250 & 820 \\
\hline & 486 & 4000 & 4375 & 800 \\
\hline & 487 & 4000 & 4500 & 790 \\
\hline & 488 & 4000 & 4625 & 795 \\
\hline & 489 & 4000 & 4750 & 820 \\
\hline & 490 & 4000 & 4875 & 840 \\
\hline & 491 & 4000 & 5000 & 875 \\
\hline & 492 & 4000 & 5125 & 900 \\
\hline & 493 & 4000 & 5250 & 920 \\
\hline & 494 & 4000 & 5375 & 940 \\
\hline & 495 & 4000 & 5500 & 945 \\
\hline
\end{tabular}


Table A6 Compiled borehole logs for geologic detail

\begin{tabular}{|c|c|c|c|c|}
\hline \multicolumn{5}{|c|}{ Borehole Log Information } \\
\hline Formation & $\begin{array}{c}\text { Info. } \\
\text { Source }\end{array}$ & $\begin{array}{c}\text { Layer } \\
\text { Thickness (ft) }\end{array}$ & $\begin{array}{l}\text { Elevation } \\
\text { (ft) }\end{array}$ & Description \\
\hline & & \multirow{2}{*}{4.63} & 1419.8 & \multirow{2}{*}{ Shale, light gray-green } \\
\hline & & & 1415.1 & \\
\hline & & \multirow{2}{*}{2.37} & 1415.1 & \multirow{2}{*}{ Shale, green w/ Limestone nodules } \\
\hline & & & 1412.8 & \\
\hline & & \multirow{2}{*}{12.50} & 1412.8 & \multirow{2}{*}{ shale, red-grn, w/LS Nod } \\
\hline & & & 1400.3 & \\
\hline & & \multirow{2}{*}{2.40} & 1400.3 & \multirow{2}{*}{ Shale, LT GRY-GRN, /w LS NOD } \\
\hline & & & 1397.9 & \\
\hline & & \multirow{2}{*}{9.35} & 1397.9 & \multirow{2}{*}{ Sandstone, gray, crossbedded } \\
\hline & & & 1388.5 & \\
\hline & & \multirow{2}{*}{7.75} & 1388.5 & \multirow{2}{*}{ Shale, gray } \\
\hline & & & 1380.8 & \\
\hline \multirow{32}{*}{ Greene } & \multirow{32}{*}{ DD95-15 } & \multirow{2}{*}{0.50} & 1380.8 & \multirow{2}{*}{ Shale, dark gray, w/ coal streaks } \\
\hline & & & 1380.3 & \\
\hline & & \multirow{2}{*}{4.35} & 1380.3 & \multirow{2}{*}{ Shale, gray, w/ limestone nodules } \\
\hline & & & 1375.9 & \\
\hline & & \multirow{2}{*}{4.55} & 1375.9 & \multirow{2}{*}{ Shaly limestone } \\
\hline & & & 1371.4 & \\
\hline & & \multirow{2}{*}{5.65} & 1371.4 & \multirow{2}{*}{ Shale, gray } \\
\hline & & & 1365.7 & \\
\hline & & \multirow{2}{*}{1.15} & 1365.7 & Shale red-orn w/LS nod \\
\hline & & & 1364.6 & Shale, red-grn, W/LS nod \\
\hline & & 687 & 1364.6 & Shale dark grav w/LS nod \\
\hline & & 0.87 & 1357.7 & Shale, dark gray, w/ LS nod \\
\hline & & 005 & 1357.7 & Interbedded limestone and shale \\
\hline & & 0.95 & 1356.7 & Interbedded limestone and shale \\
\hline & & 098 & 1356.7 & Shaly limestone \\
\hline & & 0.98 & 1355.8 & Shaly limestone \\
\hline & & 580 & 1355.8 & Interbedded limestone and shale \\
\hline & & & 1350.0 & \\
\hline & & 5.57 & 1350.0 & Shale dark orav w/I S nod \\
\hline & & & 1344.4 & \\
\hline & & 110 & 1344.4 & Shale IT orav-orn w/IS nod \\
\hline & & & 1343.3 & \\
\hline & & 303 & 1343.3 & Shale LT orv-orn w/ I S nod \\
\hline & & & 1340.3 & \\
\hline & & 1284 & 1340.3 & Sandstone orav crossbedded \\
\hline & & & 1327.4 & \\
\hline & & 039 & 1327.4 & Sandstone orav crosshedded \\
\hline & & & 1327.0 & \\
\hline & & 0.57 & 1327.0 & Shale oreen \\
\hline & & & 1326.5 & \\
\hline & & 167 & 1326.5 & Sandstone orav crosshedded \\
\hline & & & 1324.8 & \\
\hline
\end{tabular}




\section{Table A6 Continued (1)}

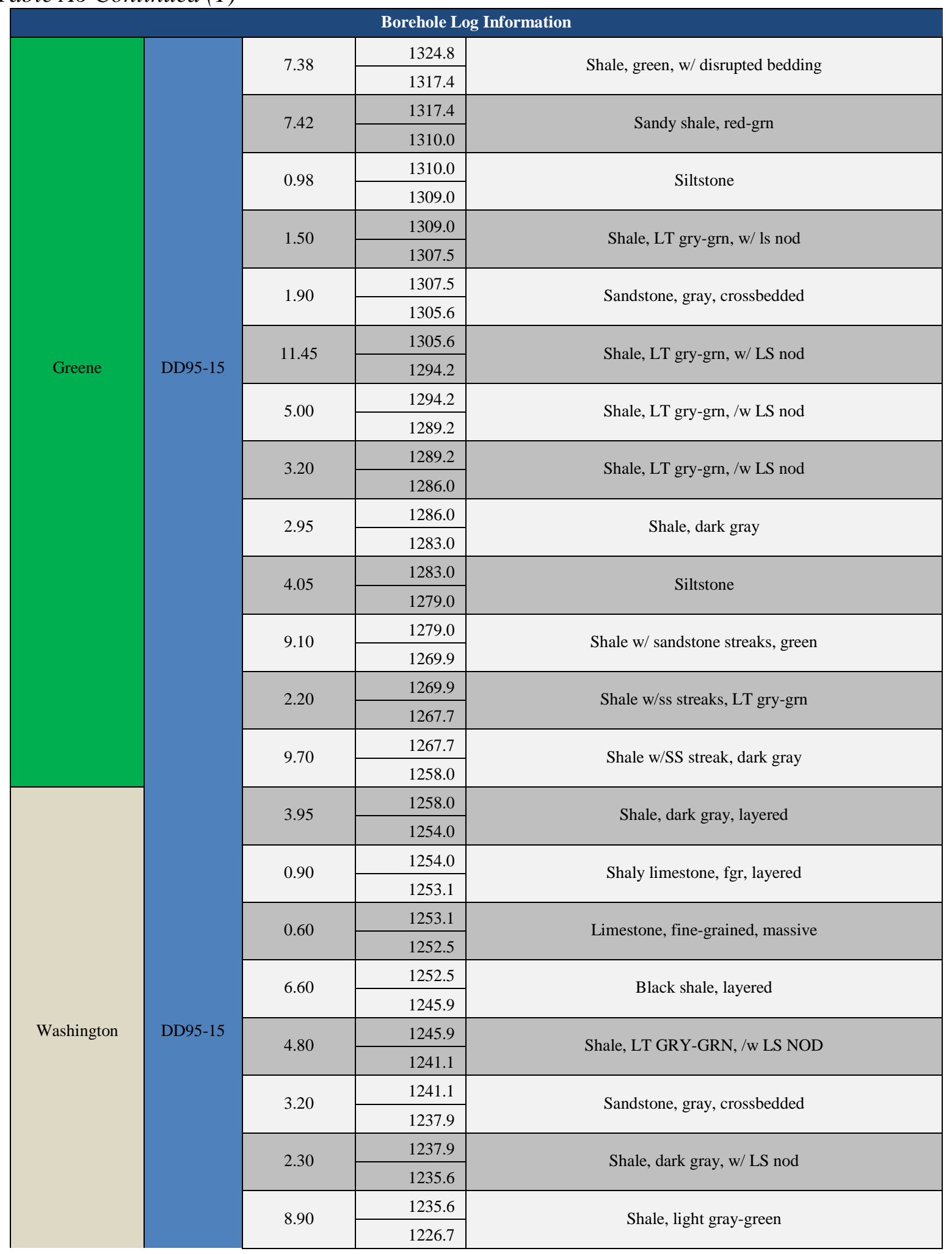


Table A6 Continued (2)

\begin{tabular}{|c|c|c|c|c|}
\hline \multicolumn{5}{|c|}{ Borehole Log Information } \\
\hline & & \multirow{2}{*}{1.65} & 1226.7 & \multirow{2}{*}{ Shale, LT gry-grn, w/ LS nod } \\
\hline & & & 1225.1 & \\
\hline & & \multirow{2}{*}{4.80} & 1225.1 & \multirow{2}{*}{ Shale, LT gry-grn, w/ LS nod, fossils } \\
\hline & & & 1220.3 & \\
\hline & & \multirow{2}{*}{2.15} & 1220.3 & \multirow{2}{*}{ Shale, light gray-green } \\
\hline & & & 1218.1 & \\
\hline & & \multirow{2}{*}{4.70} & 1218.1 & \multirow{2}{*}{ Shale, LT gry-grn } \\
\hline & & & 1213.4 & \\
\hline & & \multirow{2}{*}{7.05} & 1213.4 & \multirow{2}{*}{ Shale, dark gray, w/ disrupted bedding } \\
\hline & & & 1206.4 & \\
\hline & & \multirow{2}{*}{3.60} & 1206.4 & \multirow{2}{*}{ Impure coal } \\
\hline & & & 1202.8 & \\
\hline & & \multirow{2}{*}{4.60} & 1202.8 & \multirow{2}{*}{ Shale, dark gray } \\
\hline & & & 1198.2 & \\
\hline & & \multirow{2}{*}{0.85} & 1198.2 & \multirow{2}{*}{ Sandstone, gray } \\
\hline & & & 1197.3 & \\
\hline & & \multirow{2}{*}{4.45} & 1197.3 & \multirow{2}{*}{ Shale, dark gray, layered } \\
\hline & & & 1192.9 & \\
\hline & & \multirow{2}{*}{1.00} & 1192.9 & \multirow{2}{*}{ Shale, dark gray, w/ LS nod and fossils } \\
\hline & & & 1191.9 & \\
\hline \multirow{24}{*}{ Washington } & & \multirow{2}{*}{7.60} & 1191.9 & \multirow{2}{*}{ Shale, green, w/ limestone nodules } \\
\hline & & & 1184.3 & \\
\hline & DD95-15 & 730 & 1184.3 & Sandstone oray w/ shale streaks \\
\hline & & 1.00 & 1177.0 & 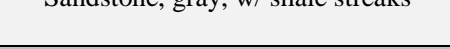 \\
\hline & & 795 & 1177.0 & Sandstone orav crosshedded \\
\hline & & 1.0 & 1169.0 & \\
\hline & & 205 & 1169.0 & Shale lioht oray-oreen \\
\hline & & & 1167.0 & \\
\hline & & 300 & 1167.0 & Shale lioht orav-oreen \\
\hline & & & 1164.0 & 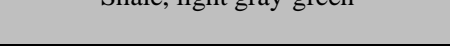 \\
\hline & & 660 & 1164.0 & Shol I T a \\
\hline & & 0.00 & 1157.4 & Milate, L1 giy-gin, w/ La Hou \\
\hline & & 115 & 1157.4 & Shaly limestone for lyd \\
\hline & & & 1156.2 & \\
\hline & & 210 & 1156.2 & Shale IT orv-orn w/ I S nod \\
\hline & & & 1154.1 & \\
\hline & & 405 & 1154.1 & Shale oreen w/limestone nodules \\
\hline & & & 1150.1 & \\
\hline & & 380 & 1150.1 & Shale LT orv-orn w/ I S nod \\
\hline & & & 1146.3 & \\
\hline & & 305 & 1146.3 & Limestone fine-grained mascive \\
\hline & & 5.05 & 1143.2 & Lintestone, min-gianted, massive \\
\hline & & 2508 & 1143.2 & Chole red on w/I C nod \\
\hline & & & 1118.1 & \\
\hline
\end{tabular}




\section{Table A6 Continued (3)}

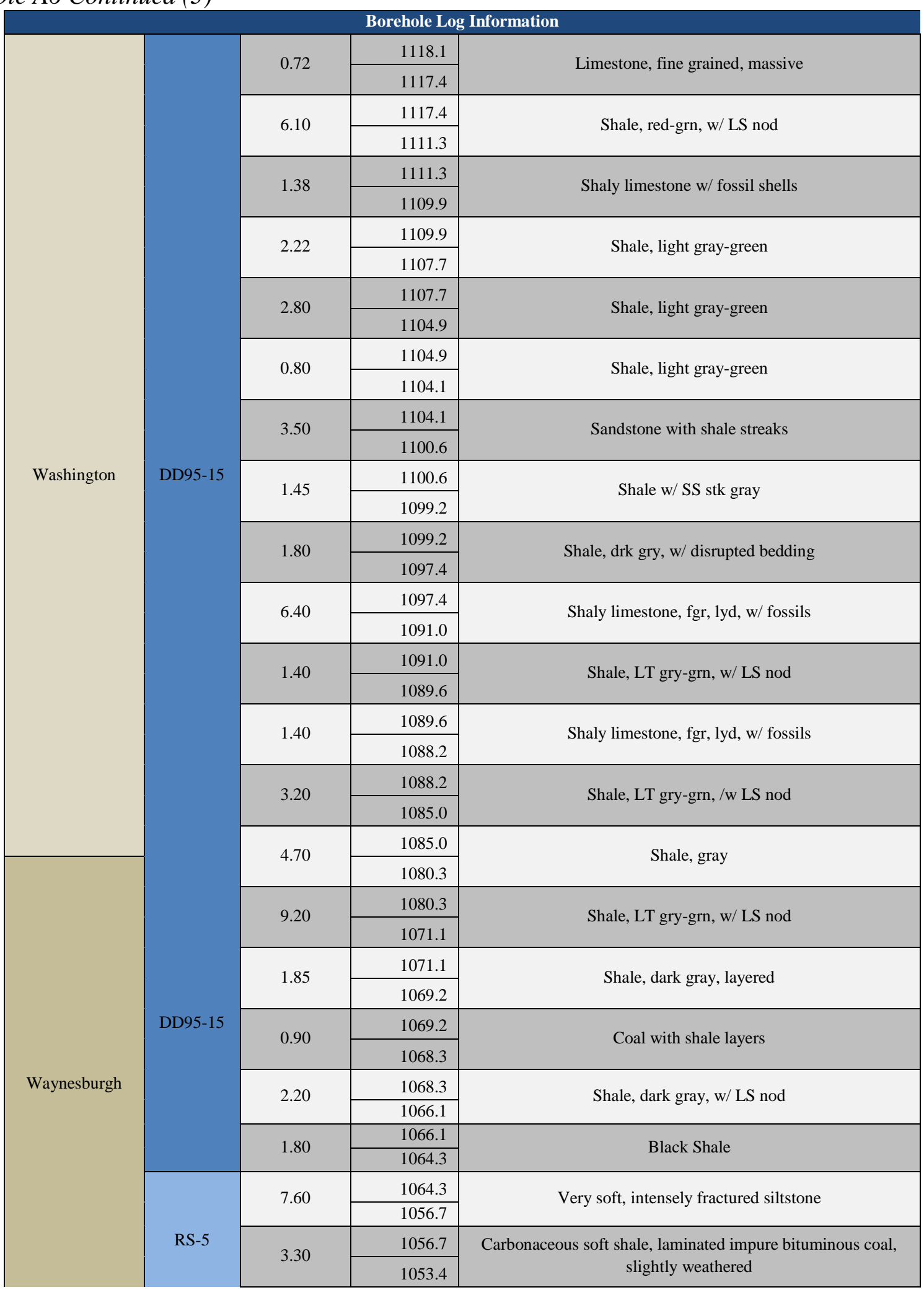




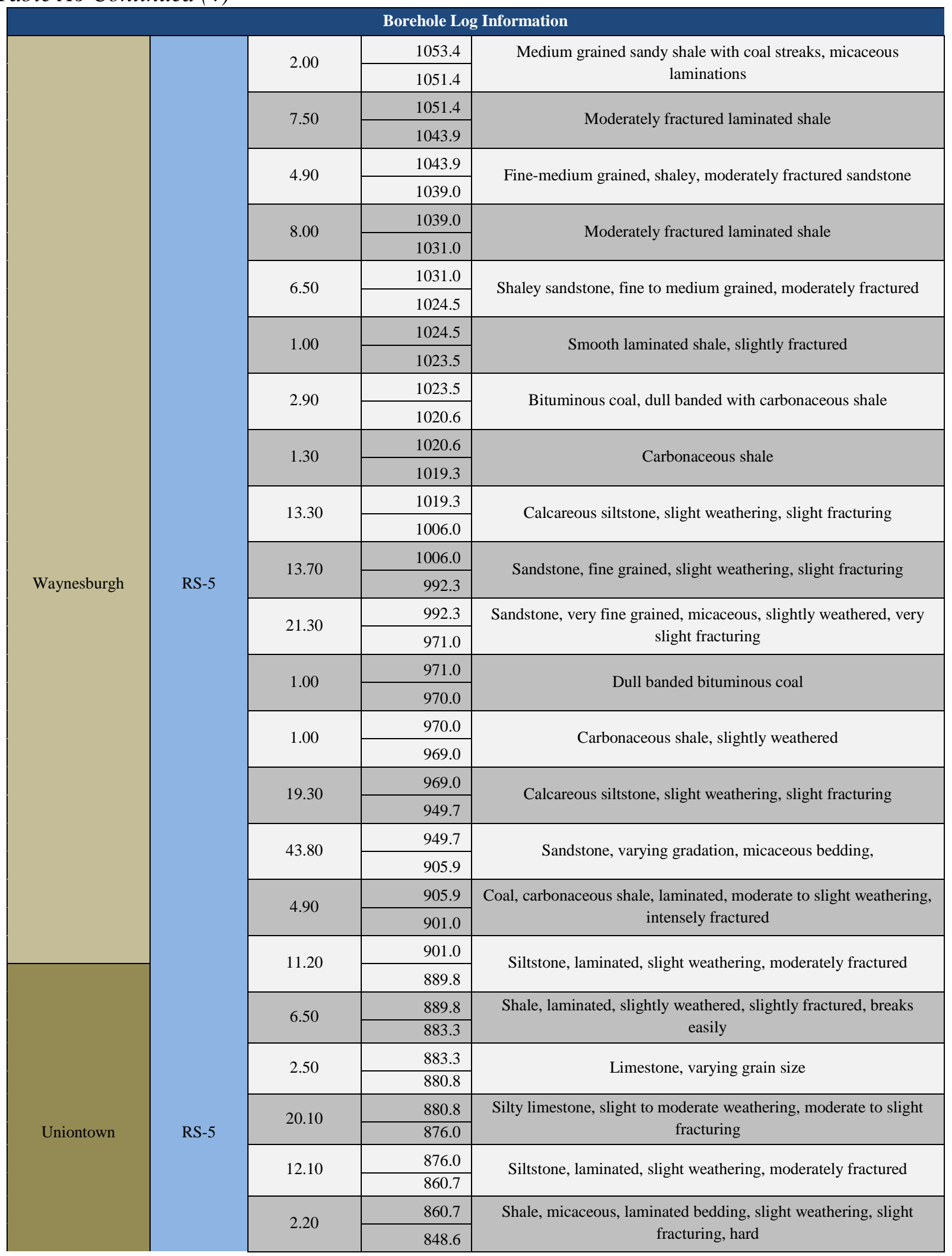


Table A6 Continued (5)

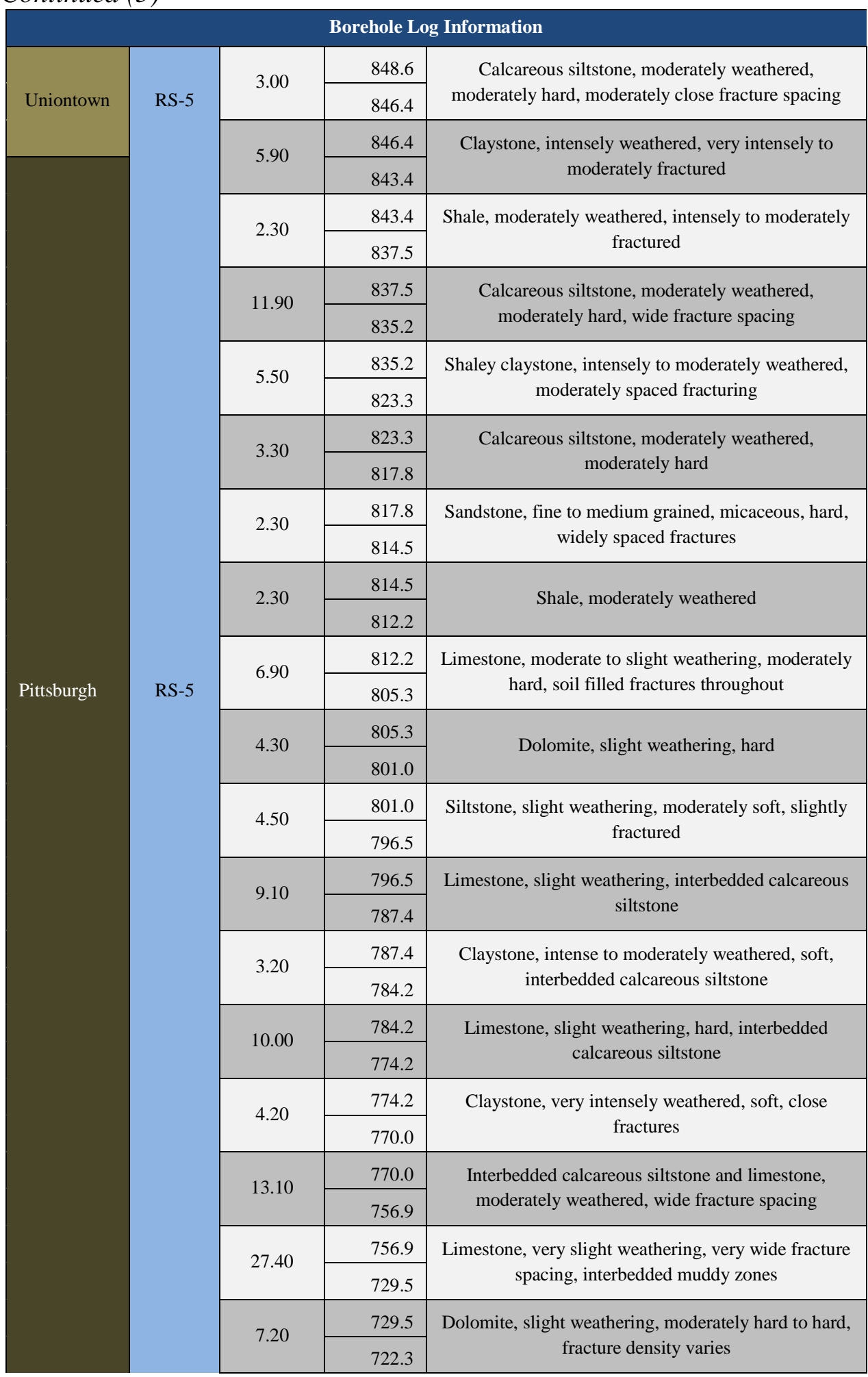


Table A6 Continued (6)

\begin{tabular}{|c|c|c|c|c|}
\hline \multicolumn{5}{|c|}{ Borehole Log Information } \\
\hline & & \multirow{2}{*}{5.90} & 722.3 & \multirow{2}{*}{$\begin{array}{l}\text { Limestone, hard, very wide fracture spacing, slightly } \\
\text { weathered }\end{array}$} \\
\hline & & & 716.4 & \\
\hline & & \multirow{2}{*}{5.80} & 716.4 & \multirow{2}{*}{$\begin{array}{c}\text { Claystone, very intensely weathered, soft, very close } \\
\text { fracture spacing }\end{array}$} \\
\hline & & & 710.6 & \\
\hline & & \multirow{2}{*}{6.70} & 710.6 & \multirow{2}{*}{$\begin{array}{l}\text { Bituminous coal, dull banded, moderately hard to } \\
\text { hard, incipient fractures throughout }\end{array}$} \\
\hline & & & 703.9 & \\
\hline & & \multirow{2}{*}{4.60} & 703.9 & \multirow{2}{*}{$\begin{array}{l}\text { Calcareous siltstone, intense weathering, moderately } \\
\text { hard, fracture spacing varies }\end{array}$} \\
\hline & & & 699.3 & \\
\hline & & \multirow{2}{*}{10.35} & 699.3 & \multirow{2}{*}{$\begin{array}{l}\text { Muddy limestone, laminated bedding, slight } \\
\text { weathering, hardness varies }\end{array}$} \\
\hline & & & 689.0 & \\
\hline & & \multirow{2}{*}{24.05} & 689.0 & \multirow{2}{*}{ Claystone, laminated, moderately fractured } \\
\hline & & & 664.9 & \\
\hline & & \multirow{2}{*}{23.60} & 664.9 & \multirow{2}{*}{ Claystone, intensely weathered, close fracture spacing } \\
\hline & & & 641.3 & \\
\hline & & \multirow{2}{*}{5.90} & 641.3 & \multirow{2}{*}{$\begin{array}{l}\text { Micaceous sandy siltstone, moderately hard, moderate } \\
\text { to wide fracture spacing }\end{array}$} \\
\hline & & & 635.4 & \\
\hline & & \multirow{2}{*}{18.90} & 635.4 & \multirow{2}{*}{$\begin{array}{l}\text { Sandstone, fine to medium grained, micaceous, slight } \\
\text { weathering, moderately hard to hard, moderately } \\
\text { fractured }\end{array}$} \\
\hline & & & 616.5 & \\
\hline & & \multirow{2}{*}{12.60} & 616.5 & \multirow{2}{*}{$\begin{array}{l}\text { Shale, slight weathering, moderately hard, } \\
\text { carbonaceous }\end{array}$} \\
\hline & & & 603.9 & \\
\hline & & \multirow{2}{*}{7.20} & 603.9 & \multirow{2}{*}{$\begin{array}{l}\text { Bituminous coal, dull banded, slightly weathered, } \\
\text { moderately hard to hard, incipient fractures } \\
\text { throughout (Pittsburgh Seam) }\end{array}$} \\
\hline & & & 596.7 & \\
\hline \multirow{8}{*}{ Casselman } & \multirow{8}{*}{ RS-5 } & \multirow{2}{*}{1.50} & 596.7 & \multirow{2}{*}{ Limestone, slight weathering, hard, no fractures } \\
\hline & & & 595.2 & \\
\hline & & \multirow{2}{*}{0.90} & 595.2 & \multirow{2}{*}{ Shale } \\
\hline & & & 594.3 & \\
\hline & & \multirow{2}{*}{6.40} & 594.3 & \multirow{2}{*}{$\begin{array}{l}\text { Siltstone, moderately weathered, moderately soft to } \\
\text { moderately hard, moderately close to wide fracture } \\
\text { spacing }\end{array}$} \\
\hline & & & 587.9 & \\
\hline & & 120 & 587.9 & Sandstone medium orined frech weathering hard \\
\hline & & 1.20 & 586.7 & moderately close fracture spacing \\
\hline
\end{tabular}




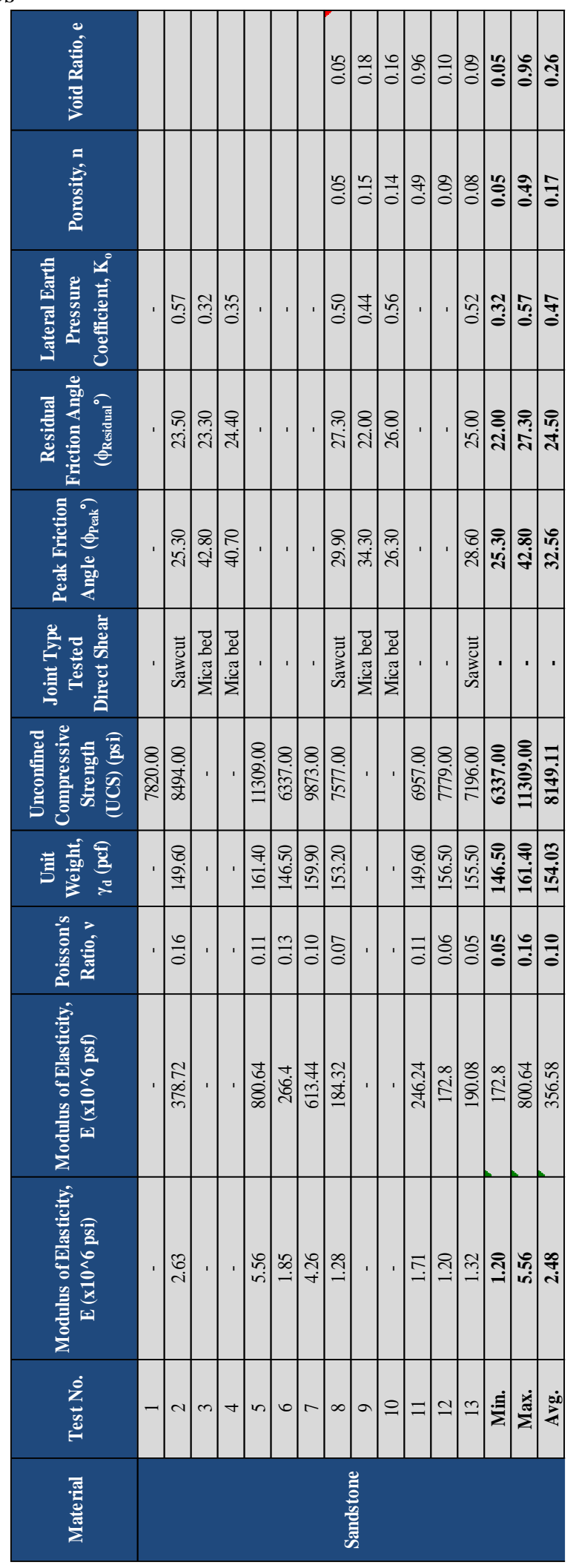


Table A7 Continued (1)

\begin{tabular}{|c|c|c|c|c|}
\hline 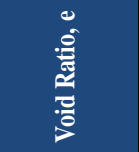 & : & $:$ & : & 象 \\
\hline 音 & $\bar{c}$ & : & $\stackrel{F}{9}$ & 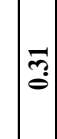 \\
\hline 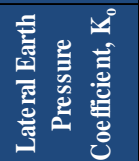 & $\bar{s}$ & : & $\stackrel{\pi}{8}$ & 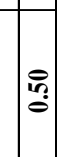 \\
\hline 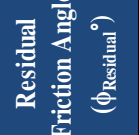 & & {$\left[\begin{array}{ll}0 \\
\infty\end{array}\right.$} & $\stackrel{8}{i j}$ & $\stackrel{\infty}{\rightarrow}$ \\
\hline 慈变 & & 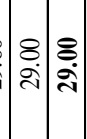 & 尺्. & : \\
\hline 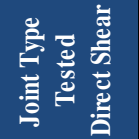 & & 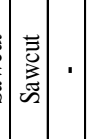 & & \\
\hline 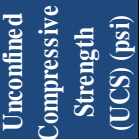 & & 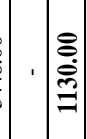 & 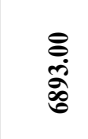 & 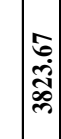 \\
\hline 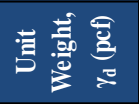 & 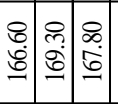 & . & $\begin{array}{l}0 \\
\overline{3} \\
30 \\
0\end{array}$ & 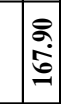 \\
\hline 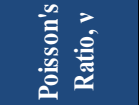 & $a$ & 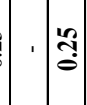 & ఝ̆ & :ั \\
\hline 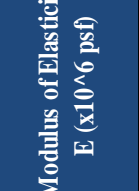 & 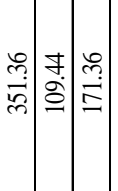 & 表 & 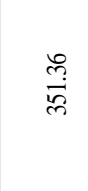 & $\left|\begin{array}{c}\hat{s} \\
\overline{\bar{c}}\end{array}\right|$ \\
\hline 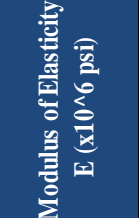 & $:=$ & $\mid \begin{array}{l}0 \\
0 \\
0\end{array}$ & $\underset{+}{+}$ & $\mid$ \\
\hline 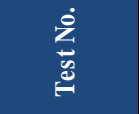 & & : & & 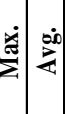 \\
\hline $\begin{array}{l}\text { 哥 } \\
\text { 彦 }\end{array}$ & & & & \\
\hline
\end{tabular}


Table A7 Continued (2)

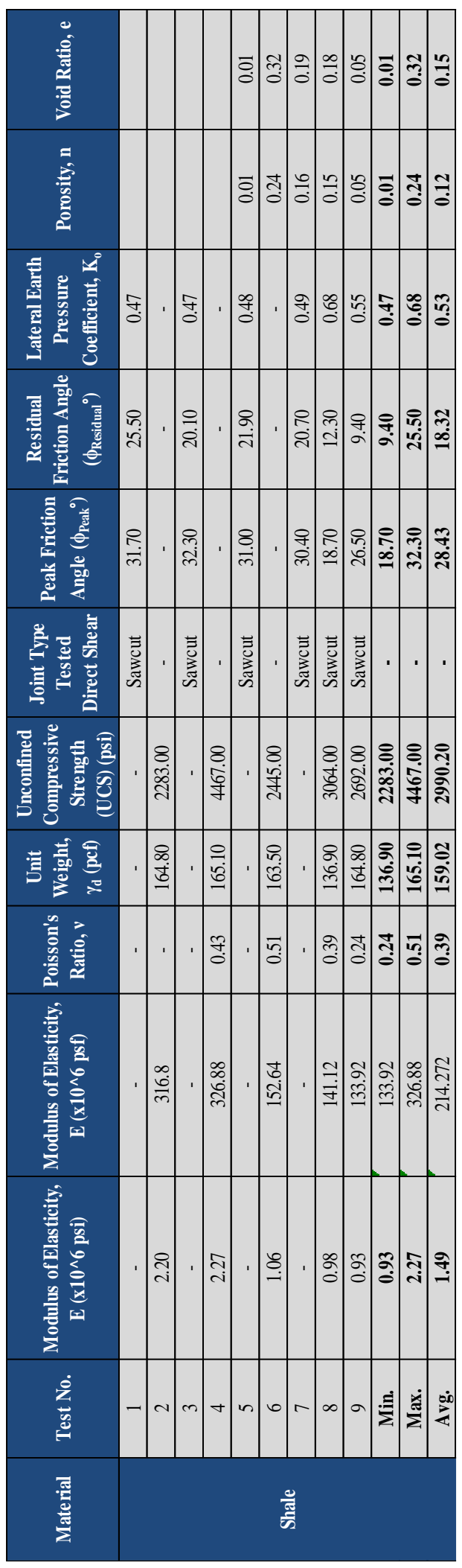


Table A7 Continued (3)

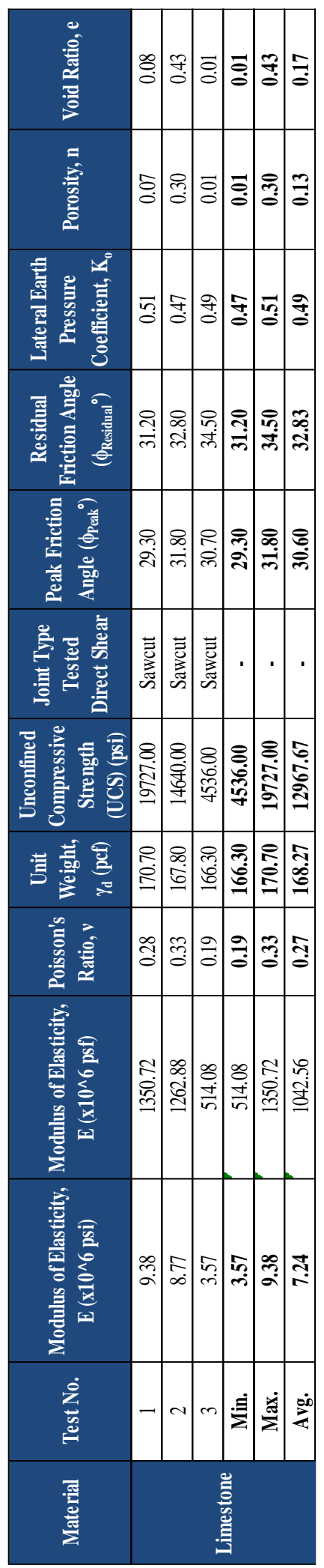


Table A7 Continued (4)

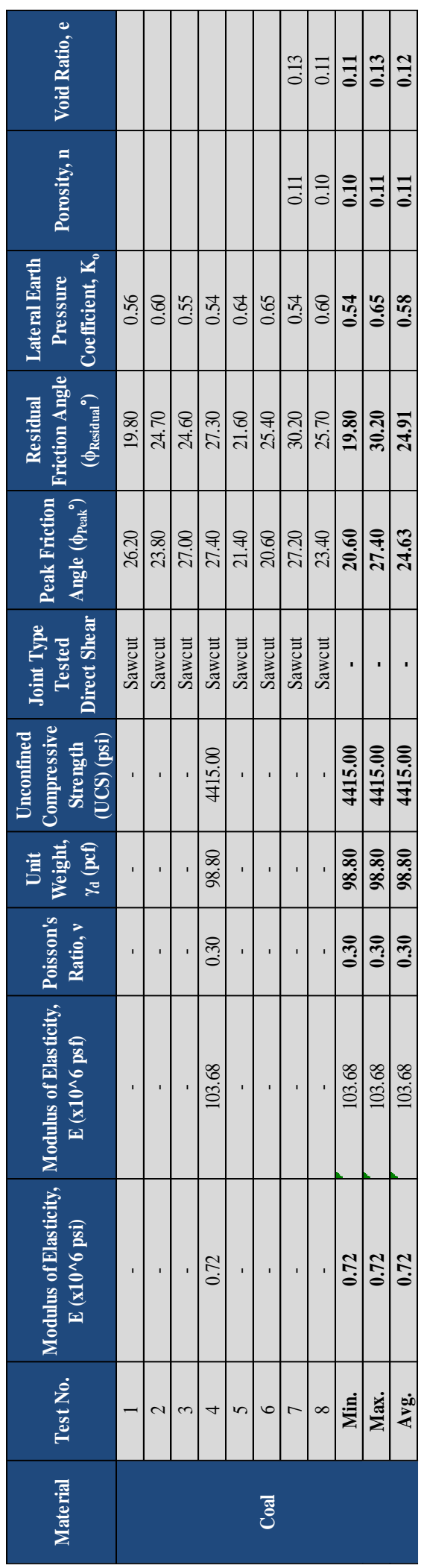




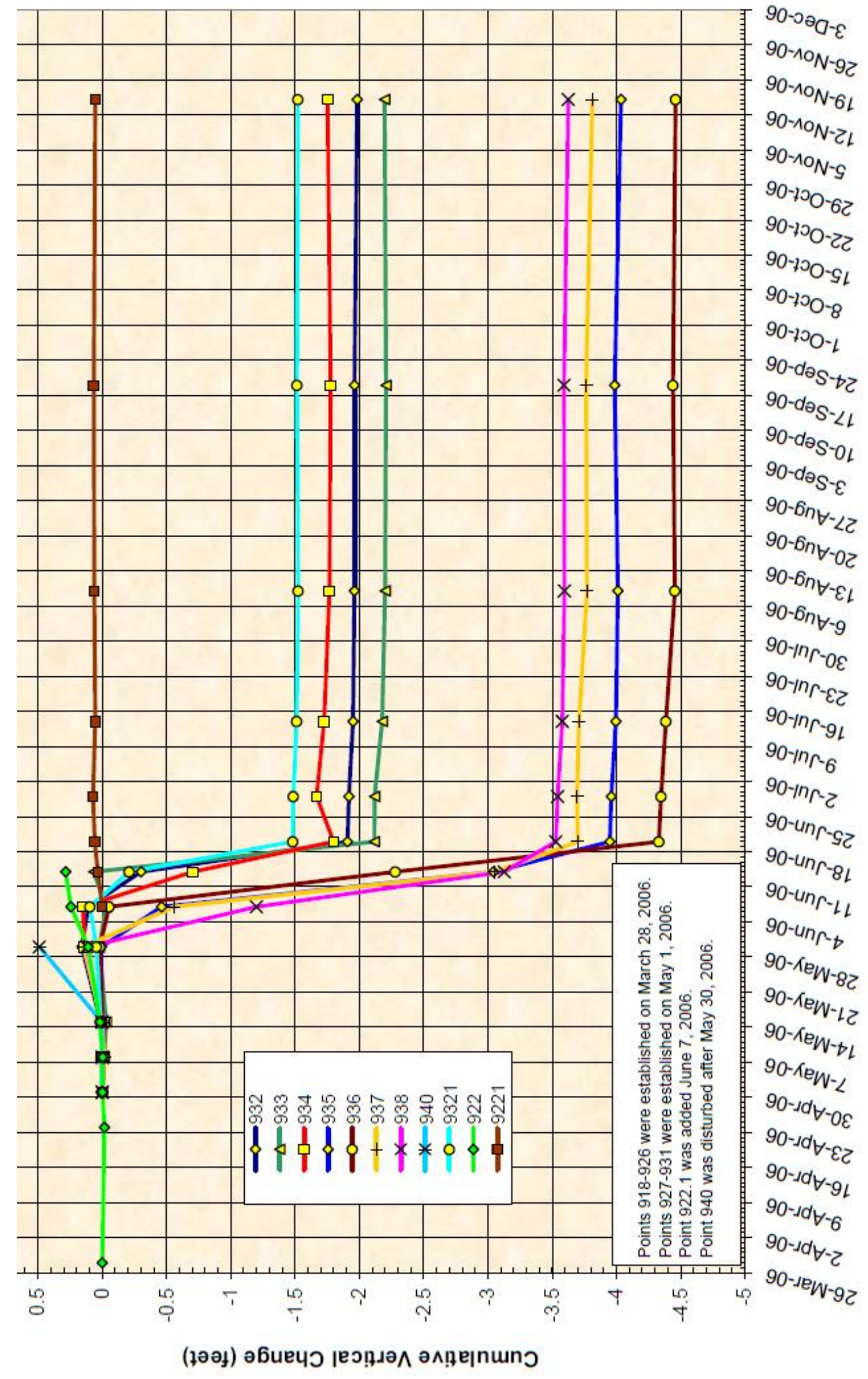

Figure A1 Elevation (Z) change data for Duke Lake western rim survey points (PADCNR, 2007) 


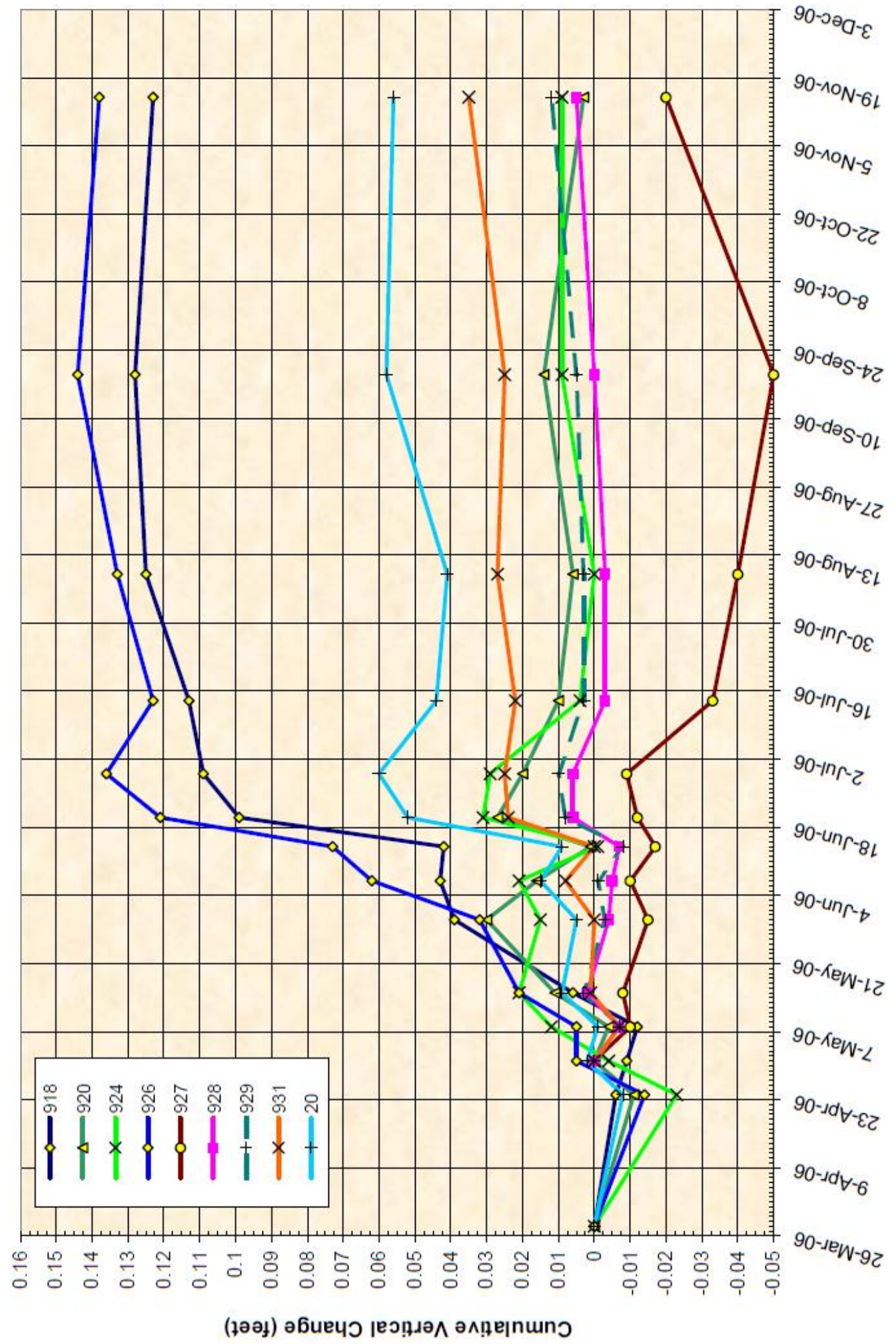

Figure A2 Elevation (Z) change data for Duke Lake western rim survey points (PADCNR, 2007) 


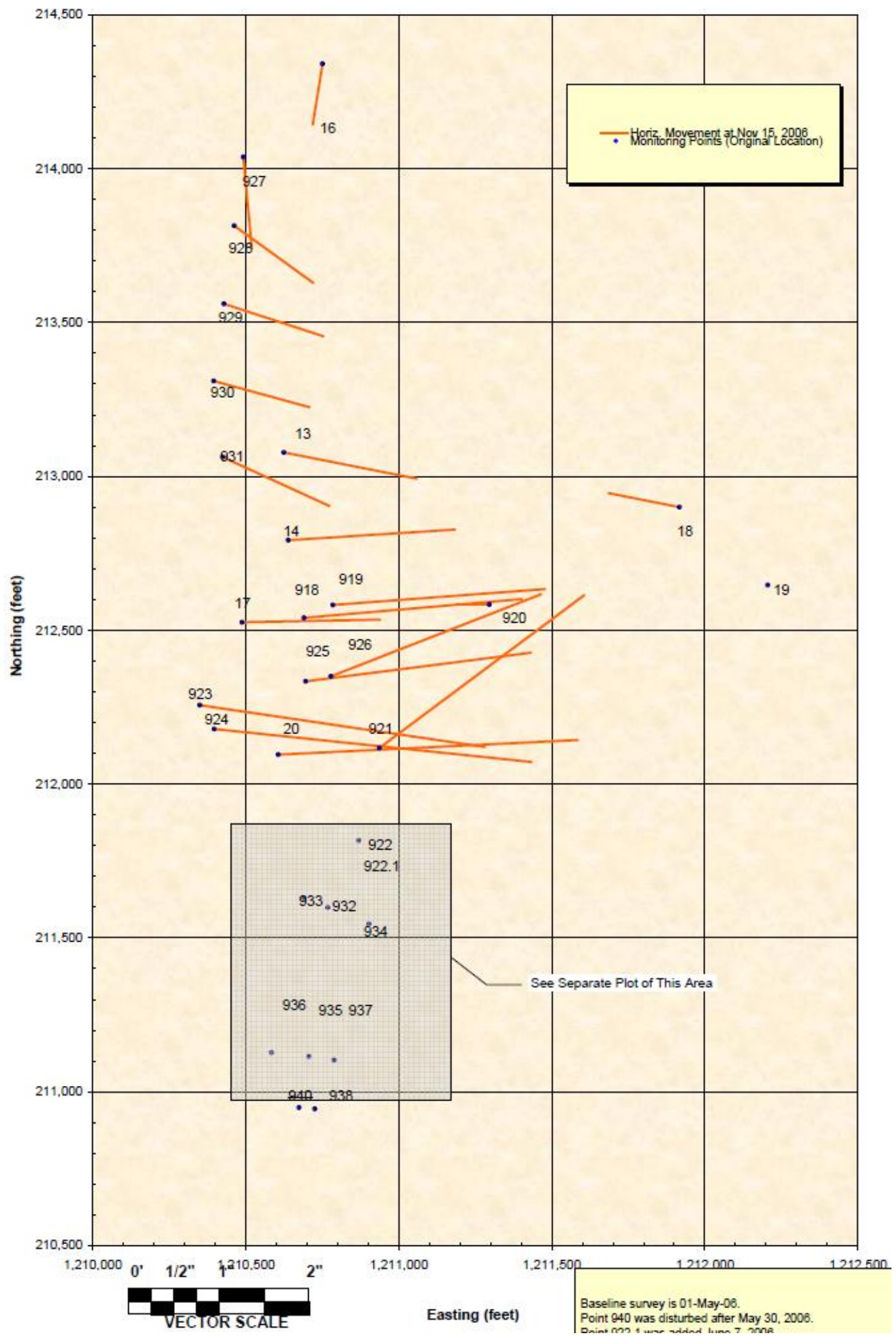

Figure A3 $(x, y)$ vector data plots for Duke Lake western rim survey points (PADCNR, 2007) 
Table A8 Ryerson Station Dam dimensions (PADCNR, 2007)

\begin{tabular}{|c|c|c|c|}
\hline Item & $\begin{array}{l}\text { Original } \\
\text { Design } \\
\text { Datum }\end{array}$ & $\begin{array}{c}\text { NAVD } s 8 \\
\text { Datum }\end{array}$ & $\begin{array}{l}\text { Notes } \\
\text { (Ref. design drawings } \\
\text { except as noted) }\end{array}$ \\
\hline & Adjustment: & +2.55 & \\
\hline \multicolumn{4}{|l|}{ Non-Overflow Section } \\
\hline Top of Dam & 976.80 & 979.35 & \\
\hline Top of Batter, downstream & 966.80 & 969.35 & \\
\hline Top of Batter, upstream & 957.80 & 960.35 & \\
\hline Top of Backfill, upstream & - & 954.00 & From GF survey \\
\hline Top of Backfill, downstream & - & 959.00 & From GF survey \\
\hline Top of Rock & 939.80 & 942.35 & From Phase I Report \\
\hline Base of Dam & 934.80 & 937.35 & From Phase I Report \\
\hline \multicolumn{4}{|l|}{ Overflow Section } \\
\hline Spillway Crest & 965.00 & 967.55 & \\
\hline Top of Vertical, upstream & 962.02 & 964.57 & \\
\hline Top of Lip & 955.02 & 957.57 & \\
\hline Bottom of Lip & 954.02 & 956.57 & \\
\hline Base of Dam & 935.00 & 937.55 & From As-built profile \\
\hline Top of Backfill, upstream & - & 956.00 & From GF survey \\
\hline Top of Rock, upstream & 945.00 & 947.55 & From As-built profile \\
\hline Top of Rock, downstream & 940.00 & 942.55 & Excavated for apron \\
\hline Top of Apron, downstream & 941.00 & 943.55 & \\
\hline Top of End Sill & 943.50 & 946.05 & \\
\hline \multicolumn{4}{|l|}{ Water Levels } \\
\hline Flood of Record Headwater & 969.00 & 971.55 & From Vol. 1, p.7-5 \\
\hline Flood of Record Tailwater & - & 959.65 & From Appendix B \\
\hline Normal Pool Headwater & 965.00 & 967.55 & Spillway crest elevation \\
\hline Normal Tailwater & 943.50 & 946.05 & End sill elevation \\
\hline
\end{tabular}




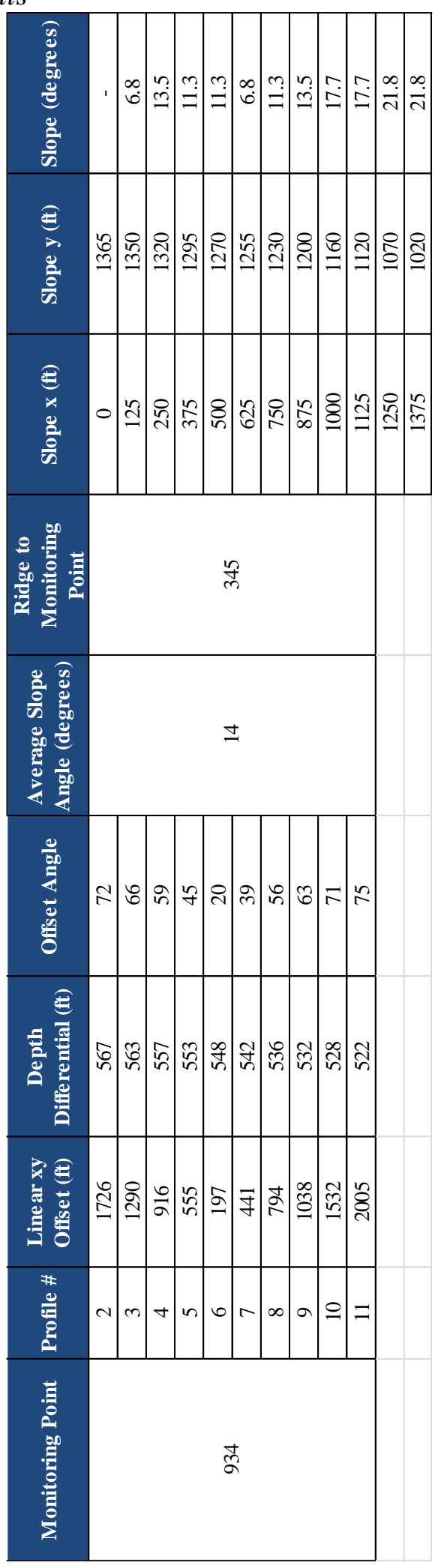




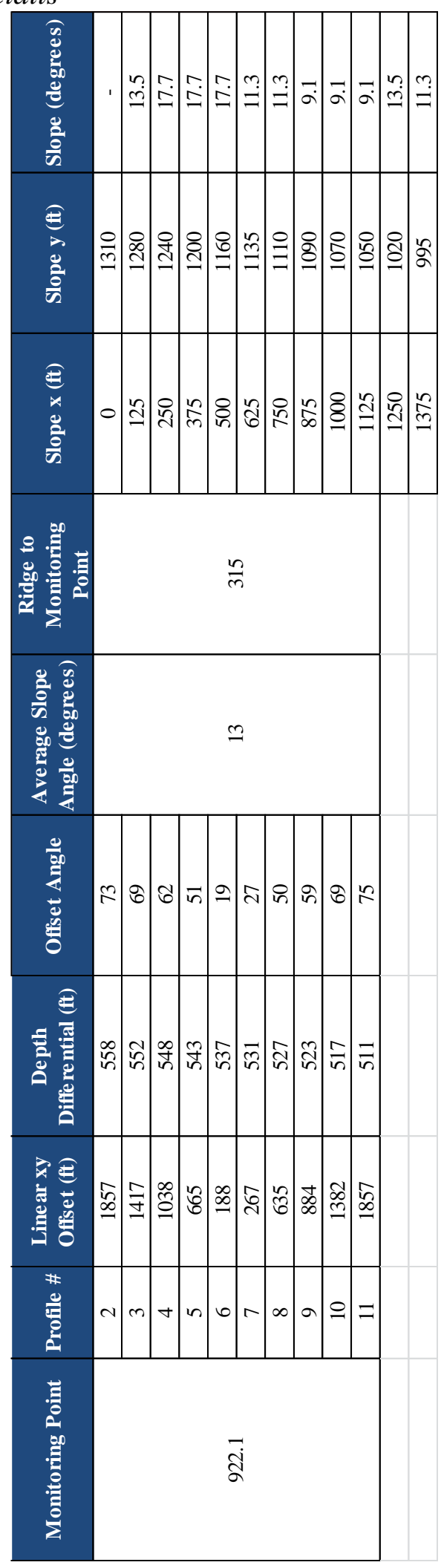




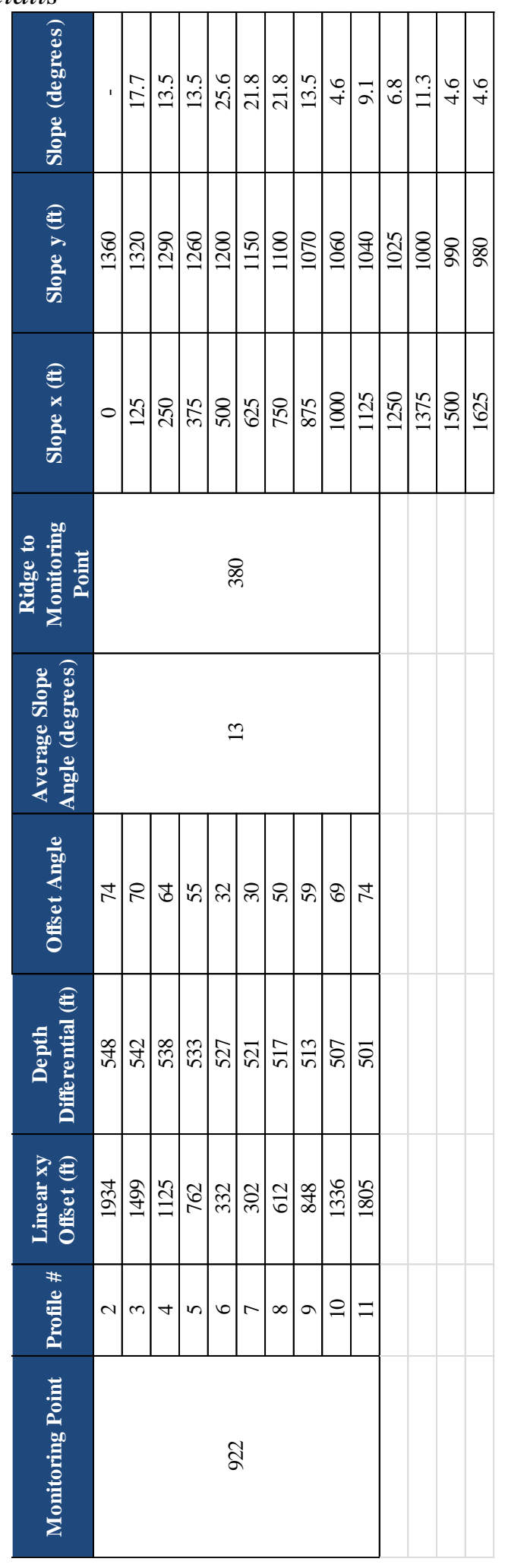




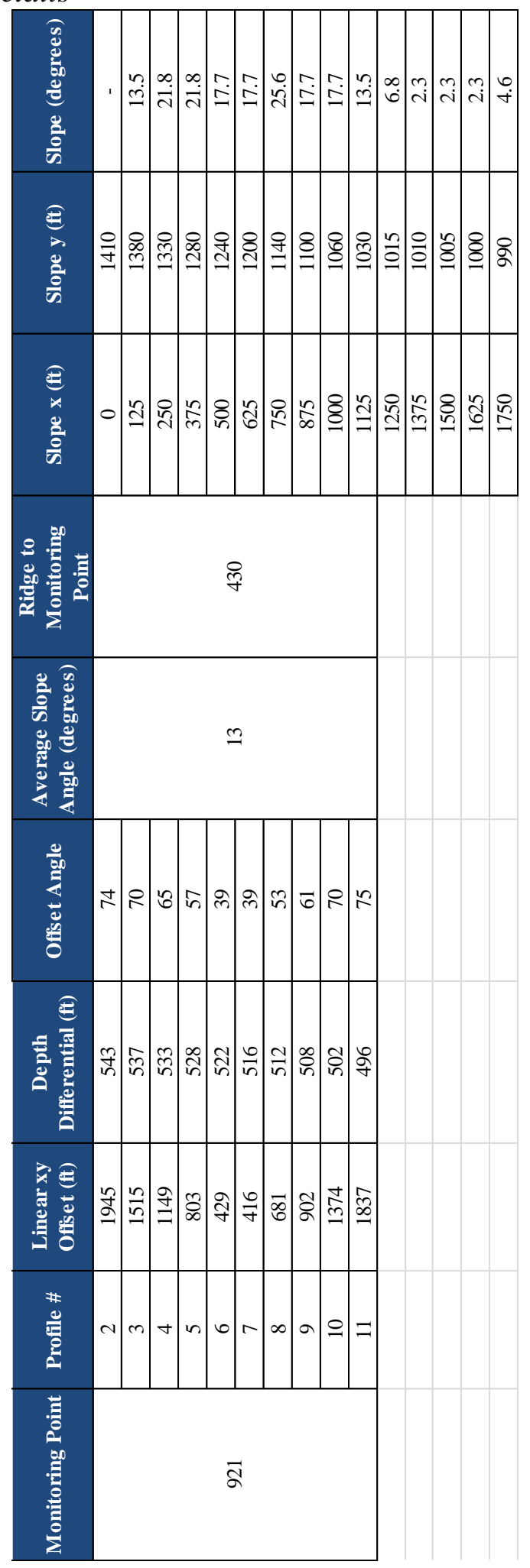




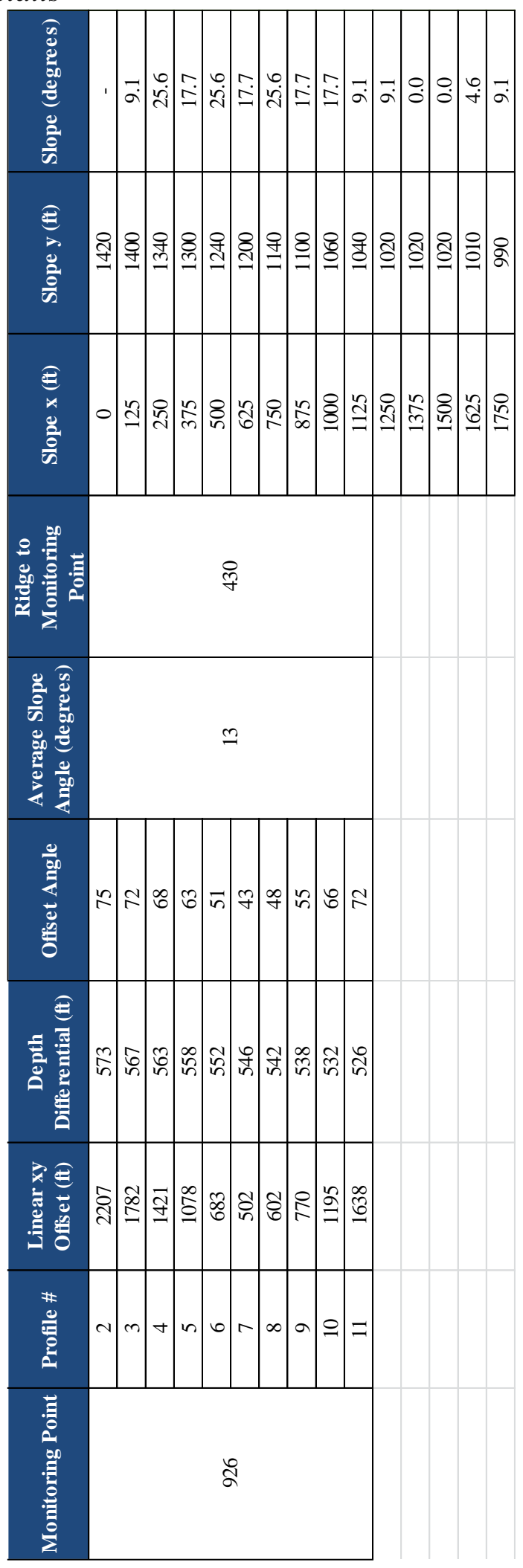




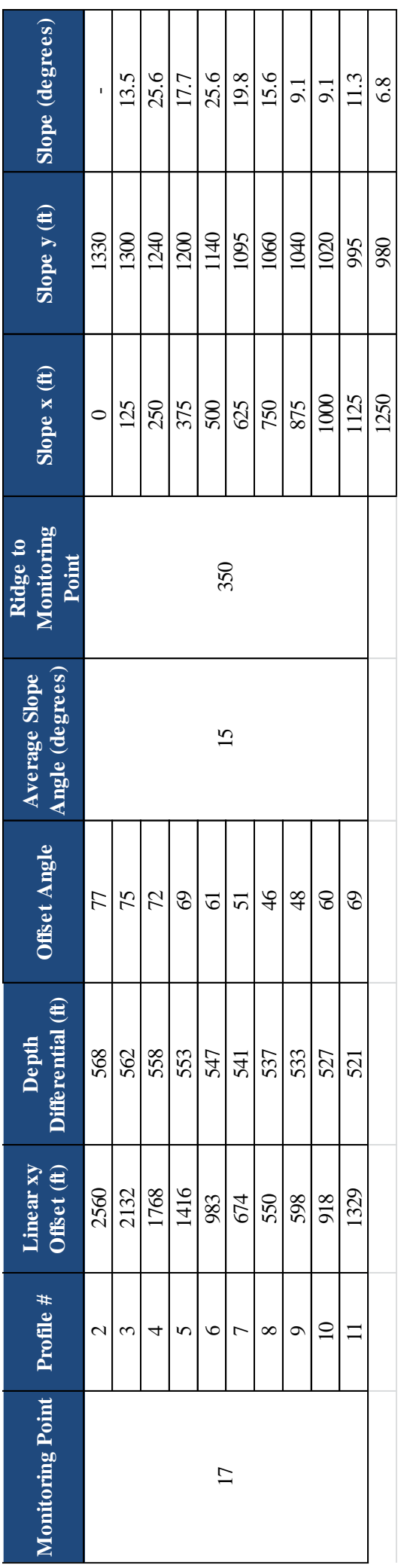




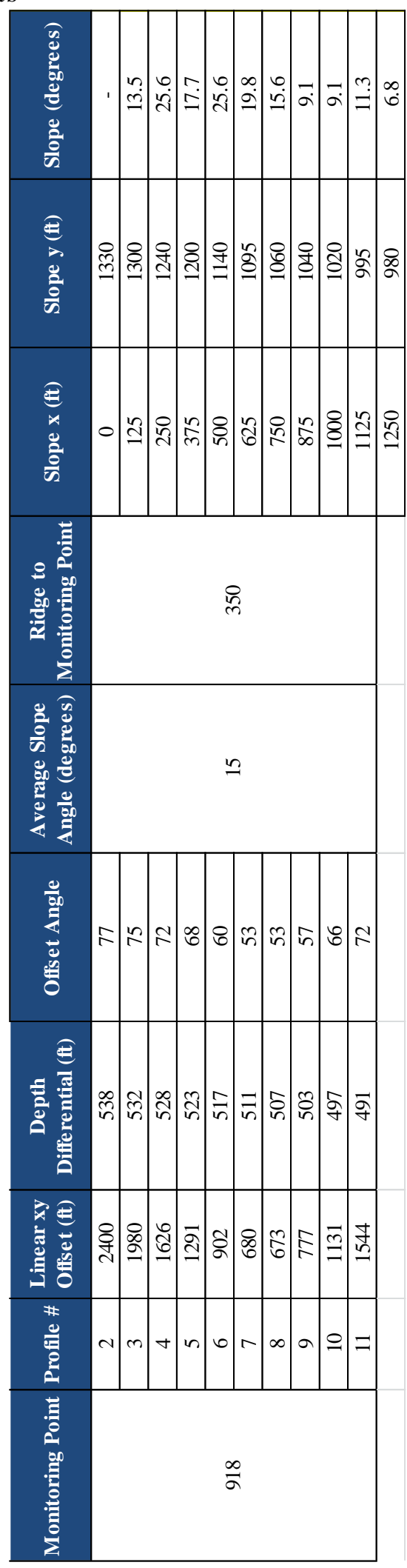




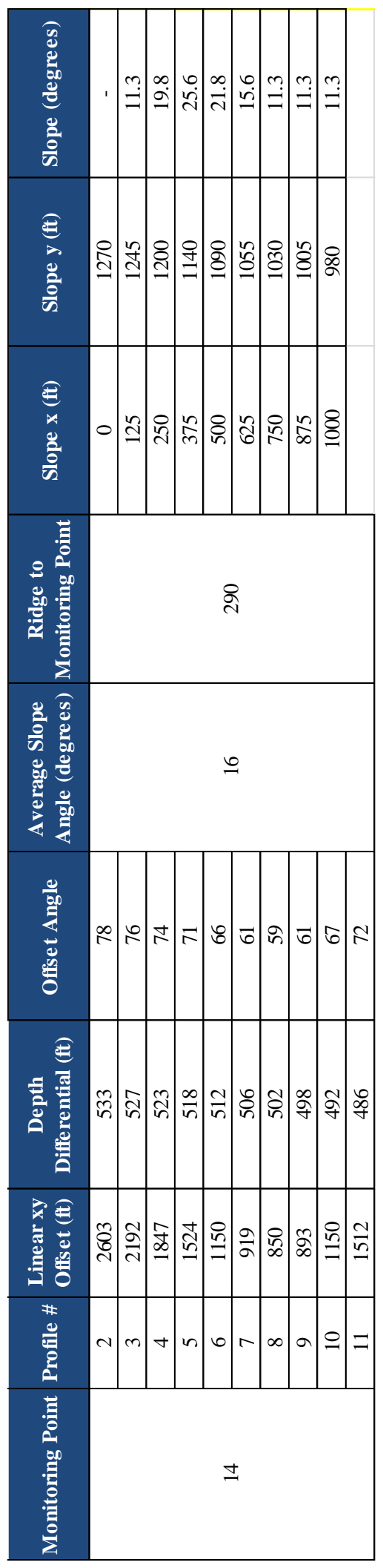




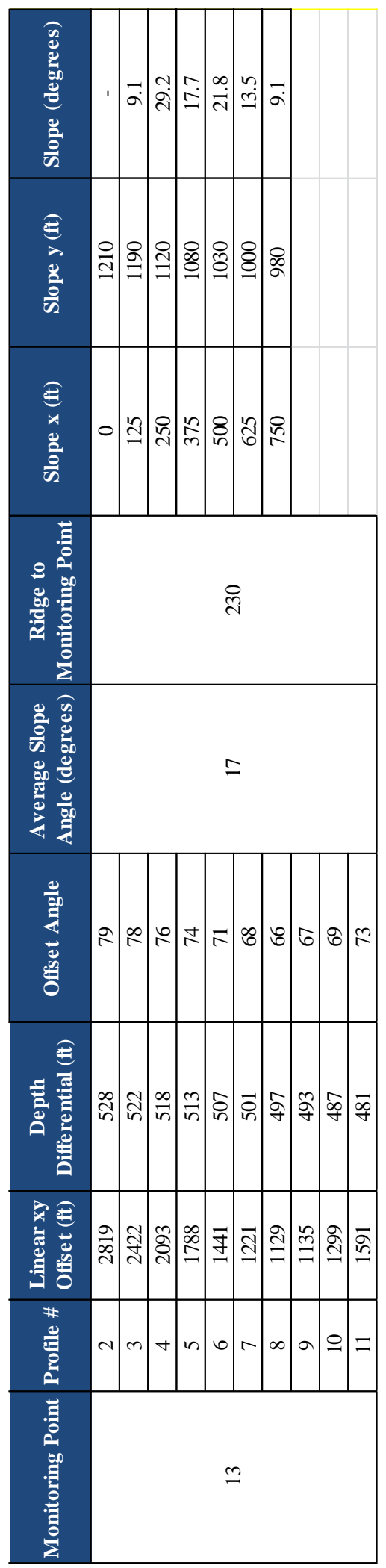




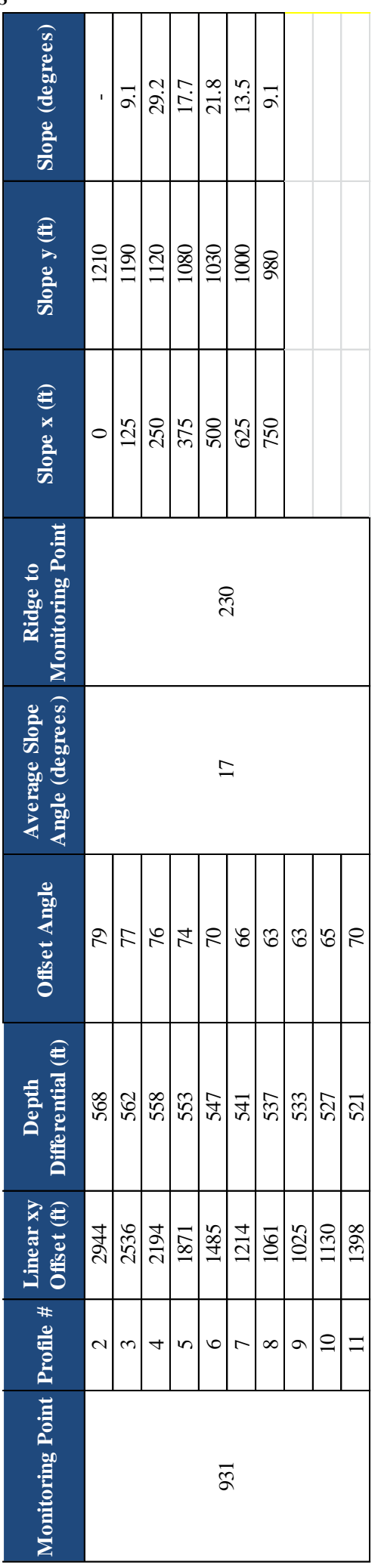




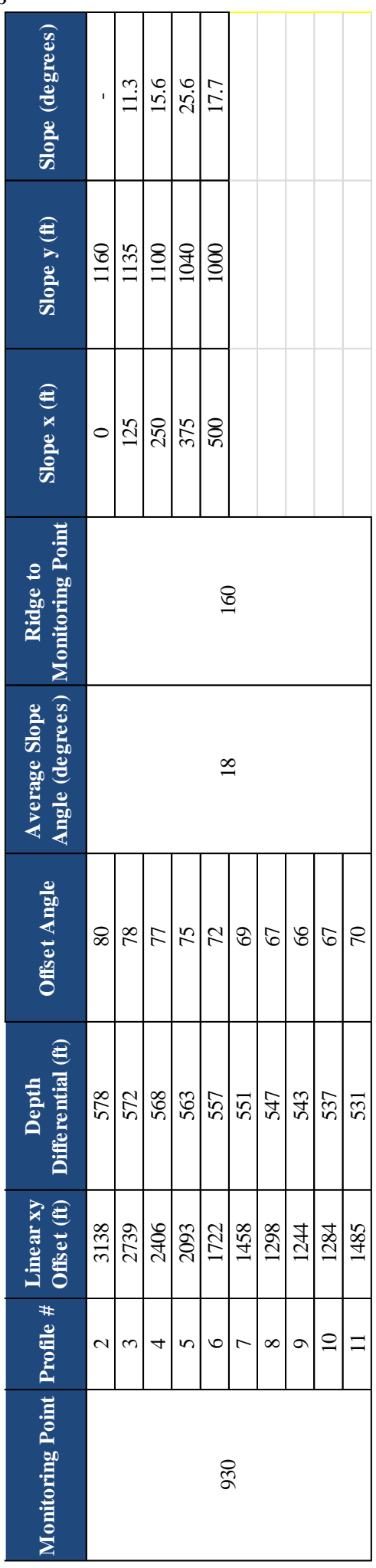




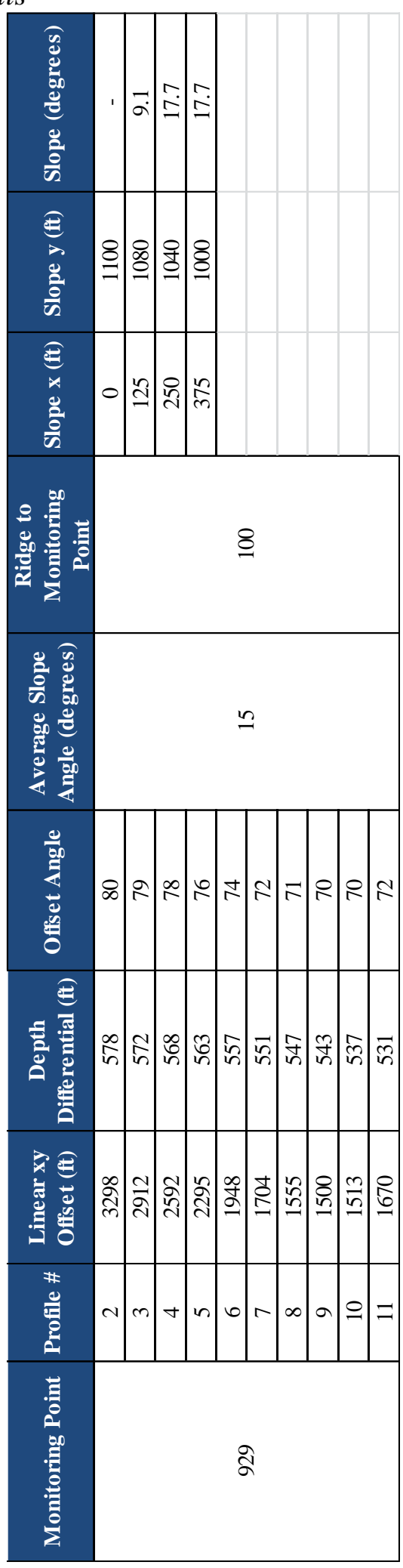




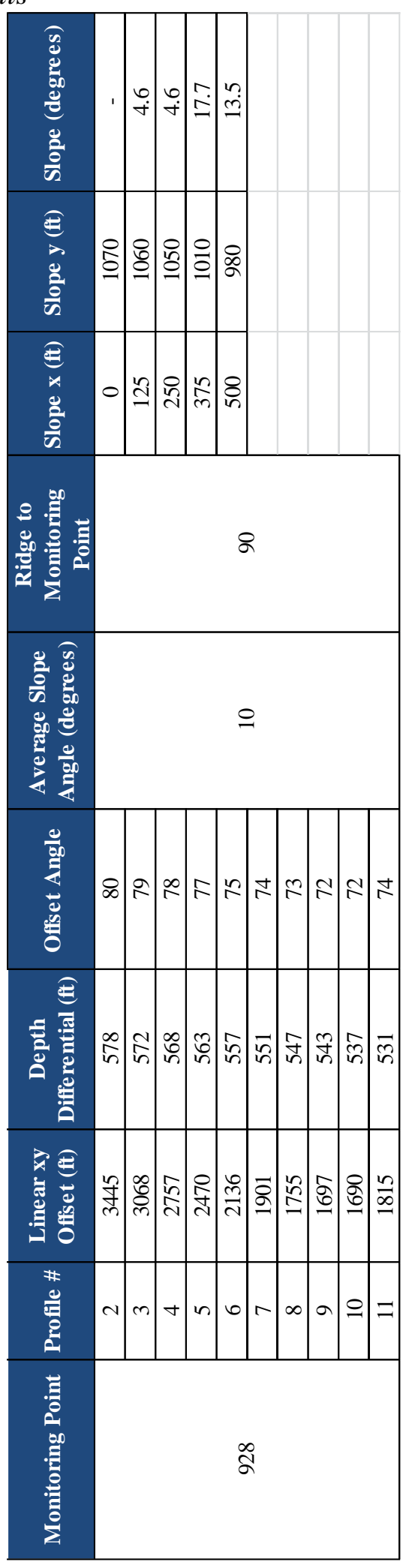




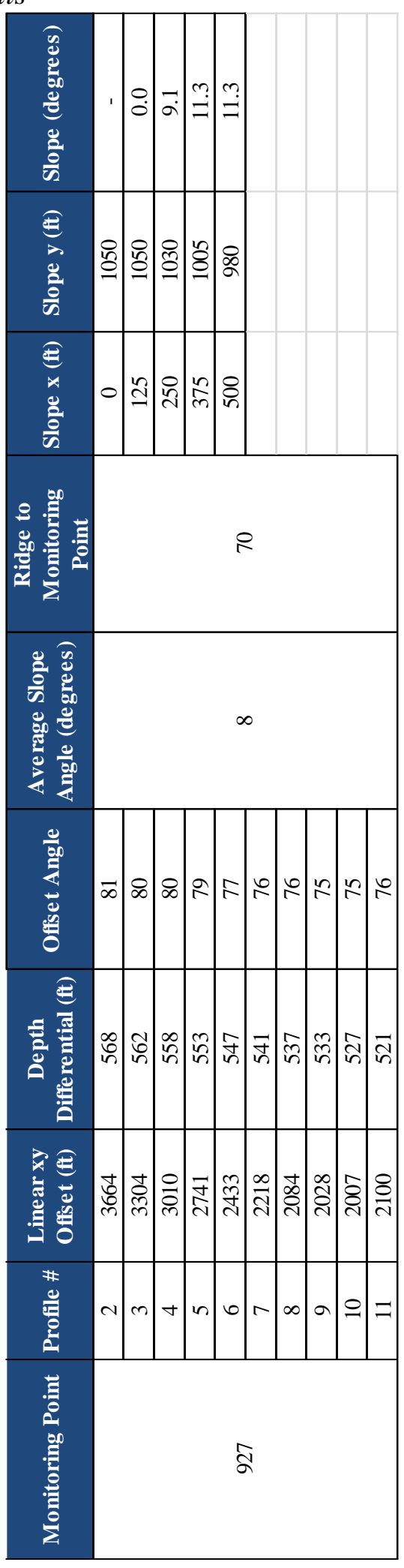




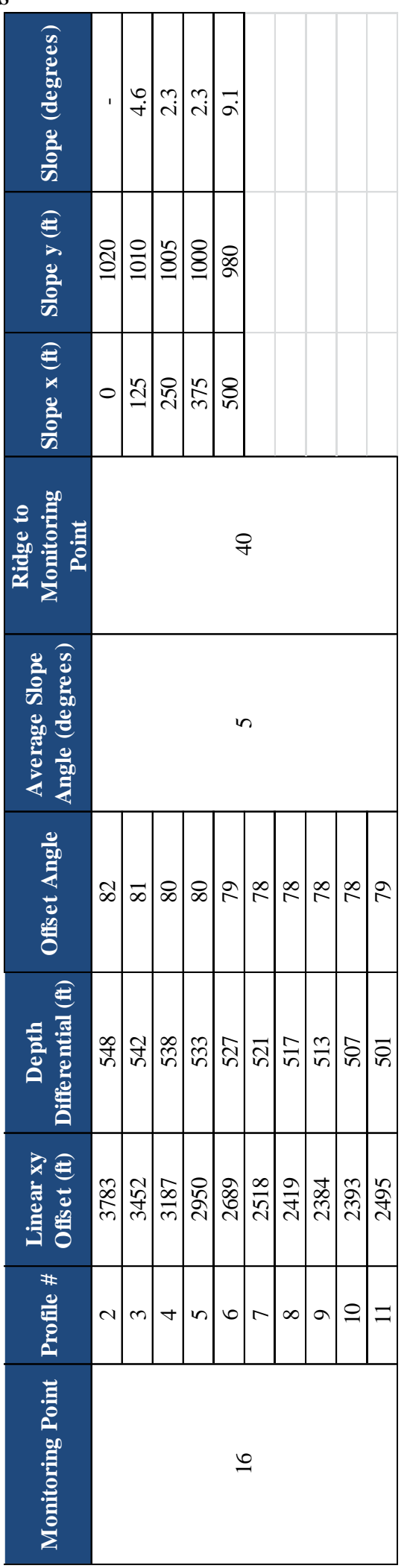


Table A9 (16) Summary station and Panel 7I profile relative model coordinates

\begin{tabular}{|c|c|c|c|c|c|c|c|}
\hline Profile \# & $X(f t)$ & $\mathbf{Y}(\mathbf{f t})$ & $\mathbf{Z}(\mathbf{f t})$ & Point ID & $X(f t)$ & $\mathbf{Y}(\mathbf{f t})$ & $\mathbf{Z}$ (ft) \\
\hline 1 & 4000 & 1100 & 8.5 & 934 & 1995 & 905 & 575 \\
\hline 2 & 3710 & 1100 & 12.1 & 932 & 1860 & 905 & 595 \\
\hline 3 & 3270 & 1100 & 17.7 & 933 & 1760 & 890 & 620 \\
\hline 4 & 2890 & 1100 & 22.5 & 922.1 & 1855 & 1180 & 570 \\
\hline 5 & 2515 & 1100 & 27.2 & 922 & 1790 & 1335 & 560 \\
\hline 6 & 2025 & 1100 & 33.3 & 20 & 1500 & 1315 & 580 \\
\hline 7 & 1600 & 1100 & 38.7 & 921 & 1800 & 1465 & 555 \\
\hline 8 & 1225 & 1100 & 43.4 & 923 & 1195 & 1340 & 610 \\
\hline 9 & 975 & 1100 & 46.5 & 924 & 1265 & 1315 & 615 \\
\hline 10 & 475 & 1100 & 52.8 & 925 & 1475 & 1615 & 580 \\
\hline \multirow[t]{12}{*}{11} & 0 & 1100 & 58.8 & 926 & 1560 & 1600 & 585 \\
\hline & & & & 17 & 1210 & 1650 & 580 \\
\hline & & & & 918 & 1400 & 1750 & 550 \\
\hline & & & & 919 & 1460 & 1825 & 540 \\
\hline & & & & 14 & 1250 & 1950 & 545 \\
\hline & & & & 13 & 1125 & 2225 & 540 \\
\hline & & & & 931 & 950 & 2125 & 580 \\
\hline & & & & 930 & 825 & 2335 & 590 \\
\hline & & & & 929 & 765 & 2585 & 590 \\
\hline & & & & 928 & 700 & 2775 & 590 \\
\hline & & & & 927 & 640 & 3100 & 580 \\
\hline & & & & 16 & 765 & 3475 & 560 \\
\hline
\end{tabular}


Table A10 (1) WC Detail 1 (R11-R8) 3D model stress results

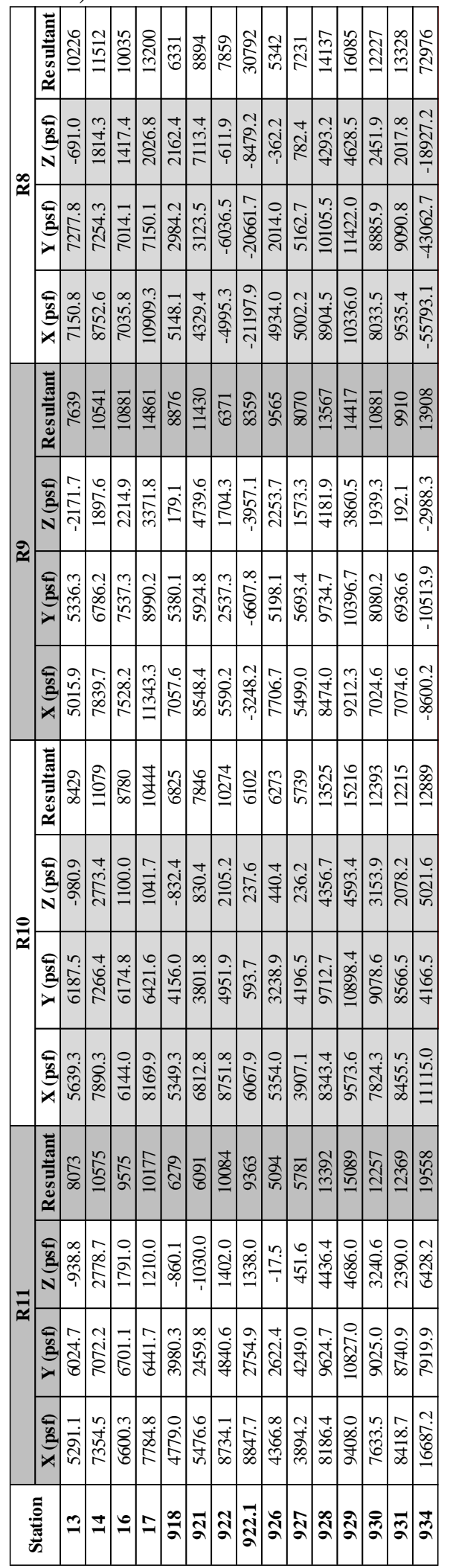


Table A10 (2) WC Detail 1 (R7-R5) 3D model stress results

\begin{tabular}{|c|c|c|c|c|c|c|c|c|c|c|c|c|c|c|c|}
\hline 童 & 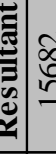 & $\frac{\infty}{\beth}$ & & $\left|\begin{array}{l}\infty \\
\tilde{\beth} \\
\beth\end{array}\right|$ & $\left|\begin{array}{l}n \\
\vdots \\
\vdots \\
\text { an }\end{array}\right|$ & $\begin{array}{l}\stackrel{\circ}{2} \\
\approx \\
=\end{array}$ & 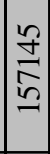 & 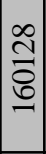 & 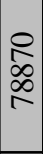 & $\vec{\delta}$ & $\left|\begin{array}{l}0 \\
0 \\
0 \\
0 \\
0\end{array}\right|$ & 章 & & 㐨 & \\
\hline & 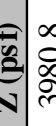 & : & 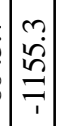 & 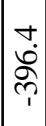 & 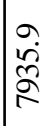 & $\begin{array}{l}= \\
\tilde{\infty} \\
\infty \\
\infty\end{array}$ & $\mid \begin{array}{l}0 \\
0 \\
2 \\
0 \\
1\end{array}$ & 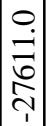 & 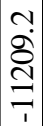 & ָे & $\begin{array}{l}-\vec{c} \\
\hat{n} \\
\text { nn }\end{array}$ & $\mid \begin{array}{l}\infty \\
\stackrel{\mathbb{ర}}{0} \\
0\end{array}$ & $\mid \begin{array}{l}n \\
\tilde{\infty} \\
\infty\end{array}$ & & \\
\hline & & & $\begin{array}{c}\infty \\
\infty \\
\dot{\zeta} \\
\dot{q} \\
\end{array}$ & 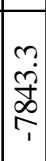 & 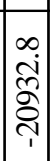 & 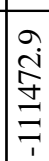 & 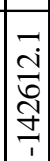 & $\mid \begin{array}{c}0 \\
0 \\
0 \\
0 \\
0 \\
0 \\
1 \\
1\end{array}$ & $\begin{array}{l}\infty \\
\dot{0} \\
0 \\
0 \\
1 \\
1\end{array}$ & $\begin{array}{l}\text { Oे } \\
\stackrel{0}{0} \\
\text { ర్రి }\end{array}$ & $\mid \begin{array}{l}0 \\
0 \\
0 \\
n \\
= \\
=\end{array}$ & $\mid \begin{array}{l}n \\
0 \\
2 \\
ٍ \\
=\end{array}$ & হ) & & \\
\hline & & 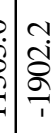 & 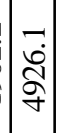 & 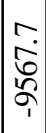 & $\underset{\substack{\infty \\
\hdashline}}{\stackrel{\infty}{+}}$ & 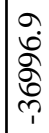 & $\mid \begin{array}{l}0 \\
0 \\
0 \\
1 \\
1\end{array}$ & $\begin{array}{l}\hat{n} \\
\hat{n} \\
\hat{\sigma} \\
\hat{n} \\
1\end{array}$ & 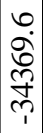 & $\begin{array}{l}\text { ○ } \\
\text { îj } \\
\text { ֶે }\end{array}$ & $\begin{array}{l}\stackrel{2}{\mathbb{8}} \\
\stackrel{8}{8}\end{array}$ & 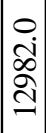 & & & \\
\hline & & & $\stackrel{2}{\Xi}$ & $\frac{\bar{\sigma}}{2}$ & $\frac{\infty}{0}$ & 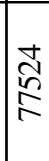 & 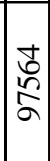 & $\mid \begin{array}{l}\overline{0} \\
0 \\
=0 \\
=\end{array}$ & 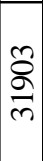 & $\underset{\infty}{\hat{\infty}}$ & $\mid$\begin{tabular}{l}
0 \\
0 \\
0 \\
$⿱ 亠 乂$ \\
\hdashline
\end{tabular} & $\mid \begin{array}{l}\mathbf{D} \\
0 \\
=\end{array}$ & & & \\
\hline & & & $\begin{array}{l}n \\
\\
\\
=\end{array}$ & $\mid \begin{array}{l}\stackrel{0}{\bar{z}} \\
\dot{7}\end{array}$ & $\begin{array}{l}0 \\
\dot{0} \\
\infty \\
\\
T\end{array}$ & $\overline{\bar{\sigma}}$ & $\begin{array}{l}0 \\
\dot{n} \\
\vec{n} \\
\tilde{n}\end{array}$ & 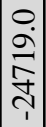 & $\begin{array}{c}\tilde{y} \\
\tilde{f} \\
m \\
m\end{array}$ & 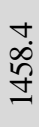 & 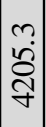 & 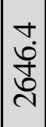 & & & $\frac{\pi}{n}$ \\
\hline & & 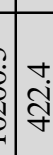 & $\begin{array}{l}n \\
n \\
n \\
\curvearrowright \\
\approx\end{array}$ & $\mid \begin{array}{l}0 \\
+\mathbb{d} \\
\frac{0}{1}\end{array}$ & $\mid \begin{array}{l}\infty \\
0 \\
\\
\frac{0}{1}\end{array}$ & $\frac{8}{8}$ & $\mid \begin{array}{l}2 \\
0 \\
5 \\
5 \\
0 \\
1 \\
1\end{array}$ & $\begin{array}{l}-1 \\
\vec{a} \\
0 \\
\vdots \\
i\end{array}$ & 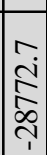 & $\frac{0}{\stackrel{0}{J}}$ & 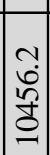 & $\left|\begin{array}{c}1 \\
\infty \\
0 \\
\infty \\
\infty\end{array}\right|$ & 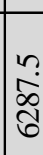 & & \\
\hline & & & $\begin{array}{l}a \\
\dot{0} \\
\infty \\
\Sigma\end{array}$ & 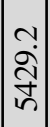 & 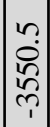 & $\begin{array}{l}\vec{D} \\
\vec{d} \\
\overrightarrow{1}\end{array}$ & $\begin{array}{c}0 \\
\dot{0} \\
\dot{0} \\
0 \\
0 \\
\dot{0}\end{array}$ & $\left|\begin{array}{c}a \\
\dot{\infty} \\
\vec{n} \\
\tilde{n}\end{array}\right|$ & $\begin{array}{l}\stackrel{2}{\rho} \\
\hat{\rho} \\
\stackrel{-}{1}\end{array}$ & 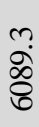 & $\left|\begin{array}{l}a \\
\dot{0} \\
\vdots \\
\vdots \\
0\end{array}\right|$ & 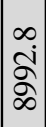 & $\frac{+}{\stackrel{+}{8}}$ & $\mid \begin{array}{l}\infty \\
\stackrel{0}{\sim} \\
\infty\end{array}$ & \\
\hline & & & ถి & $\begin{array}{l}\tilde{n} \\
\tilde{f} \\
\tilde{c}\end{array}$ & $\mid \begin{array}{l}0 \\
\hat{n} \\
i n\end{array}$ & $\mid \begin{array}{l}\hat{\infty} \\
\end{array}$ & $\begin{array}{l}\hat{\tilde{c}} \\
\hat{n}\end{array}$ & $\begin{array}{l}0 \\
\mathbb{\pi} \\
\stackrel{2}{\curvearrowright}\end{array}$ & Iิ & $\frac{m}{n}$ & 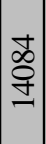 & $\mid \begin{array}{l}\mathbb{1} \\
\infty \\
\sim\end{array}$ & & & \\
\hline & $\stackrel{5}{0}$ & $\begin{array}{c}n \\
\vdots \\
1\end{array}$ & $\begin{array}{l}-7 \\
\stackrel{\oplus}{+} \\
\end{array}$ & \begin{tabular}{|l}
$\infty$ \\
$\infty$ \\
$\infty$ \\
$m$ \\
$m$
\end{tabular} & 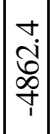 & $\begin{array}{l}\tilde{y} \\
\infty \\
\tilde{f} \\
\dot{f}\end{array}$ & 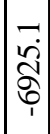 & $\begin{array}{c}0 \\
\dot{t} \\
\hat{i} \\
\\
\end{array}$ & $\begin{array}{l}\stackrel{+}{\sim} \\
\text { ते } \\
\text { フे }\end{array}$ & ले & 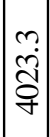 & 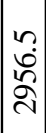 & 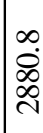 & 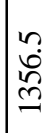 & ? \\
\hline & & 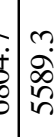 & 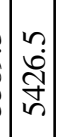 & $\mid \begin{array}{l}n \\
\dot{0} \\
\infty \\
0\end{array}$ & $\frac{\mathfrak{r}}{\stackrel{n}{r}}$ & $\frac{\infty}{\stackrel{\infty}{\kappa}}$ & \begin{tabular}{|l|}
0 \\
0 \\
$\tilde{2}$ \\
$\tilde{2}$ \\
$\infty$ \\
$\tilde{1}$
\end{tabular} & 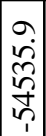 & 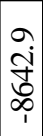 & 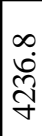 & $\mid \begin{array}{l}\infty \\
0 \\
\delta \\
\delta \\
0\end{array}$ & $\mid \begin{array}{l}0 \\
0 \\
0 \\
0 \\
0\end{array}$ & 유. & $\mid \begin{array}{l}0 \\
i \\
\infty \\
\infty \\
\infty\end{array}$ & 告 \\
\hline & $\underbrace{t}_{4}$ & & $\begin{array}{l}\infty \\
\dot{\sigma} \\
\tilde{v} \\
n\end{array}$ & 童 & $\begin{array}{c}N \\
\infty \\
\infty\end{array}$ & 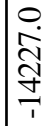 & 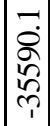 & 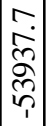 & $\begin{array}{l}\stackrel{0}{0} \\
\stackrel{0}{\sim} \\
\stackrel{2}{1}\end{array}$ & 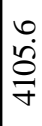 & & $\mid \begin{array}{l}\sigma \\
\hat{\tilde{s}} \\
\alpha\end{array}$ & $\begin{array}{l}\text { } \\
\stackrel{8}{0} \\
\stackrel{2}{\infty}\end{array}$ & & 18 \\
\hline. & & $7-1$ & $1=$ & & ) & $a$ & $\widehat{\widetilde{\sigma}}$ & & & & $\widehat{\alpha}$ & $a$ & & $\bar{\sigma}$ & $\approx$ \\
\hline
\end{tabular}


Table A10 (3) WC Detail 1 (R4-R2) 3D model stress results

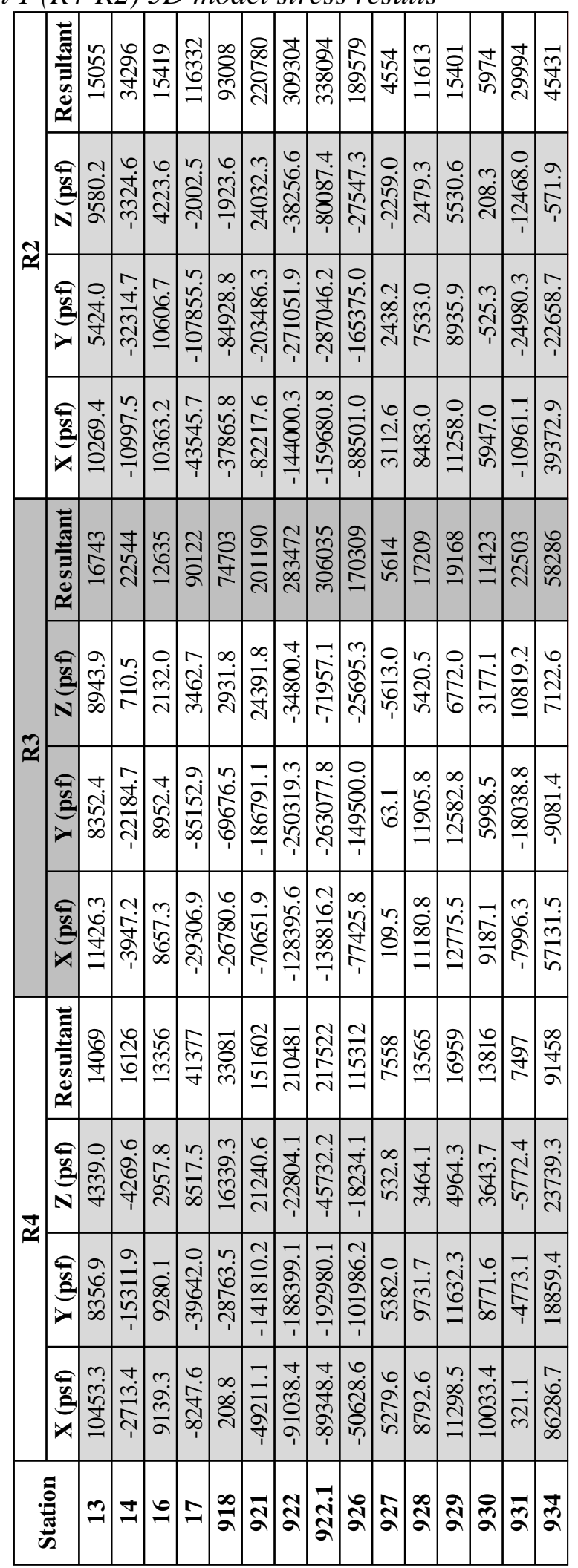


Table A11 Initial model stresses

\begin{tabular}{|c|c|c|c|}
\hline \multirow{2}{*}{ Point ID } & \multicolumn{3}{|c|}{ NVC WC } \\
\cline { 2 - 4 } & $\mathbf{X}$ (psf) & Y (psf) & $\mathbf{Z}$ (psf) \\
\hline 13 & 5163.1 & 5948.0 & -988.6 \\
\hline 14 & 7274.8 & 7074.7 & 2807.7 \\
\hline 16 & 6447.3 & 6567.0 & 1774.8 \\
\hline 17 & 7641.3 & 6379.3 & 1169.3 \\
\hline 918 & 4674.5 & 3965.4 & -856.3 \\
\hline 921 & 5357.2 & 2362.8 & -1196.7 \\
\hline 922 & 8797.0 & 4909.7 & 1392.2 \\
\hline 922.1 & 9259.9 & 3086.0 & 1505.1 \\
\hline 926 & 4242.1 & 2584.3 & -36.4 \\
\hline 927 & 4070.0 & 4432.4 & 650.3 \\
\hline 928 & 8123.6 & 9585.9 & 4411.5 \\
\hline 929 & 9355.3 & 10807.2 & 4688.3 \\
\hline 930 & 7609.2 & 9037.5 & 3275.9 \\
\hline 931 & 8346.8 & 8708.1 & 2382.4 \\
\hline 934 & 17493.9 & 8432.2 & 6581.6 \\
\hline
\end{tabular}

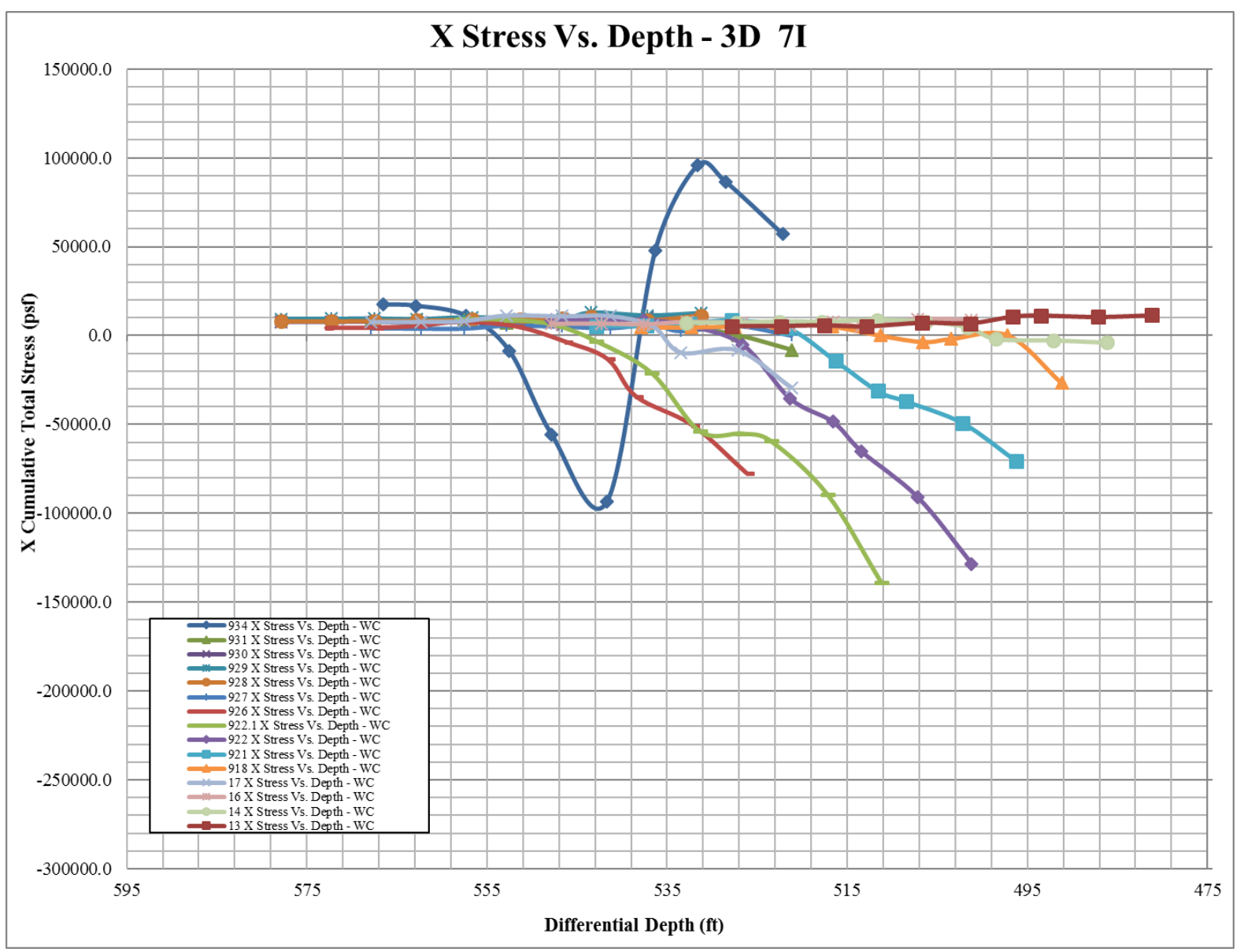

Figure A4 Total results for $X$ stress versus depth 


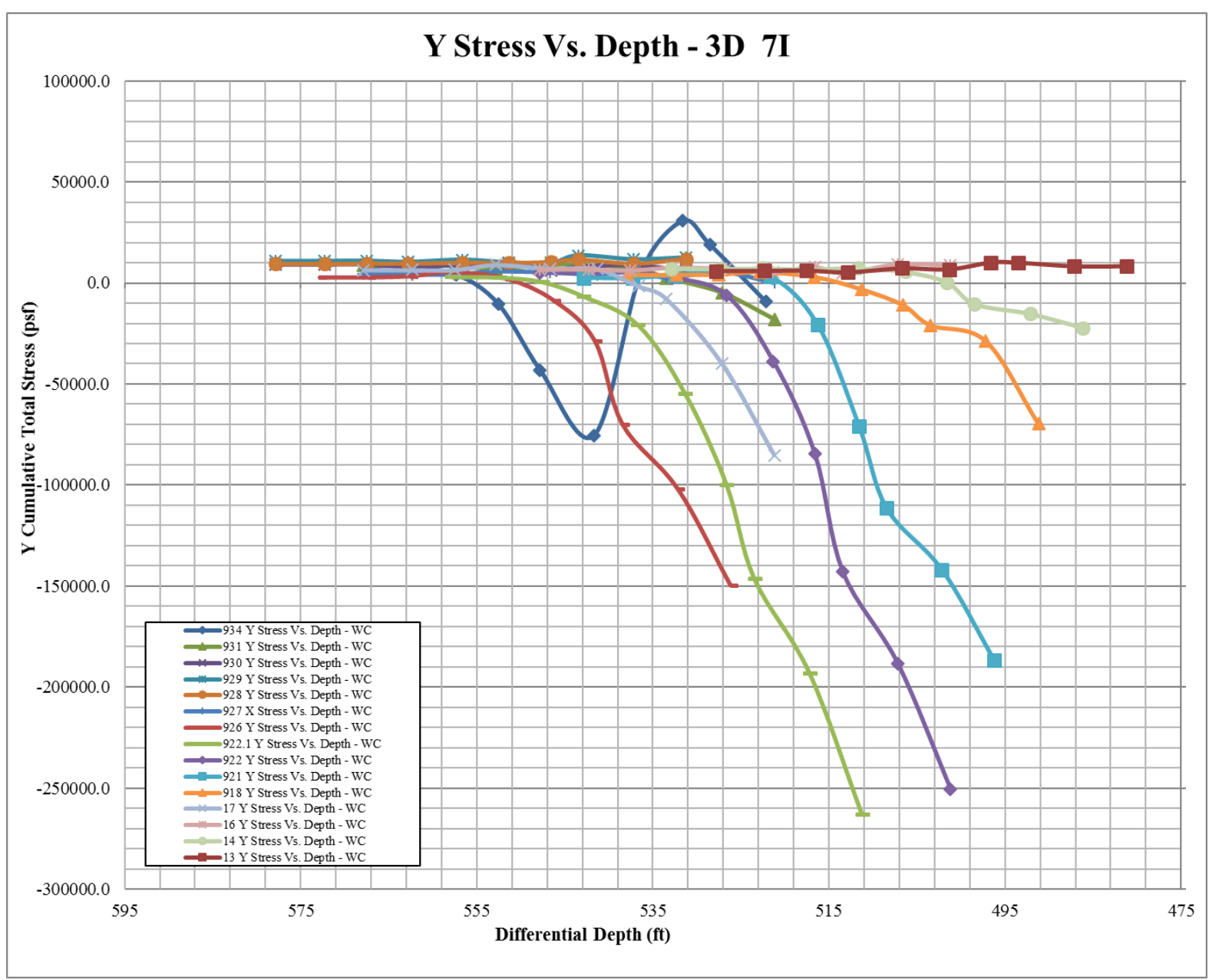

Figure A5 Total results for Y stress versus depth 


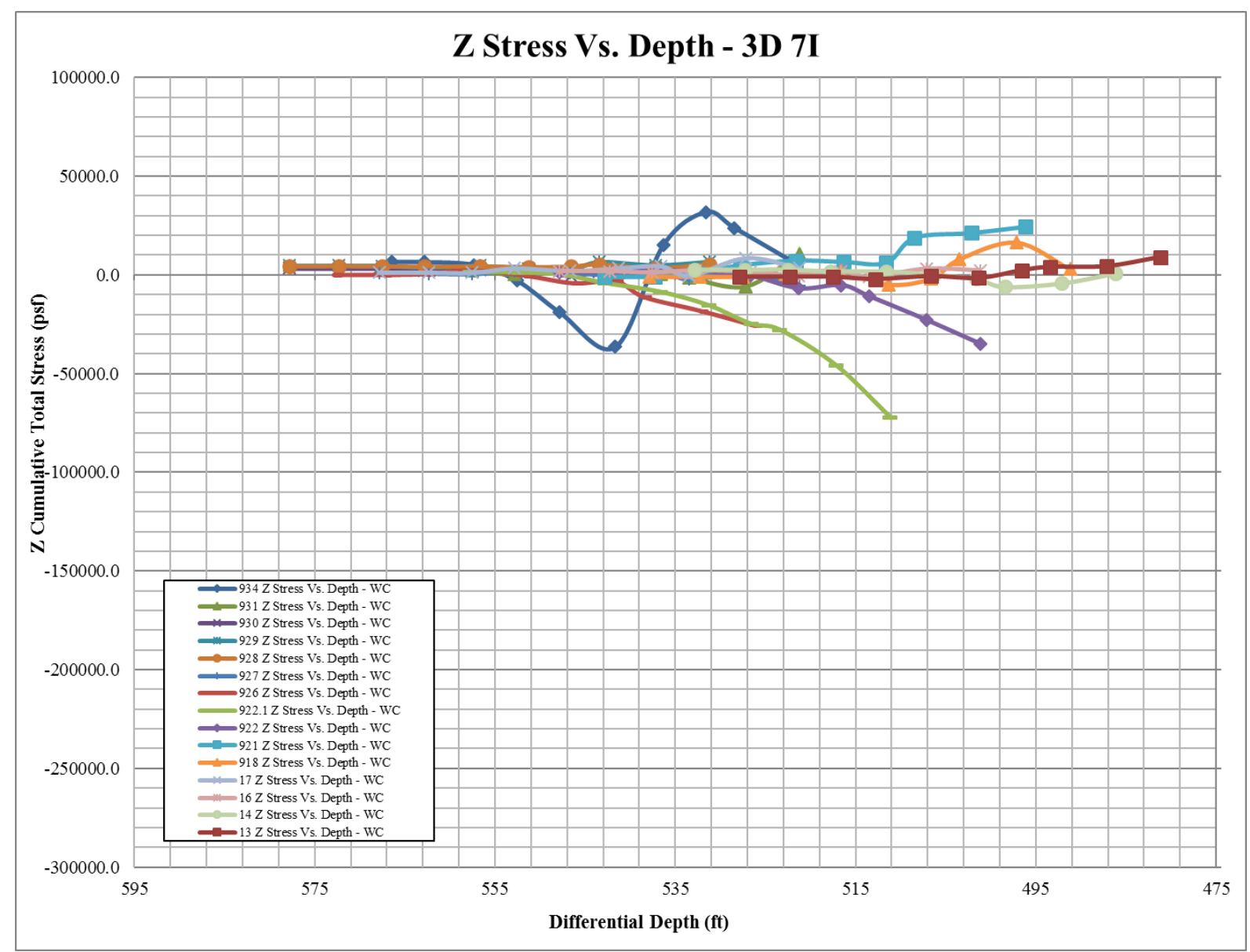

Figure A6 Total results for Z stress versus depth 